Universidad

Politécnica

de Cartagena

UNIVERSIDAD POLITÉCNICA DE CARTAGENA

DEPARTAMENTO DE INGENIERÍA CIVIL

\title{
AVANCES METODOLÓGICOS EN LA EVALUACIÓN DE LA VULNERABILIDAD SÍSMICA EN LA TRAMA URBANA
}

José Luis Ródenas Quiñonero 


\title{
Universidad Politécnica de Cartagena
}

\section{UNIVERSIDAD POLITÉCNICA DE CARTAGENA DEPARTAMENTO DE INGENIERÍA CIVIL}

\section{AVANCES METODOLÓGICOS EN LA EVALUACIÓN DE LA VULNERABILIDAD SÍSMICA EN LA TRAMA URBANA}

\section{TESIS DOCTORAL}

\author{
Presentada por: D. José Luis Ródenas Quiñonero \\ Dirigida por: Dr. D. Antonio Tomás Espín \\ Dr. D. Salvador García-Ayllón Veintimilla
}




\section{AGRADECIMIENTOS}

Al Dr. Antonio Tomás Espín y al Dr. Salvador García-Ayllón Veintimilla, directores del trabajo, por su constante ayuda, atención y asistencia durante la realización del mismo.

A mi familia, padres, por su apoyo y comprensión. 


\section{RESUMEN}

Algunas de las últimas catástrofes sísmicas (Lorca 2011, Chile 2014, Nepal 2015, Italia 2016), han vuelto a evidenciar el inadecuado comportamiento de multitud de estructuras. Por otra parte, en regiones con sismicidad baja o moderada, como la península Ibérica, la aleatoriedad del fenómeno sísmico y la escasa memoria de la población han provocado una disminución de la percepción social e institucional de la amenaza. Este hecho ha derivado en una aplicación de la normativa existente con escaso rigor, y en una relajación del empleo de reglas constructivas de buena praxis sismorresistente, por lo que resulta necesario seguir profundizando en el desarrollo de los procedimientos destinados a la evaluación de la peligrosidad, la vulnerabilidad y el riesgo sísmico en áreas urbanas.

En esta tesis se presenta una modificación de la metodología para la evaluación de la vulnerabilidad sísmica de edificaciones de hormigón armado en entornos urbanos mediante procedimientos empíricos enmarcados en el proyecto europeo RISK-UE. A partir de la revisión de los distintos métodos disponibles y del análisis del comportamiento sísmico de las edificaciones, se proponen nuevos valores para algunos de los modificadores de comportamiento relacionados con sus características tipológicas, estructurales y urbanísticas. Estos modificadores son necesarios para la caracterización del índice de vulnerabilidad de una determinada edificación, según se establece en este tipo de metodologías. Dando continuidad a distintos trabajos desarrollados previamente por otros autores, se ha simplificado la generalización del método para cualquier área urbana y se ha preparado para su implementación sistemática a partir de la información contenida en el Catastro Inmobiliario.

Se ha elaborado una base de datos de daños sísmicos en edificaciones a partir de observaciones reales tras el sismo de Lorca de 2011, sobre la cual se ha aplicado el nuevo modelo y se han contrastado los resultados con los proporcionados según distintos métodos disponibles. Mediante la utilización de Sistemas de Información Geográfica, estas metodologías pueden ser también empleadas en el planeamiento y gestión de situaciones de emergencia post-sismo, permitiendo una mejor definición de los diversos escenarios de daño. 


\section{ABSTRACT}

Some of the most recent seismic disasters (Lorca 2011, Chile 2014, Nepal 2015, Italy 2016), have once again revealed the inadequate performance of many existing structures under the seismic action. Furthermore, in low-to-moderate seismicity regions, as the Iberian Peninsula, the relatively low frequency of seismic phenomena and the short memory of the population have produced a decrease in the social and institutional perception of the seismic threat. This situation has led to scant rigor in the application of the existing regulations and a certain abandonment of good practice in seismic design, so further development of methodologies for evaluating the seismic hazard, vulnerability and risk in urban areas is necessary.

In the framework of the European RISK-UE LM1 Project, a modification of the empirical method for seismic vulnerability assessment of reinforced concrete buildings in urban areas is proposed in this thesis. New values of certain behaviour modifiers related to the typological, structural and urban parameters of the buildings have been proposed from a review of the currently available models and an analysis of the actual seismic performance of buildings. As stated in the several methodologies, these modifiers are required for the vulnerability index assessment of a certain building. Providing continuity and progress to the previous works published to date by others authors, the generalization of the methodology to any urban area and its implementation from cadastral information have been simplified.

A database of seismic damage in buildings from on-site observations after the 2011 Lorca earthquake has been performed. The new model proposed and the currently available models have been applied considering this damage database, comparing the results obtained by the different methods. These methodologies can also be used to develop the planning and management of post-earthquake emergency situations by using GIS techniques, allowing for a better definition of several damage scenarios. 
ÍNDICE

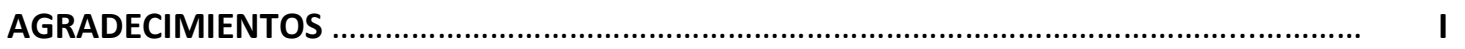

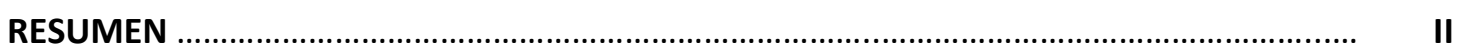



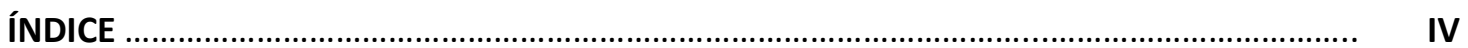

LISTADO DE FIGURAS …………………………................................................ VIII

LISTADO DE TABLAS ……........................................................................................... XVIII

CAPÍTULO 1. INTRODUCCIÓN ............................................................................................. 1

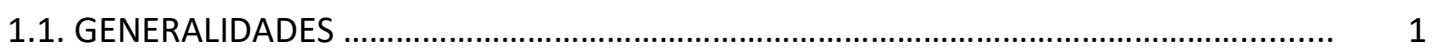

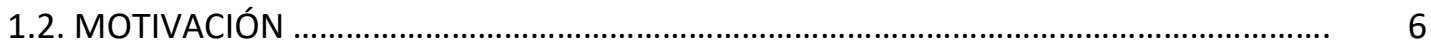

1.3. CONTENIDO Y ALCANCE DEL TRABAJO …….............................................................. 8

1.4. ORGANIZACIÓN DE LA TESIS ................................................................................

CAPÍTULO 2. EVALUACIÓN DEL RIESGO SíSMICO EN ÁREAS URBANAS. ESTADO DEL ARTE

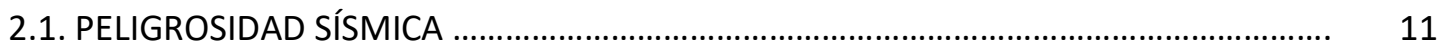

2.1.1. Introducción ....................................................................................................... 11

2.1.1.1. Sismicidad. Fuentes sismogenéticas ............................................................. 16

2.1.1.2. Leyes de atenuación sísmica ..................................................................... 19

2.1.2. Peligrosidad sísmica a escala regional ................................................................ 20

2.1.2.1. Métodos deterministas ............................................................................... 21

2.1.2.2. Métodos probabilistas .............................................................................. 21

2.1.2.3. Estudios sobre peligrosidad sísmica a escala regional en la península Ibérica

2.1.3. Peligrosidad sísmica a escala local ...................................................................... 28

2.1.3.1. Efecto sitio ................................................................................................. 28

2.1.3.2. Microzonificación sísmica .................................................................................. 29

2.2. VULNERABILIDAD SÍSMICA _..................................................................................... 32

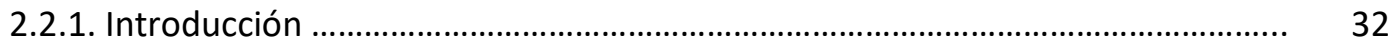


2.2.2. Clasificación de las metodologías para la evaluación de la vulnerabilidad sísmica 34

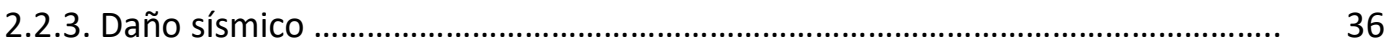

2.2.3.1. Relación Vulnerabilidad - Daño ...................................................................... 36

2.2.3.2. Elementos expuestos al daño y clases de daño ........................................... 36

2.2.3.3. Ductilidad estructural ....................................................................................... 38

2.2.3.5. Grados e índices de daño .......................................................................... 40

2.2.3.6. Configuraciones arquitectónicas y urbanísticas con influencia en el comportamiento sísmico de las edificaciones ............................................................ 44

2.2.4. Caracterización de la vulnerabilidad sísmica de edificaciones ............................ 57

2.2.4.1. Métodos basados en clases e índices de vulnerabilidad ............................ 58

2.2.4.2. Métodos basados en espectros de capacidad .............................................. 69





2.3.1.1. Definición y caracterización del riesgo sísmico ............................................ 71

2.3.1.2. Metodologías ex ante y ex post ....................................................................... 73

2.3.1.3. Cuantificación del riesgo sísmico ………………………………………..... 74

2.3.2. Diseño por prestaciones. Desempeño sísmico de edificios .................................. 76

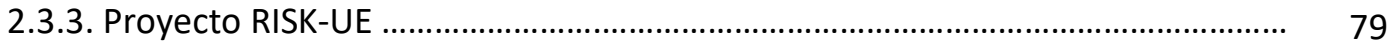

2.3.3.1. Metodología LM1 .................................................................................. 80

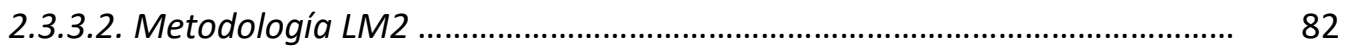

2.3.4. Estudios sobre riesgo sísmico en áreas urbanas en la península Ibérica .......... 85

2.3.5. Mitigación del riesgo sísmico .............................................................................. 90

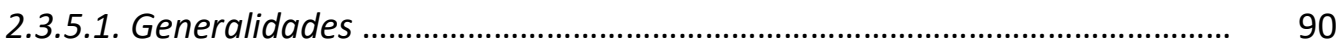

2.3.5.2. Recomendaciones para el diseño sismorresistente ....................................... 90

CAPÍTULO 3. METODOLOGÍA PARA LA EVALUACIÓN DE LA VULNERABILIDAD SÍSMICA 95

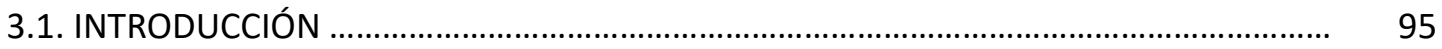

3.2. DESCRIPCIÓN DE LAS REVISIONES EXISTENTES DEL MÉTODO MIV ............................. 95

3.2.1. Modificadores de comportamiento ………………………………………....... 95

3.2.2. Modificador regional .............................................................................................. 101 
3.3. AVANCES EN LA EVALUACIÓN DE LA VULNERABILIDAD SÍSMICA DE EDIFICACIONES DE HORMIGÓN ARMADO

3.3.1. Introducción

3.3.2. Desarrollo de la metodología 103

3.3.2.1. Nivel del código sísmico de diseño 103

3.3.2.2. Número de plantas del edificio 107

3.3.2.3. Separación entre edificios

3.3.2.4. Otros modificadores del índice de vulnerabilidad

3.3.2.5. Resumen

\section{CAPÍTULO 4. EJEMPLO dE APLICACIÓN A LOS DAÑOS DERIVAdOS DEL SISMO DE} LORCA DE 2011

4.1. INTRODUCCIÓN

4.2. MARCO GENERAL DE ACTUACIÓN

4.2.1. La ciudad de Lorca

4.2.2. El terremoto del 11 de mayo de 2011

4.3.1. Organización de la información

4.3.2. Datos generales de la edificación

4.3.3. Definición del grado de daño observado según la escala EMS-98

4.3.4. Caracterización de los modificadores del índice de vulnerabilidad

4.3.5. Obtención del índice de vulnerabilidad de las edificaciones

4.3.6. Estimación del grado de daño según la metodología LM1 de RISK-UE

4.3.7. Resumen

4.4.1. Comparación entre el grado de daño estimado según el método LM1 de RISK-UE y el daño real observado en el sismo de Lorca de 2011

4.4.2. Tratamiento estadístico de los datos

4.4.2.1. Formulación de las hipótesis de contraste y de las variables del análisis

4.4.2.2. Test estadístico

4.4.2.3. Análisis e interpretación de resultados

4.5. APLICACIÓN DE LA METOdOLOGÍA A LA PLANIFICACIÓN Y GESTIÓN DE EMERGENCIAS MEDIANTE TÉCNICAS SIG 
CAPÍTULO 5. CONCLUSIONES Y LÍNEAS FUTURAS

5.1. INTRODUCCIÓN 162

5.2. TRABAJO REALIZADO 162

5.3. CONCLUSIONES 163

5.4. LÍNEAS FUTURAS 165

REFERENCIAS BIBLIOGRÁFICAS 167

PUBLICACIONES DEL DOCTORANDO RELACIONADAS CON ESTA TESIS

ANEXO A. SELECCIÓN DE FICHAS ELABORADAS PARA LA IMPLEMENTACIÓN DE LA BASE DE DATOS

ANEXO B. RESUMEN DE LA BASE DE DATOS IMPLEMENTADA 


\section{LISTADO DE FIGURAS}

Figura 1.1 Edificaciones dañadas tras un terremoto: (a) Kocaeli, Turquía (Foto: AeDES, 2009). (b) Lorca, España (Foto: García-Ayllón \& Tomás, 2013). (c) Emilia Romagna, Italia (Foto: Manfredi et al., 2014). (d) Nepal, 2015 (Foto: EERI, 2016)

Figura 1.2 Pérdidas económicas y número de fallecidos de los principales eventos sísmicos entre 2002 y 2011 (Valcárcel, 2013)

Figura 1.3 Mapa mundial de fallecidos y pérdidas económicas de los principales eventos sísmicos entre 2002 y 2011 (Valcárcel, 2013)

Figura 1.4 Distribución por países de las pérdidas económicas potenciales derivadas de fenómenos sísmicos, expresadas en USD en forma de pérdidas medias anualizadas -Average Annual Losses- (UNISDR, 2013)

Figura 1.5 Factores que condicionan el nivel de riesgo sísmico de una edificación (Aguilar, 2011)

Figura 2.1 Mecanismo de falla: hipocentro y epicentro de un sismo (Giner-Robles et al., 2010)

Figura 2.2 Comparación entre los grados de intensidad considerados en diferentes escalas macrosísmicas, junto con el porcentaje de edificios afectados en el área urbana (Mena, 2002)

Figura 2.3 Catálogo de sismicidad histórica e instrumental de la península lbérica y áreas adyacentes (IGN, 2016b)

Figura 2.4 Modelos zonificados de la península lbérica para el estudio de la actividad sísmica. (a) Primera zonificación sismogenética (Martín, 1984). (b) Zonificación propuesta en IGN (1991) y empleada para la evaluación de la peligrosidad en las normas NCSE-94 y NCSE-02 (Mezcua, Rueda, \& García-Blanco, 2011)

Figura 2.5 Leyes de atenuación del movimiento sísmico en función de la magnitud, para suelo rígido (Crespo, 2011)

Figura. 2.6 Esquema de propagación de la energía sísmica desde la fuente sismogenética hasta la cimentación de una estructura (Lozano, Bermúdez \& Ojeda, 2009)

Figura 2.7 Etapas del proceso de evaluación probabilista de la peligrosidad sísmica, siguiendo un método zonificado (Benito et al., 2006)

Figura 2.8 Mapa de peligrosidad sísmica de España en términos de aceleración básica del terreno para un período de retorno de 500 años (NCSE-02, 2002)

Figura 2.9 Mapa de peligrosidad sísmica de la Región de Murcia, en términos de PGA en roca, para un periodo de retorno de 475 años (Benito et al., 2015) 
Figura 2.10 Mapa de peligrosidad sísmica de España en términos de PGA en roca para un periodo de retorno de 475 años, según los siguientes percentiles de la distribución de probabilidad: (a) Percentil 50; (b) Percentil 15; (c) Percentil 85 (Mezcua, Rueda \& García-Blanco, 2011)

Figura 2.11 Efecto sitio. Amplificación del frente de ondas en función del tipo de material de los estratos más superficiales (Giner-Robles et al., 2010)

Figura 2.12 Clasificación del terreno en el núcleo urbano de Lorca según la escala propuesta por el EC-8, obtenida de la distribución de velocidades de las ondas $V_{s}^{30}$ (CARM, 2014)

Figura 2.13 Diagrama tensión-deformación del hormigón en función de la existencia de armadura, obtenido de ensayos a compresión (Vielma, 2008)

Figura 2.14 Espectros de respuesta normalizados elástico e inelásticos, reducidos mediante el coeficiente de ductilidad (Vielma, 2008)

Figura 2.15 Grados de daño según la escala EMS-98 para edificios de mampostería y de hormigón armado (Grünthal, 1998)

Figura 2.16 Diagrama de esfuerzos cortantes debido al mecanismo de pilar corto. Daños asociados a la presencia de estos elementos durante el terremoto de Lorca de 2011 (Fotos: Cabañas et al., 2011; Romao et al., 2013)

Figura 2.17 Configuración arquitectónica de pilares cautivos en edificaciones por interacción con cerramientos. (a) Esquema del mecanismo de daño. (b) Ejemplo de daños (Fotos: SISMIMUR, 2006; Guevara, 2012a) .

Figura 2.18 Configuraciones estructurales regulares, adecuadas desde un punto de vista sísmico (Perepérez, 2011)

Figura 2.19 Comportamiento irregular por excentricidad entre los centros de masas y rigidez (Guevara, 2012a)

Figura 2.20 Configuraciones irregulares en planta con un inadecuado comportamiento sísmico (Perepérez, 2011)

Figura 2.21 Disposiciones irregulares en alzado. (a) Edificios esbeltos unidos por su base. (b) Tipología de edificio base-torre (Perepérez, 2011)

Figura 2.22 Daños en cerramientos observados en el terremoto de Lorca de 2011 (Fotos: Cabañas et al., 2011; Carreño et al., 2012)

Figura 2.23 Configuración irregular en alzado. (a) Disposición asimétrica de paños de cerramiento. (b) Modelización de paños mediante tirantes que rigidizan cada entramado (Cabañas et al., 2011)

Figura 2.24 Caída de antepechos por insuficiente anclaje, terremoto de Lorca de 2011 (Foto: Bomberos de Cartagena, 2011)

Figura 2.25 Desprendimientos generalizados de parapetos y antepechos de cubierta, terremoto de Lorca de 2011 (Foto: Cabañas et al., 2011) 
Figura 2.26 Distribución del desplazamiento total generado por un terremoto en: (a) edificación regular; (b) edificio con irregularidad de planta blanda (Guevara, 2012b)

Figura 2.27 Casuísticas de planta blanda por irregularidad en la distribución de: (a) cerramientos; (b) espacios y pilares en planta baja; (c) particiones interiores entre diferentes plantas (Guevara, 2012b)

Figura 2.28 Casuísticas de planta blanda por: (a) mayor esbeltez de la planta baja; (b) distribución irregular de cerramientos; (c) combinación de ambos casos (Cabañas et al., 2011)

Figura 2.29 Planta blanda en: (a) planta baja; (b) nivel intermedio (Guevara, 2012b) ......

Figura 2.30 Barriada S. Fernando en Lorca, demolida tras el sismo de 2011. Se observa la irregularidad de planta blanda y la concentración de daños en pilares (Fotos: García-Ayllón \& Tomás, 2013)

Figura 2.31 Daños en edificios con planta blanda. Se observan las afecciones concentradas en este nivel (Fotos: Perepérez, 2011; Carreño et al., 2012)

Figura 2.32 Casuísticas de daño sísmico por efecto golpeteo. (a) Edificios de distinta altura y con alturas de forjado diferentes. (b) Edificio de esquina sin apoyo de medianeras. (c) Edificios de distinta altura pero con alturas de forjado similares (Perepérez, 2011)

Figura 2.33 Daños por efecto golpeteo, sismo de Lorca de 2011 (Fotos: Romao et al., 2013) .......

Figura 2.34 Efecto de la diferencia de altura entre edificios colindantes. (a) Croquis geométrico. (b) Daños concentrados en la transición entre primera y segunda planta (Martínez-Cuevas, 2014)

Figura 2.35 Afecciones en cabeza de pilares por falta de confinamiento del hormigón (Fotos: Barbat, 2011; Romao et al., 2013)

Figura 2.36 Clases de vulnerabilidad en la escala EMS-98 para distintas tipologías estructurales (Mena, 2002)

Figura 2.37 Rangos de variabilidad de los grados de daño según la escala EMS-98 (Lantada, 2007)

Figura 2.38 Funciones de pertenencia de una edificación a las diversas clases de vulnerabilidad (Giovinazzi, 2005). Tomado de Lantada (2007)

Figura 2.39 Procedimiento de obtención del espectro de capacidad de una determinada estructura (Safina, 2003)

Figura 2.40 Espectro de capacidad -trazo continuo- y espectro bilineal de capacidad -trazo discontinuo- de una estructura (Pujades, Barbat \& Lantada, 2007)

Figura 2.41 Ejemplo de función de vulnerabilidad, que relaciona el índice de vulnerabilidad $I_{v}$ con un grado de daño en la estructura, para diversos niveles de intensidad $l_{i}$. (Mena, 2002) 
Figura 2.42 Ejemplo de curva de fragilidad en la que se consideran 4 estados de daño $d s$ diferentes del daño nulo, en función del desplazamiento espectral de la estructura (Pujades, Barbat \& Lantada, 2007)

Figura 2.43 Procedimiento de obtención del espectro de demanda de una determinada estructura (Safina, 2003)

Figura 2.44 Esquema de obtención del punto de desempeño sísmico a partir de los espectros de demanda y capacidad de una determinada estructura (Pujades, Barbat \& Lantada, 2007)

Figura 2.45 Funciones de vulnerabilidad definidas por RISK-UE para distintas tipologías edificatorias (González, 2010)

Figura 2.46 Representación en el espectro de capacidad de los distintos estados de daño definidos en la metodología LM2 (Lantada, Pujades \& Barbat, 2009)

Figura 2.47 Curva de fragilidad de una estructura. Obtención de la probabilidad de daño de cada estado de daño para un desplazamiento espectral $S_{d}$ (Aguilar, 2011)

Figura 2.48 Comparación de las funciones de vulnerabilidad observada en edificios de mampostería no reforzada propuestas por Barbat (1998) para el sismo de Adra (Almería) y Mena (2002) para el sismo de Mula (Murcia), para una intensidad VII en la escala MSK (Mena, 2002)

Figura 2.49 Comparación de la función de vulnerabilidad observada en edificios de hormigón armado obtenida tras el sismo de Lorca de 2011 y las funciones de vulnerabilidad calculada propuestas en Barbat (1998) y Mena (2002), para una intensidad VII en la escala MCS (CARM, 2014)

Figura 2.50 Daño medio estimado por zonas censales para la ciudad de Barcelona según la metodología LM1 de RISK-UE y un sismo de intensidad VI-VII en la escala MSK (Pujades, Lantada \& Barbat, 2007)

Figura 2.51 Daño medio estimado por zonas censales para la ciudad de Barcelona según la metodología LM2 de RISK-UE y un sismo de intensidad VI-VII en la escala ESM-98 (Lantada et al., 2010)

Figura 2.52 Funciones de vulnerabilidad calculada para edificaciones de hormigón armado, acero y madera (Cardona et al., 2012)

Figura 2.53 Distribución de la probabilidad de que edificaciones presenten un grado de daño de colapso según la metodología LM2 de RISK-UE en los municipios de la Región de Murcia, para el sismo de 475 años de periodo de retorno (Benito et al., 2015)

Figura 2.54 Daño medio estimado en los distritos de la ciudad de Lorca según la metodología LM2 de RISK-UE y un sismo de $M_{w}=5,2$, a partir de los modelos $N G A$ de atenuación de: (a) Chiou \& Youngs (2008). (b) Abrahamson \& Silva (2008). (c) Campbell \& Bozorgnia (2008), citados en el apartado 2.1.1.2 (Rivas-Medina et al., 2014) 
Figura 2.55 Tipos de sistemas estructurales recomendables en diseño sísmico: (a) Edificio porticado. (b) Edificio apantallado. (c) Edificio con núcleo. (d) Sistemas duales (Barbat, 1998)

Figura 3.1 Valor del modificador de comportamiento en función de la diferencia de altura entre edificios adyacentes (Lantada, 2007)

Figura 3.2 Valor del modificador de comportamiento según la posición del edificio en la manzana. (Lantada, 2007)

Figura 3.3 Daños sísmicos habituales en edificaciones diseñadas con códigos sísmicos de nivel bajo. (a) Insuficiente atado de antepechos de cubierta (Foto: Murphy, 2011). (b) Cerramientos (Foto: Occhiuzzi et al., 2012). (c) Deficiente calidad de materiales. (d) Insuficiente cuantía de armado (Fotos: Dep. Ingeniería Civil, UPCT, 2011)

Figura 3.4 Falta de confinamiento del hormigón en cabeza de pilares por escasa cuantía de armadura transversal. (a) Desprendimiento del recubrimiento y presencia de barras longitudinales lisas. (b) Pandeo de la armadura longitudinal (Fotos: Ricci, 2010)

Figura 3.5 Espectro normalizado de respuesta elástica para aceleraciones horizontales (NCSE02, 2002)

Figura 3.6 Espectro normalizado de respuesta elástica para aceleraciones horizontales según el EC-8 (CEN, 2004)

Figura 3.7 Insuficiencia o inexistencia de junta sísmica. (a) Separación entre diferentes cuerpos de una misma edificación (Foto: Murphy, 2011). (b), (c), (d) Separación de medianeras entre edificaciones de nueva construcción (Foto: Dep. Ingeniería Civil, UPCT, 2016)

Figura 4.1 Situación del término municipal de Lorca dentro de la Región de Murcia

Figura 4.2 Clasificación del suelo y ordenación del territorio establecida por el PGMO de Lorca

Figura 4.3 Delimitación del núcleo urbano de la ciudad de Lorca

Figura 4.4 Ejemplos de vías de Lorca con dos tipologías edificatorias de distintos periodos. (a) Calle Pío XII, tipo tradicional en el casco antiguo. (b) Avenida Juan Carlos I, tipo tecnológico en la trama urbana (Foto: Dep. Ingeniería Civil, UPCT, 2016)

Figura 4.5 Registros sísmicos en el acelerógrafo del núcleo urbano de Lorca, para la componente horizontal de azimut N30oW, del evento principal de la serie sísmica de magnitud Mw = 5,1. (a) Desplazamiento. (b) Velocidad. (c) Aceleración (Susagna et al., 2012)

Figura 4.6 Posición del epicentro de la ruptura sísmica y profundidad del hipocentro, con dimensiones estimadas, y registro del desplazamiento para la componente horizontal N30oW (Susagna et al., 2012) 
Figura 4.7 Ficha empleada en la campaña de recopilación de datos para la evaluación del índice de vulnerabilidad y el correspondiente grado de daño de cada edificación

Figura 4.8 Detalle de la elaboración de la base de datos: bloque de información general de las edificaciones

Figura 4.9 Ejemplo, para una determinada edificación, de la ficha empleada en la campaña de recopilación de datos para evaluar el índice de vulnerabilidad y el correspondiente grado de daño

Figura 4.10 Modelización gráfica de una edificación con diversos grados de daño sísmico en la escala EMS-98. (a) $\mu_{D}=1$. (b) $\mu_{D}=2$. (c) $\mu_{D}=3$. (d) $\mu_{D}=4$ (SISMIMUR, 2015)

Figura 4.11 Daños en edificaciones tras el sismo de Lorca asociados a un grado de daño $\mu_{D}=1$ en la escala EMS-98

Figura 4.12 Daños en edificaciones tras el sismo de Lorca asociados a un grado de daño $\mu_{D}=2$ en la escala EMS-98

Figura 4.13 Daños en edificaciones tras el sismo de Lorca asociados a un grado de daño $\mu_{D}=3$ en la escala EMS-98

Figura 4.14 Detalle de la construcción de la base de datos: determinación de los modificadores de comportamiento $M_{c}$ según las distintas revisiones del método MIV

Figura 4.15 Detalle de la construcción de la base de datos: determinación de los índices de vulnerabilidad $I_{v}$ de las edificaciones, según las distintas revisiones del método MIV

Figura 4.16 Detalle de la construcción de la base de datos: determinación de los índices de vulnerabilidad $I_{v}$ de las edificaciones aplicando las funciones de pertenencia de RISK-UE, según distintas revisiones del método MIV

Figura 4.17 Detalle de la construcción de la base de datos: determinación del grado de daño medio $\mu_{D}$ de las edificaciones en la escala EMS-98 definido en la metodología LM1 de RISK-UE para un sismo de intensidad VII, según distintas revisiones del método MIV

Figura 4.18 Detalle de la construcción de la base de datos: determinación del grado de daño medio $\mu_{D}$ de las edificaciones en la escala EMS-98 definido en la metodología LM1 de RISK-UE para un sismo de intensidad VIII, según distintas revisiones del método MIV

Figura 4.19 Distribución espacial de las edificaciones seleccionadas, marcadas en color rojo, sobre el núcleo urbano de Lorca

Figura 4.20 Distribución del periodo de construcción de las edificaciones seleccionadas.....

Figura 4.21 Distribución del grado de daño $\mu_{D}$ observado en las edificaciones analizadas tras el sismo de Lorca de 2011 
Figura 4.22 Distribución del grado de daño $\mu_{D}$ observado en las edificaciones analizadas tras el sismo de Lorca de 2011, con un periodo de construcción anterior a 1963.

Figura 4.23 Distribución del grado de daño $\mu_{D}$ observado en las edificaciones analizadas tras el sismo de Lorca de 2011, con un periodo de construcción entre los años 1963 y 1970

Figura 4.24 Distribución del grado de daño $\mu_{D}$ observado en las edificaciones analizadas tras el sismo de Lorca de 2011, con un periodo de construcción entre los años 1971 y 1995

Figura 4.25 Distribución del grado de daño $\mu_{D}$ observado en las edificaciones analizadas tras el sismo de Lorca de 2011, con un periodo de construcción posterior a 1995 .

Figura 4.26 Comparación entre el daño observado en las edificaciones tras el terremoto de Lorca y el grado medio de daño obtenido según el método LM1 de RISK-UE (Milutinovic \& Trendafiloski, 2003), para un sismo de intensidad $I_{E M S-98}=$ VII .....

Figura 4.27 Comparación entre el daño observado en las edificaciones tras el terremoto de Lorca y el grado medio de daño obtenido según la revisión del método LM1 de RISK-UE (Giovinazzi, 2005), para un sismo de intensidad $I_{E M S-98}=$ VII

Figura 4.28 Comparación entre el daño observado en las edificaciones tras el terremoto de Lorca y el grado medio de daño obtenido según la revisión del método LM1 de RISK-UE (Lantada, 2007), para un sismo de intensidad $I_{E M S-98}=$ VII

Figura 4.29 Comparación entre el daño observado en las edificaciones tras el terremoto de Lorca y el grado medio de daño obtenido según la revisión del método LM1 de RISK-UE (Feriche, 2012), para un sismo de intensidad $I_{E M S-98}=$ VII

Figura 4.30 Comparación entre el daño observado en las edificaciones tras el terremoto de Lorca y el grado medio de daño obtenido según la revisión del método LM1 de RISK-UE (Martínez-Cuevas \& Gaspar-Escribano, 2016), para un sismo de intensidad $I_{E M S-98}=\mathrm{VII}$

Figura 4.31 Comparación entre el daño observado en las edificaciones tras el terremoto de Lorca y el grado medio de daño obtenido del modelo propuesto para el método LM1 de RISK-UE, para un sismo de intensidad $I_{E M S-98}=$ VII

Figura 4.32 Comparación entre el daño observado en las edificaciones tras el terremoto de Lorca y el grado medio de daño obtenido según el método LM1 de RISK-UE (Milutinovic \& Trendafiloski, 2003), para un sismo de intensidad $I_{E M S-98}=$ VIII

Figura 4.33 Comparación entre el daño observado en las edificaciones tras el terremoto de Lorca y el grado medio de daño obtenido según la revisión del método LM1 de RISK-UE (Giovinazzi, 2005), para un sismo de intensidad $I_{E M S-98}=$ VIII 
Figura 4.34 Comparación entre el daño observado en las edificaciones tras el terremoto de Lorca y el grado medio de daño obtenido según la revisión del método LM1 de RISK-UE (Lantada, 2007), para un sismo de intensidad $I_{E M S-98}=$ VIII

Figura 4.35 Comparación entre el daño observado en las edificaciones tras el terremoto de Lorca y el grado medio de daño obtenido según la revisión del método LM1 de RISK-UE (Feriche, 2012), para un sismo de intensidad $I_{E M S-98}=$ VIII

Figura 4.36 Comparación entre el daño observado en las edificaciones tras el terremoto de Lorca y el grado medio de daño obtenido según la revisión del método LM1 de RISK-UE (Martínez-Cuevas \& Gaspar-Escribano, 2016), para un sismo de intensidad $I_{E M S-98}=\mathrm{VIII}$

Figura 4.37 Comparación entre el daño observado en las edificaciones tras el terremoto de Lorca y el grado medio de daño obtenido del modelo propuesto para el método LM1 de RISK-UE, para un sismo de intensidad $I_{E M S-98}=$ VIII

Figura 4.38 Diagrama de caja para la variable $D_{i j}$ obtenida de las revisiones existentes del método MIV y la nueva propuesta, para un sismo de intensidad VII en la escala EMS-98

Figura 4.39 Diagrama de caja para la variable $D_{i j}$ obtenida según las diferentes revisiones del método MIV existentes en la literatura y la nueva propuesta, para sismo de intensidad VIII en la escala EMS-98

Figura 4.40 Proceso de georreferenciación de la base de datos implementada de daños en edificaciones de hormigón armado tras el sismo de Lorca 2011

Figura 4.41 Índices de vulnerabilidad $I_{v_{-} b}$, según el modelo propuesto del método MIV, de las edificaciones de hormigón armado seleccionadas en la trama urbana del Suroeste de Lorca

Figura 4.42 Representación mediante una función de densidad Kernel de los índices de vulnerabilidad de las edificaciones de hormigón armado seleccionadas en la ciudad de Lorca

Figura 4.43 Representación mediante una función de densidad Kernel de los índices de vulnerabilidad de las edificaciones de hormigón armado seleccionadas en la ciudad de Lorca, junto con los tipos de suelo según la clasificación del EC-8 identificados en el estudio de microzonación CARM (2014)

Figura A.1 Ejemplo A. Ficha empleada en la campaña de recopilación de datos para la evaluación del índice de vulnerabilidad y el correspondiente grado de daño de cada edificación

Figura A.2 Ejemplo A. Afecciones observadas en la edificación tras el sismo de Lorca. (a) y (b) Daños en cerramiento de fachada. (c) Daños en cubierta. (d) Inexistencia de daños en pilares de planta baja 
Figura A.3 Ejemplo B. Ficha empleada en la campaña de recopilación de datos para la evaluación del índice de vulnerabilidad y el correspondiente grado de daño de cada edificación

Figura A.4 Ejemplo B. Afecciones observadas en la edificación tras el sismo de Lorca. Daños en: (a) Cubierta. (b) Tabiquería interior. (c) Cerramiento. (d) Fachada, por efecto golpeteo

Figura A.5 Ejemplo C. Ficha empleada en la campaña de recopilación de datos para la evaluación del índice de vulnerabilidad y el correspondiente grado de daño de cada edificación

Figura A.6 Ejemplo C. Afecciones observadas en la edificación tras el sismo de Lorca. (a) Vista general del edificio. (b) Daños en cerramiento de fachada. (c) Daños en antepecho de cubierta. (d) Daños en tabiquería interior .

Figura A.7 Ejemplo D. Ficha empleada en la campaña de recopilación de datos para la evaluación del índice de vulnerabilidad y el correspondiente grado de daño de cada edificación

Figura A.8 Ejemplo D. Afecciones observadas en la edificación tras el sismo de Lorca. (a) Vista general del edificio. (b) Daños en tabiquería interior. (c) y (d) Daños en cubierta .......

Figura A.9 Ejemplo E. Ficha empleada en la campaña de recopilación de datos para la evaluación del índice de vulnerabilidad y el correspondiente grado de daño de cada edificación

Figura A.10 Ejemplo E. Afecciones observadas en la edificación tras el sismo de Lorca. (a) Vista general del edificio. (b) Daños en tabiquería interior. (c) y (d) Daños en cubierta y caída de antepechos

Figura A.11 Ejemplo F. Ficha empleada en la campaña de recopilación de datos para la evaluación del índice de vulnerabilidad y el correspondiente grado de daño de cada edificación

Figura A.12 Ejemplo F. Afecciones observadas en la edificación tras el sismo de Lorca. Daños en: (a) Fachada, por efecto golpeteo. (b) y (c) Tabiquería interior. (d) Tabiquería interior y pilares

Figura A.13 Ejemplo G. Ficha empleada en la campaña de recopilación de datos para la evaluación del índice de vulnerabilidad y el correspondiente grado de daño de cada edificación

Figura A.14 Ejemplo G. Afecciones observadas en la edificación tras el sismo de Lorca. Daños en: (a) y (b) Tabiquería interior. (c) Cerramiento. (d) Vigas en zunchos de borde ......

Figura A.15 Ejemplo H. Ficha empleada en la campaña de recopilación de datos para la evaluación del índice de vulnerabilidad y el correspondiente grado de daño de cada edificación 
Figura A.16 Ejemplo H. Afecciones observadas en la edificación tras el sismo de Lorca. Daños en: (a) Tabiquería interior. (b) Cerramiento. (c) Nudo viga-pilar con desprendimiento del recubrimiento de hormigón. (d) Fachada, por efecto golpeteo

Figura A.17 Ejemplo I. Ficha empleada en la campaña de recopilación de datos para la evaluación del índice de vulnerabilidad y el correspondiente grado de daño de cada edificación

Figura A.18 Ejemplo I. Afecciones observadas en la edificación tras el sismo de Lorca. Daños en: (a), (b) y (c) Pilares cortos en planta baja, con pandeo de armadura longitudinal. (d) Vigas y tabiquería interior

Figura A.19 Ejemplo J. Ficha empleada en la campaña de recopilación de datos para la evaluación del índice de vulnerabilidad y el correspondiente grado de daño de cada edificación

Figura A.20 Ejemplo J. Afecciones observadas en la edificación tras el sismo de Lorca. Daños en: (a), (b) y (c) Pilares cortos en planta baja, con pandeo de armadura longitudinal. (d) Vigas y tabiquería interior

Figura A.21 Ejemplo K. Ficha empleada en la campaña de recopilación de datos para la evaluación del índice de vulnerabilidad y el correspondiente grado de daño de cada edificación

Figura A.22 Ejemplo K. Afecciones observadas en la edificación tras el sismo de Lorca. Daños en: (a), (b) y (c) Pilares, con seccionamiento completo a cortante. (d) Cerramiento en fachada

Figura A.23 Ejemplo L. Ficha empleada en la campaña de recopilación de datos para la evaluación del índice de vulnerabilidad y el correspondiente grado de daño de cada edificación

Figura A.24 Ejemplo L. Afecciones observadas en la edificación tras el sismo de Lorca. Daños en: (a) Vigas. (b) Tabiquería interior. (c) y (d) Pilares, de forma generalizada 


\section{LISTADO DE TABLAS}

Tabla 2.1 Estimación de la frecuencia anual media de ocurrencia de terremotos en la Tierra (USGS, 2016)

Tabla 2.2 Estimación de ocurrencia media de terremotos en la península Ibérica (IGN, 2016a)

Tabla 2.3 Grados de intensidad definidos en la escala macrosísmica europea EMS-98 (Grünthal, 1998; Mena, 2002)

Tabla 2.4 Tipos de magnitud propuestos en la literatura, periodos del movimiento sísmico para los cuales son sensibles y límites de saturación (McGuire, 2004)

Tabla 2.5 Comparación entre los tipos de terreno propuestos en diversos códigos sísmicos (CARM, 2014)

Tabla 2.6 Comparativa entre grados de daño propuestos en diversas metodologías (Lantada, 2007)

Tabla 2.7 Grados de daño en las metodologías RISK-UE (LM1 y LM2) y HAZUS (Moreno, 2011)

Tabla 2.8 Clasificación de las edificaciones según la escala MSK-64 (Lantada, 2007)

Tabla 2.9 Parámetros I que condicionan la obtención del índice de vulnerabilidad para el caso de edificaciones de mampostería no reforzada. Coeficientes $K_{i}$ de valoración y factores de ponderación $W_{i}$ (Benedetti \& Petrini, 1984)

Tabla 2.10 Parámetros / que condicionan la obtención del índice de vulnerabilidad para el caso de edificaciones hormigón armado. Coeficientes $K_{i}$ de valoración y factores de ponderación $W_{i}$ (Benedetti, Benzoni \& Parisi, 1988)

Tabla 2.11 Cuantificación de las clases de vulnerabilidad de la EMS-98 mediante índices de vulnerabilidad (Giovinazzi, 2005)

Tabla 2.12 Índices de vulnerabilidad propuestos por Milutinovic \& Trendafiloski (2003) para las tipologías de la matriz BTM de RISK-UE (Martínez-Cuevas, 2014)

Tabla 2.13 Índices de vulnerabilidad propuestos por Lagomarsino \& Giovinazzi (2006) para algunas tipologías edificatorias basadas en pórticos de hormigón armado

Tabla 2.14 Modificadores de comportamiento $M_{C}$ del índice de vulnerabilidad propuestos por Milutinovic \& Trendafiloski (2003) para edificaciones de mampostería no reforzada (Lantada, 2007) 
Tabla 2.15 Modificadores de comportamiento $M_{C}$ del índice de vulnerabilidad propuestos por Milutinovic \& Trendafiloski (2003) para edificaciones de hormigón armado (Lantada, 2007)

Tabla 2.16 Índices de vulnerabilidad básico $I_{v}$ para algunas tipologías de monumentos en RISKUE (Lagomarsino et al., 2003) y parámetro de ductilidad $\phi$ para la obtención del grado de daño medio (Lagomarsino \& Giovinazzi, 2006) .

Tabla 2.17 Ejemplo de matriz de probabilidad de daño para edificaciones de mampostería no reforzada de baja altura (Aguilar, 2011)

Tabla 2.18 Objetivos del desempeño sísmico recomendado por VISION 2000 según la clasificación del edificio (SEAOC, 1995)

Tabla 2.19 Grados de daño en el método LM1 de RISK-UE, correspondientes a los definidos en la escala EMS-98 (Grünthal, 1998)

Tabla 2.20 Umbrales de los estados de daño definidos en la metodología LM2 de RISK-UE en función de los puntos de cedencia y de capacidad última de un espectro de capacidad (Lantada, Pujades \& Barbat, 2009)

Tabla 3.1 Modificadores de comportamiento $M_{C}$ del índice de vulnerabilidad propuestos por Giovinazzi (2005) para edificaciones de hormigón armado (Martínez-Cuevas, 2014)

Tabla 3.2 Modificadores de comportamiento relativo al número plantas del edificio (Lantada, 2007)

Tabla 3.3 Modificador $M_{i p}$ en función de la regularidad en planta del edificio (Lantada, 2007)

Tabla 3.4 Modificadores de comportamiento $M_{C}$ del índice de vulnerabilidad para edificaciones de hormigón armado propuestos por Lantada (2007) y Lantada et al. (2010)

Tabla 3.5 Modificadores de comportamiento $M_{C}$ del índice de vulnerabilidad para edificaciones de hormigón armado propuestos por Feriche (2012)

Tabla 3.6 Modificadores de comportamiento $M_{C}$ del índice de vulnerabilidad para edificaciones de hormigón armado propuestos por Martínez-Cuevas \& GasparEscribano (2016)

Tabla 3.7 Modificadores regionales del índice de vulnerabilidad para algunas tipologías edificatorias de la ciudad de Barcelona (Lantada, 2007)

Tabla 3.8 Modificadores regionales del índice de vulnerabilidad para algunas tipologías edificatorias en la ciudad de Lorca (Feriche et al., 2012a)

Tabla 3.9 Incrementos de vulnerabilidad para factores relacionados con el código sísmico de diseño y que influyen en el comportamiento estructural de edificaciones de hormigón armado 
Tabla 3.10 Valores del modificador de comportamiento $M_{c}$ para edificaciones de hormigón armado, en función de los niveles del código sísmico de diseño definidos en RISKUE

Tabla 3.11 Periodo natural de edificaciones aporticadas de hormigón armado en función del número de plantas sobre el terreno, según procedimiento simplificado en NCSE-02 (2002)

Tabla 3.12 Periodo natural de edificios de hormigón armado en función del número de plantas, según el procedimiento simplificado definido en EC-8 (CEN, 2004)

Tabla 3.13 Valores del modificador de comportamiento $M_{h}$ según el número de plantas sobre rasante para edificaciones de hormigón armado, en función de los niveles del código sísmico de diseño definidos en RISK-UE

Tabla 3.14 Valores del modificador de comportamiento $M_{j}$ relacionado la disposición de juntas sísmicas entre edificios de hormigón armado, en función del nivel del código sísmico de diseño definido en RISK-UE .

Tabla 3.15 Modificadores de comportamiento $M_{C}$ del índice de vulnerabilidad para edificaciones de hormigón armado. En negrita se muestran los parámetros modificados

Tabla 4.1 Magnitud y profundidad del hipocentro de los terremotos principales de la serie sísmica del 11 de mayo en Lorca (Cabañas et al., 2011, 2014)

Tabla 4.2 Aceleración, velocidad y desplazamiento de los tres eventos principales de la serie sísmica del 11 de mayo, registrados en el acelerógrafo del núcleo urbano de Lorca (Susagna et al., 2012)

Tabla 4.3 Comparativa de los códigos sísmicos publicados en España

Tabla 4.4 Clasificación de los niveles de código de diseño sísmico establecidos en RISK-UE en función del periodo de construcción de la edificación y de la norma sísmica española vigente

Tabla 4.5 Periodo constructivo de las edificaciones analizadas en función del código sísmico de diseño

Tabla 4.6 Medidas de tendencia central del índice de vulnerabilidad $I_{v_{-} b}{ }^{*}$ de las edificaciones seleccionadas según las revisiones de distintos autores y la nueva propuesta

Tabla 4.7 Medidas de tendencia central del grado de daño medio $\mu_{D}{ }^{*}$ de las edificaciones seleccionadas para un sismo de intensidad VII, según las revisiones de distintos autores y la nueva propuesta

Tabla 4.8 Medidas de tendencia central del grado de daño medio $\mu_{D}{ }^{*}$ de las edificaciones seleccionadas para un sismo de intensidad VIII, según las revisiones de distintos autores y la nueva propuesta 
Tabla 4.9 Medidas de tendencia central de la nueva variable de daño $Z_{i j}$ en las edificaciones analizadas según las revisiones del método MIV existentes en la literatura y la nueva propuesta, para sismo de intensidad VII en la escala EMS-98

Tabla 4.10 Medidas de tendencia central de la diferencia $D_{i j}$ en las edificaciones analizadas según las revisiones existentes del método MIV y la nueva propuesta, para un sismo de intensidad VII en la escala EMS-98

Tabla 4.11 Medidas de tendencia central de la nueva variable de daño $Z_{i j}$ en las edificaciones analizadas según las revisiones existentes del método MIV y la nueva propuesta, para un sismo de intensidad VIII en la escala EMS-98

Tabla 4.12 Medidas de tendencia central de la diferencia $D_{i j}$ en las edificaciones analizadas según las revisiones existentes del método MIV y la nueva propuesta, para un sismo de intensidad VIII en la escala EMS-98.

Tabla 4.13 Hipótesis de contraste consideradas en el test estadístico

Tabla 4.14 Número de contrastes estadísticos realizados

Tabla 4.15 Resultados del Test no paramétrico de Wilcoxon para datos apareados, para los registros correspondientes con un sismo de intensidad VII en la escala EMS-98 .......

Tabla 4.16 Resultados del Test no paramétrico de Wilcoxon para datos apareados, para los registros correspondientes con un sismo de intensidad VIII en la escala EMS-98 .......

Tabla B.1 Resumen de la base de datos implementada. Bloque A Información general y observaciones de campo. Bloque B Obtención del índice de vulnerabilidad .

Tabla B.2 Resumen de la base de datos implementada. Bloques C y D Obtención del grado medio de daño para uno sismo de intensidad $I_{E M S-98}=$ VII y VIII, respectivamente ...... 


\section{CAPÍTULO 1}

INTRODUCCIÓN

\subsection{GENERALIDADES}

Los terremotos representan uno de los fenómenos naturales con mayor capacidad para producir catástrofes con consecuencias devastadoras (Figura 1.1). Tan sólo en los últimos 30 años se pueden destacar algunos ejemplos de grandes eventos sísmicos: Loma Prieta (EEUU, 1989), Northridge (EEUU, 1994), Kobe (Japón, 1995), Kocaeli (Turquía, 1999), Bam (Irán, 2004), L'Aquila (Italia, 2009), Puerto Príncipe (Haití, 2010), Emilia Romagna (Italia, 2012), Iquique (Chile, 2014), Gorkha (Nepal, 2015) o Amatrice (Italia, 2016).

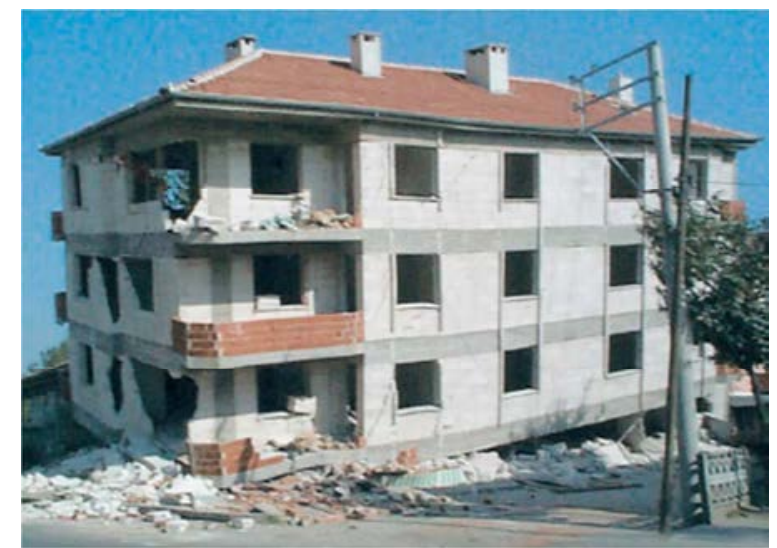

(a)

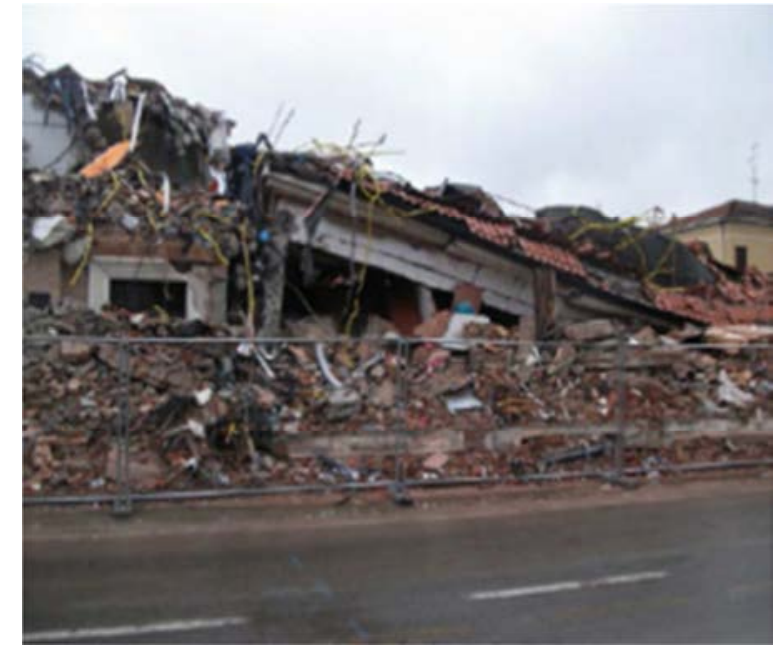

(c)

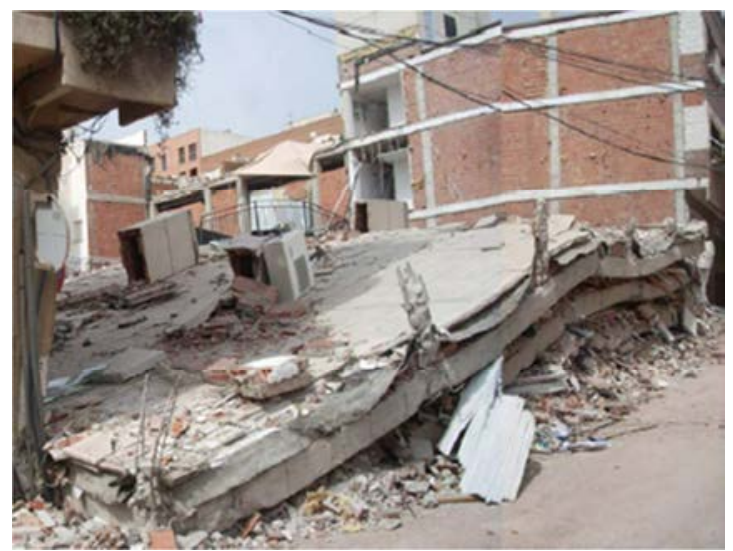

(b)

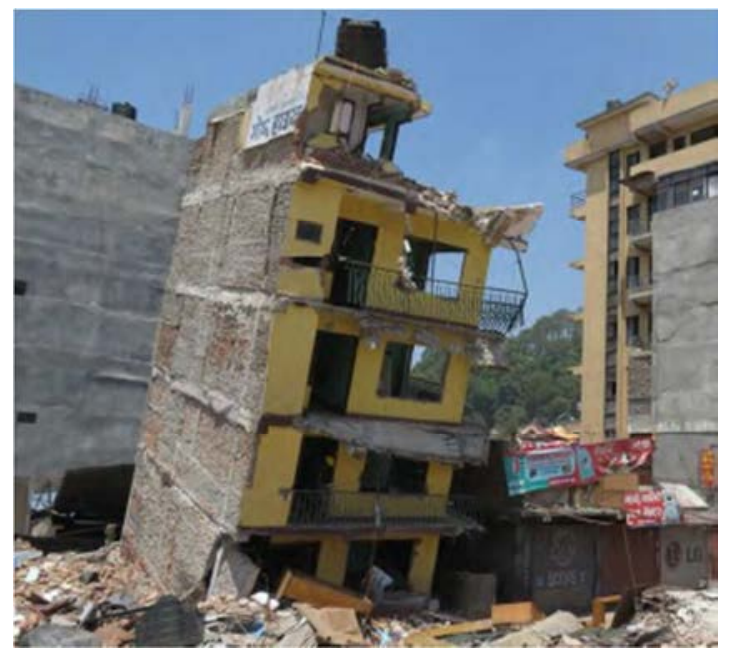

(d)

Figura 1.1. Edificaciones dañadas tras un terremoto: (a) Kocaeli, Turquía (Foto: AeDES, 2009). (b) Lorca, España (Foto: García-Ayllón \& Tomás, 2013). (c) Emilia Romagna, Italia (Foto: Manfredi et al., 2014). (d) Nepal, 2015 (Foto: EERI, 2016). 
A las pérdidas de vidas humanas han de añadirse las cuantiosas pérdidas económicas debidas, no sólo a la reconstrucción de las edificaciones e infraestructuras dañadas por el evento sísmico, sino también a la interrupción de la actividad económica, de las líneas de abastecimiento y comunicación, y de los distintos servicios públicos (ATC-25, 1991; Carreño, 2007; EERI, 2016). A estas últimas afecciones, no relacionadas directamente con los costes de reparación o reposición de las estructuras dañadas por el terremoto, se les denomina comúnmente costes indirectos de un sismo (Whitman et al., 1997).

A modo de ejemplo se resume a continuación el número de fallecidos y afectados debido a eventos sísmicos, junto con las pérdidas económicas generadas en millones de dólares (USD), de un total de 24 grandes terremotos ocurridos entre el sismo de Hindu Kush en Afganistán en 2002 y el de Lorca en el año 2011 (Valcárcel, 2013), extraído a partir de los catálogos sísmicos disponibles en diversos organismos internacionales como el US Geological Survey (USGS) o el Earthquake Engineering Research Institute (EERI). Por afectados se hace referencia al total de personas que requieren asistencia inmediata durante el periodo de emergencia, esto es, personas que requieren alimento, agua, albergue o asistencia médica, junto con aquellas personas heridas y sin hogar después del terremoto.

Según se muestra en las Figuras 1.2 y 1.3, el país más afectado en este intervalo de tiempo fue China, donde las pérdidas económicas ocasionadas sobrepasaron los 80.000 millones USD, mientras que en países como Chile, Italia o Haití se superaron los 10.000 millones USD. En cuanto al número de fallecidos, pueden observarse países como Indonesia o Haití en los que se superaron los 150.000 fallecidos durante la citada década.

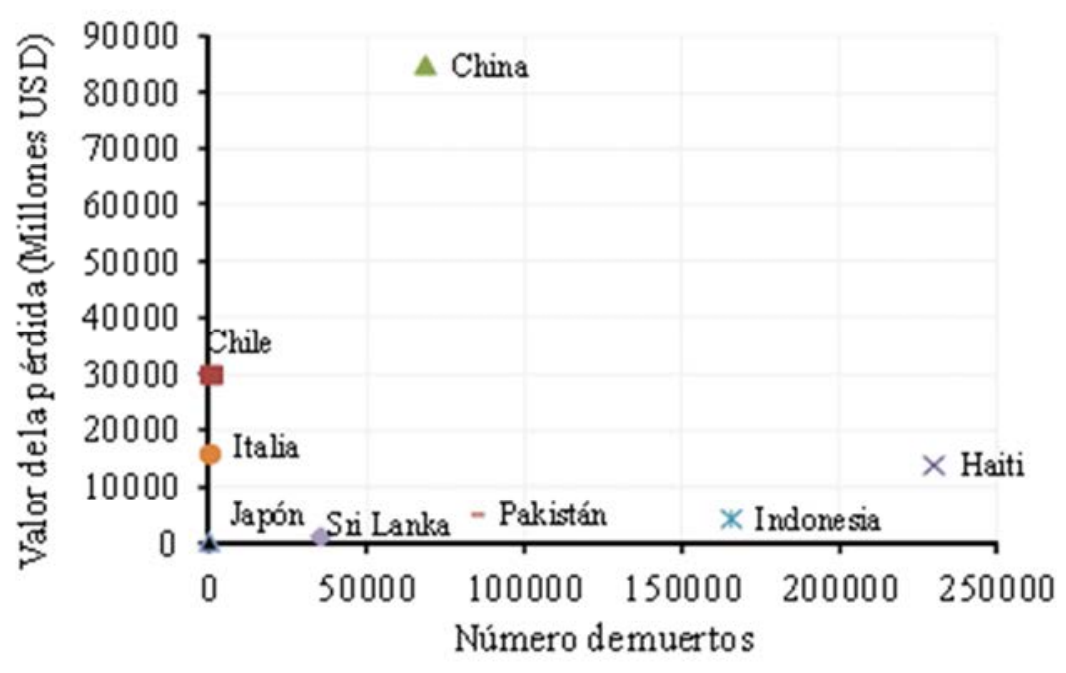

Figura 1.2. Pérdidas económicas y número de fallecidos de los principales eventos sísmicos entre 2002 y 2011 (Valcárcel, 2013).

Asimismo, se pueden destacar las conclusiones del último informe GAR - Global Assessment Report on Disaster Risk Reduction (UNISDR, 2013), impulsado por Naciones Unidas, donde se estiman las pérdidas económicas potenciales por países, relacionadas con la posible ocurrencia de terremotos y otros fenómenos naturales. Entre los países con mayores niveles 
de riesgo sísmico se encontrarían Estados Unidos, Japón o China (Figura 1.4), donde se superarían los 5.000 millones USD.

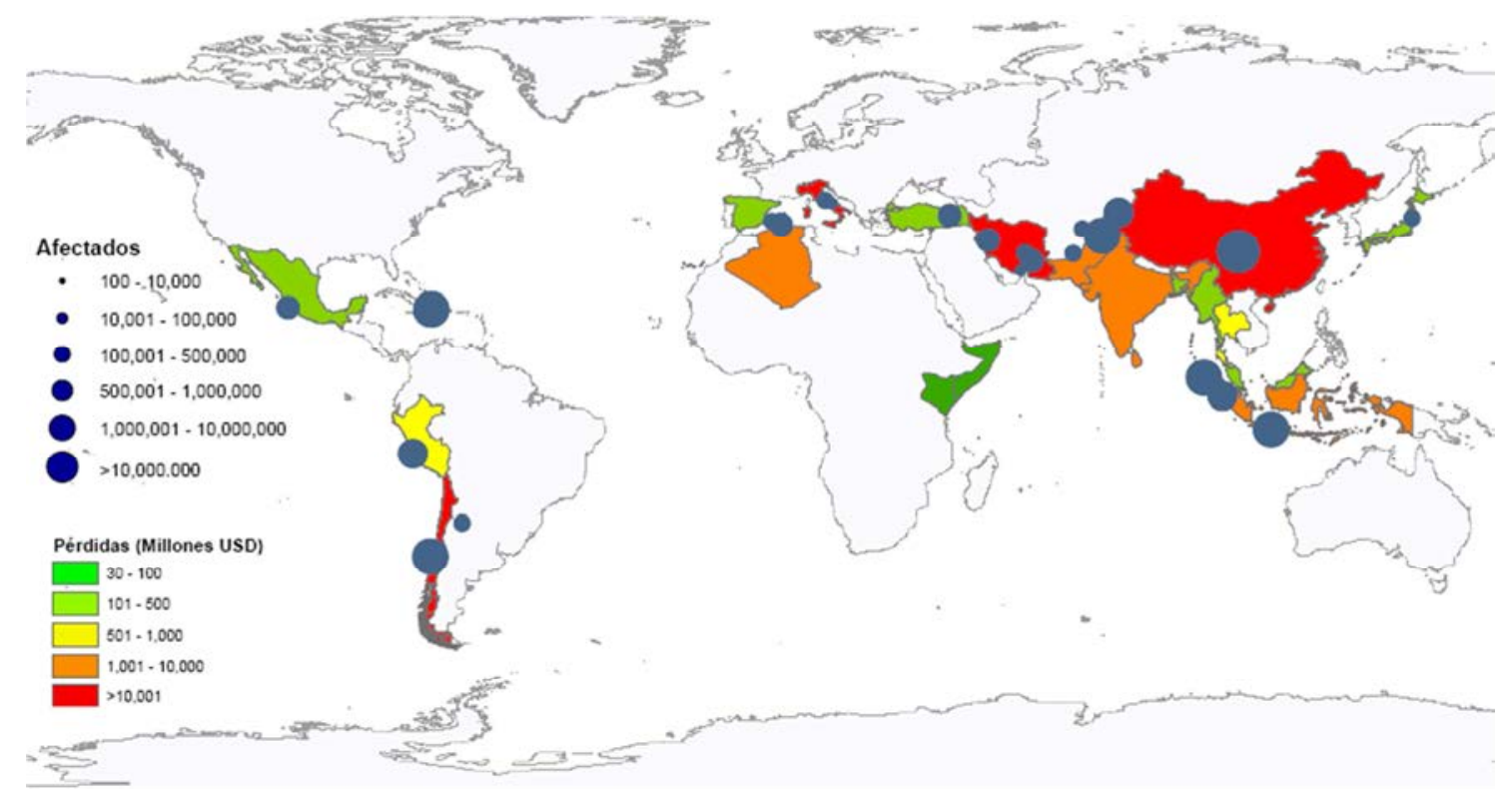

Figura 1.3. Mapa mundial de fallecidos y pérdidas económicas de los principales eventos sísmicos entre 2002 y 2011 (Valcárcel, 2013).

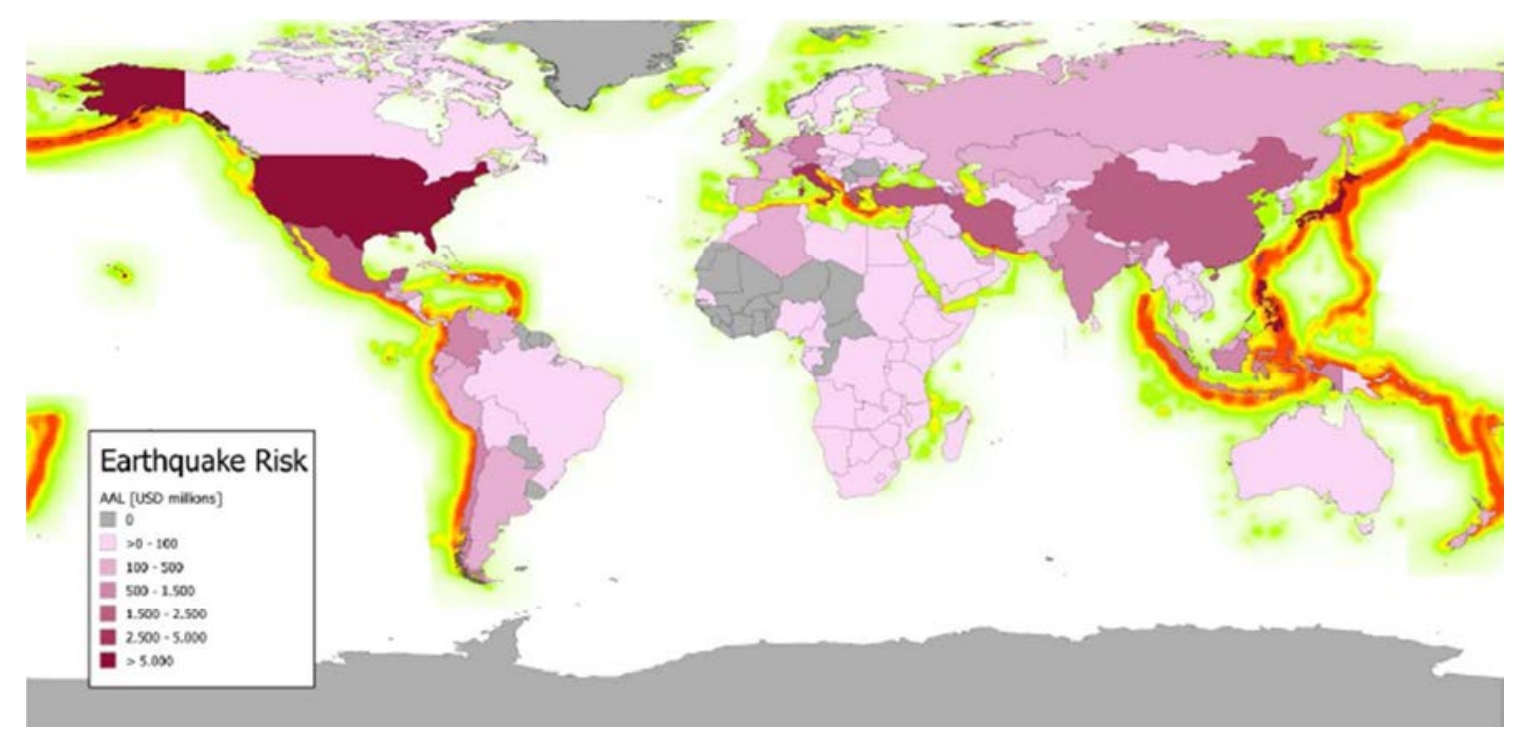

Figura 1.4. Distribución por países de las pérdidas económicas potenciales derivadas de fenómenos sísmicos, expresadas en USD en forma de pérdidas medias anualizadas -Average Annual Losses(UNISDR, 2013).

En este sentido, el riesgo sísmico se puede definir como el grado de pérdidas esperadas que sufren las estructuras durante el periodo de exposición que permanecen expuestas a la acción sísmica (Bonett, 2003). Ya desde la Antigüedad, el ser humano ha intentado mitigar, aun desconociendo su naturaleza y los mecanismos de daño intervinientes, los efectos de estos fenómenos en las edificaciones y demás estructuras mediante la aplicación de criterios y reglas intuitivas, meramente empíricas (Barbat, 1998). 
Únicamente a partir del siglo XX, se ha empezado a comprender en mayor profundidad el fundamento y las causas de la acción sísmica, gracias tanto al avance técnico de la ingeniería sísmica como a las lecciones aprendidas con las sucesivas experiencias de terremotos ocurridos (ATC-13; 1985; Bertero, 1992; EERI, 2004; FEMA P-58; 2012). Fruto de estos estudios e investigaciones se han desarrollado medidas y procedimientos destinados a reducir los efectos de estos desastres naturales, apareciendo el concepto de diseño sismorresistente de estructuras.

Bertero (1992), a partir del análisis de dichas experiencias, determina los siguientes factores como aquellos que condicionan de un modo más significativo la ocurrencia de un desastre sísmico:

$\checkmark$ Severidad del terremoto: sismos de escasa magnitud presentan menor probabilidad de producir daños de importancia en áreas urbanas.

$\checkmark$ Distancia entre el hipocentro y el área urbana afectada: la aceleración del terreno se atenúa conforme la señal sísmica se aleja del foco emisor. Exceptuando posibles efectos locales, generalmente a grandes distancias de la fuente del evento sísmico disminuye la probabilidad de que se produzcan daños significativos.

$\checkmark$ Tamaño, distribución y desarrollo económico de las poblaciones existentes en la zona afectada. Aglomeraciones urbanas intensamente concentradas suponen un mayor número de elementos en riesgo ante una cierta acción sísmica. Por otra parte, sociedades con un nivel económico y socio-cultural elevado dispondrán generalmente de un grado científico-técnico de conocimiento que les permita establecer mejores prácticas en cuanto al diseño y ejecución de sus edificaciones e infraestructuras.

$\checkmark$ Grado de preparación contra el sismo, entendido como la existencia de planes de actuación en caso de terremotos, desarrollados por las instituciones públicas responsables, así como al nivel de concienciación social frente a este tipo de fenómenos.

De este modo se observa la interrelación de dos variables independientes en la evaluación del riesgo sísmico en áreas urbanas: la peligrosidad y la vulnerabilidad sísmica (Figura 1.5). Estos conceptos han sido ampliamente abordados en la literatura (Sandi, 1986; Dolce et al., 1995; Yépez 1996), pudiéndose establecer las siguientes definiciones (Barbat et al., 2010; Blázquez, 2013):

$\checkmark \quad$ La peligrosidad sísmica representa la probabilidad de ocurrencia, dentro de un período específico de tiempo y un área dada, de un movimiento sísmico del terreno de una cierta severidad. Existen, además, una serie de efectos indirectos (Bozzo \& Barbat, 2000) o colaterales (Mena, 2002), derivados de fenómenos como la licuefacción, deslizamientos del terreno, asentamientos o inundaciones, y relacionados con las características geológicas y geotécnicas del terreno, cuyas consecuencias sobre un 
determinado emplazamiento pueden ser incluso más graves que las del propio terremoto (Blázquez \& López-Querol, 2003; García-Rodríguez, 2008; Feriche, 2012).

$\checkmark \quad$ La vulnerabilidad sísmica de una estructura, se puede definir como su predisposición intrínseca a sufrir daño ante la ocurrencia de un movimiento sísmico de una severidad determinada. Esta propiedad, directamente relacionada con las características de diseño y construcción de la edificación, como la tipología estructural, la geometría o la calidad de los materiales, constituye por tanto un factor interno de la misma, independiente de la acción sísmica.

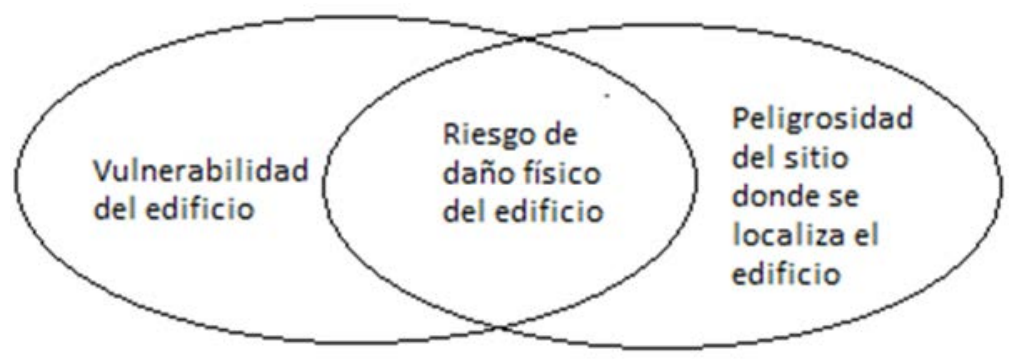

Figura 1.5. Factores que condicionan el nivel de riesgo sísmico de una edificación (Aguilar, 2011).

Al análisis de ambas variables en una determinada región, y posterior desarrollo de medidas destinadas a mejorar la respuesta sísmica de las edificaciones de la misma, se le denomina comúnmente como mitigación del riesgo sísmico. Este tipo de estudios profundizan en la comprensión y el conocimiento del impacto de los terremotos, reduciendo los efectos sísmicos sobre en el medio físico, social, económico, político y cultural de un determinado emplazamiento (EERI, 2004).

En este sentido son muchos los trabajos destinados a la evaluación del riesgo sísmico en áreas urbanas, ya sea a nivel regional, nacional o internacional. Aunque este aspecto se expondrá con mayor detalle en el Capítulo 2 de la Tesis, se pueden destacar, en una primera aproximación, tres grandes programas internacionales elaborados durante las últimas décadas en este campo:

$\checkmark$ La metodología HAZUS $(1999,2008)$, bajo el auspicio y financiación del organismo estadounidense Federal Emergency Management Agency (FEMA), dirigida a la estimación y mitigación de las pérdidas potenciales debidas a cualquier tipo de riesgo natural en EEUU. Apoyada en los sucesivos informes publicados por el Applied Technology Council (ATC-13, ATC-25, ATC-36), este programa cuenta con una amplia difusión y aceptación internacional, constituyendo una excelente base para cualquier tipo de estudio en la materia.

$\checkmark$ Los proyectos RADIUS (1999) y GAR (UNISDR, 2011; UNISDR, 2013), impulsados por Naciones Unidas con el fin de mitigar los riesgos naturales en áreas urbanas, especialmente en aquellas regiones más desfavorecidas. El primero, enmarcado dentro de la "Década Internacional para la Reducción de los Desastres Naturales" 
(IDNDR), perseguía reducir las pérdidas de vidas humanas y los daños tanto económicos como sociales causados por los terremotos, desarrollando una serie de herramientas prácticas para el tratamiento y gestión del riesgo sísmico mediante el estudio de diversos escenarios de daños en nueve ciudades del planeta. El segundo, extiende estos análisis a otros tipos de riesgos naturales como huracanes e inundaciones, ampliando el ámbito de evaluación a una escala más global.

$\checkmark$ El proyecto RISK-UE (Mouroux \& Le Brun, 2006), desarrollado por la Unión Europea, persigue crear una metodología general similar a la implementada en Estados Unidos con HAZUS, destinada a la evaluación del riesgo sísmico en Europa. Para ello analiza los diferentes niveles de sismicidad y las características de las principales tipologías edificatorias en siete ciudades europeas: Barcelona (España), Sofía (Bulgaria), Niza (Francia), Tesalónica (Grecia), Catania (Italia), Bitola (Macedonia) y Bucarest (Rumanía). Estructurado mediante una organización modular, constituye la principal herramienta existente actualmente para el análisis de la vulnerabilidad y el riesgo sísmico en cualquier zona de Europa.

En la Región de Murcia se pueden destacar asimismo dos grandes proyectos en materia de estudio y mitigación del riesgo sísmico, desarrollados a partir de las experiencias obtenidas tras los sismos de Mula (1999), Bullas (2002) y La Paca (2005), y actualizados recientemente tras el terremoto de Lorca (2011):

$\checkmark$ El proyecto RISMUR (Benito et al., 2006; Benito et al., 2015) de Riesgo Sísmico en la Comunidad Autónoma de la Región de Murcia, financiado por el Instituto Geográfico Nacional y la Dirección General de Protección Civil de la Región de Murcia. Es este documento se efectúa un completo estudio de la peligrosidad sísmica en la Región de Murcia, definiéndose mapas de peligrosidad y riesgo sísmico de todo el ámbito regional para los diversos escenarios propuestos.

$\checkmark$ El proyecto SISMIMUR (2006; 2015) de Plan Especial de Protección Civil ante el Riesgo Sísmico en Región de Murcia, elaborado por la Dirección General de Protección Civil de la Región de Murcia. Este programa tiene como objetivo asegurar la intervención eficaz y coordinada de los recursos y medios disponibles dentro de la Administración tanto autonómica como estatal, con el fin de limitar las consecuencias de los posibles terremotos que se puedan producir sobre las personas, los bienes, líneas y servicios vitales y el medio ambiente, estableciendo los procedimientos de actuación en caso de terremoto. Para ello el Plan parte de la información recogida en el RISMUR relativa a la peligrosidad sísmica existente y a la vulnerabilidad de las construcciones que pueden ser afectadas.

\subsection{MOTIVACIÓN}

A pesar de los avances técnicos logrados en diseño sismorresistente de estructuras, algunas de las últimas catástrofes sísmicas (España 2011, Nepal 2015, Italia 2016) han vuelto a evidenciar 
el inadecuado comportamiento de multitud de estructuras, no solamente aquéllas diseñadas sin normativa sísmica -o con normas antiguas-, sino también aquéllas basadas en códigos recientes (Carreño et al., 2012; Perepérez, 2014a).

Una de las causas de este inadecuado comportamiento se debe a la incorrecta predicción de las características de los terremotos esperables, es decir, de la peligrosidad sísmica, sobre la cual se fundamenta la definición de los terremotos de diseño adoptados por las diversas normas sismorresistentes (Barbat, 2011). Como ejemplo, en la experiencia de Lorca de 2011 la máxima aceleración obtenida fue de 0,365g (Benito et al., 2012; Cabañas et al., 2014), triplicando el valor de la aceleración básica propuesto por la norma sísmica NCSE-02 para la localidad, el cual estaba fijado en $a_{b}=0,12 \mathrm{~g}$.

Por otra parte, el crecimiento exponencial de la población en las grandes ciudades durante las últimas décadas del s. XX ha supuesto un aumento de los niveles de riesgo sísmico existentes, incrementando el número de elementos expuestos a la acción sísmica y, consecuentemente, los daños potenciales que puedan afectar tanto a personas como edificaciones y demás infraestructuras ante un posible terremoto (Barbat, 1998; Lantada, Pujades \& Barbat, 2009; UNISDR, 2013; Perepérez, 2014a). La escasez de recursos materiales y económicos, así como la falta de planeamiento y normativa, condicionan el comportamiento sísmico de las edificaciones, especialmente en regiones subdesarrolladas o en vías de desarrollo, según se pudo comprobar en los recientes terremotos de Haití 2010 o Nepal 2015 (Molina et al., 2014; Liang \& Zhou, 2016).

Las mejoras realizadas en materia sismorresistente se han enfocado principalmente al diseño y ejecución de estructuras o edificaciones nuevas, adaptándose en menor medida a la evaluación y rehabilitación de edificios existentes (Giovinazzi, Lagomarsino \& Pampanin, 2006). No obstante, dado que el número de edificios existentes en un área urbana es muy elevado en comparación con el número de estructuras nuevas o en construcción, estas técnicas de carácter sísmico desarrolladas no han supuesto, en la práctica, mejoras significativas en la vulnerabilidad sísmica dentro del núcleo urbano.

Asimismo, las recientes experiencias sísmicas han evidenciado de nuevo las limitaciones existentes en el diseño sismorresistente basado en resistencia y en el control de fuerzas, propuesto en algunos códigos sísmicos, mediante el cual se considera un determinado nivel de movimiento del terreno para el que la estructura no debe colapsar. Sin embargo, la seguridad frente al colapso ante grandes sismos no implica necesariamente un comportamiento aceptable de la edificación frente a terremotos de menor tamaño, puesto que se pueden producir de igual modo daños significativos debido a sismos de naturaleza más frecuente, que acaben provocando la ruina económica de la edificación.

Por tanto, el analisis del comportamiento sísmico de las edificaciones en áreas urbanas continua constituyendo uno de los principales objetivos en el ámbito de la ingeniería sísmica (Cardona et al., 2008; FEMA P-58; 2012). En base a la definición de riesgo sísmico presentada en el apartado 1.1, los trabajos destinados a su evaluación y mitigación en un determinado 
emplazamiento pueden ser abordados bajo dos vertientes distintas: definiendo de forma más precisa la peligrosidad sísmica a la que está expuesta la región analizada, o mejorando la respuesta sísmica de las edificaciones de la trama urbana, lo que sienta las bases de los estudios de vulnerabilidad sísmica (McGuire, 2004). No obstante, la vulnerabilidad es la variable sobre la cual se puede actuar de un modo más directo (Pérez-Ruiz et al, 2007), evaluando el estado y comportamiento sísmico de las estructuras y edificios existentes.

A partir de dicha predicción se puede, por un lado, definir técnicas y soluciones de reparación y rehabilitación de las edificaciones y, por otro, mejorar la planificación y gestión de las situaciones de emergencia post-sismo (SISMIMUR, 2015; García-Ayllón, Tomás \& Ródenas, 2017), pudiendo reducir de forma preventiva las pérdidas humanas y económicas esperables bajo la denominada filosofía de actuación ex ante (Carreño, 2007, Aguilar, 2011).

Con respecto a España, como país de sismicidad baja o moderada, la aleatoriedad del fenómeno sísmico y la escasa memoria de la población han provocado una disminución de la percepción social e institucional de la amenaza (Barbat, Oller \& Pujades, 2005; Blázquez, 2011; García-Arribas, 2013; Perepérez, 2014b; Ivorra, 2016), favorecida en parte por la actividad sísmica anómalamente reducida durante la segunda mitad del s. XX. Este hecho ha derivado en una aplicación de la normativa existente con escaso rigor, y en una relajación del empleo de reglas constructivas de buena praxis sismorresistente, lo que ha generado un aumento de la vulnerabilidad sísmica de las edificaciones en los entornos urbanos. Así pues, a pesar de que el estado del conocimiento permita diseñar y construir estructuras que se comporten adecuadamente frente a la acción sísmica, algunas áreas urbanas presentan un riesgo sísmico elevado debido, precisamente, a esa elevada vulnerabilidad de sus edificaciones.

La ocurrencia de terremotos bien documentados en estas zonas, como el sismo de Lorca de 2011, proporciona una excelente oportunidad para analizar el comportamiento real de las edificaciones frente al sismo. La disponibilidad de observaciones de los efectos sísmicos obtenidas in situ, y su comparación con los daños previamente estimados, permite ajustar y mejorar las diversas metodologías propuestas en la literatura para evaluar la vulnerabilidad y el riesgo sísmico de edificaciones, especialmente las basadas en procedimientos empíricos.

\subsection{CONTENIDO Y ALCANCE DEL TRABAJO}

Se entiende por trama urbana de un ámbito territorial la específica división del mismo en dos tipos básicos de espacios: a) viarios, los cuales se disponen formando una red con continuidad topológica y cuya función principal es la de permitir la movilidad y dotar de accesibilidad al territorio en su conjunto; y b) manzanas, constituidas por polígonos discontinuos separados entre sí por los espacios viarios que les dotan de accesibilidad, cuya función principal es albergar los usos y aprovechamientos humanos.

Estos espacios vienen regulados por una serie de determinaciones contempladas en los diversos instrumentos urbanísticos de ordenación, conformando, con el paso del tiempo, una malla con una configuración similar en la mayoría de áreas urbanas. Aunque el concepto de 
trama urbana puede albergar heterogeneidades en sus características estructurales, tipológicas o funcionales, se puede asumir estadísticamente un cierto grado de homogeneidad de los elementos analizados.

Así, las manzanas en el tejido urbano se encuentran habilitadas para uso residencial colectivo con posibilidad de uso terciario en planta baja, mediante edificaciones de carácter reciente con estructuras aporticadas de hormigón armado, en contraposición con los edificios de mampostería existentes en la mayoría de cascos históricos de las ciudades, articulados sin ningún tipo de ordenación previa.

El objetivo general de la tesis es el desarrollo y mejora de la metodología propuesta en el proyecto RISK-UE para la evaluación de la vulnerabilidad sísmica de las edificaciones de hormigón armado en áreas urbanas, basada en procedimientos empíricos, con el fin de caracterizar de forma más exhaustiva su comportamiento sísmico y definir, en consecuencia, las medidas y soluciones necesarias para reducir las pérdidas socioeconómicas asociadas a este tipo de fenómenos naturales en la trama urbana.

La consecución de este objetivo general implica alcanzar los siguientes objetivos específicos:

I. Realización de una revisión bibliográfica de la literatura existente, elaborando una puesta al día del estado del arte en lo referente a la evaluación de la peligrosidad, la vulnerabilidad y el riesgo sísmico en áreas urbanas.

II. Desarrollo de avances metodológicos en la caracterización de la vulnerabilidad sísmica de edificaciones aporticadas de hormigón armado mediante modelos empíricos, en el marco del proyecto RISK-UE.

III. Evaluación de la metodología planteada mediante su aplicación a una base de datos de observaciones de daños y afecciones obtenida tras inspecciones reales post-sismo.

IV. Definición de estrategias destinadas al planeamiento y gestión de escenarios de emergencia post-sismo en la trama urbana a partir de los resultados obtenidos, mediante el empleo de sistemas de información geográfica.

v. Establecimiento de criterios y conclusiones acerca de la idoneidad del modelo propuesto.

VI. Definición de posibles líneas futuras de investigación que den continuidad al presente trabajo, en base a las conclusiones extraídas en el mismo.

\subsection{ORGANIZACIÓN DE LA TESIS}

Para tal fin, el trabajo se ha estructurado en cinco capítulos, distribuidos de la siguiente manera:

En el Capítulo 1, se introduce el concepto e interés del riesgo sísmico, describiéndose de manera intuitiva los dos factores que influyen en su caracterización, es decir, la peligrosidad y 
la vulnerabilidad sísmica. Adicionalmente, se expone la problemática general existente en la evaluación del riesgo sísmico en áreas urbanas, y se plantean los objetivos perseguidos en esta tesis.

En el Capítulo 2, se aborda en detalle la definición de los conceptos de peligrosidad, vulnerabilidad y riesgo sísmico, revisando el estado del conocimiento de la materia. Una vez expuestas las principales metodologías disponibles en la literatura para la evaluación en áreas urbanas de estas variables de peligrosidad, vulnerabilidad y riesgo sísmico, se resumen las aplicaciones más relevantes de este tipo de estudios realizadas en la península Ibérica.

El Capítulo 3 se ha dedicado al desarrollo del modelo propuesto en esta tesis para la evaluación de la vulnerabilidad sísmica de edificaciones de hormigón armado en áreas urbanas, basada en modelos empíricos, describiéndose los parámetros y aspectos sísmicos y constructivos de las edificaciones sobre los cuales se fundamenta.

En el Capítulo 4, se aplica el modelo propuesto a los registros sísmicos disponibles del terremoto de Lorca de 2011 gracias a las inspecciones post-sismo realizadas, comparando los niveles de daño observados en las edificaciones de hormigón armado con los valores calculados según las diferentes metodologías disponibles y el nuevo modelo propuesto, analizando los resultados obtenidos mediante un serie de parámetros estadísticos y aplicando la información disponible al planeamiento y gestión de emergencias de tipo sísmico mediantes técnicas SIG.

Finalmente, en el Capítulo 5 se establecen una serie de conclusiones derivadas de la investigación realizada, planteándose posibles líneas de investigación que puedan dar continuidad a este documento. 


\section{CAPÍTULO 2 \\ EVALUACIÓN DEL RIESGO SÍSMICO EN ÁREAS URBANAS. ESTADO DEL ARTE}

\subsection{PELIGROSIDAD SÍSMICA}

\subsubsection{Introducción}

Como se ha comentado en el apartado 1.1, la peligrosidad sísmica o hazard se puede definir como la probabilidad de ocurrencia en un periodo de tiempo dado de un movimiento sísmico de una cierta severidad en una determinada zona del territorio (Blázquez, 2013). A la totalidad de los procedimientos experimentales y analíticos que permiten caracterizar la acción sísmica en una determinada región se le denomina comúnmente como evaluación de la peligrosidad sísmica. Dicha evaluación está asociada con la actividad sísmica que afecta al emplazamiento objeto de estudio, la cual es inducida por la liberación súbita de la energía acumulada en la litosfera terrestre a lo largo de una superficie o plano de fractura denominada falla (Figura 2.1).

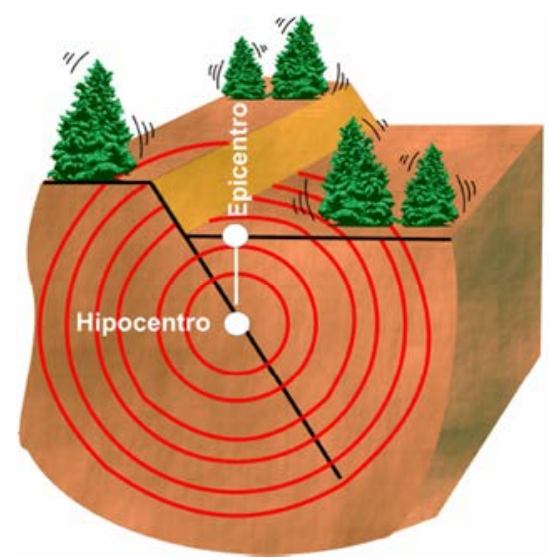

Figura 2.1. Mecanismo de falla: hipocentro y epicentro de un sismo (Giner-Robles et al., 2010).

En la Tabla 2.1 se muestra una estimación de la frecuencia media anual de ocurrencia de terremotos en el planeta en función de su magnitud, elaborada por el US Geological Survey (USGS) a partir de los registros disponibles desde el año 1900. Se determina una probabilidad media de ocurrencia de al menos un terremoto al año de magnitud superior a 8 con consecuencias destructivas. Una estadística similar se ha realizado por el Instituto Geográfico Nacional (IGN) mediante la cual se ha establecido una estimación de la ocurrencia media de terremotos en la Península Ibérica (Tabla 2.2). Destaca la probabilidad media de que un terremoto de características similares al de Lorca de 2011, con magnitud 5,1, se produzca una 
vez cada 10 meses, lo cual proporciona una idea de los niveles de peligrosidad y riesgo sísmico a los que se encuentra expuesta la población sin, generalmente, tener consciencia de ello.

Tabla 2.1. Estimación de la frecuencia anual media de ocurrencia de terremotos en la Tierra (USGS, 2016).

\begin{tabular}{ccc}
\hline Descripción & Magnitud & Media anual \\
\hline Destructivo & $\geq 8$ & 1 \\
Grande & $7,0-7,9$ & 17 \\
Fuerte & $6,0-6,9$ & 134 \\
Moderado & $5,0-5,9$ & 1.319 \\
Ligero & $4,0-4,9$ & 13.000 \\
Menor & $3,0-3,9$ & 130.000 \\
Pequeño & $2,0-2,9$ & 1.300 .000 \\
\hline
\end{tabular}

Tabla 2.2. Estimación de ocurrencia media de terremotos en la península Ibérica (IGN, 2016a).

\begin{tabular}{ccc}
\hline Descripción & Magnitud & Periodo de ocurrencia media \\
\hline Grande & $>7,0$ & 1 cada $150-175$ años \\
Fuerte & $6,1-7,0$ & 1 cada $25-30$ años \\
Moderado & $5,1-6,0^{*}$ & 1 cada 10 meses \\
Ligero & $4,1-5,0^{*}$ & 1 cada 22 días \\
Menor & $3,1-4,0^{*}$ & 1 cada 40 horas \\
Pequeño & $2,1-3,0^{*}$ & 1 cada 15 horas \\
\hline
\end{tabular}

* A partir de 1985

Para la evaluación de la peligrosidad sísmica en una cierta área urbana es necesaria, por tanto, la determinación de la actividad sísmica de la región, caracterizando los parámetros sísmicos de los posibles terremotos tales como localización, tamaño y profundidad.

La definición del tamaño de un terremoto constituyó uno de los principales problemas de la ingeniería sísmica hasta principios del siglo pasado. Debido a la falta de conocimiento de la naturaleza y causas del fenómeno sísmico, las primeras crónicas se centraron en intentar describir los efectos del sismo en el entorno, surgiendo de este modo el concepto de intensidad macrosísmica. Este parámetro evalúa, de forma cualitativa, la severidad de la sacudida de un terremoto a partir de los efectos observados sobre las personas, las edificaciones y el terreno.

Desde la primera escala de Rossi-Forel de 1873 empleada internacionalmente, fueron apareciendo sucesivamente otras escalas como la de Mercalli, en 1902; la de Mercalli-CancaniSieberg (MCS), en 1917; la de Mercalli Modificada (MM), en 1931 -y actualizada en 1956 y 
1965-; la escala Medvedev-Sponheuer-Karnik (MSK), en 1964 y 1984; o la escala macrosísmica europea (EMS) en 1992 y 1998 (Grünthal, 1998); así como otras escalas, menos conocidas en Europa, como la japonesa (JMA, 2009).

Exceptuando la escala Rossi-Forel, la mayoría presenta intervalos muy similares en la evaluación de los daños producidos, disponiendo de doce grados para describir dichos efectos, a excepción de la escala japonesa (Figura 2.2). Las más generalizadas son la Escala de Mercalli Modificada (MM) en América y la Escala MSK/EMS en Europa, a excepción de Italia donde se suele utilizar la escala MCS (Bozzo \& Barbat, 2000; Dolce et al., 2006; Moreno, 2006). En la Tabla 2.3 se describen los grados de intensidad definidos en la escala macrosísmica EMS-98.

\begin{tabular}{|c|c|c|c|c|c|}
\hline Dä̃o (\%) & Ross-Forel & MM & JMA & MSK & EMS-98 \\
\hline & \multirow{2}{*}{1} & 1 & \multirow{4}{*}{ I } & 1 & 1 \\
\hline & & \multirow{2}{*}{ II } & & ॥ & ॥ \\
\hline & II & & & \multirow{2}{*}{ III } & \multirow{2}{*}{ III } \\
\hline & III & III & & & \\
\hline & IV & IV & II & IV & IV \\
\hline & $\mathrm{V}$ & $\mathrm{V}$ & III & $V$ & $V$ \\
\hline & $\mathrm{V} l$ & \multirow{2}{*}{$\mathrm{Vl}$} & \multirow[t]{2}{*}{ IV } & & \\
\hline 0 & VII & & & $\mathrm{n}$ & $\mathrm{Vl}$ \\
\hline \multirow{3}{*}{$\begin{array}{l}10 \\
20 \\
30\end{array}$} & VIII & $\mathrm{VII}$ & \multirow[t]{2}{*}{$v$} & VII & VI \\
\hline & \multirow[b]{2}{*}{ IX } & VII & & \multirow{2}{*}{ VII } & \multirow{2}{*}{ VIII } \\
\hline & & IX & \multirow{2}{*}{$\mathrm{Vl}$} & & \\
\hline \multirow{4}{*}{$\begin{array}{l}40 \\
50 \\
70 \\
90\end{array}$} & \multirow{4}{*}{$x$} & $x$ & & $\mathrm{IX}$ & IX \\
\hline & & $\mathrm{Xl}$ & \multirow{3}{*}{ VI } & $x$ & $x$ \\
\hline & & \multirow[b]{2}{*}{ XII } & & $\mathrm{XI}$ & $x I$ \\
\hline & & & & XII & XII \\
\hline
\end{tabular}

Figura 2.2. Comparación entre los grados de intensidad considerados en diferentes escalas macrosísmicas, junto con el porcentaje de edificios afectados en el área urbana (Mena, 2002).

MM = escala de Mercalli Modificada; JMA = escala macrosísmica japonesa; $M S K=$ escala de MedvedevSponheuer-Karnik; EMS = escala macrosísmica europea

Con objeto de definir una medida cuantitativa del tamaño de un sismo, Richter (1935) propuso el concepto de magnitud sísmica relacionando semiempíricamente la severidad del terremoto con la energía liberada en el foco durante el mismo. A lo largo de los años, los avances técnicos han permitido establecer otros tipos de magnitud para caracterizar el tamaño de un sismo (Tabla 2.4) como respuesta a diversos problemas sismológicos aparecidos, como la saturación de la escala considerada o el periodo natural del registro (McGuire, 2004). Destaca principalmente la magnitud momento por su extendido uso, definida a partir del momento sísmico o producto de la superficie de ruptura en el plano de falla, el desplazamiento neto en la falla y el coeficiente de rigidez del terreno (Aki, 1966; Hanks \& Kanamori, 1979). 
Tabla 2.3. Grados de intensidad definidos en la escala macrosísmica europea EMS-98 (Grünthal, 1998; Mena, 2002).

Escala macrosísmica Europea (EMS-98)

Intensidad Descripción

I No se percibe, aun en las circunstancias más favorables. No provoca daños.

II Se percibe escasamente, principalmente en interiores. No provoca daños.

III

Débil, se percibe en interiores por pocas personas sintiendo un ligero temblor. Mueve objetos ligeramente sin provocar daños.

Observado por muchos. Lo percibe mucha gente en interiores y por pocos en el exterior.

IV Algunas personas se despiertan. Las personas sienten un ligero vaivén en los edificios, habitaciones, camas o sillas, etc. No provoca daños.

Fuerte. Se siente por todos en los interiores y por pocos en el exterior. Muchos se despiertan. Las personas sienten un fuerte movimiento o vaivén del edificio, de la habitación o de los muebles. Se asigna el grado de daño 1 a las edificios de la clase de vulnerabilidad $\mathrm{A}$ y $\mathrm{B}$.

Daños ligeros. Se siente por todas las personas en los interiores y exteriores. Las personas pierden su estabilidad. Los objetos pequeños se caen y algunos muebles pueden

VI levantarse. Muchos edificios de la clase de vulnerabilidad A y B se les asignan el grado de daño 1 y algunos pueden sufrir daño de grado 2 . Algunos de clase $C$ sufren un grado de daño 1.

Daños. Se tiene dificultad para permanecer de pie en los pisos. Los muebles se levantan y se caen. Muchos edificios de clase de vulnerabilidad A sufren un daño de grado $3 \mathrm{y}$

VII algunos de grado 4. Muchos de clase B sufren daño de grado 2 y algunos de grado 3. Algunos edificios de clase $C$ sufren un daño de grado 2. Algunos de clase $D$ sufren un daño de grado 1.

Daño fuerte. Todas las personas encuentran dificultad para permanecer de pie. Los muebles pueden caerse. Se pueden ver ondas en suelos muy suaves. Muchos edificios de

VIII clase A sufren un daño de grado 4 y algunos de grado 5 . Muchos de clase B sufren un daño de grado 3 y algunos de grado 4 . Muchos edificios de clase $C$ sufren daño de grado 2 y algunos de grado 3 . Algunos de clase $D$ sufren daño de grado 2.

Destructivo. Las personas son lanzadas fuertemente al suelo. Muchos monumentos y columnas se pueden caer. Se observan ondas en el terreno. Muchos edificios de la clase A

IX sufren un daño de grado 5 . Muchos de clase B sufren un daño de grado 4 y algunos de grado 5 . Muchos de clase $C$ sufren daño de grado 3 y algunos de grado 4 . Muchos de clase D sufren daño de grado 2 y algunos de grado 3. Algunos de clase E sufren daño de grado 2.

Muy destructivo. La mayoría de los edificios de clase A sufren un daño de grado 5 . Muchos de clase B sufren un daño de grado 5 . Muchos de clase $C$ sufren un daño de grado 4 y

$X \quad$ algunos de grado 5. Los de clase $D$ sufren un daño de grado 3 y algunos de grado 4 . Los de clase $\mathrm{E}$ sufren un daño de grado 2 y algunos de grado 3 . Algunos edificios de clase $\mathrm{F}$ sufren un daño de grado 2.

Devastador. La mayoría de los edificios de clase B sufren daño de grado 5. La mayoría de clase $C$ sufren daño de grado 4 y muchos de grado 5 . Muchos de clase $D$ sufren daño de grado 4 y algunos de grado 5 . Muchos de clase $E$ sufren daño de grado 3 y algunos de grado 4. Muchos de clase $F$ sufren daño de grado 2 y algunos de grado 3.

Completamente devastador. Todos los edificios de clase A, B y prácticamente todos los de

XII clase $C$ se destruyen. Muchos de clases D, E y F se destruyen. Los efectos del terremoto alcanzan efectos inimaginables.

A, B, C, D, E, F = clases de vulnerabilidad de las edificaciones en la escala EMS-98 (Figuras 2.36 y 2.37) 
Tabla 2.4. Tipos de magnitud propuestos en la literatura, periodos del movimiento sísmico para los cuales son sensibles y límites de saturación (McGuire, 2004).

\begin{tabular}{ccc}
\hline Designación & Periodo (s) & Magnitud de saturación \\
\hline$M_{L}$ & 0,8 & $\approx 6,8$ \\
$m_{b}$ & 1 & $\approx 7$ \\
$m_{B}$ & $>5$ & $\approx 8$ \\
$m_{b L g} m_{L g}$ & 1 & $\approx 7$ \\
$M_{S}$ & 20 & $\approx 8,3$ \\
$M, M_{W}$ & 4 & No tiene \\
\hline
\end{tabular}

$M_{L}=$ magnitud local de Richter; $m_{b}=$ magnitud de ondas internas o de volumen de banda estrecha y periodo corto; $m_{B}=$ magnitud de ondas de volumen medida en registros de banda ancha; $m_{b L g}, m_{L g}=$ magnitudes definidas a partir de la amplitud de la fase $L g ; M_{S}=$ magnitud de ondas superficiales; $M, M_{W}=$ magnitud momento sísmico

Con el fin de aprovechar los catálogos sísmicos de terremotos históricos disponibles, se han propuesto diversas expresiones empíricas que relacionan intensidad con magnitud para zonas específicas del planeta (López Casado et al., 2000b; González, 2000; Gutdeutsch, Kaiser \& Jentzsch, 2002; Mezcua, Rueda \& García-Blanco, 2004; Irizarry et al., 2011). Asimismo, con objeto de homogeneizar las distintas escalas en términos de magnitud y transformar a la misma los registros definidos en otras escalas, se han ido obteniendo relaciones empíricas de conversión entre diferentes escalas de magnitud (Hanks \& Kanamori, 1979; Nuttli, 1985; Rueda \& Mezcua, 2002, 2005; McGuire, 2004; CARM, 2014; Benito et al., 2006, 2015; Cabañas et al., 2015; entre otros).

Conviene destacar la diferencia existente entre los conceptos de magnitud e intensidad macrosísmica. Mientras que la primera es una característica objetiva, única y propia del sismo, relacionada con la energía liberada por el terremoto a partir de registros sísmicos, la intensidad depende del método o escala utilizados en su evaluación (EMS, MSK, JMA, MM, MCS) así como de la opinión de los especialistas que la determinan, con una componente marcadamente subjetiva, variando en función de la distancia epicentral al emplazamiento donde se estén evaluando los efectos del sismo (Barbat, 1998).

Por otra parte, en su caracterización se interrelacionan conjuntamente la peligrosidad y la vulnerabilidad sísmica, puesto que los efectos de una cierta acción sísmica en un área urbana son consecuencia, en parte, de la severidad del fenómeno sísmico, pero también de la predisposición intrínseca de las edificaciones de esa zona a sufrir daños. Por tanto, la intensidad sísmica sería más bien un indicador del nivel de riesgo sísmico al que está expuesto un determinado entorno urbano, tras la ocurrencia del terremoto.

Estas consideraciones han supuesto el desarrollo de definiciones analíticas de la intensidad sísmica basadas en registros instrumentales del movimiento del suelo. Se pueden destacar las escalas instrumentales de intensidad de Benioff (1934) y Housner (1970), basadas 
en el espectro de respuesta del movimiento del terreno, o las escalas de intensidad de Arias (1970) y el método CAV -Cumulative Absolute Velocity- (EPRI, 1991), a partir de la energía disipada por el sismo.

\subsubsection{Sismicidad. Fuentes sismogenéticas}

Para poder cuantificar y comparar la actividad sísmica de diferentes zonas se establece el concepto de sismicidad, entendido como la frecuencia de ocurrencia de fenómenos sísmicos por unidad de área (Barbat \& Canet, 1994). Se puede distinguir entre sismicidad histórica e instrumental, en función de la disponibilidad o no de sismógrafos capaces de determinar analíticamente las características de los terremotos (Mezcua, Rueda \& García-Blanco, 2011).

A los emplazamientos donde se concentra la aparición de terremotos se les denomina fuentes sismogenéticas. Según la teoría de deriva continental propuesta por Weneger en 1912, la mayor parte de estas zonas están asociadas al movimiento de una serie de placas tectónicas que conforman la litosfera terrestre, debido a las corrientes de convección del interior del planeta. En lo que respecta a la península Ibérica, la actividad sísmica se localiza en el Sur y Sureste debida principalmente al contacto entre las placas de Eurasia y África. En la Figura 2.3 se muestra el catálogo de sismicidad en la península Ibérica y su entorno. Los epicentros del periodo 1048-1919 se representan mediante valores de intensidad, mientras que los correspondientes al periodo instrumental 1920-2003 se representan por valores de magnitud.

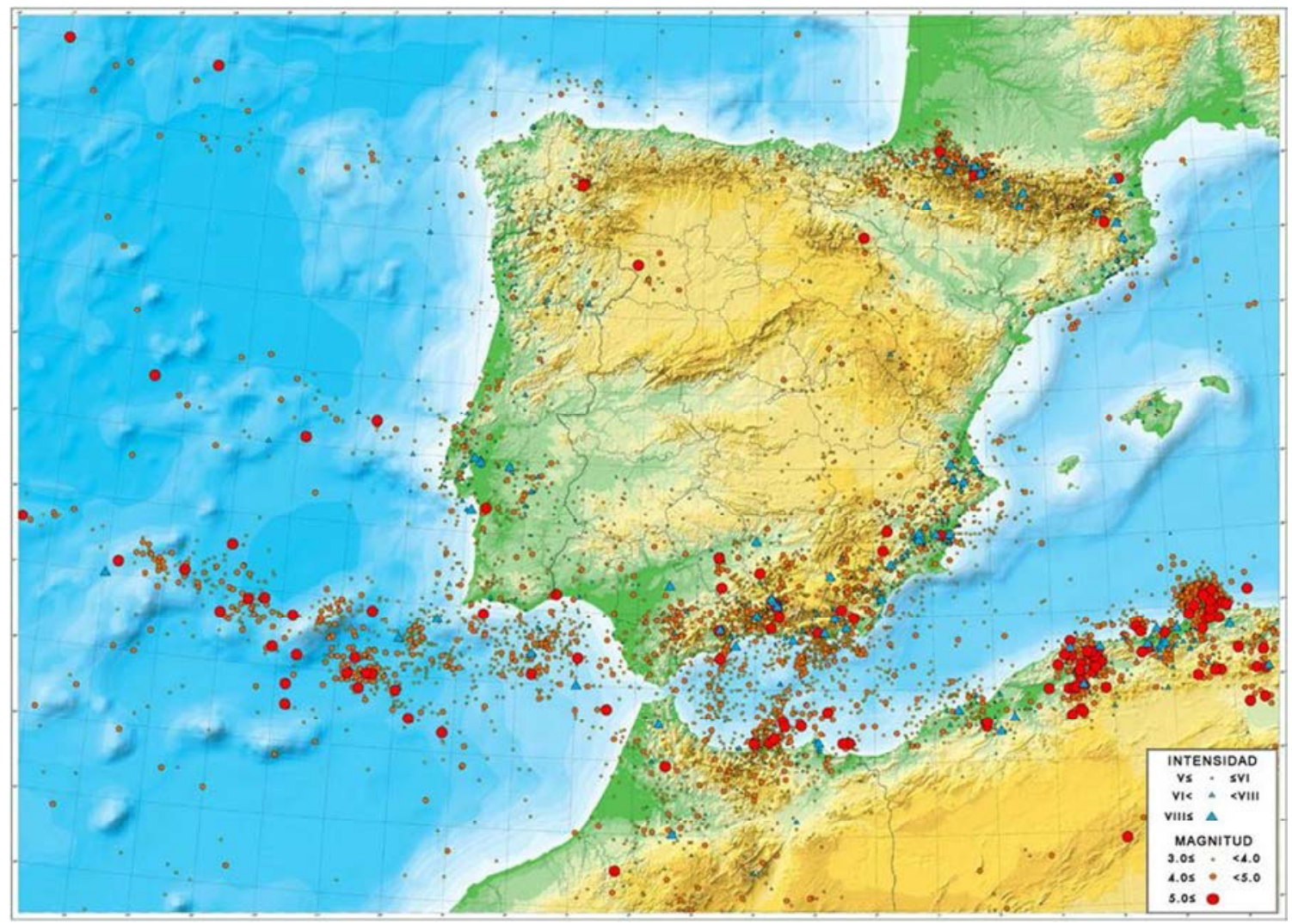

Figura 2.3. Catálogo de sismicidad histórica e instrumental de la península Ibérica y áreas adyacentes (IGN, 2016b). 
A pesar de ser una región de sismicidad baja o moderada, se pueden destacar grandes terremotos ocurridos en la península con intensidad X o IX-X en la escala MSK, como el de Cardedeu, Barcelona, en 1448 (Lantada et al., 2010); el de Málaga en 1680 (Goded, Buforn \& Muñoz, 2008); el gran terremoto de Lisboa de 1755 (Martínez-Solares, 2001); el de 1829 en Torrevieja, Alicante (Albini \& Rodríguez de la Torre, 2001); o el sismo de 1884 en Arenas del Rey, Granada (Benito et al., 2008).

No obstante, la escasez de eventos con registros instrumentalizados ha motivado la necesidad de aprovechar los catálogos históricos disponibles, proponiéndose diversas técnicas para adaptar o relacionar la intensidad macrosísmica a términos de parámetros de movimiento del suelo como, por ejemplo, la magnitud momento $M_{w}$, ajustadas específicamente para la península Ibérica (Munuera, 1963; Mezcua \& Martínez-Solares, 1983; Martínez-Solares \& Mezcua, 2002; Martínez-Solares; 2012; Cabañas et al., 2015).

En lo respectivo a la Región de Murcia, las mayores intensidades reportadas son de grado VIII en la escala EMS-98 correspondiéndose con los sismos ocurridos en 1674 en Lorca, en 1911 en Las Torres de Cotillas y Lorquí, y en 1948 en Cehegín (Benito et al., 2012). Asimismo, destaca la actividad sísmica acaecida en los últimos años, con los terremotos de Mula en 1999 con magnitud $M_{w}=4,8$, en Bullas en 2002 con $M_{w}=4,7$, en La Paca con $M_{w}=4,5$ (Buforn et al., 2005; Benito et al., 2007), y Lorca en 2011 con $M_{w}=5,1$, con una intensidad asignada de VII en escala EMS para el núcleo urbano de la ciudad (Cabañas et al., 2011; De Luca et al., 2013), aunque algunos estudios lo elevan a una intensidad VIII (Figueras et al., 2012; Alguacil et al., 2014).

Durante los últimos 150 años, destaca la actividad sísmica anómalamente baja acaecida en la península Ibérica (Blázquez, 2011; Perepérez, 2014b). Desde el sismo de Arenas del Rey (Granada) en 1884, no se ha producido ningún terremoto de intensidad superior a VIII en la escala EMS-98, lo cual ha podido influir de forma significativa en la escasa conciencia sísmica existente hoy día en todos los ámbitos de la sociedad española.

En cuanto a la caracterización de la sismicidad de las diversas fuentes sismogenéticas, el procedimiento más empleado habitualmente para el estudio de la actividad sísmica de una determinada región consiste en la adopción de modelos zonificados (Figura 2.4), los cuales asumen que los terremotos ocurren dentro de zonas sismogenéticas definidas, de potencial sísmico homogéneo, donde las fallas o estructuras geológicas presentes pueden generar patrones similares de sismicidad (Benito et al., 2006).

En la península Ibérica, los primeros estudios realizados para zonificar el territorio se basaban en la distribución de epicentros de los terremotos ocurridos y su asociación con áreas de características tectónicas supuestamente homogéneas (Muñoz, 1983, Martín, 1984; GarcíaFernández, Jiménez \& Kijko, 1989; IGN, 1991; Muñoz \& Udías, 1992; Martín-Bourgón et al., 1996; Molina, 1998; Jiménez et al., 1999). No obstante, la mayor parte de estos se centran parcialmente en determinadas regiones como, por ejemplo, la Comunidad Valenciana (Giner, 1996; Giner et al., 2003), el Norte y Noroeste peninsular (Rueda \& Mezcua, 2001; López- 
Fernández et al., 2008), Granada (Sanz de Galdeano, Peláez \& López-Casado, 2003), Cataluña y la región Pirenaica (Secanell et al. 2004, 2008), el Sur y Sureste peninsular (López-Casado et al., 1995; García-Mayordomo, 2005), o Portugal (Vilanova \& Fonseca, 2007). Recientemente se han revisado estos modelos, proponiendo patrones unificados de zonificación para la península Ibérica (Mezcua, Rueda, \& García-Blanco, 2011; García-Mayordomo et al., 2012).

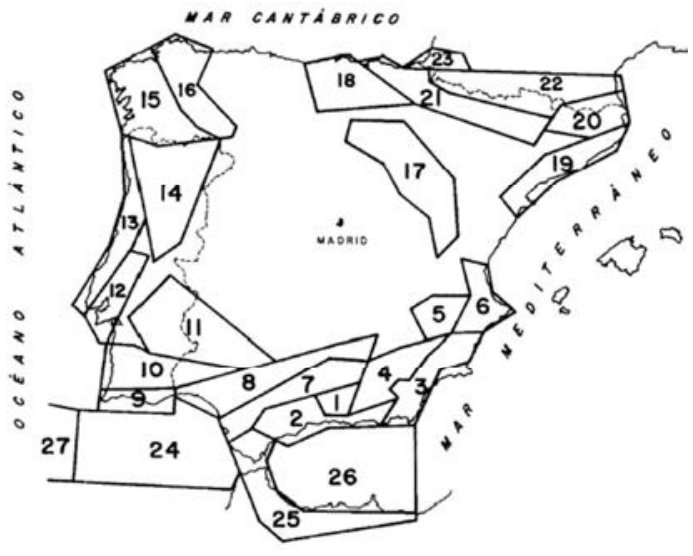

(a)

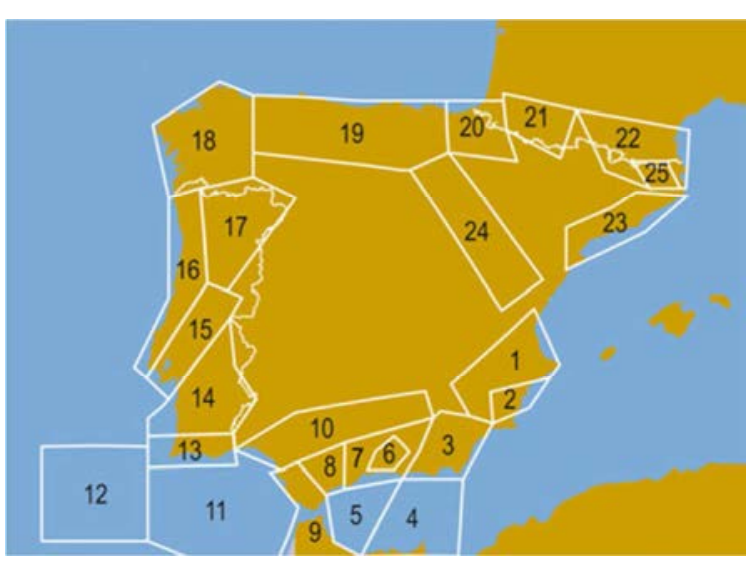

(b)

Figura 2.4. Modelos zonificados de la península Ibérica para el estudio de la actividad sísmica. (a) Primera zonificación sismogenética (Martín, 1984). (b) Zonificación propuesta en IGN (1991) y empleada para la evaluación de la peligrosidad en las normas NCSE-94 y NCSE-02 (Mezcua, Rueda, \& GarcíaBlanco, 2011).

Una vez delimitadas las distintas fuentes sismogenéticas, para la caracterización de su sismicidad se suele asumir la ley empírica descrita por Gutenberg-Richter (1942), la cual relaciona las magnitudes de los terremotos con la frecuencia con la que se producen estableciendo que el logaritmo del número de terremotos está relacionado linealmente con el tamaño de los mismos. No obstante, para cada región existe un límite en el tamaño del máximo terremoto que puede ocurrir en función de las características geomorfológicas de las fuentes existentes, por lo que han sido propuestas distintas modificaciones a la ley de Gutenberg-Richter truncando el rango de variación de magnitud con una cierta valor máximo (García-Mayordomo, 2005; Benito et al., 2006; Tapia, 2006; Baker, 2008; Martínez-Solares; 2012), por encima del cual no es esperable que se produzcan terremotos.

De este modo, la sismicidad de cada fuente sismogenética puede ser caracterizada a partir de tres parámetros: la tasa anual media de ocurrencia de terremotos, la distribución de frecuencias de las magnitudes, y la magnitud máxima posible que puede producirse en el interior de la fuente. Su obtención se formula según las expresiones (2.1) y (2.2):

$$
\begin{gathered}
\lambda_{\mathrm{m}}=\frac{\lambda_{\mathrm{o}}\left(e^{-\beta m}-e^{-\beta M \max }\right)}{\left(e^{-\beta M o}-e^{-\beta M \max }\right)} \quad M_{0} \leq m \leq M_{\max } \\
\lambda_{\mathrm{o}}=e^{\alpha-\beta M o}
\end{gathered}
$$

donde: 
$\lambda_{m}=$ tasa anual media de ocurrencia de terremotos que exceden una cierta magnitud $m$ comprendida entre la magnitud máxima $M_{\max } \mathrm{y}$ una magnitud umbral $M_{0}$, por debajo de la cual los sismos no presentan una contribución significativa a la peligrosidad.

$\lambda_{o}=$ tasa media anual asociada a terremotos con magnitud igual o superior al límite inferior $M_{0}$, con $\alpha=a \operatorname{Ln} 10$ y $\beta=b L n 10$, siendo $a$ y $b$ coeficientes de la ley Gutenberg-Richter ajustados a la zona de estudio (Aguilar, 2011).

\subsubsection{Leyes de atenuación sísmica}

Caracterizada la sismicidad de las fuentes sismogenéticas, los modelos de propagación de la energía sísmica permiten estimar el movimiento del terreno en un determinado emplazamiento a partir del generado en la fuente sísmica a una cierta distancia del mismo. Las funciones de atenuación describen, mediante una expresión analítica simplificada, la evolución de un parámetro del movimiento del suelo como la aceleración del terreno o la intensidad macrosísmica, con la distancia al epicentro, dada la ocurrencia de un terremoto de determinada severidad (Figura 2.5).

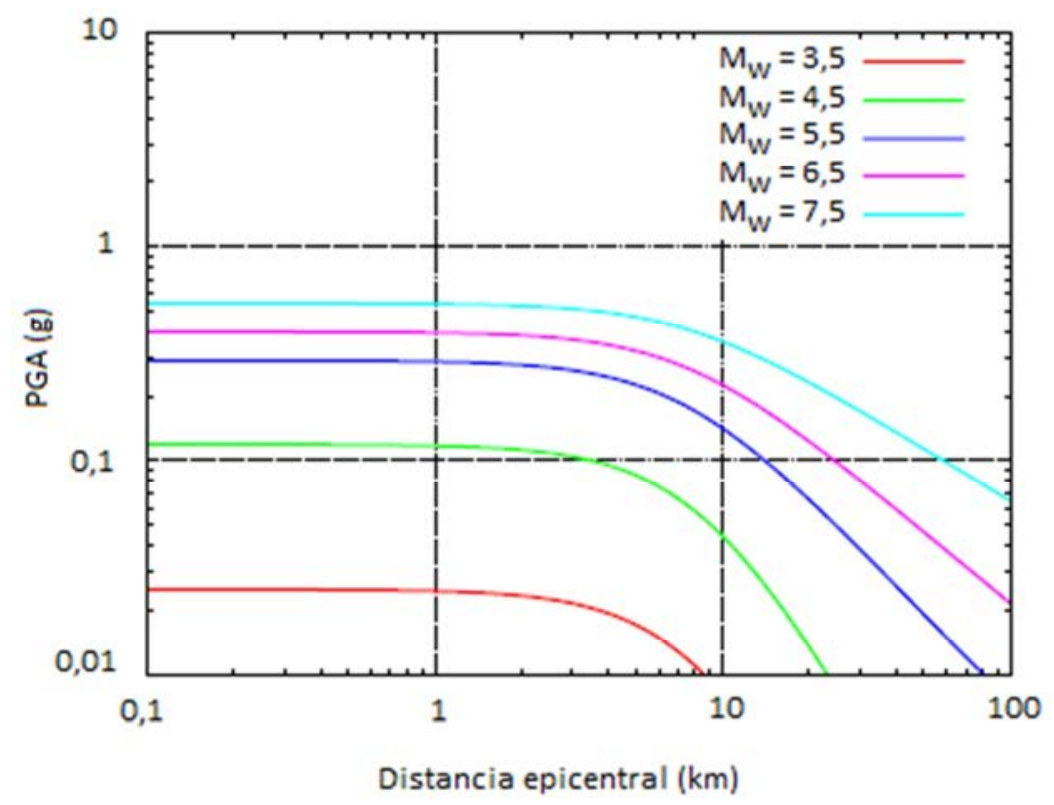

Figura 2.5. Leyes de atenuación del movimiento sísmico en función de la magnitud, para suelo rígido (Crespo, 2011).

$M_{W}=$ magnitud momento sísmico

Estos modelos de movimiento se clasifican en empíricos y teóricos. Los modelos empíricos se deducen a partir de registros sísmicos de diferentes terremotos mediante análisis de regresión y ajuste a una cierta expresión matemática. Los modelos teóricos o analíticos, se construyen a partir de un modelo físico de generación, propagación y amplificación local de la energía sísmica, basados en los fenómenos de atenuación de la energía por expansión geométrica del frente de ondas y por absorción inelástica del terreno (Benito et al., 2006). No 
obstante, todos ellos dependen de parámetros comunes tales como la distancia al foco emisor y el tamaño del evento sísmico, ya sea en términos intensidad macrosísmica o en términos de parámetros de movimiento del suelo.

Diversos estudios (Douglas, 2003; Campbell \& Bozorgnia, 2003; McGuire, 2004; García-Mayordomo, 2005; Tapia, 2006; Benito \& García Escribano, 2007; Mezcua, Rueda, \& García-Blanco, 2008; Stafford, Strasser \& Bommer, 2008; Katsanos, Sextos \& Manolis, 2010; Aguilar, 2011; Benito et al., 2015), incluyen recopilaciones las diversas leyes de atenuación definidas en la literatura para distintas regiones del planeta.

Actualmente destacan los modelos denominados como NGA - Next Generation Attenuation Models (Campbell \& Bozorgnia, 2008, 2010; Boore \& Atkinson, 2008; Chiou \& Youngs 2008, Abrahamson \& Silva, 2008; Akkar \& Boomer, 2010), en términos de PGA y magnitud $M_{w}$, los cuales incorporan aspectos como el efecto local del suelo o un análisis más detallado de las incertidumbres asociadas al cálculo (Benito et al., 2015). Tales modelos han sido revisados recientemente mejorando su aplicabilidad en zonas de sismicidad baja o moderada bajo la denominación genérica de NGA-West 2 (Abrahamson, Silva \& Kamai, 2013; Boore et al. 2013; Campbell \& Bozorgnia, 2013; Chiou \& Youngs, 2013; Idriss, 2013).

En lo relativo a los modelos desarrollados en la península Ibérica, se han propuesto modelos en términos tanto de intensidad macrosísmica (Martín, 1984; López-Casado et al, 2000a; Secanell et al., 2004), como de parámetros de movimiento del suelo (Ambraseys et al., 1996, 2005; Sabetta \& Pugliese, 1996; Berge-Thierry et al., 2003; Tapia, 2006; García-Blanco, 2009), aplicados en multitud de estudios para la evaluación de la peligrosidad sísmica en áreas urbanas (Roca et al., 2006; Lantada, Pujades \& Barbat, 2009; González, 2010; Irizarry et al., 2011; Crespo, 2011). Otros trabajos evalúan los modelas NGA a diversas regiones de la península Ibérica, comparando según los modelos empleados la variabilidad de los resultados obtenidos (Douglas, Bungum \& Schernaum, 2006; Gaspar-Escribano, Benito \& GarcíaMayordomo, 2008; Mezcua, Rueda \& García-Blanco, 2011; Benito et al., 2006, 2012, 2015; Rivas-Medina et al., 2014).

\subsubsection{Peligrosidad sísmica a escala regional}

Los estudios de peligrosidad sísmica a nivel regional o estudios de macrozonificación (Barbat, 1998), tienen como objetivo caracterizar los parámetros sísmicos de movimiento del suelo en un determinado emplazamiento al nivel del estrato de terreno firme o roca (Figura 2.6), sin tener en cuenta el efecto de las capas superiores del suelo, denominado como efecto sitio o efecto local.

Puesto que dicha peligrosidad depende de la sismicidad de la región analizada, su evaluación precisa de las siguientes etapas (Yépez, Barbat \& Canas, 1994; Benito \& Jiménez, 1999):

$\checkmark$ Definición de las zonas fuente, tanto superficiales como lineales, caracterizando su sismicidad mediante los correspondientes modelos de recurrencia. 
$\checkmark$ Elección mecanismo de propagación y atenuación de la energía sísmica.

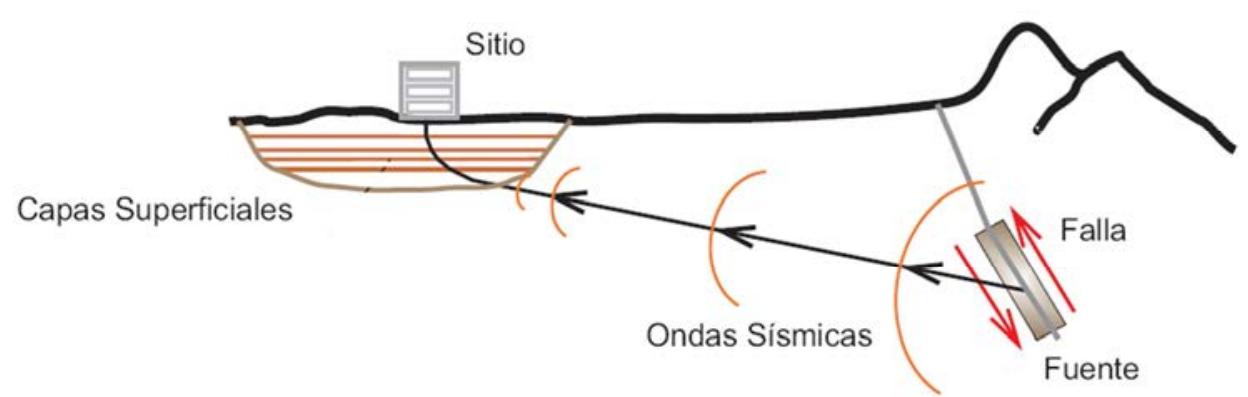

Figura. 2.6. Esquema de propagación de la energía sísmica desde la fuente sismogenética hasta la cimentación de una estructura (Lozano, Bermúdez \& Ojeda, 2009).

Los métodos de evaluación de la peligrosidad sísmica a escala regional se dividen en dos grandes grupos: métodos deterministas y métodos probabilistas, en función del procedimiento de caracterización del potencial sísmico de la fuente sismogenética.

\subsubsection{Métodos deterministas}

Los métodos deterministas (DSHA - Deterministic Seismic Hazard Asessment) parten de la hipótesis de que la sismicidad en una región es estacionaria, por lo que no se producirán terremotos cuyo tamaño sea superior a otros sismos ocurridos con anterioridad. De este modo, los valores máximos de los parámetros utilizados, principalmente la intensidad macrosísmica, se pueden estimar a partir de los máximos valores registrados en eventos pasados de los que se tenga conocimiento en la región de estudio (Faccioli, 2006).

Dado su excesivo conservadurismo esta metodología ha sido sustituida mayoritariamente por los métodos probabilistas, salvo en casos especiales como los análisis de estructuras críticas, como centrales nucleares, cuyo riesgo se quiere minimizar con probabilidades de excedencia nulas de la acción sísmica considerada, o en aquellas regiones en las que se disponga de escasos registros instrumentales para caracterizar la sismicidad del emplazamiento (García-Mayordomo, 2005).

Estos métodos son muy sensibles al nivel del conocimiento de la sismicidad histórica (Barbat, 1998; Baker, 2008), no proporcionando información acerca de las incertidumbres asociadas al cálculo ni de los niveles de riesgo asumidos. Otros autores cuestionan incluso la propia aceptación de la estacionariedad del movimiento sísmico (Crespo, 2011), aunque pueda ser utilizado de forma complementaria con el método probabilista, como un escenario sísmico adicional (Lantada et al., 2010).

\subsubsection{Métodos probabilistas}

Los métodos probabilistas (PSHA - Probabilistic Seismic Hazard Asessment) se basan en la modelización estadística de la ocurrencia temporal de terremotos a partir del análisis de la 
sismicidad de una determinada región, con objeto de generar leyes y funciones representativas que proporcionen la probabilidad de excedencia de los parámetros de movimiento del suelo. Estas metodologías permiten el diseño de estructuras asumiendo un determinado nivel de riesgo, por lo que sí que posibilitan optimizar la inversión en seguridad. En función de la distribución estadística adoptada para caracterizar la sismicidad del área objeto de estudio, estos métodos se clasifican a su vez en no paramétricos y paramétricos (Benito \& Jiménez, 1999):

Los métodos no paramétricos evalúan la peligrosidad mediante funciones de distribución de valores extremos como las de Weibull (1951) y Gumbel (1958), a las que se ajustan los valores del parámetro de movimiento elegido, fijando además valores extremos de dicho parámetro (Molina, 1998).

Los métodos paramétricos se basan en la metodología de Cornell (1968), ajustando la sismicidad a un modelo de Poisson zonificado implementado mediante el programa de cálculo EQRISK de McGuire (1976). La aceptación de dicho modelo implica asumir las hipótesis de que la ocurrencia de los terremotos es aleatoria en el tiempo y en el espacio, y que éstos constituyen sucesos aleatorios independientes entre sí, sin memoria, lo cual suele ser aceptable para los periodos de vida útil típicos de obras de ingeniería y edificación (Rosa-Oliver \& Blázquez, 2003; García-Mayordomo, 2005), quedando del lado de la seguridad los terremotos calculados bajo este criterio.

Según esta metodología, la probabilidad de que un cierto nivel del movimiento del suelo sea excedido durante un periodo de tiempo en un cierto emplazamiento se puede obtener según la expresión (2.3). Para reducidas tasas anuales medias de excedencia, típicas en obras de ingeniería, se puede admitir la simplificación recogida en (2.4):

$$
\begin{gathered}
P(A>a, t)=1-e^{-\left(\lambda_{a} t\right)} \\
P(A>a) \cong \lambda_{a}
\end{gathered}
$$

donde:

$P(A>a, t)=$ probabilidad de que la variable aleatoria poissoniana $A$ exceda un cierto valor $a$ en un periodo de tiempo de $t$ años.

$\lambda_{a}=$ tasa anual media de excedencia del valor $a$.

La determinación de esta tasa anual media de excedencia se realiza aplicando el Teorema de la Probabilidad Total, según la ecuación (2.5). De este modo, se pueden obtener curvas de peligrosidad que proporcionen la probabilidad de excedencia de un cierto nivel del parámetro de peligrosidad sísmica empleado, debido a la contribución de cada uno de las fuentes sismogenéticas caracterizadas en una determinada región.

$$
\lambda_{a}=\lambda_{m} \iint P(A>a \mid m, r) f_{M}(m) f_{R}(r) d m d r
$$

donde: 
$\lambda_{m}=\quad$ tasa anual media de ocurrencia de terremotos de la fuente sismogenética considerada, obtenida según la ecuación (2.1).

$f_{M}(m)$ = función probabilidad de la magnitud del sismo.

$f_{R}(r)=$ función de densidad de probabilidad de la distancia del foco emisor del sismo al emplazamiento.

$P(A>a \mid m, r)=$ probabilidad de excedencia de determinado nivel del movimiento del suelo $a$, condicionada a la ocurrencia de un terremoto de magnitud $m$ a una distancia $r$ (Baker, 2008).

El proceso de evaluación de la peligrosidad sísmica según esta metodología se puede resumir según las siguientes etapas (Benito \& Jiménez, 1999; Benito et al., 2006): 1) análisis de la sismicidad del área de estudio y elaboración del catálogo de proyecto; 2) definición y caracterización de cada una de las fuentes sísmicas; 3) elección del modelo del movimiento fuerte del terreno; y 4) evaluación de la peligrosidad integrando la acción de cada una de las zonas sismogenéticas que afectan al área objeto de estudio, definiendo las correspondientes curvas de peligrosidad (Figura 2.7).
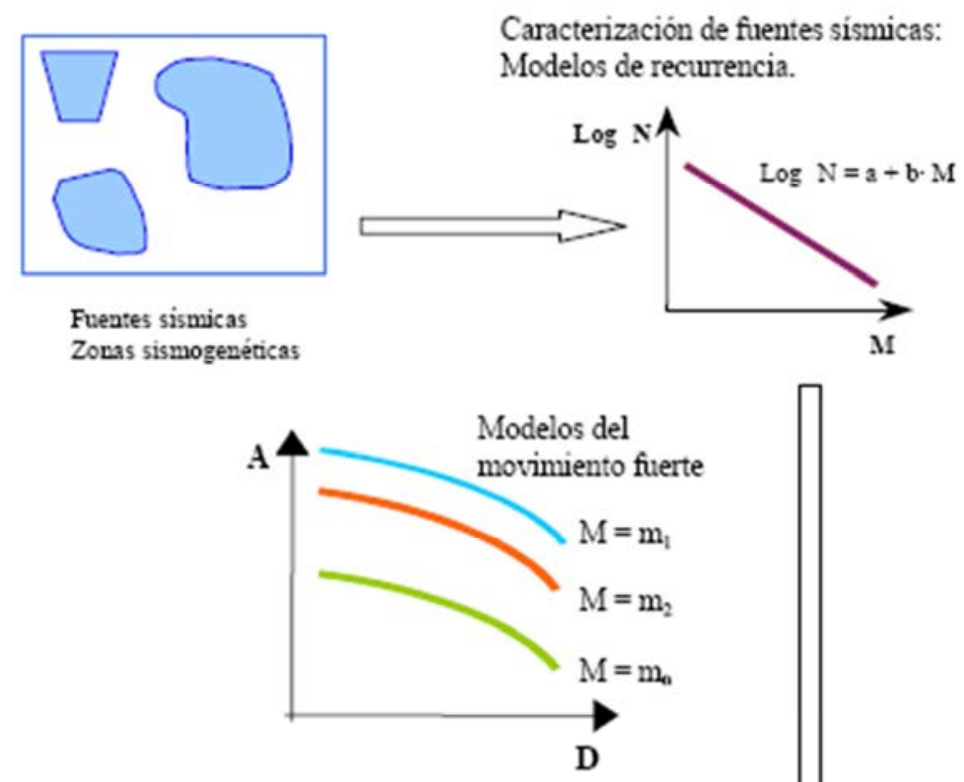

Peligrosidad

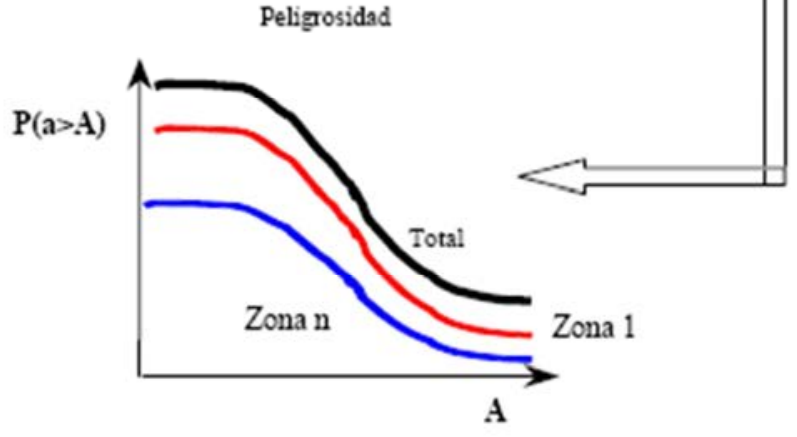

Figura 2.7. Etapas del proceso de evaluación probabilista de la peligrosidad sísmica, siguiendo un método zonificado (Benito et al., 2006). 
Basándose en este marco teórico se han desarrollado sucesivos programas de cálculo a partir del EQ-RISK de McGuire (1976), entre los que destacan el PRISK (1985), el SEISRISK III (Bender \& Perkins, 1987), el CRISIS (Ordaz et al., 1999, 2001, 2008, 2012), o el código USERISK 2011 (Aguilar, 2011).

Técnicas de tratamiento de los resultados de los estudios probabilistas de peligrosidad sísmica como la de desagregación son de creciente aplicación en la actualidad. Este tipo de herramientas permite evaluar las contribuciones relativas a dicha peligrosidad de cada una de las variables o fuentes sismogenéticas consideradas en el cálculo, para diferentes intervalos de magnitud y distancia (Bazzurro \& Cornell, 1999; Benito \& Jiménez, 1999; McGuire, 2004), posibilitando una estimación más realista de la peligrosidad sísmica y una mejor caracterización de los niveles de riego asumidos en su evaluación.

Ya sea mediante métodos deterministas o mediante modelos probabilistas, cualquier proceso de estimación de la peligrosidad conlleva incertidumbres asociadas al proceso de cálculo las cuales provocan que los resultados se puedan ver afectados por un mayor o menor grado de desviación. Estas incertidumbres pueden tener carácter tanto epistemológico como estadístico (Krinitzsky, 2002):

$\checkmark$ Epistemológicas o inherentes, asociadas con la variabilidad natural existente en cualquier proceso de la naturaleza, es decir, aquellas relacionadas con los modelos asumidos de sismicidad y zonificación de las fuentes sismogenéticas o la predicción del movimiento, que sólo podrían determinarse si se conociera el modelo real de comportamiento del terreno.

$\checkmark$ Estadísticas o aleatorias, asociadas a errores en la estimación de los parámetros empleados en el cálculo por un determinado modelo. Pueden reducirse aumentando la cantidad y calidad de los datos existentes, con objeto de estimar con mayor precisión su valor.

Por tanto, su cuantificación y calibración resulta necesaria en cualquier estudio de evaluación de la peligrosidad sísmica (Budnitz et al., 1997; Bommer \& Abrahamson, 2007; Bommer \& Crowley, 2006; Sokolov \& Wenze, 2011; Vargas, 2013). Con el fin de minimizar estas incertidumbres, se pueden destacar también las herramientas de juicio de expertos y árbol lógico:

$\checkmark$ Practicada por primera vez en estimaciones de peligrosidad sísmica realizadas por el Electric Power Research Institute en 1986 (EPRI, 1986), la aplicación formal de juicio de expertos fue empleada con el objetivo de suplir las lagunas de conocimiento existentes y controlar las incertidumbres asociadas al proceso de cálculo. Esta técnica ha quedado actualmente relegada para estudios de seguridad destinados al diseño de instalaciones especiales o críticas, donde el nivel de riesgo aceptable es muy pequeño y se requiere un detallado conocimiento de dichas incertidumbres (Benito \& Jiménez, 1999). 
$\checkmark$ La formulación del árbol lógico, descrita por Coppersmith \& Young (1986) y desarrollada en Krinitzsky (1995), Abrahamson \& Bommer (2005), Scherbaum et al. (2005) o Grünthal \& Wahlström (2006), entre otros, consiste en la estimación de las incertidumbres asociadas al cálculo mediante la asignación, de forma secuencial, de una serie de pesos en función de la naturaleza y variabilidad del parámetro analizado, a través de diagramas de nodos y barras, dirigiendo las incertidumbres de cada estimación progresivamente hasta obtener la incertidumbre de los resultados finales (Giner et al., 2003; García-Mayordomo, 2005; Benito et al., 2015). Aplicado al análisis de la peligrosidad sísmica, esta herramienta permite considerar alternativas como el uso de una u otra función de atenuación o la utilización de distintas delimitaciones de las fuentes sismogenéticas, organizando de un modo efectivo las fuentes de incertidumbres que afectan al resultado final y su sensibilidad en relación con las demás las opciones consideradas en el cálculo.

Durante las últimas décadas han sido desarrollados otros procedimientos alternativos de evaluación probabilista de la peligrosidad sísmica, basados en modelos no zonificados (Woo, 1996). Estos modelos, apoyados en técnicas de suavizado espacial de la sismicidad (Frankel, 1995; Molina et al., 2001; Crespo, 2011), permiten estimar la tasa de recurrencia del emplazamiento objeto de estudio partiendo únicamente de la información suministrada por el catálogo sísmico, reduciendo de esta forma las incertidumbres asociadas a la caracterización de las distintas fuentes sismogenéticas, especialmente en aquellas regiones de sismicidad baja o moderada donde la disponibilidad de registros es menor.

\subsubsection{Estudios sobre peligrosidad sísmica a escala regional en la península Ibérica}

Los resultados de cualquier estudio de peligrosidad a escala regional se sintetizan principalmente en mapas de peligrosidad sísmica, entendidos como la variación geográfica de los niveles de movimiento del suelo asociados a una cierta probabilidad de excedencia (González, 2010), expresada habitualmente mediante períodos de retorno. Los valores comúnmente más empleados en ingeniería para estos periodos son los asociados a 475 años y 975 años (500 y 1.000 en la literatura española tradicionalmente), correspondientes con una probabilidad de excedencia del $10 \%$ en 50 y 100 años de vida útil, respectivamente (GarcíaMayordomo, 2005).

En lo concerniente a la península Ibérica, los primeros trabajos de peligrosidad sísmica realizados (Munuera, 1963; López-Arroyo \& Steep, 1973) sirvieron de base para la realización de los mapas de las primeras normas sismorresistentes españolas (PGS-1, 1968; PDS-1, 1974). A comienzos de los años 80 aparecen los primeros mapas de peligrosidad probabilísticos calculados en base a distribuciones extremales de Gumbel (Ibargüen, 1983; Roca, LópezArroyo \& Suriñach, 1984; Martín \& Sierra, 1984; Ibargüen \& Rodríguez-Estrella, 1986).

Paralelamente, se desarrollaron otros estudios según el método poissoniano zonificado de Cornell (1968) implementados a través del código EQRISK (Muñoz et al., 1984; García- 
Fernández, Jiménez \& Kijko, 1989; IGN, 1991), sirviendo de base este último para la elaboración de los mapas de peligrosidad de las normas NCSE-94 y NCSE-02 (Figura 2.8).

Ya en el siglo XXI los estudios de peligrosidad sísmica ha sido realizados directamente en términos de aceleración pico del terreno PGA, abordando de manera más detallada las incertidumbres asociadas al proceso de cálculo incluyendo la formulación de árbol lógico así como técnicas de desagregación para determinar los intervalos de magnitud y distancia con mayor contribución en el análisis.

En este sentido, destacan los estudios de García-Blanco (2009) para todo el territorio nacional; Aguilar (2011) e Irizarry et al. (2011) para la región catalana y Pirineos; Perea \& Atakan (2007) para la Comunidad Valenciana; García-Mayordomo (2005) para el Sureste peninsular; Benito et al. $(2008,2010)$ para Andalucía; Buforn et al. (2005), García-Mayordomo, García-Escribano \& Benito (2007), Gaspar-Escribano, Benito \& García-Mayordomo (2008), y Benito et al. (2006, 2012, 2015) para la Región de Murcia (Figura 2.9); o Gaspar-Escribano, Benito \& Rivas-Medina (2011) en Navarra, entre otros.

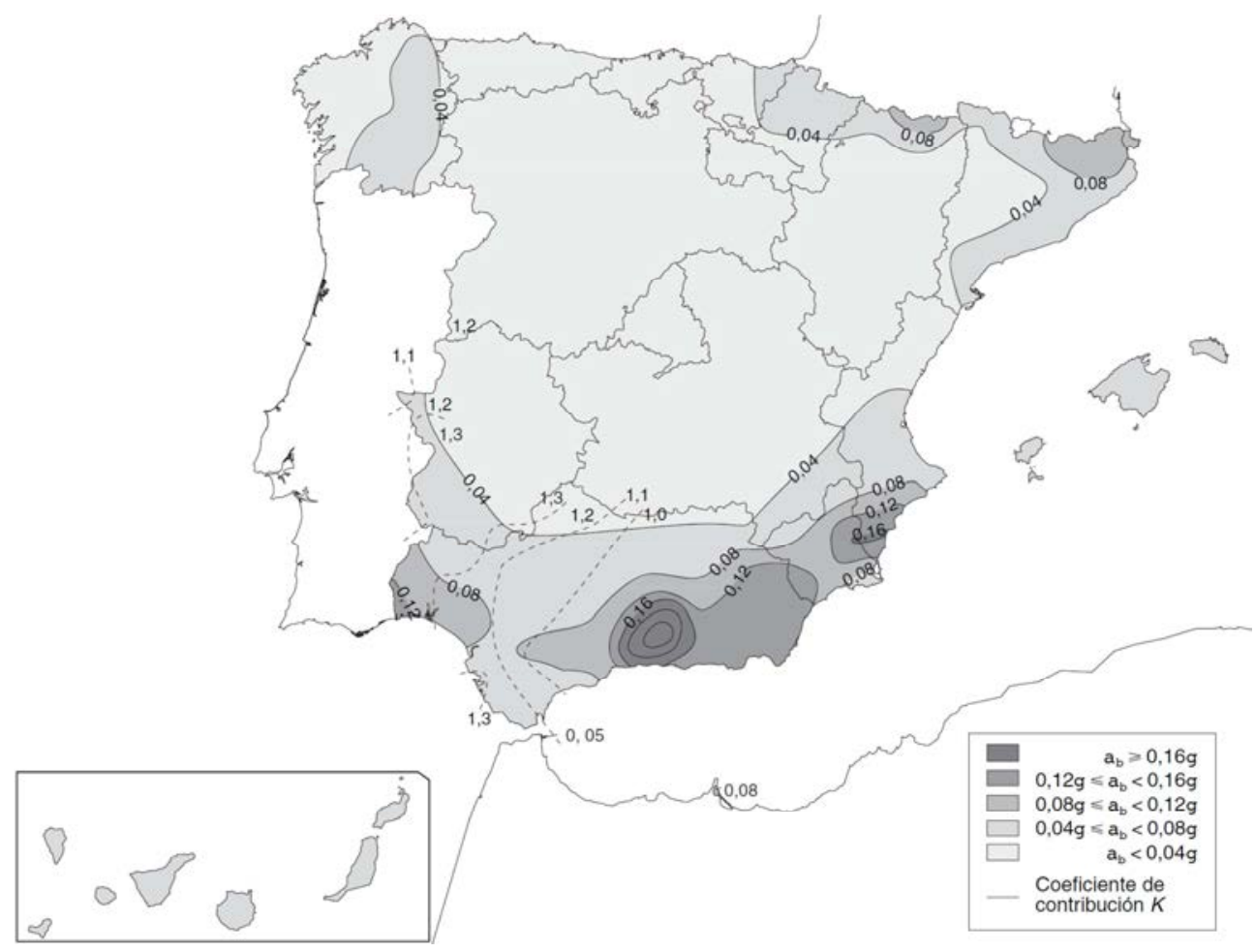

Figura 2.8. Mapa de peligrosidad sísmica de España en términos de aceleración básica del terreno para un período de retorno de 500 años (NCSE-02, 2002).

Mezcua, Rueda \& García-Blanco (2011) realizan un análisis de la peligrosidad sísmica en España (Figura 2.10), partiendo del catálogo sísmico recogido en Mezcua, Rueda \& GarcíaBlanco (2004) y combinando mediante un árbol lógico diversas zonificaciones sismogenéticas con las funciones de atenuación definidas por Sabeta \& Pugliese (1996), García-Blanco (2009) y Akkar \& Bommer (2010). 
Otros trabajos (Cabañas et al., 2011; Benito et al., 2012) aplican diversos modelos de atenuación NGA en la Región de Murcia, comparando los resultados con los registros sísmicos obtenidos durante el sismo de Lorca de 2011, y obteniendo mapas de peligrosidad sísmica de este territorio para distintos escenarios previstos.

En cuanto a la aplicación de los modelos no zonificados, se pueden encontrar diversos estudios de peligrosidad sísmica realizados para el territorio peninsular (Peláez, 1999; Crespo, Martí \& Martínez, 2003; Crespo, 2011), para el área pirenaica (Secanell et al., 2008), para el archipiélago canario (Crespo, Martí \& Martínez 2007), o para el Sureste peninsular (Peláez, Delgado \& López-Casado, 2005).

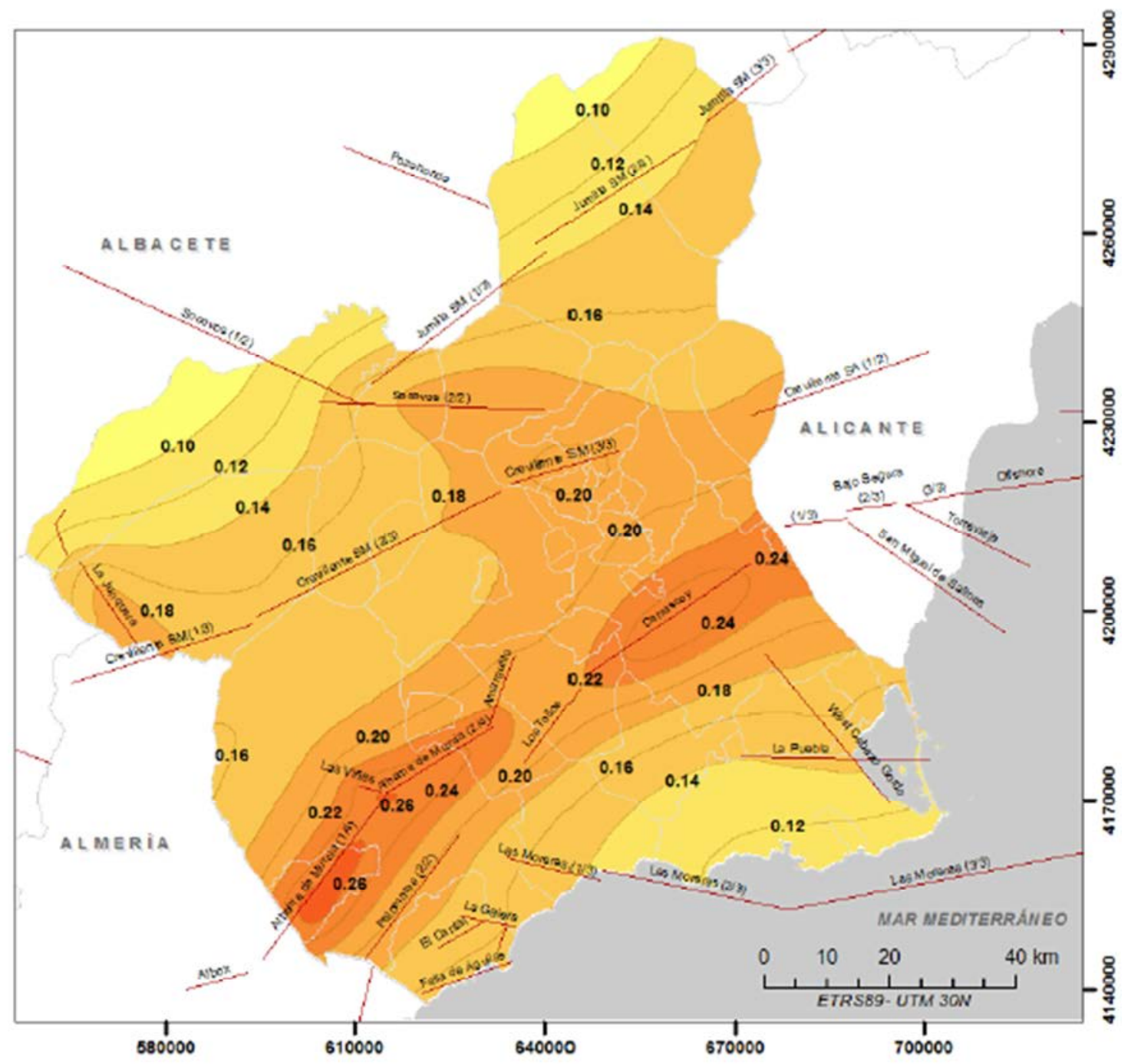

Figura 2.9. Mapa de peligrosidad sísmica de la Región de Murcia, en términos de PGA en roca, para un periodo de retorno de 475 años (Benito et al., 2015).

En este sentido, los niveles de peligrosidad obtenidos para la península Ibérica en recientes trabajos (García-Blanco, 2009; Gaspar-Escribano et al., 2010a; Cabañas et al., 2011; Barbat, 2011; Mezcua, Rueda \& García-Blanco, 2011; Benito et al., 2015), a partir de las nuevas técnicas desarrolladas y registros sísmicos disponibles, quedarían del lado de la inseguridad en 
relación a los niveles establecidos en la vigente norma sísmica NCSE-02 (2002), con unas aceleraciones básicas significativamente superiores a las definidas en este código.

\subsubsection{Peligrosidad sísmica a escala local}

\subsubsection{Efecto sitio}

Los parámetros de movimiento del suelo obtenidos en los estudios de peligrosidad sísmica a escala regional pueden ser amplificados por las condiciones geológicas, geotécnicas y topográficas de las capas más superficiales del terreno por el que se propagan las ondas sísmicas procedentes del foco emisor (Figueras \& Macau, 2009). El concepto de efecto sitio o efecto local se puede definir como la modificación del movimiento del suelo en su amplitud, duración y contenido frecuencial, al entrar en contacto la señal sísmica con las capas más superficiales del terreno (Aki, 1993).

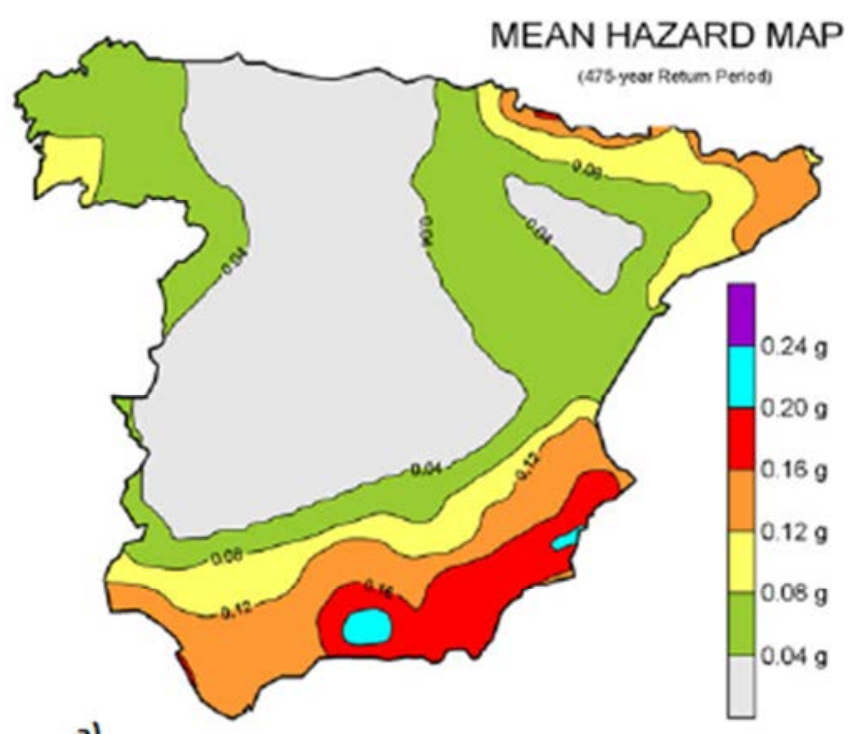

a)
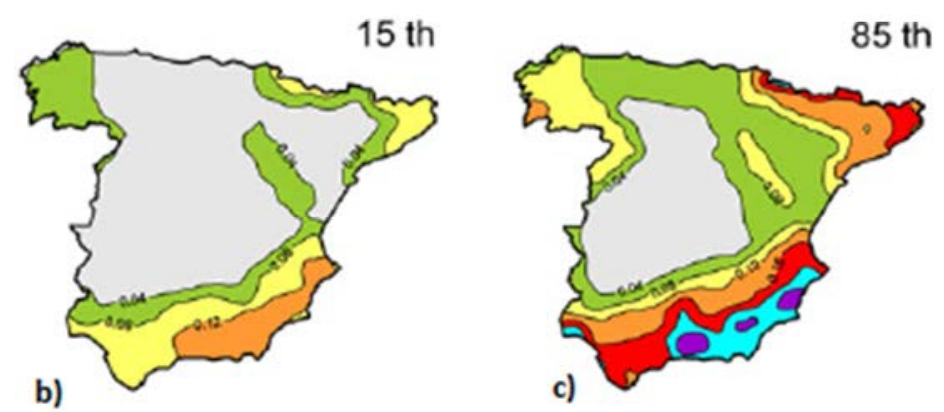

Figura 2.10. Mapa de peligrosidad sísmica de España en términos de PGA en roca para un periodo de retorno de 475 años, según los siguientes percentiles de la distribución de probabilidad: (a) Percentil 50;

(b) Percentil 15; (c) Percentil 85 (Mezcua, Rueda \& García-Blanco, 2011).

En lo respectivo a las características geológicas y geotécnicas superficiales del suelo, mientras los sustratos rocosos amplifican muy poco la señal sísmica, los depósitos de materiales sueltos, como gravas, arenas o limos, amplifican considerablemente el movimiento 
del terreno, con mayor amplificación cuanto menor es el tamaño de grano del sedimento (Le Brun, Hatzfeld \& Bard, 2001), según se muestra en Figura 2.11.

En lo relativo a los efectos de la topografía del terreno, se produce amplificaciones de las ondas sísmicas sobre topografías convexas, en zonas elevadas con relieve o cimas de montañas, y desamplificaciones sobre topografías cóncavas, tales como zonas bajas y valles. A mayor pendiente del terreno mayor será también la amplificación esperable del movimiento sísmico en función del contenido frecuencial de la onda incidente (Bard et al., 1995; Álvarez, 1999; Macau, 2008; Blázquez, 2013). Asimismo, pueden producirse otros efectos indirectos relacionados, por ejemplo, con deslizamientos y licuefacciones del terreno (Jiménez \& GarcíaFernández, 2009).

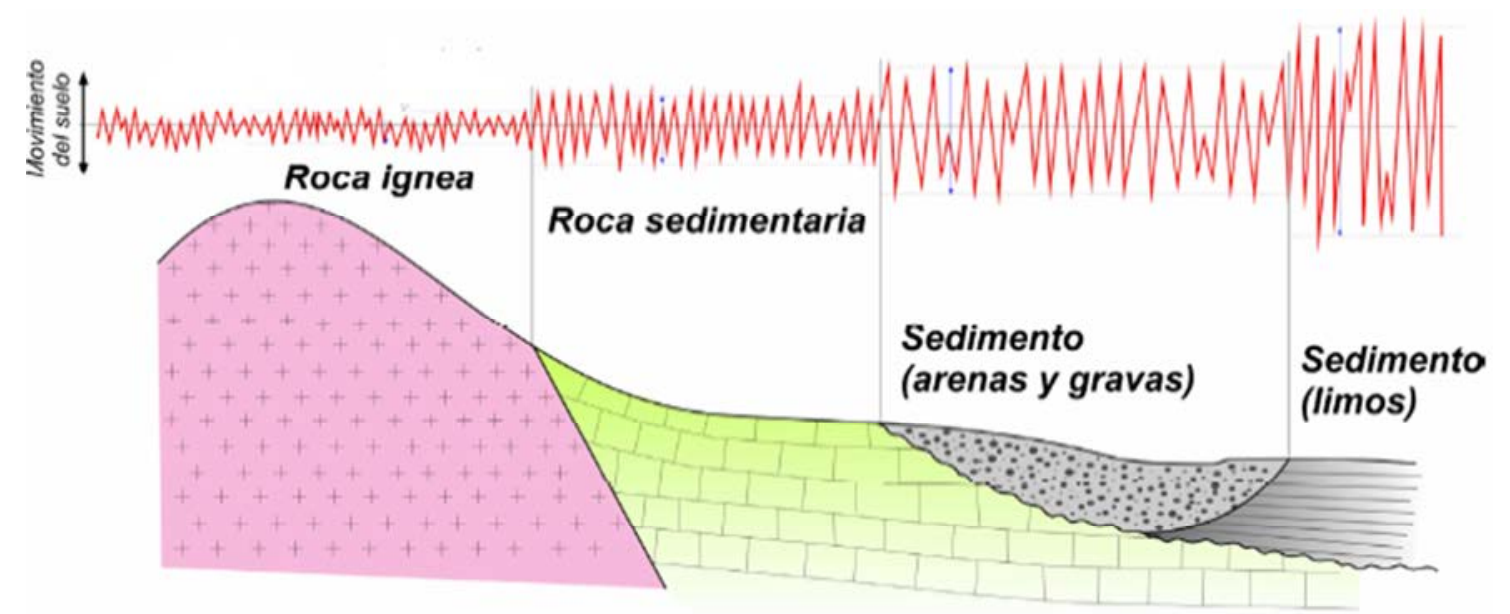

Figura 2.11. Efecto sitio. Amplificación del frente de ondas en función del tipo de material de los estratos más superficiales (Giner-Robles et al., 2010).

\subsubsection{Microzonificación sísmica}

El análisis de los efectos locales del suelo en áreas urbanas ha dado lugar a estudios de microzonación o microzonificación sísmica, en los cuales se identifican áreas homogéneas del territorio que pueden considerarse similares en cuanto a su comportamiento de amplificación del movimiento fuerte del suelo ante una acción sísmica dada (García-Mayordomo, 2005). Estos estudios se desarrollan a escalas menores que los trabajos a nivel regional, con apoyo de campañas de campo y análisis numéricos y experimentales, abarcando zonas cuya extensión es de orden municipal.

Se denomina como función de transferencia a aquella que describe la relación entre movimiento entre el basamento rocoso y el suelo en superficie, en el dominio frecuencial, de una misma columna de suelo (Barbat, 1998). Los métodos utilizados para caracterizar la contribución de los efectos de suelo a la peligrosidad sísmica, se pueden clasificar en métodos experimentales y métodos numéricos (Roca et al., 2008). 
Los métodos experimentales tienen como objeto determinar la función de transferencia de las capas de suelo superficiales a partir de los registros sísmicos o de ruido sísmico, obtenidos en el propio emplazamiento. Se pueden destacar los siguientes (Macau, 2008):

$\checkmark$ Método del cociente espectral H/V de Nakamura (Nakamura, 1989). Consiste en la estimación del comportamiento local del suelo a partir del cociente entre los espectros de Fourier de las componentes horizontal y vertical de registros de sismos o de ruido sísmico (microtremors), tomados en una misma estación. Se trata de una técnica ampliamente utilizada debido a su sencillez, fiabilidad, bajo coste y rapidez en la obtención de resultados, aunque con limitaciones en la obtención de modos de resonancia adicionales al correspondiente con la frecuencia fundamental y para frecuencias de resonancia muy bajas (Moncayo, 2002). La metodología ha sido revisada recientemente en trabajos como los de Bard (2008), Chatelain et al. (2008), Theodoulidis et al. (2008) o Schmidt (2010).

$\checkmark$ Método SSR de las razones espectrales suelo-roca (Standard Spectral Ratio method). Basado en Borcherdt (1970), se fundamenta en la comparación entre los datos registrados en una estación de referencia, considerada como libre de efectos locales, y los tomados en otra estación sobre el suelo evaluado. Por tanto, para su aplicación es necesario disponer de registros sísmicos obtenidos simultáneamente en ambas estaciones, lo cual dificulta en ocasiones su utilización en zonas urbanas debido a la larga duración de los experimentos y a los costes elevados en instrumentación (Goded, 2010).

En cuanto a los métodos numéricos, se basan principalmente en simulaciones analíticas a partir de modelos representativos del terreno, para lo cual es necesario disponer de información geológica y geotécnica de la zona de análisis. Su empleo es especialmente aplicable para la evaluación de los efectos locales en aquellos emplazamientos en donde no se dispone de los requerimientos necesarios para utilizar métodos experimentales, ya sea por falta de instrumentación o de registros disponibles.

No obstante, es recomendable la validación de los resultados obtenidos mediante su comparación con datos experimentales del movimiento del suelo registrados in situ, debido al grado de incertidumbres asociadas al cálculo (Cid, 1998). Entre las diversas técnicas propuestas en la literatura, se pueden destacar las siguientes:

$\checkmark$ Método SASW (Spectral Analysis of Surface Waves) y MASW (Multichannel Analysis of Surface Waves). Estos métodos evalúan la respuesta local del terreno mediante la obtención de perfiles verticales de velocidad de ondas de cizalla $V_{s}$ de las capas superficiales, basándose en la inversión de la curva de dispersión de las ondas Rayleigh (Park, Miller \& Xia, 1999; Foti et al., 2011).

El procedimiento se basa en la instalación de una fuente emisora de impulsos a distintas frecuencias, junto con una serie de geófonos que monitorizan estas señales. En función de la distancia entre estos aparatos y de la longitud de onda de los impulsos 
emitidos, se obtiene la velocidad de fase de la onda Rayleigh correspondiente, para cada frecuencia (Cadet, 2007).

$\checkmark$ Método lineal-equivalente 1D. Se trata de un método unidimensional lineal que estima la respuesta del terreno asociada a la propagación vertical de las ondas de cizalla a través de un medio unidimensional semi-infinito estratificado en capas planas horizontales, homogéneas y viscoelásticas. Para ello parte de la solución continua de la ecuación de propagación de una onda amortiguada en el dominio frecuencial, a través de la transformada de Fourier (Gutiérrez, 1996).

Para considerar la no elasticidad del comportamiento del suelo, se realiza un proceso iterativo de linealización mediante el ajuste de los valores del módulo de cizalla y del factor de amortiguamiento de cada una de las capas del perfil estratigráfico analizado, hasta que sean consistentes con los niveles de esfuerzos y deformaciones efectivos inducidos en el suelo (Coral, 2002; Moncayo, 2002).

De forma similar a los estudios de peligrosidad sísmica a escala regional, los resultados de este tipo de trabajos de microzonificación se suelen expresar mediante mapas de peligrosidad, con las características y la respuesta del suelo a escala local frente a la acción sísmica.

De este modo se puede obtener información relevante para la mitigación del riesgo sísmico en áreas urbanas, mediante su aplicación al desarrollo del planeamiento urbanístico del emplazamiento. La limitación del aprovechamiento y usos permitidos en las zonas con una mayor capacidad de amplificación de la señal sísmica permite la reducción de las potenciales pérdidas provocadas por este tipo de fenómenos.

Conforme se ha avanzado en el conocimiento de las propiedades del terreno, se han propuesto diversas clasificaciones del mismo con el fin de caracterizar su comportamiento sísmico a escala local, basadas la mayoría de ellas en la distribución de velocidades de las ondas de cizalla $V_{s}$. Desde las primeras clasificaciones como la establecida por Trifunac \& Brady (1975), se han ido definiendo otras escalas más completas (Phillips \& Aki, 1986; Borcherdt, 1994; IBC, 2000).

El Eurocódigo 8 (CEN, 2004) establece una clasificación del terreno en función de rangos de valores de la velocidad de propagación $V_{s}^{30}$ de las ondas de corte en los primeros $30 \mathrm{~m}$ de suelo, creciente en cuanto a amplificaciones del terreno desde el suelo tipo $A$ hasta suelo tipo S2. De forma similar, la norma NCSE-02 propone una clasificación del suelo desde tipo I a tipo IV. Ambos códigos, incorporan estos efectos locales al cálculo mediante la adopción de coeficientes mayoradores de la acción sísmica (Tabla 2.5).

El desarrollo de trabajos de microzonificación en la península Ibérica ha sido muy reciente, principalmente durante la primera década del s. XXI. Los primeros estudios elaborados se centraron en la ciudad de Barcelona (Cid, 1998; Goula et al., 1998; Cid et al., 2001), si bien en los últimos años estos trabajos se han enfocado también a otras zonas como el Pirineo Oriental y Andorra (Coral, 2002; Moncayo, 2002; Tapia, 2006; Macau et al., 2007; 
Macau, 2008; González ,2010), diversas ciudades en Andalucía (Cheddadi, 2001; Navarro et al., 2007; Goded, 2010; Schmidt, 2010; Gaspar-Escribano et al., 2010b), o el Sureste peninsular (Ribó, 2010; Rosa-Cintas et al., 2011; García-Fernández \& Jiménez, 2012).

Tabla 2.5. Comparación entre los tipos de terreno propuestos en diversos códigos sísmicos (CARM, 2014).

\begin{tabular}{|c|c|c|c|c|c|c|c|}
\hline \multicolumn{3}{|c|}{ Tipo de suelo } & \multirow{2}{*}{ Descripción general } & \multicolumn{3}{|c|}{$V_{s}^{30}(\mathrm{~m} / \mathrm{s})$} & \multirow{2}{*}{$S$} \\
\hline NEHRP & EC-8 & NCSE-02 & & NEHRP & $\mathrm{EC}-8$ & NCSE-02 & \\
\hline$A$ & \multirow{3}{*}{$A$} & \multirow{3}{*}{1} & Roca dura & $>1.500$ & \multirow{3}{*}{$>800$} & \multirow{3}{*}{$>750$} & 0,9 \\
\hline & & & & & & & \\
\hline B & & & Roca medio dura & $760-1.500$ & & & 1,0 \\
\hline C & B & II & Suelo duro y roca blanda & $360-760$ & $360-800$ & $400-750$ & 1,2 \\
\hline D & C & III & Suelo medio a blando & $180-360$ & $180-360$ & $200-400$ & 1,4 \\
\hline \multirow[t]{2}{*}{$E$} & D & \multirow{3}{*}{ IV } & Suelo blando & $<180$ & $<180$ & \multirow{3}{*}{$<200$} & 1,8 \\
\hline & & & & & & & \\
\hline $\mathrm{F}$ & $E$ & & Suelos especiales & Licuefacción & Licuefacción & & $\geq 2,0$ \\
\hline
\end{tabular}

$V_{s}^{30}=$ valor medio de velocidad de las ondas de cizalla en los primeros $30 \mathrm{~m}$ de suelo; $S=$ factor de amplificación del espectro de respuesta en función del comportamiento local del suelo. La clasificación adoptada por el National Earthquake Hazards Reduction Program (NEHRP) se corresponde con la escala propuesta por el International Building Code (IBC, 2000)

En lo relativo a la ciudad de Lorca, aunque previamente al terremoto de 2011 se habían publicado ya algunos estudios de microzonación (Navarro et al. 2006, 2008), tras el sismo estos se han intensificado notablemente (Figueras et al., 2012; Pérez-Cuevas et al., 2013; Alguacil et al., 2014; Navarro et al., 2014; Martínez-Pagán et al., 2014), pudiéndose destacar también el trabajo realizado por la Consejería de Obras Publicas y Ordenación del Territorio de la Región de Murcia en colaboración con la Universidad Politécnica de Cartagena (CARM, 2014), mostrado en la Figura 2.12.

\subsection{VULNERABILIDAD SÍSMICA}

\subsubsection{Introducción}

La vulnerabilidad sísmica es la segunda variable interviniente en el proceso de evaluación del riesgo sísmico (Figura 1.5). Se puede definir como la predisposición intrínseca a sufrir daño de una cierta estructura ante la ocurrencia de un movimiento sísmico de una determinada severidad (Barbat et al., 2010). Esta propiedad, directamente relacionada con las características de diseño y construcción de la edificación, como la tipología estructural, la geometría o la calidad de los materiales, constituye por tanto un factor interno de la misma, independiente de la peligrosidad sísmica del emplazamiento. 
De este modo, una cierta edificación puede ser muy vulnerable sísmicamente pero no presentar elevados niveles de riesgo al situarse en una región con baja sismicidad (Mena, 2002). Los estudios de vulnerabilidad sísmica pueden ser aplicados a cualquier tipo de obra de edificación e ingeniería como presas, carreteras, puentes, depósitos o centrales nucleares, cuyo comportamiento sísmico se requiera evaluar.

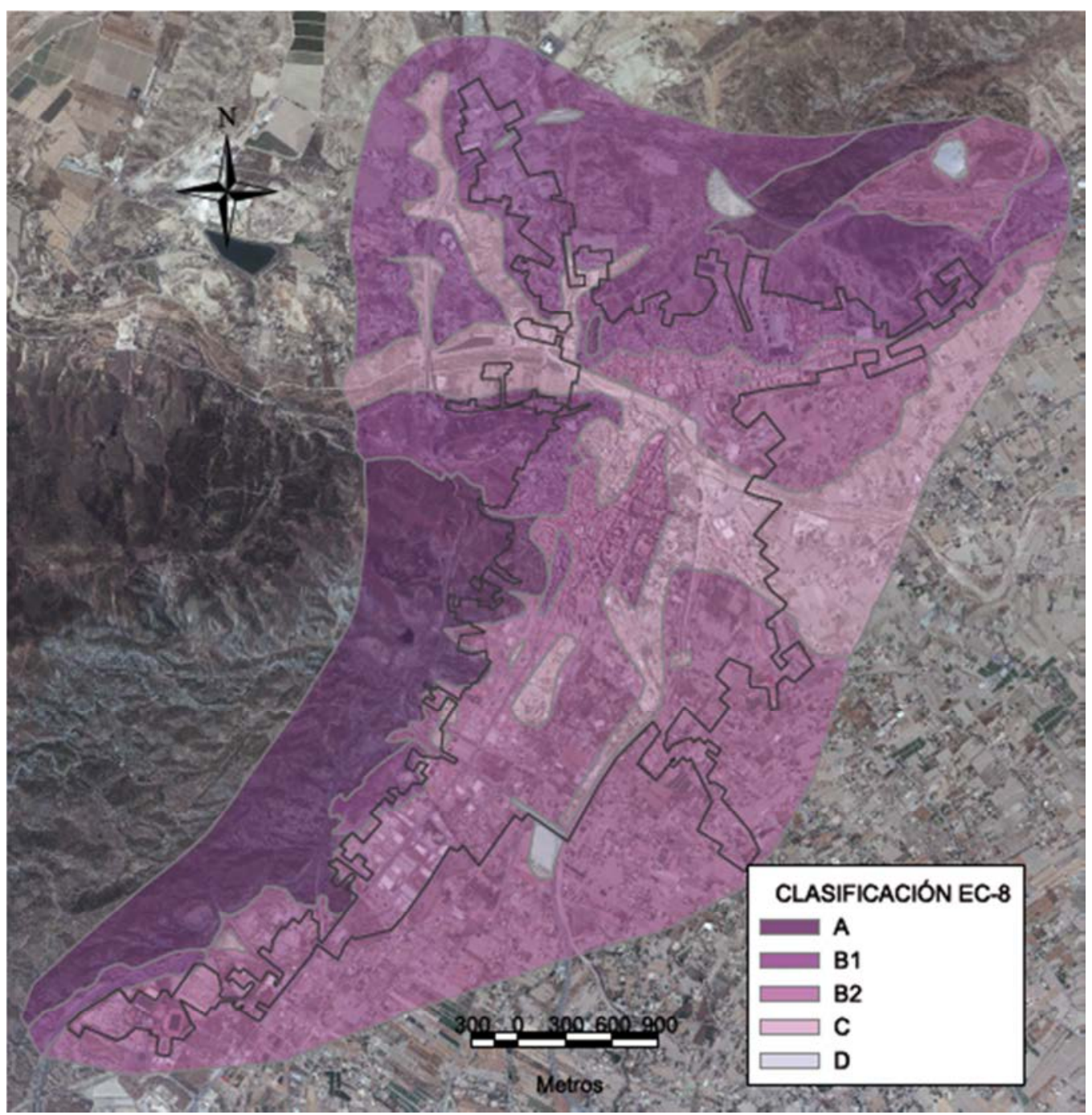

Figura 2.12. Clasificación del terreno en el núcleo urbano de Lorca según la escala propuesta por el EC-8, obtenida de la distribución de velocidades de las ondas $V_{s}^{30}$ (CARM, 2014).

Este concepto de vulnerabilidad sísmica puede abordarse bajo dos perspectivas diferentes, denominadas como vulnerabilidad observada y vulnerabilidad calculada (Barbat, 1998; Lang, 2002):

$\checkmark \quad$ La vulnerabilidad observada está basada en la cuantificación de la capacidad sísmica de un determinado edificio o estructura a partir del análisis de los datos de daño disponibles de terremotos pasados. Estos métodos de evaluación, con origen en las distintas escalas de intensidad macrosísmica, proporcionan a priori información robusta del comportamiento sísmico de las estructuras al basarse en observaciones reales experimentadas en el entorno urbano (Bermúdez, 2010). 
$\checkmark$ La vulnerabilidad calculada se centra en la caracterización de las edificaciones mediante la modelización de su estructura y la simulación numérica de su comportamiento ante una cierta acción sísmica. Aunque estas evaluaciones permiten, en términos generales, una mejor comprensión de la respuesta sísmica del sistema, los niveles de daño obtenidos no pueden ser calibrados hasta que no se produzca un escenario sísmico de características similares al considerado.

\subsubsection{Clasificación de las metodologías para la evaluación de la vulnerabilidad sísmica}

En la actualidad no existe una metodología única para la evaluación de la vulnerabilidad sísmica de las estructuras y, en particular, de edificaciones. El método elegido depende del objetivo de la evaluación planteada, de la disponibilidad de datos sísmicos, así como de la capacidad de análisis en términos computacionales (González, 2010; Herrera et al., 2011).

En primer lugar, destacar la clasificación propuesta por Corsanego \& Petrini (1990), la cual agrupa en cuatro grandes grupos las metodologías existentes para la evaluación de la vulnerabilidad sísmica de edificaciones:

\section{$\checkmark$ Técnicas directas}

Estiman en un solo paso el daño causado por un sismo en una determinada estructura. Estos métodos se pueden dividir, a su vez, en métodos tipológicos y mecánicos. Los métodos tipológicos - o estadísticos - se basan en la observación y cuantificación del daño causado por los terremotos en las edificaciones. En cuanto a los métodos mecánicos, estiman la respuesta sísmica de las mismas mediante su modelización y cálculo por medio de cualquiera de los procedimientos de análisis disponibles: estático o dinámico; lineal o no lineal.

\section{$\checkmark$ Técnicas indirectas}

Determinan, en primer lugar, un índice de vulnerabilidad de la estructura basándose en la identificación de los parámetros más relevantes que determinan su respuesta sísmica, para relacionarlo posteriormente con el daño sufrido por la misma frente a una determinada la acción sísmica a través de estudios estadísticos de afecciones post-sismo. Constituyen una metodología sencilla y rápida aplicable a evaluaciones de áreas urbanas a gran escala.

\section{$\checkmark$ Técnicas convencionales}

Esencialmente heurísticas, introducen un parámetro identificador de la vulnerabilidad sísmica independiente de la predicción de daño. Estos trabajos, entre los que se puede destacar los propuestos por el ATC-13 (1985), HAZUS (1999) o la escala EMS-98 (Grünthal, 1998), proporcionan una medida relativa de la vulnerabilidad de un área determinada ya sea empíricamente en base a las características físicas de las estructuras o mediante sus relaciones capacidad-demanda, calibradas por expertos. 
No obstante, destacar la dificultad de comparación entre edificaciones pertenecientes a diferentes tipologías estructurales, debido a la diversidad de factores considerados en su evaluación.

\section{$\checkmark$ Técnicas híbridas}

Combinan características de los métodos anteriores, relacionando los datos empíricos/estadísticos disponibles con los resultados de simulaciones numéricas (FEMA 154, 2002; Dolce et al., 2006; Kappos et al., 2006; Alam, Shahria-Alam \& Tesfamariam, 2012), sistemas de conjuntos difusos y redes neuronales (Sánchez Silva \& García, 2001), o juicio de expertos (ATC-21, 1988).

Sobre esta base, Dolce et al. (1995) propusieron un nuevo criterio de clasificación de estas metodologías a partir un análisis individualizado de las etapas fundamentales que comprenden la evaluación: "datos de entrada", "métodos empleados" y "resultados". En lo relativo a los métodos empleados, se distingue entre:

$\checkmark$ Métodos estadísticos -o empíricos-, basados en el análisis de las observaciones de daños en edificaciones durante terremotos pasados. A este respecto, Safina (2003) divide a su vez estas técnicas en dos subcategorías: métodos de categorización o caracterización, los cuales clasifican las edificaciones según su tipología en clases de vulnerabilidad; y métodos de inspección y puntaje, los cuales evalúan la vulnerabilidad sísmica mediante la obtención de un índice de vulnerabilidad, atribuyendo valores numéricos a cada componente de la edificación, ponderados en función de su importancia relativa en su respuesta sísmica.

$\checkmark$ Métodos mecánicos -o analíticos- basados en la simulación numérica del comportamiento sísmico de la edificación mediante modelos estructurales. Constituyen técnicas más laboriosas y sofisticadas a nivel computacional que los métodos empíricos, por lo que su utilización depende de la calidad de la información disponible y del grado de alcance requerido.

$\checkmark$ Métodos basados en juicios de expertos o técnicas híbridas, combinando las características y limitaciones de cada uno de los métodos anteriores (Lang, 2012).

Está clasificación ha sido, en líneas generales, comúnmente aceptada en la comunidad científica (CSSC, 1999; Ricci, 2010; CARM, 2014). A este respecto, Barbat et al. (2010) realizan una síntesis de estas clasificaciones proponiendo las siguientes corrientes metodológicas para la evaluación de la vulnerabilidad sísmica de estructuras en áreas urbanas:

$\checkmark$ Mediante descriptores o variables cualitativas, que clasifican las edificaciones en clases de vulnerabilidad. Escalas macrosísmica como la EMS-98 (Grünthal, 1998), emplean esta definición de vulnerabilidad sísmica, constituyendo técnicas relativamente subjetivas, limitadas a evaluaciones preliminares. 
$\checkmark$ Por medio de índices de vulnerabilidad, los cuales reflejan la calidad sísmica de la edificación mediante la valoración numérica ponderada de una serie de características relacionadas con la tipología y el diseño estructural del edificio, así como con ciertas prácticas y detalles constructivos del mismo. A este respecto, destacan el conocido como Método Italiano (Benedetti \& Petrini, 1984), el Método del Índice de Vulnerabilidad de RISK-UE (Milutinovic \& Trendafiloski, 2003), o el denominado como método japonés (JBDPA, 1990).

$\checkmark$ A partir de curvas de capacidad, esto es, diagramas fuerza-desplazamiento que, mediante un análisis no lineal, permiten describir el comportamiento sísmico de la estructura para cada nivel de carga frente a la acción sísmica (Lang, 2002). En este sentido, se dispone del Método del Espectro de Capacidad (Freeman, 1998) y demás metodologías encuadradas dentro de la filosofía de diseño Performed Based Design o diseño por prestaciones (ATC-40, 1996; HAZUS, 1999; HAZUS MH, 2008).

Otras síntesis más detalladas de las diversas clasificaciones de las metodologías existentes para la evaluación de la vulnerabilidad sísmica se pueden encontrar en Mena (2002), Bonett (2003), Calvi et al. (2006), Herrera et al. (2011) o Martínez-Cuevas (2014).

En resumen, los métodos empíricos, basados en índices y clases de vulnerabilidad, permiten ser aplicados de manera sencilla a gran escala, en áreas urbanas. No obstante, además de la necesaria disponibilidad de datos sísmicos en la zona de estudio, su aplicación en otras regiones puede dar lugar a resultados incoherentes debido a las diferentes costumbres constructivas. En cuanto a los métodos analíticos, permiten una mejor comprensión del comportamiento sísmico de la estructura así como su aplicación en regiones de escasa sismicidad, en la que no se disponen de los suficientes registros sísmicos para análisis estadísticos. Sin embargo, su extensión a grandes áreas puede ser muy laboriosa en términos computacionales y de recopilación de los datos de entrada necesarios para su implementación.

\subsubsection{Daño sísmico}

\subsubsection{Relación Vulnerabilidad - Daño}

A la hora de evaluar la vulnerabilidad sísmica de una determinada estructura, la definición del daño que puede sufrir esta durante un terremoto constituye uno de los principales factores a considerar. Daño y vulnerabilidad son dos conceptos íntimamente relacionados, ya que una estructura será más o menos vulnerable en función del grado de daño sísmico esperable. De hecho, las metodologías americanas de evaluación del riesgo sísmico ATC y HAZUS suelen obviar este concepto de vulnerabilidad y definir directamente una serie de funciones de daño para cada tipología de edificio (Pujades, Barbat \& Lantada, 2007).

En cualquier caso, en su acepción más genérica el concepto de daño sísmico representa el nivel de degradación que pueden experimentar los diferentes elementos de una cierta estructura como consecuencia de la acción sísmica (Yépez, 1996). 


\subsubsection{Elementos expuestos al daño y clases de daño}

En función de la naturaleza de estos elementos, el daño sísmico se clasifica generalmente en (Martínez-Cuevas, 2014):

$\checkmark$ Estructural: relacionado con el comportamiento de elementos tales como vigas, pilares, muros o forjados, que forman parte del sistema resistente tanto vertical como horizontal de la estructura.

$\checkmark$ No estructural: asociado a elementos arquitectónicos tales como cerramientos, ventanales o particiones, así como los diversos equipos mecánicos o eléctricos contenidos en la edificación.

La relevancia de estos elementos no estructurales ha sido tradicionalmente subestimada en el diseño sísmico, debido a que no están directamente relacionados con el sistema resistente del edificio (Bertero, 1992; Hermanns et al., 2012). Sin embargo, experiencias recientes como la del sismo Lorca en 2011, donde la mayoría de los fallecidos se debió al inadecuado comportamiento de este tipo de elementos (García-Ayllón \& Tomás, 2013), muestra la importancia de su consideración en los cálculos sísmicos. A este respecto, se puede establecer el concepto de vulnerabilidad no estructural (Safina, 2003), entendida como aquella asociada a la susceptibilidad de los elementos o componentes no estructurales de una determinada edificación.

Actualmente los estudios de evaluación de la vulnerabilidad y el riesgo sísmico en áreas urbanas se centran no sólo en la denominada como vulnerabilidad física (daño estructural o no estructural) de las edificaciones, sino también en la gestión global del evento sísmico, incorporando aspectos funcionales, operativos y económicos de la red urbana en su conjunto (Carreño, 2007; Gaspar-Escribano \& Iturrioz, 2011; Valcárcel, 2013; Jaramillo, 2014). De este modo, se proporciona información para la planificación y gestión de desastres sísmicos, suponiendo un referente para la toma de decisiones como, por ejemplo, la rehabilitación o demolición de edificios afectados, la ubicación de futuros centros sanitarios y educativos, o el diseño de rutas de comunicación y vías alternativas de escape de las zonas más vulnerables.

Asociado a este tipo de estudios suele aparecer el concepto de daño económico como intento de representar el evento sísmico en términos de pérdidas monetarias, considerando tanto el coste de reparación de las edificaciones e infraestructuras dañadas como el coste de las operaciones de emergencia y el de las pérdidas en la producción y actividad económica. A pesar de su difícil cuantificación (Coburn \& Spence, 2002), son diversas las metodologías recientemente planteadas de cara a la evaluación de estos costes (ATC-13, 1985; FEMA 157, 1994; Kappos \& Dimitrakopoulos, 2008; HAZUS MH, 2008; Lantada et al., 2010; Mora et al. 2011; Valcárcel et al., 2013).

En este sentido, algunos autores (Guevara, 2000; Safina, 2003) definen la vulnerabilidad funcional como la capacidad o predisposición de instalaciones o edificaciones esenciales (hospitales, centros educativos o líneas de abastecimiento) para seguir proporcionando los 
servicios básicos de atención de la población afectada, independientemente del nivel de daño físico que haya podido sufrir.

\subsubsection{Ductilidad estructural}

La ductilidad se puede definir como la capacidad que tienen las estructuras, sus componentes o los materiales que las constituyen, de deformarse más allá del límite elástico sin pérdida de resistencia (fluencia), y de acumular internamente energía durante los ciclos de carga (histéresis). Contrario a este término se encuentra el concepto de fragilidad, que implica una súbita pérdida de la resistencia de una sección, elemento o estructura en el momento en el que se produce un incremento inelástico del desplazamiento (Chopra, 2000; Vielma, 2008).

Para el caso de las estructuras de hormigón armado, el acero es el material que proporciona ductilidad dada la naturaleza frágil del hormigón, por lo que la respuesta de la estructura a este respecto dependerá de las disposiciones y cuantías de armado empleadas (Figura 2.13). Esta ductilidad puede ser evaluada a nivel seccional, mediante diagramas momento-curvatura, a nivel de ductilidad de los materiales, a través de la curvas tensióndeformación, o a nivel estructural, mediante la formación de las suficientes rótulas plásticas que produzcan el colapso del sistema (Barbat, Oller \& Pujades, 2005; Vielma, 2008).

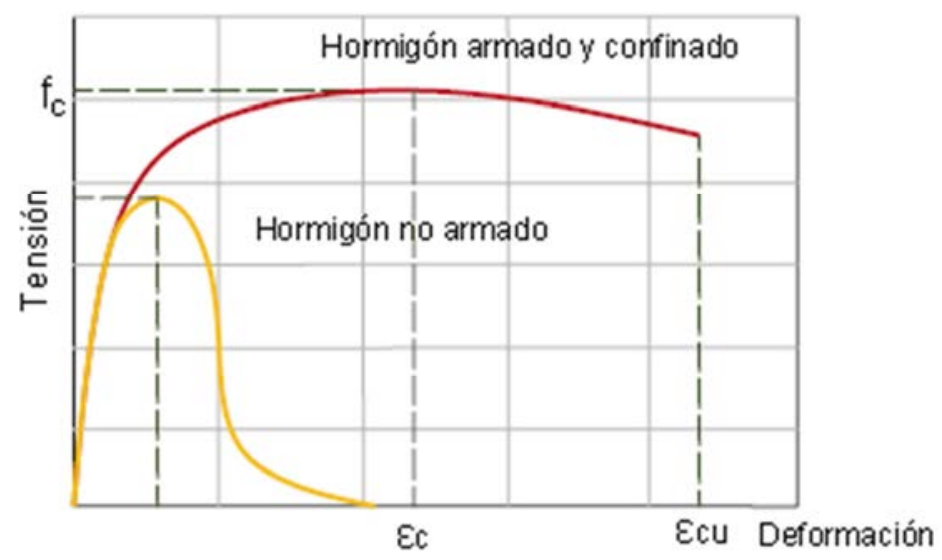

Figura 2.13. Diagrama tensión-deformación del hormigón en función de la existencia de armadura, obtenido de ensayos a compresión (Vielma, 2008).

$f_{c}=$ resistencia a compresión del hormigón; $\varepsilon_{c}=$ deformación para la resistencia a compresión; $\varepsilon_{c u}=$ deformación última del hormigón armado.

En la práctica del diseño sismorresistente, todos los factores que contribuyen a la no linealidad de una determinada estructura suelen estar incorporados de una manera global y simplificada en un término denominado como ductilidad estructural, el cual describe la capacidad de una estructura de deformarse inelásticamente sin llegar al fallo y sin una sustancial pérdida de resistencia.

Este concepto de ductilidad estructural $\mu$ suele venir expresado como el cociente entre el valor máximo del desplazamiento en rotura y el valor límite de fluencia, en el diagrama 
tensión-deformación del material, constituyendo así un índice de la reserva de resistencia de la estructura para cargas superiores a las de servicio. En este sentido, los códigos de diseño suelen emplear estos coeficientes de ductilidad como factores de reducción del espectro normalizado de proyecto (Figura 2.14), minorando así la acción sísmica de cálculo.

El valor del coeficiente de ductilidad puede ser determinado en función de la tipología estructural y resistente de la edificación, según las consideraciones recogidas en los distintos códigos sísmicos, o directamente a partir la curva de capacidad del edificio, obtenida por ejemplo mediante un análisis pushover.

No obstante, en cualquier tipo de edificación, tanto de mampostería como de hormigón armado, la absorción de la energía inducida por la acción sísmica utilizando su propia ductilidad implica daños en la misma. Y este daño producido es tanto mayor cuanto más dúctil es su comportamiento. Aunque estos daños se generen en ciertas zonas preestablecidas de la estructura, su posterior reparación o rehabilitación puede conllevar, en muchas ocasiones, la ruina económica de la edificación (Barbat, Oller \& Pujades, 2005; CARM, 2014).

Con el objetivo de minimizar los daños estructurales y no estructurales en edificaciones, además del enfoque de diseño por prestaciones o desempeño sísmico (Performance Based Design), en la actualidad se están desarrollando otras técnicas como las de aislamiento de base y disipación de energía. Estas metodologías, empleadas especialmente en países de alta sismicidad como Estados Unidos, Japón o Nueva Zelanda (Guo \& Yu, 2012), permiten minorar significativamente la acción sísmica, manteniendo la estructura en el rango lineal elástico y reduciendo, por tanto, los daños sufridos por la edificación.

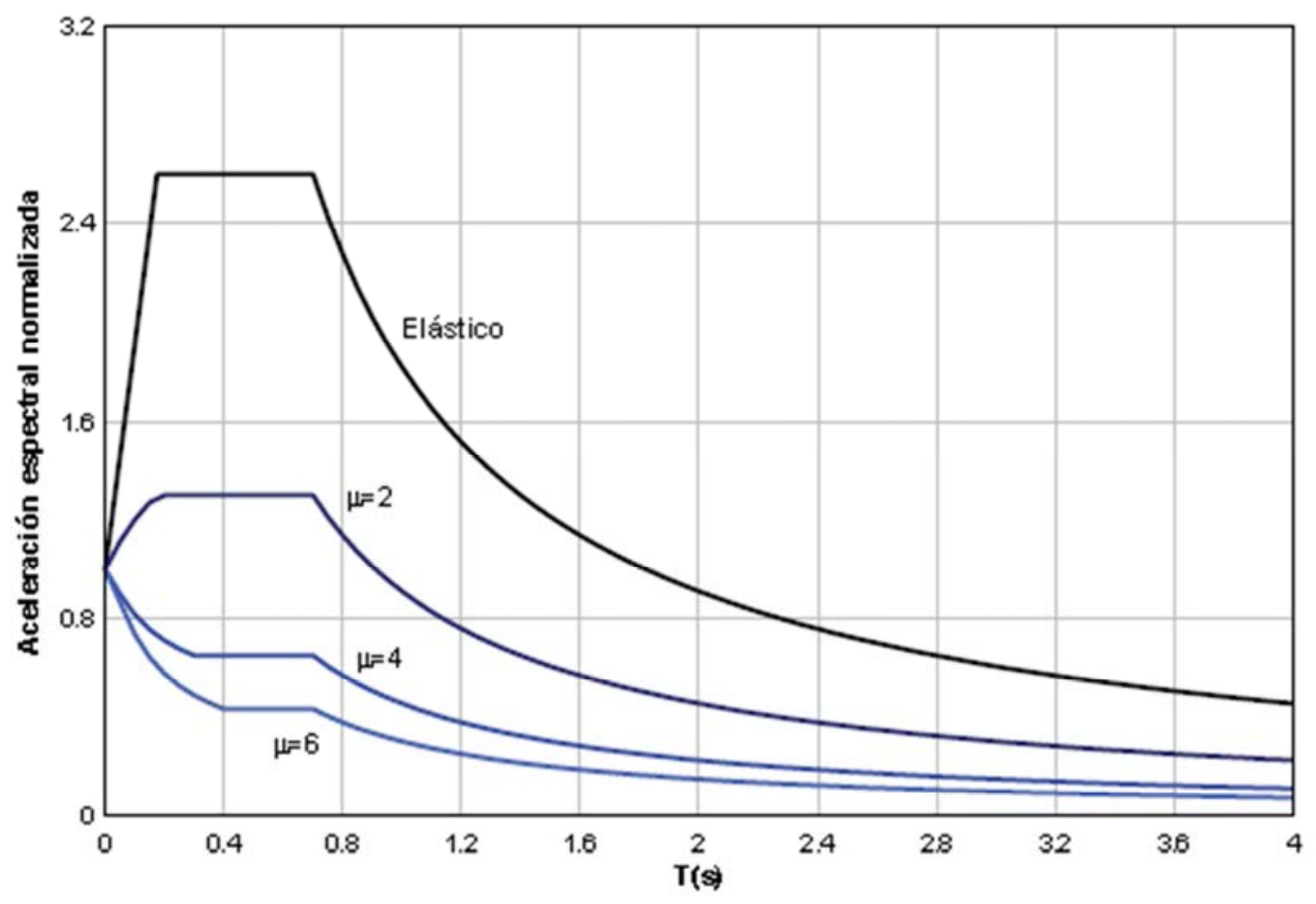

Figura 2.14. Espectros de respuesta normalizados elástico e inelásticos, reducidos mediante el coeficiente de ductilidad (Vielma, 2008). 


\subsubsection{Grados e índices de daño}

\section{Estados o grados de daño}

La mayoría de los estudios de vulnerabilidad y riesgo sísmico en áreas urbanas evalúan el daño esperable en las edificaciones basándose en los estados discretos de daño propuestos en las distintas escalas de intensidad macrosísmica (MMI, MSK, EMS, etc.). Estos estados o grados de daño se pueden definir como una condición límite o tolerable que representa el nivel de afección global de la estructura, establecidos en función de la descripción cualitativa de los efectos producido por el sismo sobre los elementos estructurales y no estructurales, los ocupantes de la edificación, y la funcionalidad post-sismo de la estructura.

En primer lugar, el modelo propuesto en ATC-13 (1985), ampliamente aceptado, asume de forma pionera la determinación de la evaluación global de los efectos del sistema sobre una edificación mediante la definición de siete grados de daño, incluyendo aspectos funcionales, operativos y económicos de la trama urbana. Posteriormente, el informe ATC-25 (1991), dedicado al análisis específico del riesgo sísmico de las líneas vitales de servicios y comunicación, simplificó los estados de daño del ATC-13 considerando sólo cinco grados, incluyendo el estado nulo.

De igual modo, se encuentran los cinco estados o grados globales de daño definidos en la escala EMS-98 (Grünthal, 1998) para edificaciones tanto de mampostería no reforzada como de hormigón armado, incorporando también una serie de orientaciones y descripciones generales para su determinación (Figura 2.15). En la Tabla 2.6 se incluye un resumen comparativo de los estados de daño propuestos en las escalas macrosísmicas MSK-84 y EMS-98 junto con los definidos en ATC-13 y ATC-25. Según se puede observar, la clasificación realizada en todas las escalas es bastante similar, únicamente con pequeñas diferencias en la zona inferior y superior de daño.

Los métodos analíticos basados en curvas de capacidad heredan este tipo de clasificaciones, definiéndose de igual modo una serie de grados de daño (Tabla 2.7). En cualquier caso, las clasificaciones más empleadas hoy en día se corresponden con los modelos propuestos en RISK-UE (metodologías LM1 y LM2) y HAZUS, los cuales actualizan principalmente los estados de daño propuestos en las escalas macrosísmicas anteriormente citadas a partir de las experiencias recientes de sismos.

\section{$\underline{\text { Índices de daño }}$}

Otra serie de indicadores, denominados como índices de daño, han sido propuestos con el fin de establecer de forma analítica una medida representativa del nivel de degradación de la estructura ante una cierta acción sísmica. Este tipo de parámetros, basados directamente en características mecánicas de comportamiento tales como deformaciones remanentes de los elementos que la componen, pueden venir expresados a nivel local, representando el grado de daño en un elemento individual de la estructura, o a nivel global mediante la definición del daño de toda ella en su conjunto. 


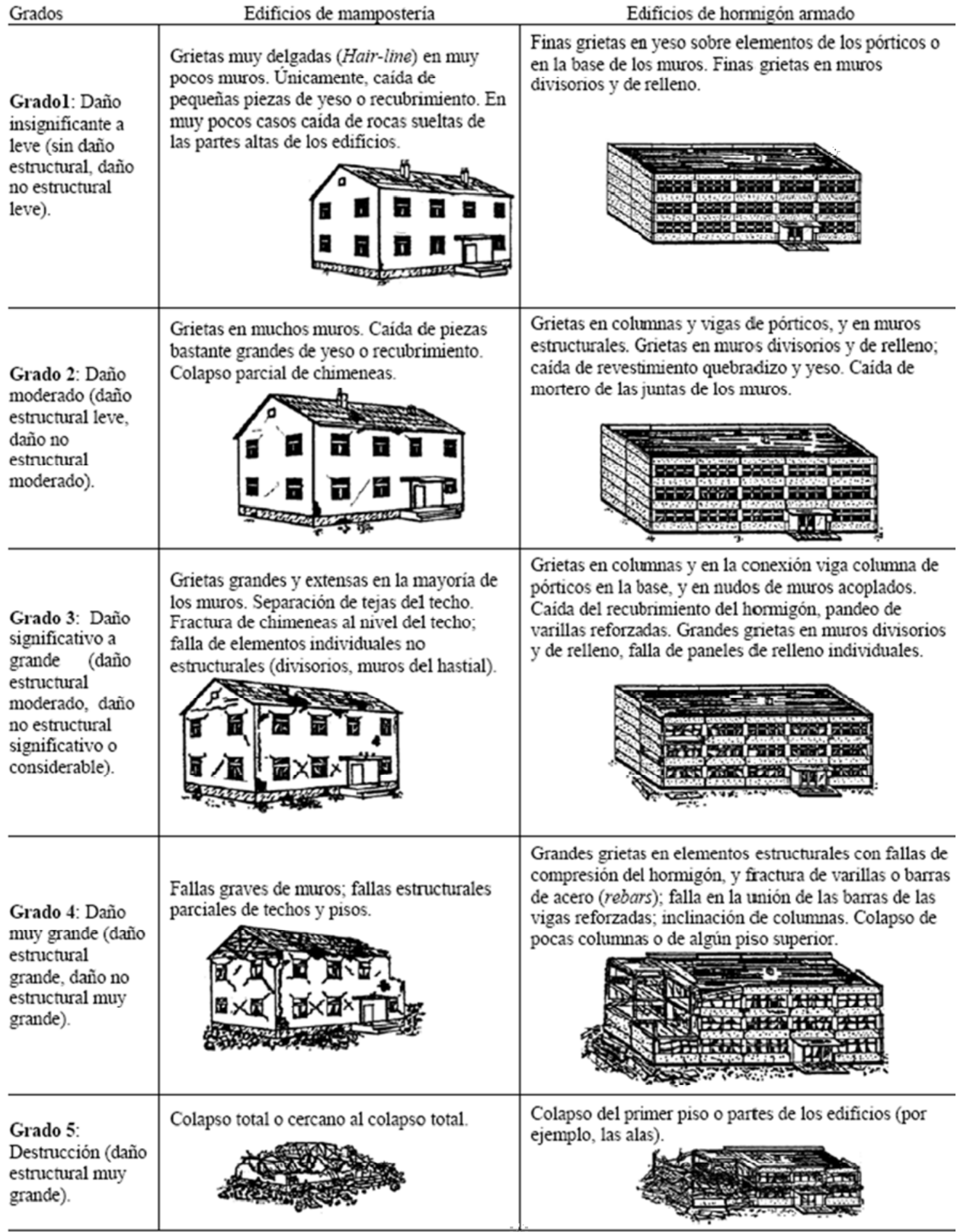

Figura 2.15. Grados de daño según la escala EMS-98 para edificios de mampostería y de hormigón armado (Grünthal, 1998).

Existen multitud de índices de daño para caracterizar el estado de una estructura después de un evento sísmico (Bonett, 2003; Vargas, 2013; López, 2015), enfocados principalmente al análisis de estructuras de hormigón armado. No obstante, a pesar del avance en el desarrollo de este tipo de modelos la complejidad de evaluar cuantitativamente el daño sísmico ha supuesto que no se disponga todavía de ningún criterio unificado a este respecto. 
Tabla 2.6. Comparativa entre grados de daño propuestos en diversas metodologías (Lantada, 2007).

\begin{tabular}{|c|c|c|c|c|}
\hline MSK & EMS-98 & ATC-25 & ATC-13 & Descripción del grado de daño \\
\hline No daño & No daño & No daño & $\begin{array}{c}\text { Estado } 1 \\
\text { Daño nulo (None) }\end{array}$ & Sin daño \\
\hline Grado 1 & $\begin{array}{c}\text { Grado } 1 \\
\text { Daño entre }\end{array}$ & Daño & $\begin{array}{c}\text { Estado } 2 \\
\text { Daño leve (Slight) }\end{array}$ & $\begin{array}{c}\text { Daño insignificante, limitado y } \\
\text { localizado, que no necesita } \\
\text { reparación }\end{array}$ \\
\hline $\begin{array}{l}\text { Daño ligero } \\
\text { (Slight) }\end{array}$ & $\begin{array}{c}\text { insignificante y leve } \\
\text { (Negligible to } \\
\text { slight) }\end{array}$ & $\begin{array}{l}\text { ligero } \\
\text { (Slight) }\end{array}$ & $\begin{array}{c}\text { Estado } 2 \\
\text { Daño ligero } \\
(\text { Light })\end{array}$ & $\begin{array}{c}\text { Daño localizado significativo en } \\
\text { algunos elementos que, en } \\
\text { general, no requieren ser } \\
\text { reparados }\end{array}$ \\
\hline $\begin{array}{l}\text { Grado } 2 \\
\text { Daño } \\
\text { moderado } \\
\text { (Moderate) }\end{array}$ & $\begin{array}{c}\text { Grado } 2 \\
\text { Daño moderado } \\
\text { (Moderate) }\end{array}$ & $\begin{array}{c}\text { Daño } \\
\text { moderado } \\
\text { (Moderate) }\end{array}$ & $\begin{array}{c}\text { Estado } 4 \\
\text { Daño moderado } \\
\text { (Moderate) }\end{array}$ & $\begin{array}{l}\text { Daño localizado significativo de } \\
\text { algunos elementos que } \\
\text { requieren ser reparados }\end{array}$ \\
\hline $\begin{array}{c}\text { Grado } 3 \\
\text { Daño severo } \\
\text { (Heavy) }\end{array}$ & $\begin{array}{c}\text { Grado } 3 \\
\text { Daño entre } \\
\text { substancial y } \\
\text { severo (Substantial } \\
\text { to heavy) }\end{array}$ & $\begin{array}{c}\text { Daño } \\
\text { severo } \\
\text { (Heavy) }\end{array}$ & $\begin{array}{c}\text { Estado } 5 \\
\text { Daño severo } \\
\text { (Heavy) }\end{array}$ & $\begin{array}{c}\text { Daño generalizado (extensive) } \\
\text { que requiere reparaciones } \\
\text { importantes }\end{array}$ \\
\hline Grado 4 & Grado 4 & & Estado 6 & $\begin{array}{l}\text { Daño importante y general que } \\
\text { puede causar que el edificio }\end{array}$ \\
\hline $\begin{array}{l}\text { Destrucción } \\
\text { (Destruction) }\end{array}$ & $\begin{array}{c}\text { Daño muy severo } \\
\text { (Very heavy) }\end{array}$ & $\begin{array}{l}\text { Entre } \\
\text { extensivo y } \\
\text { colapso }\end{array}$ & $\begin{array}{l}\text { Daño grave } \\
\text { (Major) }\end{array}$ & $\begin{array}{l}\text { quede desvastado, de forma } \\
\text { que requiera ser demolido o } \\
\text { totalmente reparado }\end{array}$ \\
\hline $\begin{array}{l}\text { Grado } 5 \\
\text { Colapso } \\
\text { (Total } \\
\text { damage) }\end{array}$ & $\begin{array}{c}\text { Grado } 5 \\
\text { Destrucción } \\
\text { (Destruction) }\end{array}$ & $\begin{array}{l}\text { (Major to } \\
\text { destroyed) }\end{array}$ & $\begin{array}{c}\text { Estado } 7 \\
\text { Colapso } \\
\text { (Destroyed) }\end{array}$ & $\begin{array}{c}\text { Total destrucción de la mayor } \\
\text { parte del edificio }\end{array}$ \\
\hline
\end{tabular}

Tabla 2.7. Grados de daño en las metodologías RISK-UE (LM1 y LM2) y HAZUS (Moreno, 2011).

\begin{tabular}{|c|c|c|c|c|}
\hline \multirow{2}{*}{$\begin{array}{l}\text { Grado de } \\
\text { daño }\end{array}$} & \multicolumn{3}{|c|}{ Etiqueta del grado de daño } & \multirow{2}{*}{ Descripción } \\
\hline & LM1 & LM2 & FEMA (HAZUS) & \\
\hline 0 (D0) & Ninguno & Ninguno & Ninguno & Sin daño \\
\hline $1(\mathrm{D} 1)$ & Leve & Leve & Leve & Daño entre insignificante y leve \\
\hline 2 (D2) & Moderado & Moderado & Moderado & $\begin{array}{l}\text { Estructuralmente leve, no } \\
\text { estructuralmente moderado }\end{array}$ \\
\hline 3 (D3) & $\begin{array}{l}\text { Sustancialmente } \\
\text { fuerte }\end{array}$ & Severo & Severo & $\begin{array}{l}\text { Estructuralmente moderado, no } \\
\text { estructuralmente fuerte }\end{array}$ \\
\hline 4 (D4) & Muy fuerte & Colanso & Colanso & $\begin{array}{l}\text { Estructuralmente fuerte, no } \\
\text { estructuralmente muy fuerte }\end{array}$ \\
\hline 5 (D5) & Destrucción & & & $\begin{array}{l}\text { Estructuralmente muy fuerte, } \\
\text { colapso total o casi total }\end{array}$ \\
\hline
\end{tabular}

En cuanto a los índices de daño locales, ya sea a nivel de punto, seccional o de un determinado elemento de la estructura, se caracterizan principalmente por su condición de acumulativos o no acumulativos: 
$\checkmark$ No acumulativos: no son capaces de representar el daño experimentado en los elementos sujetos a ciclos de carga. A su vez, éstos se pueden clasificar en función de los parámetros que intervienen en su evaluación:

- Basados en relaciones demanda-capacidad de deformación, en función de la curvatura y la capacidad de rotación de los elementos (Bracci et al., 1989).

- Basados en relaciones demanda-capacidad de resistencia, a partir de las envolventes de las curvas momento-curvatura o cortante-desplazamiento, obtenidas aplicando cargas monótonamente crecientes.

- Basados en la degradación estructural, en el deterioro de la rigidez a flexión en el rango no lineal deformación, debido al agrietamiento y a la fisuración que sufren los diferentes elementos (Roufaiel \& Meyer, 1987).

$\checkmark$ Acumulativos: sí que permiten considerar los efectos sobre los elementos sometidos a cargas cíclicas, introduciendo el concepto de fatiga en función de la deformación plástica acumulada, o incorporando términos relacionados con la energía histerética absorbida durante el sismo (Faleiro, Oller \& Barbat, 2008):

- Basados en la capacidad de deformación de los elementos (Chung, Shinozuka \& Meyer, 1988).

- Basados en la energía disipada (Bonett, 2003).

- Índices combinando los dos factores anteriores (Park \& Ang, 1985; Aguiar \& Barbat, 1999; Vargas, 2013).

En lo relativo a los índices de daño globales, pueden ser obtenidos principalmente según tres procedimientos:

$\checkmark$ Mediante factores de ponderación, a partir de índices locales de daño en los distintos elementos de la estructura (Park, 1986; Kunnath, Reinhorn \& Abel, 1991)

$\checkmark$ Mediante parámetros modales de estructura, principalmente asociados a las variaciones de su periodo natural (DiPasquale et al., 1990; Hori \& Inoue, 2002).

$\checkmark$ Mediante parámetros resistentes, en función de la representación bilineal de la curva de capacidad (Roufaiel \& Meyer, 1987; Gupta, Nielsen \& Kirkegaard, 2001).

No obstante, un cierto valor de un determinado índice de daño no suele ser suficiente, por sí mismo, para caracterizar la vulnerabilidad sísmica de la estructura. Para su interpretación es necesaria la obtención de expresiones que relacionen el rango de variación de estos indicadores con una serie de estados discretos de daño (Park, Ang \& Wen, 1987).

Estas clasificaciones basadas en índices de daño están actualmente en desuso al haber sido reemplazadas por los diversos umbrales de daño obtenidos directamente a partir de la curva de capacidad de las estructuras, dentro de la filosofía del diseño sísmico por prestaciones (apartado 2.3.2). Revisiones más detalladas de los principales índices de daño 
sísmico, definidos especialmente para estructuras de hormigón armado, pueden encontrarse en los trabajos de Aguiar \& Barbat (1998), Bonett (2003) o Vargas (2013).

\subsubsection{Configuraciones arquitectónicas y urbanísticas con influencia en el comportamiento sísmico de las edificaciones}

Se entiende como configuración arquitectónica de un edificio las características espaciales (forma, tamaño y proporciones), que determinan su disposición en la trama urbana. Estas características condicionan la denominada como configuración sísmica (Perepérez, 2011) de la edificación, es decir, su comportamiento ante un terremoto, traducido en el modo de distribución de esfuerzos y deformaciones en la estructura debido a la acción sísmica.

La experiencia adquirida en terremotos pasados ha constatado la existencia de algunas de estas disposiciones arquitectónicas y urbanísticas que influyen de forma significativa en la respuesta sísmica de las edificaciones y, por ende, en la caracterización de la vulnerabilidad sísmica de las mismas. A este respecto, la normativa sísmica suele plantear principalmente la necesidad de dotar a los sistemas constructivos más habituales de un método de cálculo que permita cumplir con la premisa fundamental de evitar la pérdida de vidas humanas (NCSE-02, 2002; CEN, 2004) incluyendo en menor medida prescripciones y recomendaciones relacionadas con especificaciones sísmico-urbanísticas, enfocadas a un control del daño más exhaustivo.

Diversos son los estudios destinados al análisis de estas configuraciones urbanísticas que aumentan la vulnerabilidad sísmica de las edificaciones (Barbat, Oller \& Pujades, 2005; Guevara, 2009, 2012a). Asimismo, a raíz del terremoto de Lorca en 2011, han sido desarrollados una serie de trabajos de observación y discusión de los daños experimentados por las edificaciones y la influencia de dichas configuraciones en estas afecciones (Cabañas et al., 2011; Perepérez, 2011; Benito et al., 2011; Álvarez, Dávila \& Díaz Pavón, 2011; Carreño et al., 2012; Feriche et al., 2012a; De Luca et al., 2013; Romao et al., 2013; García-Ayllón \& Tomás, 2013; Martínez-Cuevas, 2014).

A continuación, se revisarán las principales características tipológicas y constructivas consideradas como irregulares desde el punto de vista del diseño sismorresistente en las estructuras basadas en pórticos de hormigón armado, que condicionan el comportamiento sísmico de las edificaciones en la trama urbana.

\section{Pilares cortos}

El efecto de pilar corto tiene su origen en la mayor rigidez de estos elementos en comparación con los pilares más largos del resto del edifico. Debido a esta rigidez, los pilares cortos soportan una mayor carga sísmica, al deberse equilibrar los momentos en los extremos del pilar con los cortantes en la longitud efectiva del pilar, una distancia reducida en comparación con el resto de pilares, de longitud normal. Como consecuencia, sufrirán daños mayores que 
los pilares de mayor longitud, pudiendo llegar a causar incluso el colapso de la estructura (Figura 2.16).
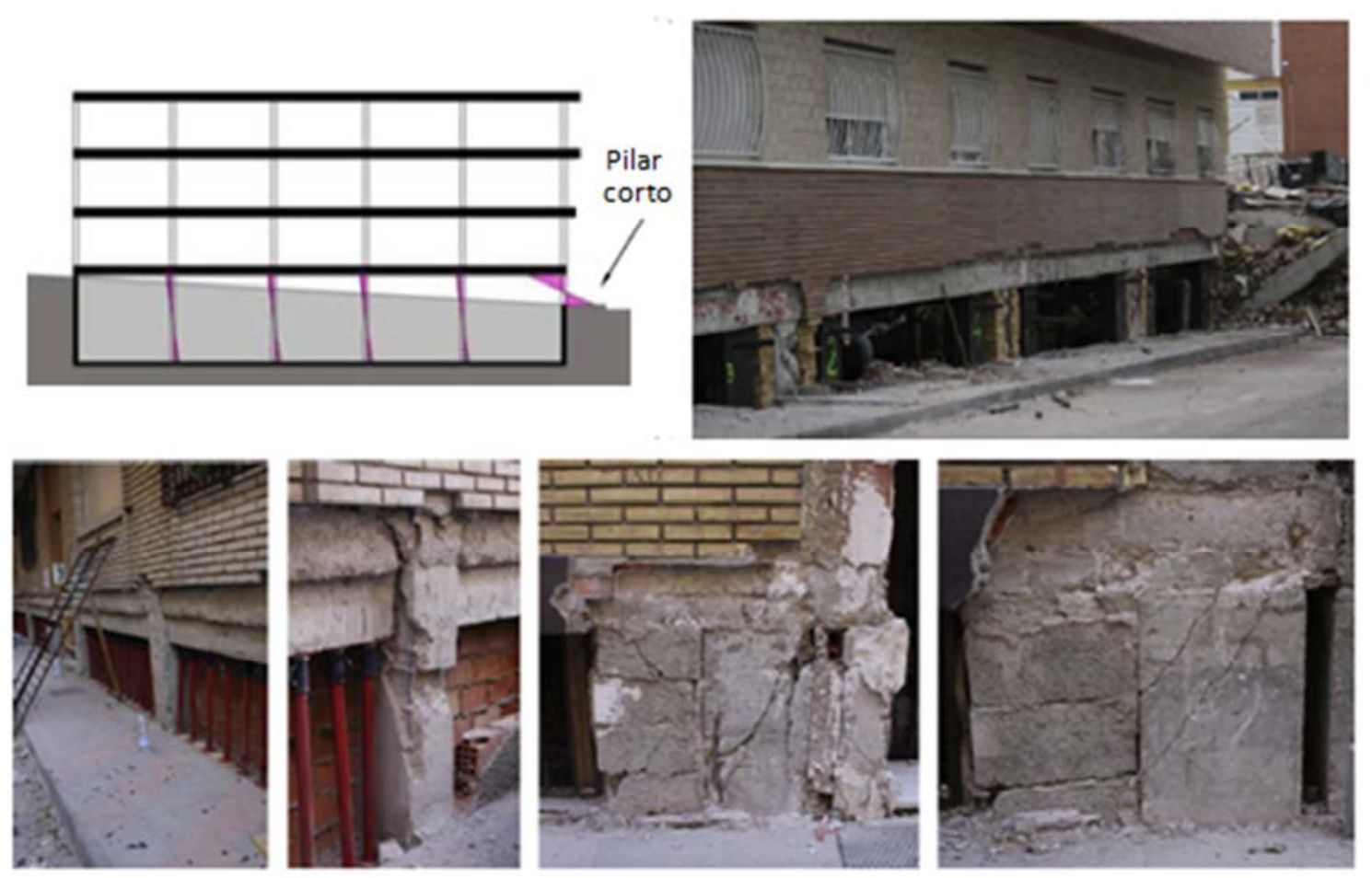

Figura 2.16. Diagrama de esfuerzos cortantes debido al mecanismo de pilar corto. Daños asociados a la presencia de estos elementos durante el terremoto de Lorca de 2011 (Fotos: Cabañas et al., 2011;

Romao et al., 2013).

Diversas disposiciones arquitectónicas propician la aparición de pilares cortos como, por ejemplo, edificaciones que descansan sobre un terreno inclinado, edificios con desnivel o disposiciones de forjado sanitario. Estudios recientes demuestran cómo estas disposiciones constructivas pueden llegar a duplicar o triplicar los esfuerzos solicitantes en estos elementos (Martínez-Díaz, 2014).

\section{Pilares cautivos o secuestrados}

Se suele denominar así a la disposición de un pilar corto de forma indirecta o accidental, debido a una modificación en la configuración original de los pilares de un pórtico. El pilar, diseñado originalmente para moverse y deformarse en toda su longitud independientemente, puede quedar inmovilizado por la interacción con otros elementos no estructurales rigidizantes, tales como paredes interiores, paredes de fachada, muros de contención, huecos de ventana, o descansos de escalera y rampas, produciéndose graves daños mediante un mecanismo de fallo por cortante similar al descrito en el apartado anterior (Figura 2.17). 




(a)

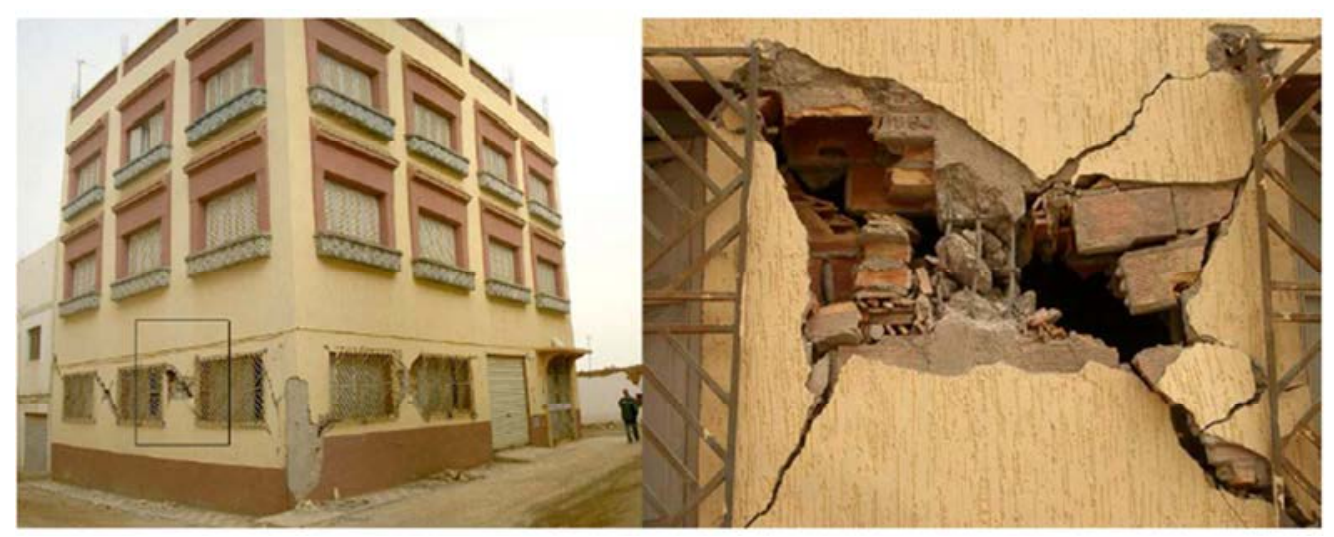

(b)

Figura 2.17. Configuración arquitectónica de pilares cautivos en edificaciones por interacción con cerramientos. (a) Esquema del mecanismo de daño. (b) Ejemplo de daños (Fotos: SISMIMUR, 2006; Guevara, 2012a).

\section{Configuraciones irregulares}

Según muestra la Figura 2.18, el término configuraciones regulares se aplica a todas aquellas estructuras que no presentan discontinuidades o asimetrías significativas ya sean geométricas o de rigidez en su disposición en planta, en alzado, así como en los sistemas resistentes tipo arriostramientos destinados a absorber los esfuerzos horizontales.

Este tipo de configuraciones, simples, simétricas y compactas, aseguran una adecuada respuesta sísmica de la estructura, con una distribución uniforme de esfuerzos y deformaciones (Martínez-Cuevas, 2014). No obstante, son relativamente habituales en la praxis constructiva configuraciones irregulares asociadas a determinadas concepciones arquitectónicas y urbanas, con marcadas asimetrías tanto geométricas como mecánicas, con excentricidades entre el centro de masas y el centro de rigidez del sistema (Figura 2.19). 

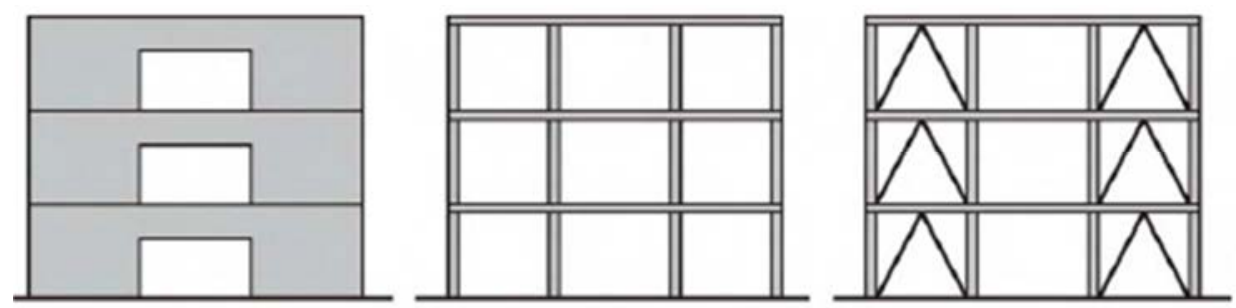

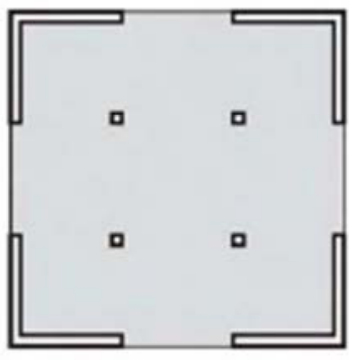

Muros de cortante

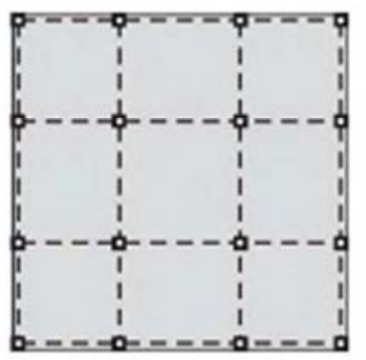

Entramado bidireccional

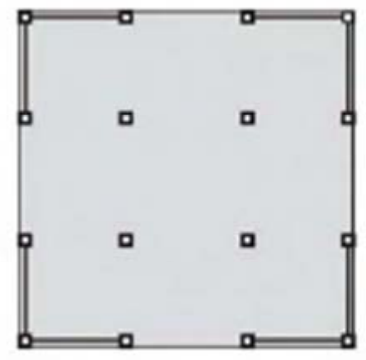

Entramado arriostrado

Figura 2.18. Configuraciones estructurales regulares, adecuadas desde un punto de vista sísmico (Perepérez, 2011).

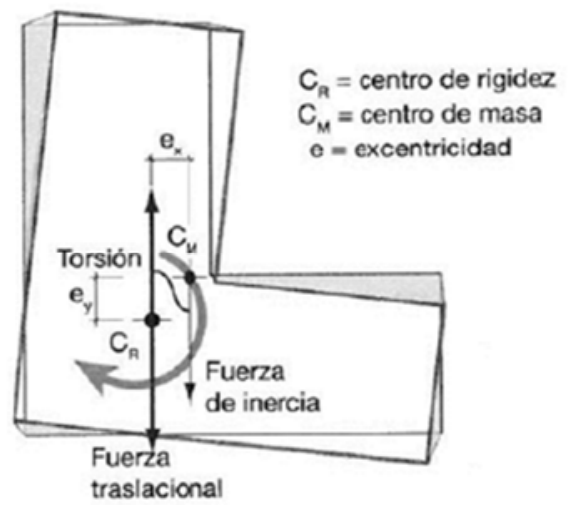

Figura 2.19. Comportamiento irregular por excentricidad entre los centros de masas y rigidez

(Guevara, 2012a).

Dentro de este tipo de disposiciones, se distingue entre aquellas desarrolladas en planta y las desarrolladas en el alzado de la estructura:

\section{$\checkmark \quad$ Irregularidades en planta:}

La configuración de los elementos estructurales en las tipologías constructivas en cruz, T, L, U, o Y (Figura 2.20), provoca una rotación de la edificio sobre su eje vertical en torno al centro de rigidez, a modo de torsión. Este giro impone en la estructura desplazamientos horizontales e incrementos de esfuerzos en los elementos resistentes verticales. Estos efectos son tanto mayores cuanto más alejados están dichos elementos del centro de rigideces, pudiéndose producir daños importantes e incluso el colapso del edificio (Lantada, 2007; Guevara, 2012a, Martínez-Cuevas, 2014).

En caso de ser necesarias estas disposiciones estructurales, la solución más adecuada consiste en la descomposición de la planta completa en figuras simples conectadas mediante 
juntas sísmicas, con un dimensionado suficiente para impedir el golpeteo entre las distintas unidades estructurales (Perepérez, 2011).
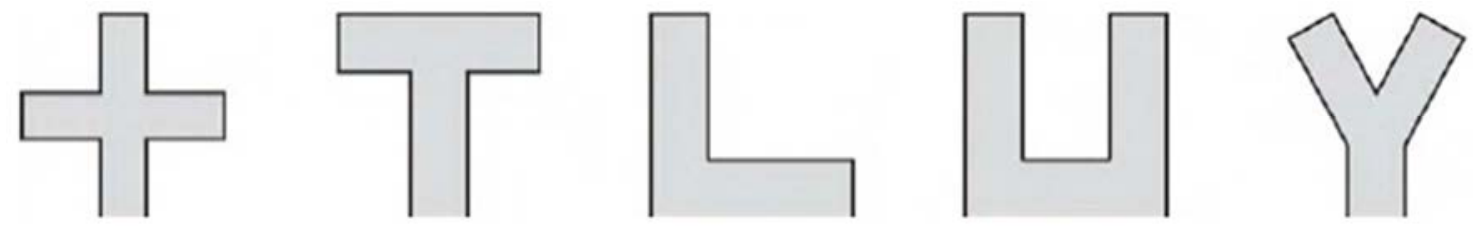

Figura 2.20. Configuraciones irregulares en planta con un inadecuado comportamiento sísmico (Perepérez, 2011).

\section{$\checkmark \quad$ Irregularidades en alzado:}

Los retranqueos, entendidos como el desplazamiento de la pared exterior de la edificación en algún plano vertical con relación a los límites verticales del volumen envolvente de la estructura, son las disposiciones más características de este tipo de irregularidades. Entre las particularidades geométricas más habituales, se pueden destacar las siguientes (MartínezCuevas, 2014):

$\checkmark$ Escalonamientos en la parte superior del edificio.

$\checkmark$ Voladizos.

$\checkmark$ Edificios tipo base-torre.

$\checkmark$ Cuerpos entrantes y salientes.

$\checkmark$ Edificios tipo péndulo invertido.

$\checkmark$ Edificaciones piramidales.

Estas disposiciones, provocan una discontinuidad en la distribución de los elementos resistentes, produciendo cambios bruscos de masa y rigidez entre las diferentes partes de la edificación (Figura 2.21). De este modo, se generan concentraciones de esfuerzos en las plantas adyacentes a estas irregularidades verticales, siendo esta la zona donde se acumulan los principales daños.

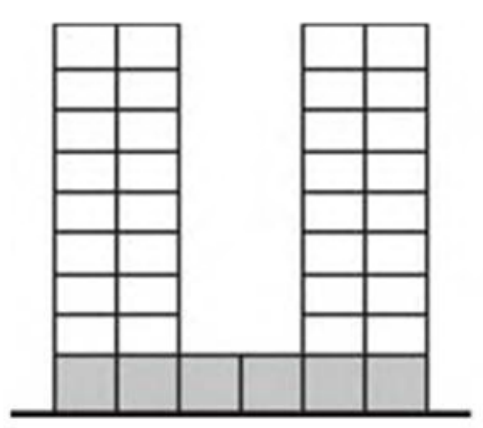

(a)

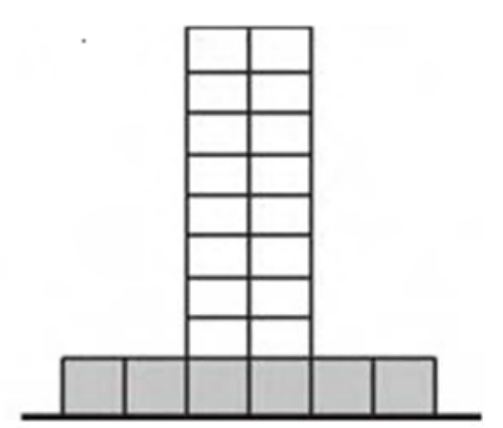

(b)

Figura 2.21. Disposiciones irregulares en alzado. (a) Edificios esbeltos unidos por su base. (b) Tipología de edificio base-torre (Perepérez, 2011). 
Este tipo de disposiciones constructivas, están penalizadas en los distintos códigos sísmicos como el EC-8 o la NCSE-02, quienes no permiten para este tipo edificios irregulares el uso de métodos de cálculo simplificados mediante fuerzas estáticas equivalentes.

\section{Cerramientos y elementos no estructurales}

Los cerramientos y particiones de albañilería son considerados habitualmente como elementos no estructurales de las edificaciones. No obstante, estos paños de fábrica adquieren carácter estructural durante un sismo al desarrollar rigidez y absorber activamente una parte significativa de las cargas actuantes, por lo que su contribución a la resistencia lateral de la edificación debe ser considerada a la hora de dimensionar los elementos estructurales (Vielma, Barbat \& Oller, 2008; Carreño et al., 2012; Ricci, Verderame \& Manfredi, 2011; Hermanns et al., 2012).

Debido a que, generalmente, las normas sísmicas no suelen fijar límites de deformación lateral de los edificios que permitan minimizar los daños no estructurales en cerramientos, tabiques y demás particiones, este tipo de afecciones pueden llegar a ser cuantiosas (Barbat, 2011) aun cuando la estructura se mantenga dentro de su rango elástico (Figura 2.22). La falta de conexión entre los paneles de mampostería y el resto de la estructura produce que estos elementos se dañen tanto por movimientos fuera del plano como por movimientos en el plano.

Según muestra la Figura 2.23, dado que la rigidización de un pórtico debido al efecto de cerramientos y particiones se puede asimilar al efecto de una cruz o tirante adicional de atado, una disposición irregular de estos elementos entre las diversas plantas de un edificio puede ser considerada como una configuración irregular en alzado adicional.

La insuficiente sujeción de antepechos y parapetos de cubierta produce, por otra parte, un inadecuado comportamiento de estos elementos durante un sismo (Figura 2.24 y Figura 2.25). Por ejemplo, el desprendimiento de estos elementos no estructurales fue la principal causa de mortandad durante el terremoto de Lorca de 2011 (Salgado-Gálvez et al., 2015). A pesar de ello, la actual norma española solo obliga a su confinamiento con enzunchados de hormigón a partir de una peligrosidad de $0,12 \mathrm{~g}$.

Recientemente, diversos trabajos se han centrado en el análisis de la participación de estos elementos en la respuesta sísmica de las edificaciones (Dolsek \& Fajfar, 2008; FEMA E-74 2011; Manfredi, Ricci \& Verderame, 2012; Moreno \& Bairán; 2012; De Luca et al., 2013; Ricci et al. 2013; Gómez-Martínez, Pérez-García \& De Luca, 2014), proponiendo incluso la publicación de una norma específica relativa a la estabilidad de las fachadas (Álvarez, Dávila \& Díaz Pavón, 2011). 

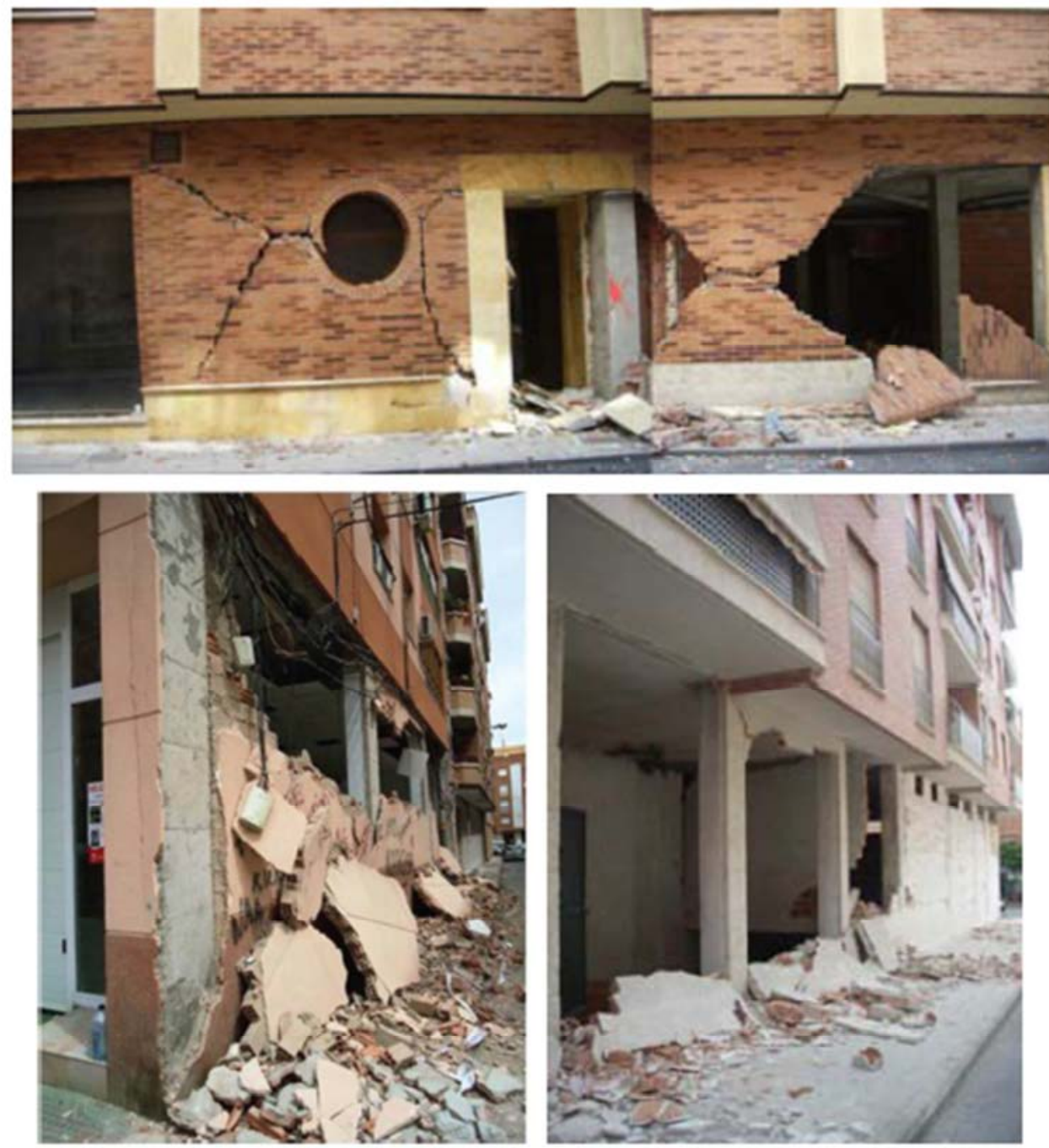

Figura 2.22. Daños en cerramientos observados en el terremoto de Lorca de 2011 (Fotos: Cabañas et al., 2011; Carreño et al., 2012).



(a)

(b)

Figura 2.23. Configuración irregular en alzado. (a) Disposición asimétrica de paños de cerramiento. (b) Modelización de paños mediante tirantes que rigidizan cada entramado (Cabañas et al., 2011). 


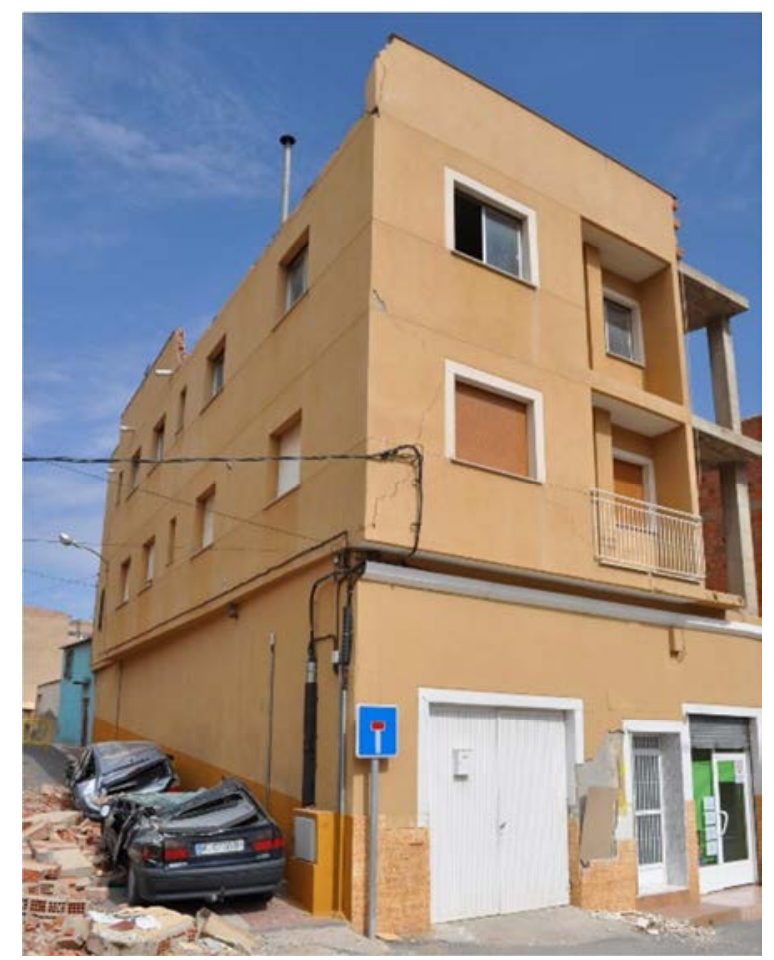

Figura 2.24. Caída de antepechos por insuficiente anclaje, terremoto de Lorca de 2011 (Foto: Bomberos de Cartagena, 2011).

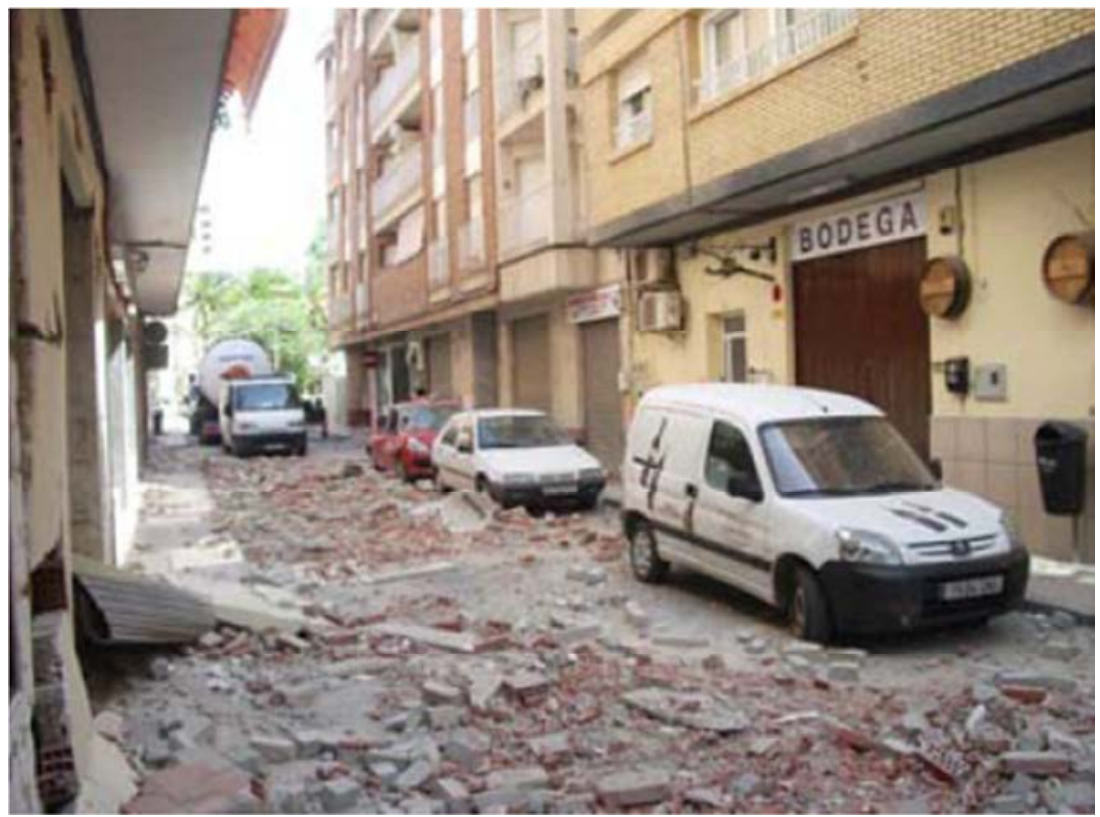

Figura 2.25. Desprendimientos generalizados de parapetos y antepechos de cubierta, terremoto de Lorca de 2011 (Foto: Cabañas et al., 2011).

\section{Plantas blandas (Soft Story)}

Se entiende como planta blanda de un determinado edificio a aquella que presenta una rigidez significativamente menor con respecto al resto de plantas del mismo, siendo por ello habitualmente denominada también como planta flexible (Guevara, 2012b). 
Según muestra la Figura 2.26, la presencia de una planta más flexible que las demás modifica la distribución uniforme de las fuerzas inducidas por el movimiento sísmico en la estructura, absorbiendo este nivel gran parte de la energía inducida por el terremoto mientras que el resto de la estructura se comporta como un sólido rígido, sin experimentar prácticamente daños.

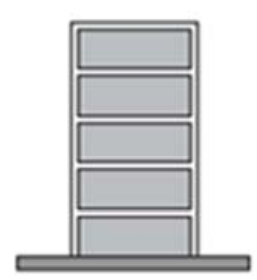

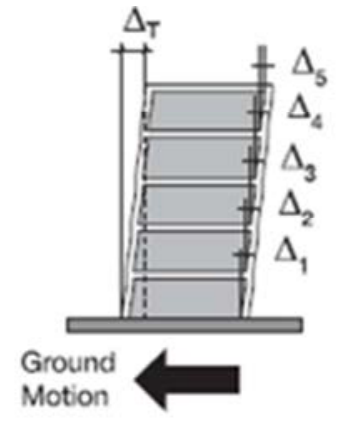

(a)

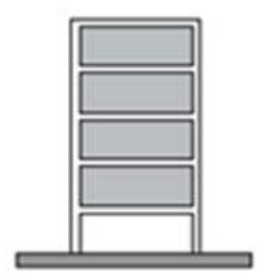

\section{Ground} Motion

(b)

Figura 2.26. Distribución del desplazamiento total generado por un terremoto en: (a) edificación regular; (b) edificio con irregularidad de planta blanda (Guevara, 2012b).

Esta reducción de rigidez se traduce también en un aumento de los desplazamientos en este nivel, lo cual puede poner en riesgo la integridad de la estructura frente al colapso dado que la planta baja sustenta al resto del edificio.

Esta singularidad de planta blanda se puede generar como consecuencia de diversas configuraciones arquitectónicas, bien sea en el diseño original de la estructura o en modificaciones constructivas posteriores (Martínez-Cuevas, 2014):

I. Planta baja sin cerramientos rígidos no estructurales adosados a los elementos estructurales flexibles, presentes en el resto de niveles de la edificación (Figura 2.27a).

II. Abertura más numerosas y amplias en las paredes exteriores de la planta baja en comparación con el resto del edificio, con una menor distribución de pilares (Figura 2.27b).

III. Diferencia en el modo de distribución de paredes y particiones interiores entre distintas plantas (Figura 2.27c).

El ejemplo más frecuente de este mecanismo de planta blanda se produce por la presencia de locales comerciales o plantas diáfanas en tipología residencial en bloque, como combinación de las casuísticas mostradas en las Figuras 2.27a y 2.27b.

Asimismo, en equipamientos hosteleros y hospitalarios no sólo se diseña la planta baja libre de cerramientos sino que generalmente este nivel, debido a su importancia, tiene mayor altura de entrepiso que la del resto de los niveles, presentando por tanto una mayor esbeltez (Figura 2.28). 


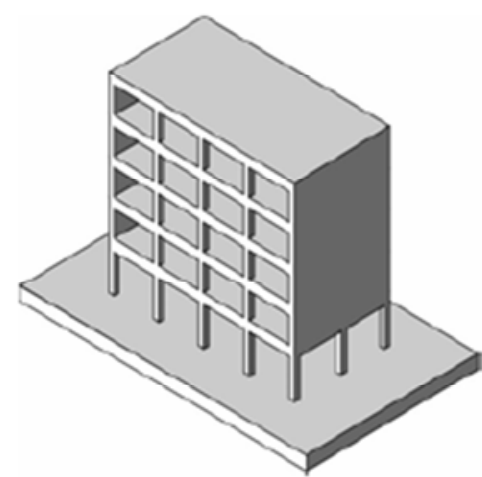

(a)

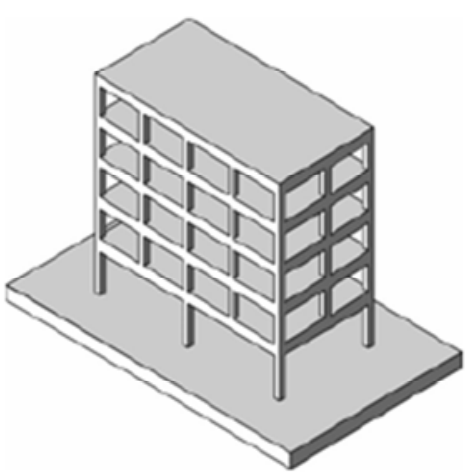

(b)

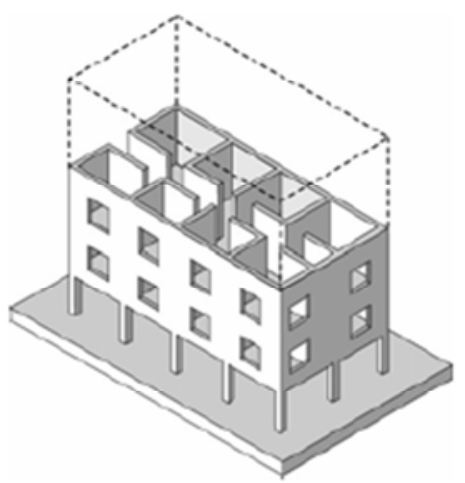

(c)

Figura 2.27. Casuísticas de planta blanda por irregularidad en la distribución de: (a) cerramientos; (b) espacios y pilares en planta baja; (c) particiones interiores entre diferentes plantas (Guevara, 2012b).



(a)

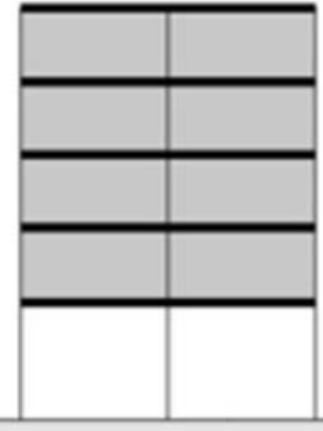

(b)

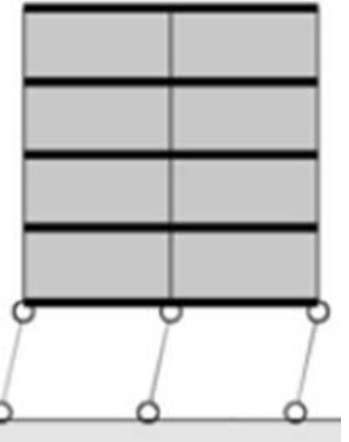

(c)

Figura 2.28. Casuísticas de planta blanda por: (a) mayor esbeltez de la planta baja; (b) distribución irregular de cerramientos; (c) combinación de ambos casos (Cabañas et al., 2011).

A pesar de que este término se relaciona generalmente al comportamiento de las plantas bajas de los edificios, esta configuración puede aparecer, no obstante, en cualquier altura dentro del mismo, siempre que haya una diferencia significativa de rigidez entre dos plantas consecutivas (Figura 2.29).

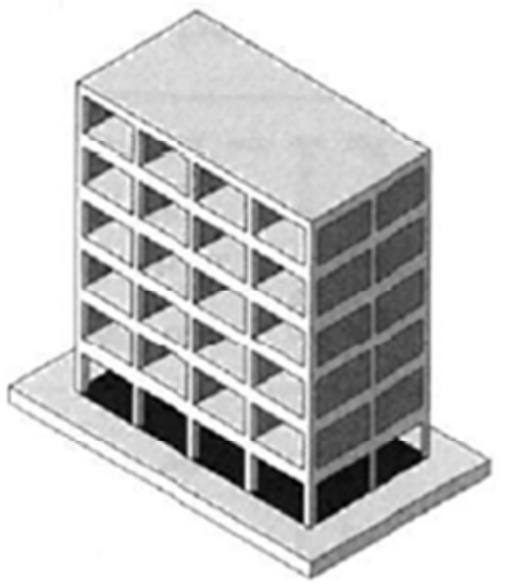

(a)

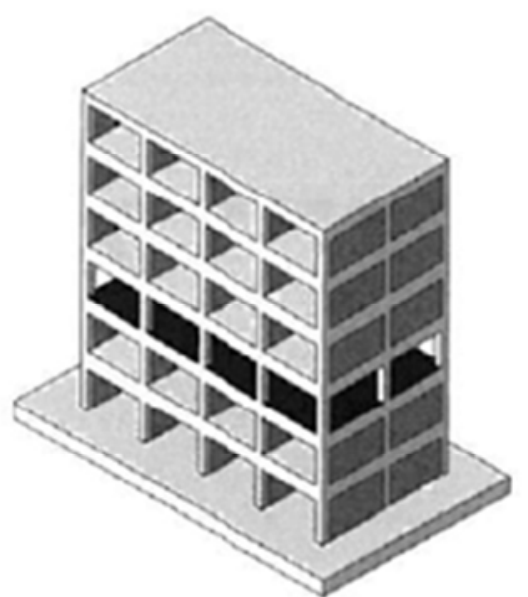

(b)

Figura 2.29. Planta blanda en: (a) planta baja; (b) nivel intermedio (Guevara, 2012b). 
Según se muestra en la Figura 2.30 y la Figura 2.31, los principales daños como consecuencia de esta singularidad de planta blanda se pueden resumir en:

$\checkmark$ Daños estructurales concentrados en cabeza de pilares de la planta afectada así como en los nudos de conexión forjado-pilar. Las grandes deformaciones plásticas experimentadas pueden llegar a producir incluso el colapso de la estructura.

$\checkmark$ Deterioro de los elementos no estructurales, tipo cerramientos, principalmente en dicha planta, disminuyendo rápidamente con la altura.

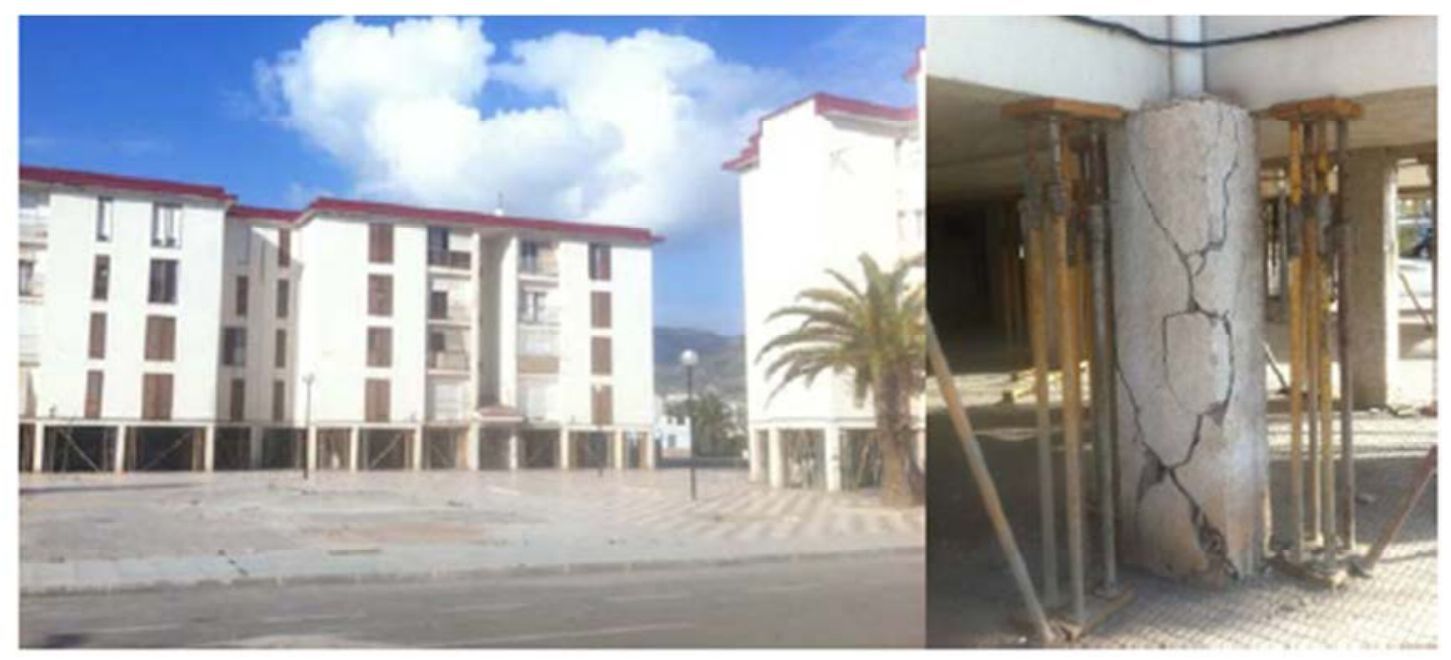

Figura 2.30. Barriada S. Fernando en Lorca, demolida tras el sismo de 2011. Se observa la irregularidad de planta blanda y la concentración de daños en pilares (Fotos: García-Ayllón \& Tomás, 2013).

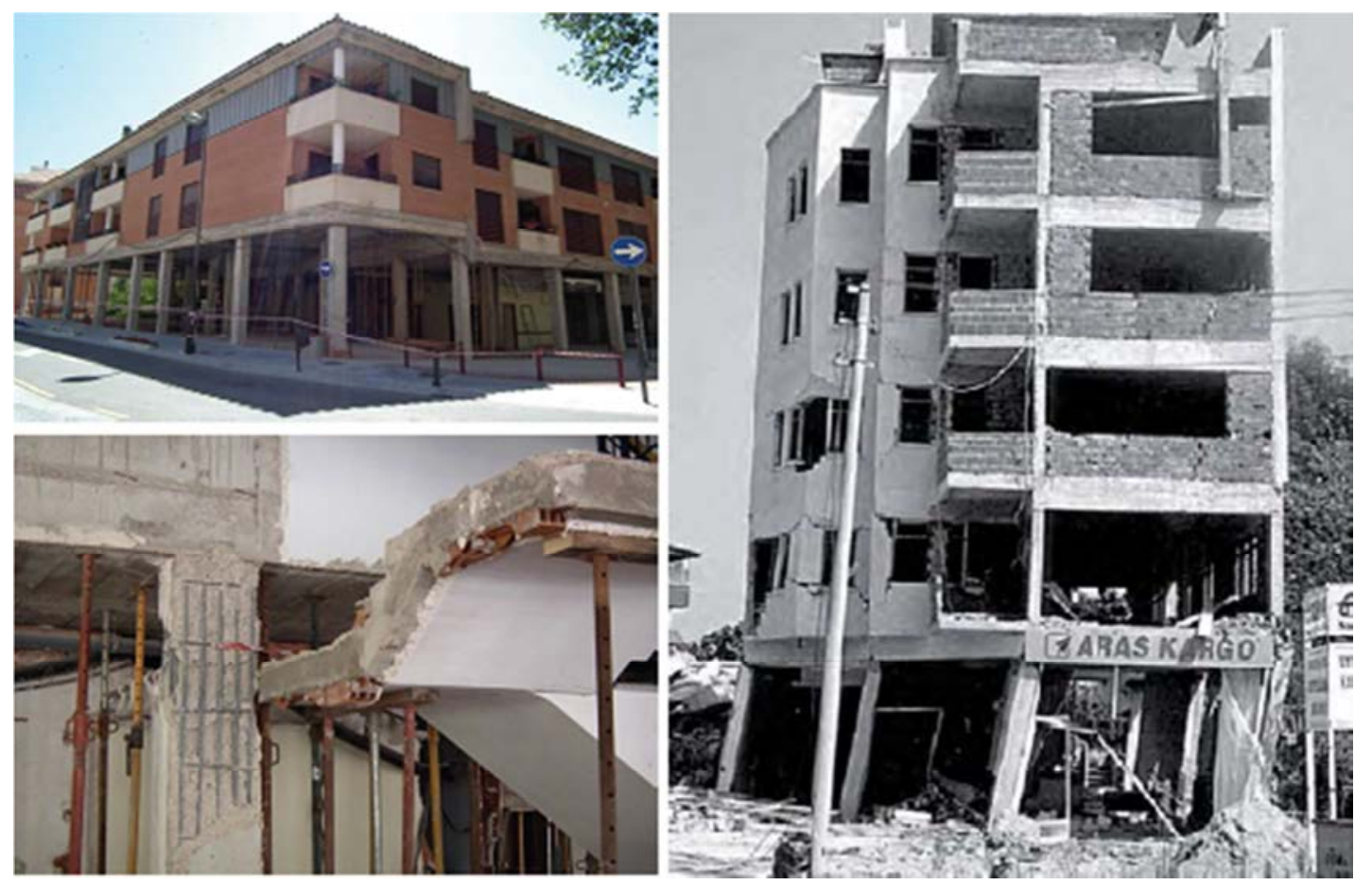

Figura 2.31. Daños en edificios con planta blanda. Se observan las afecciones concentradas en este nivel (Fotos: Perepérez, 2011; Carreño et al., 2012). 
Diversos trabajos (FEMA 454, 2006; Bonowitz \& Rabinovici, 2013; CARM; 2014) presentan medidas para prevenir el efecto de planta blanda en plantas bajas que requieran mantenerse diáfanas. Estas soluciones incluyen el aumento el número de pilares o la inclusión de refuerzo lateral o arbotantes externos que contribuyan a aumentar la rigidez de esa planta para igualarla a la de las demás.

\section{Efecto golpeteo o embestimiento. Juntas sísmicas}

Cuando dos o más edificios adyacentes están muy cercanos, la vibración de un terremoto fuerte puede hacer que estos se golpeen mutuamente si entre ellos no se dispone de una junta sísmica estructural o si esta no es lo suficiente capaz (Figura 2.32 y Figura 2.33).

Especialmente grave puede ser si dichos edificios son de diferente altura y sus plantas a nivel de forjado no coinciden, ya que las plantas y el techo del edificio más bajo pueden golpear a media altura los pilares del edificio más alto, causando considerables daños (Fig. 2.32a).

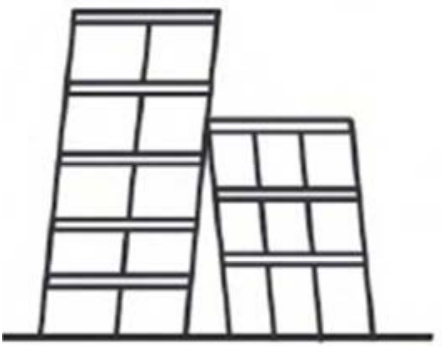

(a)

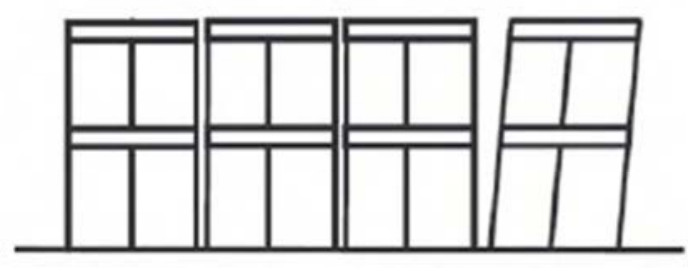

(b)

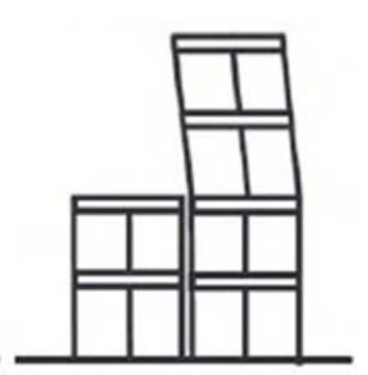

(c)

Figura 2.32. Casuísticas de daño sísmico por efecto golpeteo. (a) Edificios de distinta altura y con alturas de forjado diferentes. (b) Edificio de esquina sin apoyo de medianeras. (c) Edificios de distinta altura pero con alturas de forjado similares (Perepérez, 2011).
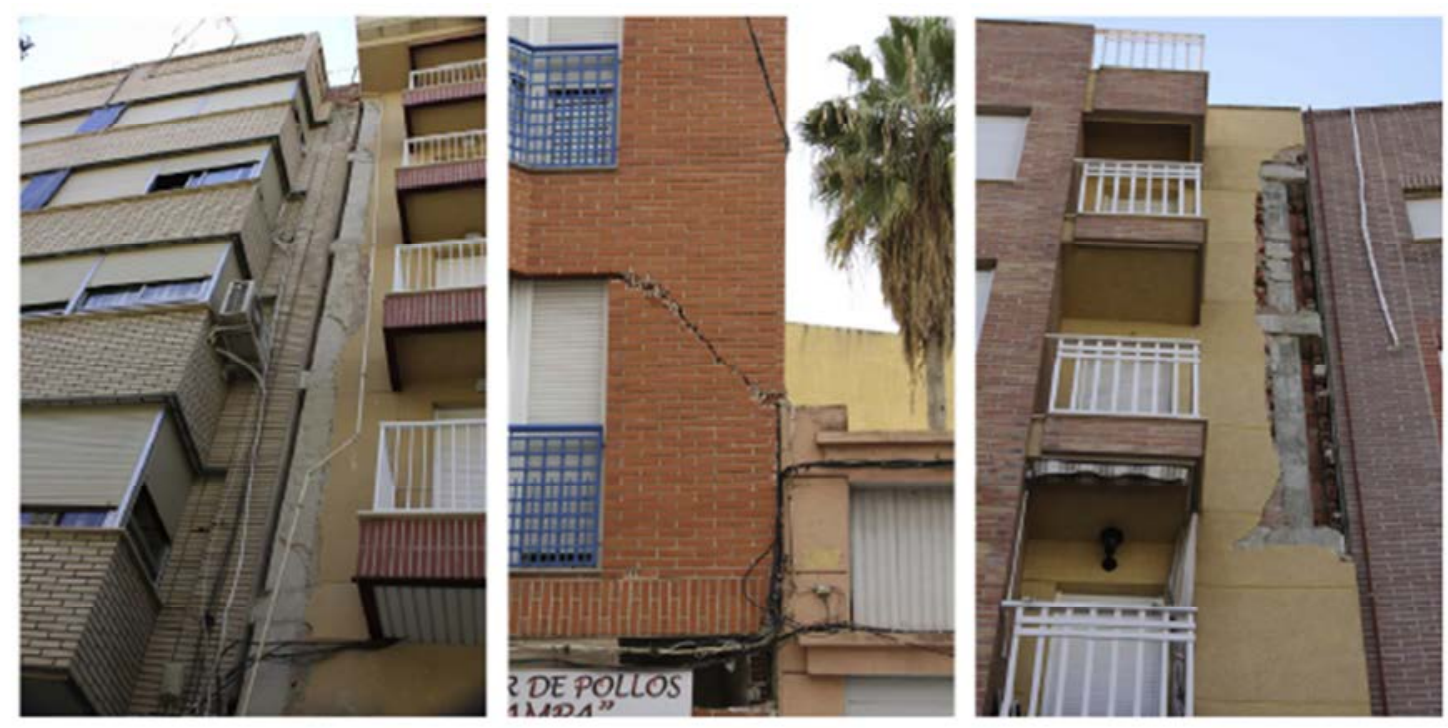

Figura 2.33. Daños por efecto golpeteo, sismo de Lorca de 2011 (Fotos: Romao et al., 2013). 
Actualmente, la NCSE-02 obliga a los edificios colindantes a retranquearse unos de otros una distancia equivalente al desplazamiento máximo calculado del edificio para evitar el embestimiento entre ellos, si bien las normas anteriores no exigían tal condición. Asimismo, este retranqueo del edificio supone una disminución del porcentaje del aprovechamiento urbanístico del inmueble, por lo que no suele ser bien asumido por los promotores.

Estas diferencias de altura entre edificios colindantes pueden provocar también efectos adicionales de planta blanda al quedar inmovilizadas parcialmente las edificaciones altas por las edificaciones bajas colindantes. Según se muestra en la Figura 2.34 , las plantas bajas de la edificación más alta quedan confinadas ante una cierta acción sísmica, mientras que el resto de la estructura se puede mover de manera libre e independiente, produciéndose por tanto un cambio brusco de rigidez esta zona, donde se concentran los principales daños.

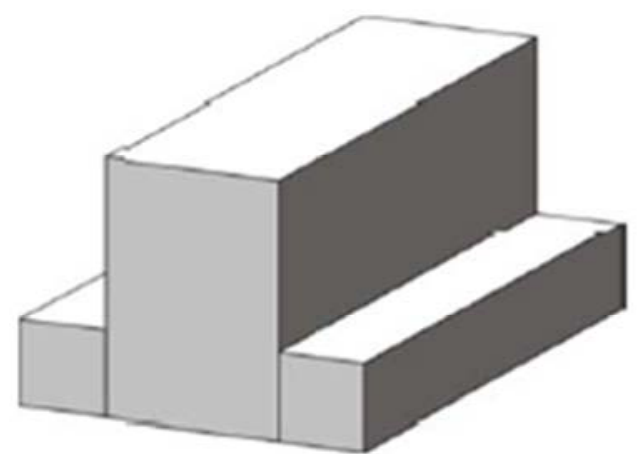

(a)

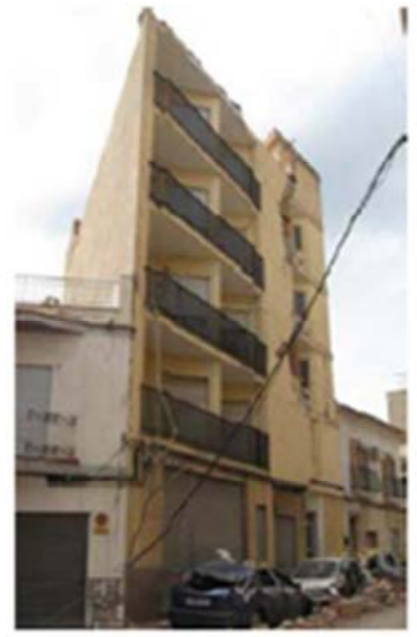

(b)

Figura 2.34. Efecto de la diferencia de altura entre edificios colindantes. (a) Croquis geométrico. (b)

Daños concentrados en la transición entre primera y segunda planta (Martínez-Cuevas, 2014).

\section{Confinamiento del hormigón}

Por último, aunque no sea propiamente una configuración arquitectónica o urbanística, la falta de confinamiento del hormigón en los elementos estructurales de las edificaciones condiciona significativamente su comportamiento sísmico. Este confinamiento, constituye una de las características básicas que mejora la respuesta dúctil del material durante una solicitación sísmica.

La utilización de una armadura transversal inadecuada en los pilares o en las conexiones viga-pilar, ya sea por una cuantía de armadura insuficiente, por una separación excesiva de los cercos o por la mala conexión entre los mismos, impide el adecuado confinamiento del material, produciéndose cuantiosos daños en la estructura debido a la respuesta frágil de sus elementos, especialmente en pilares (Figura 2.35).

Autores como Barbat, Vielma \& Oller (2007), Barbat (2011), García (2011), Carreño et al. (2012) o Domínguez, López-Almansa \& Benavent (2014), advierten además del 
comportamiento sísmico de los edificios de ductilidad limitada, compuestos por entramados de vigas planas o su extensión a forjados reticulares, muy aceptados por sus ventajas tecnológicas y arquitectónicas. En estos casos, la falta de vigas y nudos y de redundancia estructural de elementos resistentes dificulta el diseño dúctil de la estructura por la ineficacia de confinar las secciones de los forjados, al ser éstos elementos de menor canto.
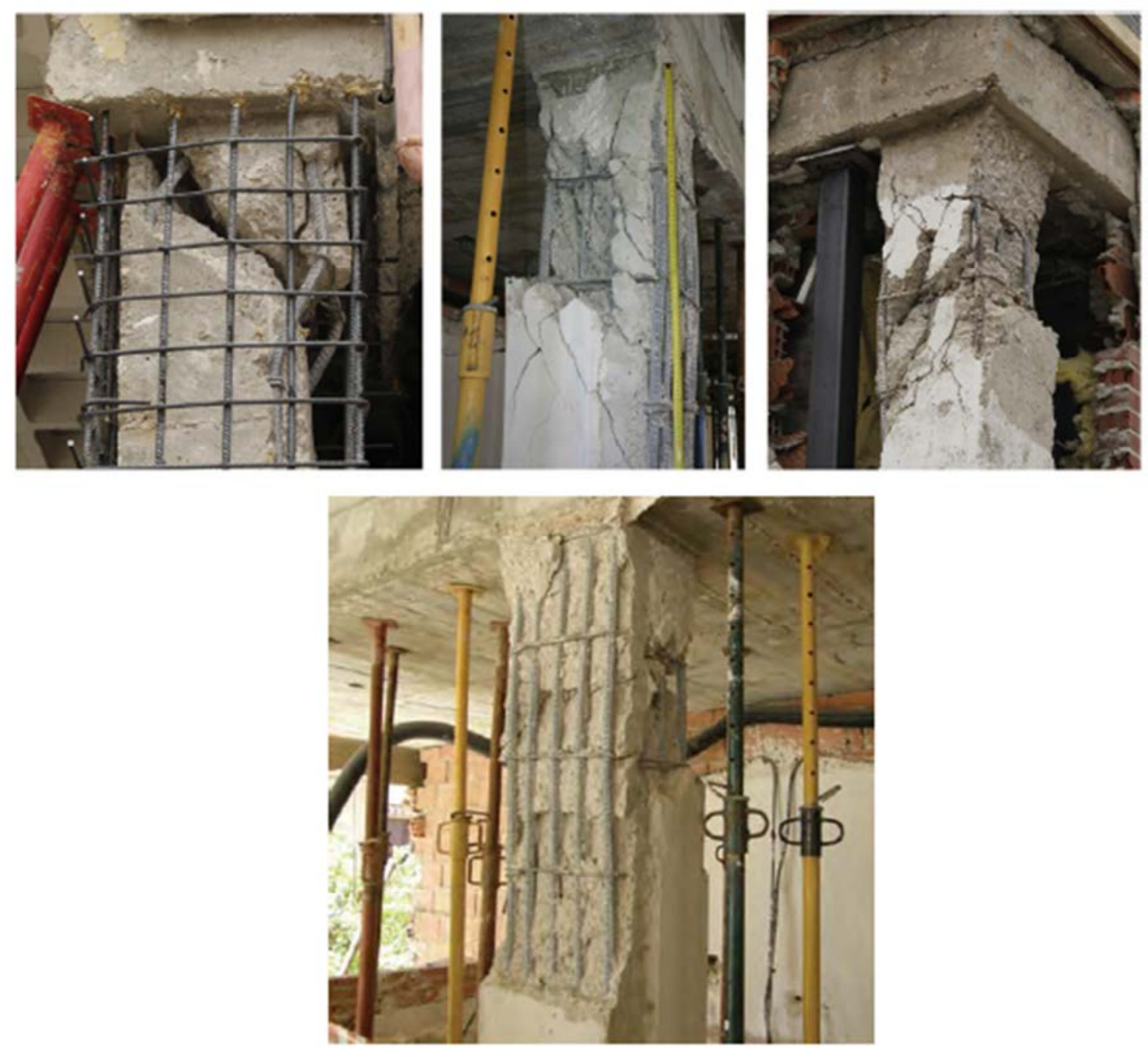

Figura 2.35. Afecciones en cabeza de pilares por falta de confinamiento del hormigón (Fotos: Barbat, 2011; Romao et al., 2013).

Su diseño depende por tanto de su mayor rigidez y resistencia y de la posibilidad de transferir las tensiones tangenciales entre los pilares y el forjado. Estas configuraciones generan un comportamiento del tipo pilar débil - forjado reticular fuerte, opuesto al de viga débil - pilar fuerte habitualmente requerido en el diseño sismorresistente, lo cual puede producir a un colapso frágil del edificio.

\subsubsection{Caracterización de la vulnerabilidad sísmica de edificaciones}

A continuación se resumen las principales metodologías propuestas en la literatura para la evaluación de la vulnerabilidad sísmica de edificaciones en áreas urbanas. 


\subsubsection{Métodos basados en clases e índices de vulnerabilidad}

Denominados también métodos uniparamétricos (Lantada, 2007), lo componen aquellos modelos en los que la capacidad sísmica del edificio se califica o cuantifica mediante un solo parámetro, el cual puede ser un código alfanumérico - clase de vulnerabilidad- o una cantidad numérica - índice de vulnerabilidad-, definiéndose generalmente en este tipo de modelos la acción sísmica en términos de intensidad macrosísmica.

\section{a) Escalas macrosísmicas}

La escala de intensidad MSK-64 puede ser considerada como la precursora del concepto de vulnerabilidad ya que, a pesar de no incluir explícitamente dicho término, clasifica los edificios en base a sus características resistentes (Tabla 2.8).

Tabla 2.8. Clasificación de las edificaciones según la escala MSK-64 (Lantada, 2007).

\begin{tabular}{cr}
\hline Tipo & Descripción \\
\hline A & Con muros de mampostería en seco o con barro, de adobe, de tapial. \\
B & $\begin{array}{r}\text { Con muros de fábrica de ladrillo, de bloques de mortero, de mampostería } \\
\text { con mortero, de sillarejo, de sillería, entramados de madera }\end{array}$ \\
C & Con estructura metálica o de hormigón armado \\
\hline
\end{tabular}

Posteriormente, se elaboró el informe ATC-13 (1985) destinado a la evaluación de los daños previsibles por terremotos en la región de California (EEUU). Este documento analiza directamente hasta 75 tipos de edificios, estructuras e infraestructuras, dividiéndolos en cinco grupos según la estructura principal del inmueble (madera, metálica, acero, hormigón o mixta), con diversas subcategorías en función del número de plantas y diseño sismorresistente. Basándose en experiencia pasadas y opinión de expertos, establece para cada clase de edificios una serie de curvas que relacionan la intensidad MM con el factor de daño medio esperado.

La escala MSK-64, fue actualizada por última bajo la denominación de escala EMS-98 (Grünthal, 1998), incorporando ya el concepto de clase de vulnerabilidad y definiendo un total quince tipologías estructurales y seis clases de vulnerabilidad ( $, B, C, D, E$ y F). Las edificaciones de clase $A$ corresponden con las más vulnerables, mientras que las pertenecientes a la clase $\mathrm{F}$ serían las menos vulnerables ante la acción sísmica (Figura 2.36).

Se establece una distribución binomial para la obtención de la probabilidad $P_{k}$ de un cierto grado de daño $d$, según la ecuación (2.6a). Asimismo, se define un parámetro de daño medio $d^{*}$ de la distribución, según la expresión (2.6b):

$$
P_{K}(\mathrm{~N}, \mathrm{~d})=\frac{(\mathrm{N}-1) !}{(N-1-k) ! k !} \mathrm{d}^{\mathrm{k}}(1-\mathrm{d})^{\mathrm{N}-1-\mathrm{k}} \quad \mathrm{k}=0, \ldots,(\mathrm{N}-1)
$$




$$
d^{*}=\sum_{\mathrm{k}=0}^{5} \mathrm{kP}_{\mathrm{k}}(6, \mathrm{~d})
$$

donde:

$N=$ número de grados de daño definidos.

$P_{k}(N, d)=$ probabilidad de obtención de un cierto grado de daño $d$.

\begin{tabular}{|l|l|l|l|l|}
\hline \multicolumn{2}{|c|}{ Tipo de estructura } & \multicolumn{2}{|c|}{ Clase de Vulnerabilidad } \\
\hline & Cascotes de piedra, piedra de campo \\
\hline
\end{tabular}

Figura 2.36. Clases de vulnerabilidad en la escala EMS-98 para distintas tipologías estructurales (Mena, 2002).

La principal diferencia entre la escala EMS-98 y el resto de escalas de intensidad macrosísmica radica en el detalle con el cual se definen los diferentes términos usados, relativos al tipo de edificio o al grado de daño alcanzado (Figura 2.15), siendo además la primera en ser ilustrada (Martínez-Cuevas, 2014).

No obstante, según estas metodologías diferentes tipos de edificaciones pueden pertenecer a una misma clase de vulnerabilidad y, por el contrario, edificios de una misma tipología podrían presentar a su vez respuestas sísmicas diferentes (Barbat \& Pujades, 2004). La propia escala EMS-98 considera que no se puede determinar con certeza el número de edificaciones que se verán dañadas ante la ocurrencia de un determinado terremoto, introduciendo esta incertidumbre mediante una serie de rangos de pertenencia de cada tipología a una determinada clase de vulnerabilidad. 
De este modo, cada edificio es caracterizado por una clase de vulnerabilidad predominante o característica, junto con unos intervalos de variación que permiten expresar los resultados de daño obtenidos según los términos cualitativos Algunos, Muchos y La Mayoría (Figura 2.37).



Figura 2.37. Rangos de variabilidad de los grados de daño según la escala EMS-98 (Lantada, 2007).

\section{b) Método italiano}

Las primeras metodologías basadas en índices de vulnerabilidad comenzaron a ser desarrolladas en Italia a partir de las experiencias obtenidas tras el terremoto de Friuli del año 1976. En 1984 se propone el primer método para la evaluación de la vulnerabilidad sísmica de las edificaciones de mampostería no reforzada (Benedetti \& Petrini, 1984).

Posteriormente, fue adoptado por el Gruppo Nazionale per la Difesa dai Terremoti para su utilización en la evaluación del riesgo sísmico en edificios (GNDT, 1986), extendiendo su aplicación a otras tipologías constructivas basadas en pórticos de hormigón armado (Benedetti, Benzoni \& Parisi, 1988).

Según esta metodología, la vulnerabilidad sísmica de una cierta edificación se determina mediante la definición de un índice $I_{v}$ obtenido a partir de la evaluación de once parámetros relacionados con los componentes estructurales y no estructurales del edificio, ponderados en función de su influencia estimada sobre el comportamiento sísmico del mismo de acuerdo a datos obtenidos en inspecciones post-sismo y opinión de expertos. Cada parámetro, cuenta por tanto con un coeficiente $K_{i}$ de valoración del parámetro y un factor de ponderación $W_{i}$.

Se establecen dos niveles en la determinación de la vulnerabilidad sísmica de las edificaciones (Barbat, 1998; Carreño, 2007):

$\checkmark$ Evaluación del índice de vulnerabilidad ex-post, mediante la obtención de datos referentes al daño sufrido por los edificios durante un terremoto a partir de la inspección post-sismo. El resultado final es un índice de daño con su correspondiente índice de vulnerabilidad, lo cual permite definir, si se dispone de suficiente muestra, de funciones de vulnerabilidad observada para un determinado nivel de peligrosidad.

$\checkmark$ Evaluación del índice de vulnerabilidad ex-ante. Esta operación, aunque requiere también la inspección de los edificios, esta puede realizarse independientemente de la existencia de daños por sismo, puesto que en este caso dicha evaluación está orientada a evaluar la respuesta sísmica de la edificación con carácter preventivo. 
Para la obtención de los citados índices, en el caso de las edificaciones de mampostería no reforzada cada parámetro se califica en categorías A, B, C y D, desde condiciones favorables a más desfavorables, respectivamente. A cada una de ellas le corresponde un valor numérico $K_{i}$ que varía entre 0 y 45, de tal modo que cuanto mayor es el índice de vulnerabilidad, peor es la respuesta sísmica del edificio. Finalmente, el índice de vulnerabilidad $I_{v}$ se obtiene mediante la expresión (2.7), aplicando los factores de ponderación $W_{i}$ establecidos para cada uno de los once parámetros.

En la Tabla 2.9 se muestra la descripción, categorías y pesos correspondientes a cada uno de los once parámetros definidos para esta tipología edificatoria. El peso de los parámetros 5,7 y 9 varía entre 0,5 y 1 dependiendo de algunos elementos como, por ejemplo, el porcentaje de diafragmas rígidos bien conectados, la presencia de galerías y pasillos o el peso del tejado.

$$
I_{\mathrm{v}}=\sum_{i=1}^{11} K_{\mathrm{i}} W_{\mathrm{i}}
$$

Tabla 2.9. Parámetros / que condicionan la obtención del índice de vulnerabilidad para el caso de edificaciones de mampostería no reforzada. Coeficientes $K_{i}$ de valoración y factores de ponderación $W_{i}$ (Benedetti \& Petrini, 1984).

\begin{tabular}{ccccccc}
\hline & \multirow{2}{*}{ Descripción del parámetro I } & Valor $K_{i}$ según categoría & \multirow{2}{*}{$W_{i}$} \\
\hline 1 & Organización del sistema resistente & 0 & 0 & 20 & 45 & 1,0 \\
2 & Calidad del sistema resistente & 0 & 5 & 25 & 45 & 0,25 \\
3 & Resistencia convencional & 0 & 5 & 25 & 45 & 1,5 \\
4 & Posición del edificio y cimentación & 0 & 5 & 25 & 45 & 0,75 \\
5 & Diafragmas horizontales & 0 & 5 & 15 & 45 & 1,0 (variable) \\
6 & Configuración en planta & 0 & 5 & 25 & 45 & 0,5 \\
7 & Configuración en elevación & 0 & 15 & 25 & 45 & 1,0 (variable) \\
8 & Separación máxima entre muros & 0 & 5 & 25 & 45 & 0,25 \\
9 & Tipo de cubierta & 0 & 5 & 25 & 45 & 1,0 (variable) \\
10 & Elementos no estructurales & 0 & 5 & 25 & 45 & 0,25 \\
11 & Estado de conservación & 0 & 5 & 25 & 45 & 1,0 \\
\hline
\end{tabular}

Para los edificios de hormigón armado, se consideran también once parámetros con influencia en su comportamiento sísmico, calificados en una escala que va desde A (óptimo) hasta C (deficiente). En la Tabla 2.10 se muestra la descripción y cuantificación de cada uno de estos parámetros. En Barbat (1998) o CARM (2014) se incluye un resumen de las condiciones particulares que han de cumplir cada uno de estos parámetros para su calificación, tanto para los edificios de mampostería no reforzada como para los de hormigón armado. 
Tabla 2.10. Parámetros / que condicionan la obtención del índice de vulnerabilidad para el caso de edificaciones hormigón armado. Coeficientes $K_{i}$ de valoración y factores de ponderación $W_{i}$ (Benedetti, Benzoni \& Parisi, 1988).

\begin{tabular}{cccccc}
\hline I & Descripción del parámetro I & \multicolumn{2}{c}{ Valor $K_{i}$ según categoría } & $W_{i}$ \\
\hline 1 & Organización del sistema resistente & 0 & 1 & 2 & 4,0 \\
2 & Calidad del sistema resistente & 0 & 1 & 2 & 1,0 \\
3 & Resistencia convencional & -1 & 0 & 1 & 1,0 \\
4 & Posición del edificio y cimentación & 0 & 1 & 2 & 1,0 \\
5 & Diafragmas horizontales & 0 & 1 & 2 & 1,0 \\
6 & Configuración en planta & 0 & 1 & 2 & 1,0 \\
7 & Configuración en elevación & 0 & 1 & 3 & 2,0 \\
8 & Separación máxima entre muros & 0 & 1 & 2 & 1,0 \\
9 & $\quad$ Tipo de cubierta & 0 & 1 & 2 & 1,0 \\
10 & Elementos no estructurales & 0 & 1 & 2 & 1,0 \\
11 & Estado de conservación & 0 & 1 & 2 & 1,0 \\
\hline
\end{tabular}

Estos índices pueden ser normalizados para obtener valores entre 0 , nada vulnerable, y 1 , muy vulnerable, o entre 0 y 100, mediante por ejemplo la ecuación (2.8) para el caso de que el valor máximo de este índice sea de 25 :

$$
I_{\mathrm{v}}=100 \frac{\left(\sum_{i=1}^{11} K_{\mathrm{i}} W_{\mathrm{i}}\right)+1}{25}
$$

Este método ha sido empleado en numerosos estudios de evaluación de riesgo sísmico áreas urbanas, pudiéndose destacar por ejemplo los realizados para la ciudad de Barcelona (Yépez, 1996; Barbat, 1998; Mena, 2002), siendo adoptado y revisado también por el proyecto europeo SERGISAI (Cella et al., 1998). Recientemente, se suele denominar a esta metodología como método Italiano para distinguirla del Método del Índice de Vulnerabilidad propuesto dentro del marco del Proyecto RISK-UE.

\section{c) Método del Índice de Vulnerabilidad (MIV)}

EL Método del Índice de Vulnerabilidad (MIV) constituye un procedimiento que combina la escala EMS-98 y el método italiano de Benedetti \& Petrini (1984) para la caracterización de la vulnerabilidad sísmica de edificaciones. Propuesto inicialmente por Giovinazzi \& Lagomarsino (2002) y desarrollado por Giovinazzi (2005), fue adoptado por el Proyecto RISK-UE como una de las herramientas propuestas para la evaluación de la vulnerabilidad y riesgo de edificaciones en áreas urbanas (Milutinovic \& Trendafiloski, 2003). 
El método cuantifica las diferentes clases de vulnerabilidad propuestas en la escala EMS-98 mediante un índice de vulnerabilidad según sus características estructurales y tipológicas (Tabla 2.11). Las funciones de pertenencia $\chi$ a cada una de las seis clases de vulnerabilidad (Figura 2.38) se definen de forma difusa (Lantada, 2007), estableciendo unos rangos plausibles $(\alpha=1)$ junto con unos intervalos posibles que determinan la transición entre dos clases de vulnerabilidad adyacentes.

Tabla 2.11. Cuantificación de las clases de vulnerabilidad de la EMS-98 mediante índices de vulnerabilidad (Giovinazzi, 2005).

\begin{tabular}{cccccc}
\hline Clase de vulnerabilidad & $V^{\min }$ & $V^{-}$ & $V_{0^{*}}$ & $V^{+}$ & $V^{\max }$ \\
\hline A & 0,78 & 0,86 & 0,90 & 0,94 & 1,02 \\
B & 0,62 & 0,70 & 0,74 & 0,78 & 0,86 \\
C & 0,46 & 0,54 & 0,58 & 0,62 & 0,70 \\
D & 0,30 & 0,38 & 0,42 & 0,46 & 0,54 \\
E & 0,14 & 0,22 & 0,26 & 0,30 & 0,38 \\
F & $-0,02$ & 0,06 & 0,10 & 0,14 & 0,22 \\
\hline
\end{tabular}

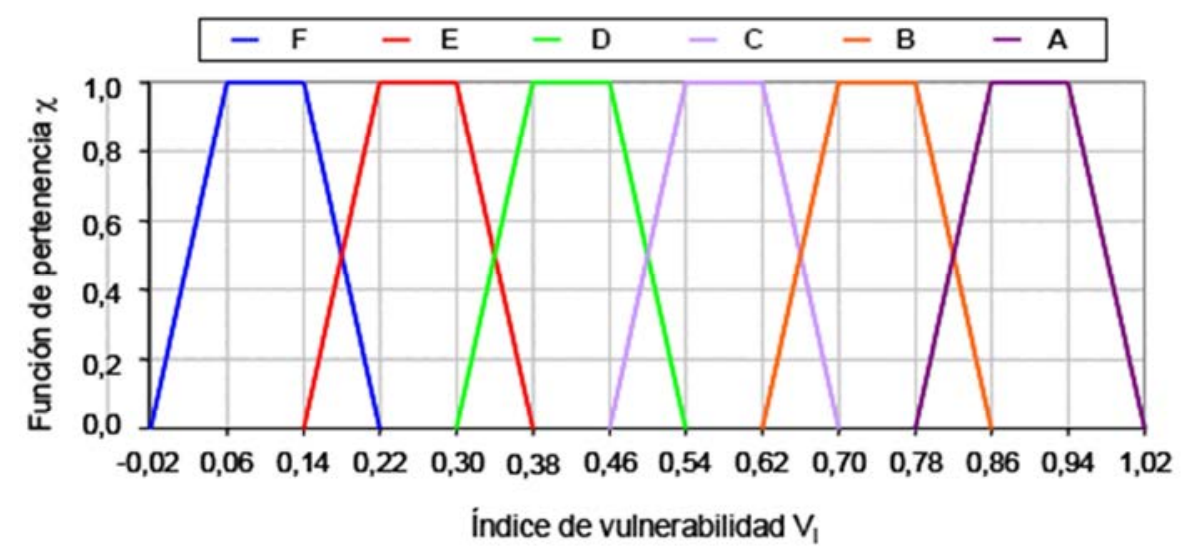

Figura 2.38. Funciones de pertenencia de una edificación a las diversas clases de vulnerabilidad (Giovinazzi, 2005). Tomado de Lantada (2007).

De este modo, para cada edificio, además del valor básico $V_{o}{ }^{*}$ del índice $(\chi=1)$, se contemplan rangos de índices posibles $(\chi \geq 0,6)$ e índices menos probables $(0,6>\chi \geq 0,2)$.

Estos índices, se generalizaron para las tipologías estructurales más habituales en áreas urbanas a partir del inventario de daños sísmicos en edificios disponibles en los países europeos participantes en el proyecto RISK-UE, recogidas en una matriz de clasificación de edificios denominada como Building Typology Matrix o matriz BTM (Lungu et al., 2002).

De este modo, se sintetiza el comportamiento sísmico de los principales sistemas constructivos, definiendo un total de veintitrés tipologías de edificios: diez de mampostería no reforzada; siete de hormigón armado; cinco de estructura metálica y una con estructura de madera (Milutinovic \& Trendafiloski, 2003). A modo de ejemplo, para la clase de vulnerabilidad A de la escala EMS-98, la matriz define principalmente dos tipologías estructurales distintas 
(M1 y M2), modificando ligeramente el índice de vulnerabilidad asociado de $V_{0}{ }^{*}=0,9$ en sendos valores $I_{v}{ }^{*}=0,873$ y $I_{v}{ }^{*}=0,8$ (Tabla 2.12$)$.

Tabla 2.12. Índices de vulnerabilidad propuestos por Milutinovic \& Trendafiloski (2003) para las tipologías de la matriz BTM de RISK-UE (Martínez-Cuevas, 2014).

\begin{tabular}{|c|c|c|c|c|c|c|c|}
\hline \multirow{2}{*}{\multicolumn{2}{|c|}{ Tipología }} & \multirow[t]{2}{*}{ Descripción } & \multicolumn{5}{|c|}{$\begin{array}{l}\text { Índices de vulnerabilidad } \\
\text { representativos }\end{array}$} \\
\hline & & & $I_{v}^{\min }$ & $I_{v}^{-}$ & $I_{V}{ }^{*}$ & $I_{v}^{+}$ & $I_{v}^{\max }$ \\
\hline \multirow{10}{*}{ 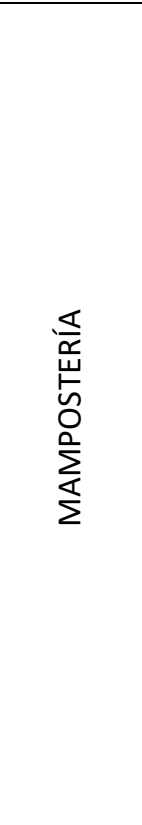 } & M1.1 & $\begin{array}{c}\text { Muros de carga con mampostería de } \\
\text { piedras y cascotes }\end{array}$ & 0,62 & 0,81 & 0,873 & 0,98 & 1,02 \\
\hline & M1.2 & Muros de carga con roca simple & 0,46 & 0,65 & 0,74 & 0,83 & 1,02 \\
\hline & M1.3 & Muros de carga con roca masiva & 0,30 & 0,49 & 0,616 & 0,793 & 0,86 \\
\hline & $\mathrm{M} 2$ & Adobe & 0,62 & 0,687 & 0,84 & 0,98 & 1,02 \\
\hline & M3.1 & $\begin{array}{l}\text { Muros de carga de fábrica y forjados de } \\
\text { madera }\end{array}$ & 0,46 & 0,65 & 0,74 & 0,83 & 1,02 \\
\hline & M3.2 & $\begin{array}{l}\text { Muros de carga de fábrica y bóvedas de } \\
\text { mampostería }\end{array}$ & 0,46 & 0,65 & 0,776 & 0,953 & 1,02 \\
\hline & M3.3 & $\begin{array}{c}\text { Muros de carga de mampostería no } \\
\text { reforzada con forjados mixtos de acero y } \\
\text { cerámica }\end{array}$ & 0,46 & 0,527 & 0,704 & 0,83 & 1,02 \\
\hline & M3.4 & $\begin{array}{l}\text { Muros de carga de mampostería no } \\
\text { reforzada y forjados de losas de HA }\end{array}$ & 0,30 & 0,49 & 0,616 & 0,793 & 0,86 \\
\hline & M4 & $\begin{array}{c}\text { Muros de carga de mampostería confinados } \\
\text { y reforzados }\end{array}$ & 0,14 & 0,33 & 0,451 & 0,633 & 0,70 \\
\hline & M5 & $\begin{array}{c}\text { Edificios de mampostería totalmente } \\
\text { reforzada }\end{array}$ & 0,30 & 0,49 & 0,694 & 0,953 & 1,02 \\
\hline \multirow{7}{*}{ 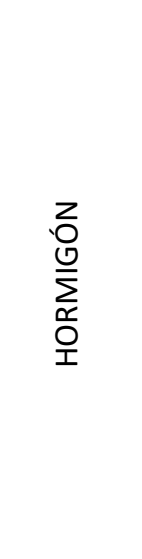 } & $\mathrm{RC1}$ & $\begin{array}{l}\text { Estructuras de hormigón resistentes al } \\
\text { momento }\end{array}$ & $-0,02$ & 0,047 & 0,442 & 0,80 & 1,02 \\
\hline & $\mathrm{RC2}$ & $\begin{array}{l}\text { Estructuras de hormigón resistentes al } \\
\text { cortante }\end{array}$ & $-0,02$ & 0,047 & 0,386 & 0,67 & 0,86 \\
\hline & $\mathrm{RC} 3.1$ & $\begin{array}{l}\text { Estructuras de hormigón con tabiquería } \\
\text { regular }\end{array}$ & $-0,02$ & 0,007 & 0,402 & 0,76 & 0,98 \\
\hline & $\mathrm{RC} 3.2$ & $\begin{array}{l}\text { Estructuras de hormigón armado } \\
\text { irregularmente tabicadas }\end{array}$ & 0,06 & 0,127 & 0,522 & 0,88 & 1,02 \\
\hline & $\mathrm{RC4}$ & Sistemas duales de muros y pórticos de HA & $-0,02$ & 0,047 & 0,386 & 0,67 & 0,86 \\
\hline & RC5 & Prefabricados de hormigón & 0,14 & 0,207 & 0,384 & 0,51 & 0,70 \\
\hline & $\mathrm{RC6}$ & $\begin{array}{l}\text { Prefabricados de hormigón resistentes al } \\
\text { cortante }\end{array}$ & 0,30 & 0,367 & 0,544 & 0,67 & 0,86 \\
\hline \multirow{5}{*}{\begin{tabular}{l} 
O \\
岃 \\
\multirow{4}{\varangle}{}
\end{tabular}} & S1 & $\begin{array}{l}\text { Estructuras metálicas resistentes al } \\
\text { momento }\end{array}$ & $-0,02$ & 0,467 & 0,363 & 0,64 & 0,86 \\
\hline & $\mathrm{S} 2$ & Estructuras metálicas arriostradas & $-0,02$ & 0,467 & 0,287 & 0,48 & 0,70 \\
\hline & S3 & Metálicas con muros de relleno de fábrica & 0,14 & 0,33 & 0,484 & 0,64 & 0,86 \\
\hline & S4 & Metálicas con muros de corte & $-0,02$ & 0,047 & 0,224 & 0,35 & 0,54 \\
\hline & S5 & Sistemas compuestos de acero y HA & $-0,02$ & 0,257 & 0,402 & 0,72 & 1,02 \\
\hline MADERA & W & Estructuras de madera & 0,14 & 0,207 & 0,447 & 0,64 & 0,86 \\
\hline
\end{tabular}

En González (2010) o García-García (2010) se incluyen descripciones pormenorizadas de cada una de estas tipologías estructurales. En la Tabla 2.13 se muestran los valores del índices 
de vulnerabilidad para algunas tipologías estructurales propuestos por Lagomarsino \& Giovinazzi (2006), miembros del grupo de trabajo del proyecto RISK-UE, calibrando los índices originales mediante modelos empíricos de daño, según la teoría de conjuntos difusos.

Tabla 2.13. Índices de vulnerabilidad propuestos por Lagomarsino \& Giovinazzi (2006) para algunas tipologías edificatorias basadas en pórticos de hormigón armado.

\begin{tabular}{cccccccc}
\hline \multicolumn{2}{c}{ Tipología } & & Descripción & \multicolumn{4}{c}{ Índices de vulnerabilidad } \\
& & & & \multicolumn{3}{c}{ representativos } \\
& RC1 & Estructuras de hormigón resistentes al momento & 0,14 & 0,33 & 0,484 & 0,64 & 0,86 \\
Hormigón & RC2 & Estructuras de hormigón resistentes al cortante & 0,14 & 0,21 & 0,384 & 0,51 & 0,70 \\
armado & RC3 & Sistemas duales & 0,06 & 0,127 & 0,522 & 0,88 & 1,02 \\
\hline
\end{tabular}

De este modo, se establecen una serie funciones de pertenencia $\chi$ definiendo cuatro subíndices para cada tipología constructiva. Para una cierta tipología edificatoria, se establece un valor $I_{v}{ }^{*}$ como el más probable para el índice de vulnerabilidad, un par $\left[I_{v}{ }^{-} I_{v}{ }^{+}\right]$que define el intervalo plausible del índice, habitualmente para un valor de la función de pertenencia de $\chi=0,5$, y una dupla $\left[I_{v}^{\min }, I_{v}{ }^{\max }\right]$ con los límites inferior $\mathrm{y}$ superior, menos probables $\mathrm{o}$ excepcionales.

Puesto que el comportamiento sísmico de una determinada edificación depende también de factores como su estado de conservación o el nivel del código sísmico de diseño, así como de otros parámetros estructurales y urbanísticos tales como el número de alturas, la regularidad geometría y en rigideces, o la posición relativa del edificio en la manzana, la metodología modifica el índice de vulnerabilidad asignado según la tipología estructural correspondiente mediante una serie de valores de penalización o mejora $M_{c}$, conocidos como modificadores por comportamiento.

Estos modificadores, definidos en rangos de $\pm 0,02$ sobre un intervalo que oscila entre $-0,08$ y +0,08 en función de las características específicas de la edificación evaluada, han sido propuestos en base a modelos empíricos de daño obtenidos a partir de observaciones reales post-sismo (ATC-21, 1988; FEMA 154, 2002) tanto para edificaciones de mampostería no reforzada como para aquellas basadas en pórticos de hormigón armado. De este modo, el método MIV establece un procedimiento similar a la suma ponderada de parámetros constructivos establecida en el método italiano (GNDT, 1986), considerando las características específicas de cada edificación.

De este modo, el índice de vulnerabilidad global de cada edificio $I_{V \text {-ed }}$ puede ser obtenido según la ecuación (2.9):

$$
I_{\mathrm{v}-\mathrm{ed}}=I_{\mathrm{v}-\mathrm{o}}+\sum_{j=1}^{n} M_{\mathrm{Cj}}+\Delta M_{\mathrm{R}}
$$

donde: 
$I_{V_{-}}=$índice de vulnerabilidad básico de la edificación asignado según la matriz BTM en función de la tipología estructural a la que pertenece.

$\Sigma M_{C}=$ modificadores del comportamiento sísmico que consideran las características estructurales y urbanísticas de la edificación.

$M_{R}=$ modificador regional dependiente de las disposiciones constructivas específicas de la zona de estudio, del nivel de los códigos sísmicos de diseño del país o de la fecha de construcción de la edificación, obtenido a partir de juicio de expertos y datos empíricos procedentes evaluaciones de daños reales post-sismo (Lantada, Pujades \& Barbat, 2009),

\section{Modificadores por comportamiento sísmico}

En las Tablas 2.14 y 2.15 se recogen los modificadores por comportamiento adoptados por RISK-UE (Milutinovic \& Trendafiloski, 2003) para edificaciones tanto de mampostería no reforzada como de hormigón armado.

Tabla 2.14. Modificadores de comportamiento $M_{C}$ del índice de vulnerabilidad propuestos por Milutinovic \& Trendafiloski (2003) para edificaciones de mampostería no reforzada (Lantada, 2007).

\begin{tabular}{|c|c|c|}
\hline Factores de comportamiento & Parámetros & $\begin{array}{l}\text { Valoraciones del } \\
\text { modificador } M c_{j}\end{array}$ \\
\hline \multirow{2}{*}{ Estado de conservación } & Buen mantenimiento & $-0,04$ \\
\hline & Mal mantenimiento & 0,04 \\
\hline \multirow{3}{*}{ Altura o número de plantas } & Bajo $(1 \circ 2)$ & $-0,02$ \\
\hline & Medio (3 a 5) & 0,02 \\
\hline & Alto (6 o más) & 0,06 \\
\hline \multirow{4}{*}{ Sistema estructural } & Grosor de los muros & \\
\hline & Distancia entre muros & \\
\hline & $\begin{array}{l}\text { Conexión entre muros: barras de unión, } \\
\text { soportes en las esquinas }\end{array}$ & {$[-0,04,0,04]$} \\
\hline & Conexión horizontal estructura-muros & \\
\hline Piso blando (soft-storey) & Demolición/Transparencia, diáfana & 0,04 \\
\hline Irregularidad en planta & & 0,04 \\
\hline Irregularidad vertical & & 0,02 \\
\hline Plantas superpuestas & & 0,02 \\
\hline Cubierta & $\begin{array}{l}\text { Peso y acometida (thrust) de la cubierta } \\
\text { Conexiones con la cubierta }\end{array}$ & 0,04 \\
\hline Intervenciones de reparación & & {$[-0,08,0,08]$} \\
\hline \multirow{3}{*}{$\begin{array}{l}\text { Edificio en agregado: posición } \\
\text { en planta }\end{array}$} & Intermedio & $-0,04$ \\
\hline & Esquina & 0,04 \\
\hline & Terminal & 0,06 \\
\hline \multirow{2}{*}{$\begin{array}{l}\text { Edificio en agregado: posición } \\
\text { en elevación }\end{array}$} & Plantas escalonadas & 0,02 \\
\hline & Edificios adyacentes de diferente altura & {$[-0,04,0,04]$} \\
\hline Cimientos & Cimientos a diferente nivel & 0,04 \\
\hline \multirow{2}{*}{ Morfología del terreno } & Pendiente & 0,02 \\
\hline & Precipicio o acantilado & 0,04 \\
\hline
\end{tabular}


Tabla 2.15. Modificadores de comportamiento $M_{C}$ del índice de vulnerabilidad propuestos por Milutinovic \& Trendafiloski (2003) para edificaciones de hormigón armado (Lantada, 2007).

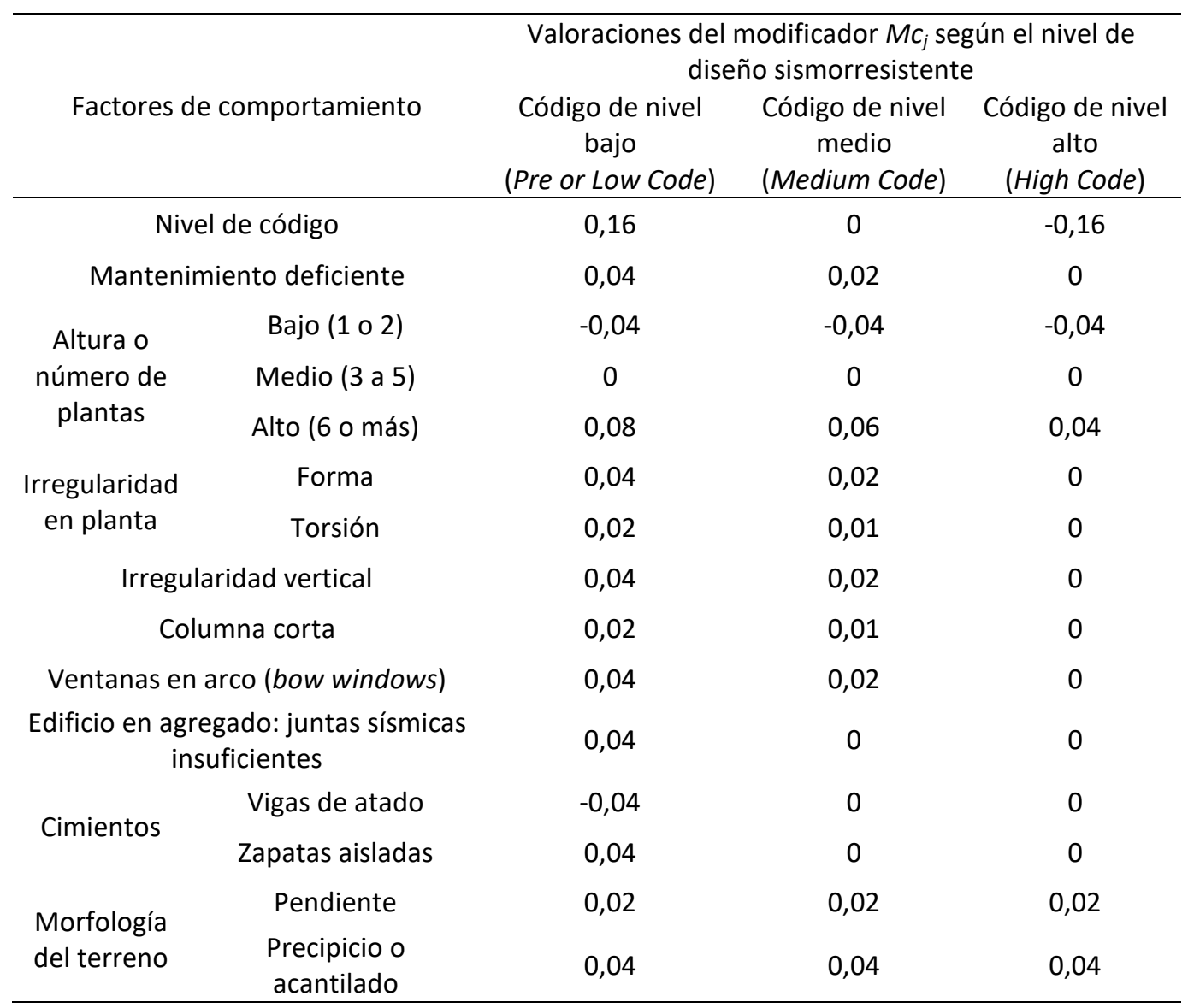

Según se puede observar, estos valores permiten incorporar a la evaluación de la vulnerabilidad sísmica aspectos tales como el número de plantas del edificio, irregularidades en altura y en planta, su estado de conservación, descritos en el apartado 2.2.3.6 por su influencia de manera significativa en el comportamiento sísmico de las edificaciones. Una exposición más detallada de los mismos se puede encontrar, por ejemplo, en FEMA 154 (2002) o Martínez-Cuevas (2014).

A partir de la primera versión del proyecto RISK-UE, se han desarrollado una serie de trabajos enfocados a la revisión de la definición y cuantificación de cada uno de estos modificadores (Giovinazzi, 2005; Lantada, 2007; Feriche, 2012; Martínez-Cuevas \& Gaspar-Escribano, 2016), calibrando la influencia de diversas disposiciones constructivas en la respuesta sísmica de las edificaciones. Los valores propuestos por cada autor se describen en el apartado 3.1.

\section{Modificador regional}

El modificador regional $\Delta M_{R}$ expuesto en la ecuación (2.9) permite la adaptación de los índices de vulnerabilidad a las características y calidades propias de los edificios de la zona de estudio, pudiendo ser asignado en función de juicio de expertos, de correlaciones empíricas procedentes de vulnerabilidad observada o de la normativa sísmica vigente en cada momento. 
Actualmente no se dispone de una propuesta unificada para la obtención de este modificador. En el apartado 3.1 se presentan algunas de las propuestas disponibles desarrolladas para la península Ibérica.

\section{d) Vulnerabilidad sísmica de edificios históricos y monumentales}

Los terremotos constituyen una de las principales causas daños en monumentos de carácter histórico-artístico, dado el comportamiento muy frágil de este tipo de estructuras basadas en muros de mampostería no reforzada (Feriche et al., 2012b). Asimismo, constituye una de las tipologías más complejas de modelar debido a sus características tecnológicas y constructivas (Ivorra et al., 2015).

Por este motivo, RISK-UE establece una variante del método VIM específica para edificios monumentales, recogida en el módulo WP05 (Lagomarsino et al., 2003) y revisada posteriormente en Lagomarsino (2006) y Lagomarsino \& Resemini (2009), modificando los índices de vulnerabilidad a partir de observaciones post-sismo en este tipo de edificaciones.

Dado que muchos monumentos constituyen edificios singulares que no pueden correlacionarse con ninguna de las tipologías definidas en la matriz BTM, se establece una nueva matriz de clasificación (Tabla 2.16). Así, cada monumento viene caracterizado por un índice de vulnerabilidad obtenido como la suma de dos contribuciones: 1) el índice básico obtenido según la tipología a la que pertenece; y 2) diversos modificadores tanto a nivel general según la calidad del material, el estado de mantenimiento o la existencia de intervenciones posteriores, como a nivel particular según configuraciones específicas de cada monumento como el número de naves, la existencia de torres o cúpulas o el tipo de arcos.

Tabla 2.16. Índices de vulnerabilidad básico $I_{V}$ para algunas tipologías de monumentos en RISK-UE (Lagomarsino et al., 2003) y parámetro de ductilidad $\phi$ para la obtención del grado de daño medio (Lagomarsino \& Giovinazzi, 2006).

\begin{tabular}{ccccc}
\hline Tipología del monumento & $I_{v}{ }^{-}$ & $I_{v}{ }^{*}$ & $I_{v}{ }^{+}$ & $\phi$ \\
\hline Palacios/edificios & 0,496 & 0,616 & 0,956 & 2,3 \\
Monasterios/conventos & 0,616 & 0,736 & 1,076 & 2,3 \\
Castillos & 0,356 & 0,456 & 0,766 & 2,3 \\
Iglesias & 0,77 & 0,89 & 1,26 & 3,0 \\
Ermitas/capillas & 0,65 & 0,77 & 1,14 & 3,0 \\
Mezquitas & 0,67 & 0,73 & 0,94 & 2,65 \\
Teatros & 0,616 & 0,736 & 1,086 & 2,65 \\
Torres/campanarios & 0,636 & 0,776 & 1,136 & 2,3 \\
Arcos del triunfo & 0,376 & 0,456 & 0,706 & 2,3 \\
Obeliscos & 0,396 & 0,456 & 0,746 & 1,95 \\
Estatuas/fuentes & 0,236 & 0,296 & 0,606 & 1,95 \\
\hline
\end{tabular}


e) Otros métodos basados en índices de vulnerabilidad

Finalmente, países de gran sismicidad como Japón o Nueva Zelanda, así como otras naciones sudamericanas (Colombia, Venezuela o México, entre otros), disponen de sus propias metodologías basadas en índices de vulnerabilidad, adaptadas y calibradas para las respectivas regiones. En diversos trabajos (Hill \& Rossetto, 2008; Alam, Shahria-Alam \& Tesfamariam, 2012), se puede encontrar una completa revisión de las distintas metodologías disponibles.

\subsubsection{Métodos basados en espectros de capacidad}

Ante las limitaciones evidenciadas por el diseño sismorresistente basado en resistencia y en el control de fuerzas, durante la última década del siglo XX se ha avanzado en el análisis de la respuesta sísmica de las edificaciones según la filosofía de desempeño sísmico o diseño basado en prestaciones (Performed Based Design), enfocadas a la preparación de la estructura para satisfacer distintos niveles de comportamiento frente a sismos de diferente severidad.

Estos procedimientos evalúan la vulnerabilidad sísmica de las estructuras en términos de sus respectivas curvas de capacidad, en coordenadas fuerza-desplazamiento, las cuales constituyen modelos mecánicamente representativos capaces de caracterizar de forma analítica su comportamiento sísmico. Pueden ser obtenidas mediante análisis estáticos no lineales tipo pushover (Chopra \& Goel, 2002; FEMA 440, 2005; Borzi, Phino \& Crowley, 2008; Kim \& Kuruma, 2008), determinando para diversos incrementos del estado de carga lateral los correspondientes desplazamientos laterales a nivel de cubierta. Este tipo de metodologías también se pueden denominar como métodos multiparamétricos (Lantada, 2007).

Una vez obtenida la curva de capacidad, es habitual su transformación a coordenadas de aceleración y desplazamientos espectrales ( $S_{a}$ y $S_{d}$, respectivamente) o formato ADRS Acceleration-Displacement Response Spectra, a partir de las propiedades modales asociadas al primer modo de vibración de la estructura. Así, se determina una nueva representación conocida como espectro de capacidad (Figura 2.39). Las ecuaciones (2.10) y (2.11) permiten la transformación de la curva al espectro de capacidad (Moreno et al., 2004):

$$
\begin{aligned}
S_{a} & =\frac{V_{o} / W}{\alpha_{1}} \\
S_{d} & =\frac{\Delta_{n}}{P F_{1} \phi_{1 n}}
\end{aligned}
$$

donde:

$$
\begin{aligned}
& W=\text { peso modal de la estructura } \\
& V_{o}=\text { cortante basal } \\
& \alpha_{1}=\text { coeficiente de la masa modal efectiva del primer modo de vibración } \\
& P F_{1}=\text { factor de participación modal del primer modo de vibración } \\
& \Delta_{n}=\text { desplazamiento del primer modo de vibración a nivel de cubierta del edificio }
\end{aligned}
$$


$\phi_{1 n}=$ amplitud del primer modo de vibración a nivel de cubierta del edificio.
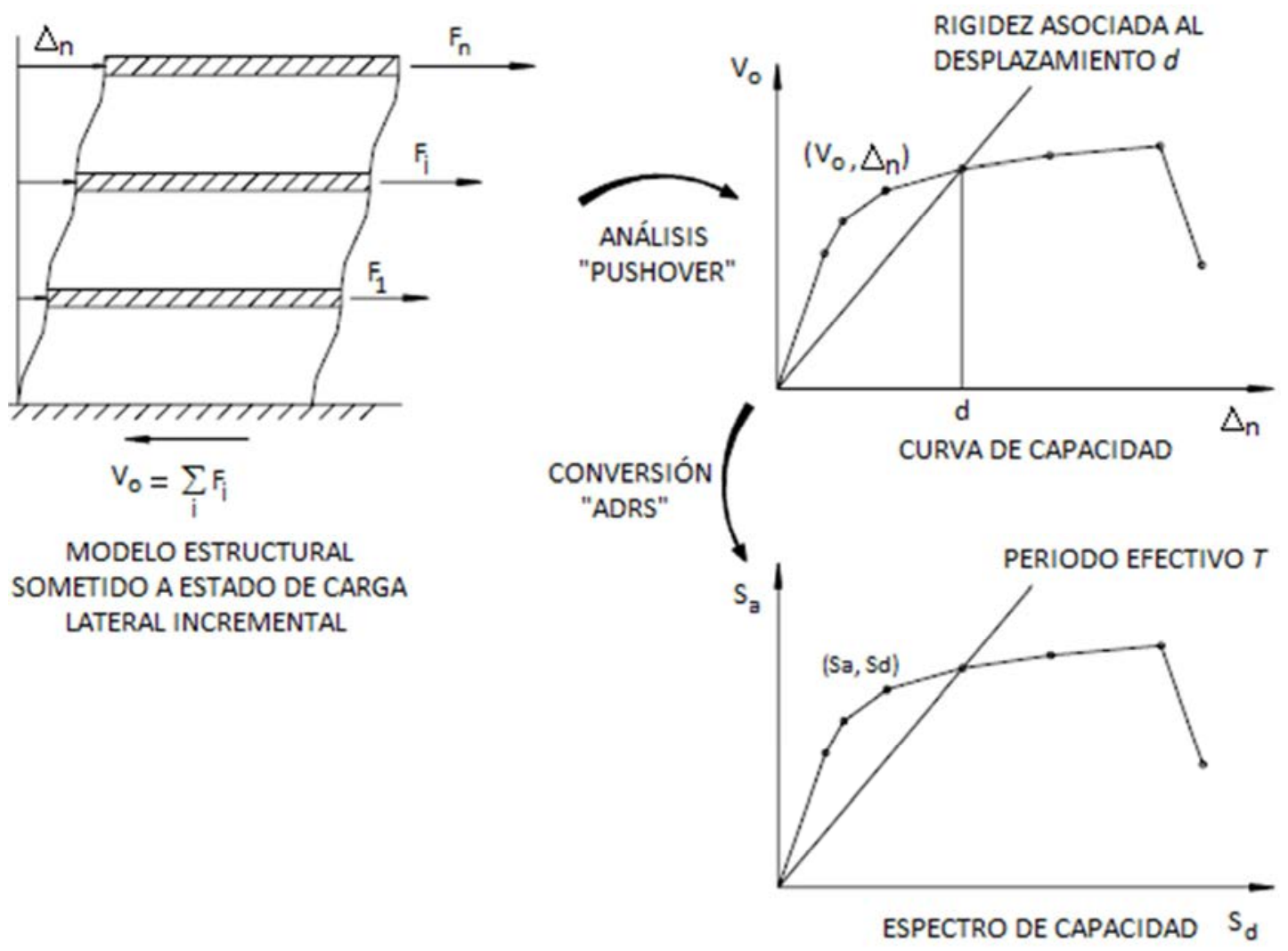

Figura 2.39. Procedimiento de obtención del espectro de capacidad de una determinada estructura (Safina, 2003).

Es frecuente la representación de la curva y espectro de capacidad según su forma bilineal simplificada (Borzi et al. 2006; Pujades, Barbat \& Lantada, 2007), mediante su aproximación a dos tramos rectos: el primero define el periodo propio del edificio y representa su comportamiento lineal para desplazamientos y aceleraciones espectrales pequeños; mientras que el tramo entre los puntos de cedencia y de capacidad última modela el comportamiento no lineal de la estructura, hasta su colapso (Figura 2.40). Los puntos de control que definen esta representación son (Moreno, 2006):

$\checkmark$ El de capacidad de cedencia $\left(S_{d y}, S_{a y}\right)$, donde la respuesta de la estructura comienza a ser no lineal.

$\checkmark$ El de capacidad última $\left(S_{d u}, S_{a u}\right)$, donde el sistema estructural global ha alcanzado el mecanismo de colapso.

Existen diversos procedimientos para la obtención de esta forma bilineal simplificada (FEMA 273, 1996, ATC-40, 1996; Fajfar, 2000), difiriendo entre ellos en los convencionalismos adoptados para la determinación de los citados punto de control.

Estas metodologías fueron adoptadas también por el Proyecto RISK-UE como herramienta para la evaluación de la vulnerabilidad y riesgo de edificaciones en áreas urbanas y la 
definición de escenarios sísmicos, dentro del método denominado como LM2 o de nivel II (Lagomarsino \& Penna, 2003). A este respecto, diversos trabajos (p.e. Bonett, 2003; Moreno, 2006; Lagomarsino \& Giovinazzi, 2006; Kappos, 2007; Bermúdez, 2010; Lestuzzi et al., 2017), proponen espectros de capacidad para diversas tipologías edificatorias recogidas en la matriz de edificios BTM del proyecto RISK-UE.

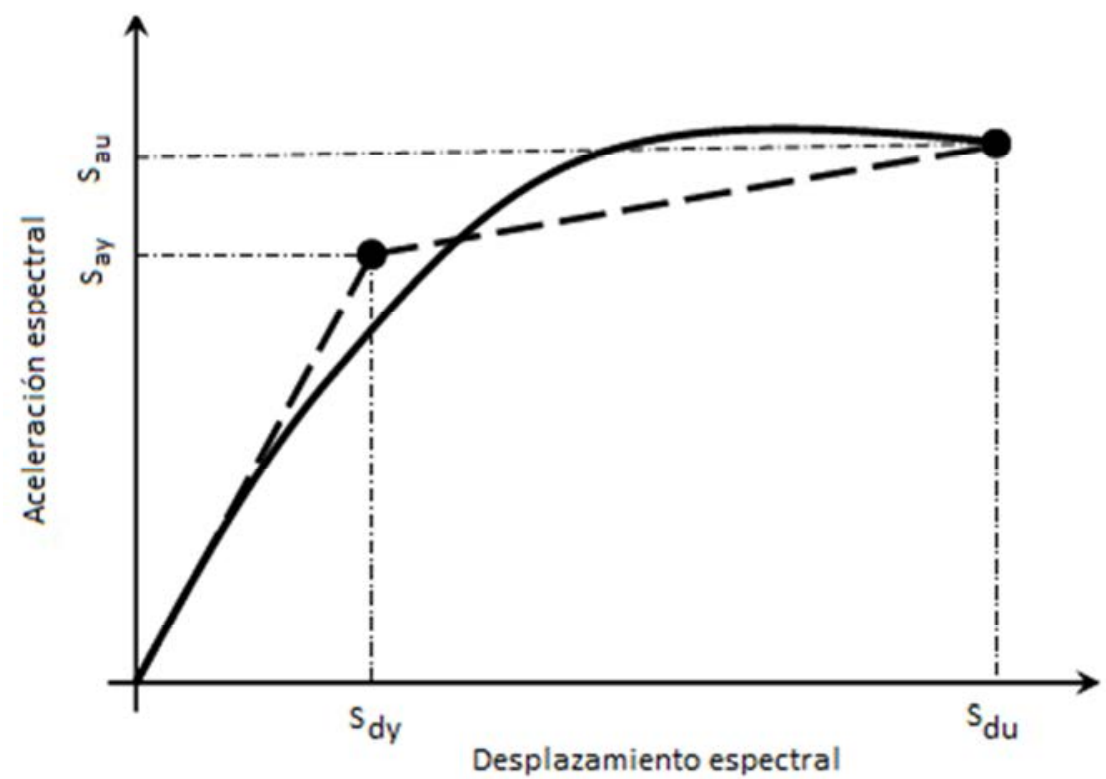

Figura 2.40. Espectro de capacidad -trazo continuo- y espectro bilineal de capacidad -trazo discontinuode una estructura (Pujades, Barbat \& Lantada, 2007).

$S d y$, Say = desplazamiento y aceleración espectral, respectivamente, correspondientes con el punto de cedencia de la estructura; $S d u, S a u=$ desplazamiento y aceleración espectral, respectivamente, correspondientes con el punto de capacidad última de la estructura

\subsection{RIESGO SÍSMICO}

\subsubsection{Introducción}

\subsubsection{Definición y caracterización del riesgo sísmico}

Una vez revisados los principales aspectos relativos a la peligrosidad y vulnerabilidad sísmica en áreas urbanas, es necesario abordar finalmente el concepto de riesgo sísmico, entendido, con carácter general, como el grado de pérdidas esperadas debidas a la acción sísmica (Moreno, 2006). Basándose en las propuestas iniciales de UNDRO (United Nations Disaster Relief Office) y la UNESCO, se desarrolló un marco matemático para la cuantificación de dicho concepto (Sandi, 1983, 1986).

En primer lugar, se define como Riesgo Sísmico Específico $S$ a la probabilidad de que una estructura sufra un determinado nivel de daño durante un tiempo de exposición dado, obtenido según la expresión (2.12) mediante la operación de convolución entre la peligrosidad 
sísmica $H$, según la probabilidad de ocurrencia de un terremoto de un cierto tamaño en dicho tiempo de exposición, y la vulnerabilidad $V$ de la estructura:

$$
\mathrm{S}=\mathrm{H} \otimes \mathrm{V}
$$

Asimismo, el Riesgo Sísmico $R$ se obtiene mediante la convolución entre el riesgo sísmico específico $S$ y el valor $E$ de los elementos expuestos al riesgo, según la ecuación (2.13), expresados éstos ya sea según los costes directos de los elementos estructurales, no estructurales y del contenido del edificio, los costes debidos o a la interrupción de líneas y servicios vitales, o de otras afecciones sociales tales como pérdidas de vidas humanas, heridos, o personas sin hogar.

$$
\mathrm{R}=\mathrm{S} \otimes \mathrm{E}
$$

Esta operación de convolución suele ser simplificada según establecen las diversas metodologías disponibles para la evaluación del riesgo sísmico en áreas urbanas. De este modo, la mayoría de estudios emplean matrices de probabilidad de daño o funciones de vulnerabilidad para caracterizar, de forma discreta o continua, respectivamente, los niveles de riesgo existentes.

Estas representaciones pueden ser obtenidas a partir de experiencias de terremotos pasados o bien mediante técnicas de simulación (Yépez, 1996). Recientemente, bajo la filosofía del diseño por prestaciones, ha aparecido una nueva forma de cuantificación del riesgo sísmico basada en curvas de fragilidad (HAZUS, 1999). La elección del modo de caracterización depende de la información y de las técnicas de computación disponibles en cada caso (Mena, 2002; Moreno, 2006; Barbat et al., 2010). En este sentido, las técnicas SIG de computación aparecidas han permitido simplificar y optimizar estas técnicas de evaluación mediante un manejo adecuado de las bases de datos disponibles (Lantada, 2007).

En líneas generales, cualquier estudio de riesgo sísmico requiere la consideración de los siguientes aspectos:

I. El terremoto.

II. El edificio o bien expuesto al riesgo.

III. Las funciones de daño o funciones de pérdida.

IV. El análisis de riesgo.

V. Toma de decisiones.

Generalmente los estudios de evaluación del riesgo sísmico en áreas urbanas se centran en el análisis de los tres primeros: el terremoto, el edificio y el daño esperado. Los dos restantes, requieren estudios multidisciplinares en los que participen responsables de protección civil y de la planificación y gestión de emergencias (Pujades, Barbat \& Lantada, 2007). 
Recientemente se ha desarrollado una nueva metodología para la gestión de riesgos a nivel integral, denominada como enfoque holístico, mediante el uso de teoría de conjuntas difusos y redes neuronales (Cardona, 2001; Carreño, 2007; Valcárcel, 2013; Jaramillo, 2014; Carreño, Cardona \& Barbat, 2015), según se comentó en el apartado 2.2.3.2.

\subsubsection{Metodologías ex ante y ex post}

La evaluación del riesgo sísmico áreas urbanas se puede abordar bajo dos perspectivas diferentes, denominadas como acciones o técnicas ex ante y ex post (Carreño, 2007; Aguilar, 2011).

Como medidas de reducción del riesgo sísmico ex ante se denominan a las evaluaciones realizadas con anterioridad a la ocurrencia de un terremoto. Los términos prevención y mitigación se han utilizado habitualmente para referirse a ese tipo de actividades que pretenden reducir los factores de amenaza y vulnerabilidad de las estructuras para así atenuar los efectos de futuros desastres naturales. Bajo este contexto se enmarcan, por ejemplo, los proyectos ATC, RADIUS, HAZUS o RISK-UE.

Por el contrario, las acciones ex post están relacionadas con la gestión de las situaciones de emergencia generadas tras la ocurrencia de un determinado sismo, en lo relativo tanto a los daños y la habitabilidad de los edificios afectados como respuesta social de ayuda humanitaria a la población por parte de las administraciones y organismos competentes (Carreño et al., 2007; Vidal, Feriche \& Ontiveros, 2009; Erdik et al., 2011; Tomás \& Díaz, 2013; García-Ayllón \& Tomás, 2014; García-Ayllón, Tomás \& Ródenas, 2017).

Los procedimientos para la evaluación post-sismo se aplican normalmente según dos niveles o etapas de desarrollo:

$\checkmark$ Una primera evaluación rápida o de habitabilidad, basada en el nivel de riesgo inminente que presenta un edificio para los ocupantes y demás usuarios de la vía pública.

$\checkmark$ Una posterior evaluación detallada, que describe de forma pormenorizada el nivel de daño sísmico en las estructuras y el impacto económico y social, generando información para la toma de decisiones por parte de técnicos y autoridades con objeto de optimizar las estrategias de actuación ante situaciones de emergencia y de reconstrucción de las edificaciones afectadas, para mitigar a largo plazo reducir los efectos de futuros eventos sísmicos.

Entre las principales metodologías post-sismo implementadas destacan las realizadas en Macedonia (1985), Japón (1985), México (1998), Italia (2000), Turquía (1999), Colombia (2009) o Chile (2010), a raíz terremotos ocurridos en estos países. Asimismo, destaca el informe americano ATC-20 (1989), posteriormente revisado en 1995, 2003 y 2005, incluyendo una versión con portabilidad para móviles y demás dispositivos electrónicos (Carreño, 2007). 


\subsubsection{Cuantificación del riesgo sísmico}

La mayor parte de los estudios de riesgo sísmico emplean matrices de probabilidad de daño o funciones de vulnerabilidad para evaluar el nivel de riesgo existente en la trama urbana, obtenidas bien a partir de experiencias de terremotos pasados o bien mediante técnicas de simulación (Yépez, 1996). Más recientemente, bajo la filosofía del diseño por prestaciones (Performance Based Design), ha aparecido una nueva forma de cuantificación del riesgo sísmico, basada en curvas de fragilidad (HAZUS, 1999). La utilización de una u otra depende de la información y de las técnicas de computación disponibles en cada caso (Mena, 2002; Barbat et al., 2010).

Por tanto, se pueden destacar las siguientes herramientas para la evaluación del riesgo sísmico de edificaciones:

$\checkmark$ Matrices de probabilidad de daño. Expresan, de forma discreta, el riesgo sísmico específico $S$ como la probabilidad condicional $P\left[N_{D}=j / i\right]$ de que se produzca en la edificación un nivel de daño $N_{D}$ igual a $j$ para un terremoto de severidad $i$, multiplicado por la probabilidad de que se produzca dicho terremoto para un periodo de exposición dado (Tabla 2.17), según la ecuación (2.14). Fueron propuestas originalmente por Whitman, Reed \& Hong (1973).

$$
\mathrm{S}=\sum_{\mathrm{j}} \sum_{\mathrm{i}} \mathrm{P}\left[\mathrm{N}_{\mathrm{D}}=\mathrm{j} \mid \mathrm{i}\right] \mathrm{P}[\mathrm{i}]
$$

Tabla 2.17. Ejemplo de matriz de probabilidad de daño para edificaciones de mampostería no reforzada de baja altura (Aguilar, 2011).

\begin{tabular}{cccccccc}
\hline & \multicolumn{7}{c}{ Intensidad Mercalli Modificada } \\
Estado de daño & VI & VII & VIII & IX & X & XI & XII \\
\hline 1-Nulo & $*$ & $*$ & $*$ & $*$ & $*$ & $*$ & $*$ \\
2-Leve & 9,1 & 0,6 & $*$ & $*$ & $*$ & $*$ & $*$ \\
3-Ligero & 90,5 & 55,5 & 10,9 & 0,5 & $*$ & $*$ & $*$ \\
4-Moderado & 0,4 & 43,4 & 66,0 & 22,4 & 2,0 & 0,1 & 0,1 \\
5-Severo & $*$ & 0,5 & 22,9 & 65,9 & 35,0 & 10,1 & 0,4 \\
6-Grave & $*$ & $*$ & 0,2 & 11,2 & 62,5 & 83,1 & 50,4 \\
7-Colapso & $*$ & $*$ & $*$ & $*$ & $*$ & $*$ & $*$ \\
\hline
\end{tabular}

Funciones de vulnerabilidad. Describen esta operación de convolución de forma continua mediante relaciones semiempíricas (Figura 2.41). El riesgo específico $S$ viene dado según las expresiones (2.18a) y (2.18b):

$$
\begin{gathered}
\mathrm{F}(\overline{\mathrm{d}})=\int_{0}^{\overline{\mathrm{d}}} \int_{0}^{\mathrm{I}_{\max }} \mathrm{f}(\mathrm{j} \mid \mathrm{i}) \mathrm{f}(\mathrm{i}) \mathrm{di} \mathrm{dj} \\
\mathrm{S}=\mathrm{F}\left(\mathrm{d}_{\max }\right)=\sum_{i} P\left[d_{i}<d<d_{i+1}\right]
\end{gathered}
$$


donde:

$F(\bar{d})$ = función de distribución de probabilidad de daño acumulado para un daño $j=\bar{d}$.

$\bar{d}=$ valor máximo de la función de distribución de probabilidad de daño.

$f(j / i)=$ función de densidad de probabilidad de daño $j$ condicionada a la severidad $i$ del sismo.

$f(i)=$ función de densidad de probabilidad de dicha severidad $i$.

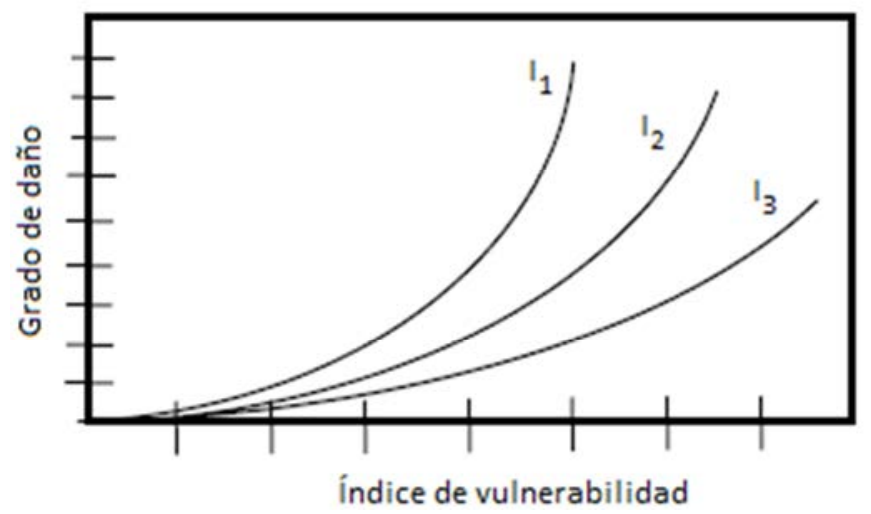

Figura 2.41. Ejemplo de función de vulnerabilidad, que relaciona el índice de vulnerabilidad $I_{v}$ con un grado de daño en la estructura, para diversos niveles de intensidad $l_{i}$. (Mena, 2002).

$\checkmark$ Curvas de fragilidad. Expresan la probabilidad de que un daño global $d$ de una estructura iguale o exceda un estado de daño considerado $d_{s}$ para una acción sísmica dada (Figura 2.42). Se suele adoptar una distribución de probabilidad lognormal para estas funciones. La función de densidad de probabilidad de daño para una tipología edificatoria $T$ dada viene determinada por la ecuación (2.19):

$$
\mathrm{F}_{\mathrm{T}, \mathrm{ds}}\left(\mathrm{S}_{\mathrm{d}}\right)=\frac{1}{\beta_{\mathrm{ds}} \mathrm{Sd} \sqrt{2 \pi}} \exp \left[-\frac{1}{2}\left(\frac{1}{\beta_{\mathrm{ds}}} \ln \left(\frac{\mathrm{S}_{\mathrm{d}}}{\mathrm{S}_{\mathrm{d}, \mathrm{ds}}}\right)^{2}\right]\right.
$$

donde:

$S_{d}=$ desplazamiento espectral o parámetro de la acción sísmica.

$\overline{S_{d, d s}}=$ valor medio del desplazamiento en el que el edificio alcanza un umbral del estado de daño $d_{s}$.

$\beta_{\mathrm{ds}}=$ desviación estándar del logaritmo natural del desplazamiento espectral del estado de daño $d_{s}$.

La curva de fragilidad, es decir, la probabilidad de que una edificación $T$ iguale o exceda el grado de daño $d_{s}$ considerado para un desplazamiento espectral $S_{d}$ dado, viene definida por la expresión (2.20):

$$
P\left(S_{d}\right)=P_{T, d s}\left[d \geq d s \mid S_{d}\right]=\int_{0}^{S d} F_{T, d s}\left(S_{d}\right) d\left(S_{d}\right)
$$






Figura 2.42. Ejemplo de curva de fragilidad en la que se consideran 4 estados de daño ds diferentes del daño nulo, en función del desplazamiento espectral de la estructura (Pujades, Barbat \& Lantada, 2007).

Estas curvas de fragilidad, constituyen en la realidad una generalización de las matrices de probabilidad de daño para cualquier grado de severidad sísmica, ya que cada valor de dichas matrices corresponde con un punto concreto de la función de fragilidad.

\subsubsection{Diseño por prestaciones. Desempeño sísmico de edificios}

Según se mencionó en el apartado 2.2.4.2, las experiencias obtenidas de terremotos recientes han manifestado una cierta limitación del enfoque tradicional de diseño sismorresistente basado en resistencia y en el control de fuerzas. El hecho de que una estructura no colapse frente a un sismo de una determinada severidad no implica que esta no sufra daños significativos durante otros terremotos de naturaleza más frecuente, los cuales pueden llegar a provocar la ruina económica de la edificación. Por tanto, resulta necesario que las estructuras sean capaces de satisfacer distintos niveles de comportamiento para sismos de diferente severidad.

Por este motivo, en los últimos años se ha desarrollado una nueva filosofía de diseño sísmico basada en el concepto de desempeño sísmico o diseño por prestaciones (Performance Based Design). Esta metodología establece una serie de niveles de desempeño o comportamiento según los daños experimentados por la estructura, asociados a unos correspondientes umbrales de daño considerados como aceptables, de tal modo que sea posible un adecuado control de los daños sísmicos sufridos por la edificación para cada nivel de carga.

La metodología fue desarrollada principalmente a partir de 1995 a raíz de los terremotos de Northridge (EEUU) y Kobe (Japón), y recogida por primera vez en un informe elaborado por el organismo americano Structural Engineers Association of California, denominado "VISION 
2000, a framework for Performance-Based Engineering" (SEAOC, 1995), siendo posteriormente revisada en los informes ATC-40 (1996) y HAZUS $(1999,2008)$.

Para evaluar el comportamiento sísmico de la estructura, el método superpone el espectro de capacidad de la misma con el espectro de demanda sísmica del terremoto de diseño, expresados ambos en formato espectral ADRS (Figura 2.39 y Figura 2.43, respectivamente).

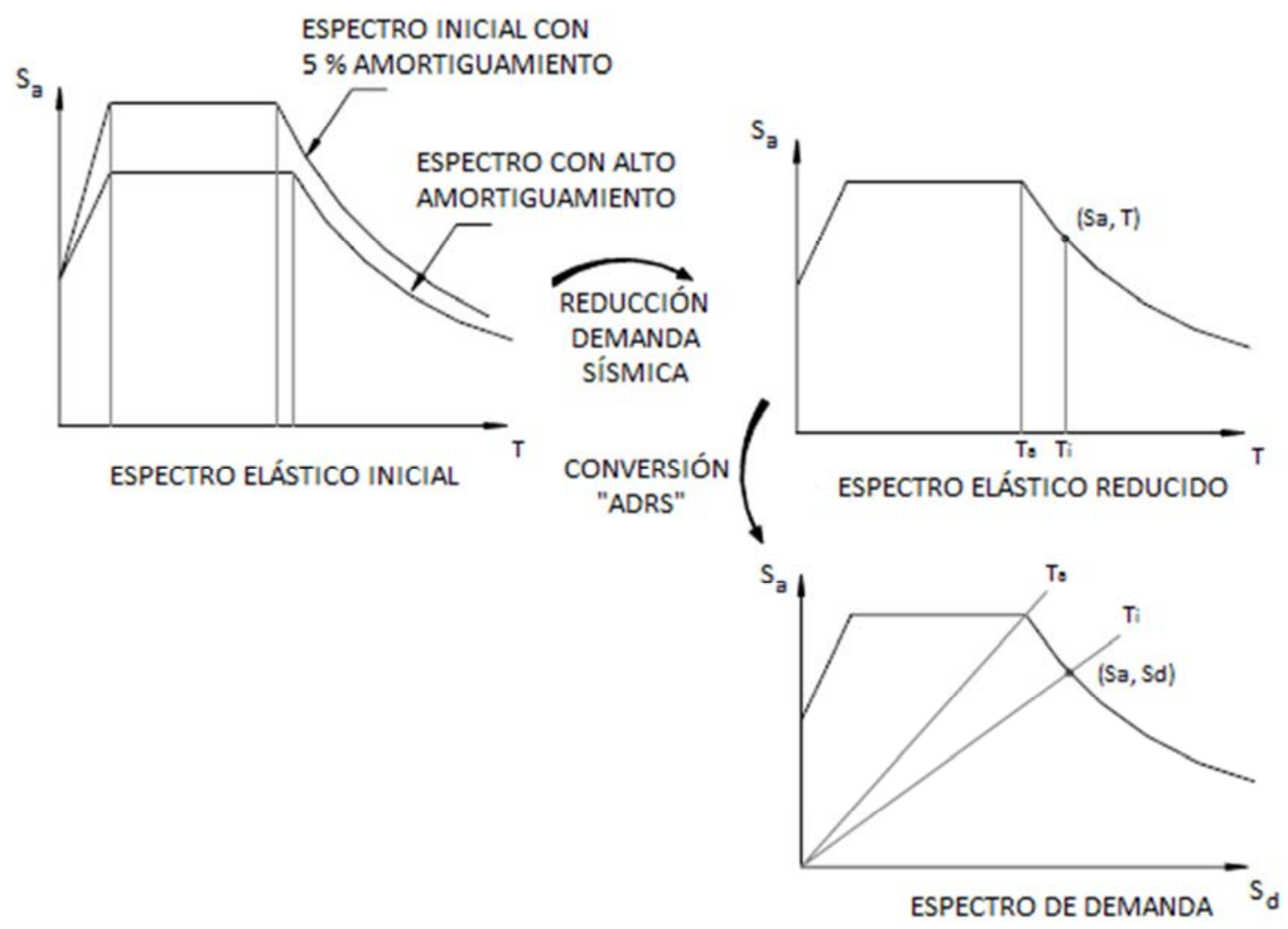

Figura 2.43. Procedimiento de obtención del espectro de demanda de una determinada estructura

(Safina, 2003).

De este modo, se puede identificar el desplazamiento máximo o punto de desempeño sísmico (Performance Point) para el cual se igualan la capacidad de la estructura con la demanda externa (Figura 2.44), permitiendo estimar así la respuesta máxima de la edificación y comparar este comportamiento con el nivel de desempeño o umbral de daño admisible previamente definido.

En la actualidad no existe una metodología unificada para la determinación del punto de desempeño sísmico de una cierta estructura (Bonett, 2003; Moreno, 2006). Aunque el procedimiento más utilizado es el denominado como CSM (Capacity Spectrum Method) o Método del Espectro de Capacidad (Freeman, 1990, 1998; ATC-40, 1996), se dispone de otras variantes metodológicas destacadas como el Método N2 (Fajfar \& Gaspersic, 1996; Fajfar, 2000; Kreslin \& Fajfar, 2012) o el Método del Coeficiente de Desplazamiento (FEMA 273, 1996). 


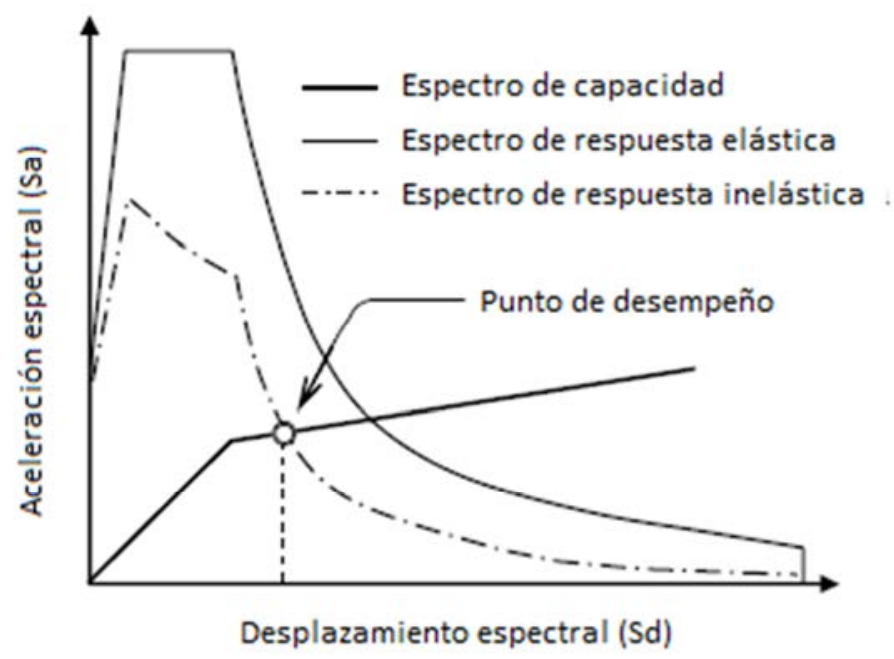

Figura 2.44. Esquema de obtención del punto de desempeño sísmico a partir de los espectros de demanda y capacidad de una determinada estructura (Pujades, Barbat \& Lantada, 2007).

Por tanto, estos métodos requieren de la caracterización de las variables intervinientes en la evaluación del riesgo sísmico del siguiente modo:

$\checkmark$ La vulnerabilidad sísmica de la estructura está representada mediante su respectiva curva y espectro de capacidad, caracterizada habitualmente según su representación bilineal simplificada.

$\checkmark$ La peligrosidad sísmica viene caracterizada por el correspondiente espectro de demanda del terremoto de diseño adoptado, ya sea elástico o en su formato reducido (inelástico), considerando la capacidad de disipación de energía de la estructura mediante su comportamiento dúctil según cualquiera de las diversas metodologías disponibles (Borzi et al., 2006; Vielma, 2008).

Una vez obtenido el punto de desempeño sísmico, se establecen una serie de requerimientos mínimos de comportamiento ante los diferentes grados de severidad sísmica, en función de los objetivos de daño admisibles para cada uno de los escenarios de diseño considerados. De este modo, se definen una serie de niveles de desempeño o umbrales de daño discretos que representan una condición límite o tolerable establecida en función de la amenaza sobre la seguridad de los ocupantes, los daños físicos y su reparabilidad, y la funcionalidad posterior al sismo (Moreno, 2006; Vielma, Barbat \& Oller, 2009).

A este respecto, destacan los niveles de desempeño definidos en los informes VISION 2000 (SEAOC, 1995) y ATC-40 (1996). Según se muestra en la Tabla 2.18, en función del terremoto de diseño considerado y la clasificación del edificio han de verificarse unos determinados niveles de comportamiento o desempeño sísmico.

De este modo, además del requerimiento de diseño habitual en la mayoría de códigos sísmico, correspondiente con el nivel de Seguridad asociada a un periodo de 475 años, se comprobarían otros tres niveles de respuesta de la estructura para daños tanto inferiores 
como superiores, permitiendo así un mayor control de su comportamiento sísmico para cada nivel de carga.

Tabla 2.18. Objetivos del desempeño sísmico recomendado por VISION 2000 según la clasificación del edificio (SEAOC, 1995).

\begin{tabular}{ccccc}
\hline $\begin{array}{c}\text { Movimiento sísmico de } \\
\text { diseño }\end{array}$ & $\begin{array}{c}\text { Notalmente } \\
\text { operacional de desempeño de la estructura }\end{array}$ & Operacional & Seguridad & $\begin{array}{c}\text { Próximo al } \\
\text { colapso }\end{array}$ \\
\hline Frecuente (43 años) & 1 & 0 & 0 & 0 \\
Ocasional (72 años) & 2 & 1 & 0 & 0 \\
Raro (475 años) & 3 & 2 & 1 & 0 \\
Muy raro (975 años) & - & 3 & 2 & 1 \\
\hline
\end{tabular}

0 = Desempeño inaceptable; 1 = Objetivo esperado para estructuras básicas; 2 = Objetivo para estructuras esenciales; 3 = Objetivo para estructuras de seguridad crítica.

En este sentido, el EC-8 (CEN, 2004) adopta en parte esta filosofía y establece sus propios requisitos de comportamiento aunque no sean denominados como niveles de desempeño, dejando a expensas de los correspondientes anejos nacionales la definición de cada uno de ellos:

$\checkmark$ Requisito de No Colapso, asociado a una acción sísmica con un periodo de retorno de 475 años, en función de los desplomes del nivel de cubierta.

$\checkmark$ Requisito de Limitación de Daños, asociado a una acción sísmica con un periodo de retorno de 95 años.

\subsubsection{Proyecto RISK-UE}

El proyecto europeo RISK-UE (Mouroux \& Le Brun, 2006), constituye una iniciativa financiada con fondos europeos con el fin implementar una propuesta avanzada sobre los escenarios de riesgo sísmico para su posible aplicación en distintas ciudades europeas.

El principal objetivo de RISK-UE es la definición de metodologías de análisis de riesgo sísmico que permitan incorporar las características de los edificios, del patrimonio cultural y de la organización social y funcional típicas de Europa, desarrollando una serie de procedimientos homogéneos y avanzados para el estudio de la peligrosidad, de la vulnerabilidad y del riesgo sísmico en áreas urbanas. En líneas generales, se establecieron dos procedimientos para la evaluación del riesgo sísmico en áreas urbanas: el primero, denominado como metodología LM1, basada en procedimientos empíricos; y el segundo, conocido como metodología LM2, en términos analíticos de espectros de demanda y capacidad (Mouroux \& Le Brun, 2006).

El proyecto se organizó mediante una estructura modular, comprendiendo los siguientes módulos de trabajo o workpackages (WP): 
$\checkmark$ WP01: Características distintivas europeas. Sistema de Información Geográfica (SIG), inventario, base de datos y tipologías de los edificios.

$\checkmark$ WP02: Evaluación de la peligrosidad sísmica, tanto a nivel regional como local.

$\checkmark$ WP03: Análisis de la Exposición del Sistema Urbano.

$\checkmark$ WP04: Evaluación de vulnerabilidad de los edificios actuales.

$\checkmark$ WP05: Estudio de vulnerabilidad de en edificios monumentales e históricos.

$\checkmark$ WP06: Estudio de vulnerabilidad de las líneas vitales y las estructuras esenciales.

$\checkmark$ WP07: Escenarios de riesgo sísmico.

Los módulos comprendidos entre el WP08 y WP14, se dedican a la aplicación de las metodologías propuestas a siete ciudades europeas: Barcelona (España), Bucarest (Rumania), Catania (Italia), Sofía (Bulgaria), Bitola (Yugoslavia), Thessaloniki (Grecia) y Niza (Francia).

\subsubsection{Metodología LM1}

En primer lugar, RISK-UE propone como método de nivel I o metodología LM1 un procedimiento para evaluar el riesgo sísmico en áreas urbanas bajo un enfoque empírico. La peligrosidad sísmica se define en términos de intensidad macrosísmica en la escala EMS-98 (Faccioli et al., 2003; Faccioli, 2006), mientras que la vulnerabilidad de las edificaciones es caracterizada mediante el Método del Índice de Vulnerabilidad (Giovinazzi \& Lagomarsino, 2002; Milutinovic \& Trendafiloski, 2003).

Para evaluar el nivel de daño sísmico medio $\mu_{D}$ de cada edificio, la metodología establece la función semiempírica de vulnerabilidad recogida en la ecuación (2.21) (Giovinazzi, Lagomarsino \& Pampanin, 2006). En Giovinazzi \& Lagomarsino (2002) y Milutinovic \& Trendafiloski (2003), se proponen funciones de vulnerabilidad para las diferentes tipologías edificatorias de la matriz BTM de RISK-UE (Figura 2.45).

$$
\mu_{\mathrm{D}}=2,5\left[1+\tanh \left(\frac{\mathrm{I}+6,25 \mathrm{I}_{\mathrm{V}}-13,1}{\mathrm{Q}}\right)\right]
$$

donde:

$$
\begin{aligned}
I_{v}= & \text { Índice de vulnerabilidad de la edificación. } \\
I= & \text { Tamaño del terremoto en términos de intensidad macrosísmica en la escala } \\
& \text { EMS-98. } \\
Q= & \text { Coeficiente de ductilidad. Lagomarsino \& Giovinazzi (2006) recomiendan } \\
& \text { adoptar un valor de 2,3 para la mayoría de las tipologías de la matriz BTM. }
\end{aligned}
$$

La metodología LM1 adopta los grados discretos de daño definidos en la escala EMS-98 (Tabla 2.6 y 2.19), definiendo cinco estados de daño además del nulo. 




Figura 2.45. Funciones de vulnerabilidad definidas por RISK-UE para distintas tipologías edificatorias (González, 2010).

M1.1, M3.1, M3.4, RC3.1, S1 = tipologías edificatorias recogidas en la matriz BTM (Tabla 2.12).

Tabla 2.19. Grados de daño en el método LM1 de RISK-UE, correspondientes a los definidos en la escala EMS-98 (Grünthal, 1998).

\begin{tabular}{cc}
\hline Grado de daño & Descripción \\
\hline 0-Nulo & Sin daño \\
1-Ligero & Daño insignificante a daño ligero \\
2-Moderado & Daño estructural ligero, daño no estructural moderado \\
3-Susbstancial a fuerte & Daño estructural moderado, daño no estructural fuerte \\
4- Muy fuerte & Daño estructural fuerte, daño no estructural muy fuerte \\
5-Destrucción & Daño estructural muy fuerte, colapso total o cercal del colapso total \\
\hline
\end{tabular}

Una vez estimado el grado de daño medio $\mu_{D}$ de la edificación, la metodología propone estimar la distribución de probabilidad de daño suponiendo que esta sigue una función tipo beta, más versátil que la binomial adoptada en los estados de daño de la escala EMS-98 (Pujades, Barbat \& Lantada, 2007), y cuya función de densidad de daño viene dada por la ecuación (2.13):

$$
\mathrm{p}_{\beta}(\mathrm{x})=\frac{\Gamma(t)}{\Gamma(q)-\Gamma(t-q)} \frac{(x-a)^{q-1}(b-x)^{t-q-1}}{(b-a)^{t-1}} \quad a \leq x \leq b
$$

donde:

$p_{\beta}(x)=$ función de densidad de daño.

$\Gamma(x)$ = función gamma. 
$(a, b)=$ coeficientes relacionados con la definición de la distribución de probabilidad de daño y, por lo tanto, con el número de estados de daño.

$(t, q)$ = parámetros de modulación de la distribución de probabilidad de daño.

Por último, la probabilidad de que se dé cierto nivel de daño $x$ viene por la ecuación (2.23):

$$
P_{\beta}(x)=\int_{a}^{x} p_{\beta}(x) d x
$$

donde:

$P_{\beta}(x)=$ función de probabilidad de un cierto daño $x$ en la edificación.

De este modo, la operación de convolución expresada en la ecuación (2.12) para la evaluación del riesgo sísmico en áreas urbanas se reduciría en la metodología LM1 de RISK-UE al siguiente procedimiento.

$\checkmark$ Asignación de cada edificación a una de las tipologías recogidas en la matriz BTM.

$\checkmark$ Obtención del correspondiente índice de vulnerabilidad según el Método del Índice de Vulnerabilidad.

$\checkmark$ Evaluación de la peligrosidad sísmica del emplazamiento, a escala regional y local, en términos de intensidad macrosísmica en la escala EMS-98.

$\checkmark$ Determinación del grado de daño medio de cada edificio y de la distribución de cada uno estados de daño definidos.

Recientemente, se ha propuesto una variante de esta metodología LM1 la cual persigue dotar de un mayor enfoque probabilista al procedimiento de evaluación establecido por RISK-UE (Aguilar et al., 2010; Aguilar, 2011).

\subsubsection{Metodología LM2}

Por otra parte, RISK-UE establece el método de nivel II o metodología LM2 para la evaluación del riesgo sísmico en mediante un enfoque mecánico o analítico, denominado también como Método del espectro de capacidad al tener como referencia principal los procedimientos establecidos en Freeman (1990, 1998), ATC-40 (1996) o HAZUS (1999), descritos en el apartado 2.3.2.

La peligrosidad sísmica del emplazamiento se expresa, por tanto, en términos de su espectro de respuesta lineal con un amortiguamiento tipo del $5 \%$ y su espectro de demanda equivalente, mientras que la vulnerabilidad sísmica de las edificaciones viene definida mediante los correspondientes espectros de capacidad (Lagomarsino \& Penna, 2003; Barbat, Pujades \& Lantada, 2008). El comportamiento de la edificación se evalúa mediante la obtención del punto de desempeño como intersección entre los espectros de demanda y capacidad de la estructura, según la filosofía de diseño por prestaciones (Figura 2.44). 
La metodología establece una serie de umbrales de daño de la estructura en función de la ubicación de dichos puntos de control en el espectro de capacidad (Figura 2.46) definidos mediante las relaciones descritas en la Tabla 2.20. A partir del desplazamiento espectral del punto de desempeño obtenido, se pueden obtener las probabilidades condicionales de superar cada uno de los estados de daño definidos, mediante la correspondiente curva de fragilidad de la tipología estructural a la que pertenezca el edificio.



Figura 2.46. Representación en el espectro de capacidad de los distintos estados de daño definidos en la metodología LM2 (Lantada, Pujades \& Barbat, 2009).

Tabla 2.20. Umbrales de los estados de daño definidos en la metodología LM2 de RISK-UE en función de los puntos de cedencia y de capacidad última de un espectro de capacidad (Lantada, Pujades \& Barbat, 2009).

\begin{tabular}{cc}
\hline Grado de daño & Umbral del estado de daño \\
\hline 1. Ligero & $\overline{S d_{1}}=0,70 S d_{y}$ \\
2. Moderado & $\overline{S d_{2}}=S d_{y}$ \\
3. Extensivo & $\overline{S d_{3}}=S d_{y}+0,25\left(S d_{u}-S d_{y}\right)$ \\
4. Colapso & $\overline{S d_{4}}=S d_{u}$ \\
\hline
\end{tabular}

$\overline{S d_{\imath}}=$ valor medio o umbral de cada estado de daño; $S d_{y}, S u_{y}=$ desplazamientos espectrales correspondientes con los puntos de cedencia y capacidad última de la estructura, respectivamente (Figura 2.40)

Para el caso de la metodología LM2, la operación de convolución expresada en la ecuación (2.10) quedaría simplificada según el siguiente procedimiento:

$\checkmark \quad$ Evaluación de la peligrosidad sísmica mediante la obtención del espectro de respuesta elástico del terremoto de diseño considerado. 
$\checkmark$ Selección del modelo de edificio en la matriz de tipologías edificatorias de RISK-UE o determinación directa de la curva y el espectro de capacidad de la estructura.

$\checkmark$ Intersección entre los espectros de demanda y capacidad de la estructura para obtener el punto de desempeño sísmico.

$\checkmark$ Estimación de la distribución de cada uno estados de daño definidos a partir de las curvas de fragilidad de la tipología considerada.

La matriz de probabilidad de daño de cada edificio puede ser obtenida directamente a partir la respectiva curva de fragilidad, en función del desplazamiento espectral $S_{d}$ del punto de desempeño sísmico. La intersección de este desplazamiento con los distintos umbrales de daño permite determinar las probabilidades de ocurrencia de cada uno de los estados de daño establecidos (Figura 2.47).

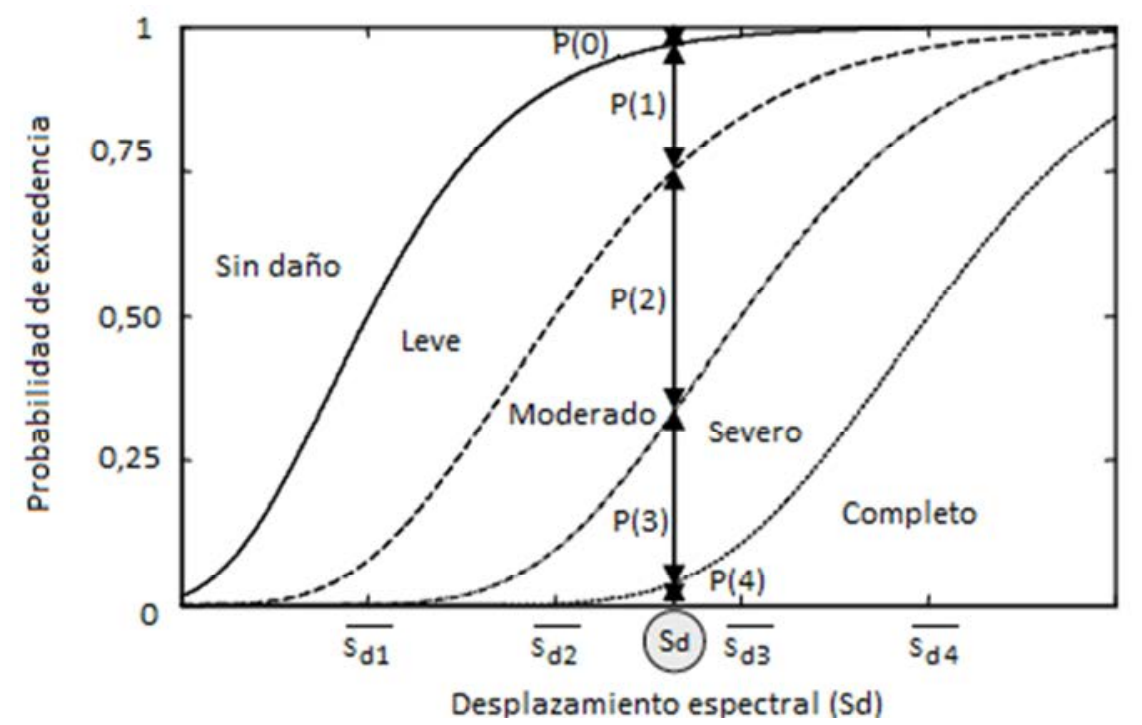

Figura 2.47. Curva de fragilidad de una estructura. Obtención de la probabilidad de daño de cada estado de daño para un desplazamiento espectral $S_{d}$ (Aguilar, 2011).

$\overline{S d_{l}}=$ valor medio o umbral de cada estado de daño; $P(i)=$ probabilidad de ocurrencia del estado de daño $i$.

Por último, mediante la expresión (2.24) se define un parámetro de daño medio $D S_{m}$ con el fin de poder comparar los resultados obtenidos con esta metodología con el grado de daño medio $\mu_{D}$ propuesto en el método LM1 (Lantada, Pujades \& Barbat, 2009). En la Tabla 2.7 se mostraba la comparación entre los estados de daño definidos en ambas metodologías.

$$
\mathrm{DS}_{\mathrm{m}}=\sum_{\mathrm{i}=0}^{4} \mathrm{DS}_{\mathrm{i}} \mathrm{P}\left[\mathrm{DS} \mathrm{i}_{\mathrm{i}}\right]
$$

donde:

$$
i \text { = número correspondiente al estado de daño } D S_{i} \text {. }
$$

$P\left[D S_{1}\right]=$ probabilidad de ocurrencia del estado de daño $i$. 


\subsubsection{Estudios sobre riesgo sísmico en áreas urbanas en la península lbérica}

Entre los diversos estudios de evaluación del riesgo sísmico en entornos urbanos realizados en la península Ibérica, se pueden destacar los siguientes:

\section{Estudios independientes de RISK-UE}

En primer lugar, fueron obtenidas funciones de vulnerabilidad observada en edificios de mampostería no reforzada a partir de los datos registrados en los terremotos de Adra (Almería) en 1993 (Barbat, Yépez \& Canas, 1996) y Mula (Murcia) en 1999 (Mena et al., 1999; Mena, 2002), siguiendo para ello el método italiano junto con el procedimiento propuesto en Italia por Braga et al. (1986) y Angeletti et al. (1988) (Figura 2.48).

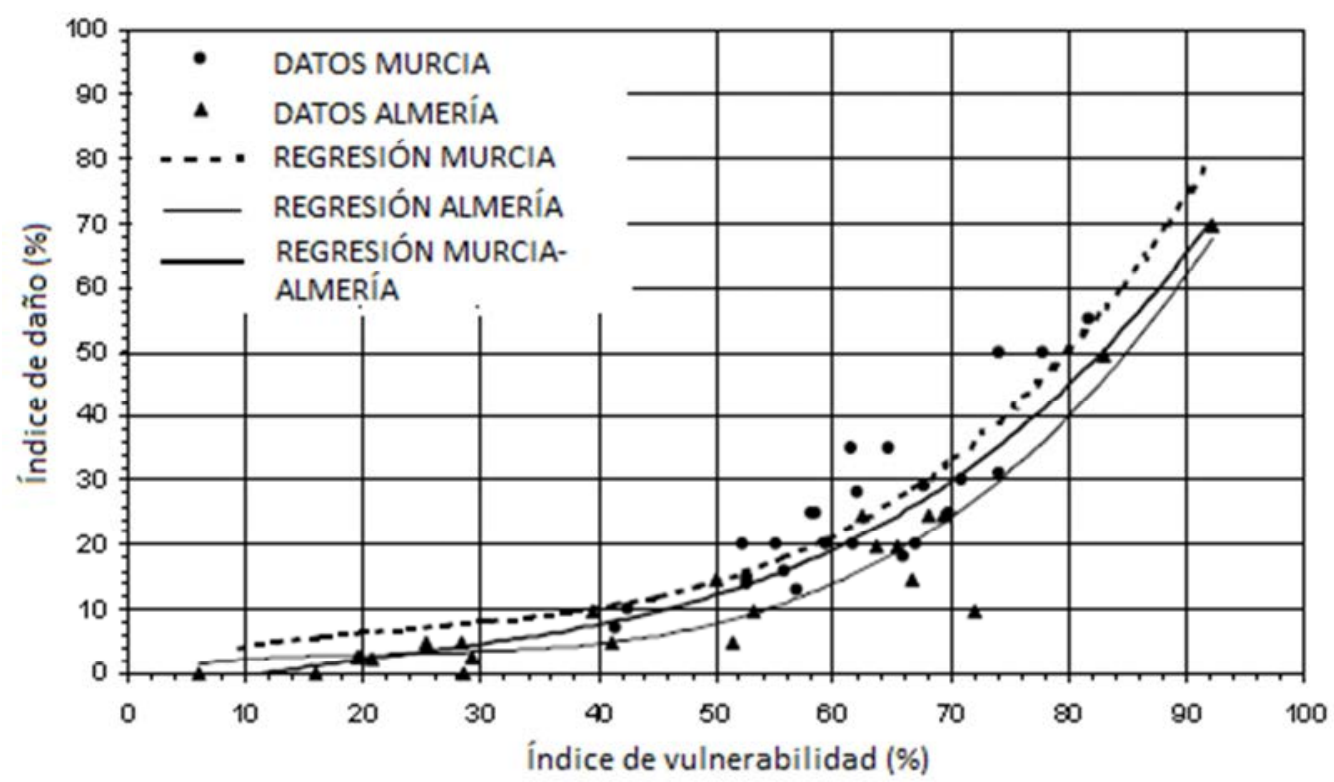

Figura 2.48. Comparación de las funciones de vulnerabilidad observada en edificios de mampostería no reforzada propuestas por Barbat (1998) para el sismo de Adra (Almería) y Mena (2002) para el sismo de Mula (Murcia), para una intensidad VII en la escala MSK (Mena, 2002).

Con objeto de generalizar estas expresiones para otras tipologías y niveles de peligrosidad, se desarrollaron técnicas de simulación numérica para obtener funciones de vulnerabilidad calculada, aplicadas principalmente a la ciudad de Barcelona (Yépez, 1996; Barbat, 1998; Mena, 2002; Barbat \& Pujades, 2004).

La revisión del método italiano de Benedetti \& Petrini (1984) adoptada en el proyecto SERGISAI (Cella et al., 1998) incorpora funciones de vulnerabilidad observada en términos de aceleración del terreno, obtenidas a partir de relaciones de transformación intensidadaceleración desarrolladas específicamente para cada país.

Recientemente, CARM (2014) compara las funciones de vulnerabilidad propuestas por Barbat, Yépez \& Canas (1996), Barbat (1998) y Mena (2002) con las funciones de vulnerabilidad observada obtenidas de los daños en edificaciones del sismo de Lorca de 2011 para intensidades VII y VIII en la escala MCS (Figura 2.49), y Serrano-Lanzarote \& Temes-Córdovez 
(2015) emplean el método italiano para la evaluación de la vulnerabilidad y riesgo sísmico del parque inmobiliario residencial en la Comunidad Valenciana.

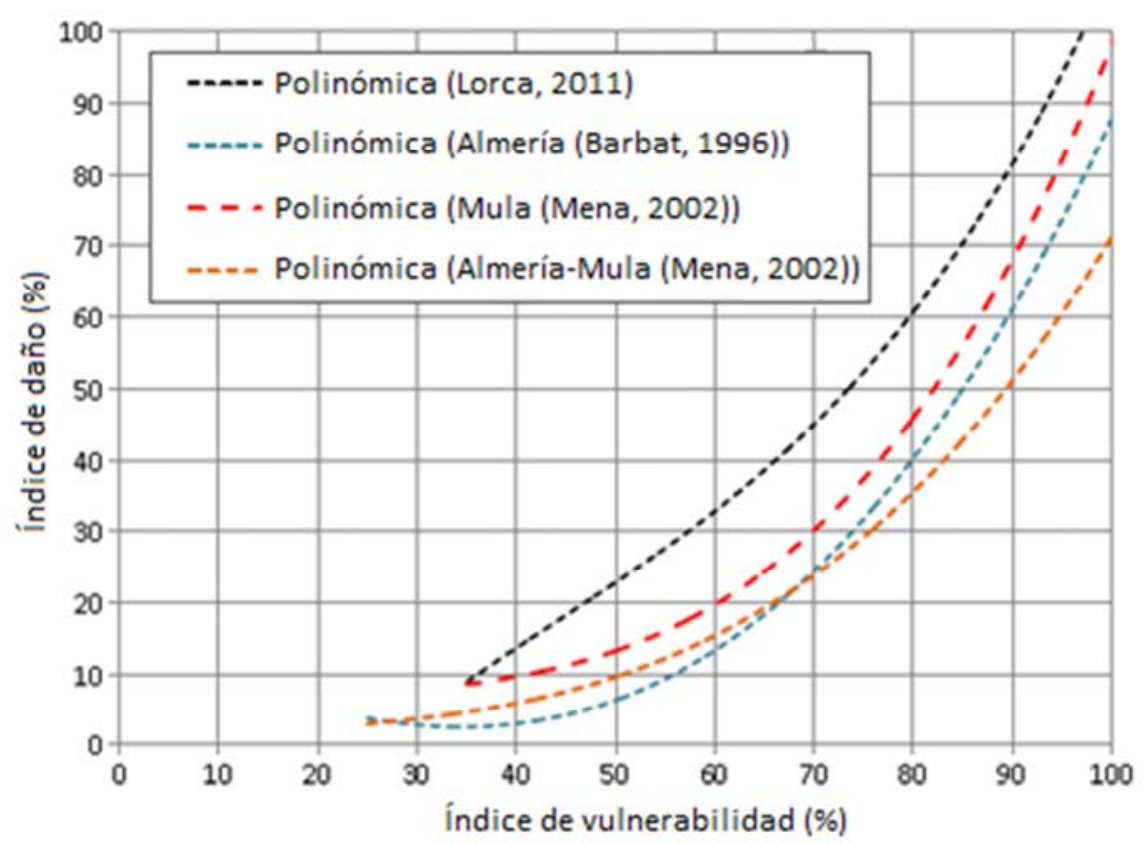

Figura 2.49. Comparación de la función de vulnerabilidad observada en edificios de hormigón armado obtenida tras el sismo de Lorca de 2011 y las funciones de vulnerabilidad calculada propuestas en Barbat (1998) y Mena (2002), para una intensidad VII en la escala MCS (CARM, 2014).

Otros estudios (Bonett 2003; Moreno; 2006) aplican el Método del espectro de capacidad a la trama urbana de Barcelona, obteniendo matrices de probabilidad de daño y curvas de fragilidad para las principales tipologías constructivas de esta ciudad.

\section{Estudios desarrollados en el marco de RISK-UE}

Lantada (2007) aplica y revisa las metodologías LM1 y LM2 en la evaluación del riesgo sísmico a la ciudad de Barcelona mediante la utilización de técnicas SIG, apoyándose para ello en las funciones de vulnerabilidad definidas por Giovinazzi \& Lagomarsino (2002) dentro de RISK-UE, y en los espectros de capacidad propuestos por Bonett (2003) y Moreno (2006) para las principales tipologías estructurales de la ciudad. Asimismo, extiende el análisis sísmico a la evaluación de los daños sufridos en la población, como número de fallecidos o personas sin hogar, así como a los daños económicos esperables, a partir de las propuestas del ATC-13 (1985) y el módulo WP07 de RISK-UE (Vacareanu et al., 2004).

Este estudio tuvo continuidad en una serie de trabajos enfocados también a la evaluación del riesgo sísmico en la ciudad de Barcelona (Pujades, Barbat \& Lantada, 2007; Barbat et al., 2008; Lantada, Pujades \& Barbat, 2009; Moreno et al., 2009; Lantada et al., 2010; Bermúdez, 2010; Vielma; Barbat \& Oller, 2010; Barbat et al., 2010; Irizarry et al., 2011), expresando los resultados en términos de curvas de fragilidad y matrices de probabilidad de daño de las tipologías edificatorias consideradas (Figuras 2.50 y 2.51). 

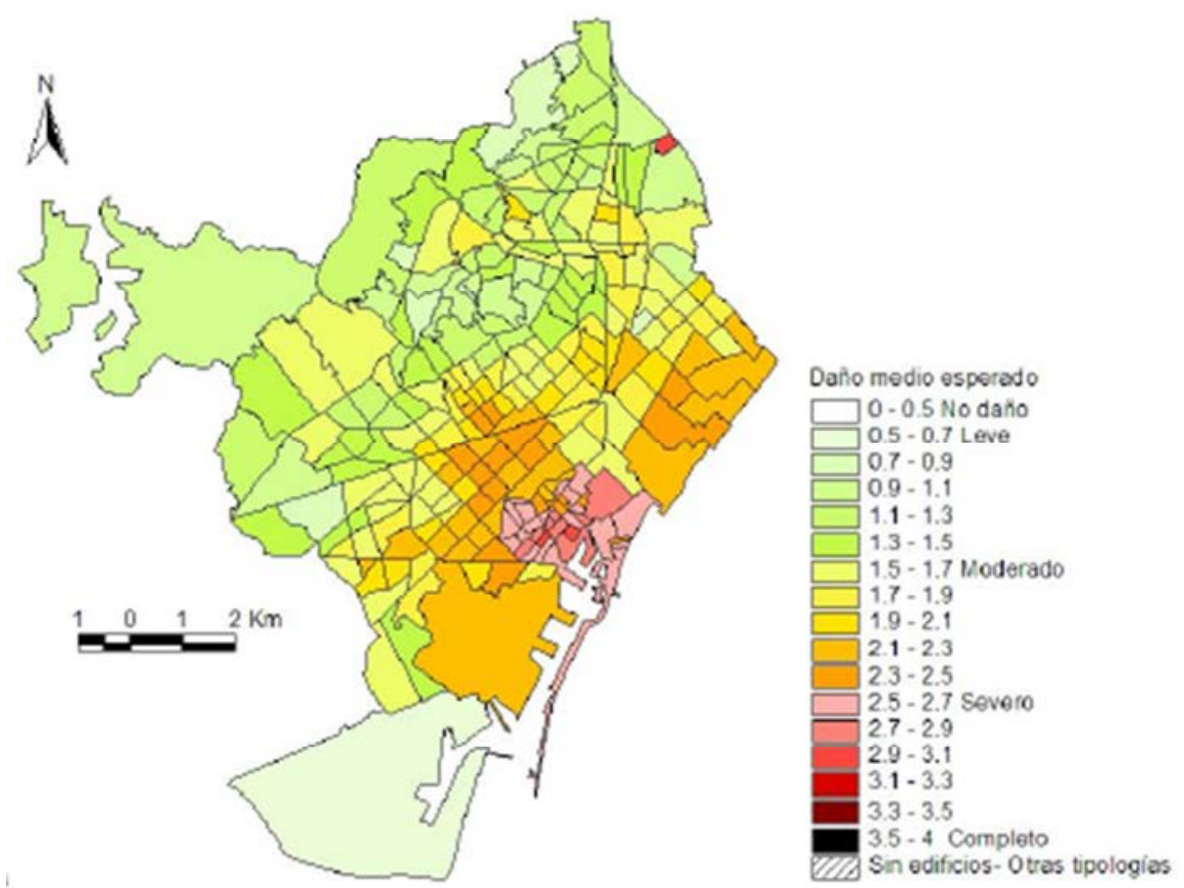

Figura 2.50. Daño medio estimado por zonas censales para la ciudad de Barcelona según la metodología LM1 de RISK-UE y un sismo de intensidad VI-VII en la escala MSK (Pujades, Lantada \& Barbat, 2007).

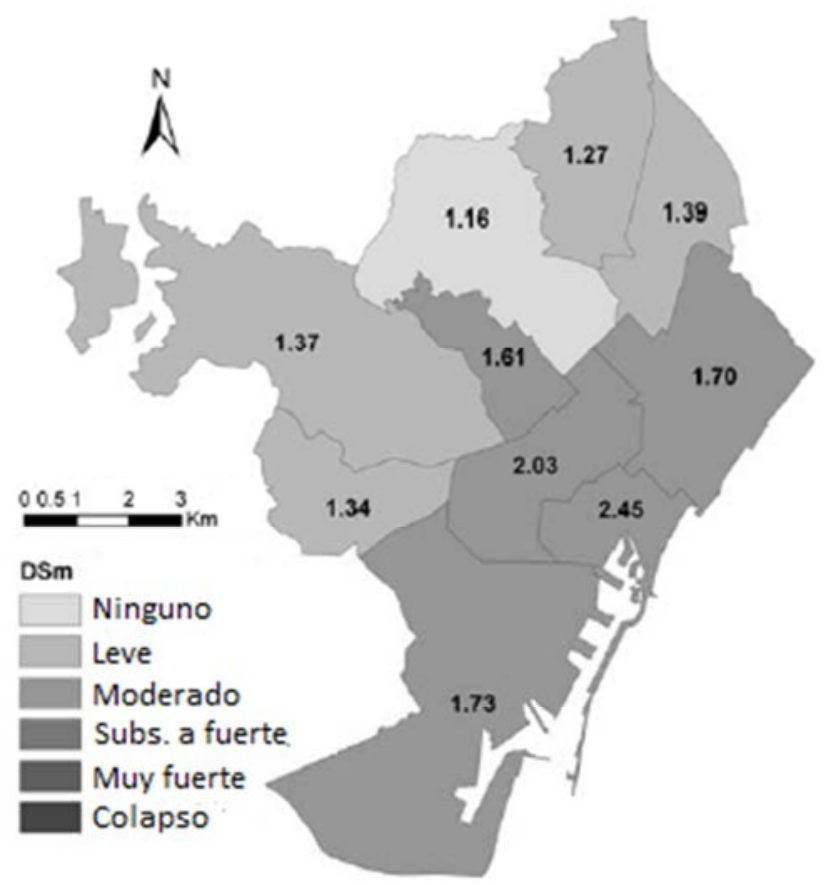

Figura 2.51. Daño medio estimado por zonas censales para la ciudad de Barcelona según la metodología LM2 de RISK-UE y un sismo de intensidad VI-VII en la escala ESM-98 (Lantada et al., 2010). $D S_{m}=$ parámetro de daño medio definido en ecuación (2.24)

Otros trabajos analizan el comportamiento sísmico de los edificios monumentales de esta ciudad según la variante de RISK-UE para este tipo de edificaciones (Irizarry, 2004; Roca et al., 
2006; Lantada et al., 2010), así como el de edificaciones de carácter especial como escuelas y hospitales (Safina, 2003; García-García, 2010; Valcárcel, 2013).

Cardona et al. (2012) implementan, mediante la aplicación ERN-CAPRA, funciones de vulnerabilidad en términos de aceleración espectral para las tipologías de la matriz BTM más habituales en Barcelona (Figura 2.52). Por último, en estudios como los de Aguilar (2011) o Barbat et al. (2012) se profundiza en el enfoque probabilista de la metodología RISK-UE, estimando el riesgo sísmico en términos de frecuencias anuales de excedencia de los diferentes estados de daño.

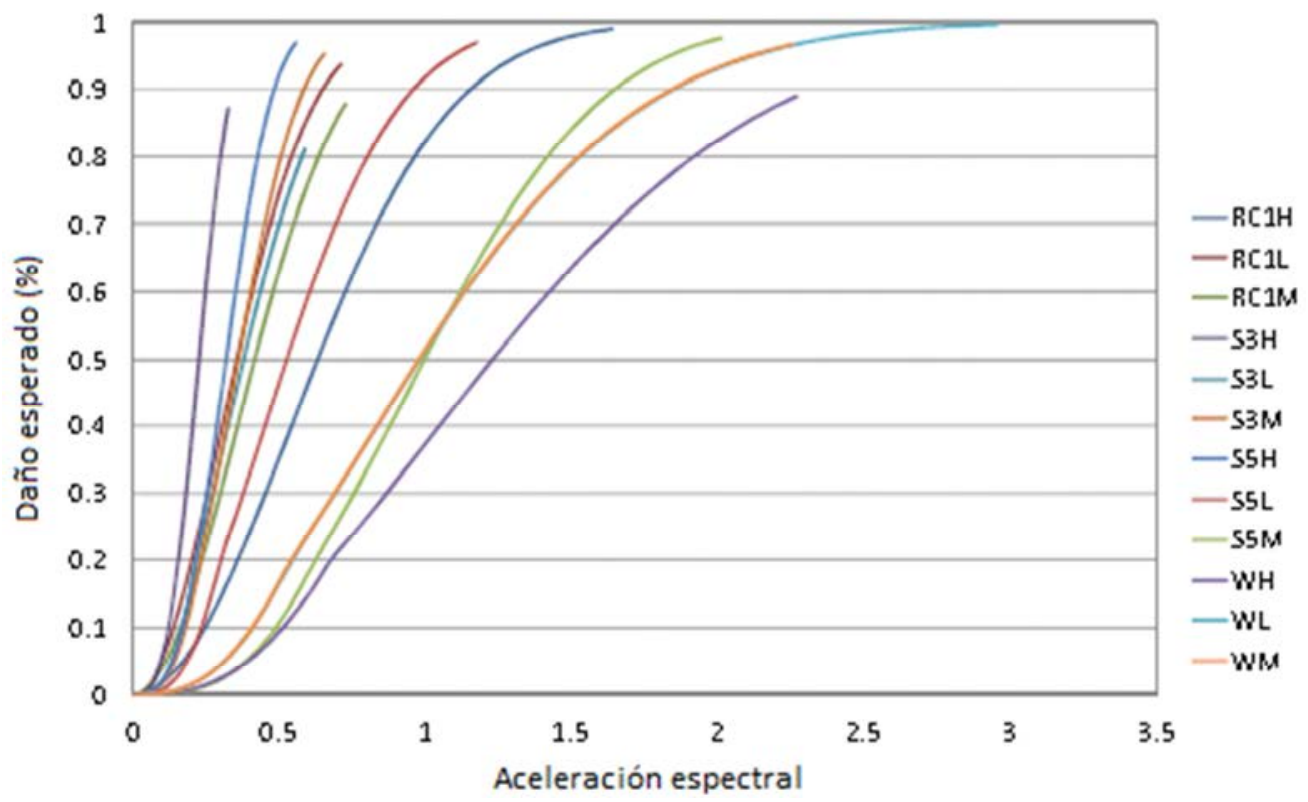

Figura 2.52. Funciones de vulnerabilidad calculada para edificaciones de hormigón armado, acero y madera (Cardona et al., 2012).

$\mathrm{RC1}, \mathrm{S}, \mathrm{W}=$ tipologías edificatorias recogidas en la matriz BTM (Tabla 2.12); H, L, M = clasificación en función de la altura de la edifición (high, low, medium).

De forma independiente, se dispone de las aplicaciones de RISK-UE realizadas por Vicente et al. (2008), en el Sureste de Portugal; Goded (2010), en la ciudad de Málaga; Feriche et al., (2009), en la provincia de Almería; González (2010), en Andorra; Basset \& Guardiola (2011), en la Comunidad Valenciana; o Feriche (2012) en la ciudad de Granada.

En lo relativo a la Región de Murcia, además de los proyectos RISMUR (Benito et al., 2006; Benito et al., 2015) y SISMIMUR $(2006,2015)$, destacan los recientes estudios realizados en la ciudad de Lorca a raíz del terremoto de 2011 (Feriche et al., 2012a; Martínez-Cuevas; 2014; CARM; 2014; Rivas-Medina et al., 2014, Salgado-Gálvez et al., 2015; Martínez-Cuevas \& Gaspar-Escribano, 2016). En las Figuras 2.53 y 2.54 se muestran sendos ejemplos de estos trabajos realizados recientemente en la Región de Murcia. 


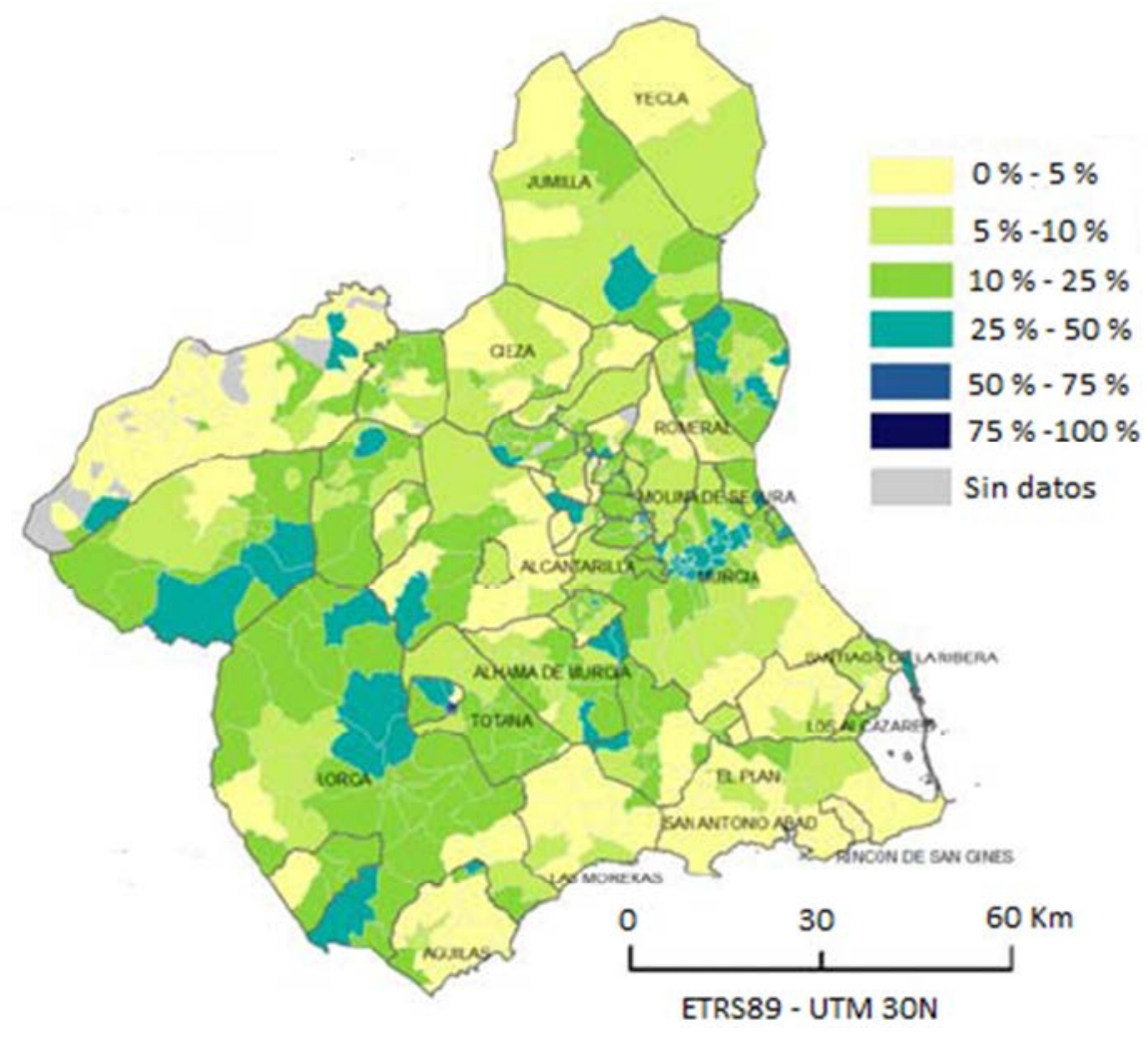

Figura 2.53. Distribución de la probabilidad de que edificaciones presenten un grado de daño de colapso según la metodología LM2 de RISK-UE en los municipios de la Región de Murcia, para el sismo de 475 años de periodo de retorno (Benito et al., 2015).

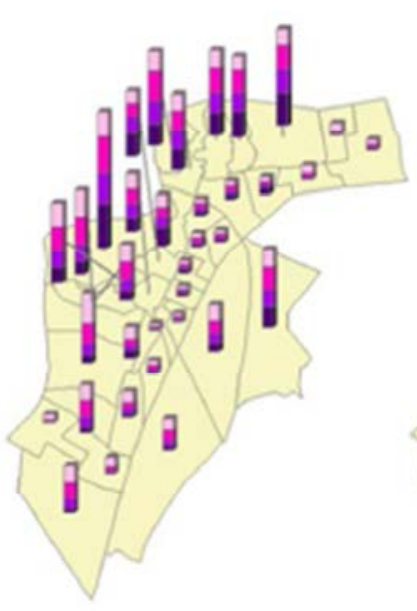

(a)

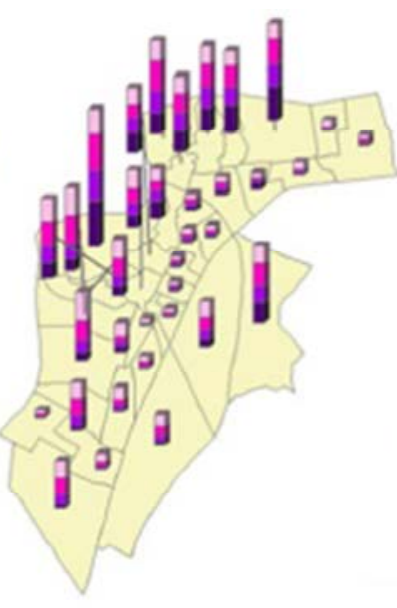

(b)

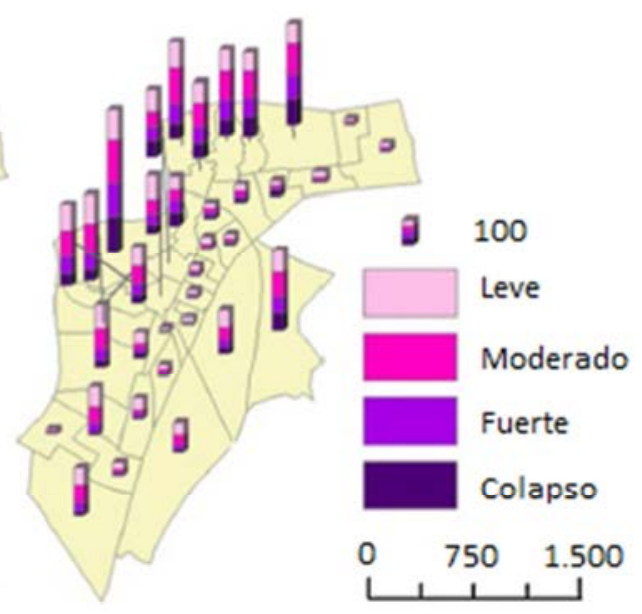

(c)

Figura 2.54. Daño medio estimado en los distritos de la ciudad de Lorca según la metodología LM2 de RISK-UE y un sismo de $M_{w}=5,2$, a partir de los modelos NGA de atenuación de: (a) Chiou \& Youngs (2008). (b) Abrahamson \& Silva (2008). (c) Campbell \& Bozorgnia (2008), citados en el apartado 2.1.1.2 (Rivas-Medina et al., 2014). 


\subsubsection{Mitigación del riesgo sísmico}

\subsubsection{Generalidades}

Por mitigación del riesgo sísmico se puede definir al conjunto de acciones de carácter preventivo, antes de la ocurrencia del terremoto, destinadas a disminuir su impacto sobre las edificaciones, líneas y sistemas vitales, y la población, reduciendo así las pérdidas económicas asociadas al evento sísmico.

Considerando la definición de riesgo sísmico planteada en las ecuaciones (2.12) y (2.13), las medidas destinadas a esta mitigación los efectos de los posibles terremotos sobre una cierta área urbana han de estar enfocadas a disminuir una de las siguientes variables: la peligrosidad sísmica $H$, la vulnerabilidad $V$ o el coste de los elementos expuestos $E$.

$\checkmark$ Reducción de la peligrosidad sísmica. Evidentemente, los niveles de peligrosidad a los que se encuentra expuesta una determinada área urbana son invariables al ser un factor característico del emplazamiento en cuestión. No obstante, la consideración de los efectos locales del terreno posibilita la identificación de suelos blandos o de determinadas topografías del terreno con mayor capacidad de amplificación de la señal sísmica. Asimismo, otros efectos indirectos tales como licuefacciones o deslizamientos del terreno en gran medida pueden ser evitados mediante un adecuado planeamiento urbanístico.

$\checkmark$ Reducción la vulnerabilidad. A partir de un correcto diseño sismorresistente y posterior ejecución de las estructuras se puede mejorar su comportamiento sísmico intrínseco frente a este tipo de acciones. Esta es la variable del riesgo sísmico sobre la cual se puede actuar de un modo más directo. En este sentido, es necesario diferenciar entre aquellas edificaciones de nueva planta, todavía en fase de proyecto, en las cuales no existen a priori factores limitantes que condicionen el planteamiento general, y aquellas edificaciones ya existentes en la cual las acciones destinadas a disminuir su vulnerabilidad han de poderse adaptar a las características y disposiciones constructivas existentes, siendo esta la casuística más común al ser las que se encuentran en mayor número dentro de las áreas urbanas.

$\checkmark$ Reducción de los elementos expuestos. Con el desarrollo de las grandes áreas urbanas desde finales del pasado s. XX y el crecimiento de los bienes muebles e inmuebles en su interior, esta variable no sólo es muy difícil de reducir si no que su valor se verá progresivamente incrementando con el transcurso de los años y los avances tecnológicos.

\subsubsection{Recomendaciones para el diseño sismorresistente}

El diseño de una estructura es un proceso complejo en el que, partiendo de una serie de condicionantes como su función estructural, el proceso constructivo, el coste y la estética, se consigue una descripción completa de las características de todos sus componentes. Los 
razonamientos y toma de decisiones referentes a estos aspectos están condicionados a la obtención de una solución de diseño viable desde el punto de vista económico.

Con objeto de reducir la vulnerabilidad sísmica de las edificaciones de hormigón armado en áreas urbanas, se identifican cuatro vías destinadas a la mejora y optimización de su diseño sismorresistente (Barbat, 1998, 2011; CARM, 2014).

\section{ELECCIÓN DEL TIPO DE SISTEMA ESTRUCTURAL}

Los objetivos del diseño sismorresistente de edificios se alcanzan utilizando sistemas estructurales que proporcionen una adecuada disipación de energía, evitando de esta manera los fallos frágiles. Refinar los detalles de cálculo y diseño en un edificio no resulta efectivo si éste no presenta una tipología estructural correctamente concebida.

En esta línea, el principal aspecto a considerar en el diseño sismorresistente de los edificios es el empleo de aquellos sistemas estructurales que proporcionen una mayor ductilidad, de tal modo que el mecanismo de colapso disponga de previo aviso y que constituya asimismo una reserva de resistencia como margen de seguridad ante terremotos mayores que el de proyecto.

Para conseguir un adecuado nivel de ductilidad estructural en un edificio emplazado en una zona sísmica, es necesario el empleo de sistemas estructurales que cumplan los siguientes requisitos:

$\checkmark$ Permitir un comportamiento inelástico global de la estructura, más allá de su límite elástico, sin pérdida significativa de resistencia.

$\checkmark$ Predefinir las zonas donde se concentrar las deformaciones inelásticas, es decir, las rótulas plásticas.

$\checkmark$ Incrementar la resistencia estructural de aquellas zonas de la estructura que deban permanecer en rango elástico, mediante un adecuado confinamiento de las secciones.

Entre los sistemas estructurales más utilizados en los edificios de nuevo diseño proyectados en zonas sísmicas, se pueden destacar los siguientes:

$\checkmark$ Edificios porticados. Los pórticos son estructuras planas o espaciales, constituidas por vigas y pilares unidos entre sí en nudos, de manera que se asegure una correcta transmisión de esfuerzos y se cuente con una adecuada rigidez lateral (Figura 2.55a).

$\checkmark$ Edificios apantallados. La resistencia a cargas horizontales de estos edificios viene proporcionada por pantallas de hormigón armado. Esta disposición suele resultar necesaria en el caso de edificios de más de tres plantas situados en zonas de sismicidad alta. Estos elementos presentan una rigidez muy elevada respecto a los pilares, por lo que soportan la mayor parte de las cargas horizontales inducidas por la acción sísmica (Figura 2.55b). 
$\checkmark$ Edificios con núcleo. Los núcleos son elementos destinados a contener, principalmente, ascensores y escaleras en una edificación. Adicionalmente, desempeñan una función estructural, utilizándose ampliamente en el diseño sismorresistente para reducir los desplazamientos laterales del edificio (Figura 2.55c).

$\checkmark$ Edificios con sistemas duales. Cuando la resistencia lateral y la rigidez de un entramado de pórticos son insuficientes frente a acciones sísmicas, especialmente para el caso de edificios altos, puede ser conveniente combinar diferentes tipologías estructurales. Los pórticos de hormigón armado pueden complementarse mediante la disposición de muros de cortante. De este modo, ambos sistemas estructurales interaccionan para proporcionar la resistencia lateral necesaria. La utilización de ambos sistemas reduce el desplazamiento horizontal de las diferentes plantas, aspecto que ayuda a proteger también los componentes no estructurales del edificio (Figura $2.55 d)$.

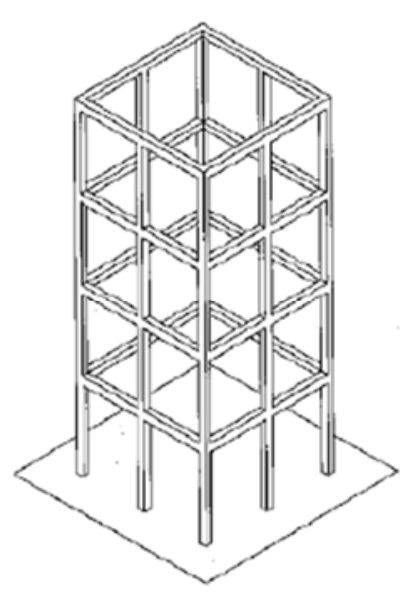

(a)

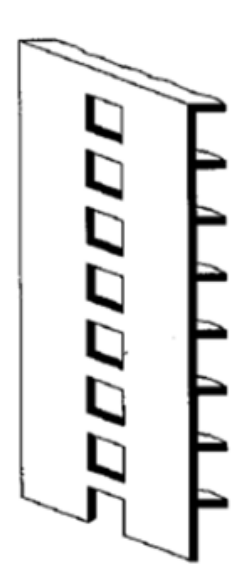

(b)

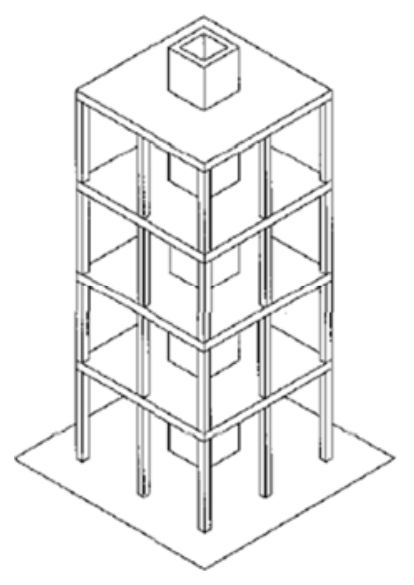

(c)

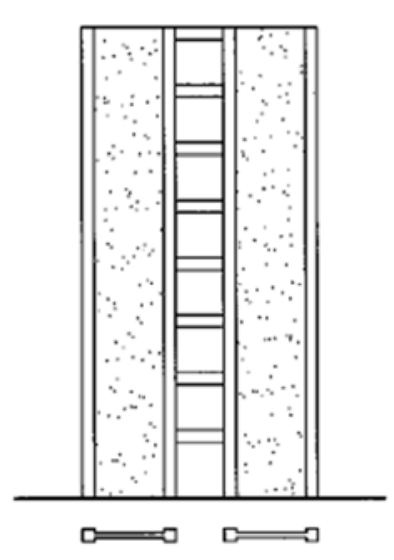

(d)

Figura 2.55. Tipos de sistemas estructurales recomendables en diseño sísmico: (a) Edificio porticado. (b) Edificio apantallado. (c) Edificio con núcleo. (d) Sistemas duales (Barbat, 1998).

\section{ELECCIÓN DE LOS MATERIALES DE CONSTRUCCIÓN}

Resulta necesario el empleo de materiales de construcción de suficiente calidad, tales como hormigones y aceros. A pesar de que el hormigón armado ha sustituido a la mampostería no reforzada como compuesto más empleado para la construcción de edificaciones, su mera utilización no garantiza un comportamiento sísmico satisfactorio de los edificios. Es necesario que estos materiales se dispongan correctamente, asegurando una adecuada resistencia y ductilidad.

Un ejemplo de esta consideración lo constituyen las edificaciones de ductilidad limitada, formadas por entramados de vigas planas o forjados reticulares. En este tipo de estructuras, la falta de vigas y nudos imposibilita una adecuada eficacia del confinamiento de las secciones en el forjado, al ser elementos de menor canto. Su comportamiento será adecuado siempre que la estructura se mantenga dentro de su rango elástico (Vielma, 2008). 


\section{EVITAR DEFICIENCIAS O FALLOS DE DISEÑO}

Una vez seleccionada la tipología estructural adecuada, se identifican una serie de disposiciones o reglas de carácter básico las cuales son requisito necesario para un correcto comportamiento sísmico de las edificaciones:

$\checkmark$ Resistencia lateral. Aunque la fuerza horizontal pueda ser absorbida por los mecanismos resistentes adecuados para tal fin como pantallas de hormigón o arriostramientos, es necesario asegurar un correcto efecto de atado de zapatas así como una rigidez suficiente de los forjados en su plano (efecto diafragma), de tal modo que la estructura tienda a comportarse como un único sólido.

$\checkmark$ Redundancia estructural. Es indispensable establecer una adecuada redundancia estructural, con el fin de que los elementos estructurales sean capaces de proporcionar mecanismos alternativos para transmitir las cargas laterales inducidas por un sismo. El grado de hiperestaticidad de la estructura ha de ser lo más elevado posible.

$\checkmark$ Simétrica mecánica en planta. Relativa principalmente a simetría de rigideces, no tanto a simetría geométrica, para evitar así posibles efectos de torsión como consecuencia de la excentricidad entre el centro de masas del sistema y el centro de rigidez. Asimismo, disposiciones de arriostramientos irregularmente distribuidas por la estructura puede generar también asimetrías mecánicas accidentales. Ante la falta de simetría, una solución comúnmente empleada consiste en dividir el edificio en sistemas independientes desde el punto de vista dinámico mediante la construcción de juntas sísmicas, las cuales han de estar suficientemente dimensionadas.

$\checkmark$ Regularidad en alzado. Retranqueos bruscos en altura, generan concentraciones de tensiones y, por ende, de daños en estas zonas de la estructura.

$\checkmark$ Configuraciones urbanísticas regulares. Disposiciones constructivas tales como pilares cortos, pilares cautivos, plantas blandas, o el efecto golpeteo por separación insuficiente en las medianeras entre edificios o ausencia de juntas sísmicas (especialmente si los respectivos forjados se encuentran a distinto nivel), se ha constatado que influyen negativamente en el comportamiento sísmico de las edificaciones.

$\checkmark$ Ligereza. La ecuación del movimiento determina como una mayor masa contribuye a que se movilice una mayor aceleración al sistema, especialmente si esta se encuentra en altura.

$\checkmark$ Disposición incorrecta de elementos no estructurales. Elementos como tabiquerías o cerramientos, habitualmente no considerados en el cálculo sismorresistente de la estructura, pueden ocasionar efectos negativos y generar daños no previstos. Los elementos no estructurales pueden, fundamentalmente: 1) modificar el período fundamental de vibración del edificio; 2) producir torsiones por desplazamiento del 
centro de torsión del edificio respecto del centro de masas; y 3) generar pilares cortos. Asimismo, su incorrecta sujeción y anclaje puede provocar el desprendimiento de parapetos y antepechos.

$\checkmark$ Principio de funcionamiento de columna fuerte-viga débil. Este mecanismo resistente se basa en que la disipación de la energía inducida a la estructura durante un sismo se produzca en los elementos horizontales (vigas), mediante la formación del suficiente número de roturas plásticas evitando, de este modo, el desarrollo de un mecanismo de colapso de la estructura por el fallo de los pilares.

$\checkmark$ Amortiguamiento. En las estructuras más recientes, técnicas avanzadas como el aislamiento de base y otros mecanismos disipadores de energía han demostrado un adecuado comportamiento sísmico, si bien es necesario considerar sus limitaciones tecnológicas y constructivas, especialmente de cara a su aplicación en edificaciones y estructuras existentes.

\section{EJECUCIÓN DE DETALLES CONSTRUCTIVOS CORRECTOS}

Un objetivo fundamental del diseño sismorresistente es evitar un fallo frágil que ocasione la pérdida brusca de capacidad portante del edificio. Por tanto, la definición y ejecución de los detalles constructivos ha de ser la adecuada para un correctos comportamiento sísmico, especialmente en aquellos elementos estructurales que proporcionan ductilidad al sistema. Los requisitos principales son los siguientes:

$\checkmark$ Se debe garantizar una ductilidad necesaria en la estructura sin que su rigidez disminuya excesivamente.

$\checkmark$ Las rótulas plásticas deben aparecer primero en las vigas y después en los pilares.

$\checkmark$ El mecanismo de fallo por momento flector debe producirse antes que el de fallo por esfuerzo cortante, ya que este último se produce de forma repentina.

$\checkmark$ Los nudos de la estructura deben ser más rígidos que los elementos estructurales que se conectan en ellos

De este modo, la gran mayoría de normas sísmicas actuales exigen el cumplimiento de ciertos requisitos de ductilidad global de las edificaciones, estableciendo una serie de prescripciones acerca de detalles constructivos aplicables a los diferentes elementos de la estructura: cimentación, muros de fábrica, entramados de hormigón armado, entramados de acero, o la consideración de elementos no estructurales. 


\section{CAPÍTULO 3}

\section{METODOLOGÍA PARA LA EVALUACIÓN DE LA VULNERABILIDAD SÍSMICA}

\subsection{INTRODUCCIÓN}

A partir de la primera versión del Método del Índice de Vulnerabilidad (MIV) adoptada por el proyecto RISK-UE (Milutinovic \& Trendafiloski, 2003), se han desarrollado una serie de trabajos enfocados a la revisión de la definición y cuantificación de los distintos modificadores establecidos en la metodología para la obtención del índice de vulnerabilidad de una determinada edificación (Giovinazzi, 2005; Lantada, 2007; Feriche, 2012; Martínez-Cuevas \& Gaspar-Escribano, 2016), tanto para edificaciones de mampostería no reforzada como para edificaciones aporticadas de hormigón armado.

Estos modificadores permiten el ajuste de ciertos factores que influyen en el comportamiento sísmico del edificio, como su estado de conservación, el nivel del código sísmico de diseño utilizado, o disposiciones constructivas como el número de alturas o las irregularidades geométricas y en rigideces.

En este capítulo se describen los parámetros, definidos en las distintas revisiones publicadas, relativos a los modificadores de comportamiento y a los modificadores regionales considerados en la ecuación (2.9). Posteriormente se expone el nuevo modelo propuesto a partir del análisis realizado de las variantes existentes del método MIV.

\subsection{DESCRIPCIÓN DE LAS REVISIONES EXISTENTES DEL MÉTODO MIV}

\subsubsection{Modificadores de comportamiento}

En primer lugar, Giovinazzi (2005) propone cambios en la ponderación de algunos modificadores de comportamiento tanto de edificaciones de mampostería como de hormigón armado (Tabla 3.1).

Lantada (2007) realiza variaciones tanto en la descripción como en la ponderación de algunos parámetros con objeto de sistematizar el método para su implementación en Sistemas de Información Geográfica (SIG), incorporando nuevos modificadores que consideran aspectos urbanísticos tales como la diferencia de altura entre las edificaciones adyacentes o la posición relativa del edificio evaluado en la manzana. 
Tabla 3.1. Modificadores de comportamiento $M_{C}$ del índice de vulnerabilidad propuestos por Giovinazzi (2005) para edificaciones de hormigón armado (Martínez-Cuevas, 2014).

\begin{tabular}{|c|c|c|c|c|}
\hline \multirow{2}{*}{\multicolumn{2}{|c|}{ Factores de comportamiento }} & \multicolumn{3}{|c|}{$\begin{array}{l}\text { Valoraciones del modificador } M c_{j} \text { según el nivel de } \\
\text { diseño sismorresistente }\end{array}$} \\
\hline & & Código de nivel & Código de nivel & Código de nivel \\
\hline \multirow{3}{*}{$\begin{array}{l}\text { Estado de } \\
\text { conservación }\end{array}$} & Bueno & 0 & 0 & 0 \\
\hline & Deficiente & 0,04 & 0,02 & 0 \\
\hline & 0 a 3 & $-0,02$ & $-0,02$ & $-0,02$ \\
\hline \multirow[t]{2}{*}{$\begin{array}{l}\text { Altura o número } \\
\text { de plantas }\end{array}$} & 4 a 7 & 0 & 0 & 0 \\
\hline & $\geq 8$ & 0,04 & 0,04 & 0,04 \\
\hline \multirow{2}{*}{$\begin{array}{l}\text { Irregularidad en } \\
\text { planta }\end{array}$} & Forma & 0,04 & 0,02 & 0 \\
\hline & Torsión & 0,02 & 0,01 & 0 \\
\hline \multicolumn{2}{|c|}{ Irregularidad vertical } & 0,04 & 0,02 & 0 \\
\hline \multicolumn{2}{|c|}{ Columna corta } & 0,02 & 0,01 & 0 \\
\hline \multicolumn{2}{|c|}{$\begin{array}{l}\text { Edificios adyacentes: juntas sísmicas } \\
\text { insuficientes }\end{array}$} & 0,04 & 0,02 & 0 \\
\hline \multirow{3}{*}{ Cimientos } & Zunchos & $-0,04$ & 0 & 0 \\
\hline & & & & O \\
\hline & Lapatas alsiadas & 0,04 & 0 & 0 \\
\hline
\end{tabular}

En la Tabla 3.2 se recogen los valores propuestos para el parámetro relacionado con el número de plantas del edificio, evaluado en función de su tipología y su periodo de construcción.

Tabla 3.2. Modificadores de comportamiento relativo al número plantas del edificio (Lantada, 2007).

\begin{tabular}{cccc}
\hline Tipología & No de plantas & $\begin{array}{c}\text { Modificios de 1940 o } M_{h} \\
\text { anteriores }\end{array}$ & $\begin{array}{c}\text { Edificios posteriores } \\
\text { a 1940 }\end{array}$ \\
\hline Bajo (1 o 2) & $-0,02$ & $-0,04$ \\
Mampostería & Medio (3 a 5) & 0,02 & 0 \\
$\begin{array}{c}\text { Hormigón } \\
\text { (nivel de diseño } \\
\text { bajo) }\end{array}$ & Blto (6 o más) & 0.06 & 0,04 \\
& Medio (4 a 7) & & $-0,04$ \\
& Alto (8 o más) & 0 & 0 \\
\hline
\end{tabular}


Para cuantificar el modificador relacionado con la irregularidad en altura del edificio, se define previamente un parámetro $\delta$ de la estructura mediante la ecuación (3.1):

$$
\delta=h_{\max }-h_{\mathrm{v}}=h_{\max }-\frac{\sum_{\mathrm{k}=1}^{\mathrm{n}} A_{\mathrm{k}} h_{\mathrm{k}}}{\sum_{\mathrm{k}=1}^{\mathrm{n}} A_{\mathrm{k}}}
$$

donde:

$h_{\max }=$ máximo de los números de plantas del edificio.

$h_{v}=$ número de plantas que tendría un edificio que tuviera el mismo volumen total del edificio y su misma superficie en planta.

$n=$ número de subparcelas diferentes del edificio con diferentes números de plantas.

$h_{k}=$ número de plantas de la subparcela $k$.

$A_{k}=$ área correspondiente de la subparcela.

A partir del valor de este parámetro $\delta$ se puede obtener el modificador $M_{c}$ según las expresiones (3.2a) y (3.2b):

$$
\begin{gathered}
M_{\mathrm{c}}=+0,02 \quad \text { si } 1<\delta \leq 3 \\
M_{\mathrm{c}}=+0,04 \quad \text { si } \delta>3
\end{gathered}
$$

Para incorporar la posible irregularidad en planta de la estructura a la evaluación de la vulnerabilidad, se emplea el denominado índice o razón de compacidad RC (Compactness Ratio), determinado por la ecuación (3.3):

$$
R C=\sqrt{A / A_{C}}
$$

donde:

$A$ = área del polígono que define la planta del edificio estudiado.

$A_{C}=$ área del círculo que tiene el mismo perímetro que dicho polígono.

Este índice de compacidad vale la unidad cuando el polígono es un círculo, tendiendo a cero cuanto más diferente de un círculo sea el polígono estudiado. En la Tabla 3.3 se muestran los valores adoptados por este modificador para todas las tipologías y materiales constructivos, en función del valor del índice de compacidad $R C$.

Tabla 3.3. Modificador $M_{i p}$ en función de la regularidad en planta del edificio (Lantada, 2007).

\begin{tabular}{cc}
\hline Parámetro $R C$ & Modificador $M_{l p}$ \\
\hline$R C<0,5$ & 0,04 \\
$0,5>R C>0,7$ & 0,02 \\
\hline
\end{tabular}

En lo relativo a la diferencia de altura entre edificios, para cada inmueble este modificador se obtiene en función de las diferencias entre el número de plantas entre el edificio evaluado y el de los edificios adyacentes. En la Figura 3.1 se esquematiza la casuística 
considerada por la autora y se cuantifica el valor de los modificadores propuestos. Estos factores únicamente se aplican cuando la diferencia entre el número de plantas del edificio objeto de estudio y los edificios contiguos difieren en al menos dos plantas.



Figura 3.1. Valor del modificador de comportamiento en función de la diferencia de altura entre edificios adyacentes (Lantada, 2007).

Se considera un nuevo modificador relacionado con la posición del edificio en la manzana. Se establecen tres tipos de edificios en función de su posición relativa dentro de la trama urbana. En una determinada manzana se puede diferenciar entre:

$\checkmark$ Edificio esquina: cuando su fachada forma parte de un cruce de calles o chaflán, estando en contacto con el resto de la manzana por dos de sus lados.

$\checkmark$ Edificio terminal: cuando se halla en contacto con el resto de la manzana tan sólo por uno de sus lados.

$\checkmark$ Edificios intermedios al resto de inmuebles de la manzana en cuestión, con al menos dos medianeras con los edificios adyacentes.

Se considera una penalización de $+0,06$ y $+0,04$ para los edificios terminal y esquina, respectivamente, y una bonificación de -0,04 para los intermedios (Figura 3.2).

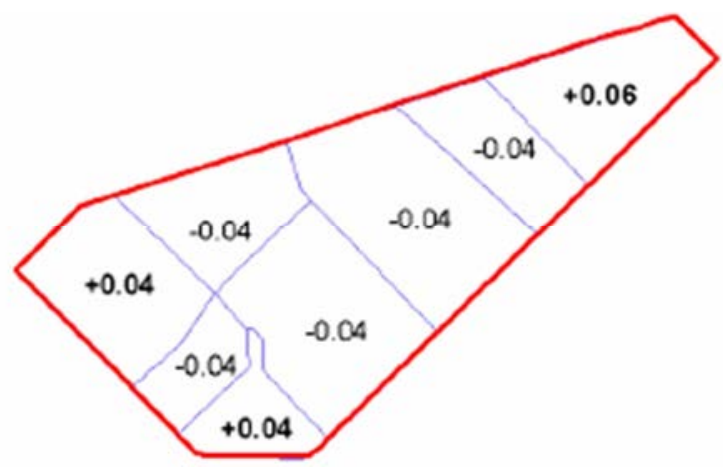

Figura 3.2. Valor del modificador de comportamiento según la posición del edificio en la manzana.

(Lantada, 2007).

En la Tabla 3.4 se resumen los modificadores de comportamiento propuestos por Lantada (2007) y Lantada et al. (2010) para las edificaciones de hormigón armado. 
Tabla 3.4. Modificadores de comportamiento $M_{C}$ del índice de vulnerabilidad para edificaciones de hormigón armado propuestos por Lantada (2007) y Lantada et al. (2010).

\begin{tabular}{|c|c|c|c|}
\hline \multirow{2}{*}{\multicolumn{2}{|c|}{ Factores de comportamiento }} & \multicolumn{2}{|c|}{$\begin{array}{l}\text { Valoraciones del modificador } M c_{j} \text { según el nivel } \\
\text { de diseño sismorresistente }\end{array}$} \\
\hline & & $\begin{array}{l}\text { Código de nivel bajo } \\
\text { (Pre or Low Code) }\end{array}$ & $\begin{array}{l}\text { Código de nivel medio } \\
\text { (Medium Code) }\end{array}$ \\
\hline \multirow{3}{*}{$\begin{array}{l}\text { Estado de } \\
\text { conservación }\end{array}$} & Bueno & $-0,04$ & $-0,04$ \\
\hline & Deficiente & 0,04 & 0,04 \\
\hline & 0 a 3 & $-0,04$ & 0 \\
\hline \multirow{2}{*}{$\begin{array}{l}\text { Altura o número de } \\
\text { plantas }\end{array}$} & 4 a 7 & 0 & 0 \\
\hline & $\geq 8$ & 0,08 & 0 \\
\hline \multicolumn{2}{|c|}{ Irregularidad en planta } & 0,02 si $0,5>R C>0,7$ & 0,04 si $R C<0,5$ \\
\hline \multicolumn{2}{|c|}{ Irregularidad vertical } & \multicolumn{2}{|c|}{$\begin{array}{c}0,04 \text { si } \partial>3 \\
0.02 \text { si } 1<\partial<3\end{array}$} \\
\hline & Intermedio & $-0,04$ & $-0,04$ \\
\hline \multirow[t]{2}{*}{$\begin{array}{l}\text { Edificios adyacentes: } \\
\text { posición en manzana }\end{array}$} & Esquina & 0,04 & 0,04 \\
\hline & Terminal & 0,06 & 0,06 \\
\hline \multicolumn{2}{|c|}{$\begin{array}{l}\text { Edificios adyacentes: diferencia de } \\
\text { altura entre edificios }\end{array}$} & \multicolumn{2}{|c|}{$[-0,04,0,04] f\left(h_{\text {relat }}\right)$} \\
\hline
\end{tabular}

$R C=$ razón de compacidad del edificio según ecuación (3.3); $\partial=$ parámetro relacionado con la irregularidad en altura de la edificación definido en ecuación (3.1); $h_{\text {relat }}=$ diferencia entre el número de plantas de dos edificaciones adyacentes, según Figura 3.1.

Feriche (2012) adapta el trabajo de Lantada (2007) para la ciudad de Granada, revisando asimismo algunos modificadores de comportamiento en base a las experiencias obtenidas tras los daños causados en las edificaciones por el terremoto de Lorca de 2011 (Feriche et al., 2012a). Las variaciones planteadas con respecto a los trabajos anteriores son las siguientes (Tabla 3.5):

$\checkmark \quad$ Irregularidad en altura: se enfatiza en las disposiciones constructivas de pilar corto y de piso blando/débil, proponiendo aumentar la ponderación de estos factores hasta $+0,06$ y $+0,08$, respectivamente.

$\checkmark$ Pendiente del terreno: se aumenta también la penalización de este modificador hasta un valor de $+0,04$.

Martínez-Cuevas (2014) profundiza en el análisis de la influencia de algunas de las configuraciones arquitectónicas descritas en el apartado 2.2.3.6 y su relación con los modificadores por comportamiento definidos en el método MIV, en edificios tanto de 
mampostería como de hormigón armado, apoyándose para ello en las experiencias obtenidas del sismo de Lorca de 2011.

Tabla 3.5. Modificadores de comportamiento $M_{C}$ del índice de vulnerabilidad para edificaciones de hormigón armado propuestos por Feriche (2012).

\begin{tabular}{|c|c|c|c|}
\hline \multirow{2}{*}{\multicolumn{2}{|c|}{ Factores de comportamiento }} & \multicolumn{2}{|c|}{$\begin{array}{l}\text { Valoraciones del modificador } M c_{j} \text { según el nivel } \\
\text { de diseño sismorresistente }\end{array}$} \\
\hline & & $\begin{array}{l}\text { Código de nivel bajo } \\
\text { (Pre or Low Code) }\end{array}$ & $\begin{array}{l}\text { Código de nivel medio } \\
\text { (Medium Code) }\end{array}$ \\
\hline \multirow{3}{*}{$\begin{array}{l}\text { Estado de } \\
\text { conservación }\end{array}$} & Bueno & 0 & 0 \\
\hline & Deficiente & 0,04 & $\begin{array}{l}0,02 \text { si }<=1996 \\
0,04 \text { si }>1996\end{array}$ \\
\hline & 0 a 3 & $-0,04$ & $-0,04$ \\
\hline \multirow[t]{2}{*}{$\begin{array}{l}\text { Altura o número de } \\
\text { plantas }\end{array}$} & 4 a 7 & 0 & 0 \\
\hline & $\geq 8$ & 0,08 & 0,06 \\
\hline \multicolumn{2}{|c|}{ Irregularidad en planta } & \multicolumn{2}{|c|}{$\begin{array}{c}0,04 \text { si } R C<0,5 \\
0,02 \text { si } 0,5>R C>0,7\end{array}$} \\
\hline \multicolumn{2}{|c|}{ Irregularidad vertical } & 0,06 & 0,06 \\
\hline \multicolumn{2}{|c|}{ Columna corta } & 0,08 & 0,08 \\
\hline \multicolumn{2}{|c|}{$\begin{array}{l}\text { Edificios adyacentes: juntas } \\
\text { sísmicas insuficientes }\end{array}$} & 0,04 & 0 \\
\hline \multicolumn{2}{|c|}{ Pendiente del terreno } & 0,04 & 0,04 \\
\hline & Intermedio & $-0,04$ & $-0,04$ \\
\hline \multirow[t]{2}{*}{$\begin{array}{l}\text { Edificios adyacentes: } \\
\text { posición en manzana }\end{array}$} & Esquina & 0,04 & 0,04 \\
\hline & Terminal & 0,06 & 0,06 \\
\hline \multicolumn{2}{|c|}{$\begin{array}{l}\text { Edificios adyacentes: diferencia de } \\
\text { altura entre edificios }\end{array}$} & \multicolumn{2}{|c|}{$[-0,04,0,04] f\left(h_{\text {relat }}\right)$} \\
\hline \multicolumn{2}{|c|}{ Planta blanda } & 0,06 & 0,06 \\
\hline
\end{tabular}

$R C=$ razón de compacidad del edificio según ecuación (3.3); $h_{\text {relat }}=$ diferencia entre el número de plantas de dos edificaciones adyacentes, según Figura 3.1

Por último, Martínez-Cuevas \& Gaspar-Escribano (2016) proponen una nueva modificación en el factor relacionado con la irregularidad en altura de la edificación, y más concretamente, en la presencia de planta blanda, incrementando la penalización de este modificador hasta un valor de $+0,2$ (Tabla 3.6) a partir también de los daños sísmicos en edificaciones observados tras el sismo de Lorca de 2011. 
Tabla 3.6. Modificadores de comportamiento $M_{C}$ del índice de vulnerabilidad para edificaciones de hormigón armado propuestos por Martínez-Cuevas \& Gaspar-Escribano (2016).

\begin{tabular}{|c|c|c|c|}
\hline \multirow{2}{*}{\multicolumn{2}{|c|}{ Factores de comportamiento }} & \multicolumn{2}{|c|}{$\begin{array}{l}\text { Valoraciones del modificador } M c_{j} \text { según el nivel } \\
\text { de diseño sismorresistente }\end{array}$} \\
\hline & & $\begin{array}{l}\text { Código de nivel bajo } \\
\text { (Pre or Low Code) }\end{array}$ & $\begin{array}{l}\text { Código de nivel medio } \\
\text { (Medium Code) }\end{array}$ \\
\hline \multirow{3}{*}{$\begin{array}{c}\text { Estado de } \\
\text { conservación }\end{array}$} & Bueno & $-0,04$ (<10 años) & $-0,04$ (<10 años) \\
\hline & Deficiente & 0,04 (>40 años) & 0,04 (>40 años) \\
\hline & 0 a 3 & $-0,04$ & $-0,04$ \\
\hline \multirow[t]{2}{*}{$\begin{array}{l}\text { Altura o número de } \\
\text { plantas }\end{array}$} & 4 a 7 & 0 & 0 \\
\hline & $\geq 8$ & 0,06 & 0,06 \\
\hline \multicolumn{2}{|c|}{ Irregularidad en planta } & \multicolumn{2}{|c|}{$\begin{array}{c}0,04 \text { si } R C<0,5 \\
0,02 \text { si } 0,5>R C>0,7\end{array}$} \\
\hline \multicolumn{2}{|c|}{ Irregularidad vertical } & \multicolumn{2}{|c|}{$\begin{array}{c}0,04 \text { si } \partial>3 \\
0,02 \text { si } 1<\partial \leq 3\end{array}$} \\
\hline \multicolumn{2}{|c|}{ Pendiente del terreno } & 0,04 & 0,04 \\
\hline & Intermedio & $-0,04$ & $-0,04$ \\
\hline \multirow[t]{2}{*}{$\begin{array}{l}\text { Edificios adyacentes: } \\
\text { posición en manzana }\end{array}$} & Esquina & 0,04 & 0,04 \\
\hline & Terminal & 0,06 & 0,06 \\
\hline \multicolumn{2}{|c|}{$\begin{array}{l}\text { Edificios adyacentes: diferencia de } \\
\text { altura entre edificios }\end{array}$} & \multicolumn{2}{|c|}{$[-0,04,0,04] f\left(h_{\text {relat }}\right)$} \\
\hline \multicolumn{2}{|c|}{ Planta blanda } & 0,2 & 0,2 \\
\hline
\end{tabular}

$R C=$ razón de compacidad del edificio según ecuación (3.3); $\partial=$ parámetro relacionado con la irregularidad en altura de la edificación definido en ecuación (3.1); $h_{\text {relat }}=$ diferencia entre el número de plantas de dos edificaciones adyacentes, según Figura 3.1.

\subsubsection{Modificador regional}

El modificador regional $\Delta M_{R}$, expuesto en la expresión (2.9), permite la adaptación de los índices de vulnerabilidad a las características y calidades propias de las edificaciones de la zona de estudio, pudiendo ser asignado en función de juicio de expertos, de correlaciones empíricas procedentes de daños sísmicos observados o de la normativa sísmica vigente.

Actualmente no se dispone de una propuesta unificada para la obtención de este modificador regional. Lantada (2007) obtiene valores de este parámetro para la ciudad de Barcelona según su fecha de construcción y la normativa sísmica vigente (Tabla 3.7). Feriche et al. (2012a) proponen para Lorca otra serie de modificadores basándose en criterios similares (Tabla 3.8), siendo aplicados posteriormente por Martínez-Cuevas \& Gaspar-Escribano (2016) para la misma localidad. 
Tabla 3.7. Modificadores regionales del índice de vulnerabilidad para algunas tipologías edificatorias de la ciudad de Barcelona (Lantada, 2007).

\begin{tabular}{|c|c|c|c|c|c|c|c|}
\hline \multirow{2}{*}{$\begin{array}{l}\text { Periodo de } \\
\text { construcción }\end{array}$} & \multirow{2}{*}{$\begin{array}{l}\text { Código sísmico } \\
\text { vigente }\end{array}$} & \multirow{2}{*}{$\begin{array}{c}\text { Nivel de } \\
\text { diseño sísmico }\end{array}$} & \multicolumn{5}{|c|}{ Valoraciones del modificador $M_{R}$} \\
\hline & & & M31 & M32 & M33 & M34 & $\mathrm{RC} 32$ \\
\hline$<1940$ & - & - & 0,198 & 0,162 & 0,234 & - & - \\
\hline 1941-1962 & - & - & 0,135 & 0,099 & 0,171 & - & - \\
\hline $1963-1968$ & $\begin{array}{l}\text { Recomendación } \\
\text { MV-101 (1962) }\end{array}$ & - & 0,073 & 0,037 & 0,109 & 0,134 & 0,228 \\
\hline 1969-1974 & $\begin{array}{l}\text { Norma sísmica } \\
\text { PGS-1 (1968) }\end{array}$ & Bajo & 0,010 & $-0,026$ & 0,046 & 0,009 & 0,103 \\
\hline 1975-1994 & $\begin{array}{l}\text { Norma sísmica } \\
\text { PDS (1974) }\end{array}$ & Bajo & $-0,052$ & $-0,088$ & $-0,016$ & $-0,053$ & $-0,022$ \\
\hline 1995-1996 & Norma NCSE-1994 & Bajo & $-0,052$ & $-0,088$ & $-0,016$ & $-0,053$ & $-0,022$ \\
\hline
\end{tabular}

Tabla 3.8. Modificadores regionales del índice de vulnerabilidad para algunas tipologías edificatorias en la ciudad de Lorca (Feriche et al., 2012a).

\begin{tabular}{cccccc}
\hline $\begin{array}{c}\text { Periodo de } \\
\text { construcción }\end{array}$ & $\begin{array}{c}\text { Código sísmico } \\
\text { vigente }\end{array}$ & $\begin{array}{c}\text { Nivel de } \\
\text { diseño sísmico }\end{array}$ & \multicolumn{3}{c}{$\begin{array}{c}\text { Valoraciones del } \\
\text { modificador } M_{R}\end{array}$} \\
\hline$<1926$ & - & - & 0,14 & 0,08 & - \\
$1926-1945$ & - & - & 0,12 & 0,08 & - \\
$1946-1960$ & - & - & 0,10 & 0,08 & 0,14 \\
$1961-1969$ & $\begin{array}{c}\text { Recomendación } \\
\text { MV-101 (1962) }\end{array}$ & Bajo & 0,08 & 0,08 & 0,12 \\
$1970-1976$ & $\begin{array}{c}\text { Norma sísmica } \\
\text { PGS-1 (1968) }\end{array}$ & Bajo & - & 0,08 & 0,10 \\
$1977-1996$ & $\begin{array}{c}\text { Norma sísmica } \\
\text { PDS (1974) }\end{array}$ & Bajo & - & 0,08 & 0,10 \\
$1997-2004$ & Norma NCSE-1994 & Moderado & - & 0,08 & 0,08 \\
\hline 2004 & Norma NCSE-2002 & Moderado & - & 0,08 & - \\
\hline
\end{tabular}

\subsection{AVANCES EN LA EVALUACIÓN DE LA VULNERABILIDAD SÍSMICA DE EDIFICACIONES DE HORMIGÓN ARMADO}

\subsubsection{Introducción}

Los trabajos desarrollados previamente por otros investigadores a partir de la versión del método MIV adoptada por RISK-UE (Milutinovic \& Trendafiloski, 2003), se han enfocado principalmente en la discusión, análisis y calibración de los modificadores de comportamiento relacionados con diversas configuraciones arquitectónicas y urbanísticas como plantas blandas, columnas cortas o irregularidades en planta y en alzado, a partir del análisis del 
comportamiento estructural y de los daños aparecidos en las edificaciones para los eventos sísmicos disponibles.

No obstante, dada la complejidad del fenómeno sísmico y las experiencias obtenidas en recientes terremotos, otros modificadores relacionados con ciertos parámetros estructurales y urbanísticos de las edificaciones pueden ajustarse para una mejor representación de su comportamiento sísmico, especialmente aquellas basadas en pórticos de hormigón armado, las más habituales dentro de la trama urbana de las ciudades.

La información contenida en el Servicio Catastral puede constituir una herramienta muy útil para la aplicación de este tipo de metodologías basadas en índices de vulnerabilidad. Con apoyo de técnicas SIG, la posibilidad de manejar esta base de datos de forma sistematizada permite una implementación más sencilla de estos procedimientos en áreas urbanas (Lantada, 2007; Martínez-Cuevas, 2014). La mayor parte de países desarrollados disponen de servicios de información catastral destinados principalmente a la gestión tributaria de las propiedades, incluyendo descripciones pormenorizadas de los bienes inmuebles con su titularidad, localización, superficie, uso o destino, aprovechamiento y calidad de sus construcciones. En España, este servicio está facilitado por la Dirección General de Catastro del Ministerio de Hacienda y Función Pública (MEH, 2017).

Las sucesivas revisiones del método MIV han simplificado la implementación de la metodología a partir de la información catastral (Lantada, 2007). No obstante, se considera necesario seguir adaptando los distintos modificadores de comportamiento con el fin de facilitar un mejor tratamiento de las bases de datos disponibles y una aplicación más sencilla de la metodología en áreas urbanas.

\subsubsection{Desarrollo de la metodología}

Tras el análisis realizado de las variantes disponibles del método MIV dentro del marco de RISK-UE, se plantea la siguiente propuesta de revisión de los modificadores de comportamiento definidos en la metodología para la obtención del índice de vulnerabilidad de las edificaciones de hormigón armado, exponiéndose a continuación los parámetros modificados.

\subsubsection{Nivel del código sísmico de diseño}

El código sísmico con el que ha sido diseñada una determinada edificación condiciona sus características tipológicas y estructurales y, por tanto, su comportamiento frente a acciones sísmicas. Dado que la normativa sísmica no suele obligar al retrofitting estructural, es decir, a la revisión de las prestaciones sismorresistentes de los edificios existentes con carácter retroactivo, la respuesta de estas estructuras dentro de la trama urbana puede ser muy variada (Cabañas et al., 2011). 
Factores como los métodos de cálculo empleados, su ámbito y criterio de aplicación, o las prescripciones y reglas establecidas para el dimensionamiento del sistema resistente, determinan el comportamiento sísmico esperable ante un cierto evento sísmico, en función del código sísmico empleado en su diseño. La determinación de las acciones sísmicas de cálculo a partir de la peligrosidad sísmica del área de aplicación de la norma, ya sea mediante procedimientos deterministas o probabilistas, condiciona también la respuesta del sistema resistente del edificio.

Con carácter general, edificaciones con una fecha de construcción más antigua presentan un peor comportamiento sísmico que aquellas construidas en periodos más recientes (FEMA, 154, 2002; AeDES, 2009; Cabañas et al., 2011; Manfredi et al., 2013; Andreini et al. 2014; Dolce \& Bucci, 2014; Ivorra, 2016). Junto con el esperable deterioro de los materiales y el deficiente o nulo- control de calidad de los mismos durante la construcción, el dimensionamiento de los elementos resistentes a partir de métodos estáticos de cálculo muy básicos, o la falta de atado de los elementos de cimentación, constituyen aspectos que condicionan la respuesta sísmica de las edificaciones.

En la Figura 3.3 se muestra el posible comportamiento sísmico de este tipo de edificios diseñados con códigos sísmicos de bajo nivel. Se observa un mal estado de conservación de los materiales e incorrectos detalles constructivos que generan, por ejemplo, insuficientes cuantías de armado e inadecuada sujeción de antepechos de cubierta.

Otras patologías, como la falta de confinamiento del hormigón en elementos estructurales, se pueden considerar asimismo que están relacionadas con el código sísmico de diseño (Figura 3.4). Las normas recientes aseguran, a priori, unas mínimas disposiciones y cuantías de armado y unos recubrimientos suficientes para asegurar un correcto comportamiento dúctil del hormigón, especialmente en aquellas zonas más solicitadas, como la cabeza de pilares, lo cual no puede asegurarse en aquellas edificaciones diseñadas con códigos sísmicos más antiguos.

De este modo, se identifican los siguientes factores dependientes del código de diseño sísmico con influencia en el comportamiento sísmico de las edificaciones y, por tanto, en la determinación de su vulnerabilidad sísmica:

- Procedimientos y métodos simplificados de cálculo empleados.

- Recomendaciones y reglas de diseño de carácter normativo, esto es, la mayor o menor presencia de prescripciones y detalles constructivos.

- Especificaciones y detalles de la disposición de las cimentaciones, básicamente las condiciones de atado.

- Estado de conservación y calidad de los materiales. 


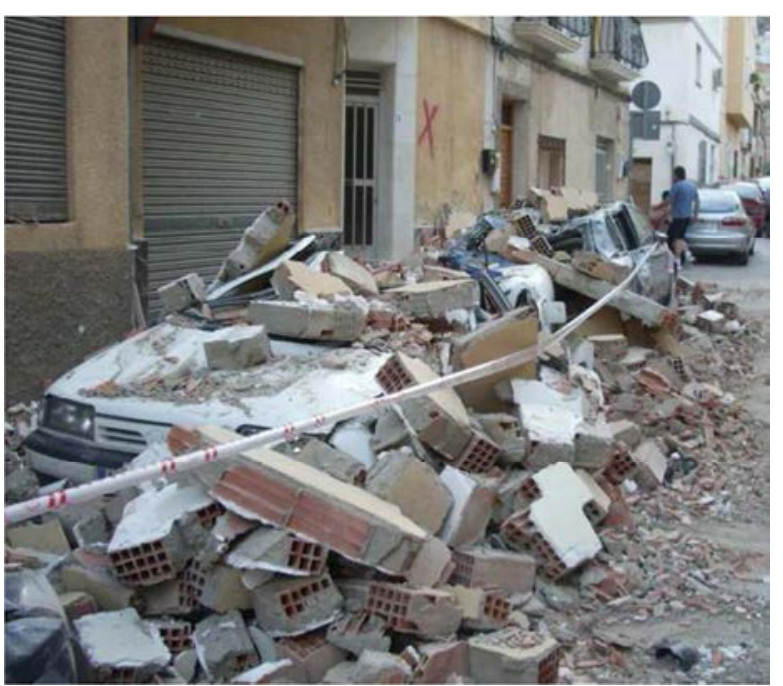

(a)



(c)



(b)

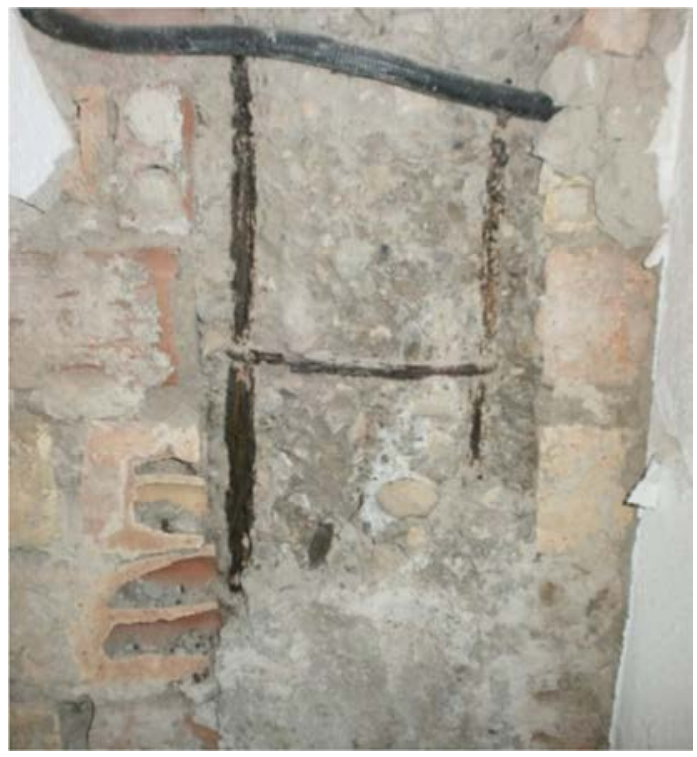

(d)

Figura 3.3. Daños sísmicos habituales en edificaciones diseñadas con códigos sísmicos de nivel bajo. (a) Insuficiente atado de antepechos de cubierta (Foto: Murphy, 2011). (b) Cerramientos (Foto: Occhiuzzi et al., 2012). (c) Deficiente calidad de materiales. (d) Insuficiente cuantía de armado (Fotos: Dep. Ingeniería Civil, UPCT, 2011).

Según la calibración y cuantificación de estos factores adoptada por RISK-UE y las sucesivas revisiones de la metodología, se establecen los siguientes incrementos de vulnerabilidad sísmica para cada uno de los mismos, en el caso de edificaciones de hormigón armado (Tabla 3.9).

A partir de esta ponderación se pueden establecer, por tanto, los siguientes valores para el modificador de comportamiento $M_{c}$ relacionado con el nivel del código sísmico de diseño para edificaciones de hormigón armado (Tabla 3.10), considerando la clasificación de estos niveles definida en la metodología RISK-UE. 


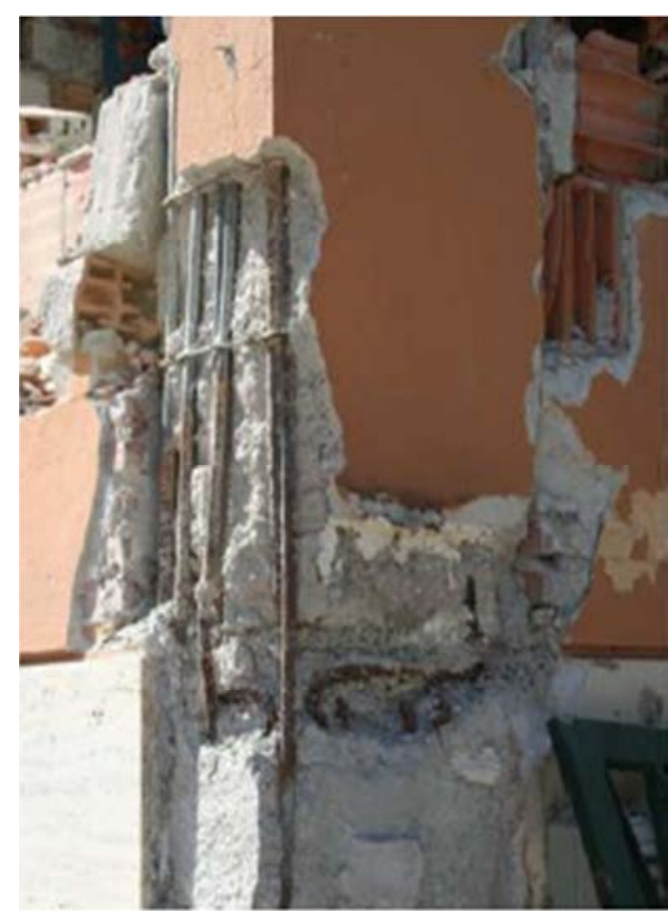

(a)

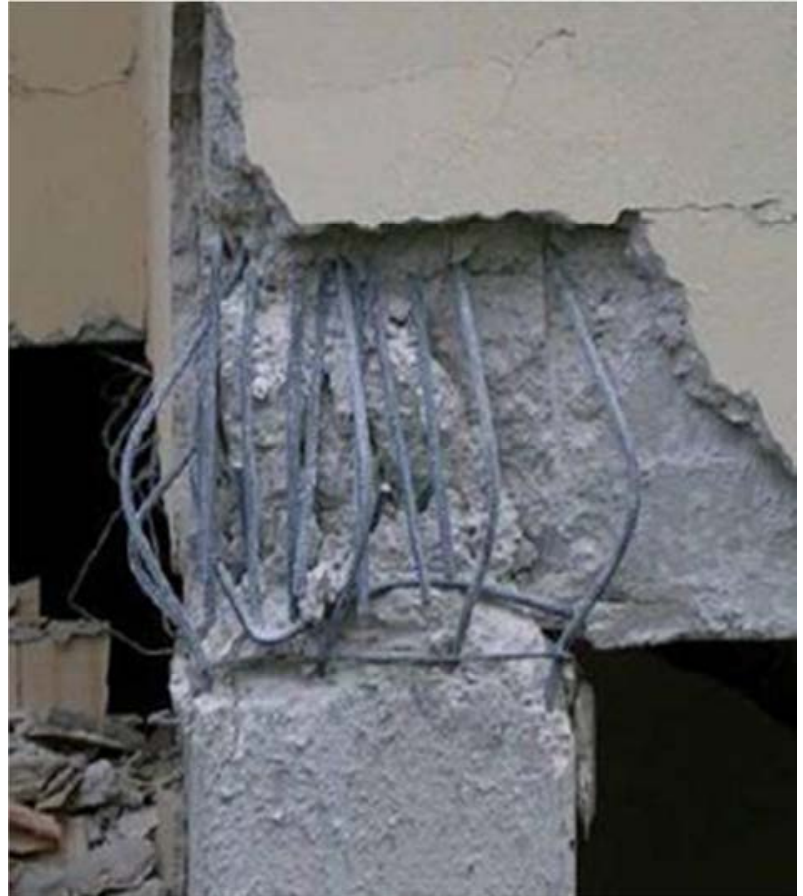

(b)

Figura 3.4. Falta de confinamiento del hormigón en cabeza de pilares por escasa cuantía de armadura transversal. (a) Desprendimiento del recubrimiento y presencia de barras longitudinales lisas. (b) Pandeo de la armadura longitudinal (Fotos: Ricci, 2010).

Tabla 3.9. Incrementos de vulnerabilidad para factores relacionados con el código sísmico de diseño y que influyen en el comportamiento estructural de edificaciones de hormigón armado.

\begin{tabular}{cc}
\hline Factor & $\begin{array}{r}\text { Incremento de } \\
\text { vulnerabilidad }\end{array}$ \\
\hline Métodos simplificados de cálculo empleados & $+0,04$ \\
Recomendaciones y reglas de diseño de \\
carácter normativo & $+0,04$ \\
Especificaciones y detalles de la disposición \\
$\begin{array}{c}\text { de cimentaciones } \\
\text { Estado de conservación y calidad de los } \\
\text { materiales }\end{array}$
\end{tabular}

De forma previa a la aplicación del método en una determinada área urbana, es necesaria, por tanto, la categorización de las normas sísmicas nacionales en pre code, low code, medium code y high code, en función de las consideraciones recogidas en las Tablas 3.9 y 3.10. Una vez realizada esta clasificación, este modificador de comportamiento relacionado con el código sísmico de diseño puede ser evaluado directamente a partir del periodo de construcción de la edificación y, por tanto, de la información contenida en el correspondiente servicio catastral. 
Tabla 3.10. Valores del modificador de comportamiento $M_{c}$ para edificaciones de hormigón armado, en función de los niveles del código sísmico de diseño definidos en RISK-UE.

\begin{tabular}{|c|c|c|}
\hline Nivel de diseño & $\begin{array}{l}\text { Valoración del } \\
\text { modificador } M c\end{array}$ & Observaciones \\
\hline Pre code & 0,16 & $\begin{array}{l}\text { Edificaciones diseñadas sin regulación sísmica. Se } \\
\text { cumplen simultáneamente: uso de métodos de } \\
\text { análisis simplificado de la estructura, ausencia de } \\
\text { especificaciones y detalles constructivos, falta de } \\
\text { prescripciones y detalles relativos a las } \\
\text { cimentaciones, y deficiente estado de conservación } \\
\text { y/o calidad de los materiales. }\end{array}$ \\
\hline Low code & 0,08 & $\begin{array}{l}\text { Edificaciones diseñadas con las primeras normas } \\
\text { sísmicas. EL empleo de algunas recomendaciones } \\
\text { sísmicas para la estructura y las cimentaciones } \\
\text { reduce la vulnerabilidad de } 0,16 \text { a } 0,08 \text {, ya que sólo } \\
\text { se consideran en este caso los métodos simplificados } \\
\text { de cálculo y el mal estado de conservación y/o } \\
\text { calidad de los materiales. }\end{array}$ \\
\hline Medium code/High code & 0,00 & $\begin{array}{l}\text { Edificaciones diseñadas con códigos sísmicos } \\
\text { recientes. Se incorporan métodos de cálculo } \\
\text { avanzados y mejores prescripciones de diseño de la } \\
\text { estructura, destinadas a asegurar un } \\
\text { comportamiento dúctil de la misma y un adecuado } \\
\text { estado de conservación. }\end{array}$ \\
\hline
\end{tabular}

\subsubsection{Número de plantas del edificio}

Tradicionalmente, a las edificaciones con un mayor número de alturas sobre rasante se les ha asociado una vulnerabilidad sísmica más elevada. En las estructuras de mampostería no reforzada, la imposibilidad de desarrollar un comportamiento dúctil debido a la naturaleza frágil de los materiales que las componen limita sus condiciones de estabilidad y su respuesta sísmica. Así lo recogieron las primeras versiones del método MIV adoptadas por RISK-UE, las cuales penalizan el comportamiento de las edificaciones con mayor número de plantas y reducen la vulnerabilidad de aquellas estructuras más bajas (Tabla 2.14 y 2.15 ).

En las edificaciones de hormigón armado, diseñadas a priori para presentar una adecuada ductilidad ante acciones sísmicas, la mayor rigidez que presentan las estructuras más bajas, con pocas plantas sobre rasante, puede condicionar su comportamiento frente a este tipo de solicitaciones. Esta mayor rigidez viene representada en la forma de los espectros de respuesta sísmica definidos en los distintos códigos. En la Figura 3.5 se muestra el espectro normalizado de respuesta elástica para aceleraciones horizontales propuesto en la norma NCSE-02 (2002). Según se puede observar, el tramo amplificado de aceleración espectral constante viene comprendido por los periodos característicos $T_{A}$ y $T_{B}$, los cuales pueden ser obtenidos a partir de las ecuaciones (3.4) y (3.5). 


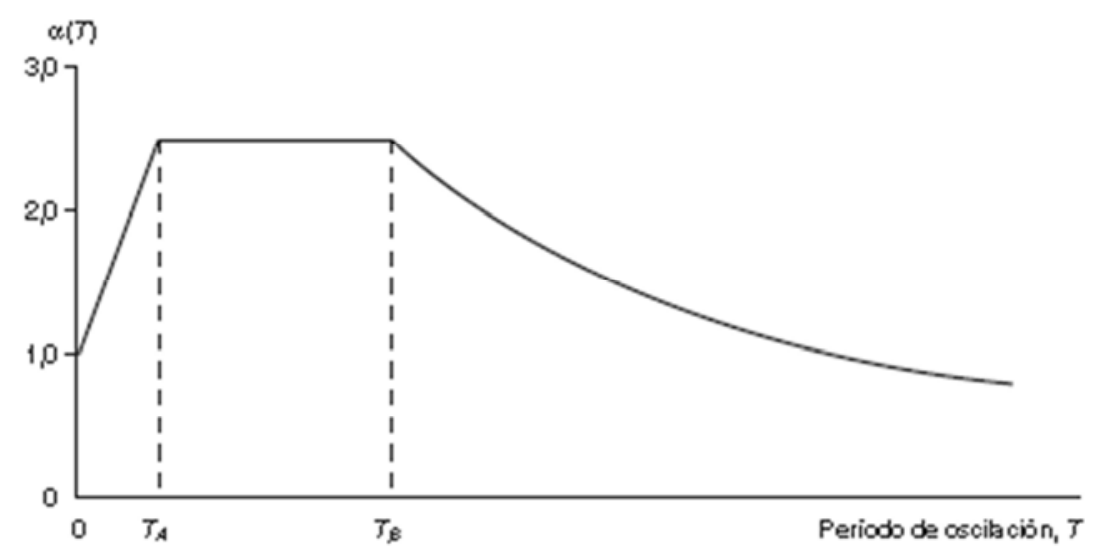

Figura 3.5. Espectro normalizado de respuesta elástica para aceleraciones horizontales (NCSE-02, 2002).

$\alpha(T)=$ valor del espectro normalizado de respuesta elástica; $T_{A}, T_{B}=$ periodos característicos del espectro de respuesta en segundos; $K=$ coeficiente de contribución; $C=$ coeficiente de amplificación local del terreno.

$$
\begin{aligned}
& T_{A}=K C / 10 \\
& T_{B}=K C / 2,5
\end{aligned}
$$

De este modo, adoptando un coeficiente de contribución genérico de $K=1$ y $\sin$ considerar los posibles efectos locales del terreno $(C=1)$, se obtendría un tramo de aceleración espectral constante comprendido entre los periodos $T_{A}=0,1 \mathrm{~s}$ y $T_{B}=0,40 \mathrm{~s}$. Según la NCSE-02, el periodo o frecuencia natural de las edificaciones puede ser obtenido, de manera aproximada, según la expresión recogida en la ecuación (3.6), para el caso de aquellas basadas en pórticos de hormigón armado.

En la Tabla 3.11 se muestran distintos periodos naturales de las edificaciones en función del número de plantas sobre rasante que presentan. Según se puede observar, este tramo de aceleración espectral constante coincidiría prácticamente con la frecuencia natural de las edificaciones de entre 1 y 4 plantas sobre rasante, por lo que estas estructuras se verían afectadas por una mayor aceleración de cálculo dada su mayor rigidez.

$$
T_{F}=0,09 n
$$

donde:

$T_{F}=$ periodo fundamental de la edificación.

$n=$ número de plantas sobre rasante.

En el EC-8 (CEN, 2004), el espectro normalizado de respuesta de aceleraciones horizontales presenta una forma similar (Figura 3.6). A expensas de la aprobación del correspondiente anexo nacional, el EC-8 establece un tramo de aceleración espectral constante comprendido entre los periodos $T_{B}=0,05 \mathrm{~s}$ y $T_{c}=0,25 \mathrm{~s}$ para el espectro tipo $2 \mathrm{y}$ suelo firme o roca. 
Tabla 3.11. Periodo natural de edificaciones aporticadas de hormigón armado en función del número de plantas sobre el terreno, según procedimiento simplificado en NCSE-02 (2002).

\begin{tabular}{cc}
\hline Número de plantas & $T_{F}(s)$ \\
\hline 1 & 0,09 \\
2 & 0,18 \\
3 & 0,27 \\
4 & 0,36 \\
5 & 0,45 \\
6 & 0,54 \\
7 & 0,63 \\
8 & 0,72 \\
9 & 0,81 \\
10 & 0,90 \\
\hline
\end{tabular}

Este espectro es recomendado por la norma si la sismicidad del emplazamiento viene caracterizada por una magnitud de ondas superficiales $M_{s}$ no superior a 5,5 grados, lo cual puede asumirse en términos probabilistas en el ámbito de actuación contemplado en RISK-UE (Woessner et al., 2015).

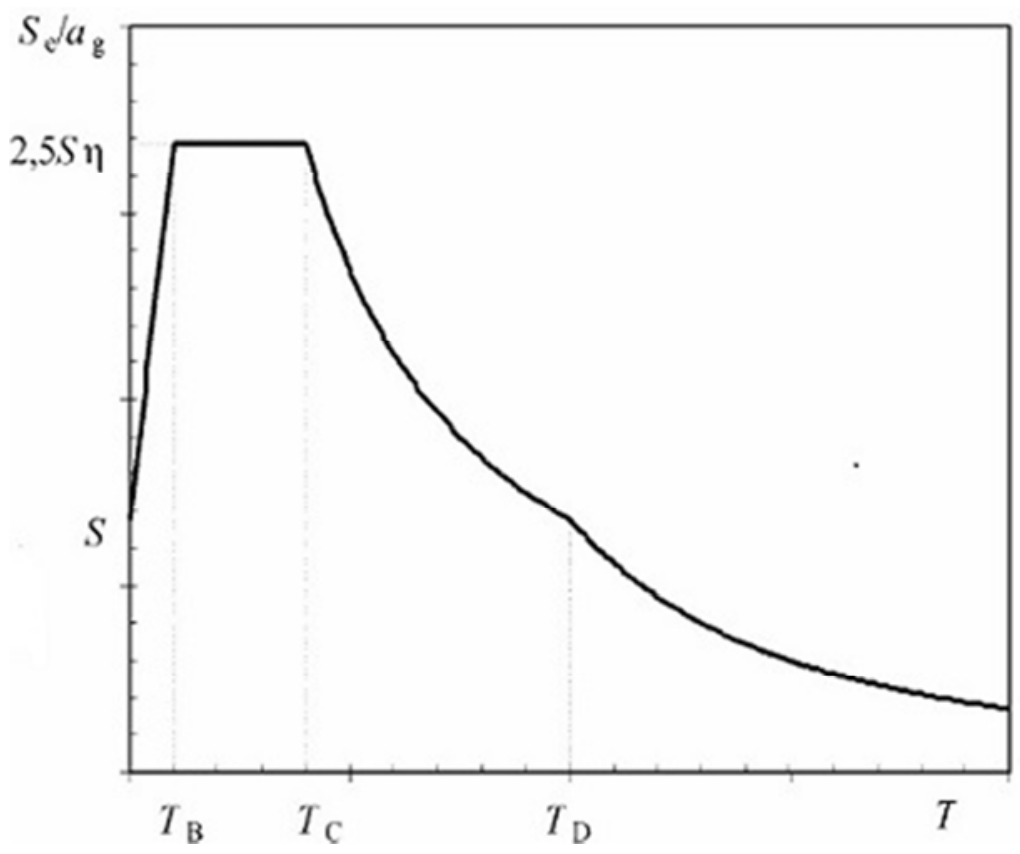

Figura 3.6. Espectro normalizado de respuesta elástica para aceleraciones horizontales según el EC-8

(CEN, 2004)

$S_{e}(T)=$ valor del espectro normalizado de respuesta elástica; $T_{B}, T_{C}, T_{D}=$ periodos característicos del espectro de respuesta en segundos; $a_{g}=$ valor de la aceleración horizontal de cálculo; $\eta=$ coeficiente de corrección del amortiguamiento de referencia definido en el EC-8; $S=$ coeficiente de amplificación local del terreno. 
EI EC-8 establece su propia expresión simplificada para la obtención del periodo natural de las edificaciones, recogida en la ecuación (3.7). En la Tabla 3.12 se muestran distintos periodos naturales de edificaciones en función del número de plantas sobre rasante obtenidos según esta expresión. En este caso, se observa de nuevo que el tramo de aceleración espectral constante coincidiría con los periodos fundamentales de las estructuras más bajas, aunque ampliando el rango a edificaciones de entre 1 y 4 o 5 plantas.

$$
T_{F}=C_{t} h^{3 / 4}
$$

donde:

$$
\begin{aligned}
& T_{F}=\text { periodo fundamental de la edificación. } \\
& h=\text { número de plantas sobre rasante. } \\
& C_{t}=0,075 \text { para pórticos espaciales de hormigón armado resistentes a flexión. }
\end{aligned}
$$

Tabla 3.12. Periodo natural de edificios de hormigón armado en función del número de plantas, según el

\begin{tabular}{cc} 
procedimiento simplificado definido en EC-8 (CEN, 200 \\
\hline Número de plantas del edificio & $T_{F}(s)$ \\
\hline 1 & 0,08 \\
2 & 0,13 \\
3 & 0,17 \\
4 & 0,21 \\
5 & 0,25 \\
6 & 0,29 \\
7 & 0,32 \\
8 & 0,36 \\
9 & 0,39 \\
10 & 0,42 \\
\hline
\end{tabular}

Según la tendencia observada en la Tabla 3.12, las edificaciones más bajas o con un menor número de plantas sobre rasante, presentan mayores niveles de solicitación sísmica al coincidir su frecuencia natural con el tramo de aceleración constante del espectro de respuesta, dada la mayor rigidez de estas estructuras. Por tanto, la vulnerabilidad de este tipo de edificaciones se vería incrementada con respecto a aquellas estructuras con un mayor número de plantas, cuya frecuencia natural coincide con el tramo de aceleraciones decrecientes del espectro.

De este modo, el modificador de comportamiento $M_{h}$ relacionado con el número de plantas del edificio puede ser asignado en función de la forma de los espectros de respuesta definidos en las normas sísmicas. Manteniendo la ponderación establecida en RISK-UE para este modificador, se han adoptado los valores recogidos en la Tabla 3.13. 
Tabla 3.13. Valores del modificador de comportamiento $M_{h}$ según el número de plantas sobre rasante para edificaciones de hormigón armado, en función de los niveles del código sísmico de diseño definidos en RISK-UE.

\begin{tabular}{ccccc}
\hline & \multicolumn{4}{c}{ Valoraciones del modificador $M_{h}$ según el nivel de diseño } \\
Número de plantas & $\begin{array}{c}\text { Sismosistente } \\
\text { Sin código } \\
\text { (Pre Code) }\end{array}$ & $\begin{array}{c}\text { Código de } \\
\text { nivel bajo } \\
\text { (Low Code) }\end{array}$ & $\begin{array}{c}\text { Código de nivel } \\
\text { medio } \\
\text { (Medium Code) }\end{array}$ & $\begin{array}{c}\text { Código de nivel } \\
\text { alto } \\
\text { (High Code) }\end{array}$ \\
\hline 0 a 3 & 0,04 & 0,04 & 0,04 & 0,04 \\
4 a 7 & 0 & 0 & 0 & 0 \\
$\geq 8$ & $-0,04$ & $-0,04$ & $-0,04$ & $-0,04$ \\
\hline
\end{tabular}

\subsubsection{Separación entre edificios}

Como se ha comentado en el apartado 1.2, la escasa conciencia sísmica a nivel social e institucional en algunas regiones de sismicidad baja o moderada, ha derivado en una aplicación de la normativa existente con insuficiente rigor y un abandono de las costumbres constructivas y reglas de buenas praxis sismorresistente tradicionalmente empleadas en las edificaciones.

Uno de los efectos de esta escasa percepción de la amenaza sísmica es la inadecuada disposición de juntas sísmicas en la medianera entre edificios adyacentes. En la práctica, la mayoría de las edificaciones en la trama urbana no disponen de junta sísmica entre dichas medianerías o éstas no se encuentran lo suficientemente dimensionadas y/o correctamente ejecutadas (Figura 3.7). Como consecuencia, son frecuentes los fenómenos de golpeteo entre edificios durante un terremoto con daños en cerramientos, e incluso en elementos estructurales como pilares, por la interacción con el forjado del edificio adyacente (Cabañas et al., 2011; Romao et al. 2013; Hermanns et al. 2012; Martínez-Díaz. 2014).

Por este motivo se ha adoptado, del lado de la seguridad, una penalización de la vulnerabilidad de las edificaciones emplazadas en este tipo de regiones (Tabla 3.14). Esta penalización no se aplica para aquellas estructuras diseñas con códigos de nivel alto, donde se considera que, dado el carácter avanzado de este tipo de normativa, sí que se contemplan de forma exhaustiva estas consideraciones.

Tabla 3.14. Valores del modificador de comportamiento $M_{j}$ relacionado la disposición de juntas sísmicas entre edificios de hormigón armado, en función del nivel del código sísmico de diseño definido en RISK-UE.

\begin{tabular}{ccccc}
\hline $\begin{array}{c}\text { Edificios adyacentes: juntas } \\
\text { sísmicas insuficientes }\end{array}$ & $\begin{array}{c}\text { Sin Código } \\
\text { (Pre Code) }\end{array}$ & $\begin{array}{c}\text { Código de } \\
\text { nivel bajo } \\
\text { (Low Code) }\end{array}$ & $\begin{array}{c}\text { Código de nivel } \\
\text { medio } \\
\text { (Medium Code) }\end{array}$ & $\begin{array}{c}\text { Código de nivel } \\
\text { alto } \\
\text { (High Code) }\end{array}$ \\
\hline $\begin{array}{c}\text { Valoraciones del } \\
\text { modificador } M_{j}\end{array}$ & 0,04 & 0,04 & 0,04 & 0 \\
\hline
\end{tabular}




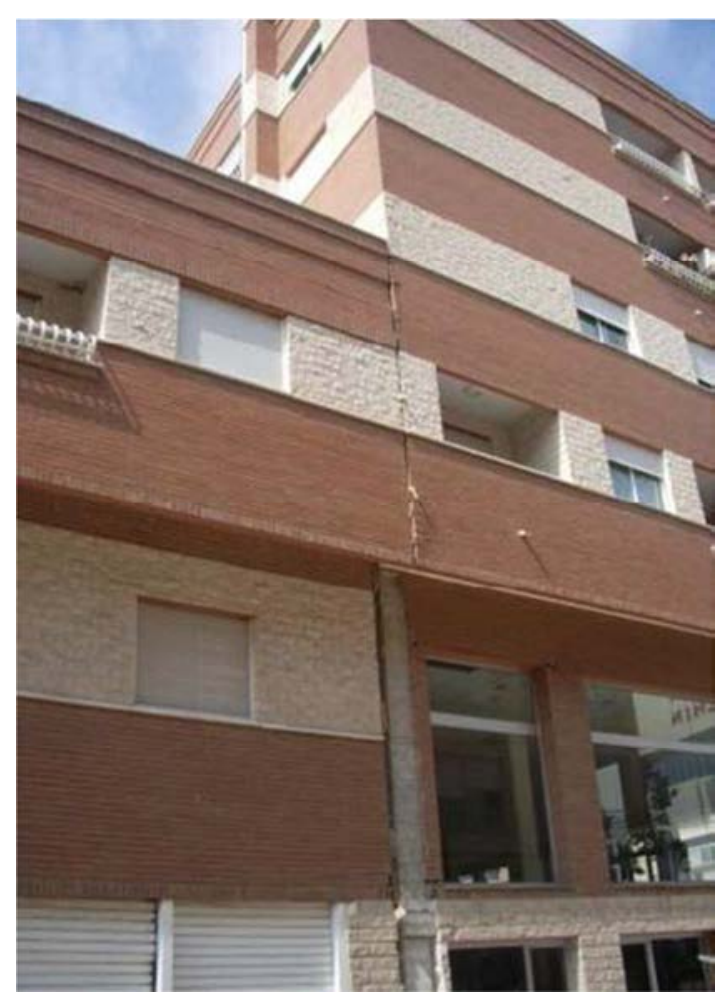

(a)

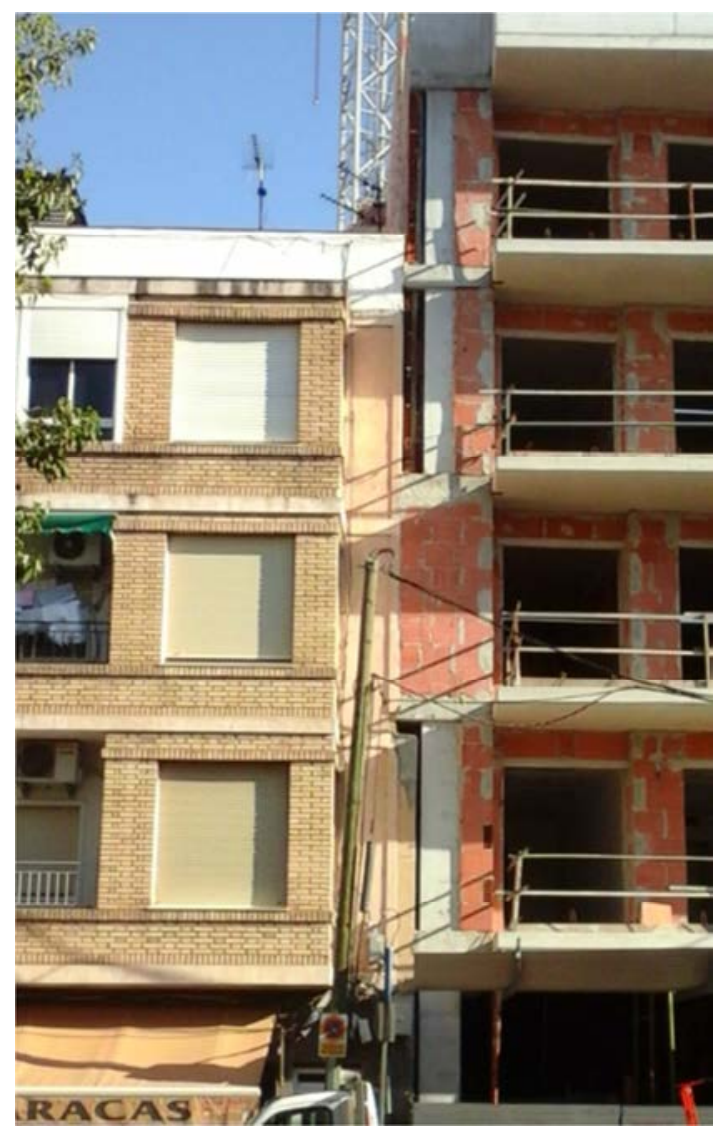

(c)

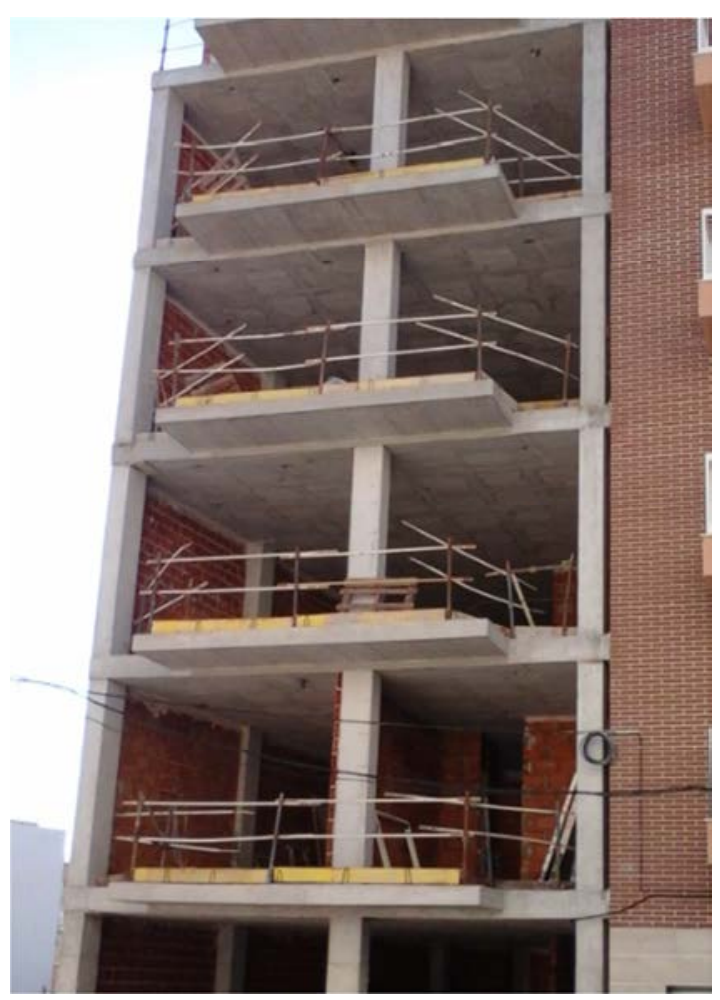

(b)

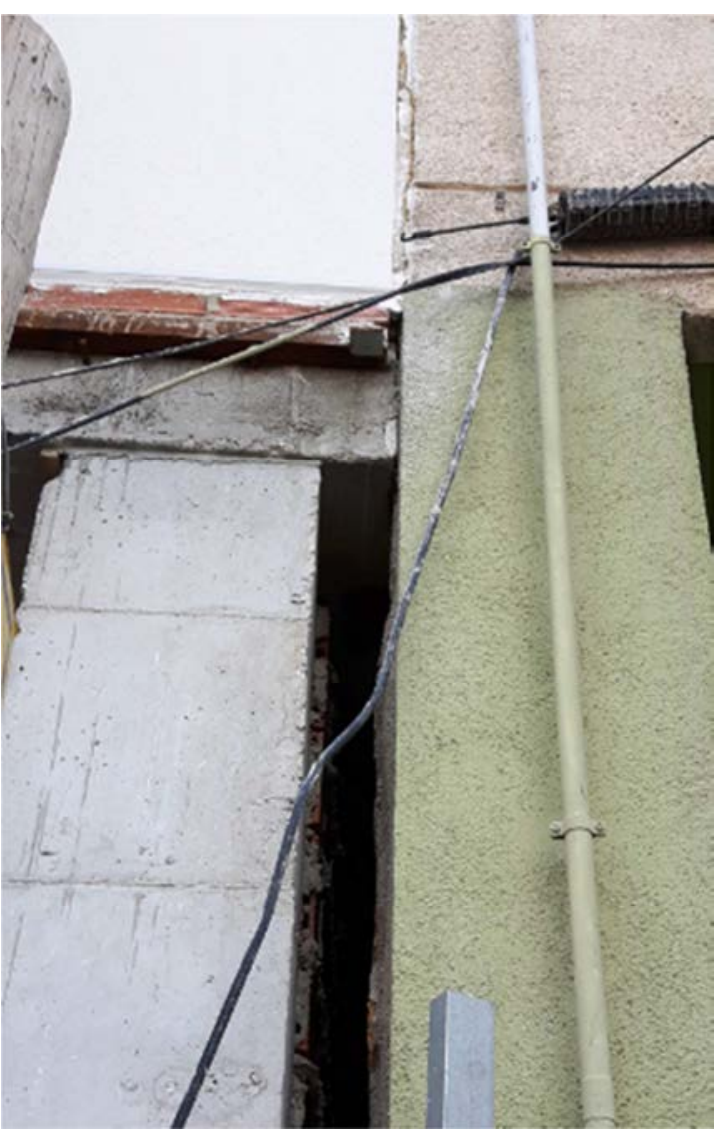

(d)

Figura 3.7. Insuficiencia o inexistencia de junta sísmica. (a) Separación entre diferentes cuerpos de una misma edificación (Foto: Murphy, 2011). (b), (c), (d) Separación de medianeras entre edificaciones de nueva construcción (Foto: Dep. Ingeniería Civil, UPCT, 2016). 


\subsubsection{Otros modificadores del índice de vulnerabilidad}

Los modificadores de comportamiento relacionados con el estado de conservación del edificio y el tipo y disposición de su cimentación definidos en algunas de las versiones del método MIV de RISK-UE (Tablas 2.15, 3.1, 3.4, 3.5 y 3.6), han sido suprimidos para la obtención del índice de vulnerabilidad de una determinada edificación.

Estos parámetros ya están considerados en la determinación del modificador relacionado con el nivel del código sísmico de diseño (Tablas 3.9 y 3.10). Asimismo, su cuantificación es difícil en muchos casos, y dependiente de estimaciones subjetivas del evaluador, por lo que, con la supresión de estos modificadores, se reducirían parte de las incertidumbres asociadas a la estimación de la vulnerabilidad sísmica de edificaciones.

De forma similar, considerando la definición del modificador regional presentado en la ecuación (2.9): "parámetro dependiente de las disposiciones constructivas específicas de la zona de estudio, del nivel de los códigos sísmicos de diseño del país o de la fecha de construcción de la edificación, obtenido a partir de juicio de expertos y datos empíricos procedentes evaluaciones de daños reales post-sismo" (Lantada, Pujades \& Barbat, 2009), se propone su eliminación, ya que los aspectos incluidos en su obtención estarían también contemplados en los diferentes modificadores de comportamientos $M_{c}$.

De este modo se simplifica la generalización del método en cualquier área urbana, dado que se elimina un parámetro que requiere calibración previa en función de las características de las edificaciones del área de estudio. Asimismo, se mejora la implementación de la metodología a partir de la información contenida en los servicios catastrales y mediante técnicas SIG.

\subsubsection{Resumen}

A modo de resumen final, en la Tabla 3.15 se muestran los valores de los modificadores de comportamiento propuestos para la obtención del índice de vulnerabilidad de una determinada edificación, dando continuidad a los distintos trabajos publicados con anterioridad por otros autores en el marco del Método del Índice de Vulnerabilidad (MIV). 
Tabla 3.15. Modificadores de comportamiento $M_{C}$ del índice de vulnerabilidad para edificaciones de hormigón armado. Los parámetros modificados aparecen resaltados en negrita.

\begin{tabular}{|c|c|c|c|c|c|}
\hline & & \multicolumn{4}{|c|}{$\begin{array}{l}\text { Valoraciones del modificador } M c_{j} \text { según el nivel de diseño } \\
\text { sismorresistente }\end{array}$} \\
\hline \multicolumn{2}{|c|}{ Factores de comportamiento } & $\begin{array}{l}\text { Sin código } \\
\text { (Pre Code) }\end{array}$ & $\begin{array}{l}\text { Código de } \\
\text { nivel bajo } \\
\text { (Low Code) }\end{array}$ & $\begin{array}{l}\text { Código de nivel } \\
\text { medio } \\
\text { (Medium Code) }\end{array}$ & $\begin{array}{c}\text { Código de } \\
\text { nivel alto } \\
\text { (High Code) }\end{array}$ \\
\hline \multicolumn{2}{|c|}{ Nivel de código sísmico de diseño } & 0,16 & 0,08 & 0 & 0 \\
\hline \multirow{3}{*}{ Número de plantas } & 0 a 3 & 0,04 & 0,04 & 0,04 & 0,04 \\
\hline & 4 a 7 & 0 & 0 & 0 & 0 \\
\hline & $\geq 8$ & $-0,04$ & $-0,04$ & $-0,04$ & $-0,04$ \\
\hline \multicolumn{2}{|c|}{ Irregularidad en planta } & \multicolumn{4}{|c|}{$\begin{array}{c}0,04 \text { si } R C<0,5 \\
0,02 \text { si } 0,5>R C>0,7\end{array}$} \\
\hline \multicolumn{2}{|c|}{ Irregularidad vertical } & \multicolumn{4}{|c|}{$\begin{array}{c}0,04 \text { si } \partial>3 \\
0,02 \text { si } 1<\partial \leq 3\end{array}$} \\
\hline \multicolumn{2}{|c|}{ Columna corta } & 0,08 & 0,08 & 0,08 & 0,08 \\
\hline \multicolumn{2}{|c|}{$\begin{array}{l}\text { Edificios adyacentes: juntas sísmicas } \\
\text { insuficientes }\end{array}$} & 0,04 & 0,04 & 0,04 & 0 \\
\hline \multicolumn{2}{|c|}{ Pendiente del terreno } & 0,04 & 0,04 & 0,04 & 0,04 \\
\hline & Intermedio & $-0,04$ & $-0,04$ & $-0,04$ & $-0,04$ \\
\hline \multirow[t]{2}{*}{$\begin{array}{l}\text { Edificios adyacentes: } \\
\text { posición en manzana }\end{array}$} & Esquina & 0,04 & 0,04 & 0,04 & 0,04 \\
\hline & Terminal & 0,06 & 0,06 & 0,06 & 0,06 \\
\hline \multicolumn{2}{|c|}{$\begin{array}{l}\text { Edificios adyacentes: diferencia de } \\
\text { altura entre edificios }\end{array}$} & \multicolumn{4}{|c|}{$[-0,04,0,04] f\left(h_{\text {relat }}\right)$} \\
\hline \multicolumn{2}{|c|}{ Planta blanda } & 0,2 & 0,2 & 0,2 & 0,2 \\
\hline
\end{tabular}

$R C=$ razón de compacidad del edificio según ecuación (3.3); $\partial=$ parámetro relacionado con la irregularidad en altura de la edificación definido en ecuación (3.1); $h_{\text {relat }}=$ diferencia entre el número de plantas de dos edificaciones adyacentes, según Figura 3.1. 


\section{CAPÍTULO 4 EJEMPLO DE APLICACIÓN A LOS DAÑOS DERIVADOS DEL SISMO DE LORCA DE 2011}

\subsection{INTRODUCCIÓN}

En este capítulo se aplican las distintas variantes disponibles del Método del Índice de Vulnerabilidad (MIV) y el nuevo modelo propuesto en esta tesis a los daños en edificaciones observados en el sismo de Lorca de 2011, con objeto de comprobar el ajuste de las distintas metodologías a una base de datos de daños reales en edificaciones.

\subsection{MARCO GENERAL DE ACTUACIÓN}

\subsubsection{La ciudad de Lorca}

Situado en el Sureste de la península Ibérica, el término municipal de Lorca (Murcia) es el segundo de mayor extensión de España, por detrás de Cáceres, con una superficie de 1.600 $\mathrm{km}^{2}$ (Figura 4.1). Comprende un territorio con una elevada variedad y diversidad natural, paisajística y productiva, con grandes contrastes entre la franja costera del sur, las amplias zonas de huerta en el entorno del río Guadalentín y el núcleo urbano de Lorca y las áreas más montañosas de las pedanías altas al Norte (Figura 4.2).



Figura 4.1. Situación del término municipal de Lorca dentro de la Región de Murcia. 


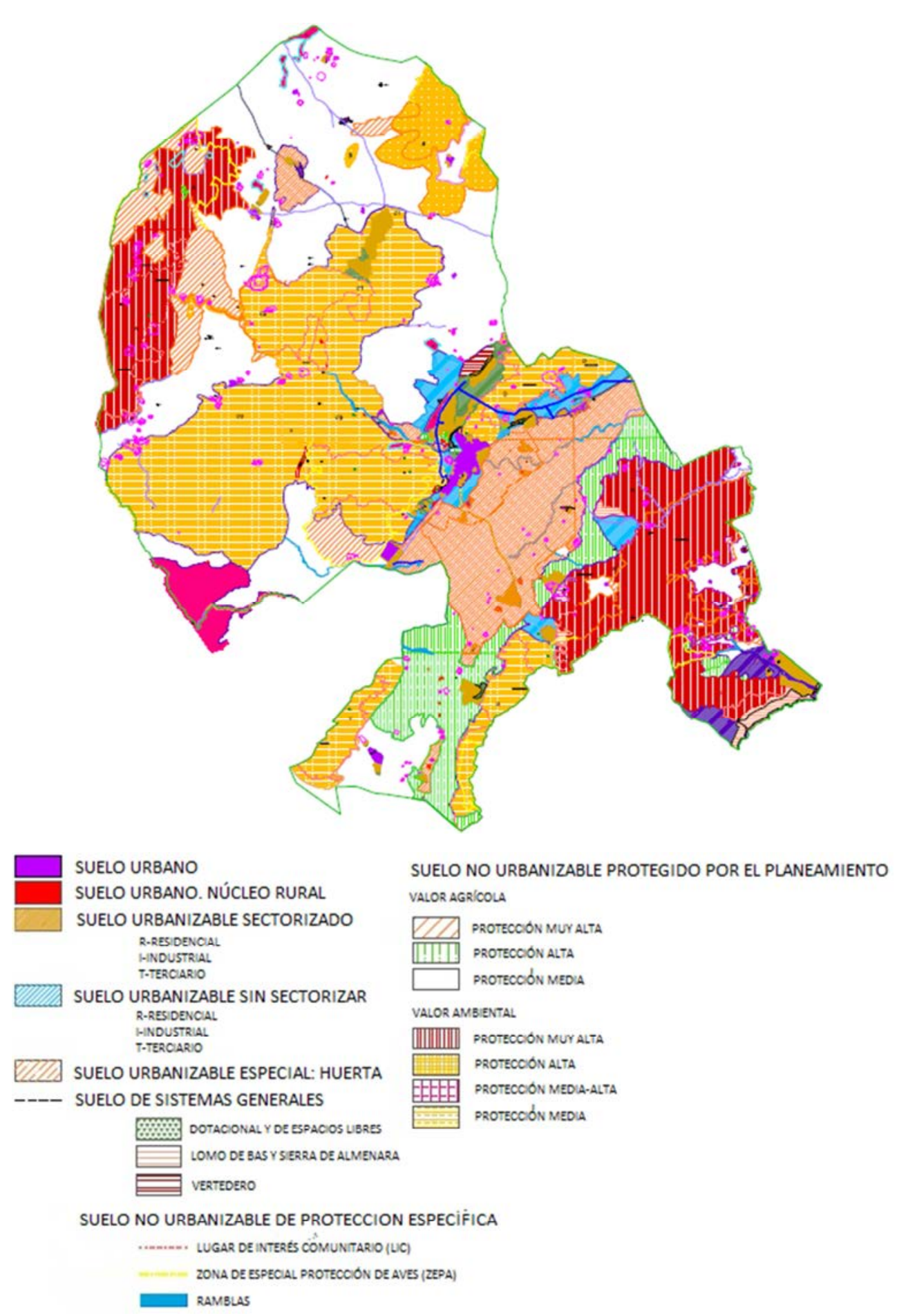

Figura 4.2. Clasificación del suelo y zonificación establecida por el PGMO de Lorca.

En cuanto a su desarrollo urbanístico, la ciudad de Lorca presenta un carácter eminentemente lineal. La expansión del casco histórico, situado en las faldas del escarpe montañoso elevado donde se encuentra el castillo, ha estado condicionada por la topografía, los cauces de la rambla de Tiata y el río Guadalentín, y el trazado de la línea ferroviaria (Figura 4.3):

$\checkmark$ La orografía del terreno ha impedido el desarrollo urbano hacia el Oeste. 
$\checkmark$ La rambla de Tiata, y posteriormente la línea ferroviaria, han contenido la expansión por el Este, separando el núcleo urbano de la ciudad de las zonas rurales y de huerta, las cuales ocupan el amplio valle del río hasta la sierra de Almenara.

$\checkmark$ El cauce seco del río Guadalentín (sólo discurre agua en episodios de fuertes lluvias torrenciales) aísla también a la zona Norte de la ciudad, dada la presencia de únicamente dos puentes con tráfico rodado.

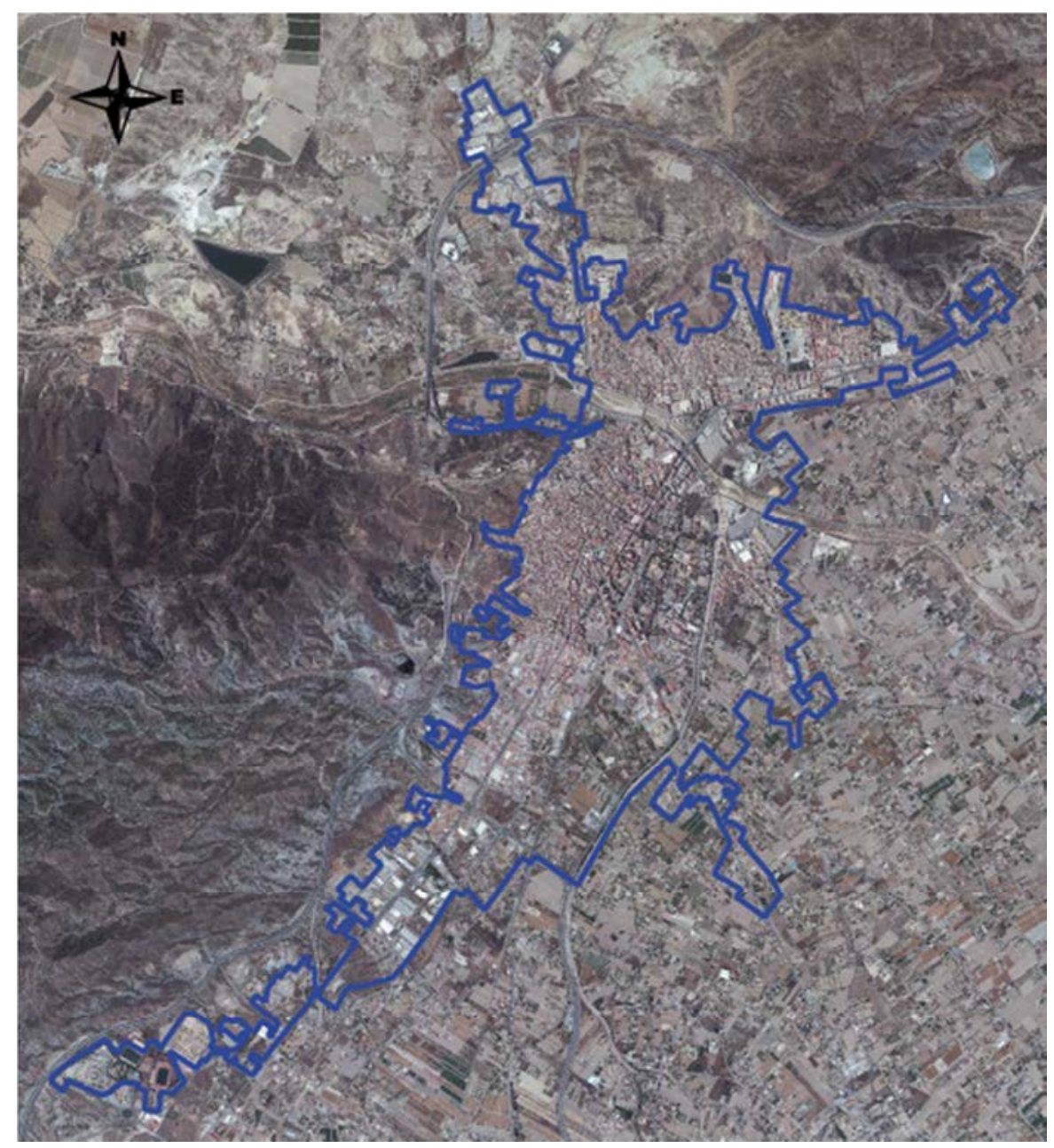

Figura 4.3. Delimitación del núcleo urbano de la ciudad de Lorca.

De este modo, el crecimiento urbano se ha producido principalmente a lo largo de la carretera nacional N-340 que une Murcia y Almería, la cual discurre por el borde de las sierras de la Torrecilla y Tercia que delimitan el valle del Guadalentín por su lado Oeste.

Las principales estructuras urbanas que componen la ciudad se sitúan en torno al eje viario principal, fuertemente colapsado, constituido por la avenida de Europa, la avenida Juan Carlos I, la calle Jerónimo de Santa Fe y la carretera de Granada. Este eje ha sustituido al eje histórico tradicional, constituido por las calles Mayor, Santo Domingo, Corredera, Nogalte y Pérez Casas, sensiblemente paralelo, pero de mucha menor capacidad, habilitado actualmente para tránsito peatonal en su mayor parte. 
Este crecimiento lineal se ha visto modificado ligeramente por el ensanche transversal desarrollado en torno a la alameda de Cervantes en dirección a la carretera RM-621 (antigua C3211), que conecta la ciudad con la costa y el municipio de Águilas.

Los denominados Barrios Altos, situados en las proximidades del castillo, presentan problemas estructurales por su nula o escasa conexión viaria con el resto de la ciudad, mostrando además una profunda degradación de su parque edificado y la carencia casi absoluta de equipamientos y servicios. En cuanto a los barrios de San Cristóbal, Apolonia y Los Ángeles, localizados al otro lado del río Guadalentín, muestran un elevado grado de aislamiento con escasez de equipamientos y estructuras urbanas. Al Este destaca la zona de viviendas residenciales unifamiliares situada entre la línea ferroviaria y la rambla de Tiata.

Las diversas actuaciones de renovación y regeneración urbana realizadas en la ciudad tras el terremoto del año 2011, financiadas por la Comunidad Autónoma de la Región de Murcia y el Banco Europeo de Inversiones, han mejorado notablemente las redes de infraestructuras, servicios y equipamientos de la ciudad, minorando en parte las citadas deficiencias estructurales en materia urbanística.

Al tratarse de una ciudad histórica, Lorca posee un parque inmobiliario variado, donde conviven tipologías constructivas de edad y naturaleza diversa (Martínez-Cuevas, 2014; Benito et al., 2015):

$\checkmark$ En lo relativo a la edificación tradicional, el casco antiguo de Lorca está compuesto principalmente por estructuras murarias de mampostería de piedra con forjados de madera, diseñadas según reglas de buena práctica constructiva. Estas tipologías presentan una elevada vulnerabilidad debido a la gran masa que poseen y al escaso empotramiento entre los planos murarios. Edificios singulares, como iglesias, palacios y algunos de la expansión del siglo XIX, poseen fábrica de ladrillo que mejoran el empotramiento entre planos murarios y reducen la masa de la edificación, presentado menores niveles de vulnerabilidad (Figura 4.4a).

$\checkmark \quad$ A mediados del siglo XX se produce un cambio conceptual en el diseño estructural. Aparecen las primeras edificaciones basadas en pórticos de hormigón armado o acero, en las que el cerramiento del edificio pasa a tener un carácter no estructural, configurando la trama urbana de la ciudad (Figura 4.4b). Se publican también los primeros códigos de diseño de obligado cumplimiento, dando lugar a la denominada edificación tecnológica. Las características y la respuesta sísmica esperable de estas edificaciones dependen de su periodo de construcción y de la normativa de diseño vigente en ese momento. 


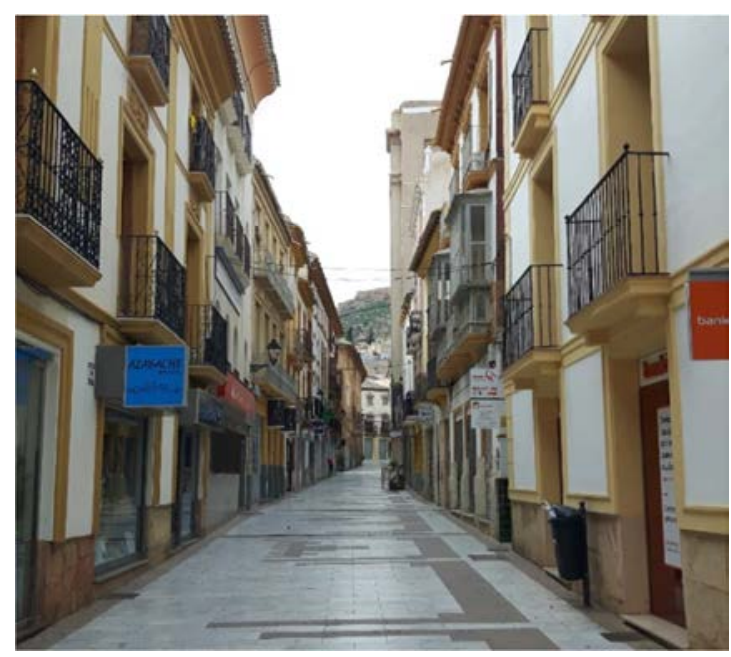

(a)

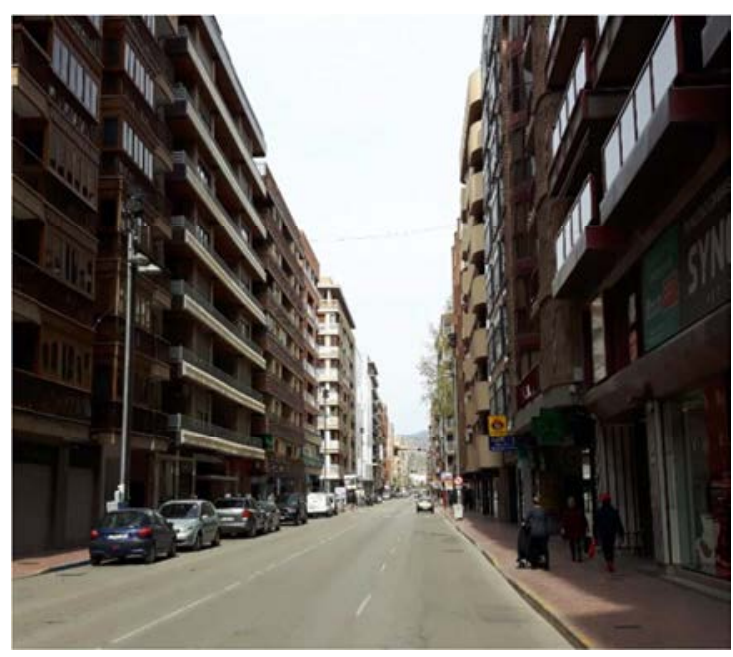

(b)

Figura 4.4. Ejemplos de vías de Lorca con dos tipologías edificatorias de distintos periodos. (a) Calle Pío XII, tipo tradicional en el casco antiguo. (b) Avenida Juan Carlos I, tipo tecnológico en la trama urbana (Foto: Dep. Ingeniería Civil, UPCT, 2016).

\subsubsection{El terremoto del 11 de mayo de 2011}

A las 16:47 UTC del 11 de mayo del 2011, un terremoto de magnitud $M_{w}=5,1$ sacudió la ciudad de Lorca. Con epicentro a pocos kilómetros del núcleo urbano, el sismo causó daños generalizados en el parque edificado de la ciudad, tanto en edificaciones tradicionales como en aquellas de tipo tecnológico, más recientes. Se registraron 9 fallecidos y más de 300 heridos, y unas 10.000 personas no pudieron volver a sus casas (Salgado-Gálvez et al 2015).

El terremoto principal fue precedido por otro evento de magnitud $M_{w}=4,5$ a las 15:05 UTC. Aunque causó daños limitados, debilitó y aumentó la vulnerabilidad de las edificaciones frente a posteriores sismos. La réplica de mayor tamaño se produjo a las 20:37 UTC con una magnitud de $M_{w}=3,9$. Destaca la superficialidad del hipocentro de todos los eventos, con profundidades de entre 2 y $4 \mathrm{~km}$ (Tabla 4.1 ).

Tabla 4.1. Magnitud y profundidad del hipocentro de los terremotos principales de la serie sísmica del 11 de mayo en Lorca (Cabañas et al., 2011, 2014).

\begin{tabular}{cccc}
\hline Evento & $\begin{array}{c}\text { Hora } \\
\text { (GMT) }\end{array}$ & $M_{w}$ & $\begin{array}{c}\text { Profundidad } \\
\text { aproximada } \\
(\mathrm{km})\end{array}$ \\
\hline Premonitorio & $15: 05$ & 4,5 & 2 \\
Principal & $16: 47$ & 5,1 & 3 \\
Réplica & $20: 37$ & 3,9 & 4 \\
\hline
\end{tabular}

En la Tabla 4.2 se muestran los valores máximos de aceleración, velocidad y desplazamiento del terreno para los tres terremotos principales, registrados en el acelerógrafo situado en el núcleo urbano de Lorca. 
Tabla 4.2 Aceleración, velocidad y desplazamiento de los tres eventos principales de la serie sísmica del 11 de mayo, registrados en el acelerógrafo del núcleo urbano de Lorca (Susagna et al., 2012).

\begin{tabular}{ccccc}
\hline Sismo & Componente & $\begin{array}{c}\text { Aceleración } \\
\left(\mathrm{cm} / \mathrm{s}^{2}\right)\end{array}$ & $\begin{array}{c}\text { Velocidad } \\
(\mathrm{cm} / \mathrm{s})\end{array}$ & $\begin{array}{c}\text { Desplazamiento } \\
(\mathrm{cm} / \mathrm{s})\end{array}$ \\
\hline $\begin{array}{c}\text { Premonitorio } \\
15: 05: 13\end{array}$ & $\mathrm{E} 30^{\circ} \mathrm{N}$ & 128,03 & 4,05 & 0,31 \\
$M_{w}=4,5$ & $\mathrm{~N} 30^{\circ} \mathrm{W}$ & 270,39 & 12,99 & 0,98 \\
& $\mathrm{~V}$ & 75,03 & 2,31 & 0,24 \\
$\begin{array}{c}\text { Principal } \\
16: 47: 25\end{array}$ & $\mathrm{E} 30^{\circ} \mathrm{N}$ & 151,18 & 14,36 & 1,26 \\
$M_{w}=5,1$ & $\mathrm{~N} 30^{\circ} \mathrm{W}$ & 359,48 & 35,76 & 2,99 \\
& $\mathrm{~V}$ & 114,16 & 7,61 & 1,19 \\
& $\mathrm{E} 30^{\circ} \mathrm{N}$ & 25,89 & 0,81 & 0,04 \\
$\begin{array}{c}\text { Réplica } \\
20: 37: 45\end{array}$ & $\mathrm{~N} 30^{\circ} \mathrm{W}$ & 63,59 & 1,78 & 0,13 \\
$M_{w}=3,9$ & $\mathrm{~V}$ & 19,64 & 0,55 & 0,04 \\
\hline
\end{tabular}

Según la base de datos del IGN, los valores máximos de aceleración registrados para la componente horizontal de azimut $\mathrm{N} 30^{\circ} \mathrm{W}$ en los eventos premonitorio y principal de la serie, de 270,39 y $359,48 \mathrm{~cm} / \mathrm{s}^{2}$, respectivamente, son los más grandes instrumentalizados nunca en la península Ibérica. En la Figura 4.5 se muestran los registros sísmicos de aceleración, velocidad y desplazamiento correspondientes con esta componente $\mathrm{N} 30^{\circ} \mathrm{W}$ para el sismo principal, el cual se correspondería esencialmente con un pulso simétrico de aproximadamente $1 \mathrm{~s}$ de periodo (Cabañas et al., 2011).

Estos elevados valores de aceleración pico son poco frecuentes en terremotos de magnitudes moderadas, entre 4 y 5 , los cuales suelen causar daños limitados. No obstante, la somera profundidad de la superficie de ruptura y su proximidad al núcleo urbano de Lorca condicionaron las características de la serie sísmica. Asimismo, efectos adicionales de directividad pudieron dar lugar a este carácter impulsivo de corta duración (Susagna et al., 2012; Alguacil et al., 2014). En la Figura 4.6 se muestra un esquema de la posición del epicentro, situado al Noreste de la ciudad, y la profundidad y dimensiones de la superficie de ruptura sísmica.

En cuanto a la estimación de la intensidad macrosísmica del terremoto, según se comentó en el apartado 2.1.1, se ha establecido un grado VII en la escala EMS-98 en el núcleo urbano de Lorca (Cabañas et al., 2011; De Luca et al. 2013). No obstante, otros autores elevan hasta un grado VIII esta intensidad para algunos barrios de la ciudad (Figueras et al., 2012; Alguacil et al., 2014) debido a la gravedad de los daños observados y a las características del movimiento del terreno obtenidas. 


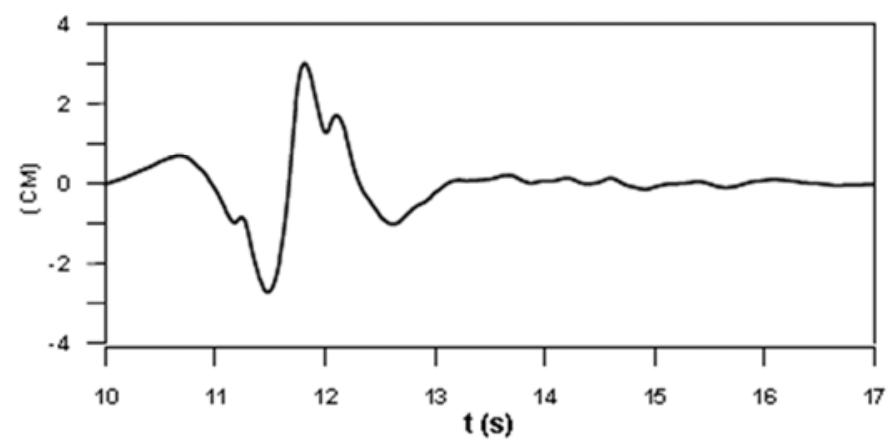

(a)

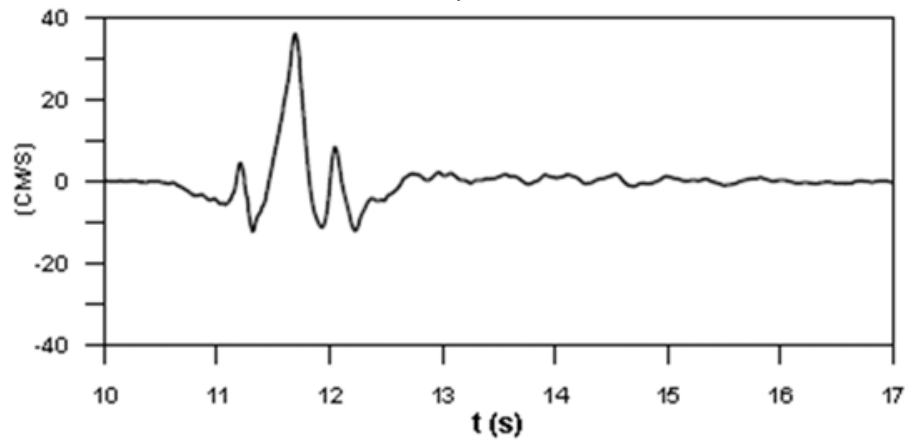

(b)

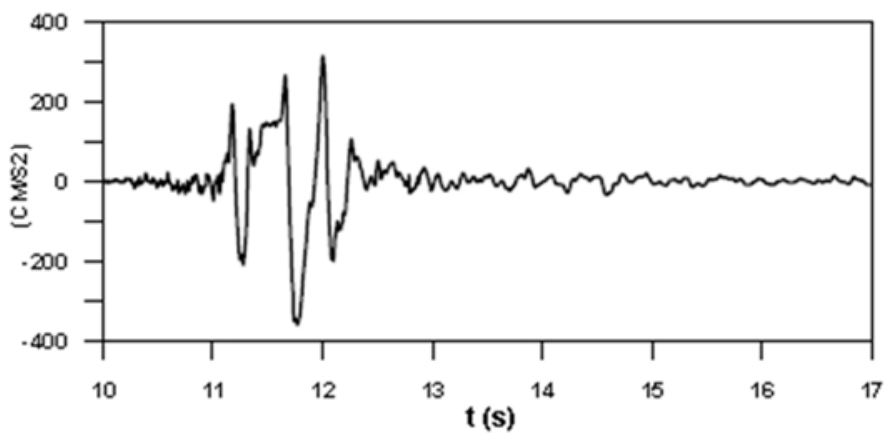

(c)

Figura 4.5. Registros sísmicos en el acelerógrafo del núcleo urbano de Lorca, para la componente horizontal de azimut $\mathrm{N} 30^{\circ} \mathrm{W}$, del evento principal de la serie sísmica de magnitud $M_{w}=5,1$. (a)

Desplazamiento. (b) Velocidad. (c) Aceleración (Susagna et al., 2012).

\subsection{IMPLEMENTACIÓN DE LA BASE DE DATOS}

Con el fin de comprobar el adecuado ajuste de la modificación metodológica propuesta en esta tesis para la evaluación de la vulnerabilidad sísmica de edificaciones de hormigón armado, se ha realizado la aplicación de la metodología a los daños observados en el sismo de Lorca de 2011.

A partir de las campañas de campo realizadas por el Departamento de Ingeniería Civil de la UPCT tras el terremoto de 2011, y las inspecciones post-sismo documentadas por la Consejería de Obras Públicas de la Comunidad Autónoma de la Región de Murcia, se ha abordado un proceso de organización, gestión y cribado de la información disponible para elaborar una base de datos de daños en las edificaciones de hormigón armado. 


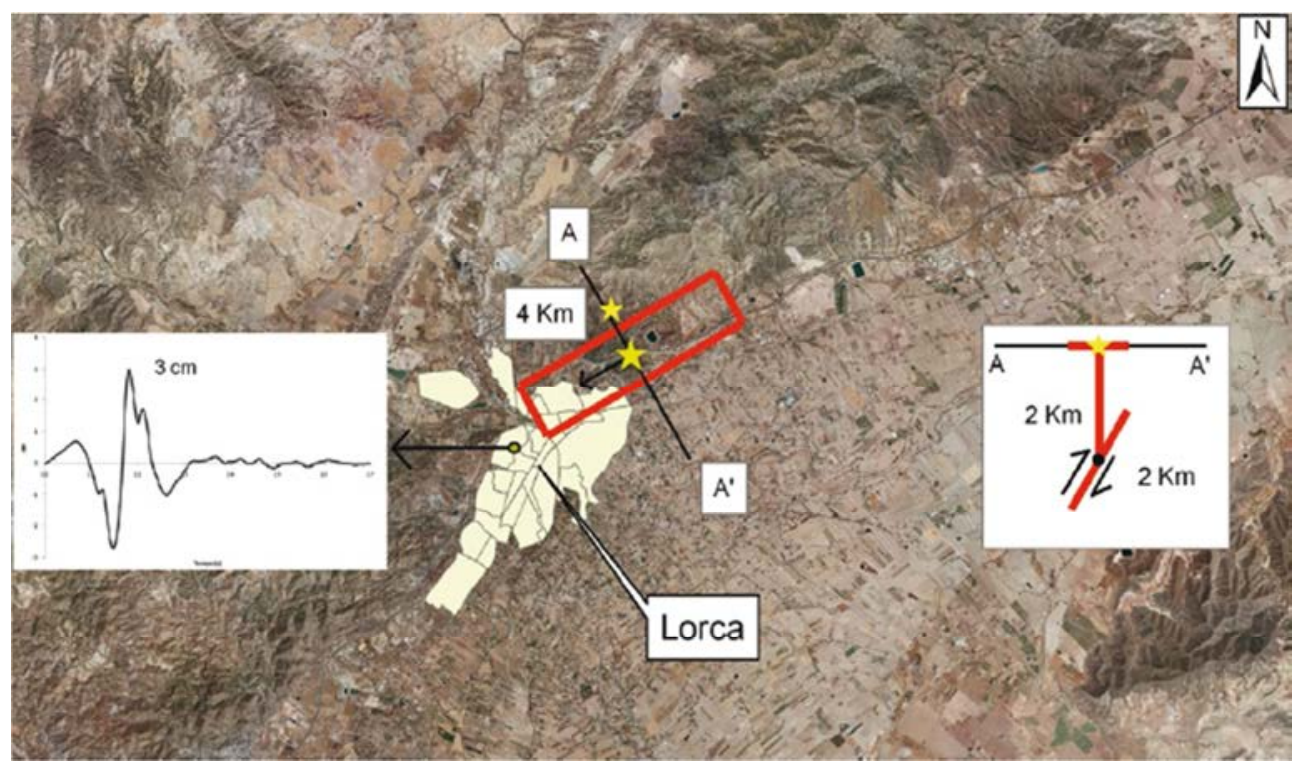

Figura 4.6. Posición del epicentro de la ruptura sísmica y profundidad del hipocentro, con dimensiones estimadas, y registro del desplazamiento para la componente horizontal N30 $\mathrm{W}$ (Susagna et al., 2012).

Junto con los datos generales del edificio, como su referencia catastral, dirección o número de plantas, se han identificado las características urbanísticas y arquitectónicas necesarias para la obtención del índice de vulnerabilidad de la edificación según el Método del Índice de Vulnerabilidad (MIV). Asimismo, a partir de la documentación gráfica disponible, se ha determinado el grado de daño sísmico del edificio según la escala EMS-98.

De este modo, el daño observado en cada edificación puede compararse con el correspondiente grado de daño calculado según la metodología LM1 de RISK-UE, para un sismo de características similares al de Lorca de 2011. Los resultados obtenidos según el modelo propuesto en la tesis se han comparado con los obtenidos al aplicar las distintas revisiones publicadas de la metodología (Giovinazzi, 2005; Lantada, 2007; Feriche, 2012; Martínez-Cuevas \& Gaspar-Escribano, 2016).

En los siguientes apartados se describe el procedimiento empleado para la construcción de la base de datos y el posterior análisis y discusión de los resultados obtenidos.

\subsubsection{Organización de la información}

Para sistematizar la recolección de datos se empleó la ficha mostrada en la Figura 4.7, adaptada a partir de trabajos previos de evaluación rápida post-sismo de daños en edificaciones (Tomás \& Díaz, 2013; Alhama et al. 2015; SISMIMUR, 2015; Martínez-Cuevas \& Gaspar-Escribano, 2016). Esta hoja permitía registrar, para cada edificación evaluada, los daños sísmicos que presentaba y los parámetros con mayor influencia en la respuesta sísmica. 


\section{DAÑOS EN EDIFICACIONES. SISMO DE LORCA 2011}

\section{DATOS GENERALES DE LA EDIFICACIÓN}

ID:

$\mathrm{N}^{\mathrm{o}}$ de plantas sobre rasante: $\square$

Dirección:

Tipología edificatoria:

U. Man.

Otras:

\section{CONFIGURACIÓN URBANÍSTICA Y ARQUITECTÓNICA}

Irregularidad en planta:

Sí:

No:

Irregularidad en altura:

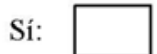

No:

Junta sísmica entre edificios:

Sí:

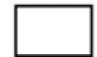

No:

Relación con edificios adyacentes: Mismo nivel

Dif. nivel:

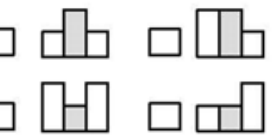

Posición del edif. en la manzana: Aislado: Intermedio:

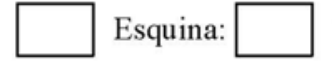

Terminal:

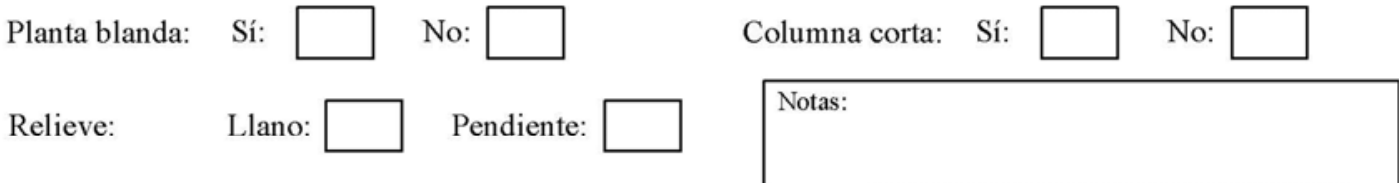

\section{EVALUACIÓN DEL GRADO DE DAÑO MEDIO $\mu D$}

$\mu D=1$

- Fisuras en elementos no estructurales. Severidad leve (ancho $>2 \mathrm{~mm}$ en menos del $20 \%$ de los elem. dañados).

$\square$ Cubierta $\square$ Cerramientos $\square$ Particiones interiores - Sin daño en los elementos estructurales.

$\mu D=2$

- Fisuras en elementos no estructurales. Severidad moderada (ancho $>2 \mathrm{~mm}$ en más del $60 \%$ de los elem. dañados).

$\square$ Cubierta $\square$ Cerramientos $\square$ Particiones interiores

- Fisuras leves en elementos estructurales (tipo 1, 2,3), con ancho $<2 \mathrm{~mm}$, en menos del $40 \%$ de los elem. dañados.

Notas: $\mu D=3$

- Fisuras en elementos no estructurales. Severidad moderada (ancho $>2 \mathrm{~mm}$ en más del $60 \%$ de los elem. dañados).

$\square$ Cubierta $\square$ Cerramientos $\square$ Particiones interiores

- Fisuras leves en elementos estructurales (tipo 1, 2,3), con ancho $<2 \mathrm{~mm}$, en más del $40 \%$ de los elem. dañados.

- Fisuras moderadas en elementos estructurales (tipo 1, 2,3) con ancho $>2 \mathrm{~mm}$, en más del $20 \%$ de los elem. dañados.

- Pérdida de recubrimiento y pandeo de las armaduras.

$\mu D=4 \square$
- Colapso general $\square \quad$ - Asiento de la cimentación $\square$

Figura 4.7. Ficha empleada en la campaña de recopilación de datos para la evaluación del índice de vulnerabilidad y el correspondiente grado de daño de cada edificación.

La ficha para el registro de los daños en las edificaciones se divide en tres secciones: 
I. Datos generales de la edificación, como la dirección, el número de plantas o la tipología estructural.

II. Identificación de configuraciones constructivas y urbanísticas de la edificación, como la presencia de columnas cortas o plantas blandas, con influencia en la respuesta sísmica de la estructura.

III. Evaluación del grado daño de la edificación en la escala EMS-98 a partir de las afecciones observadas.

En una segunda etapa de trabajo, esta información era cotejada y completada con los datos procedentes del Catastro Inmobiliario, como la referencia catastral, el periodo de construcción de la edificación y su superficie, de tal modo que se pudieran obtener todos los modificadores de comportamiento definidos en el método MIV de RISK-UE.

De este modo, la base de datos se fue estructurando según los siguientes bloques:

A. Datos identificativos y de información general de cada edificación.

B. Definición del grado de daño observado tras el terremoto, en la escala EMS-98.

C. Caracterización de los modificadores del índice de vulnerabilidad según las distintas revisiones propuestas en la literatura.

D. Obtención del índice de vulnerabilidad de cada edificación a partir del índice de vulnerabilidad básico, según su tipología estructural, y la suma de los distintos modificadores.

E. Estimación del grado de daño medio de la edificación a partir del índice de vulnerabilidad obtenido, según la metodología LM1 de RISK-UE, para un sismo de intensidad VII en la escala EMS-98. Como cálculo adicional, se determinaron también los grados de daño correspondientes a una intensidad $I_{E M S 98}=$ VIII .

\subsubsection{Datos generales de la edificación}

En la Figura 4.8 se muestra un extracto del bloque de información de carácter general de la base de datos para cada edificación: referencia catastral, dirección, superficie, número de plantas y periodo de construcción. Asimismo, se incluyen coordenadas geográficas, en sistema ETRS-89, con objeto de georreferenciar los edificios mediante técnicas SIG.

En la Figura 4.9 se muestra un ejemplo de la ficha implementada para una determinada edificación. En el Anexo A se incluye una selección de las fichas elaboradas para la construcción de la base de datos. 


\begin{tabular}{|c|c|c|c|c|c|c|c|}
\hline \multicolumn{8}{|c|}{ INFORMACIÓN GENERAL } \\
\hline FID & REFCAT & DIRECCIÓN & COOR. $x$ & COOR.Y & $\begin{array}{r}\text { SUPERFICIE } \\
-\end{array}$ & $\begin{array}{c}\text { No } \\
\text { PLANTF - }\end{array}$ & AÑo \\
\hline 의 & 4495001XG1649E & Ctra. Granada, 1 & 614360 & 4169461 & 109 & 1 & 1960 \\
\hline 1 & $4707909 \times \mathrm{XG1740F}$ & C/Granero, 3 & 614630 & 4170560 & 254 & 4 & 1984 \\
\hline 4 & $4699125 \times G 1649 \mathrm{H}$ & C/Jerónimo de Santa Fe, 42 & 614516 & 4169773 & 518 & 4 & 2008 \\
\hline 5 & $4699125 \times G 1649 \mathrm{H}$ & C/Puerto Lumbreras, 39 & 614501 & 4169773 & 518 & 2 & 2008 \\
\hline 6 & 4505218 XG1740F & C/Soledad, 3 & 614435 & 4170396 & 198 & 2 & 2007 \\
\hline 7 & 5212017XG1751A & C/Carril de Caldereros, 33 & 615113 & 4170921 & 247 & 3 & 1977 \\
\hline 8 & 4600907 XG1740B & C/José Mouliaá, 48 & 614535 & 4169837 & 343 & 4 & 1981 \\
\hline 9 & 4706024 XG1740F & C/Narciso Yepes, 2 & 614604 & 4170327 & 264 & 4 & 1986 \\
\hline 10 & $4500021 X G 1740 B$ & C/Salado, 3 & 614385 & 4169800 & 159 & 2 & 2003 \\
\hline 11 & 6015811XG1761E & C/Galicia, 1 & 615900 & 4171358 & 506 & 4 & 1995 \\
\hline 12 & $4395803 \times$ X $1649 \mathrm{E}$ & C/Guitarrista Cano, 17 & 614197 & 4169328 & 180 & 2 & 1956 \\
\hline 13 & 5414703XG1751C & $\mathrm{C} /$ Huercal Overa, 2 & 615325 & 4171173 & 139 & 4 & 1962 \\
\hline 14 & 4915909 XG1741F & C/Eulogia Periago, 38 & 614842 & 4171337 & 61 & 4 & 1997 \\
\hline 15 & 4704614XG1740D & Avda. Portugal, 9 & 614623 & 4170207 & 149 & 4 & 1960 \\
\hline 16 & 4799021XG1649H & C/Ministro Pérez de Meca, 6 & 614618 & 4169702 & 109 & 4 & 2009 \\
\hline 17 & 6317008XG1761E & C/Francisco Salzillo, 4 & 616135 & 4171535 & 912 & 3 & 1972 \\
\hline 18 & 5395005XG1659E & Alameda de Cervantes, 85 & 615186 & 4169286 & 167 & 3 & 1980 \\
\hline 19 & 4804013 XG1740D & C/Abenhalaj, 7 & 614680 & 4170186 & 299 & 4 & 1968 \\
\hline 20 & $4697013 \times G 1649 \mathrm{~F}$ & C/Jerónimo de Santa Fe, 49 & 614408 & 4169525 & 674 & 4 & 1978 \\
\hline 21 & 4396301XG1649E & C/Sagrada Familia, 7 & 614266 & 4169491 & 185 & 3 & 1960 \\
\hline 22 & $5802005 \times$ X 17508 & Alameda Virgen de las Huerta & 615724 & 4170004 & 411 & 3 & 1968 \\
\hline
\end{tabular}

Figura 4.8. Detalle de la elaboración de la base de datos: bloque de información general de las edificaciones.

\subsubsection{Definición del grado de daño observado según la escala EMS-98}

La documentación gráfica disponible posibilitó la obtención del grado de daño observado en las edificaciones tras el terremoto de Lorca. Para ello, además de las directrices establecidas por la propia escala EMS-98 (Figura 2.15), se consideraron las recomendaciones establecidas en otros trabajos (SISMIMUR, 2015). En el caso de edificaciones aporticadas de hormigón armado, los daños símicos más habituales para cada grado de daño definido en la escala EMS98 se pueden resumir en:

$\checkmark \quad \boldsymbol{\mu}_{D}=1$ : Fisuras en tabiquería interior y cerramientos de albañilería, especialmente en encuentros con pilares y forjados (Figura 4.10a).

$\checkmark \boldsymbol{\mu}_{\boldsymbol{D}}=\mathbf{2}$ : Fisuras en pilares y vigas. Grietas en tabiquerías y cerramientos. Desconchados y caída de aplacados frágiles, antepechos de cubierta, alicatados cerámicos o zócalos recibidos con mortero (Figura 4.10 b).

$\checkmark \quad \boldsymbol{\mu}_{D}=3$ : Grietas en bases de pilares y en nudos estructurales con caída de recubrimiento de hormigón y pandeo de las armaduras. Grandes grietas en tabiquerías y muros de cerramiento con fallo de tabiques individuales (Figura 4.10c).

$\checkmark \boldsymbol{\mu}_{D}=4$ : Daños graves en elementos estructurales con fallo de nudos estructurales $y$ fallo de pilares a cortante. Posibilidad de fallo de pilares a nivel de planta y colapso general de la estructura (Figura 4.10d). 


\section{DAÑOS EN EDIFICACIONES. SISMO DE LORCA 2011}

DATOS GENERALES DE LA EDIFICACIÓN

ID: $\quad \mathrm{N}^{\circ}$ de plantas sobre rasante: 3

Dirección: C/Carril de Caldereros, 38

Tipología edificatoria:

U. Man.:

RC: Otras:

Mal estado de conservación del edificio.

Presencia de humedades generalizada

\section{CONFIGURACIÓN URBANISTICA Y ARQUITECTÓNICA}

$\begin{array}{lll}\text { Irregularidad en planta: } & \text { Sí: } \square \\ \text { Irregularidad en altura: } & \text { Sí: } \square \\ & \text { No: } \\ \text { Junta sísmica entre edificios: } & \text { Sí: } \square\end{array}$

Relación con edificios adyacentes: Mismo nivel

Dif. nivel:

Posición del edif. en la manzana: Aislado: Intermedio:
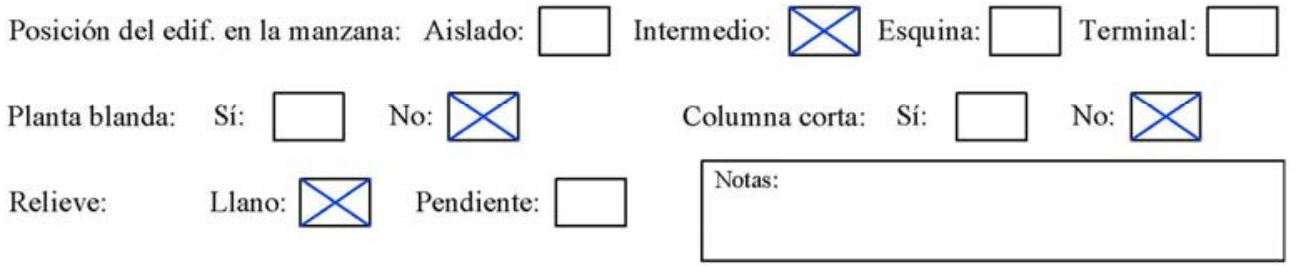

EVALUACIÓN DEL GRADO DE DAÑO MEDIO $\mu D$

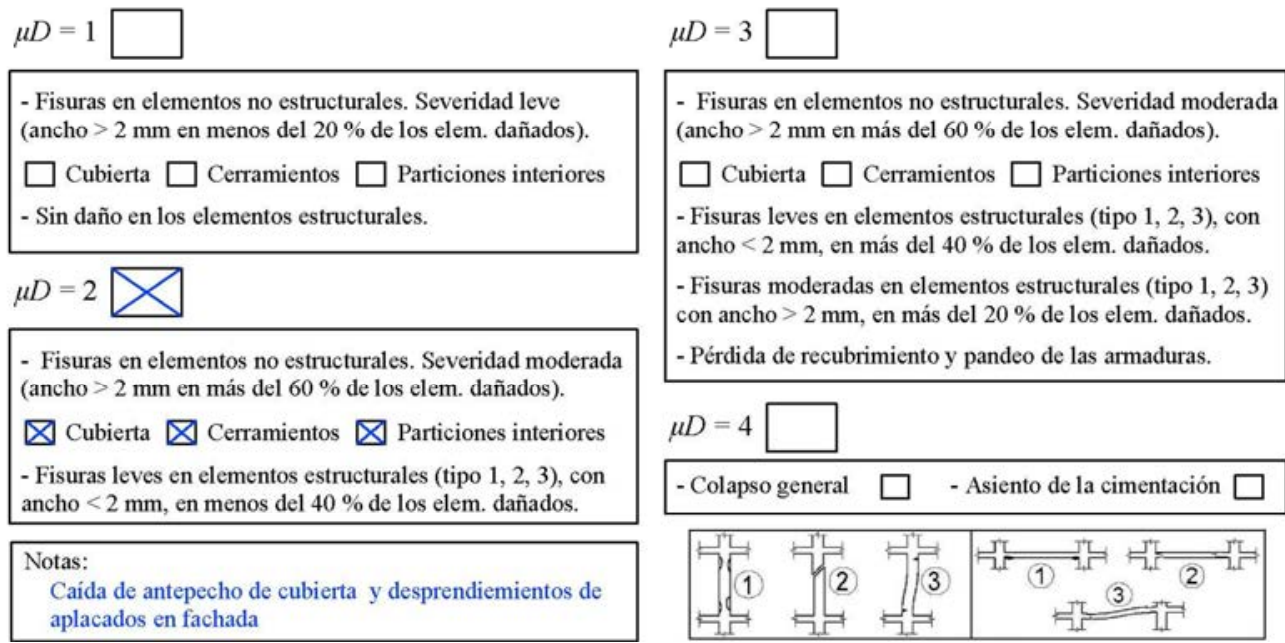

Figura 4.9. Ejemplo, para una determinada edificación, de la ficha empleada en la campaña de recopilación de datos para evaluar el índice de vulnerabilidad y el correspondiente grado de daño.

En las Figuras 4.11 a 4.13 se muestra un ejemplo de las afecciones más representativas observadas en las edificaciones tras el sismo de Lorca, para los principales grados de daño. Para aquellos casos en los que la determinación de dichos grados era dudosa o susceptible de interpretación, se adoptaron grados de daño intermedios de $\mu_{D}=1,5$ y $\mu_{D}=2,5$ con objeto de permitir un mejor ajuste numérico de los resultados obtenidos. 


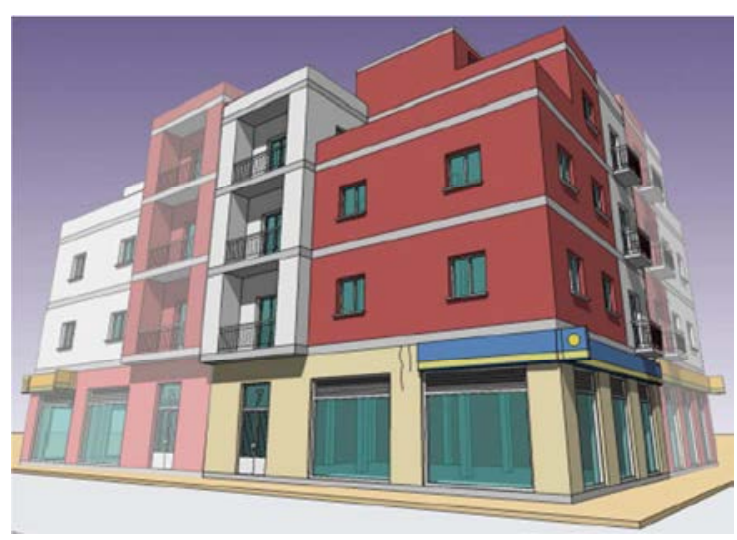

(a)

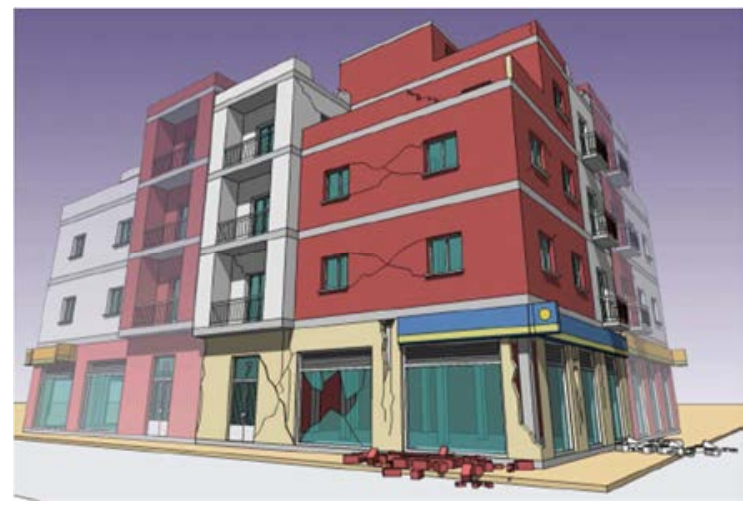

(c)

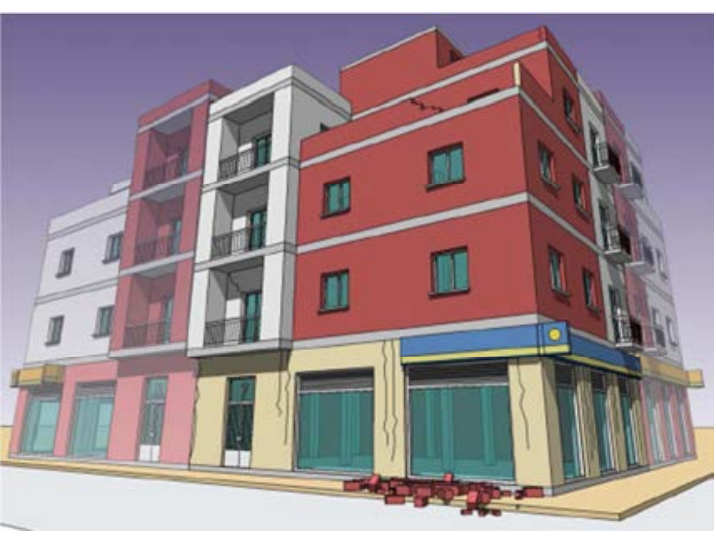

(b)

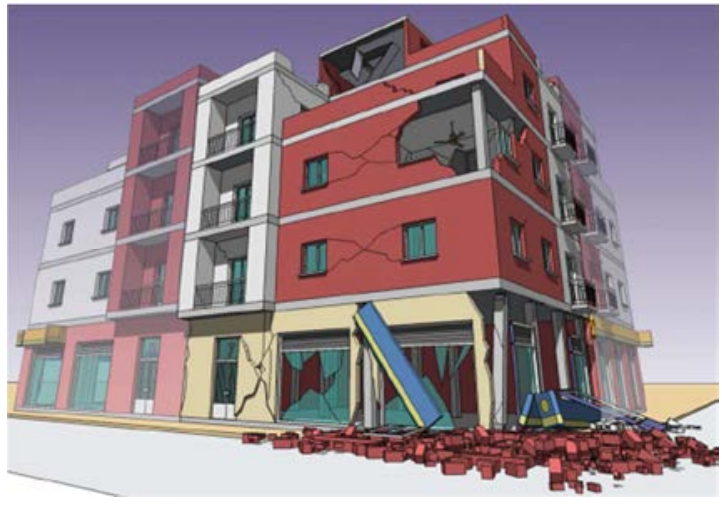

(d)

Figura 4.10. Modelización gráfica de una edificación con diversos grados de daño sísmico en la escala EMS-98. (a) $\mu_{D}=1$. (b) $\mu_{D}=2$. (c) $\mu_{D}=3$. (d) $\mu_{D}=4$ (SISMIMUR, 2015).

\subsubsection{Caracterización de los modificadores del índice de vulnerabilidad}

Para obtener los modificadores de comportamiento $M_{c}$ del índice vulnerabilidad fue necesaria la clasificación previa de la normativa sísmica española en los niveles de diseño sismorresistente pre-code, low-code, medium-code y high-code establecidos en RISK-UE.

La primera norma de ámbito nacional en la que se incluyen acciones sísmicas para el cálculo de estructuras fue la norma MV-101-1962 "Acciones de la edificación", publicada a inicios del año 1963. Este código fue sucesivamente renovado en los siguientes documentos específicamente destinados a acciones sísmicas:

$\checkmark$ Norma sismorresistente PGS-1-1968, aprobada por el D. 106/1969, de 16 de enero.

$\checkmark$ Norma sismorresistente PDS-1-1974, aprobada por el D. 3200/1974, de 30 de agosto.

$\checkmark$ Norma de Construcción Sismorresistente: Parte general y edificación (NCSE-94), aprobada por el R.D. 2543/1994, de 29 de diciembre.

$\checkmark$ Norma de Construcción Sismorresistente: Parte general y edificación (NCSE-02), aprobada por el R.D. 997/2002, de 27 de septiembre. 

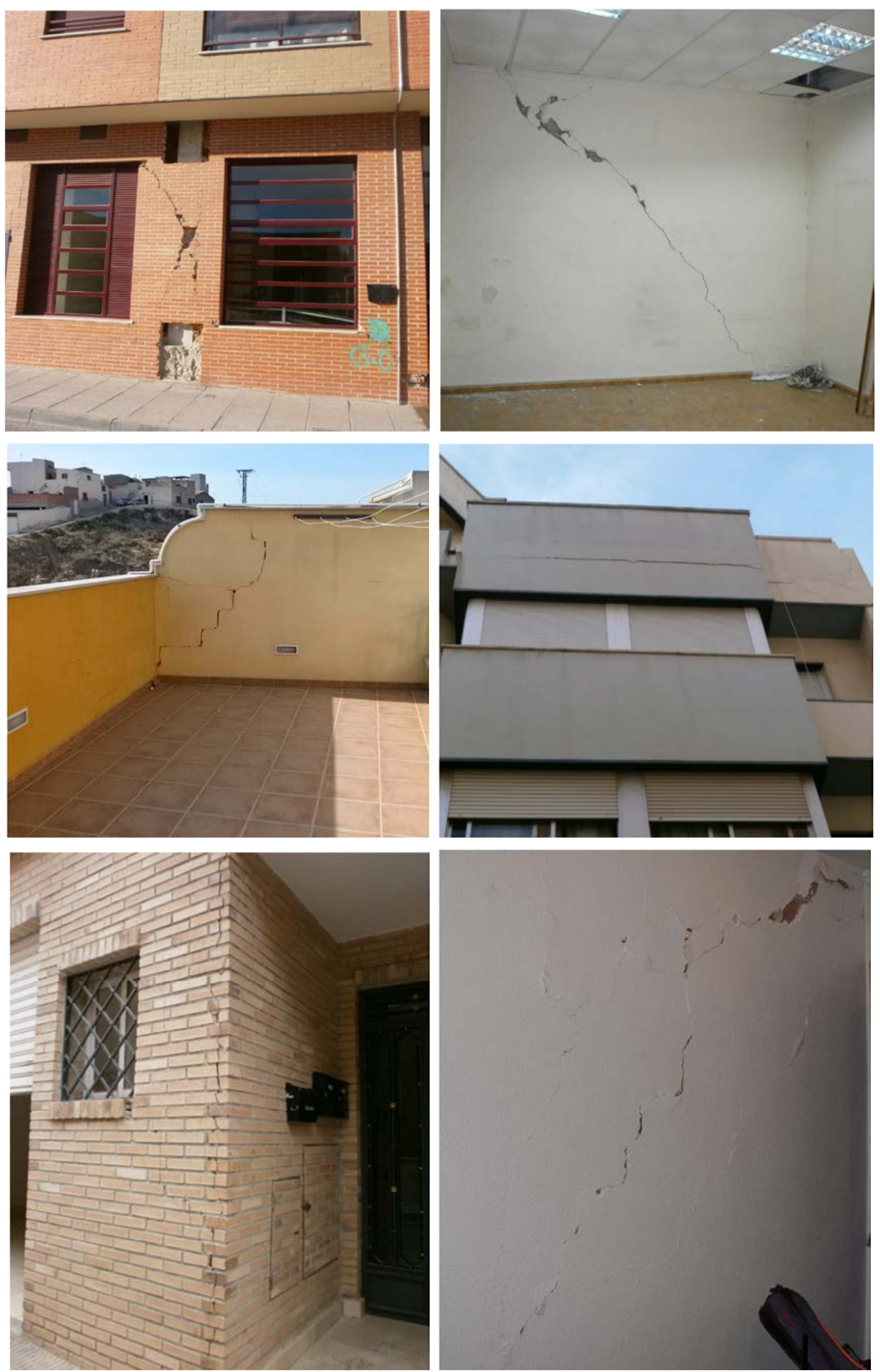

Figura 4.11. Daños en edificaciones tras el sismo de Lorca asociados a un grado de daño $\mu_{D}=1$ en la escala EMS-98. 

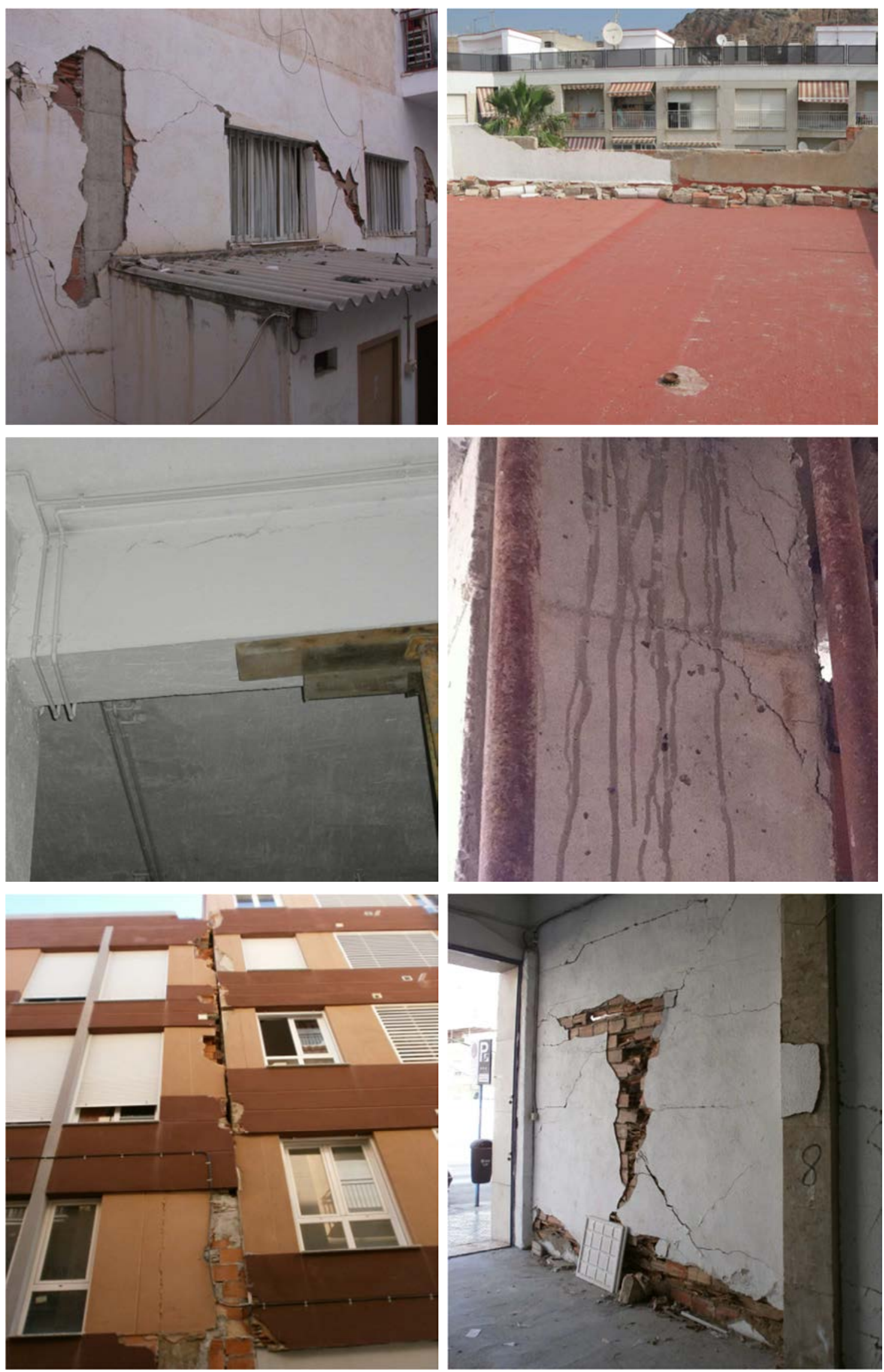

Figura 4.12. Daños en edificaciones tras el sismo de Lorca asociados a un grado de daño $\mu_{D}=2$ en la escala EMS-98. 

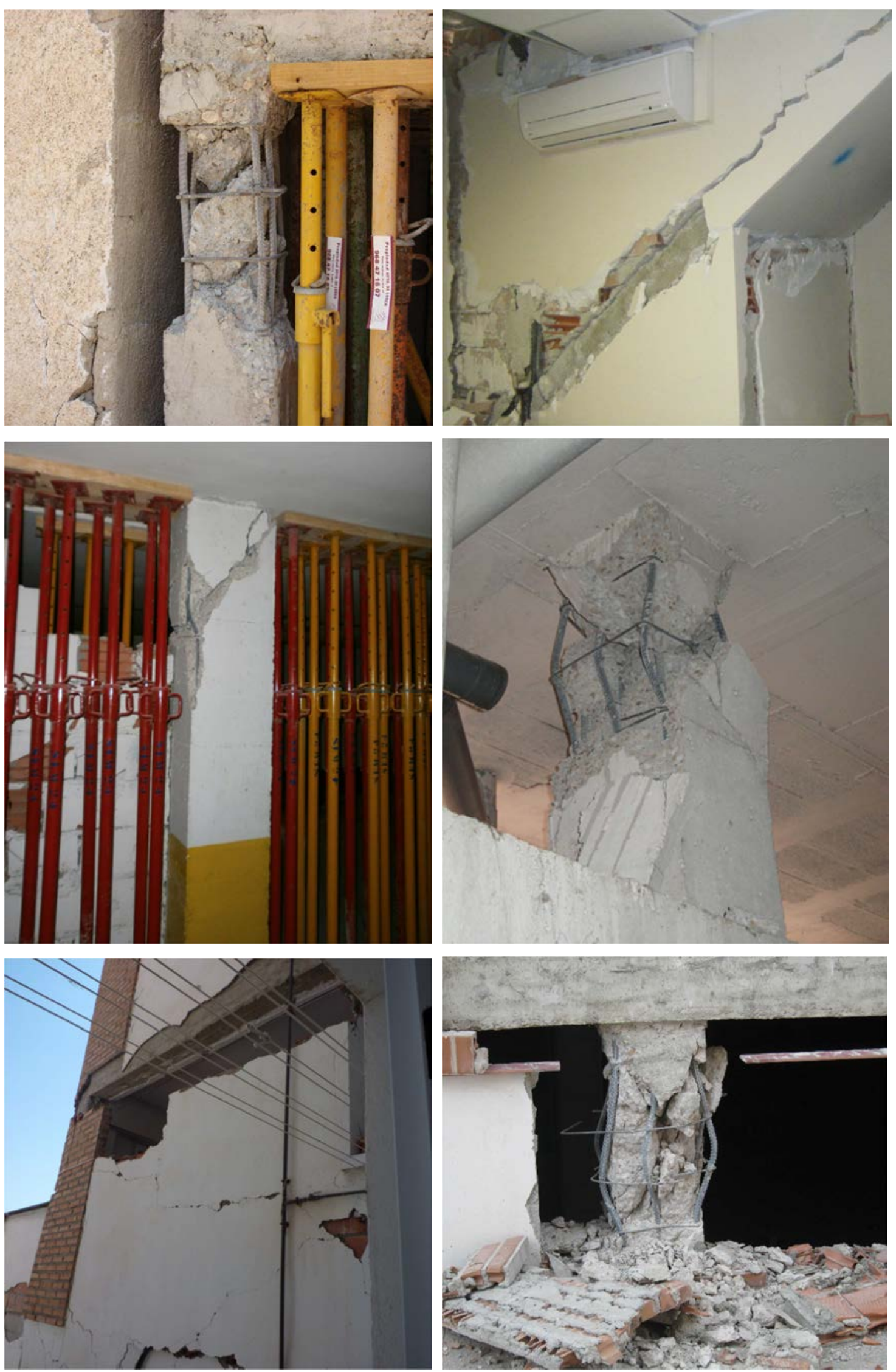

Figura 4.13. Daños en edificaciones tras el sismo de Lorca asociados a un grado de daño $\mu_{D}=3$ en la escala EMS-98. 
En la Tabla 4.3 se resume el análisis realizado de cada uno de estos códigos sísmicos en función de tres aspectos: los métodos de cálculo empleados, los aspectos relativos a la evaluación de la peligrosidad sísmica del ámbito de actuación, y las prescripciones y reglas establecidas para el dimensionamiento del sistema resistente.

Tabla 4.3. Comparativa de los códigos sísmicos publicados en España.

\begin{tabular}{|c|c|c|c|}
\hline Código sísmico & $\begin{array}{c}\text { Año de } \\
\text { publicación }\end{array}$ & $\begin{array}{c}\text { Plazo de } \\
\text { adaptación }\end{array}$ & $\begin{array}{c}\text { Definición de la } \\
\text { peligrosidad sísmica }\end{array}$ \\
\hline
\end{tabular}

MV-101-1962
(D. 195/1963)

Norma de acciones de la edificación, no específica para acciones de tipo sísmico. Basada en registros de sismicidad histórica, incluye reglas de cálculo de carácter muy básico.

Aprobada con carácter provisional, a expensas de la redacción del documento definitivo. Incorpora registros

PGS-1-1968

(D. 106/1969)

PDS-1-1974

(D. 3200/1974)

1974

2 años

$f\left(\mathrm{I}_{\mathrm{MSK}}\right)$ Determinista

instrumentales para la

evaluación de la peligrosidad sísmica. Incluye reglas de diseño y cálculo así como prescripciones constructivas generales, de carácter muy básico.

Incluye reglas de diseño y cálculo así como prescripciones constructivas generales, de carácter muy básico.

Incluye reglas de diseño y prescripciones constructivas tanto generales como específicas para edificaciones murarias, de hormigón armado y metálicas, así como consideraciones diversas acerca de otros elementos como cerramientos y particiones. Primer documento que incorpora detalles de disposiciones de armado en nudos.

Similar a NCSE-94. Incluye un mayor número de reglas $y$ detalles constructivos, incorporando una gran variedad de casuísticas, especialmente para edificaciones de hormigón armado.

Mejora NCSE-02, profundizando especialmente en el estudio de las estructuras metálicas. 
A partir de este estudio, y de las consideraciones descritas en el apartado 3.3, se establecen los siguientes niveles de código sísmico para la normativa sísmica española (Tabla 4.4).

Tabla 4.4. Clasificación de los niveles de código de diseño sísmico establecidos en RISK-UE en función del periodo de construcción de la edificación y de la norma sísmica española vigente.

\begin{tabular}{ccc}
\hline Periodo de construcción & Código sísmico de diseño & Nivel del código \\
\hline Anterior a 1963 & - & Pre-code \\
$1963-1970$ & MV-101 (1962) & Pre-code \\
$1971-1995$ & PGS-1 (1968) y PDS-1 (1974) & Low code \\
Posterior a 1995 & NCSE-1994 y NCSE-2002 & Medium code \\
\hline
\end{tabular}

Clasificaciones similares se han empleado en otros trabajos (Lantada et al., 2010; Feriche et al., 2012a; Martínez-Cuevas \& Gaspar-Escribano, 2016) aplicados a Lorca, entre otras ciudades.

La definición de estos niveles de diseño permitió caracterizar los modificadores de comportamiento de las edificaciones a partir de la base de datos implementada y de la información disponible en el servicio catastral, en función de los parámetros urbanísticos y arquitectónicos de cada una de ellas.

Estos modificadores fueron determinaron según la versión del método MIV adoptada por RISK-UE (Milutinovic \& Trendafiloski, 2003), las posteriores revisiones de Giovinazzi (2005), Lantada (2007), Feriche (2012) y Martínez-Cuevas \& Gaspar-Escribano (2016), y el modelo propuesto. Los valores establecidos para cada modificador según los distintos autores se resumen en la Tabla 2.15 del apartado 2.2.4.1 y en las Tablas 3.1, 3.4, 3.5 y 3.6 del apartado 3.2. La propuesta de nuevos modificadores se recoge en la Tabla 3.15 del apartado 3.3.

Por otra parte, se obtuvieron los modificadores regionales dependientes de las disposiciones constructivas y de las calidades específicas de las edificaciones de la zona de estudio, según las diferentes revisiones propuestas por Lantada (2007) y Feriche et al. (2012a), mostrados en las Tablas 2.16 y 2.17.

En la Figura 4.14 se muestra un extracto del bloque de la base de datos correspondiente a la obtención de los modificadores de comportamiento según las características específicas de cada edificación.

\subsubsection{Obtención del índice de vulnerabilidad de las edificaciones}

La tipología edificatoria RC1 fue la seleccionada para la obtención del índice de vulnerabilidad básica de las edificaciones de hormigón armado. Esta tipología se corresponde con entramados de hormigón armado resistentes a momento, con diseño sismorresistente 
ordinario y con cerramientos de fábrica no estructurales (Lungu et al. 2002; González 2010; Benito et al., 2015).

El índice de vulnerabilidad básico asociado a esta tipología puede determinarse según lo definido en la matriz BTM (Tablas 2.12 y 2.13).

\begin{tabular}{|c|c|c|c|c|c|c|c|}
\hline & \multicolumn{7}{|c|}{ OBTENCIÓN MODIFICADORES DE COMPORTAMIENTO $M_{C}$} \\
\hline FID & MC_PLT_MIL03 & MC_PIT_GIO05 & MC_PLT_LAN07 & MC_PLT_FER12 & MC_PLT_ROD17 & MC_IRP_MILO3 & MC_IRP_LAN07 \\
\hline 137 & $-0,04$ & $-0,02$ & $-0,04$ & $-0,04$ & 0,04 & 0 & 0,02 \\
\hline 138 & $-0,04$ & $-0,02$ & $-0,04$ & $-0,04$ & 0,04 & 0,06 & 0,02 \\
\hline 139 & 0 & 0 & 0 & 0 & 0 & 0 & 0 \\
\hline 140 & $-0,04$ & $-0,02$ & $-0,04$ & $-0,04$ & 0,04 & 0 & 0 \\
\hline 141 & $-0,04$ & $-0,02$ & $-0,04$ & $-0,04$ & 0,04 & 0 & 0 \\
\hline 142 & $-0,04$ & $-0,02$ & $-0,04$ & $-0,04$ & 0,04 & 0 & 0 \\
\hline 143 & $-0,04$ & $-0,02$ & 0 & $-0,04$ & 0,04 & 0 & 0 \\
\hline 144 & $-0,04$ & $-0,02$ & $-0,04$ & $-0,04$ & 0,04 & 0,04 & 0,02 \\
\hline 145 & $-0,04$ & $-0,02$ & $-0,04$ & $-0,04$ & 0,04 & 0 & 0,02 \\
\hline 146 & 0 & 0 & 0 & 0 & 0 & 0,04 & 0,02 \\
\hline 147 & $-0,04$ & $-0,02$ & $-0,04$ & $-0,04$ & 0,04 & 0 & 0 \\
\hline 148 & 0,08 & 0,04 & 0,08 & 0,08 & $-0,04$ & 0,04 & 0,02 \\
\hline 149 & $-0,04$ & $-0,02$ & $-0,04$ & $-0,04$ & 0,04 & 0 & 0 \\
\hline 150 & 0 & 0 & 0 & 0 & 0 & 0 & 0 \\
\hline 151 & 0 & 0 & 0 & 0 & 의 & 의 & 0 \\
\hline 152 & $-0,04$ & $-0,02$ & 0 & $-0,04$ & 0,04 & 0 & 0 \\
\hline 154 & $-0,04$ & $-0,02$ & 0 & $-0,04$ & 0,04 & 0 & 0,02 \\
\hline 155 & 0 & 0 & 0 & 0 & 0 & 0 & 0 \\
\hline 156 & 0 & 0 & 0 & 0 & 0 & 0 & 0 \\
\hline 157 & $-0,04$ & $-0,02$ & $-0,04$ & $-0,04$ & 0,04 & 0 & 0 \\
\hline 159 & 0 & 0 & 0 & 0 & 0 & 0 & 0 \\
\hline 160 & 0 & 의 & 의 & 0 & 의 & 의 & 0 \\
\hline 162 & 0,08 & 0,04 & 0,08 & 0,08 & $-0,04$ & 0,04 & 0,02 \\
\hline 164 & 0 & 0 & 의 & 0 & 0 & 0,04 & 0,02 \\
\hline
\end{tabular}

Figura 4.14. Detalle de la construcción de la base de datos: determinación de los modificadores de comportamiento $M_{c}$ según las distintas revisiones del método MIV.

MC_PLT = modificador relacionado con el número de plantas de la edificación; $M C \_I R P=$ modificador relacionado con irregularidades en planta; MIL03, GIO05, LAN07, FER12, ROD17 = valores obtenidos según las versiones de Milutinovic \& Trendafiloski (2003), Giovinazzi (2005), Lantada (2007), Feriche (2012) y la nueva propuesta, respectivamente; FID = número identificativo de la edificación.

De este modo, el índice de vulnerabilidad de la edificación se pudo obtener, según la ecuación (2.9), a partir del índice de vulnerabilidad básico de la edificación, la suma de los modificadores de comportamiento y el modificador regional. En la Figura 4.15 se muestra un extracto del bloque de la base de datos correspondiente con la obtención de los índices de vulnerabilidad de las edificaciones, según las revisiones del método MIV de los distintos autores.

Junto con el índice de vulnerabilidad $I_{v}{ }^{*}$ característico de la edificación, fueron determinados los valores correspondientes con el intervalo plausible $\left[I_{v}{ }^{-}, I_{v}{ }^{+}\right]$del índice y el menos probable o excepcional $\left[I_{v}{ }^{\min }, I_{v}{ }^{\max }\right]$, aplicando las funciones de pertenencia $\chi$ definidas en RISK-UE. 
En la Figura 4.16 se recoge un resumen del bloque de la base de datos relacionado con la obtención de los distintos intervalos de pertenencia del índice de vulnerabilidad de las edificaciones.

\begin{tabular}{|c|c|c|c|c|c|c|}
\hline & \multicolumn{6}{|c|}{ ÍNDICE DE VULNERABILIDAD DE LAS EDIFICACIONES } \\
\hline FID & IV ED_MIL03 & IV*ED_GIO05 V & IV*ED_LAN07 & IV $^{*}$ ED_FER12 & IV*ED_MAN16 & $\mathrm{V}^{*}$ ED_ROD17 \\
\hline 205 & 0,804 & 0,604 & 0,727 & 0,704 & 0,724 & 0,664 \\
\hline 206 & 0,724 & 0,564 & 0,587 & 0,684 & 0,784 & 0,844 \\
\hline 207 & 0,684 & 0,544 & 0,647 & 0,684 & 0,644 & 0,784 \\
\hline 209 & 0,704 & 0,544 & 0,587 & 0,664 & 0,624 & 0,764 \\
\hline 210 & 0,484 & 0,504 & 0,382 & 0,604 & 0,524 & 0,644 \\
\hline 211 & 0,684 & 0,544 & 0,462 & 0,624 & 0,584 & 0,724 \\
\hline 212 & 0,684 & 0,544 & 0,587 & 0,524 & 0,484 & 0,724 \\
\hline 213 & 0,724 & 0,564 & 0,442 & 0,644 & 0,564 & 0,624 \\
\hline 215 & 0,484 & 0,524 & 0,482 & 0,584 & 0,584 & 0,624 \\
\hline 217 & 0,644 & 0,484 & 0,382 & 0,544 & 0,504 & 0,564 \\
\hline 218 & 0,444 & 0,464 & 0,382 & 0,404 & 0,404 & 0,524 \\
\hline 219 & 0,484 & 0,504 & 0,462 & 0,604 & 0,564 & 0,564 \\
\hline 220 & 0,444 & 0,484 & 0,462 & 0,484 & 0,484 & 0,604 \\
\hline 221 & 0,684 & 0,504 & 0,402 & 0,604 & 0,524 & 0,584 \\
\hline 222 & 0,684 & 0,544 & 0,752 & 0,704 & 0,664 & 0,764 \\
\hline 223 & 0,484 & 0,484 & 0,482 & 0,624 & 0,584 & 0,584 \\
\hline 224 & 0,684 & 0,544 & 0,547 & 0,484 & 0,444 & 0,684 \\
\hline 225 & 0,764 & 0,564 & 0,482 & 0,644 & 0,604 & 0,544 \\
\hline 226 & 0,644 & 0,504 & 0,462 & 0,624 & 0,584 & 0,604 \\
\hline 227 & 0,524 & 0,524 & 0,382 & 0,524 & 0,484 & 0,484 \\
\hline 228 & 0,644 & 0,504 & 0,422 & 0,624 & 0,544 & 0,684 \\
\hline 229 & 0,684 & 0,524 & 0,482 & 0,644 & 0,604 & 0,664 \\
\hline 230 & 0,644 & 0,504 & 0,342 & 0,544 & 0,464 & 0,684 \\
\hline 231 & 0.484 & 0.504 & 0.422 & 0.524 & 0,524 & 0.564 \\
\hline
\end{tabular}

Figura 4.15. Detalle de la construcción de la base de datos: determinación de los índices de vulnerabilidad $I_{v}$ de las edificaciones, según las distintas revisiones del método MIV.

$I_{v}{ }_{E D}=$ índice de vulnerabilidad característico de la edificación; MIL03, GIO05, LAN07, FER12, MAN16, ROD17 = valores obtenidos según las versiones de Milutinovic \& Trendafiloski (2003), Giovinazzi (2005), Lantada (2007), Feriche (2012); Martínez-Cuevas \& Gaspar-Escribano (2016) y la nueva propuesta, respectivamente; FID = número identificativo de la edificación.

\subsubsection{Estimación del grado de daño según la metodología LM1 de RISK-UE}

Una vez obtenido el índice de vulnerabilidad de cada edificación, se determinó el grado de daño medio en la escala EMS-98 para un sismo de intensidad VII, según la expresión (2.21) establecida por la metodología LM1 de RISK-UE.

Junto con el grado de daño medio característico $\mu_{D}{ }^{*}$ de la edificación, se obtuvieron los valores correspondientes con el intervalo plausible $\left[\mu_{D}{ }^{-}, \mu_{D}{ }^{+}\right]$del grado de daño y el menos probable o excepcional $\left[\mu_{D}{ }^{\min }, \mu_{D}{ }^{\max }\right]$, según las funciones de pertenencia $\chi$ definidas en RISK-UE. 
En la Figura 4.17 se muestra un extracto del bloque de la base de datos correspondiente a la obtención del grado de daño en la escala EMS-98 estimado en las edificaciones, según la metodología LM1 de RISK-UE, para cada una de las distintas revisiones del método MIV propuestas en la literatura.

\begin{tabular}{|c|c|c|c|c|c|c|c|c|}
\hline \multirow[b]{2}{*}{ FID } & \multicolumn{8}{|c|}{ ÍNDICE DE VULNERABILIDAD DE LAS EDIFICACIONES } \\
\hline & $\mathrm{IV}^{+} \mathrm{ED}$ GIOS & lv ${ }^{\operatorname{mex}}$ Eo_GIO5 & $I_{v}^{\min }$ ED_LANO7 & VVED_LAN07 & $\mathrm{IV}_{V}^{+} \mathrm{ED} \_$LAN07 & IV $^{\operatorname{mex}}{ }_{\text {ED_LAN07 }}$ & $\mathrm{IV}_{\mathrm{V}}^{\min }{ }_{\text {ED_FER12 }}$ & IV ED_FER12 \\
\hline 263 & 0,620 & 0,840 & 0,098 & 0,288 & 0,598 & 0,818 & 0,260 & 0,450 \\
\hline 264 & 0,640 & 0,860 & 0,118 & 0,308 & 0,618 & 0,838 & 0,260 & 0,450 \\
\hline 265 & 0,740 & 0,960 & 0,363 & 0,553 & 0,863 & 1,083 & 0,500 & 0,690 \\
\hline 266 & 0,720 & 0,940 & 0,263 & 0,453 & 0,763 & 0,983 & 0,180 & 0,370 \\
\hline 267 & 0,720 & 0,940 & 0,058 & 0,248 & 0,558 & 0,778 & 0,260 & 0,450 \\
\hline 268 & 0,720 & 0,940 & 0,138 & 0,328 & 0,638 & 0,858 & 0,300 & 0,490 \\
\hline 269 & 0,720 & 0,940 & 0,363 & 0,553 & 0,863 & 1,083 & 0,340 & 0,530 \\
\hline 270 & 0,700 & 0,920 & 0,098 & 0,288 & 0,598 & 0,818 & 0,260 & 0,450 \\
\hline 271 & 0,660 & 0,880 & 0,018 & 0,208 & 0,518 & 0,738 & 0,220 & 0,410 \\
\hline 272 & 0,660 & 0,880 & 0,018 & 0,208 & 0,518 & 0,738 & 0,220 & 0,410 \\
\hline 273 & 0,720 & 0,940 & 0,058 & 0,248 & 0,558 & 0,778 & 0,300 & 0,490 \\
\hline 274 & 0,760 & 0,980 & 0,178 & 0,368 & 0,678 & 0,898 & 0,360 & 0,550 \\
\hline 275 & 0,620 & 0,840 & 0,178 & 0,368 & 0,678 & 0,898 & 0,200 & 0,390 \\
\hline 276 & 0,760 & 0,980 & 0,263 & 0,453 & 0,763 & 0,983 & 0,300 & 0,490 \\
\hline 278 & 0,660 & 0,880 & 0,078 & 0,268 & 0,578 & 0,798 & 0,260 & 0,450 \\
\hline 280 & 0,660 & 0,880 & 0,038 & 0,228 & 0,538 & 0,758 & 0,180 & 0,370 \\
\hline 281 & 0,660 & 0,880 & 0,138 & 0,328 & 0,638 & 0,858 & 0,260 & 0,450 \\
\hline 282 & 0,720 & 0,940 & 0,218 & 0,408 & 0,718 & 0,938 & 0,380 & 0,570 \\
\hline 283 & 0,720 & 0,940 & 0,158 & 0,348 & 0,658 & 0,878 & 0,360 & 0,550 \\
\hline 284 & 0,680 & 0,900 & 0,018 & 0,208 & 0,518 & 0,738 & 0,220 & 0,410 \\
\hline 285 & 0,680 & 0,900 & 0,038 & 0,228 & 0,538 & 0,758 & 0,240 & 0,430 \\
\hline 286 & 0,700 & 0,920 & 0,328 & 0,518 & 0,828 & 1,048 & 0,260 & 0,450 \\
\hline 287 & 0,660 & 0,880 & 0,078 & 0,268 & 0,578 & 0,798 & 0,180 & 0,370 \\
\hline 288 & 0,700 & 0,920 & 0,078 & 0,268 & 0,578 & 0,798 & 0,240 & 0,430 \\
\hline
\end{tabular}

Figura 4.16. Detalle de la construcción de la base de datos: determinación de los índices de vulnerabilidad $I_{v}$ de las edificaciones aplicando las funciones de pertenencia de RISK-UE, según distintas revisiones del método MIV.

$\left[I_{V}^{\min }{ }_{E D} ; I_{v}^{\max }{ }_{E D}\right]=$ intervalo poco probable del índice de vulnerabilidad de la edificación; $\left[I_{V E D}^{-} ; I_{v E D}^{+}\right]=$ intervalo posible del índice de vulnerabilidad; GIO05, LAN07, FER12 = valores obtenidos según las versiones de Giovinazzi (2005), Lantada (2007) y Feriche (2012), respectivamente; FID = número identificativo de la edificación.

Dada la descripción realizada por diversos autores de las características y efectos del terremoto en algunos barrios de la ciudad de Lorca (Figueras et al., 2012; Alguacil et al., 2014), se estimaron de forma adicional los grados de daño en las edificaciones para un sismo de intensidad VIII en la escala EMS-98, con el fin de poder comparar los resultados obtenidos para ambos niveles de peligrosidad sísmica.

En la Figura 4.18 se recoge una síntesis de la obtención del grado de daño estimado en las edificaciones para una intensidad de VIII en la escala EMS-98, según la metodología LM1 de RISK-UE y las revisiones del método MIV de distintos autores. 


\begin{tabular}{|c|c|c|c|c|c|c|c|c|c|}
\hline \multirow[b]{2}{*}{ FID } & \multicolumn{9}{|c|}{ GRADO DE DAÑO MEDIO LM1 RISK-UE } \\
\hline & $\begin{array}{r}\mu D^{*} \text { GIO005 } \\
(I=V I I)\end{array}$ & $\begin{array}{c}\mu D^{\operatorname{mex}}=G 1005 \\
(I=V I I)\end{array}$ & $\begin{array}{c}\mu D^{\min } \text { _LAN07 } \\
(I=V I I)\end{array}$ & $\begin{array}{l}\text { HD_LAN07 } \\
(I=\text { VIII })\end{array}$ & $\begin{array}{r}\mu \mathrm{D}^{*} \text { _LAN07 } \\
(\mathrm{I}=\mathrm{VII})\end{array}$ & $\begin{array}{c}\mu \mathrm{D}^{+} \text {LAN07 } \\
((\mathrm{I}=\mathrm{VIII})=\end{array}$ & $\begin{array}{c}\mu \mathrm{D}^{\operatorname{mex}} \text { LAN 07 } \\
(1=\mathrm{VII})\end{array}$ & $\begin{array}{c}\mu \mathrm{D}^{\min } \text { _FER12 } \\
(I=V I I)\end{array}$ & $\begin{array}{l}\mu D_{\text {_FER12 }} \\
(I=\mathrm{VII})\end{array}$ \\
\hline 352 & 0,83 & 1,99 & 0,05 & 0,14 & 0,32 & 0,69 & 1,72 & 0,15 & 0,41 \\
\hline 353 & 0,83 & 1,99 & 0,05 & 0,14 & 0,32 & 0,69 & 1,72 & 0,15 & 0,41 \\
\hline 354 & 0,76 & 1,86 & 0,10 & 0,28 & 0,59 & 1,20 & 2,55 & 0,11 & 0,30 \\
\hline 355 & 0,69 & 1,74 & 0,02 & 0,07 & 0,15 & 0,35 & 0,99 & 0,07 & 0,20 \\
\hline 356 & 0,91 & 2,12 & 0,11 & 0,31 & 0,65 & 1,30 & 2,68 & 0,14 & 0,37 \\
\hline 357 & 0,69 & 1,74 & 0,04 & 0,10 & 0,23 & 0,52 & 1,38 & 0,09 & 0,24 \\
\hline 358 & 0,91 & 2,12 & 0,06 & 0,18 & 0,39 & 0,83 & 1,98 & 0,19 & 0,50 \\
\hline 359 & 0,83 & 1,99 & 0,09 & 0,25 & 0,54 & 1,10 & 2,41 & 0,07 & 0,20 \\
\hline 360 & 0,91 & 2,12 & 0,22 & 0,57 & 1,14 & 2,04 & 3,48 & 0,17 & 0,45 \\
\hline 361 & 0,83 & 1,99 & 0,05 & 0,14 & 0,32 & 0,69 & 1,72 & 0,21 & 0,55 \\
\hline 362 & 1,09 & 2,39 & 0,08 & 0,22 & 0,48 & 0,99 & 2,24 & 0,23 & 0,60 \\
\hline 363 & 1,39 & 2,80 & 0,12 & 0,33 & 0,70 & 1,38 & 2,78 & 0,29 & 0,73 \\
\hline 364 & 0,76 & 1,86 & 0,06 & 0,16 & 0,35 & 0,75 & 1,85 & 0,10 & 0,27 \\
\hline 365 & 0,83 & 1,99 & 0,03 & 0,08 & 0,19 & 0,42 & 1,17 & 0,09 & 0,24 \\
\hline 366 & 0,91 & 2,12 & 0,13 & 0,34 & 0,72 & 1,40 & 2,82 & 0,10 & 0,27 \\
\hline 367 & 0,83 & 1,99 & 0,06 & 0,16 & 0,35 & 0,75 & 1,85 & 0,10 & 0,27 \\
\hline 368 & 0,76 & 1,86 & 0,03 & 0,08 & 0,19 & 0,42 & 1,17 & 0,05 & 0,15 \\
\hline 370 & 1,00 & 2,26 & 0,10 & 0,28 & 0,59 & 1,20 & 2,55 & 0,07 & 0,20 \\
\hline 371 & 0,69 & 1,74 & 0,04 & 0,10 & 0,23 & 0,52 & 1,38 & 0,07 & 0,20 \\
\hline 372 & 0,76 & 1,86 & 0,03 & 0,09 & 0,21 & 0,47 & 1,27 & 0,11 & 0,30 \\
\hline 373 & 0,91 & 2,12 & 0,14 & 0,38 & 0,80 & 1,55 & 2,98 & 0,11 & 0,30 \\
\hline 375 & 0,83 & 1,99 & 0,05 & 0,13 & 0,29 & 0,63 & 1,60 & 0,19 & 0,50 \\
\hline 376 & 0,69 & 1,74 & 0,05 & 0,14 & 0,32 & 0,69 & 1,72 & 0,14 & 0,37 \\
\hline 377 & 0,91 & 2,12 & 0,14 & 0,38 & 0,80 & 1,55 & 2,98 & 0,11 & 0,30 \\
\hline
\end{tabular}

Figura 4.17. Detalle de la construcción de la base de datos: determinación del grado de daño medio $\mu_{D}$ de las edificaciones en la escala EMS-98 definido en la metodología LM1 de RISK-UE para un sismo de intensidad VII, según distintas revisiones del método MIV.

$\mu_{D}{ }^{*}=$ grado de daño medio característico de la edificación; $\left[\mu_{D}{ }^{-}, \mu_{D}^{+}\right]=$intervalo posible el grado de daño medio; $\left[\mu_{D}^{\min }, \mu_{D}^{\max }\right]=$ intervalo poco probable del grado de daño medio; GIO05, LAN07, FER12 = valores obtenidos según las revisiones de Giovinazzi (2005), Lantada (2007) y Feriche (2012), respectivamente; FID = número identificativo de la edificación.

\subsubsection{Resumen}

A partir de una muestra inicial de 1050 edificaciones, fueron seleccionados 364 casos homogéneos tras un proceso de validación y eliminación de elementos anómalos. Los principales filtros aplicados se derivaron de los siguientes condicionantes:

- Imposibilidad de identificar la ubicación del edificio.

- Insuficiente documentación gráfica para la determinación del grado de daño observado en la edificación.

- Edificaciones pertenecientes a otras tipologías estructurales basadas, por ejemplo, en muros de mampostería no reforzada con forjados de madera, entramados de acero o estructuras mixtas hormigón-acero.

En la Figura 4.19 se muestra la distribución espacial de la selección de 364 edificaciones evaluadas, uniformemente repartidas por el núcleo urbano de Lorca. 


\begin{tabular}{|c|c|c|c|c|c|c|c|c|c|}
\hline \multicolumn{10}{|c|}{ GRADO DE DAÑO MEDIO LM1 RISK-UE } \\
\hline FID & $\begin{array}{l}\mu D^{+} \text {LAN07 } \\
(I=\text { VIII) }\end{array}$ & $\begin{array}{c}\mu 0^{\max } \quad \text { LAN07 } \\
(I=V I I I)\end{array}$ & $\begin{array}{r}\mu \mathrm{D}^{\min } \quad \text { FER12 } \\
(I=\mathrm{VIIII})\end{array}$ & $\begin{array}{l}\mu D^{\prime} \text { _FER12 } \\
(I=\mathrm{VIIII})\end{array}$ & $\begin{array}{c}\mu \mathrm{D}^{*} \text { _FER12 } \\
(\mathrm{I}=\mathrm{VIII})\end{array}$ & $\begin{array}{c}\mu \mathrm{D}^{+} \text {_FER12 } \\
(\mathrm{I}=\mathrm{V} \text { VIII) }\end{array}$ & $\begin{array}{c}\mu D^{\max } \text { _FER12 } \\
(I=\text { VIII) }\end{array}$ & $\begin{array}{c}\mu \mathrm{D}^{\min } \text { _MAN16 } \\
(I=V I I I)\end{array}$ & $\begin{array}{l}\text { HD_MAN16 } \\
(I=\text { VIII) }\end{array}$ \\
\hline 300 & 0,90 & 2,11 & 0,23 & 0,60 & 1,20 & 2,12 & 3,55 & 0,15 & 0,41 \\
\hline 301 & 0,90 & 2,11 & 0,12 & 0,33 & 0,71 & 1,39 & 2,80 & 0,08 & 0,22 \\
\hline 302 & 1,08 & 2,38 & 0,35 & 0,87 & 1,64 & 2,66 & 3,95 & 0,47 & 1,13 \\
\hline 303 & 1,27 & 2,65 & 0,15 & 0,41 & 0,85 & 1,62 & 3,06 & 0,12 & 0,33 \\
\hline 304 & 3,24 & 4,29 & 0,39 & 0,95 & 1,76 & 2,80 & 4,04 & 0,32 & 0,80 \\
\hline 305 & 1,17 & 2,51 & 0,39 & 0,95 & 1,76 & 2,80 & 4,04 & 0,52 & 1,23 \\
\hline 306 & 0,90 & 2,11 & 0,21 & 0,55 & 1,10 & 1,99 & 3,43 & 0,14 & 0,37 \\
\hline 307 & 0,90 & 2,11 & 0,12 & 0,33 & 0,71 & 1,39 & 2,80 & 0,10 & 0,27 \\
\hline 308 & 1,38 & 2,78 & 0,35 & 0,87 & 1,64 & 2,66 & 3,95 & 0,23 & 0,60 \\
\hline 309 & 1,38 & 2,78 & 0,29 & 0,73 & 1,41 & 2,39 & 3,76 & 0,39 & 0,95 \\
\hline 311 & 1,38 & 2,78 & 0,35 & 0,87 & 1,64 & 2,66 & 3,95 & 0,23 & 0,60 \\
\hline 312 & 1,38 & 2,78 & 0,35 & 0,87 & 1,64 & 2,66 & 3,95 & 0,23 & 0,60 \\
\hline 313 & 2,14 & 3,56 & 0,26 & 0,66 & 1,30 & 2,26 & 3,66 & 0,29 & 0,73 \\
\hline 314 & 0,75 & 1,85 & 0,17 & 0,45 & 0,93 & 1,74 & 3,19 & 0,11 & 0,30 \\
\hline 315 & 2,28 & 3,67 & 0,32 & 0,80 & 1,52 & 2,53 & 3,86 & 0,26 & 0,66 \\
\hline 316 & 1,08 & 2,38 & 0,21 & 0,55 & 1,10 & 1,99 & 3,43 & 0,17 & 0,45 \\
\hline 317 & 1,60 & 3,05 & 0,43 & 1,04 & 1,89 & 2,93 & 4,12 & 0,35 & 0,87 \\
\hline 318 & 2,01 & 3,45 & 0,17 & 0,45 & 0,93 & 1,74 & 3,19 & 0,12 & 0,33 \\
\hline 319 & 3,11 & 4,22 & 0,39 & 0,95 & 1,76 & 2,80 & 4,04 & 0,32 & 0,80 \\
\hline 320 & 1,38 & 2,78 & 0,47 & 1,13 & 2,02 & 3,06 & 4,20 & 0,21 & 0,55 \\
\hline 321 & 1,85 & 3,30 & 0,52 & 1,23 & 2,15 & 3,19 & 4,27 & 0,35 & 0,87 \\
\hline 324 & 2,38 & 3,75 & 0,63 & 1,44 & 2,42 & 3,43 & 4,39 & 0,52 & 1,23 \\
\hline 325 & 1,49 & 2,92 & 0,23 & 0,60 & 1,20 & 2,12 & 3,55 & 0,15 & 0,41 \\
\hline 326 & 0,90 & $2,11 \mid$ & 0,21 & 0,55 & 1,10 & 1,99 & 3,43 & 0,14 & 0,37 \\
\hline
\end{tabular}

Figura 4.18. Detalle de la construcción de la base de datos: determinación del grado de daño medio $\mu_{D}$ de las edificaciones en la escala EMS-98 definido en la metodología LM1 de RISK-UE para un sismo de intensidad VIII, según distintas revisiones del método MIV.

$\mu_{D}{ }^{*}=$ grado de daño medio característico de la edificación; $\left[\mu_{D}{ }^{-}, \mu_{D}^{+}\right]=$intervalo posible el grado de daño medio; $\left[\mu_{D}{ }^{\min }, \mu_{D}{ }^{\max }\right]=$ intervalo poco probable del grado de daño medio; LAN07, FER12, MAN16 = valores obtenidos según las revisiones de Lantada (2007), Feriche (2012), Martínez-Cuevas \& Gaspar-Escribano (2016) y respectivamente; FID = número identificativo de la edificación.

En la Figura 4.20 se muestra la distribución del periodo de construcción de las edificaciones seleccionadas. Más del 50 \% de los edificios presentan una fecha de construcción entre los años 1971 y 1995, estando diseñados por tanto con un código sísmico de bajo nivel. En la Tabla 4.5 se recoge esta distribución, junto con el nivel del código sísmico de diseño vigente en cada periodo y la tipología estructural de las edificaciones.

En la Figura 4.21 se muestra el grado de daño en la escala EMS-98 observado en las edificaciones seleccionadas. El 33,2 \% de los casos evaluados presentaron niveles de daño leves, con un grado de daño de $\mu_{D}=1$, mientras que el $15,7 \%$ sufrieron daños graves $\left(\mu_{D}=3\right)$.

En las Figuras 4.22 a 4.25 se recoge en detalle la distribución del grado de daño en función del periodo de construcción de las edificaciones. Según se puede observar, el 54,3 \% de las estructuras construidas antes de 1963 presentan altos niveles de daño, mientras que este porcentaje disminuye hasta el 7,4 \% en las edificaciones construidas después de 1995.

Por el contrario, solo el 8,6 \% de las edificaciones anteriores a 1963 presentan daños de carácter leve, mientras que este porcentaje crece hasta el 44,7 \% en las edificaciones construidas más recientemente. En términos generales, la tendencia observada en el 
comportamiento de las edificaciones indica una mejor respuesta de las mismas conforme su fecha de construcción es más reciente.

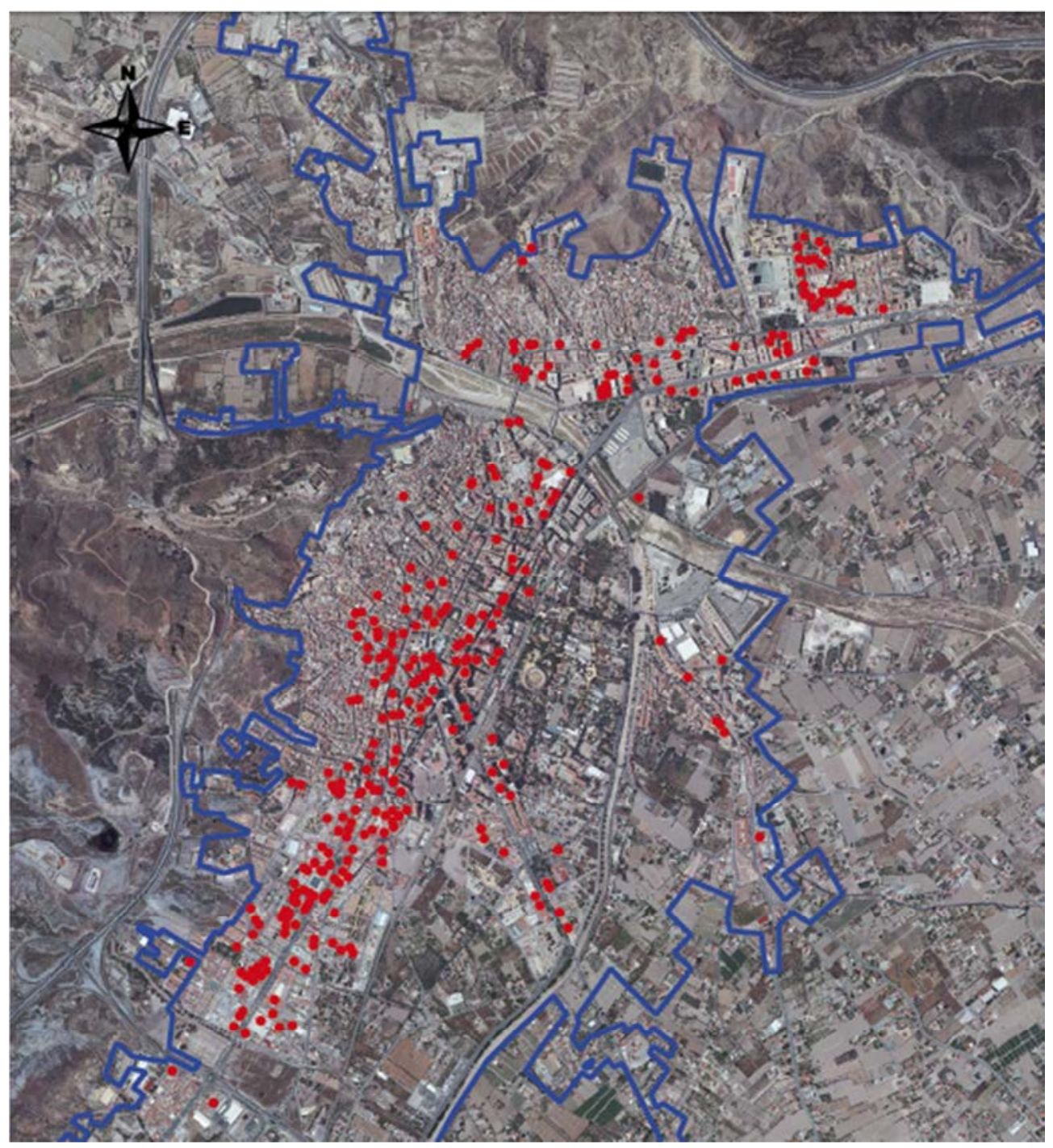

Figura 4.19. Distribución espacial de las edificaciones seleccionadas, marcadas en color rojo, sobre el núcleo urbano de Lorca.

Tabla 4.5. Periodo constructivo de las edificaciones analizadas en función del código sísmico de diseño.

\begin{tabular}{|c|c|c|c|c|c|}
\hline $\begin{array}{l}\text { Periodo de } \\
\text { construcción }\end{array}$ & $\begin{array}{c}\text { Código sísmico de } \\
\text { diseño }\end{array}$ & $\begin{array}{l}\text { Nivel del } \\
\text { código }\end{array}$ & $\begin{array}{c}\text { № de } \\
\text { edificaciones }\end{array}$ & $\begin{array}{c}\text { Edificaciones } \\
\%\end{array}$ & $\begin{array}{c}\text { Tipología } \\
\text { edificatoria BTM }\end{array}$ \\
\hline Anterior a 1963 & - & Pre-code & 35 & 9,6 & $\mathrm{RC1}$ \\
\hline $1963-1970$ & $\begin{array}{c}\text { Recomendaciones } \\
\text { MV-101 (1962) }\end{array}$ & Pre-code & 48 & 13,2 & $\mathrm{RC1}$ \\
\hline 1971-1995 & $\begin{array}{l}\text { PGS-1 (1968) y } \\
\text { PDS-1 (1974) }\end{array}$ & Low code & 187 & 51,4 & $\mathrm{RC} 1$ \\
\hline Posterior a 1995 & $\begin{array}{l}\text { NCSE-1994 y } \\
\text { NCSE-2002 }\end{array}$ & $\begin{array}{c}\text { Medium } \\
\text { code }\end{array}$ & 94 & 25,8 & $\mathrm{RC1}$ \\
\hline
\end{tabular}

$\mathrm{BTM}=$ matriz de tipologías edificatoria de RISK-UE; RC1 = tipología basada en pórticos de hormigón armado con cerramientos de fábrica no estructurales, definida en la matriz BTM. 


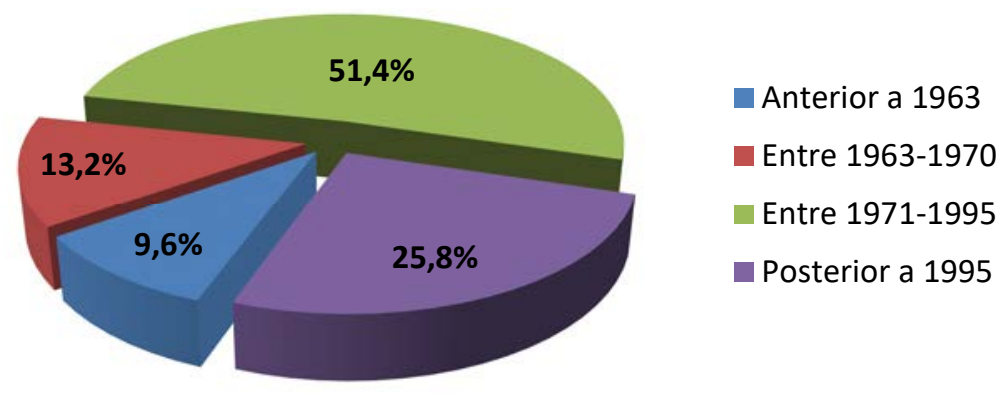

Figura 4.20. Distribución del periodo de construcción de las edificaciones seleccionadas.

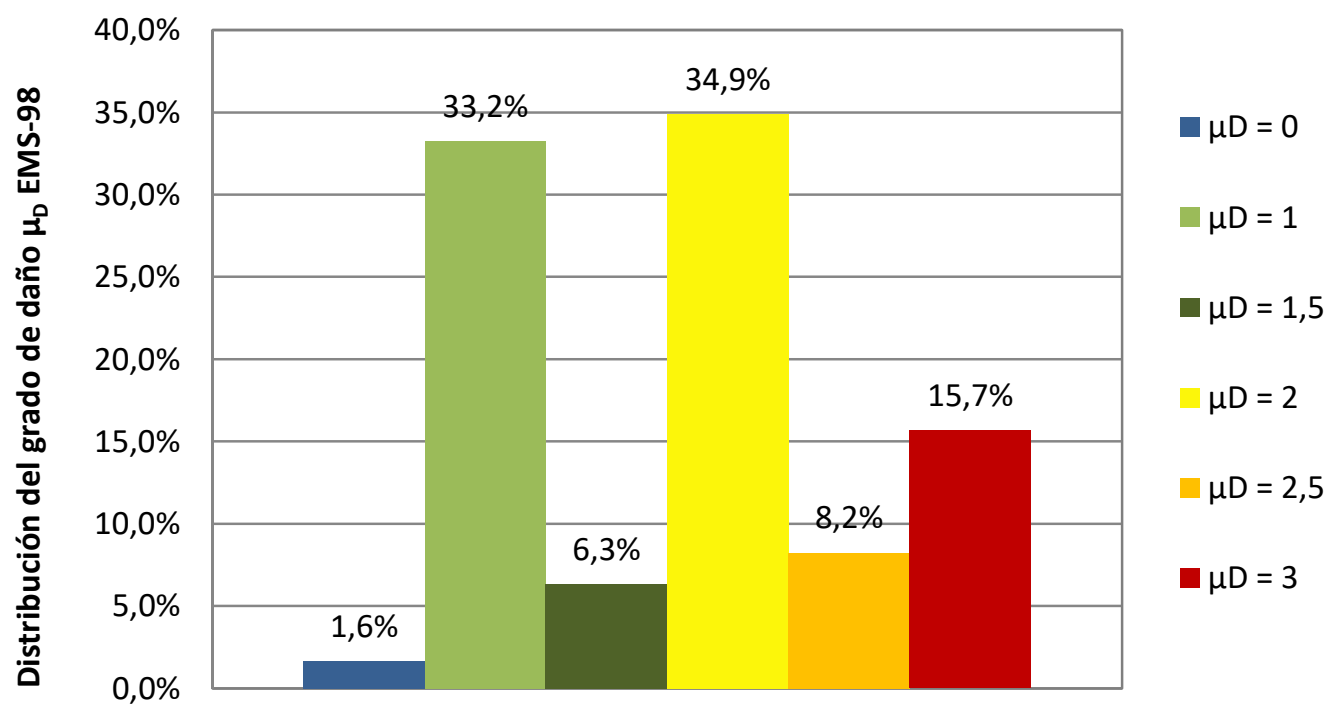

Grado de daño $\mu_{D} E M S-98$

Figura 4.21. Distribución del grado de daño $\mu_{D}$ observado en las edificaciones analizadas tras el sismo de Lorca de 2011.

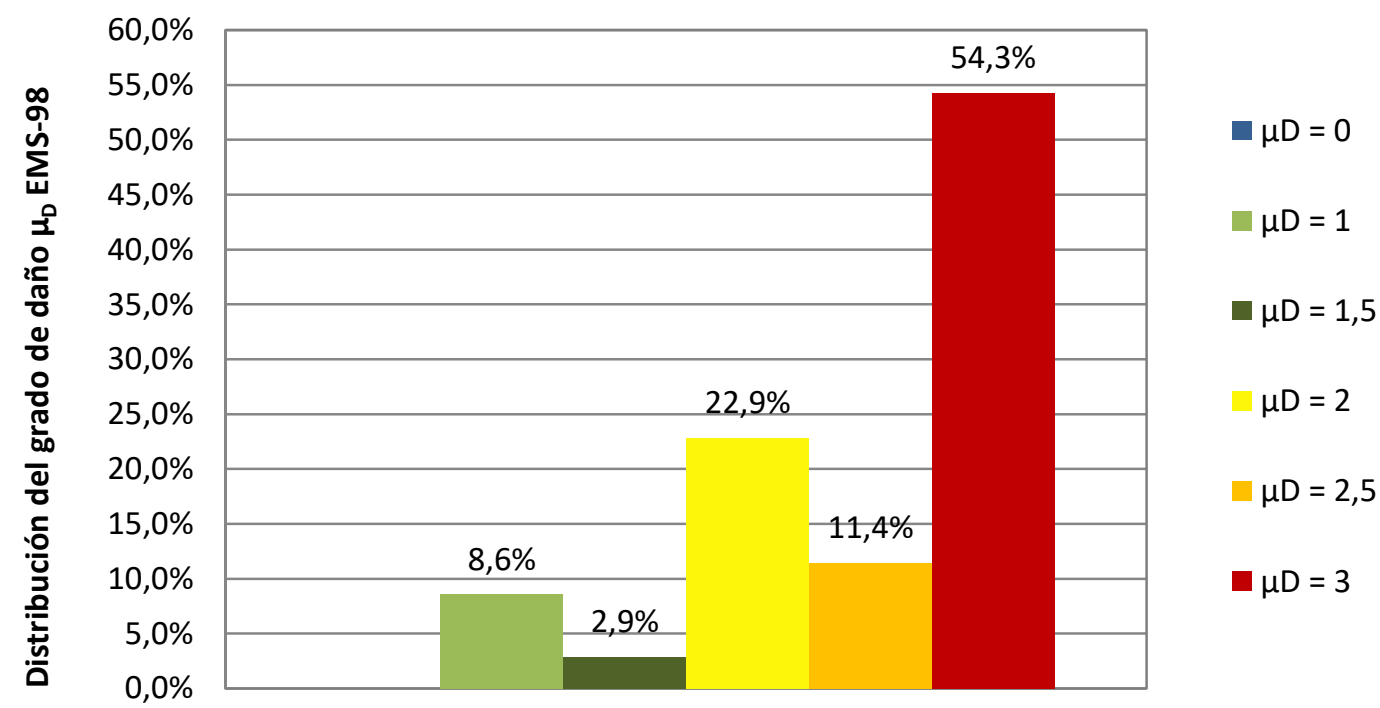

Grado de daño $\mu_{D}$ EMS-98

Figura 4.22. Distribución del grado de daño $\mu_{D}$ observado en las edificaciones analizadas tras el sismo de Lorca de 2011, con un periodo de construcción anterior a 1963. 




Figura 4.23. Distribución del grado de daño $\mu_{D}$ observado en las edificaciones analizadas tras el sismo de Lorca de 2011, con un periodo de construcción entre los años 1963 y 1970.

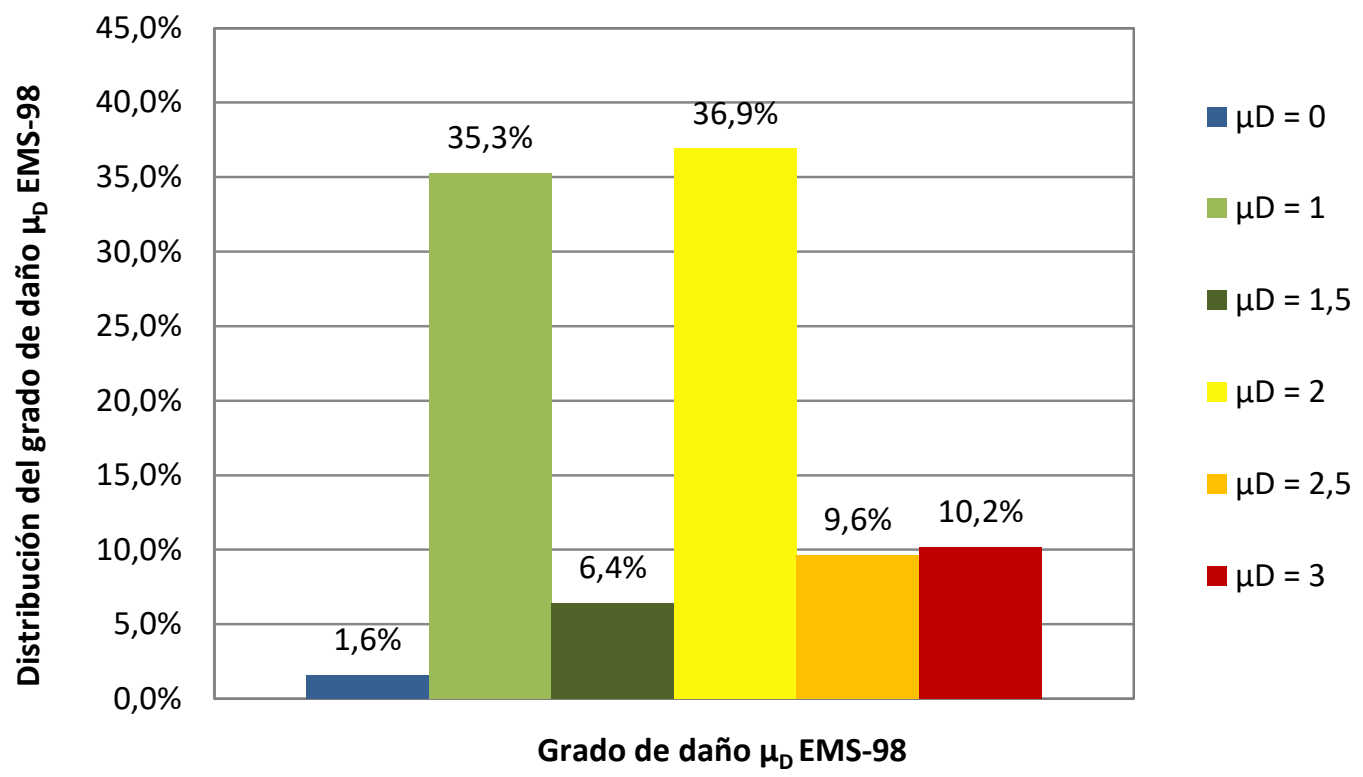

Figura 4.24. Distribución del grado de daño $\mu_{D}$ observado en las edificaciones analizadas tras el sismo de Lorca de 2011, con un periodo de construcción entre los años 1971 y 1995.

En lo relativo al índice de vulnerabilidad de las edificaciones, en la Tabla 4.6 se incluye un resumen de los parámetros de tendencia central de esta variable, obtenidos según las distintas revisiones existentes y el modelo propuesto. 


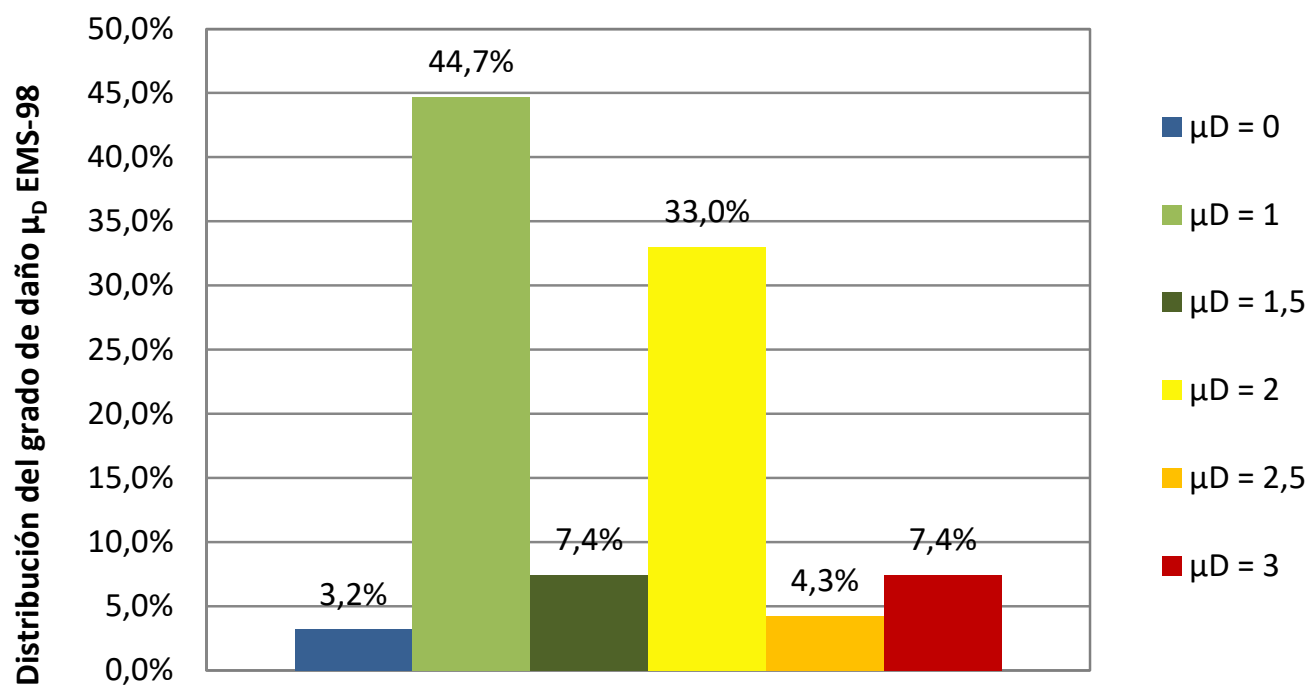

Grado de daño $\mu_{D}$ EMS-98

Figura 4.25. Distribución del grado de daño $\mu_{D}$ observado en las edificaciones analizadas tras el sismo de Lorca de 2011, con un periodo de construcción posterior a 1995.

Tabla 4.6. Medidas de tendencia central del índice de vulnerabilidad $I_{v_{-}}{ }^{*}$ de las edificaciones seleccionadas según las revisiones de distintos autores y la nueva propuesta.

\begin{tabular}{ccccccc}
\hline $\begin{array}{c}\text { Medidas de } \\
\text { tendencia } \\
\text { central } I_{v \_}{ }^{*}\end{array}$ & $\begin{array}{c}\text { Milutinovic \& } \\
\text { Trendafiloski } \\
(2003)\end{array}$ & $\begin{array}{c}\text { Giovinazzi } \\
(2005)\end{array}$ & $\begin{array}{c}\text { Lantada } \\
(2007)\end{array}$ & $\begin{array}{c}\text { Feriche } \\
(2012)\end{array}$ & $\begin{array}{c}\text { Martinez-Cuevas } \\
\text { \& Gaspar- } \\
\text { Escribano (2016) }\end{array}$ & $\begin{array}{c}\text { Ródenas } \\
(2017)\end{array}$ \\
\hline $\begin{array}{c}\text { Media } \\
\text { Desv. típica }\end{array}$ & 0,641 & 0,529 & 0,520 & 0,625 & 0,591 & 0,677 \\
Mín. & 0,0985 & 0,0352 & 0,1241 & 0,0828 & 0,0942 & 0,1013 \\
Máx. & 0,444 & 0,464 & 0,352 & 0,404 & 0,404 & 0,484 \\
\hline
\end{tabular}

Para los mismos casos evaluados, la metodología propuesta por Lantada (2007) sería la que presentaría menores niveles de vulnerabilidad con un índice medio de $I_{v_{-} b}=0,52$. Por el contrario, la nueva propuesta incluida en esta tesis sería la que presentaría mayores niveles de vulnerabilidad media, con un valor de $I_{v_{-} b}=0,677$.

En la Tabla 4.7 se resumen los parámetros de tendencia central del grado de daño medio estimado en las edificaciones para un sismo de intensidad $I=$ VII. En este caso sería la variante propuesta por Giovinazzi (2005) la que presentaría menores niveles de daño, con un grado de daño $\mu_{D}{ }^{*}=0,41$. La nueva propuesta sería la que presentaría también mayores niveles medios de daño, con un valor $\mu_{D}{ }^{*}=0,89$.

En la Tabla 4.8 se resumen los parámetros de tendencia central del grado de daño medio estimado en las edificaciones correspondiente con un terremoto de intensidad $I=$ VIII. Conforme a lo establecido en la ecuación (2.21), se han obtenido grados de daño más elevados para todas las metodologías evaluadas. La variante propuesta por Giovinazzi (2005) sería la que presentaría de nuevo niveles de daño más bajos, con un grado medio $\mu_{D}{ }^{*}=0,88$, mientras 
que la nueva propuesta del método MIV sería la que presentaría unos grados de daño más elevados, con un valor medio $\mu_{D}{ }^{*}=1,65$.

En el Anexo B se incluye un resumen más amplio de la información disponible de las 364 edificaciones seleccionadas que componen la base de datos implementada a partir de las observaciones disponibles tras el sismo de Lorca de 2011.

Tabla 4.7. Medidas de tendencia central del grado de daño medio $\mu_{D}{ }^{*}$ de las edificaciones seleccionadas para un sismo de intensidad VII, según las revisiones de distintos autores y la nueva propuesta.

\begin{tabular}{ccccccc}
\hline $\begin{array}{c}\text { Medidas de } \\
\text { tendencia } \\
\text { central } \mu_{D}{ }^{*}\end{array}$ & $\begin{array}{c}\text { Milutinovic \& } \\
\text { Trendafiloski } \\
(2003)\end{array}$ & $\begin{array}{c}\text { Giovinazzi } \\
(2005)\end{array}$ & $\begin{array}{c}\text { Lantada } \\
(2007)\end{array}$ & $\begin{array}{c}\text { Feriche } \\
(2012)\end{array}$ & $\begin{array}{c}\text { Martinez-Cuevas } \\
\text { \& Gaspar- } \\
\text { Escribano (2016) }\end{array}$ & $\begin{array}{c}\text { Ródenas } \\
(2017)\end{array}$ \\
\hline Media & 0,75 & 0,41 & 0,46 & 0,69 & 0,60 & 0,89 \\
Desv. típica & 0,288 & 0,073 & 0,316 & 0,274 & 0,301 & 0,404 \\
Mín. & 0,26 & 0,29 & 0,15 & 0,21 & 0,21 & 0,32 \\
Máx. & 1,64 & 0,71 & 1,57 & 1,89 & 2,15 & 2,28 \\
\hline
\end{tabular}

Tabla 4.8. Medidas de tendencia central del grado de daño medio $\mu_{D}{ }^{*}$ de las edificaciones seleccionadas para un sismo de intensidad VIII, según las revisiones de distintos autores y la nueva propuesta.

\begin{tabular}{ccccccc}
\hline $\begin{array}{c}\text { Medidas de } \\
\text { tendencia } \\
\text { central } \mu_{D}{ }^{*}\end{array}$ & $\begin{array}{c}\text { Milutinovic \& } \\
\text { Trendafiloski } \\
(2003)\end{array}$ & $\begin{array}{c}\text { Giovinazzi } \\
(2005)\end{array}$ & $\begin{array}{c}\text { Lantada } \\
(2007)\end{array}$ & $\begin{array}{c}\text { Feriche } \\
(2012)\end{array}$ & $\begin{array}{c}\text { Martinez-Cuevas } \\
\text { \& Gaspar- } \\
\text { Escribano (2016) }\end{array}$ & $\begin{array}{c}\text { Ródenas } \\
(2017)\end{array}$ \\
\hline Media & 1,46 & 0,88 & 0,94 & 1,35 & 1,20 & 1,65 \\
Desv. típica & 0,484 & 0,139 & 0,545 & 0,434 & 0,477 & 0,589 \\
Mín. & 0,58 & 0,64 & 0,35 & 0,48 & 0,48 & 0,71 \\
Máx. & 2,69 & 1,41 & 2,61 & 2,96 & 3,21 & 3,34 \\
\hline
\end{tabular}

\subsection{RESULTADOS}

\subsubsection{Comparación entre el grado de daño estimado según el método LM1 de RISK-UE y el daño real observado en el sismo de Lorca de 2011}

En las Figuras 4.26 a 4.30 se compara la distribución del daño observado en las edificaciones tras el sismo de 2011 con el grado de daño medio calculado según la metodología LM1 de RISK-UE, a partir de las propuesta de Milutinovic \& Trendafiloski (2003) y las posteriores revisiones de Giovinazzi (2005), Lantada (2007), Feriche (2012) y Martínez-Cuevas \& GasparEscribano (2016), para un sismo de intensidad VII en la escala EMS-98.

Para cada edificación el daño observado se representa mediante un aspa azul en relación con su correspondiente índice de vulnerabilidad $I_{V-b}$. Asimismo, se muestra el grado de daño medio calculado según la metodología LM1 asociado a los mismos valores de vulnerabilidad, incluyendo el intervalo posible $\left[\mu_{D}{ }^{-}, \mu_{D}^{+}\right]$correspondiente con el rango $\left[I_{v}{ }^{-}, I_{v}^{+}\right]$definido en la matriz BTM. La alta variabilidad apreciada en la distribución del grado de daño observado en las Figuras 4.26 a 4.30 se debe a los distintos modificadores de comportamiento considerados 
por cada autor, los cuales proporcionan diferentes valores de $I_{v-b}$ para una misma edificación según la ecuación (2.9).



Figura 4.26. Comparación entre el daño observado en las edificaciones tras el terremoto de Lorca y el grado medio de daño obtenido según el método LM1 de RISK-UE (Milutinovic \& Trendafiloski, 2003), para un sismo de intensidad $I_{E M S-98}=$ VII.

$\mu_{D}^{*}=$ daño medio representativo; $\left[\mu_{D}^{-}, \mu_{D}^{+}\right]=$intervalo probable del grado de daño estimado; MIL2003 = valores obtenidos según la propuesta de Milutinovic \& Trendafiloski (2003).

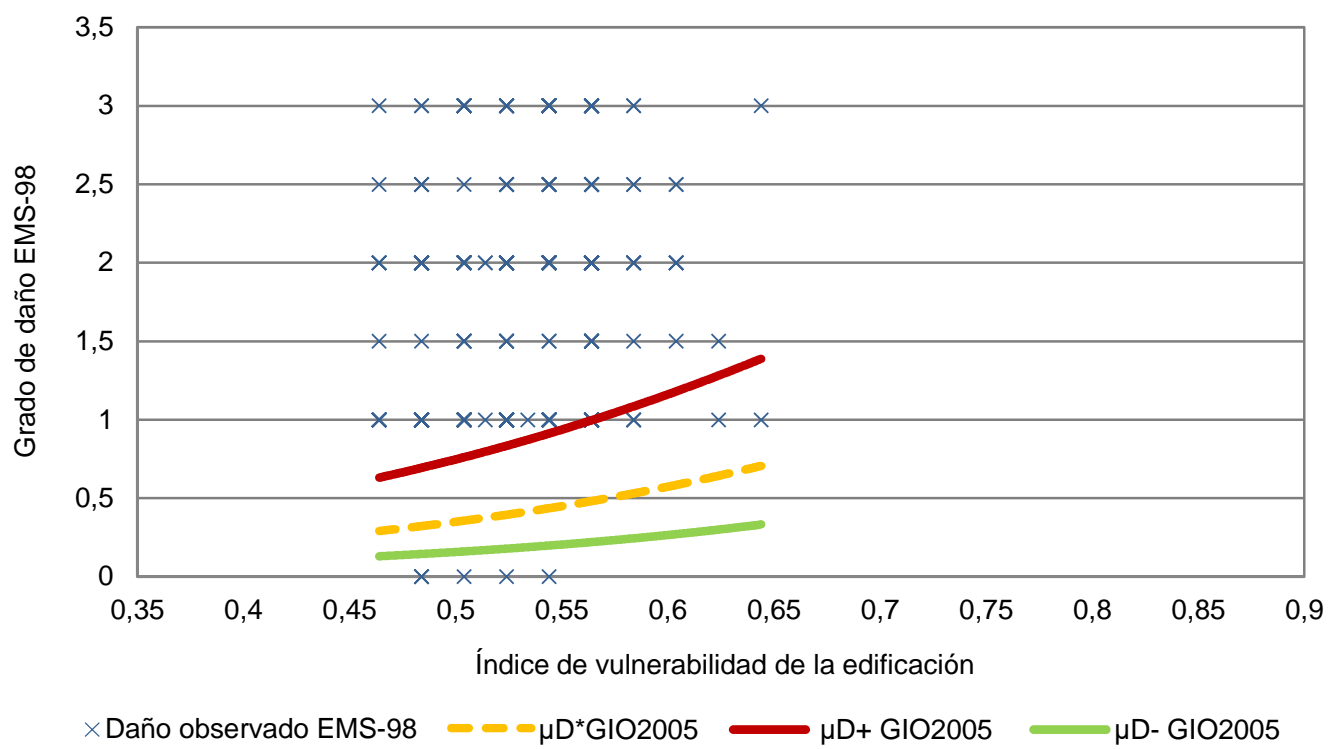

Figura 4.27. Comparación entre el daño observado en las edificaciones tras el terremoto de Lorca y el grado medio de daño obtenido según la revisión del método LM1 de RISK-UE (Giovinazzi, 2005), para un sismo de intensidad $I_{E M S-98}=$ VII.

$\mu_{D}^{*}=$ daño medio representativo; $\left[\mu_{D}^{-}, \mu_{D}^{+}\right]=$intervalo probable del grado de daño estimado; GIO2005 = valores obtenidos según la propuesta de Giovinazzi (2005). 


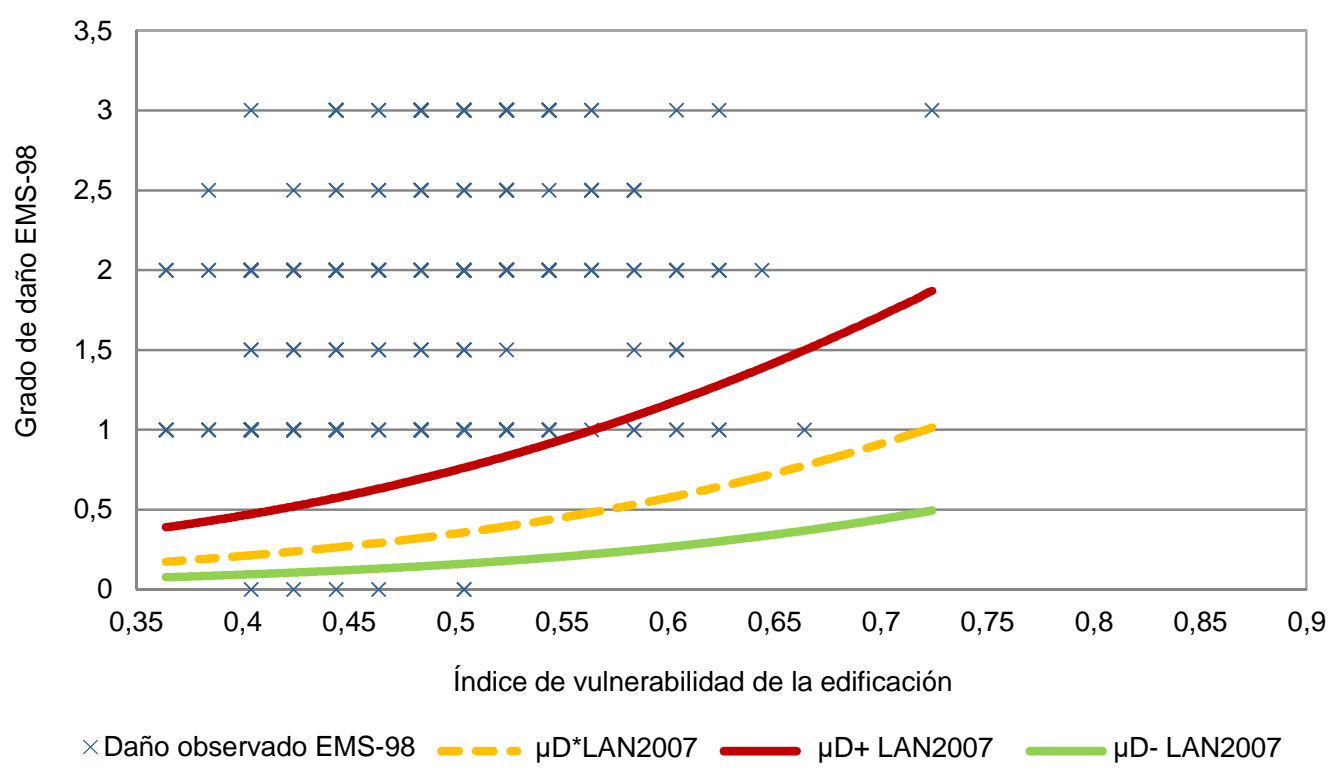

Figura 4.28. Comparación entre el daño observado en las edificaciones tras el terremoto de Lorca y el grado medio de daño obtenido según la revisión del método LM1 de RISK-UE (Lantada, 2007), para un sismo de intensidad $I_{E M S-98}=$ VII.

$\mu_{D}{ }^{*}=$ daño medio representativo; $\left[\mu_{D}^{-}, \mu_{D}^{+}\right]=$intervalo probable del grado de daño estimado; LAN2007 = valores obtenidos según la propuesta de Lantada (2007).

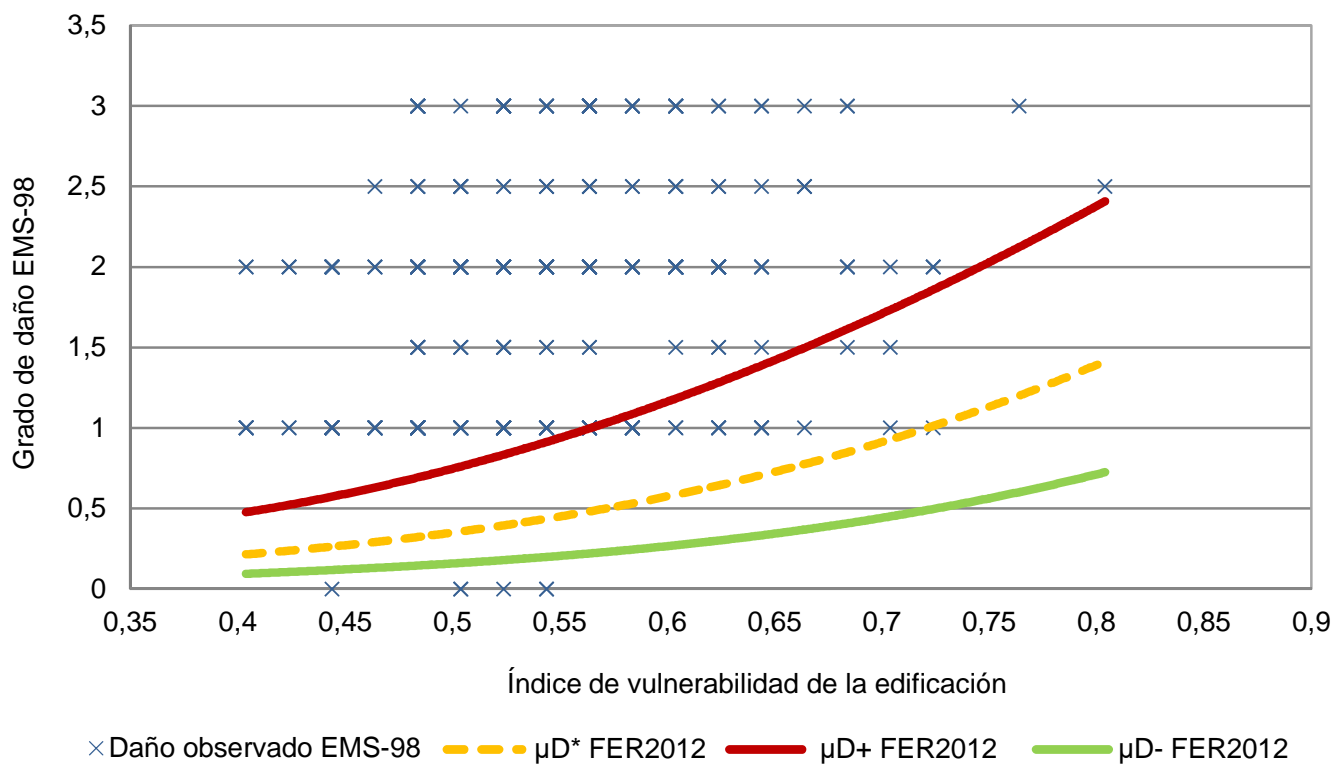

Figura 4.29. Comparación entre el daño observado en las edificaciones tras el terremoto de Lorca y el grado medio de daño obtenido según la revisión del método LM1 de RISK-UE (Feriche, 2012), para un sismo de intensidad $I_{E M S-98}=$ VII.

$\mu_{D}^{*}=$ daño medio representativo; $\left[\mu_{D}^{-}, \mu_{D}^{+}\right]=$intervalo probable del grado de daño estimado; FER2012 = valores obtenidos según la propuesta de Feriche (2012). 


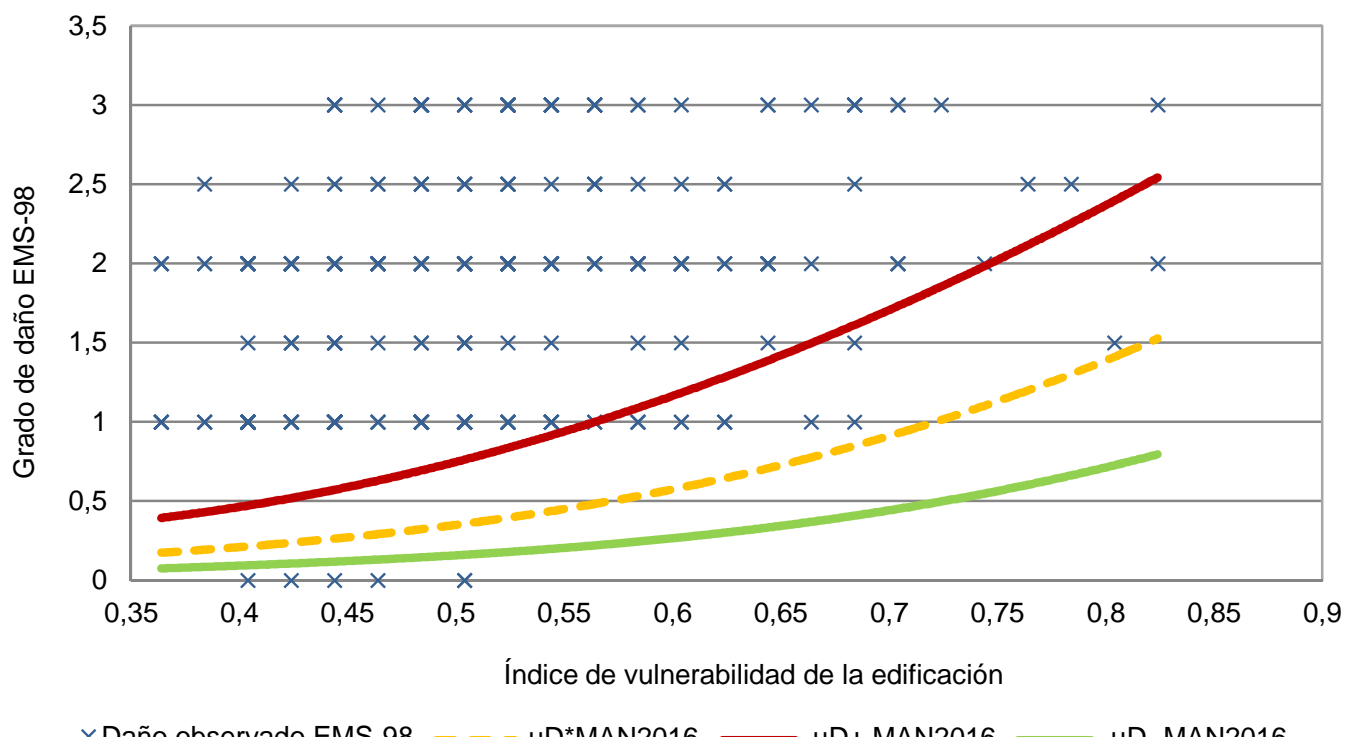

Figura 4.30. Comparación entre el daño observado en las edificaciones tras el terremoto de Lorca y el grado medio de daño obtenido según la revisión del método LM1 de RISK-UE (Martínez-Cuevas \& Gaspar-Escribano, 2016), para un sismo de intensidad $I_{E M S-98}=$ VII.

$\mu_{D}{ }^{*}=$ daño medio representativo; $\left[\mu_{D}^{-}, \mu_{D}^{+}\right]=$intervalo probable del grado de daño estimado; MAN2016 = valores obtenidos según la propuesta de Martínez-Cuevas \& Gaspar-Escribano (2016).

No obstante, un mayor rango de valores del índice de vulnerabilidad implicaría una mayor capacidad de ajuste del modelo, ya que puede considerarse una mayor casuística. En cualquier caso, el daño simulado según las distintas versiones del método MIV estaría por debajo de los niveles de daño real observado para un terremoto de intensidad VII en la escala EMS-98. Por tanto, estos modelos no representarían totalmente el comportamiento sísmico de este tipo de edificaciones de hormigón armado.

En la Figura 4.31 se muestra la comparación entre el grado de daño medio calculado según la metodología LM1 a partir de la nueva propuesta del método MIV y el correspondiente daño observado en el sismo de Lorca. Se observa una mejor correlación entre los daños sísmicos reales y simulados, con un mayor número de casos incluidos en el rango probable de valores $\left[\mu_{D}{ }^{-}, \mu_{D}^{+}\right]$definido en la metodología.

En las Figuras 4.32 a 4.36 se compara la distribución del grado de daño observado en las edificaciones tras el sismo de 2011 con los niveles de daño medio, estimados según la metodología LM1 y las distintas revisiones del método MIV propuestas en la literatura, para un sismo de intensidad VIII en la escala EMS-98. Se observa una mejor correlación de los resultados obtenidos entre los niveles de daño observado y calculado para cada una de las revisiones del método MIV, en comparación con lo mostrado en las Figuras 4.26 a 4.30, con un mayor número de casos incluidos en el rango probable de valores $\left[\mu_{D}{ }^{-}, \mu_{D}{ }^{+}\right]$. 


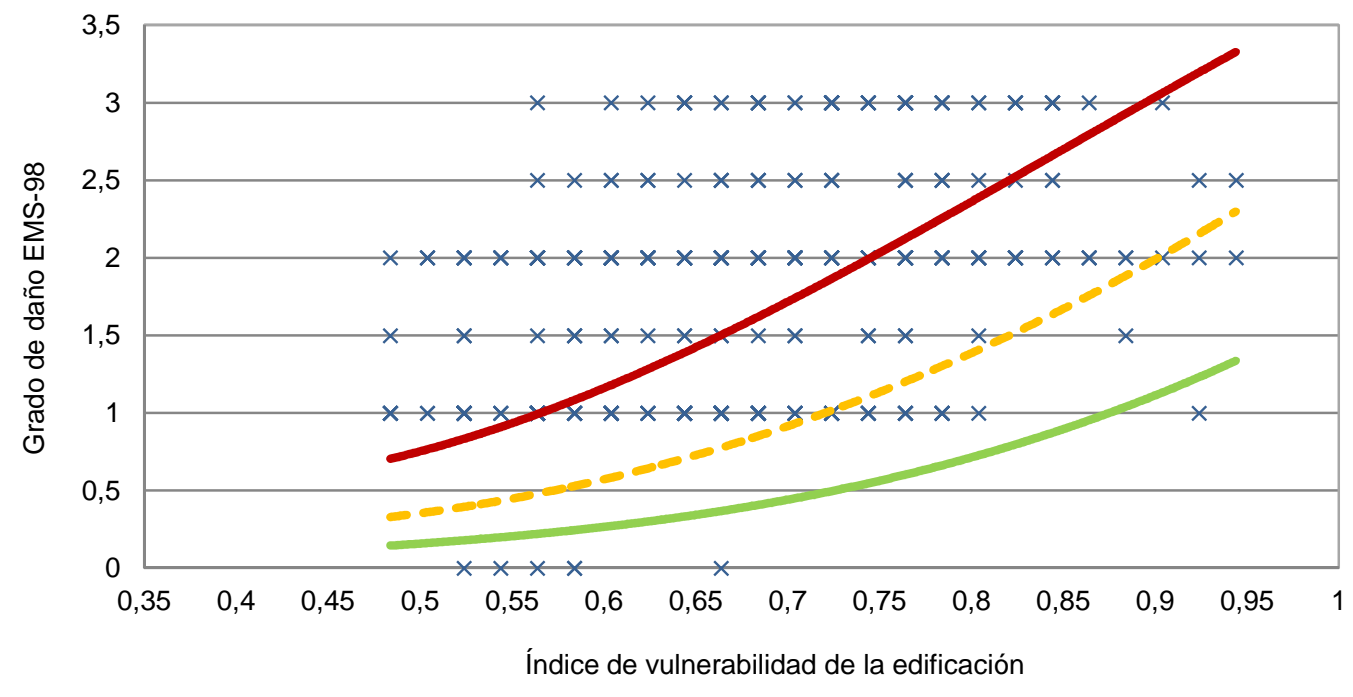

$\times$ Daño observado EMS-98 $-\mu D^{*}$ ROD2017 $-\mu D+R O D 2017 \longrightarrow$ ROD2017

Figura 4.31. Comparación entre el daño observado en las edificaciones tras el terremoto de Lorca y el grado medio de daño obtenido según el modelo propuesto para el método LM1 de RISK-UE, para un sismo de intensidad $I_{E M S-98}=$ VII.

$\mu_{D}{ }^{*}=$ daño medio representativo; $\left[\mu_{D}^{-}, \mu_{D}^{+}\right]=$intervalo probable del grado de daño estimado; ROD2017 = valores obtenidos según el modelo propuesto.

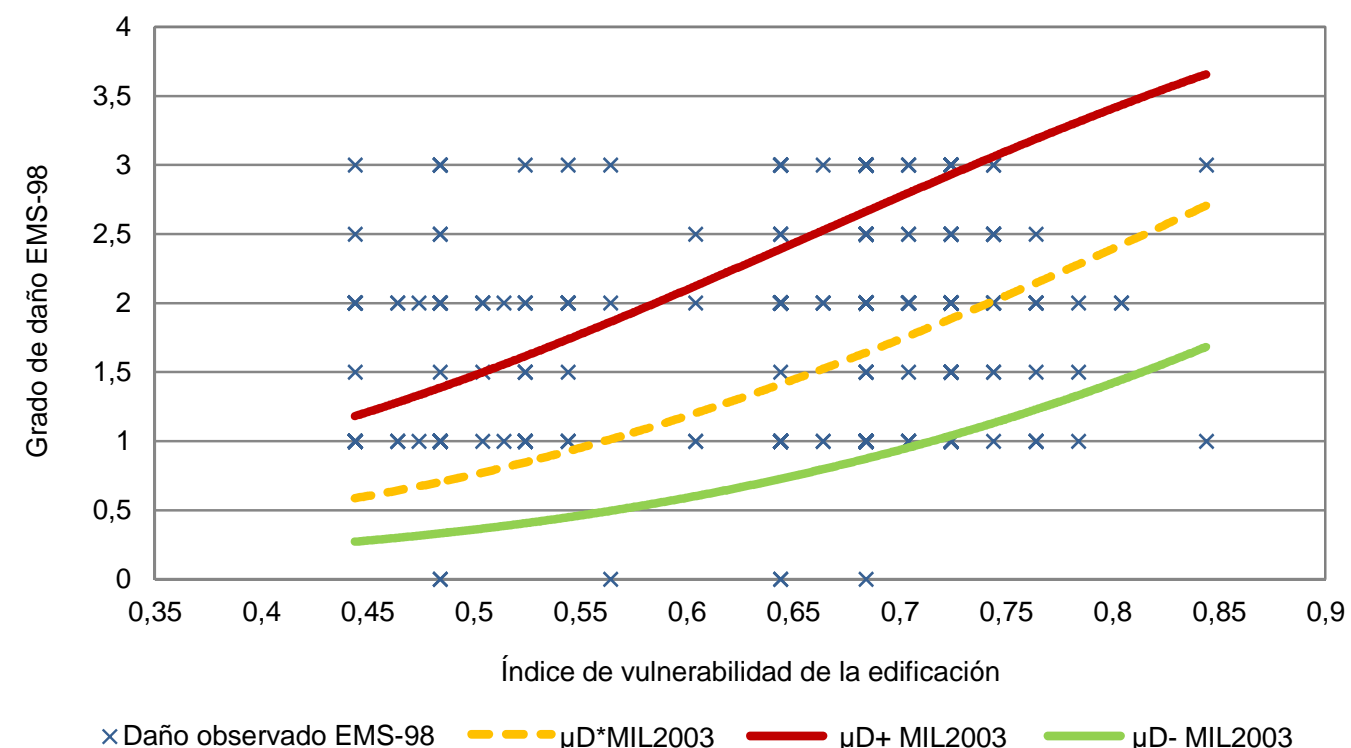

Figura 4.32. Comparación entre el daño observado en las edificaciones tras el terremoto de Lorca y el grado medio de daño obtenido según el método LM1 de RISK-UE (Milutinovic \& Trendafiloski, 2003), para un sismo de intensidad $I_{E M S-98}=$ VIII.

$\mu_{D}^{*}=$ daño medio representativo; $\left[\mu_{D}^{-}, \mu_{D}^{+}\right]=$intervalo probable del grado de daño estimado; MIL2003 = valores obtenidos según la propuesta de Milutinovic \& Trendafiloski (2003). 


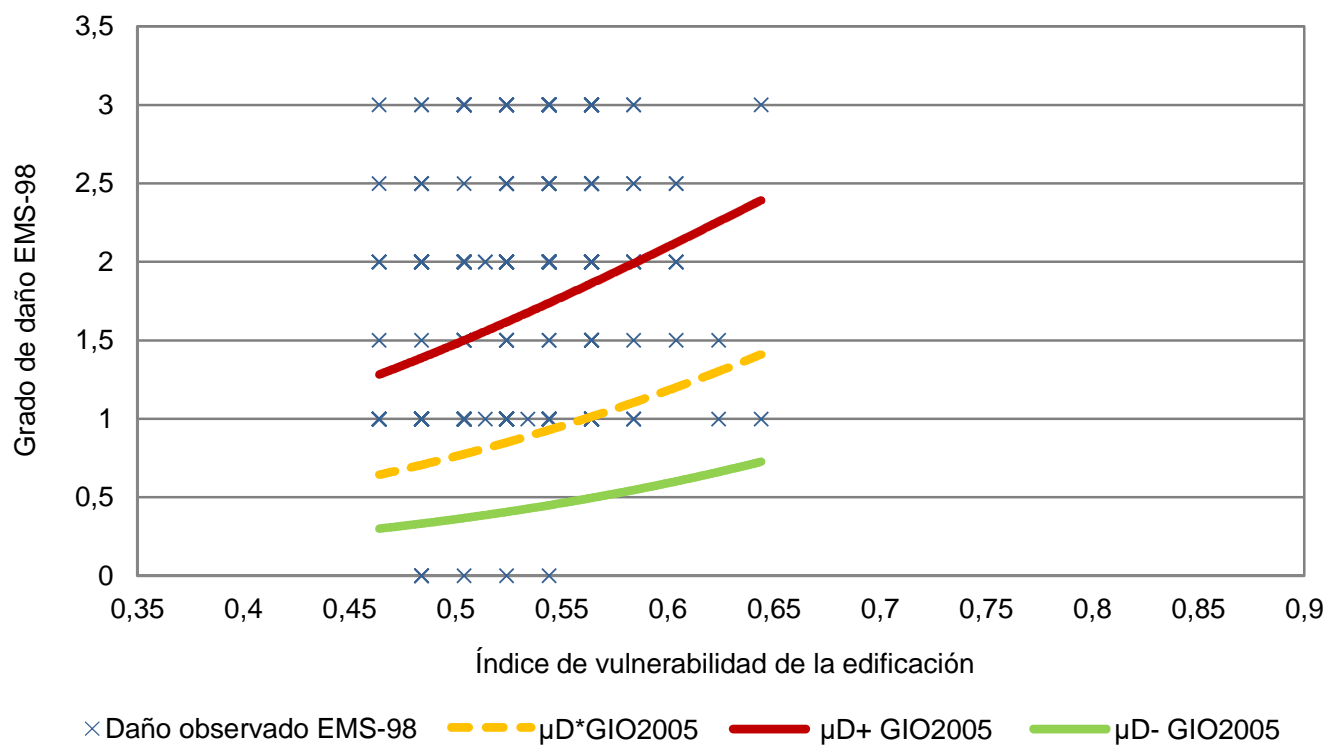

Figura 4.33. Comparación entre el daño observado en las edificaciones tras el terremoto de Lorca y el grado medio de daño obtenido según la revisión del método LM1 de RISK-UE (Giovinazzi, 2005), para un sismo de intensidad $I_{E M S-98}=$ VIII.

$\mu_{D}{ }^{*}=$ daño medio representativo; $\left[\mu_{D}^{-}, \mu_{D}^{+}\right]=$intervalo probable del grado de daño estimado; GIO2005 = valores obtenidos según la propuesta de Giovinazzi (2005).

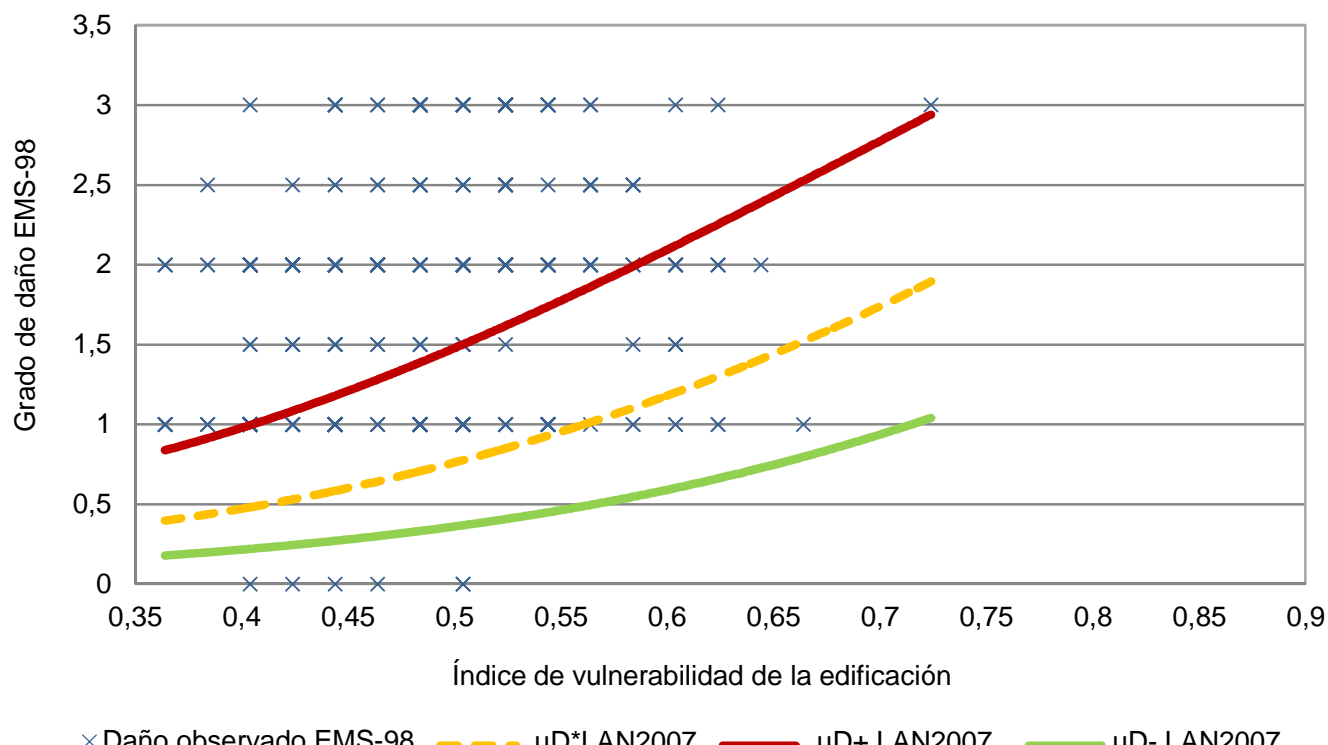

Figura 4.34. Comparación entre el daño observado en las edificaciones tras el terremoto de Lorca y el grado medio de daño obtenido según la revisión del método LM1 de RISK-UE (Lantada, 2007), para un sismo de intensidad $I_{E M S-98}=$ VIII.

$\mu_{D}{ }^{*}=$ daño medio representativo; $\left[\mu_{D}^{-}, \mu_{D}^{+}\right]=$intervalo probable del grado de daño estimado; LAN2007 = valores obtenidos según la propuesta de Lantada (2007). 


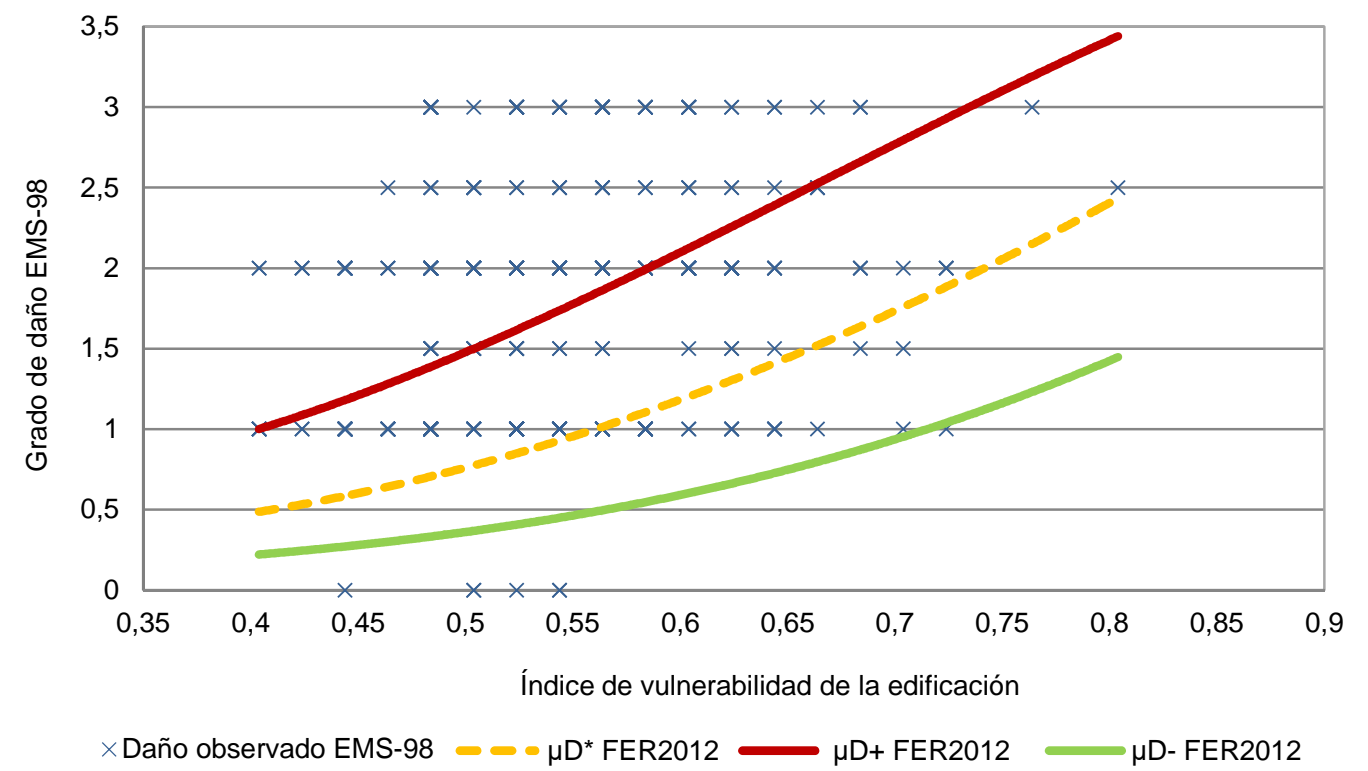

Figura 4.35. Comparación entre el daño observado en las edificaciones tras el terremoto de Lorca y el grado medio de daño obtenido según la revisión del método LM1 de RISK-UE (Feriche, 2012), para un sismo de intensidad $I_{E M S-98}=$ VIII.

$\mu_{D}{ }^{*}=$ daño medio representativo; $\left[\mu_{D}^{-}, \mu_{D}^{+}\right]=$intervalo probable del grado de daño estimado; FER2012 = valores obtenidos según la propuesta de Feriche (2012).

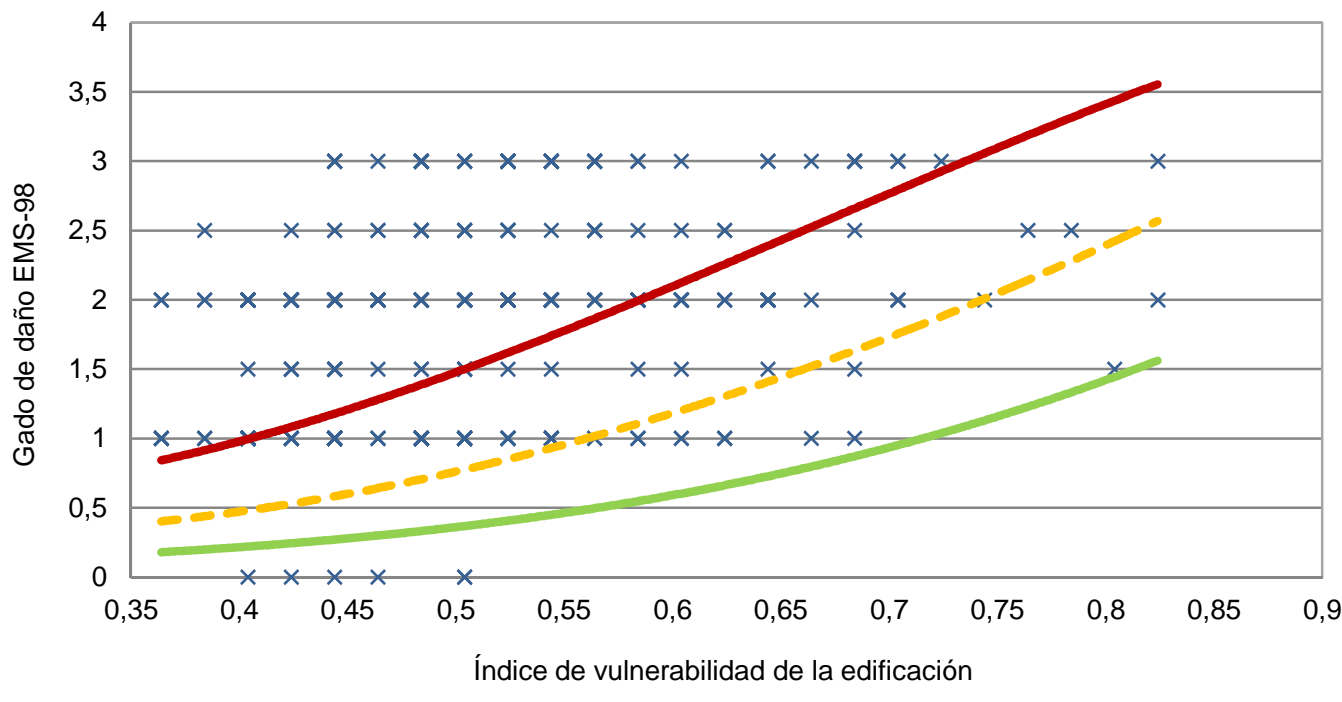

$\times$ Daño observado EMS-98 $-\mu D^{*}$ MAN2016 $\sim \mu D+$ MAN2016 $-\mu D-$ MAN2016

Figura 4.36. Comparación entre el daño observado en las edificaciones tras el terremoto de Lorca y el grado medio de daño obtenido según la revisión del método LM1 de RISK-UE (Martínez-Cuevas \& Gaspar-Escribano, 2016), para un sismo de intensidad $I_{E M S-98}=$ VIII.

$\mu_{D}{ }^{*}=$ daño medio representativo; $\left[\mu_{D}^{-}, \mu_{D}^{+}\right]=$intervalo probable del grado de daño estimado; MAN2016 = valores obtenidos según la propuesta de Martínez-Cuevas \& Gaspar-Escribano (2016). 
En la Figura 4.37 se muestra la comparación entre el grado de daño calculado según la nueva propuesta, para un sismo de intensidad VIII, y el correspondiente daño observado en el sismo de Lorca. Se identifica una mejor correlación entre los datos reales y simulados con respecto a los resultados recogidos en la Figura 4.31.

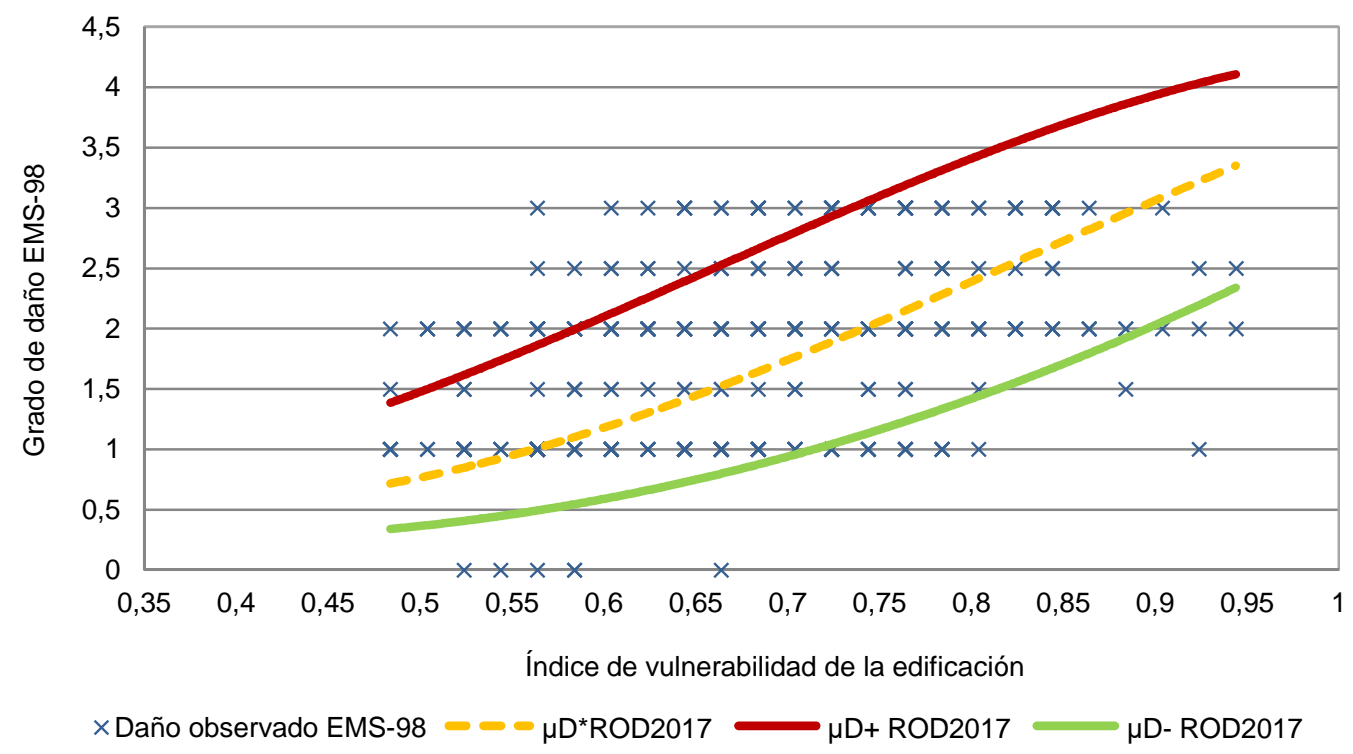

Figura 4.37. Comparación entre el daño observado en las edificaciones tras el terremoto de Lorca y el grado medio de daño obtenido según el modelo propuesto para el método LM1 de RISK-UE, para un sismo de intensidad $I_{E M S-98}=$ VIII.

$\mu_{D}^{*}=$ daño medio representativo; $\left[\mu_{D}^{-}, \mu_{D}^{+}\right]=$intervalo probable del grado de daño estimado; ROD2017 = valores obtenidos según el modelo propuesto.

La distribución de los grados de daño observado en el sismo de Lorca de 2011 se ajustaría mejor, por tanto, a los niveles de daño calculados según la metodología LM1 para un sismo de intensidad VIII en la escala EMS-98 que para los resultados obtenidos con un sismo de intensidad VII. De este modo, se identifica de nuevo la tendencia de que, en este tipo de edificaciones aporticadas de hormigón armado, los niveles de daño calculados según las distintas versiones del método MIV quedarían por debajo del grado de daño observado en la realidad.

\subsubsection{Tratamiento estadístico de los datos}

\subsubsection{Formulación de las hipótesis de contraste y de las variables del análisis}

Se dispone de un conjunto de 364 edificaciones de hormigón armado en las que se conoce el daño real observado en el sismo de Lorca de 2011 y el grado de daño calculado según la metodología LM1 de RISK-UE, obtenido a partir de las diversas variantes del método MIV propuestas en la literatura. 
Se pretende demostrar que la diferencia entre daño observado y calculado es significativamente menor con la nueva propuesta que la diferencia resultante con las anteriores versiones del método. Para tal fin, es necesario establecer un contraste de igualdad de la tendencia central de las variables afectadas, en el que las hipótesis planteadas se formulan del siguiente modo:

$\checkmark \quad H_{0}$ - Hipótesis nula: no existente diferencia significativa entre la comparación de daño real y calculado según el nuevo modelo y la comparación realizada según cada versión existente del método.

$\checkmark \quad H_{1}$ - Hipótesis alternativa: existe diferencia significativa entre la comparación de daño real y calculado según el nuevo modelo y la comparación realizada según cada versión existente del método.

Las variables utilizadas en el análisis estadístico son las siguientes:

$\checkmark \quad$ El grado de daño en la edificación obtenido según la metodología LM1 de RISK-UE (variable cuantitativa).

$\checkmark \quad$ El método empleado para la obtención del índice de vulnerabilidad de las edificaciones (variable cualitativa). Con objeto de comprobar el funcionamiento del modelo propuesto con respecto a las distintas variantes del método MIV, se han analizado de forma independiente los resultados obtenidos según las metodologías de Milutinovic \& Trendafiloski (2003), Giovinazzi (2005), Lantada (2007), Feriche (2012) y MartínezCuevas \& Gaspar-Escribano (2016).

Cada sujeto de la muestra presenta dos observaciones, una a partir de una de las metodologías previas del método MIV, y otra según el modelo propuesto. Por tanto, el análisis estadístico se ha implementado considerando datos apareados.

El contraste de hipótesis se ha realizado tanto para los niveles de daño correspondientes a un sismo de intensidad VII en la escala EMS-98 como para los resultados correspondientes a un sismo de intensidad VIII.

En primer lugar se define una nueva variable de daño $Z_{i j}$ determinada mediante la expresión (4.1).

$$
Z_{\mathrm{ij}}=D O_{\mathrm{i}}-\mu_{\mathrm{Dij}}
$$

donde:

$Z_{i j}=$ diferencia entre el grado de daño observado en la edificación $i$ y el grado de daño medio calculado según la revisión $j$ del método MIV.

$D O_{i}=$ grado de daño observado en la escala EMS-98 para cada edificación $i$.

$\mu_{D i j}=$ grado de daño medio obtenido según la versión $j$ del método MIV, para cada edificación $i$. 
En la Tabla 4.9 se muestran los parámetros de tendencia central de la variable $Z_{i j}$ para las edificaciones de hormigón armado analizadas, obtenidos para un terremoto de intensidad VII en la escala EMS-98. Según se puede observar, las variantes de Milutinovic \& Trendafiloski (2003), Feriche (2012) y la nueva propuesta serían las que presentarían un mejor ajuste entre daño observado y calculado, con valores medios más bajos para esta variable $Z_{i j}$.

Tabla 4.9. Medidas de tendencia central de la nueva variable de daño $Z_{i j}$ en las edificaciones analizadas según las revisiones del método MIV existentes en la literatura y la nueva propuesta, para sismo de intensidad VII en la escala EMS-98.

\begin{tabular}{ccccccc}
\hline $\begin{array}{c}\text { Medidas de } \\
\text { tendencia } \\
\text { central } Z_{i j}\end{array}$ & $\begin{array}{c}\text { Milutinovic \& } \\
\text { Trendafiloski } \\
(2003)\end{array}$ & $\begin{array}{c}\text { Giovinazzi } \\
(2005)\end{array}$ & $\begin{array}{c}\text { Lantada } \\
(2007)\end{array}$ & $\begin{array}{c}\text { Feriche } \\
(2012)\end{array}$ & $\begin{array}{c}\text { Martinez-Cuevas } \\
\text { \& Gaspar- } \\
\text { Escribano (2016) }\end{array}$ & $\begin{array}{c}\text { Ródenas } \\
(2017)\end{array}$ \\
\hline Media & 1,16 & 1,39 & 1,34 & 1,11 & 1,20 & 0,91 \\
Desv. típica & 0,727 & 0,730 & 0,697 & 0,716 & 0,696 & 0,694 \\
\hline
\end{tabular}

Asimismo, se ha definido otra variable como la diferencia $D_{i j}$ según la ecuación (4.2):

$$
D_{\mathrm{ij}}=Z_{\mathrm{ij}}-Z_{\mathrm{i} \_ \text {ROD }}
$$

donde:

$$
\begin{aligned}
Z_{i j}= & \text { valor de la variable obtenida según la ecuación (4.1), para una determinada } \\
& \text { versión } j \text { del método MIV. } \\
Z_{i-R O D}= & \text { valor de la variable de daño } Z_{i j} \text { obtenida para cada edificación } i \text { según el nuevo } \\
& \text { modelo propuesto. }
\end{aligned}
$$

En la Tabla 4.10 se recogen los parámetros de tendencia central de esta variable $D_{i j}$. Para los datos registrados en el sismo de Lorca de 2011, la correlación más ajustada entre las diferencias de daño real y estimado en las edificaciones se corresponde con los resultados obtenidos según las variantes de Feriche (2012) y Milutinovic \& Trendafiloski (2003) con el nuevo modelo propuesto. Por el contrario, el peor ajuste se obtendría para la variante de Giovinazzi (2005) con la nueva propuesta. Asimismo, al comparar las medidas de tendencia central y dispersión de esta variable $D_{i j}$, se observa una cierta asimetría en la distribución de los resultados obtenidos según se muestra en la Tabla 4.10 y en la Figura 4.38.

Por otra parte, en la Tabla 4.11 se muestran los parámetros de tendencia central de la variable $Z_{i j}$ determinados para un sismo de intensidad VIII en la escala EMS-98. En comparación con los resultados mostrados en la Tabla 4.9, se observa valores medios más bajos en todas las variantes del método MIV evaluadas. En las Figuras 4.32 a 4.36 ya se podía identificar esta mejor correlación entre los niveles de daño observado y estimado, con un mayor número de casos incluidos en el rango probable de valores $\left[\mu_{D}^{-}, \mu_{D}{ }^{+}\right]$. De nuevo, las variantes de Milutinovic \& Trendafiloski (2003), Feriche (2012) y la nueva propuesta serían con las que obtendrían valores medios más bajos para esta variable $Z_{i j}$, mientras que la versión de Giovinazzi (2005) sería la que presentaría una desviación más elevada. 
Tabla 4.10. Medidas de tendencia central de la diferencia $D_{i j}$ en las edificaciones analizadas según las revisiones existentes del método MIV y la nueva propuesta, para un sismo de intensidad VII en la escala EMS-98.

\begin{tabular}{cccccc}
\hline $\begin{array}{c}\text { Medidas de } \\
\text { tendencia } \\
\text { central } D_{i j}\end{array}$ & MIL03-ROD17 & GIO05-ROD17 & LAN07-ROD17 & FER12-ROD17 & MAN16-ROD17 \\
\hline Media & 0,247 & 0,478 & 0,426 & 0,200 & 0,288 \\
Desv. típica & 0,367 & 0,378 & 0,382 & 0,285 & 0,249 \\
Mediana & 0,165 & 0,384 & 0,324 & 0,159 & 0,238 \\
\hline
\end{tabular}

MIL03, GIO05, LANO7, FER12, MAN16, ROD17 = variantes del método MIV propuestas por Milutinovic \& Trendafiloski (2003), Giovinazzi (2005), Lantada (2007), Feriche (2012), Martínez-Cuevas \& GasparEscribano (2016) y el nuevo modelo, respectivamente.

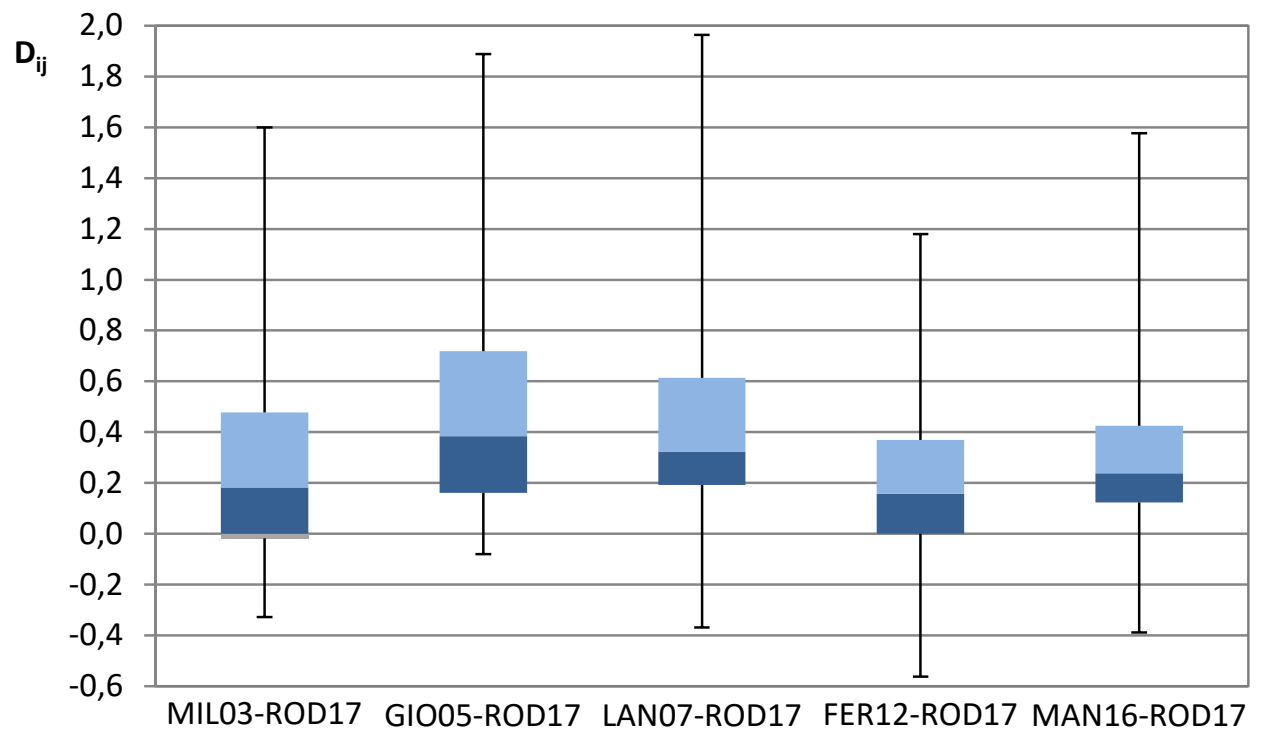

Figura 4.38. Diagrama de caja para la variable $D_{i j}$ obtenida según las revisiones existentes del método MIV y la nueva propuesta, para un sismo de intensidad VII en la escala EMS-98.

MIL03, GIO05, LANO7, FER12, MAN16, ROD17 = variantes del método MIV propuestas por Milutinovic \& Trendafiloski (2003), Giovinazzi (2005), Lantada (2007), Feriche (2012), Martínez-Cuevas \& GasparEscribano (2016) y el nuevo modelo, respectivamente.

Tabla 4.11. Medidas de tendencia central de la nueva variable de daño $Z_{i j}$ en las edificaciones analizadas según las revisiones existentes del método MIV y la nueva propuesta, para un sismo de intensidad VIII en la escala EMS-98.

\begin{tabular}{ccccccc}
\hline $\begin{array}{c}\text { Medidas de } \\
\text { tendencia } \\
\text { central } Z_{i j}\end{array}$ & $\begin{array}{c}\text { Milutinovic \& } \\
\text { Trendafiloski } \\
(2003)\end{array}$ & $\begin{array}{c}\text { Giovinazzi } \\
(2005)\end{array}$ & $\begin{array}{c}\text { Lantada } \\
(2007)\end{array}$ & $\begin{array}{c}\text { Feriche } \\
(2012)\end{array}$ & $\begin{array}{c}\text { Martinez-Cuevas } \\
\text { \& Gaspar- } \\
\text { Escribano (2016) }\end{array}$ & $\begin{array}{c}\text { Ródenas } \\
(2017)\end{array}$ \\
\hline Media & 0,35 & 0,93 & 0,87 & 0,45 & 0,61 & 0,15 \\
Desv. típica & 0,795 & 0,725 & 0,744 & 0,744 & 0,718 & 0,739 \\
\hline
\end{tabular}


En la Tabla 4.12 se muestran los parámetros de tendencia central de la variable $D_{i j}$ obtenidos para un sismo de intensidad VIII en la escala EMS-98 y los datos procedentes del sismo de Lorca. De nuevo, la correlación más ajustada entre las diferencias de daño real y estimado en las edificaciones se corresponde con los resultados obtenidos según con las variantes de Feriche (2012) y Milutinovic \& Trendafiloski (2003) con el nuevo modelo propuesto. Se observa una mayor dispersión en la comparación de los niveles de daño obtenidos con las metodologías de Giovinazzi (2005) y Lantada (2007) respecto a la nueva propuesta. Al comparar las medidas de tendencia central y dispersión de esta variable $D_{i j}$, se observa también una distribución asimétrica de los resultados obtenidos (Figura 4.39).

Tabla 4.12. Medidas de tendencia central de la diferencia $D_{i j}$ en las edificaciones analizadas según las revisiones existentes del método MIV y la nueva propuesta, para un sismo de intensidad VIII en la escala

EMS-98.

\begin{tabular}{cccccc}
\hline $\begin{array}{c}\text { Medidas de } \\
\text { tendencia } \\
\text { central } D_{i j}\end{array}$ & MIL03-ROD17 & GIO05-ROD17 & LAN07-ROD17 & FER12-ROD17 & MAN16-ROD17 \\
\hline Media & 0,192 & 0,772 & 0,712 & 0,297 & 0,453 \\
Desv. típica & 0,540 & 0,540 & 0,561 & 0,411 & 0,355 \\
Mediana & 0,209 & 0,703 & 0,627 & 0,270 & 0,387 \\
\hline
\end{tabular}

MIL03, GIO05, LANO7, FER12, MAN16, ROD17 = variantes del método MIV propuestas por Milutinovic \& Trendafiloski (2003), Giovinazzi (2005), Lantada (2007), Feriche (2012), Martínez-Cuevas \& GasparEscribano (2016) y el nuevo modelo, respectivamente.

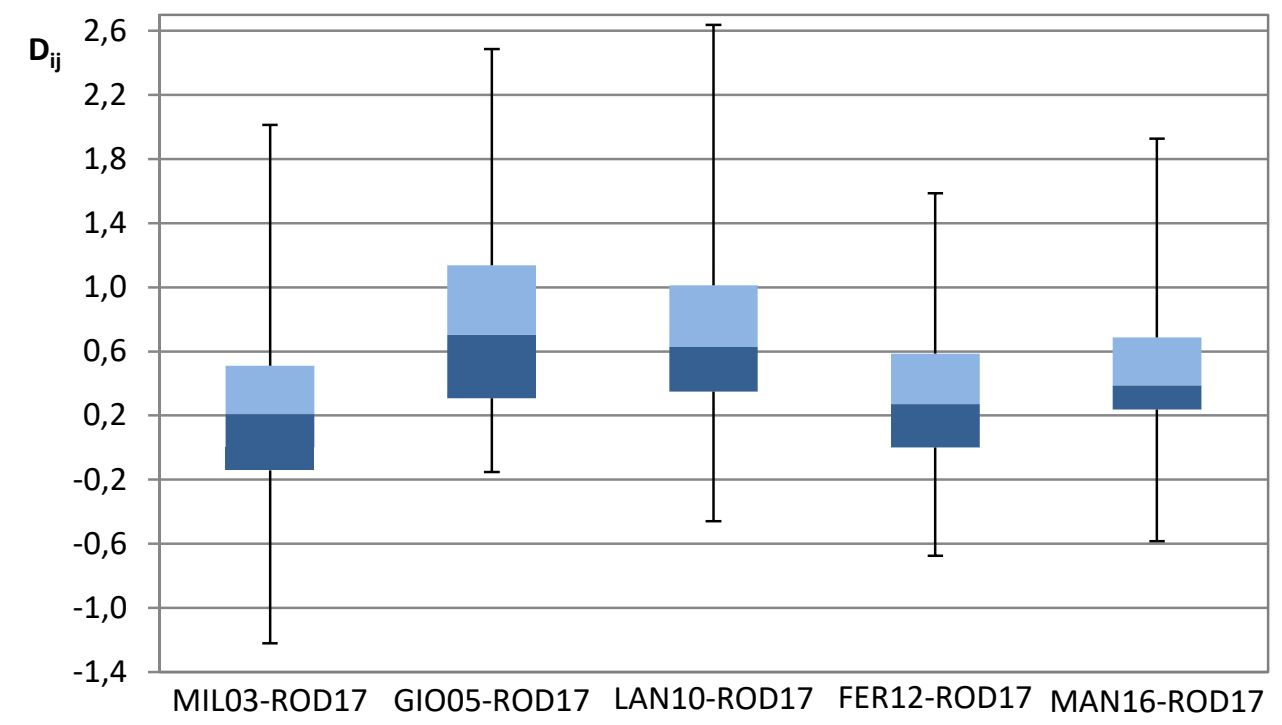

Figura 4.39. Diagrama de caja para la variable $D_{i j}$ obtenida según las diferentes revisiones del método MIV existentes en la literatura y la nueva propuesta, para sismo de intensidad VIII en la escala EMS-98. MILO3, GIO05, LAN07, FER12, MAN16, ROD17 = variantes del método MIV propuestas por Milutinovic \& Trendafiloski (2003), Giovinazzi (2005), Lantada (2007), Feriche (2012), Martínez-Cuevas \& GasparEscribano (2016) y el nuevo modelo, respectivamente. 


\subsubsection{Test estadístico}

Para seleccionar el test estadístico necesario para resolver las hipótesis de contraste descritas en el apartado 4.4.2.1, se han evaluado los siguientes factores:

$\checkmark$ Comparación de la tendencia central entre una variable cualitativa y otra cuantitativa.

$\checkmark$ Presencia de datos apareados de cada observación de la muestra.

$\checkmark$ Distribución asimétrica de los datos disponibles.

El estadístico $t$-Student suele emplearse en observaciones apareadas, para analizar la relación entre una variable cualitativa y otra cuantitativa. No obstante, su aplicación requiere que la distribución de la variable cuantitativa sea normal en ambos grupos de comparación, lo cual no sucede en este caso, dada la distribución asimétrica de los datos (Figuras 3.38 y 4.39). Se ha seleccionado el Test de Wilcoxon para datos apareados, pues está más indicado para el caso en que los resultados no sigan una distribución normal. Se trata de un test no paramétrico, para datos no normales, cuyas características se pueden resumir en que:

$\checkmark$ Analiza las medianas de las variables de contraste como parámetro de tendencia central, en vez de las medias de la muestra.

$\checkmark$ Trabaja con rangos de orden de la distribución de datos.

$\checkmark$ Es menos potente que el test $t$-Student para datos apareados, es decir, existe una mayor probabilidad de no rechazar la hipótesis nula, aun siendo falsa. No obstante, el gran tamaño de la muestra disponible en este caso permite asegurar un correcto funcionamiento del test.

Las hipótesis de contraste planteadas se formularían, por tanto, en términos de igualdad de medianas. Asumir que las medianas de las variables $D_{i j}$ son iguales es equivalente a establecer que la mediana de las diferencias es nula. Así, se definen las hipótesis de contraste finalmente consideradas (Tabla 4.13).

Tabla 4.13. Hipótesis de contraste consideradas en el test estadístico.

\begin{tabular}{cc}
\hline Hipótesis & Contraste \\
\hline$H_{0}$ : Hipótesis nula & Med_ $D_{i j}=0$ \\
$H_{1}$ : Hipótesis alternativa & Med_ $D_{i j}<0$ \\
\hline
\end{tabular}

Med_ $D_{i j}=$ mediana de la variable $D_{i j}$ definida en la ecuación (4.2) para una determinada versión $j$ del método MIV.

La implementación del test consta de los siguientes pasos:

I. Cálculo de las diferencias de cada elemento para las dos variables estudiadas.

II. Eliminación de los elementos con diferencias nulas. 
III. Ordenación de las diferencias en valor absoluto, prescindiendo de los signos.

IV. Asignación de un rango de orden a cada diferencia.

V. Corrección de posibles ligaduras -valores repetidos- mediante la asignación de un rango medio.

VI. Suma de rangos según los signos que presenten las diferencias. Determinación de los siguientes estimadores:

$T(+)=$ suma de rangos correspondientes a diferencias positivas.

$T(-)=$ Suma de rangos correspondientes a diferencias negativas.

A partir de estos valores se define estadígrafo $T$ de contraste establecido en el test, según la ecuación (4.3).

$$
\mathrm{T}=\min [\mathrm{T}(+) ; \mathrm{T}(-)]
$$

Para un número de muestra superior a 25 unidades, como este caso, se demuestra que, mediante una pequeña transformación, el estadígrafo $T$ se ajusta a una distribución normal, obteniendo el parámetro $V$ según la expresión (4.4).

$$
\mathrm{V}=\frac{T-n(n+1) / 4}{\sqrt{n(n+1)(2 n+1) / 24}} \equiv N(0,1)
$$

Para determinar el resultado del contraste, únicamente es necesaria la comparación del valor de este parámetro $V$ con el punto crítico $Z_{\alpha}$ de una distribución normal correspondiente con un nivel de confianza del $95 \%$, o determinar directamente el p-valor asociado.

Si $|Z| \leq\left|Z_{\alpha}\right| \rightarrow$ No se dispone de datos suficientes para rechazar la hipótesis nula $H_{0}$.

Si $|Z|>\left|Z_{\alpha}\right| \rightarrow$ Se rechaza la hipótesis nula $H_{0}$ y se acepta la hipótesis alternativa $H_{1}$.

\subsubsection{Análisis e interpretación de resultados}

El número de contrastes estadísticos realizados se resume en la Tabla 4.14. Las hipótesis planteadas en la Tabla 4.13 se han evaluado para cada una de las variantes existentes del método MIV, con el fin de comprobar el mejor funcionamiento del modelo propuesto con respecto a cada una de ellas. Asimismo, cada contraste de hipótesis se ha realizado tanto para los resultados obtenidos con un sismo de intensidad VII en la escala EMS-98, como para los obtenidos según un sismo de intensidad VIII.

El test ha sido programado e implementado en la hoja de cálculo Excel. En la Tabla 4.15 se muestra un resumen de los resultados del test para cada análisis considerado, con los datos calculados para un sismo de intensidad VII. Con un $p$-valor $<0,05$, la hipótesis nula de igualdad de medianas puede ser rechazada con un nivel de significancia $\alpha=0,05$ para cada contraste realizado. 
Tabla 4.14. Número de contrastes estadísticos realizados.

\begin{tabular}{ccc}
\hline No de contraste & Hipótesis nula $H_{0}$ & $\begin{array}{c}\text { Determinación de la } \\
\text { variable } D_{i j}\end{array}$ \\
\hline C1 & Med_D $D_{1}=0$ & $D_{1}=Z_{i_{-} M I L 2003}-Z_{i_{-} R O D 2017}$ \\
C2 & Med_D $D_{2}=0$ & $D_{2}=Z_{i_{-} G I O 2005}-Z_{i_{-} \text {ROD2017 }}$ \\
C3 & Med_D $D_{3}=0$ & $D_{3}=Z_{i_{-} L A N O 7}-Z_{i_{-} \text {ROD2017 }}$ \\
C4 & Med_D $D_{4}=0$ & $D_{4}=Z_{i_{-} \text {FER12 }}-Z_{i_{-} \text {ROD2017 }}$ \\
C5 & Med_D $D_{5}=0$ & $D_{5}=Z_{i_{-} M A N 16}-Z_{i_{-} R O D 2017}$ \\
\hline
\end{tabular}

Med_ $D_{i j}=$ Mediana de la variable $D_{i j}$ definida en la ecuación (4.2) para una determinada versión $j$ del método VIM. MILO3, GIO05, LAN07, FER12, MAN16, ROD17 = variantes del método MIV propuestas por Milutinovic \& Trendafiloski (2003), Giovinazzi (2005), Lantada (2007), Feriche (2012), Martínez-Cuevas \& Gaspar-Escribano (2016) y el nuevo modelo, respectivamente.

Tabla 4.15. Resultados del Test no paramétrico de Wilcoxon para datos apareados, para los registros correspondientes con un sismo de intensidad VII en la escala EMS-98.

\begin{tabular}{|c|c|c|c|c|c|}
\hline \multirow[b]{2}{*}{$\begin{array}{c}\text { Resultados del } \\
\text { test }\end{array}$} & \multicolumn{5}{|c|}{ Contrastes estadísticos } \\
\hline & $\begin{array}{c}C_{1} \\
\text { MIL03-ROD17 }\end{array}$ & $\begin{array}{c}C_{2} \\
\text { GIO05-ROD17 }\end{array}$ & $\begin{array}{c}C_{3} \\
\text { LAN07-ROD17 }\end{array}$ & $\begin{array}{c}C_{4} \\
\text { FER12-ROD17 }\end{array}$ & $\begin{array}{c}C_{5} \\
\text { MAN16-ROD17 }\end{array}$ \\
\hline$T=\min [T(+), T(-)]$ & 11.071 & 159 & 2.070 & 7.501 & 1.550 \\
\hline V & $-10,89$ & $-16,29$ & $-15,42$ & $-11,55$ & $-14,99$ \\
\hline$Z \alpha-$ Una rama & $-1,64$ & $-1,64$ & $-1,64$ & $-1,64$ & $-1,64$ \\
\hline$p$-valor & 0.000 & 0.000 & 0.000 & 0.000 & 0.000 \\
\hline
\end{tabular}

$T, Z$ = estadígrafos definidos en el test de Wilcoxon; $Z_{\alpha}=$ punto de crítico de una distribución normal correspondiente con una nivel de confianza del 95 \%; MILO3, GIO05, LANO7, FER12, MAN16, ROD17 = variantes del método MIV propuestas por Milutinovic \& Trendafiloski (2003), Giovinazzi (2005), Lantada (2007), Feriche (2012), Martínez-Cuevas \& Gaspar-Escribano (2016) y el nuevo modelo, respectivamente.

De este modo, se observaría una menor dispersión entre los datos reales y calculados con la nueva propuesta respecto a las versiones existentes en la literatura para las edificaciones de hormigón armado analizadas en el sismo de Lorca. Se aceptaría, por tanto, la hipótesis alternativa $H_{1}$ recogida en la Tabla 4.14 .

En la Tabla 4.16 se incluye el resume de los resultados del test para cada análisis considerado con los registros correspondientes a un sismo de intensidad VIII. De nuevo, con un p-valor $<0,05$, la hipótesis nula de igualdad de medianas puede ser rechazada con un nivel de significancia $\alpha=0,05$ para cada contraste realizado, por lo que se podría también aceptar la hipótesis alternativa $H_{1}$ recogida en la Tabla 4.14. 
Tabla 4.16. Resultados del Test no paramétrico de Wilcoxon para datos apareados, para los registros correspondientes con un sismo de intensidad VIII en la escala EMS-98.

\begin{tabular}{cccccc}
\hline $\begin{array}{c}\text { Resultados del } \\
\text { test }\end{array}$ & \multicolumn{5}{c}{ Contrastes estadísticos } \\
& MILO3-ROD17 & GIO05-ROD17 & LAN07-ROD17 & FER12-ROD17 & MAN16-ROD17 \\
\hline$T=\min [T(+), T(-)]$ & 14.298 & 159 & 1.596 & 9.838 & 1.323 \\
$V$ & $-9,26$ & $-16,29$ & $-15,66$ & $-11,51$ & 15,20 \\
$Z \alpha$ - Una rama & $-1,64$ & $-1,64$ & $-1,64$ & $-1,64$ & $-1,64$ \\
$p$-valor & 0.000 & 0.000 & 0.000 & 0.000 & 0.000 \\
\hline
\end{tabular}

$T, Z$ = estadígrafos definidos en el test de Wilcoxon; $Z_{\alpha}=$ punto de crítico de una distribución normal correspondiente con una nivel de confianza del 95 \%; MIL03, GIO05, LAN07, FER12, MAN16, ROD17 = variantes del método MIV propuestas por Milutinovic \& Trendafiloski (2003), Giovinazzi (2005), Lantada (2007), Feriche (2012), Martínez-Cuevas \& Gaspar-Escribano (2016) y el nuevo modelo, respectivamente.

Por tanto, los resultados obtenidos permitirían asegurar con un nivel de significancia del $95 \%$ que, para el caso de los datos procedentes del sismo de Lorca de 2011, existe una menor diferencia entre el daño real observado en las edificaciones y el daño simulado según el nuevo modelo propuesto, respecto a la diferencia existente empleando las versiones anteriores del método MIV.

\subsection{APLICACIÓN DE LA METOdOLOGÍA A LA PLANIFICACIÓN Y GESTIÓN DE EMERGENCIAS MEDIANTE TÉCNICAS SIG}

La posibilidad de evaluar el comportamiento sísmico del parque edificado de un área urbana, a partir de la información disponible en el servicio catastral, facilita un análisis de los distintos escenarios sísmicos de forma sencilla y estandarizada. Los sistemas de información geográfica (SIG) constituyen una herramienta efectiva para el estudio y mitigación de riesgos naturales en núcleos urbanos.

La visualización del índice de vulnerabilidad de las edificaciones y del daño estimado, mediante la georreferenciación de los resultados obtenidos, permite la identificación de las áreas más vulnerables de un determinado núcleo urbano ante una cierta acción sísmica (Figura 4.40).

Dado que la vulnerabilidad de una edificación no sólo depende de sus características estructurales, sino también de factores relacionados con el planeamiento urbanístico, la evaluación del comportamiento sísmico de las edificaciones, en una escala detallada para cada manzana, posibilita mejorar el análisis de la respuesta esperable de las estructuras, así como planificar y gestionar, de forma pormenorizada, las diferentes situaciones de emergencia postsismo (Figura 4.41). 


\begin{tabular}{|c|c|c|c|c|c|c|c|}
\hline Vista: Sin tit & tulo - 0 & & & & & & \\
\hline (3) Tabla: Loca & Database.csv & & & & 0 & $\square$ & \\
\hline FID & REFCAT & ADDRESS & COOR.X & COOR.Y & NO HEIGHTS & YEF & \\
\hline 0 & $4495001 X G \ldots$ & Ctra. Grana... & 614360 & 4169461 & 1 & 1960 & \\
\hline 1 & $4707909 \times G \ldots$ & C/Granero, 3 & 614630 & 4170560 & 4 & 1984 & \\
\hline 2 & $4395305 \times G \ldots$ & C/Guitarrist... & 614356 & 4169570 & 2 & 1956 & \\
\hline 3 & $4600910 X G \ldots$ & C/Puerto Lu... & 614512 & 4169841 & 3 & 1970 & \\
\hline 4 & $4699125 \times \mathrm{XG} \ldots$ & C/Jerónimo .... & 614516 & 4169773 & 4 & 2008 & \\
\hline 5 & $4699125 \times G \ldots$ & C/Puerto Lu... & 614501 & 4169773 & 2 & 2008 & \\
\hline 6 & $4505218 \times G \ldots$ & C/Soledad, 3 & 614435 & 4170396 & 2 & 2007 & \\
\hline 7 & $5212017 \times G \ldots$ & C/Carril de ... & 615113 & 4170921 & 3 & 1977 & \\
\hline 8 & $4600907 \times \mathrm{XG} .$. & C/José Mouli... & 614535 & 4169837 & 4 & 1981 & \\
\hline 9 & $4706024 \times G \ldots$ & C/Narciso Y... & 614604 & 4170327 & 4 & 1986 & \\
\hline 10 & $4500021 \times G \ldots$ & C/Salado, 3 & 614385 & 4169800 & 2 & 2003 & \\
\hline 11 & 6015811XG... & C/Galicia, 1 & 615900 & 4171358 & 4 & 1995 & \\
\hline 12 & $4395803 \times G \ldots$ & C/Guitarrist... & 614197 & 4169328 & 2 & 1956 & \\
\hline 13 & $5414703 X \mathrm{X} \ldots$ & C/Auercal O... & 615325 & 4171173 & 4 & 1962 & \\
\hline 14 & $4915909 \times 6 \ldots$ & C/Eulogia Pe... & 614842 & 4171337 & 4 & 1996 & \\
\hline 15 & $4704614 X G \ldots$ & Avda. Portu... & 614623 & 4170207 & 4 & 1960 & \\
\hline 16 & $4799021 X G \ldots$ & C/Ministro P... & 614618 & 4169702 & 4 & 2000 & \\
\hline 17 & $6317008 \times G \ldots$ & C/Francisco ... & 616135 & 4171535 & 3 & 1972 & \\
\hline 18 & $5395005 \times G \ldots$ & Alameda de ... & 615186 & 4169286 & 3 & 1980 & \\
\hline 19 & $4804013 \times 6 \ldots$ & C/Abenhalaj, 7 & 614680 & 4170186 & 4 & 1968 & \\
\hline 20 & $4697013 X G \ldots$ & C/Jerónimo .... & 614408 & 4169525 & 4 & 1978 & \\
\hline 21 & $4396301 X G \ldots$ & C/Sagrada F... & 614266 & 4169491 & 3 & 1960 & \\
\hline 22 & $5802005 X \mathrm{~K} \ldots$ & Alameda Vir... & 615724 & 4170004 & 3 & 1968 & \\
\hline 23 & $4497608 \times 6 \ldots$ & C/Castillo Xi... & 614345 & 4169509 & 4 & 1994 & \\
\hline 24 & $4809709 \times 6 \ldots$ & Plaza de Esp... & 614683 & 4170708 & 2 & 1996 & \\
\hline 25 & 4293001 XG... & C/Albañileria... & 614074 & 4169101 & 3 & 1981 & \\
\hline 26 & $4606203 \times \mathrm{X} \ldots$ & CNicente R... & 614567 & 4170479 & 2 & 1950 & \\
\hline 27 & $50981 \cap 3 X G \ldots$ & S.Finenin N... & 614919 & 4169673 & 17 & 1973 & \\
\hline
\end{tabular}

Figura 4.40. Proceso de georreferenciación de la base de datos implementada de daños en edificaciones de hormigón armado tras el sismo de Lorca 2011.

$I_{V_{-} b}=$ Índice de vulnerabilidad de las edificaciones obtenido según el modelo propuesto del método MIV.

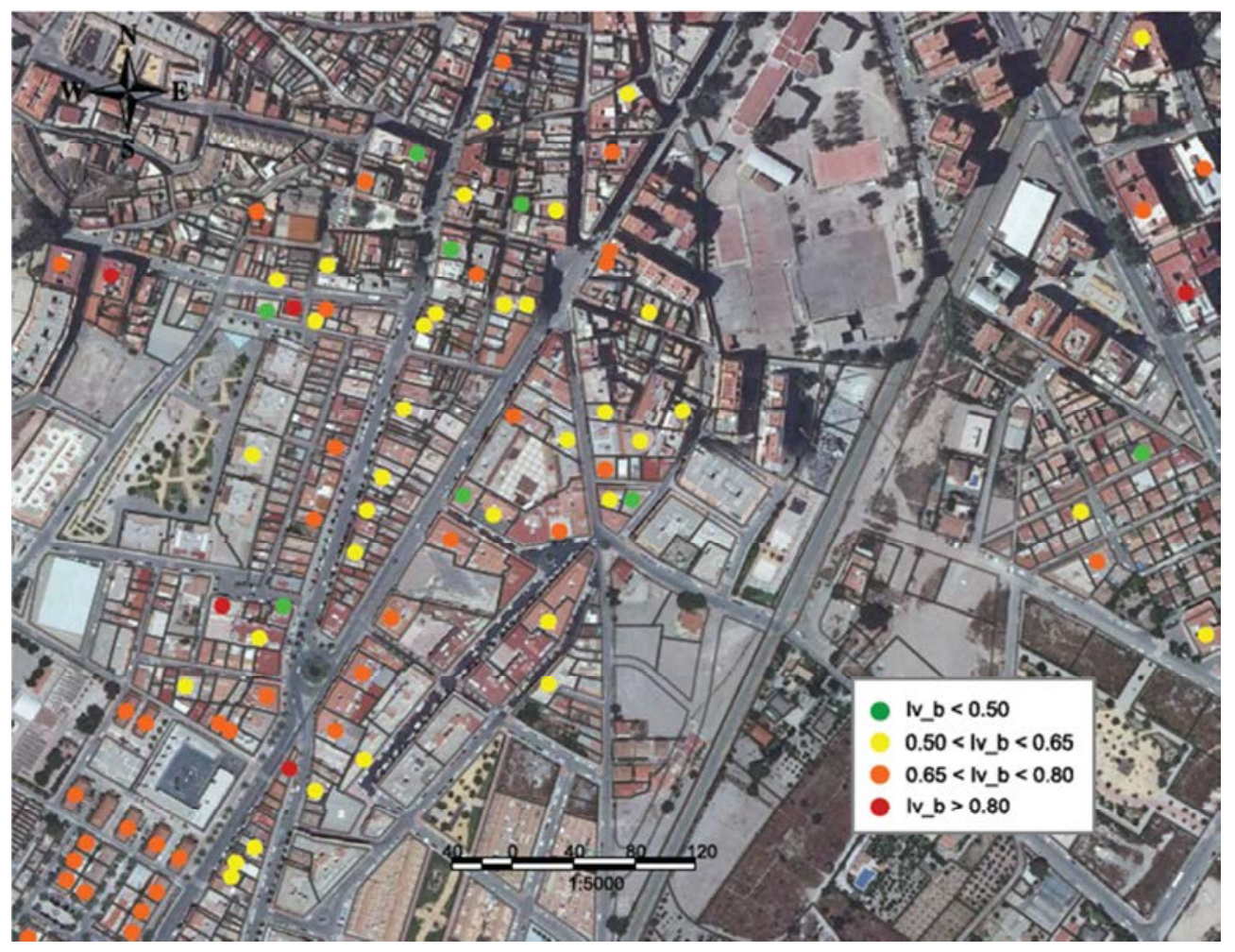

Figura 4.41. Índices de vulnerabilidad $I_{v_{-} b}$, según el modelo propuesto del método MIV, de las edificaciones de hormigón armado seleccionadas en la trama urbana del Suroeste de Lorca. 
En la Figura 4.42 se muestra, mediante una función de densidad Kernel, la distribución espacial del índice de vulnerabilidad de las edificaciones seleccionadas en Lorca obtenido según el modelo propuesto del método MIV. Las áreas más vulnerables ante una cierta acción sísmica se encuentran concentradas principalmente en los barrios del Noreste, centro y el Suroeste de la ciudad. Destacan los niveles obtenidos en los barrios de la Viña y Cristo-Rey, donde precisamente se observaron graves daños en las edificaciones tras el sismo de 2011. Resultados similares fueron obtenidos de forma previa en otros estudios (p.e. Rivas-Medina et al. 2014; Salgado-Gálvez et al., 2015).

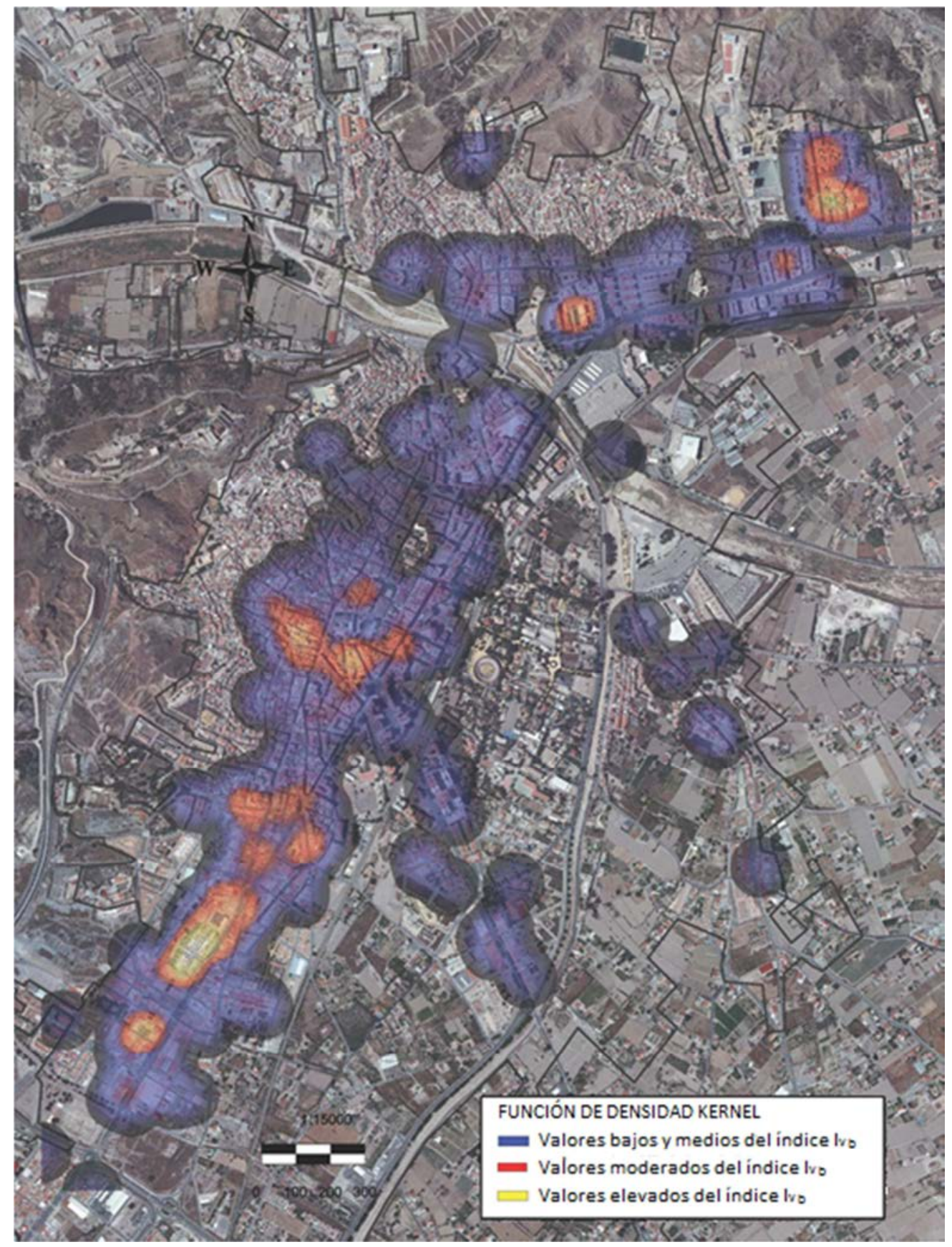

Figura 4.42. Representación mediante una función de densidad Kernel de los índices de vulnerabilidad de las edificaciones de hormigón armado seleccionadas en la ciudad de Lorca.

$I_{V_{-} b}=$ Índice de vulnerabilidad de las edificaciones obtenido según el modelo propuesto del método MIV. 
Con el fin de realizar una evaluación integral del riesgo sísmico, estos resultados pueden ser combinados con otros aspectos relacionados con el fenómeno sísmico como, por ejemplo, estudios de microzonificación que determinan los efectos locales del terreno. En la Figura 4.43, se muestra la distribución de densidad Kernel de los niveles de vulnerabilidad obtenidos según el modelo propuesto junto con los tipos de suelo según la clasificación del EC-8, identificados en una de las microzonificaciones sísmicas realizadas en el núcleo urbano de Lorca (CARM, 2014).

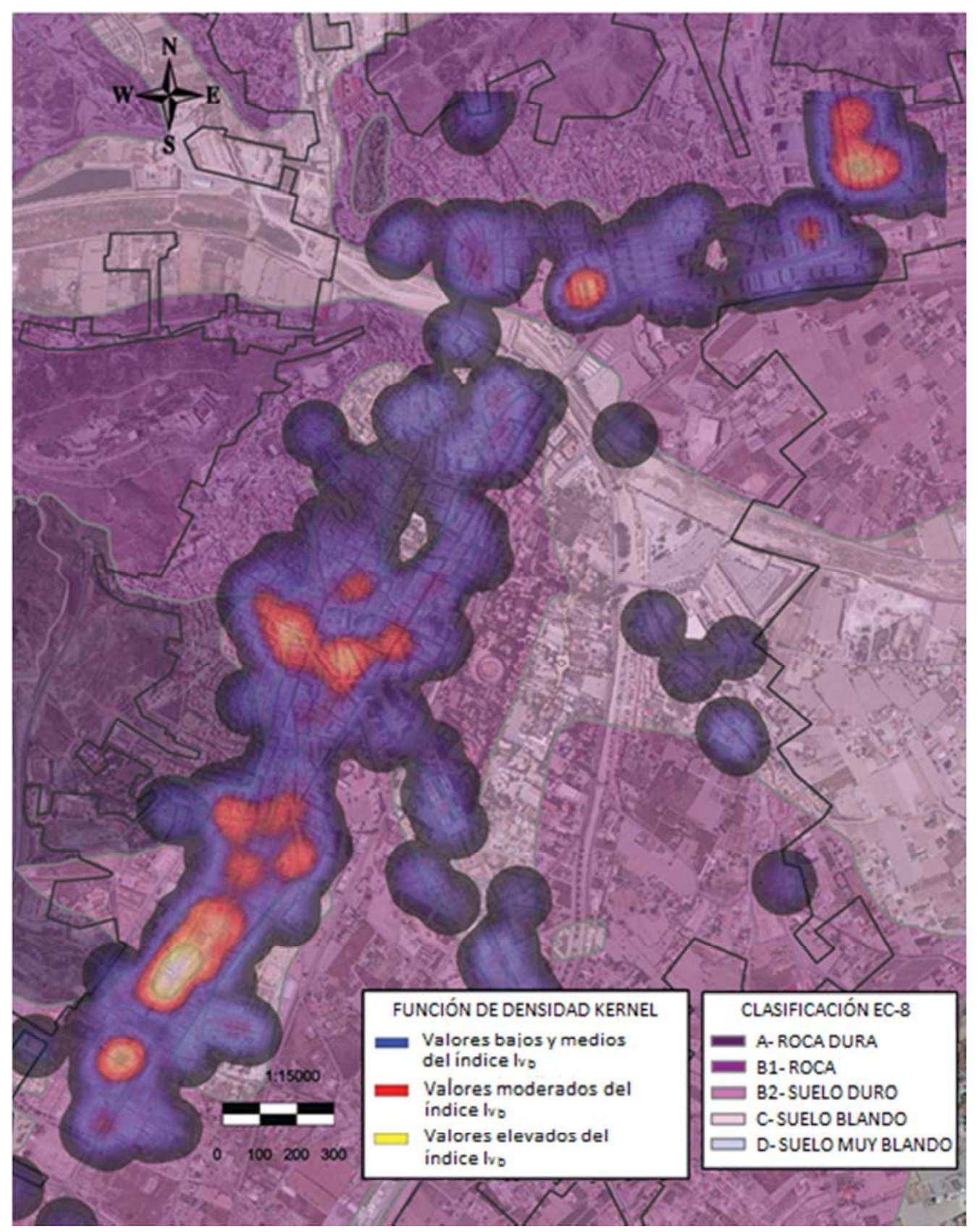

Figura 4.43. Representación mediante una función de densidad Kernel de los índices de vulnerabilidad de las edificaciones de hormigón armado seleccionadas en la ciudad de Lorca, junto con los tipos de suelo según la clasificación del EC-8 identificados en el estudio de microzonación CARM (2014)

$I_{V_{-} b}=$ Índice de vulnerabilidad de las edificaciones obtenido según el modelo propuesto del método MIV. 
Escenarios especialmente graves serán aquéllos en los que coincidan niveles de vulnerabilidad elevados y terrenos blandos que amplifiquen el movimiento sísmico. Esta situación se produjo, por ejemplo, en la barriada de S. Fernando en Lorca, la cual tuvo que ser demolida tras el terremoto de 2011 (Figura 2.30).

En resumen, estas metodologías pueden ser empleadas, de forma preventiva, para el proceso de toma de decisiones relacionado con el planeamiento y gestión de situaciones de emergencia post-sismo. Aspectos como la identificación de las áreas más vulnerables, donde concentrar los recursos en las primeras horas tras el terremoto, la selección de la ubicación más recomendada para los campamentos base y de acogida de la población civil, o las rutas de evacuación y comunicación más seguras, pueden ser evaluados de modo exhaustivo mediante la aplicación de estos métodos. 



\section{CAPÍTULO 5 CONCLUSIONES Y LÍNEAS FUTURAS}

\subsection{INTRODUCCIÓN}

En este capítulo se resume el trabajo de investigación realizado en la tesis, exponiendo las principales conclusiones obtenidas y planteando futuras líneas de investigación derivadas del estudio realizado.

\subsection{TRABAJO REALIZADO}

En la elaboración de la tesis se han realizado los siguientes trabajos:

$\checkmark$ Planteamiento de los fundamentos del riesgo sísmico y descripción de los dos factores que influyen en su caracterización: la peligrosidad y la vulnerabilidad sísmica.

$\checkmark$ Exposición de la motivación y de la problemática general existente en la evaluación del riesgo sísmico de edificaciones en áreas urbanas.

$\checkmark$ Revisión bibliográfica del estado del arte relativo a la caracterización de la peligrosidad, la vulnerabilidad y el riesgo sísmico en entornos urbanos, a partir de publicaciones en congresos, libros y artículos de revistas, con especial detalle tanto en el desarrollo de las metodologías existentes para la evaluación de la vulnerabilidad sísmica de edificaciones aporticadas de hormigón armado, como en las principales aplicaciones realizadas en trabajos previos en la península Ibérica.

$\checkmark$ Análisis de las distintas variantes del Método del Índice de Vulnerabilidad (MIV) propuestas en la literatura para la caracterización de la vulnerabilidad sísmica de edificaciones de hormigón armado, dentro del marco de la metodología LM1 del proyecto RISK-UE.

$\checkmark$ Propuesta de nuevos modificadores de comportamiento para la obtención del índice de vulnerabilidad de las edificaciones de hormigón armado según el método MIV, a partir de la revisión de los distintos métodos disponibles y del análisis del comportamiento sísmico observado en las edificaciones. Estos modificadores son los relacionados con: (i) el nivel del código sísmico de diseño de la edificación; (ii) el número de plantas del inmueble sobre el terreno; y (iii) la existencia de junta sísmica entre edificios adyacentes. 
$\checkmark$ Propuesta de eliminación de otros modificadores de comportamiento relacionados con el estado de conservación del inmueble o la tipología y disposición de la cimentación. Estos parámetros, difíciles de cuantificar en la práctica, se encuentran ya intrínsecamente considerados en la determinación de otros modificadores.

$\checkmark$ Propuesta de eliminación del modificador regional definido en el método MIV, por considerar aspectos como las disposiciones constructivas específicas de la zona de estudio o el nivel de los códigos sísmicos de diseño, aspectos que estarían también ya intrínsecamente contemplados en la obtención de otros modificadores de comportamiento.

$\checkmark$ Descripción del procedimiento empleado para elaborar una base de datos de daños sísmicos en edificaciones, a partir de observaciones post-sismo realizadas tras el evento de Lorca de 2011.

$\checkmark$ Aplicación, a los datos procedentes del sismo de Lorca, de las distintas variantes disponibles del método MIV, y del nuevo modelo propuesto según la metodología LM1 de RISK-UE, con el fin de determinar la vulnerabilidad y el riesgo sísmico de las edificaciones para un sismo de características similares. Con carácter previo se han descrito los principales parámetros de movimiento del suelo de la serie sísmica del 11 de mayo de 2011.

$\checkmark$ Contraste de los resultados obtenidos comparando, en las edificaciones seleccionadas, la diferencia entre el grado de daño observado en el sismo de Lorca y los niveles de daño simulado obtenidos, tanto con el nuevo modelo propuesto como con las distintas variantes del método MIV.

$\checkmark$ Realización de un análisis estadístico de las hipótesis planteadas mediante el test no paramétrico de Wilcoxon para datos apareados, con objeto de comparar la diferencia existente entre el daño real observado y el grado de daño calculado con cada método, tanto con el nuevo modelo como con las distintas variantes disponibles del método MIV. De este modo se determina cuál de las metodologías presenta una mayor aproximación entre daño estimado y daño observado.

$\checkmark$ Aplicación de la metodología a la generación de escenarios post-sismo y a la planificación y gestión de situaciones de emergencia mediante la utilización de Sistemas de Información Geográfica (SIG).

\subsection{CONCLUSIONES}

Del trabajo desarrollado en esta tesis se pueden extraer las siguientes conclusiones:

$\checkmark$ A pesar de que el estado del conocimiento permite diseñar y construir estructuras que se comporten adecuadamente frente acciones sísmicas, existen áreas urbanas que todavía presentan niveles de riesgo sísmico elevado debido principalmente a la elevada vulnerabilidad de sus edificaciones. Algunas de las últimas catástrofes sísmicas 
han vuelto a evidenciar el inadecuado comportamiento de multitud de estructuras, no solamente aquéllas diseñadas sin normativa sísmica -o con normas antiguas-, sino también aquéllas basadas en códigos recientes.

$\checkmark$ Dando continuidad a diversos trabajos publicados previamente por otros autores, la variante propuesta en esta tesis del método MIV simplifica la generalización de la metodología a cualquier área urbana, al suprimir un parámetro -el modificador regional- que requiere de calibración previa en función del área de estudio. Asimismo, al sintetizar algunos de los modificadores de comportamiento existentes en el método, se posibilita una implementación más estandarizada del mismo a partir de la información contenida en el Catastro Inmobiliario.

$\checkmark$ Aplicadas las distintas variantes existentes del método MIV a la base de datos de daños en edificaciones, elaborada a partir de la información disponible del sismo de Lorca de 2011, los niveles de daño calculados mediante la metodología LM1 de RISK-UE para un sismo de características similares al de Lorca estarían por debajo, de forma generalizada, del grado de daño real observado en las edificaciones, por lo que estos modelos no representarían completamente el comportamiento sísmico de este tipo de edificaciones de hormigón armado.

$\checkmark$ En este sentido, si se considera el escenario adicional de peligrosidad sísmica correspondiente a una intensidad VIII en la escala EMS-98, se obtiene una mejor aproximación de los resultados de daño real y simulado para todas las variantes disponibles del método MIV, por lo que se muestra de nuevo que los niveles de daño obtenidos en las edificaciones de hormigón armado según estos modelos resultan demasiado optimistas con respecto a las afecciones realmente experimentadas tras el evento sísmico.

$\checkmark$ Se observa un mejor ajuste entre daño real y simulado en las edificaciones al emplear el nuevo modelo propuesto. A partir del contraste estadístico realizado, se identifica, con un nivel de significancia del $5 \%$, una mejor correspondencia entre el grado de daño observado en las edificaciones y los niveles de daño obtenidos mediante la metodología LM1 según la nueva propuesta, si se compara con la diferencia existente entre daño real y simulado según las distintas variantes del método MIV, tanto para los resultados obtenidos con un sismo de intensidad VII como para los obtenidos con uno de intensidad VIII.

$\checkmark$ Esta mejor aproximación permite reducir el nivel de incertidumbre asociado a este tipo de metodologías, proporcionando una evaluación más exhaustiva de los niveles de riesgo sísmico existentes en una determinada área urbana.

$\checkmark$ A pesar de que este tipo de comparaciones difícilmente puedan servir para validar un modelo de comportamiento estructural, debido al gran número de variables involucradas en el proceso, los resultados obtenidos muestran la tendencia de que los niveles de daño simulados según las distintas variantes del método MIV quedarían por 
debajo de los daños realmente observados en muchas edificaciones, por lo que la definición de los escenarios de daño y pérdidas potenciales no serían del todo adecuados.

$\checkmark$ No obstante, conviene destacar que no es frecuente disponer de terremotos con daños y afecciones en edificaciones e infraestructuras tan bien documentados como el sismo de Lorca de 2011. Una vez que ha ocurrido este tipo de eventos, se genera una oportunidad para el desarrollo y mejora de las diferentes metodologías disponibles para la evaluación de la vulnerabilidad y el riesgo sísmico en áreas urbanas, especialmente aquéllas basadas en procedimientos empíricos, como el caso de la metodología LM1 de RISK-UE.

$\checkmark$ El empleo de Sistemas de Información Geográfica posibilita la implementación de los diferentes escenarios de daño y pérdidas potenciales, lo que supone una herramienta útil para el planeamiento y gestión de situaciones de emergencia post-sismo. Este tipo de instrumentos asociados a las mejoras metodológicas planteadas van a permitir introducir la variable de la planificación sísmica en la ordenación urbanística y territorial de las ciudades, mejorando a futuro su comportamiento frente a eventos sísmicos.

\subsection{LÍNEAS FUTURAS}

Se plantean las siguientes líneas de investigación que puedan dar continuidad al trabajo desarrollado en esta tesis:

$\checkmark$ Adaptación de la metodología LM1 de RISK-UE considerando la acción sísmica en términos de parámetros de movimiento del suelo, como la aceleración pico o Peak Ground Acceleration (PGA), con el fin, por un parte, de eliminar las incertidumbres asociadas a la caracterización del tamaño de un terremoto mediante el concepto de intensidad macrosísmica, y por otra, de incorporar al proceso de cálculo los posibles efectos locales de amplificación de la señal sísmica.

$\checkmark$ Calibración de funciones de vulnerabilidad observada para diferentes tipologías edificatorias, expresando la peligrosidad sísmica mediante parámetros de movimiento del suelo, y contraste con las distintas funciones de vulnerabilidad propuestas en la literatura.

$\checkmark$ Propuesta de otros modificadores de comportamiento del Método del Índice de Vulnerabilidad (MIV) para edificaciones de hormigón armado, relacionados, por ejemplo, con la disposición e influencia de los elementos no estructurales del edificio en su respuesta sísmica.

$\checkmark$ Desarrollo de modificadores de comportamiento destinados a la obtención del índice de vulnerabilidad de otras tipologías edificatorias, como aquéllas basadas en pórticos de acero o estructuras mixtas, a partir de la influencia de las características 
estructurales, arquitectónicas y urbanísticas de estas edificaciones en su comportamiento sísmico.

$\checkmark$ Implementación de una metodología similar, basada en índices de vulnerabilidad, destinada a la evaluación de la vulnerabilidad sísmica de construcciones de ingeniería civil, como puentes, depósitos o presas, con el fin de posibilitar la caracterización de la respuesta estructural esperable de un modo rápido e intuitivo, en una primera aproximación. Las características particulares de diseño de cada estructura podrían ser consideradas, de igual modo, mediante una serie de modificadores de comportamiento.

$\checkmark$ Ampliación del campo de aplicación del modelo propuesto a bases de datos de daños en edificaciones procedentes de otros eventos sísmicos, con objeto de comprobar si se mantiene la tendencia observada para la información obtenida del sismo de Lorca de 2011, y seguir ajustando el valor de los distintos modificadores de comportamiento para obtener una mejor aproximación entre el daño real observado y el grado de daño calculado. 



\section{REFERENCIAS BIBLIOGRÁFICAS}

Abrahamson, N., \& Bommer, J. (2005). Probability and uncertaintly in seismic hazard analysis. Earthquake Spectra, 21(2), 603-607.

Abrahamson, N., \& Silva, W. (2008). Summary of the Abrahamson \& Silva NGA Ground-Motion Relations. Earthquake Spectra, 24(1), 67-97.

Abrahamson, N., Silva, A., \& Kamai, R. (2013). Update of the ASO8 Ground-Motion Prediction Equations Based on the NGA-West2 Data Set. PEER 2013/04. Pacific Earthquake Engineering Research Center. University of California, Berkeley, EEUU.

AeDES. (2009). Manuale per la compilazione della scheda di $1^{\circ}$ livello di rilevamento danno, pronto intervento e agibilità per edifici ordinari nell'emergenza post-sismica. Dipartimento della Protezione Civile, Presidenza del Consiglio dei Ministri, Italia.

Aguiar, R., \& Barbat, A. (1998). Índices de daño sísmico en edificios de hormigón armado. Hormigón y Acero, 210(4), 73-92.

Aguiar, R., \& Barbat, A. (1999). Método simplificado de evaluación del índice de daño sismico global en edificios de hormigón armado. Hormigón y Acero, 211(1), 71-84.

Aguilar, A. (2011). Evaluación probabilista del riesgo sísmico de edificios en zonas urbanas. Tesis Doctoral. Universidad Politécnica de Cataluña, España.

Aguilar, A., Barbat, A., Pujades, L., \& Lantada, N. (2010). Probabilistic assessment of the seismic risk of buildings in urban areas. 14th European Conference on Earthquake Engineering, Ohrid, Macedonia, pp. 1-8.

Aki, K. (1966). Generation and propagation of G waves from the Nigata eartquake of June 16, 1964. Part 2: Estimation of earthquake moment, released energy, and stress-strain drop from the $\mathrm{G}$ wave spectrum. Bulletin of the Earthquake Research Institute, 44, 7388.

Aki, K. (1993). Local site effects on weak and strong ground motion. Tectonophysics, 218(1), 93-111.

Akkar, S., \& Boomer, J. (2010). Empirical Equations for the Prediction of PGA, PGV, and Spectral Accelerations in Europe, the Mediterranean Region, and the Middle East. Seismological Research Letters, 81, 195-206. 
Alam, N., Shahria-Alam, M., \& Tesfamariam, S. (2012). Building's seismic vulnerability assessment methods: a comparative study. Natural Hazards, 62(2), 405-424.

Albini, P., \& Rodríguez de la Torre, F. (2001). The 1828-1829 Earthquake Sequence in the Provinces of Alicante and Murcia (S-E Spain): Historical Sources and Macroseismic Intensity Assessment. Advances in Natural and Technological Hazards Research, 17, 35-53.

Alguacil, G., Vidal, F., Navarro, M., García-Jerez, A., \& Pérez-Muelas, J. (2014). Characterization of earthquake shaking severity in the town of Lorca during the May 11, 2011 event. Bulletin of Earthquake Engineering, 12(5), 1889-1908.

Alhama, I., Ballesteros, J., Blázquez, R., Frías, A., Gómez, J., Guzmán, J., . . Trigueros, E. (2015). Evaluación rápida de daños en emergencias. Protocolos de Activación y actuación del Grupo de Evaluación de Daños. Dirección General de Seguridad Ciudadana y Emergencias de la Consejería de Presidencia y Empleo de la Región de Murcia.

Álvarez, R., Dávila, S., \& Díaz Pavón, E. (2011). Comportamiento de los cerramientos y particiones durante el terremoto de Lorca. Zuncho, 30, 31-45.

Álvarez, S. (1999). El efecto local sobre el movimiento sísmico del suelo: fenomenología y resultados recientes. Física de la Tierra, 11, 141-173.

Ambraseys, N., Douglas, J., Sarma, S., \& Smit, P. (2005). Equations for the estimation of ground motion from shallow crustal earthquakes using data from Europe and the Middle East: Horizontal peak ground acceleration and spectral acceleration. Bulletin of Earthquake Engineering, 37, 1-53.

Ambraseys, N., Simpson, K., \& Bommer, J. (1996). Prediction of horizontal response spectra in Europe. Earthquake Engineering and Structural Dynamics, 25, 371-400.

Angeletti, P., Bellina, A., Grandori, E., Moretti, A., \& Petrini, V. (1988). Comparison between vulnerability assessment and damage index, some results. 9th World Conference on Earthquake Engineering, Tokio, Japón, pp. 181-186.

Arias, A. (1970). A measure of earthquake intensity. En R.J. Hansen (ed.) Seismic Design of Nuclear Plants, 438-483, MIT Press.

ATC-13. (1985). Earthquake damage evaluation Data for California. Applied Technology Council, California, EEUU.

ATC-20. (1989). Procedures for postearthquake safety evaluation of buildings. Applied Technology Council, California, EEUU.

ATC-21. (1988). Rapid Visual Screening of buildings for Potential Seismic Hazards: a Handbook. Applied Technology Council, California, EEUU. 
ATC-25. (1991). Seismic Vulnerability and Impact of Disruption of Lifelines in the Conterminous United States. Applied Technology Council, California, EEUU.

ATC-36. (1997). Earthquake Damage and Loss Estimation Methodology and Data for Salt Lake County, Utah. Applied Technology Council, California, EEUU.

ATC-40. (1996). Seismic evaluation and retrofit of concrete buildings. Volumen I. Reporte SSC 96-01. Applied Technology Council, California, EEUU.

Baker, J. (2008). An Introduction to Probabilistic Seismic Hazard Analysis (PSHA). V. 1.3. US Nuclear Regulatory Commission.

Barbat, A. (1998). El riesgo sísmico en el diseño de edificios. Madrid: Calidad Siderúrgica.

Barbat, A. (2011). Lorca, el terremoto improbable. Zuncho, 30, 5-11.

Barbat, A., \& Canet, M. (1994). Estructuras sometidas a acciones sísmicas (Segunda ed.). Barcelona: Centro Internacional de Métodos Numéricos, CIMNE, Barcelona, España.

Barbat, A., \& Pujades, L. (2004). Evaluación de la vulnerabilidad y del riesgo sísmico en zonas urbanas. Aplicación a Barcelona. 6o Congresso Nacional de Sismologia e Engenharia Sísmica, Universidad do Minho, Guimaraes, Portugal, pp. 229-252.

Barbat, A., Carreño, M., Pujades, L., Lantada, N., Cardona, O., \& Marulanda, M. (2010). Seismic vulnerability and risk evaluation methods for urban areas. A review with application to a pilot area. Structure and Infrastructure Engineering, 6, 17-38.

Barbat, A., Oller, S., \& Pujades, L. (2005). Conceptos de vulnerabilidad y ductilidad en el proyecto sismorresistente de edificios. Hormigón y Acero, 238, 61-73.

Barbat, A., Pujades, L., \& Lantada, N. (2008). Seismic damage evaluation in urban areas using the capacity spectrum method: application to Barcelona. Soil Dynamics and Earthquake Engineering, 28, 851-865.

Barbat, A., Vargas, Y., Pujades, L., \& Hurtado, J. (2012). Probabilistic assessment of the seismic damage in reinforced concrete buildings. Computational Civil Engineering (CCE). International Symposium, Iasi, Rumania. ISSN 2285-2735, pp. 43 - 61.

Barbat, A., Vielma, J., \& Oller, S. (2007). Edificios con forjados reticulares: una tipología estructural habitual en España. Revista Internacional de Ingeniería de Estructuras, 12(1), 87-104.

Barbat, A., Yépez, F., \& Canas, J. (1996). Damage scenarios simulation for seismic risk assessment in urban zones. Earthquake Spectra, 12(3), 371-394. 
Bard, P. (2008). The H/V technique: capabilities and limitations based on the results of the SESAME project. Bulletin of Earthquake Engineering, 6, 1-2.

Bard, P., Czitrom, G., Durville, J., Godefroy, P., Meneorud, J., Moroux, P., \& Pecker, A. (1995). Guidelines for seismic microzonation studies. French Association for Earthquake Engineering, $45 \mathrm{pp}$.

Basset, L., \& Guardiola, A. (2011). Evaluación de la vulnerabilidad sísmica del distrito 2L'Eixample de la ciudad de Valencia. 4o Congreso Nacional de Ingeniería Sísmica, Granada, España.

Bazzurro, P., \& Cornell, C. (1999). Disaggregation of seismic hazard. Bulletin of the Seismological Society of America, 89, 501-520.

Bender, B., \& Perkins, D. (1987). SEISRISK III. A computes program for seismic hazard estimation. US Geological Survey. Boletin no1772.

Benedetti, D., \& Petrini, V. (1984). Sulla vulnerabilitá sismica di edifici in muratura: Proposte di un metodo di valutazione. L'industria delle Construzioni, 149, 66-78.

Benedetti, D., Benzoni, G., \& Parisi, M. (1988). Seismic vulnerability and risk evaluation for old urban nuclei. Earthquake Engineering \& Structural Dynamics, 16(2), 183-201.

Benioff, H. (1934). The Physical Evaluation of Seismic Destructiveness. Bulletin of the Seismological Society of America, 24, 398-403.

Benito, B., \& Gaspar-Escribano, J. (2007). Ground motion characterization and seismic hazard assessment in Spain: context, problems and recent developments. Journal of Seismology, 11, 433-452.

Benito, B., \& Jiménez, M. (1999). Peligrosidad Sísmica. Física de la Tierra, 11, 13-47.

Benito, B., Capote, R., Murphy, P., Gaspar-Escribano, J., Martínez-Díaz, J., Tsige, M., . . Canora, C. (2007). An overview of the Damaging and Low Magnitude La Paca Earthquake (Mw 4.8) on January 29th, 2005. Context, seismotectonics, and seismic risk implications for south east Spain. Bulletin of the Seismological Society of America, 97(3), 671-690.

Benito, B., Carreño, E., Jiménez, M., Murphy, P., Martínez, J., Tsige, M., . . García Flores, I. (2006). RISMUR: Riesgo Sísmico en la Región de Murcia. Instituto Geográfico Nacional y Dirección General de Protección Civil de la Región de Murcia.

Benito, B., Gaspar-Escribano, J., Rivas-Medina, A., Martínez, J., Rodríguez, O., \& Ramírez, M. (2011). Evaluación de la peligrosidad sísmica en España para aplicaciones relacionadas con la seguridad nuclear. Resultados preliminares. 4ํ Congreso Nacional de Ingeniería Sísmica, Asociación Española de Ingeniería Sísmica, Granada, España. 
Benito, B., Navarro, M., Gaspar-Escribano, J., Vidal, F., Góngora, A., García-Rodríguez, M., \& Martínez-Solares, J. (2008). Seismic hazard in Andalusia region (Southern Spain). 14th World Conference on Earthquake Engineering, Beijing, China.

Benito, B., Navarro, M., Vidal, F., Gaspar-Escribano, J., García-Rodríguez, M., \& MartínezSolares, J. (2010). A new seismic hazard assessment in the region of Andalusia (Southern Spain). Bulletin of Earthquake Engineering, 8(4), 739-766.

Benito, B., Rivas-Medina, A., Gaspar-Escribano, J., \& Murphy, P. (2012). El terremoto de Lorca (2011) en el contexto de la peligrosidad y el riesgo sísmico en Murcia. Física de la Tierra, 24, 255-287.

Benito, B., Rivas-Medina, A., Pérez, M., Quirós, L., Ruiz, S., Gaspar-Escribano, G., \& Hernández, M. (2015). RISMUR II: Servicio de actualización del análisis de riesgo sísmico en la Región de Murcia. Instituto Geográfico Nacional y Dirección General de Protección Civil de la Región de Murcia.

Bergue-Thierry, C., Cotton, F., Scotti, O., Griot-Pommera, D., \& Fukushima, Y. (2003). New Empirical Response Spectral Attenuation Laws for Moderate European Earthquakes. Journal of Earthquake Engineering, 7(2), 193-222.

Bermúdez, C. (2010). Vulnerabilidad sísmica de edificios de acero. Tesis Doctoral. Universidad Politécnica de Cataluña, España.

Bertero, V. (1992). Lessons Learned From Recent Catastrophic Earthquakes and Associated Research. 1을 Conferencia Internacional Torroja. Instituto Torroja, Madrid, España.

Blázquez, R. (2011). Ciencia y conciencia sísmica en España. Zuncho, 30, 13-19.

Blázquez, R. (2013). Sismología Ingenieril. Conceptos básicos. Jornadas de Proyecto y Rehabilitación Sismorresistente de Edificios. Universidad Politécnica de Cartagena, España.

Blázquez, R., \& López-Querol, S. (2003). Probabilistic analysis of liquefaction models of soil layers subjected to seismic loading. En Der Kiureghian, Madanat \& Pestana (eds.), Applications of Statistics and Probability in Civil Engineering, pp. 1203-1209. Millpress, Rotterdam, Países Bajos.

Bommer, J., \& Abrahamson, N. (2007). Why do modern Probabilistic Seismic-Hazard Analysis often lead incresead Hazard estimates. Bulletin of the Seismological Society of America, 96(6), 1967-1977.

Bommer, J., \& Crowley, H. (2006). The influence of ground motion variability in earthquake loss modelling. Bulletin of Earthquake Engineering, 4(3), 231-248. 
Bonett, R. (2003). Vulnerabilidad y riesgo sísmico de edificios. Aplicación a entornos urbanos en zonas de amenaza alta o moderada. Tesis Doctoral. Universidad Politécnica de Cataluña, España.

Bonowitz, D., \& Rabinovici, S. (2013). Soft Story Risk Reduction: Lessons from the Berkeley data. Earthquake Engineering Research Institute (EERI), EEUU.

Boore, D., \& Atkinson, G. (2008). Ground-motion prediction equations for the average horizontal component of PGA, PGV, and 5\%-Damped PSA at spectral periods between 0.01s and 10.0s. Earthquake Spectra, 24(1), 99-138.

Boore, D., Stewart, J., Seyhan, E., \& Atkinson, G. (2013). NGA-West2 Equations for Predicting Response Spectral Accelerations for Shallow Crustal Earthquakes. PEER 2013/05. Pacific Earthquake Engineering Research Center. University of California, Berkeley, EEUU.

Borcherdt, R. (1970). Effects of local geology on ground motion near San Francisco. Bulletin of the Seismological Society of America, 60, 29-61.

Borcherdt, R. (1994). Estimates of site-dependent reponse spectra for design (methodology and justification). Earthquake Spectra, 10, 617-673.

Borzi, B., Calvi, G., Elnashai, .., Faccioli, E., \& Bommer, J. (2006). Inelastic spectra for displacement-based seismic design. Soil Dynamics and Earthquake Engineering, 21, 4761.

Borzi, B., Phino, R., \& Crowley, H. (2008). Simplified Pushover analysis for large-scale assessment of RC buildings. Engineering Structures, 30, 804-820.

Bozzo, L., \& Barbat, A. (2000). Diseño sismorresistente de edificios. Técnicas convencionales y avanzadas. Madrid: Reverté, S.A.

Bracci, J., Reinhorns, A., Mander, J., \& Kunnath, S. (1989). Deterministic model for seismic damage evaluation of reinforced concrete structures. National Center for Earthquake Engineering Research. Technical Report NCEER-89-0033, EEUU.

Braga, F., Dolce, M., Fabrizi, C., \& Liberatore, D. (1986). Evaluation of aconventionally defined vulnerability of buildings based on surveyed damage data. 8th European Conference on Eartquake Engineering, Lisboa, Portugal, pp. 33-40.

Budnitz, R., Apostolakis, G., Boore, D., Cluff, L., Coppersmith, K., Cornell, C., \& Morris, P. (1997). Recommendations for Probabilistic Seismic Hazard Analysis: Guidance on Uncertainty and Use of Experts. Senior Seismic Hazard Analysis Committee. United States Nuclear Regulatory Commission, NUREG/CR-6372. 
Buforn, E., Benito, B., Sanz de Galdeano, C., Fresno, C., del Muñoz, D., \& Rodríguez, I. (2005). Study of the damaging earthquakes of 1911, 1999, and 2002 in the Murcia, Southeastern Spain region: seismotectonic and seismic-risk implications. Bulletin of the Seismological Society of America, 95, 549-567.

Cabañas, L., Alcalde, J., Carrelo, E., \& Bravo, J. (2014). Characteristics of observed strong motion accelerograms from the 2011 Lorca (Spain) earthquake. Bulletin of Earthquake Engineering, 12(5), 1909-1932.

Cabañas, L., Carreño, E., Izquierdo, A., Martínez-Solares, J., Capote, R., Martínez-Díaz, J., . . . Murphy, P. (2011). Informe del sismo de Lorca del 11 de mayo de 2011. Instituto Geográfico Nacional, Madrid, España.

Cabañas, L., Rivas-Medina, A., Martínez-Solares, J., Gaspar-Escribano, J., Benito, B., Antón, R., \& Ruiz-Barajas, S. (2015). Relationships between $\mathrm{Mw}$ and other earthquake size parameters in the Spanish IGN seismic catalog. Pure and Applied Geophysics, 172, 2397-2411.

Cadet, H. (2007). Utilisation combinée des méthodes basés sur le bruit de fond dans le cadre du microzonage sismique. Tesis Doctoral. Université Joseh Fourier de Grenoble, Francia, $285 \mathrm{pp}$.

Calvi, G., Pinho, R., Magenes, G., Bommer, J., Restrepo-Vélez, L., \& Crowley, H. (2006). Development of seismic vulnerability assessment methodologies over the past 30 years. ISET Journal of Earthquake Techonology, 43(3), 75-104.

Campbell, K., \& Bozorgnia, Y. (2003). Updated near-source ground motion (attenuation) relations for the horizontal and vertical components of peak ground acceleration and acceleration response spectra. Bulletin of the Seismological Society of America, 93(1), 314-331.

Campbell, K., \& Bozorgnia, Y. (2008). NGA ground motion model for the geometric mean horizontal component of PGA, PGV, PGD and 5\% damped linear elastic response spectra for periods ranging from 0.01 to 10s. Earthquake Spectra, 24(1), 139-171.

Campbell, K., \& Bozorgnia, Y. (2010). A Ground Motion Prediction Equation for the Horizontal Component of Cumulative Absolute Velocity (CAV) Based on the PEER-NGA Strong Motion Database. Earthquake Spectra, 26(3), 635-650.

Campbell, K., \& Bozorgnia, Y. (2013). NGA-West2 Campbell-Bozorgnia Ground Motion Model for the Horizontal Components of PGA, PGV, and 5\%-Damped Elastic PseudoAcceleration Response Spectra for Periods Ranging from 0.01 to 10 s. PEER 2013/06. Pacific Earthquake Engineering Research Center. University of California, Berkeley, EEUU. 
Cardona, O., Marulanda, M., Carreño, M., \& Barbat, A. (2012). Probabilistic Seismic Risk Assessment of Barcelona, Spain. International Symposium on Computational Civil Engineering, at lasi, Romania.ISSN 2285-2735, pp. 91-108.

Cardona, O., Ordaz, M., Yarim, L., Marulanda, M., \& Barbat, A. (2008). Earthquake Loss Assessment for Integrated Disaster Risk Management. Journal of Earthquake Engineering, 12(2), 48-59.

CARM. (2014). Estudio de microzonificación sísmica en el municipio de Lorca. Consejería de Obras Publicas y Ordenación del Territorio de la Región de Murcia y Universidad Politécnica de Cartagena, España.

Carreño, M. (2007). Técnicas innovadoras para la evaluación del riesgo sísmico y su gestión en centros urbanos: Acciones ex ante y ex post. Tesis Doctoral. Universidad Politécnica de Cataluña, España.

Carreño, M., Cardona, O., \& Barbat, A. (2015). Estimación holística del riesgo sísmico - nuevos enfoques. VII Congreso Nacional de Ingeniería Sísmica, Bogotá, Colombia.

Carreño, M., Cardona, O., Marulanda, M., \& Barbat, A. (2007). Herramienta computacional para la evaluación post-sísmica de daños en edificios. Revista Internacional de Desastres Naturales, Accidentes e Infraestructura Civil, 7(1), 3-24.

Carreño, M., Lantada, N., Irizarry, J., Valcárcel, J., Barbat, A., \& Goula, X. (2012). Comportamiento Sísmico de los Edificios de Lorca. Física de la Tierra, 24, 289-314.

Cella, F., Luzi, L., Meroni, F., Ober, G., Pergalani, F., Petrini, V., .. . Zonno, G. (1998). SERGISAI Project final report. By the partner CNR-IRRS. Contract Number: ENV4-CT96-0279. 220 p.p.

CEN. (2004). Comité Européen de Normalisation, Eurocode-8: Design of structures for earthquake resistance. Doc CEN/TC250/SC8/N335, January. Bruselas, Bélgica, 229 pp.

Chatelain, J., Guillier, B., Cara, F., Duval, A., Atakan, K., \& Bard, P. (2008). Evaluation of the influence of experimental conditions on $\mathrm{H} / \mathrm{V}$ results from ambient noise recordings. Bulletin of Earthquake Engineering, 6, 33-74.

Cheddadi, A. (2001). Caracterización sísmica del subsuelo de la ciudad de Granada mediante el análisis espectral del ruido de fondo sísmico y la exploración de ondas de cizalla horizontales. Tesis Doctoral. Universidad de Granada, España.

Chiou, B., \& Youngs, R. (2008). An NGA model for the average horizontal component of peak ground motion and response spectra. Earthquake Spectra, 24(1), 173-215. 
Chiou, B., \& Youngs, R. (2013). Update of the Chiou and Youngs NGA Ground Motion Model for Average Horizontal Component of Peak Ground Motion and Response Spectra. PEER 2013/07. Pacific Earthquake Engineering Research Center. University of California, Berkeley, EEUU.

Chopra, A. (2000). Dynamics of structures. Theory and applications to earthquake engineering. Prentice-Hall.

Chopra, A., \& Goel, R. (2002). Modal pushover analysis procedure for estimating seismic demands for buildings. Earthquake Engineering and Structural Dynamics, 31, 561-582.

Chung, Y., Shinozuka, M., \& Meyer, C. (1988). SARCF User's Guide: Seismic Analysis of Reinforced Concrete Frames. National Center for Earthquake Engineering Reserch. Technical Report NCEER-88-0044. State University of New York, EEUU.

Cid, J. (1998). Zonificación sísmica de la ciudad de Barcleona basada en métodos de simulación numérica de efectos locales. Tesis Doctoral. Universidad Politécnica de Cataluña, España.

Cid, J., Susagna, T., Goula, X., Chavarria, L., Figueras, S., Fleta, J., . . Roca, A. (2001). Seismic Zonation of Barcelona Based on Numerical Simulation of Site Effects. Pure and Applied Geophysics, 158, 2559-2577.

Coburn, A., \& Spence, R. (2002). Earthquake Protection. (2ºd.). John Wiley., 436 pp.

Coppersmith, K., \& Youngs, R. (1986). Capturing Uncertainty in Probabilistic Seismic Hazard Assessment within Intraplate Tectonic Environments. 3th US National Conference on Earthquake Engineering, 1, págs. 301-312. Charleston, EEUU.

Coral, H. (2002). Utilización de métodos experimentales y de simulación numérica para la microzonificación sísmica de zonas urbanizadas en Andorra. Tesis Doctoral. Universidad Politécnica de Cataluña, España.

Cornell, C. (1968). Engineering seismic risk analysis. Bulletin of the Seismological Society of America, 58, 1583-1606.

Corsanego, A., \& Petrini, V. (1990). Seismic vulnerability of buildings. Workshop III, Cooperative Proyect for Seismic Risk Reduction in the Mediterranean Region, SEISMED, Trieste, Italia.

Crespo, M. (2011). Análisis de la peligrosidad sísmica en la Península Ibérica con un método basado en estimadores de densidad Kernel. Tesis Doctoral. Universidad Politécnica de Madrid, España. 
Crespo, M., Martí, J., \& Martínez, F. (2003). Metodología con y sin zonas para cinco emplazamientos y comparación con la NCSE. 2o Congreso Nacional de Ingeniería Sísmica, Asociación Española de Ingeniería Sísmica, Málaga, España.

Crespo, M., Martí, J., \& Martínez, F. (2007). Peligrosidad sísmica en la zona central del archipiélago canario. 3o Congreso Nacional de Ingeniería Sísmica, Asociación Española de Ingeniería Sísmica, Gerona, España.

CSSC. (1999). Earthquake Risk Management: A Toolkit for Decision-Makers. California Seismic Safety Commission, EEUU.

De Luca, F., Verderame, G., Gómez-Martínez, F., \& Pérez-García, A. (2013). The structural role played by masonry infills on RC building performances after the 2011 Lorca, Spain, earthquake. Bulletin of Earthquake Engineering, 12(5), 1999-2026.

DiPasquale, E., Ju, J., Askar, A., \& Cakmak, A. (1990). Relation between global damage indices and local stiffness degradation. Journal of Structural Engineering, ASCE, 116, 14401456.

Dolce, M., Kappos, A., Masi, A., Penelis, G., \& Vona, M. (2006). Vulnerability assessment and earthquake damage scenarios of the building stock of Potenza (Southern Italy) using Italian and Greek methodologies. Engineering Structures, 28, 357-371.

Dolce, M., Kappos, A., Zuccaro, G., \& Coburn, A. (1995). Report of the EAEE Working Group 3: Vulnerability and risk anaylisis. 10th European Conference on Earthquake Engineering, Viena, Austria, pp. 3049-3077.

Dolsek, M., \& Fajfar, P. (2008). The effect of masonry infills on the seismic response of a fourstorey reinforced concrete frame - a probabilistic assessment. Engineering Structures, 30(11), 3186-3192.

Domínguez, D., López-Almansa, F., \& Benavent, A. (2014). Comportamiento, para el sismo de Lorca de 11-05-2011, de edificios de vigas planas proyectados sin tener en cuenta la acción sísmica. Informes de la Construcción, 66(533).

Douglas, J. (2003). Earthquake ground motion estimation using strong-motion records: a review of equations for the estimation of peak ground acceleration and response spectral ordinates. Earth-Science Reviews, 61, 43-104.

Douglas, J., Bungum, H., \& Schernaum, F. (2006). Ground-motion prediction equations for southern Spain and southern Norway obtained using the composite model perspective. Journal of Earthquake Engineering, 10, 33-72.

EERI. (2004). The EERI Learning from Earthquakes Program: A Brief Synopsis Of Major Contributions. Earthquake Engineering Research Institute, Oakland, CA, EEUU. 
EERI. (2016). M7.8 Gorkha, Nepal Earthquake on April 25, 2015 and its Aftershocks. EERI Earthquake Reconnaissance Team Report. Earthquake Engineering Research Institute, Oakland, CA, EEUU.

EPRI. (1986). QHAZARD: Seismic Hazard Methodology for the Eastern and Central United States. Vol. 1-3. Electric Power Research Institute, CA, EEUU.

EPRI. (1991). Standardization of the Cumulative Absolute Velocity. Report TR-100082. Electrical Power Research Intitute, CA, EEUU.

Erdik, M., Sesetyan, K., Demircioglu, M., Hancilar, U., \& Zülfikar, C. (2011). Rapid earthquake loss assessment after damaginf earthquakes. Soil Dynamics and Earthquake Engineering, 31, 247-266.

Faccioli, E. (2006). Seismic hazard assessment for derivation of earthquake scenarios in RiskUE. Bulletin of Earthquake Engineering, 4, 341-364.

Faccioli, E., Pessina, V., Pitilakis, K., \& Ordaz, M. (2003). WP2: Basis of a handbook of earthquake ground motions scenarios. . RISK-UE project: An advanced approach to earthquake risk scenarios with applications to different European towns.

Fajfar, P. (2000). A non linear analysis method for performance-based seismic design. Earthquake Spectra, 16(3), 573-594.

Fajfar, P., \& Gaspersic, P. (1996). The N2 method for the seismic damage anaylisis of RC buildings. Earthquake Engineering and Structural Dynamics, 25, 23-67.

Faleiro, J., Oller, S., \& Barbat, A. (2008). Plastic - damage seismic model for reinforced concrete frames. Computers and Structures, 86(7), 581-597.

FEMA 154. (2002). Rapid Visual Screening of Buildings for Potential Seismic Hazards. A Handbook. Federal Emergency Management Agency, Washington DC, EEUU.

FEMA 157. (1994). Typical costs for seismic rehabilitation of existing buildings. Federal Emergency Management Agency, Washington DC, EEUU.

FEMA 273. (1996). NEHRP Guidelines for the seismic rehabilitation of buildings. Federal Emergency Management Agency, Washington DC, EEUU.

FEMA 440. (2005). Improvement of Nonlinear Static Seismic Analysis Procedures. Federal Emergency Management Agency, Washington DC, EEUU.

FEMA 454. (2006). Designing for Earthquakes, a manual for architects, Risk Management Series. Report № 454. Federal Emergency Management Agency, Washington DC, EEUU. 
FEMA E-74. (2011). Reducing the Risks of Nonstructural Earthquake Damage. A Practical Guide. 4th Edition. Federal Emergency Management Agency, Washington DC, EEUU.

FEMA P-58. (2012). Seismic Performance Assessment of Buildings. Federal Emergency Management Agency, Washington DC, EEUU.

Feriche, M. (2012). Elaboración de escenarios de daños sísmicos en la ciudad de Granada. Tesis Doctoral. Universidad de Granada, España, 287 pp.

Feriche, M., Vidal, F., Alguacil, G., Aranda, C., Pérez-Muelas, J., Navarro, M., \& Lemme, A. (2012b). Performance of cultural heritage of Lorca (Spain) during the two small earthquakes of May 11th, 2011. 15th WCEE World Conference on Earthquake Engineering, Lisboa, Portugal.

Feriche, M., Vidal, F., Alguacil, G., Navarro, M., \& Aranda, C. (2012a). Vulnerabilidad y daño en el terremoto de Lorca de 2011. 7ㅁ Asamblea Hispano-Portuguesa de Geodesia y Geofísica, San Sebastián, España.

Feriche, M., Vidal, F., García, R., Navarro, M., Vidal, M., Montilla, P., \& Piñero, L. (2009). Earthquake Damage Scenarios in Vélez- Málaga urban area (Southern Spain) applicable to Local Emergency Planning. 8th International Workshop on Seismic Microzoning and Risk Reduction, Almería, España.

Figueras, S., \& Macau, A. (2009). Efectos locales y microzonificación sísmica. ¿Se pueden producir daños lejos de la zona epicentral? En A. Ugalde, Terremotos. Cuando la Tierra tiembla (págs. 135-144). Colección divulgación CSIC. Ed. Catarata. Madrid.

Figueras, S., Macau, A., Belvaux, M., Peix, M., Benjumea, B., Gabás, A., . . Goula, X. (2012). Caracterización de efectos sísmicos locales en la ciudad de Lorca. Física de la Tierra, 24, 235-254.

Foti, S., Parolai, S., Albarello, D., \& Picozzi, M. (2011). Application of surface-wave methods for seismic site characterization. Surveys in Geophysics, 32(6), 777-825.

Frankel, A. (1995). Mapping seismic hazard in the Central and Easternl United States. Seismological Research Letters, 66(4), 8-21.

Freeman, S. (1990). Development and use of capacity spectrum method. 6th Conference on Earthquake Engineering, EERI, Oakland, EEUU.

Freeman, S. (1998). The capacity spectrum method. 11th European Conference on Earthquake Engineering, Paris, Francía.

García Blanco, R. (2009). Caracterización del potencial sísmico y su influencia en la determinación de la peligrosidad sísmica probabilista. Tesis Doctoral. Universidad Politécnica de Madrid, España. 
García, N. (2011). Análisis del comportamiento sísmico de edificios de hormigón armado: comparación entre un edificio porticado y uno de forjado reticular sometido al sismo de Lorca. Tesis Doctoral. Universidad Politécnica de Cataluña, España.

García-Arribas, R. (2013). Vulnerabilidad Sísmica en España. Daños observados en terremotos recientes e implicación y responsabilidad del urbanismo. Jornadas de Proyecto y Rehabilitación Sismorresistente de Edificios. Universidad Politécnica de Cartagena, España.

García-Ayllón, S., \& Tomás, A. (2013). Actions, diagnosis and territorial management of the disaster in the city of Lorca after earthquake of May 11, 2011. En C. Brebbia (ed.), Risk Analysis IX, pp. 381-392. WIT Transactions on Information and Communication Technologies, Southampton, Reino Unido.

García-Ayllón, S., Tomás, A., \& Ródenas, J. (2017). Advances in urban planning and territorial management in the city of Lorca after the earthquake of May 11, 2011. En S. Syngellakis (ed.), Management of Natural Disasters, pp. 231-244. WIT Press, Southampton, Reino Unido.

García-Blanco, R. (2009). Caracterización del potencial sísmico y su influencia en la determinación de la peligrosidad sísmica probabilista. Tesis Doctoral. Universidad Politécnica de Madrid, España.

García-Fernández, M., \& Jiménez, M. (2012). Site characterization in the Vega Baja, SE Spain, using ambient-noise H/V analysis. Bulletin of Earthquake Engineering, 10, 1163-1191.

García-Fernández, M., Jiménez, M., \& Kijko, A. (1989). Seismic hazard parameters estimation in Spain from historical and instrumental catalogues. Tectonophysics, 197, 245-251.

García-García, A. (2010). El Riesgo Sísmico y Los Edificios Esenciales: Aplicación a Barcelona. Trabajo Fin de Máster. Universidad Politécnica de Cataluña, España.

García-Mayordomo, J. (2005). Caracterización y análisis de la peligrosidad sísmica en el sureste de España. Tesis Doctoral. Universidad Complutense de Madrid, España.

García-Mayordomo, J., García-Escribano, J., \& Benito, B. (2007). Seismic hazard asessment of the Province of Murcia (SE Spain): analysis of source contribution to hazard. Journal of Seismology, 11, 457-471.

García-Mayordomo, J., Martínez-Díaz, J., Capote, R., Martín-Banda, R., Insua, J., Álvarez, J., . . . Baize, S. (2012). Modelo de Zonas Sismogénicas para el Cálculo de la Peligrosidad Sísmica en España. 7a Asamblea Hispano Portuguesa de Geodesia y Geofísica, San Sebastián, España. 
García-Rodríguez, M. (2008). Metodologías para la evaluación de peligrosidad a los deslizamientos inducidos por terremotos. Tesis doctoral. Universidad Politécnica de Madrid, España.

Gaspar-Escribano, J., \& Iturrioz, T. (2011). Communicating earthquake risk: mapped parameters and cartographic representation. Natural Hazards and Earth System Sciences, 11, 359-366.

Gaspar-Escribano, J., Benito, B., \& García-Mayordomo, J. (2008). Hazard-consistent response spectra in the Region of Murcia (Southeast Spain): comparison to earthquake-resistant provisions. Bulletin of Earthquake Engineering, 6(2), 179-196.

Gaspar-Escribano, J., Benito, B., \& Rivas-Medina, A. (2011). Nuevo estudio de peligrosidad sísmica en Navarra. 4o Congreso Nacional de Ingeniería Sísmica en Eespña, Asociación Española de la Ingeniería Sísmica, Granada, España.

Gaspar-Escribano, J., Benito, B., García-Rodríguez, M., Rivas, A., Cabañas, L., Martínez-Díaz, J., \& Crespo, M. (2010a). Towards a new seismic hazard assessment in Spain. 14th European Conference on Earthquake Engineering, Ohrid, Macedonia.

Gaspar-Escribano, J., Navarro, M., Benito, B., García-Jerez, A., \& Vidal, F. (2010b). From regional- to local- scale seismic hazard assessment: examples from Southern Spain. Bulletin of Earthquake Engineering, 8(6), 1547-1567.

Giner, J. (1996). Sismicidad y peligrosidad sísmica en la Comunidad Autónoma de Valencia. Análisis de incertidumbres. Tesis Doctoral. Universidad Politécnica de Granada, España.

Giner, J., Molina, S., Delgado, J., \& Jauregui, P. (2003). Mixing methodologies in seismic hazard assessment via logic tree procedure: an application for Eastern Spain. Natural Hazards, $25,59-81$.

Giner-Robles, J., Pozo, M., Carenas, B., Domínguez, C., García, R. A., Regadío, M., \& De Soto, I. (2010). Riesgo Sísmico. Facultad de Ciencias, Universidad Autónoma de Madrid, España.

Giovinazzi, S. (2005). The vulnerability asessment and the damage scenario in seismic risk analysis. Tesis Doctoral. Technical University Carolo-Wihelmina, Alemania. University of Florence, Italia.

Giovinazzi, S., \& Lagomarsino, S. (2002). WP04: Guidelines for the implementation of the I level methodology for the vulnerability assessment of current buildings. Universidad de Genoa, Italia. 
Giovinazzi, S., \& Lagomarsino, S. (2004). A macroseismic method for the vulnerability assessment of buildings. 13th World Conference on Earthquake Engineering, Vancouver, Canada. Paper no 896.

Giovinazzi, S., Lagomarsino, S., \& Pampanin, S. (2006). Vulnerability Methods and Damage Scenario for Seismic Risk Analysis as Support to Retrofit Strategies: an European Perspective. NZSEE Conference, Napier, New Zeland. 10 pp.

GNDT. (1986). Instruzioni per la compilazione delle scheda di relivamento esposizione e vulnerabilitá degli edifici. Gruppo Nazionale per la Difesa dai Terremoti, C.N.R., Italia.

Goded, T. (2010). Evaluación del riesgo sísmico en la ciudad de Málaga. Tesis Doctoral. Universidad Complutense de Madrid, España.

Goded, T., Buforn, E., \& Muñoz, D. (2008). The 1494 and 1680 Málaga (Southern Spain) earthquakes. Seismological Research Letters, 79, 707-715.

Gómez-Martínez, F., Pérez-García, A., \& De Luca, F. (2014). Generalized FAST approach for seismic asessment of infilled RC MRF buildings: application to the 2011 Lorca earthquake. WIT Transactions on The Built Environment, 141, 427-443.

González, M. (2000). Simulación post evento de los efectos de un terremoto. Instituto Cartográfico de Cataluña. Informe no GS-128/00, 241 pp.

González, M. (2010). Evaluación del riesgo sísmico en el Principado de Andorra. Tesis Doctoral. Universidad Politécnica de Cataluña, España.

Gou, W., \& Yu, Z. (2012). Application of an efficient stochastic calculation method on the seismic anaylisis of an isolated structure. Frontiers of Structural and Civil Engineering, 26(4), 379-384.

Goula, X., Susagna, T., Figueras, S., Cid, J., Alfaro, A., \& Barchiesi, A. (1998). Comparison of numerical simulation and microtremor measurement for the analysis of site effects in the city of Barcelona (Spain). 11th European Conference on Earthquake Engineering. París, Francia, 13 pp.

Grünthal, G. (1998). European Macroseismic Scale (EMS-98). Conceil de L'Europe, Cahiers du Centre Européen de Géodynamique et de Séismologie, Luxemburgo.

Grünthal, G., \& Wahlström, R. (2006). New generation of probabilistic seismic hazard assessment for the area Cologne/Aachen considering the uncertainties of the input data. Natural Hazards, 38, 159-176.

Guevara, L. (2000). Evaluación de la vulnerabilidad no estructural de hospitales. International Worshop: Study on Countermeasures for Earthquake Disaster in Caracas 1999-2001, Venezuela. 
Guevara, L. (2009). Arquitectura moderna en zonas sísmicas. Barcelona: Gustavo Gili, S.L., 207 pp.

Guevara, L. (2012a). Configuraciones urbanas contemporáneas en zonas sísmicas. Caracas: Sidetur. Facultad de Arquitectura y Urbanismo, Universidad Central de Venezuela, 374 pp.

Guevara, T. (2012b). "Soft Story" and "Weak Story" in Earthquake Resistant Design: A Multidisciplinary Approach. 15th WCEE World Conference on Earthquake Engineering, Lisboa, Portugal.

Gumbel, E. (1958). Statistics of Extremes. Columbia University Press. New York, 375 pp.

Gupta, V., Nielsen, S., \& Kirkegaard, P. (2001). A preliminary prediction of seismic damagebased degradation in RC structures. Earthquake Engineering and Structural Dynamics, 30, 981-993.

Gutdeutsch, R., Kaiser, D., \& Jentzsch, G. (2002). Estimation of earthquakes magnitudes from epicentral intensities and other focal parameters in Central and Southern Europe. Geophysical Journal International, 151(3), 824-834.

Gutenberg, B., \& Richter, C. (1942). Earthquake Magnitude, Intensity, Energy and Acceleration. Bulletin of the Seismological Society of America, 32(3), 163-191.

Gutenberg, B., \& Richter, C. (1956). Magnitude and energy of earthquakes. Annali di Geofisica, 9, 1-15.

Gutiérrez, F. (1996). Evaluación de los efectos de sitio mediante al uso de microterremotos y simulación 1D: Una aplicación a Microzonificación Sísmica. Tesis Doctoral. Universidad Politécnica de Cataluña, España.

Hanks, T., \& Kanamori, H. (1979). A Moment Magnitude Scale. Journal of Geophysical Research, 84, 480-500.

HAZUS. (1999). Estimated Annualized Earthquake Losses for de United States. Federal Emergency Management Agency, FEMA 366.

HAZUS MH. (2008). Estimated Annualized Earthquake Losses for de United States. Federal Emergency Management Agency, FEMA 366.

Hermanns, L., Fraile, A., Alarcón, E., \& Álvarez, R. (2012). Comportamiento de las fábricas no estructurales en el terremoto de Lorca. Física de la Tierra, 12, 315-341.

Herrera, G., Vielma, J., Barbat, A., \& Pujades, L. (2011). Estado del conocimiento sobre metodologías de evaluación de vulnerabilidad sísmica de edificios. Revista de Ingeniería UC, 18(3). 
Hill, M., \& Rossetto, T. (2008). Comparison of building damage scales and damage descriptions for use in earthquake loss modelling in Europe. Bulletin of Earthquake Engineering, 6, 335-365.

Hori, N., \& Inoue, N. (2002). Damaging properties of ground motions and prediction of maximum response of structures based on momentary energy response. Earthquake Engineering and Structural Dynamics, 31, 1657-1679.

Housner, G. (1970). Strong ground motion in earthquake engineering. En Earthquake engineering. R.L. Wiegel.

Ibargüen, J. (1983). Optimización del Ajuste Estadístico a Series Temporales de Máximos de Intensidad Histórica en el Sureste de España. V Asamblea Nacional de Geodesia y Geofísica, (págs. 567-585). Madrid.

Ibargüen, J., \& Rodríguez-Estrella, T. (1996). Peligrosidad Sísmica en la Región de Murcia. En C. Montero, \& I. Fernández, Sexto Congreso Nacional y Conferencia Internacional de Geología Ambiental y Ordenación del Territorio, ITGE, Madrid, España, pp. 407-423.

IBC. (2000). International Building Code. International Code Consortium. Illinois, EEUU.

Idriss, I. (2013). NGA-West2 Model for Estimating Average Horizontal Values of PseudoAbsolute Spectral Accelerations Generated by Crustal Earthquakes. PEER 2013/08. Pacific Earthquake Engineering Research Center. University of California, Berkeley, EEUU.

IGN. (1991). Mapa de Peligrosidad Sísmica en España. Madrid: Instituto Geográfico Nacional.

IGN. (2016a). Tablas estadísticas de sismicidad en España. Instituto Geográfico Nacional. Obtenido de http://www.ign.es/ign/resources/sismologia/pdfTerremotos/ Tablas_estadisticas_Plberica.pdf

IGN. (2016b). Mapa general de la sismicidad de la Península Ibérica. Instituto Geográfico Nacional. Obtenido de http://www.ign.es/ign/layoutIn/sismoDetalleMapasSismicos. do?mapa=sismicidad_peq.jpg\&titulo=Mapa general de la sismicidad de la Península Ibérica\&leyenda=no\&mapabig=sismicidad.jpg

Irizarry, J. (2004). An Advanced Approach to Seismic Risk Assessment. Application to the Cultural Heritage and the Urban system of Barcelona. Tesis Doctoral. Universidad Politécnica de Cataluña, España.

Irizarry, J., Lantada, N., Pujades, L., Barbat, A., Goula, X., Susagna, T., \& A., R. (2011). Groundshaking scenarios and urban risk evaluation of Barcelona using the Risk-UE capacity spectrum based method. Bulletin of Earthquake Engineering, 9(2), 441-466. 
Jaramillo, N. (2014). Evaluación holística del riesgo sísmico en zonas urbanas y estrategias para su mitigación. Aplicación a la ciudad de Mérida (Venezuela). Tesis Doctoral. Universidad Politécnica de Cataluña, España.

Ivorra, S. (2016). ¿Un sismo como el de Italia en Alicante?. Diario Información de Alicante, España. Publicado el 31/08/2016. DOI: 10.13140/RG.2.2.21059.20007.

Ivorra, S., Reynau, R., Bru, D., \& García-Barba, J. (2015). Estudio y caracterización de la chimenea industrial "cerámica la paz" en Agost (Alicante) para su evaluación sísmica. 12 ․ Congresso Latino-Americano de Patologia da Construção, Lisboa, Portugal.

JBDPA. (1990). Standard for Seismic Capacity Assessment of Existing Reinforced Concrete Buildings . Japanese Building Disaster Prevention Association, Ministry of Construction, Tokio, Japón.

Jiménez, M., \& García-Fernández, M. (2009). Peligrosidad sísmica. ¿Qué efectos podemos esperar de los terremotos, dónde, cuándo y de qué tamaño? En Catarata (ed.) Terremotos. Cuando la Tierra tiembla. Colección divulgación CSIC, pp. 123-134, Madrid, España.

Jiménez, M., Giardini, D., \& Grünthal, G. (2001). Unified seismic hazard modeling throughout the Mediterranean region. Bollettino di Geofisica Teorica ed Applicata, 42, 3-18.

JMA. (2009). JMA Seismic Intensity Scale. Obtenido de Japan Meteorological Agency. Ministry of Land, Infraestructure, Transport and Tourism: http://www.jma.go.jp/jma/en/ Activities/inttable.html

Kappos, A. (2007). Seismic Vulnerability and risk assessment of urban habitat in Southern European cities. En Urban Habitat Constructions under Catastrophic Events Workshop. Praga, : COST C26.

Kappos, A., \& Dimitrakopoulos, E. (2008). Feasibility of pre-earthquake strengthening of buildings based on cost-benefit and life-cycle cost analysis, with the aid of fragility curves. Natural Hazards, 45(1), 33-54.

Kappos, A., Panagopoulos, G., Panagiotopoulos, C., \& Penelis, G. (2006). A hybrid method for the vulnerability assessment of R/C and URM buildings. Bulletin of Earthquake Engineering, 4, 391-413.

Katsanos, E., Sextos, A., \& Manolis, G. (2010). Selection of earthquake ground motion records:A state-of-the-art review from a structural engineering perspective. Soil Dynamics and Earthquake Engineering, 30, 157-169.

Kim, S., \& Kuruma, Y. (2008). An alternative pushover analysis procedure to estimate seismic displacement demands. Engineering structures, 30, 3793-3807. 
Kreslin, M., \& Fajfar, P. (2012). The extended N2 method considering higher mode effects in both plan and elevation. Bulletin of Earthquake Engineering, 10(2), 695-715.

Krinitzsky, E. (1995). Problems with Logic Trees in earthquake hazard evaluation. Environmental \& Engineering Geoscience, 4(4), 425-443.

Krinitzsky, E. (2002). Epistematic and aleatory uncertainty: a new shtick for probabilistic seismic hazard analysis. Engineering Geology, 66, 157-159.

Kunnath, S., Reinhorn, A., \& Abel, J. (1991). A computational tool for evaluation of seismic performance of reinforced concrete buildings. Computers \& Structures, 41(1), 157-173.

Lagomarsino, S. (2006). On the vulnerability assessment of monumental buildings. Bulletin of Earthquake Engineering, 4, 445-463.

Lagomarsino, S., \& Giovinazzi, S. (2006). Macroseismic and mechanical models for the vulnerability and damage assessment of current buildings. Bulletin of Earthquake Engineering, 4(4), 415-443.

Lagomarsino, S., \& Penna, A. (2003). Guidelines for the implementation the II level vulnerability methodology. WPO4: Vulnerability assessment of current buildings. Technical presentation RISK-UE project: An advanced approach to earthquake risk scenarios with application to different European towns.

Lagomarsino, S., \& Resemini, S. (2009). The assessment of damage limitation state in the seismic analysis of monumental buildings. Earthquake Spectra, 25, 323-346.

Lagomarsino, S., Giovinazzi, S., Podestá, S., \& Resemini, S. (2003). WP05 Report: Vulnerability assessment of historical and monumental buildings. RISK-UE project: An advanced approach to earthquake risk scenarios with applications to different European towns. University of Genoa, Italia, 90 pp.

Lang, D. (2012). Earthquake damage and loss assessment - Predicting the unpredictable. Tesis Doctoral. University of Bergen, Noruega.

Lang, K. (2002). Seismic vulnerability of existing buildings. Tesis Doctoral. Institute of Structural Engineering. Swiss Federal Institute of Technology, Suiza.

Lantada, N. (2007). Evaluación del riesgo sísmico mediante métodos avanzados y técnicas GIS. Aplicación a la ciudad de Barcelona. Tesis Doctoral. Universidad Politécnica de Cataluña, España.

Lantada, N., Irizarry, J., Barbat, A., Goula, X., Roca, A., Susagna, T., \& Pujades, L. (2010). Seismic hazard and risk scenarios for Barcelona, Spain, using the Risk-UE Vulnerability Index Method. Bulletin of Earthquake Engineering, 8(2), 201-229. 
Lantada, N., Pujades, L., \& Barbat, A. (2009). Vulnerability index and capacity spectrum based methods for urban seismic risk evaluation. A comparison. Natural Hazards, 51, 501524.

Le Brun, B., Hatzfeld, D., \& Bard, P. (2001). Site effect study in urban area: experimental results in Grenoble (France). Pure and Applied Geophysics, 158, 2543-2557.

Lestuzzi, P., Podestà, S., Luchini, C., Garofano, A., Kazantzidou, D., \& Bozzano, C. (2017). Validation and improvement of RISK-UE LM2 capacity curves for URM buildings with stiff floors and RC shear walls buildings. Bulletin of Earthquake Engineering, 15(3), 1111-1134.

Liang, G., \& Zhou, N. (2016). Background and reflections on Gorkha earthquake of April 25, 2015. Natural Hazards, 81(2), 1385-1392.

López, A. (2015). Modelos de comportamiento seccional del hormigón armado ajustados a ensayos mediante algoritmos metaheurísticos. Tesis Doctoral. Universidad Politécnica de Cartagena, España.

López-Arroyo, A., \& Steep, C. (1973). Application of extreme value techniques to earthquake occurrence in the Iberian Region. Bulletin of the Seismological Society of America.

López-Casado, C., Molina, S., Delgado, J., \& Peláez, J. (2000a). Attenuation of Intensity with Epicentral Distance in the Iberian Peninsula. Bulletin of the Seismological Society of America, 90, 34-47.

López-Casado, C., Molina, S., Giner, J., \& Delgado, J. (2000b). Magnitude-Intensity Relationships in the Ibero-Magrebhian Region. Natural Hazards, 22, 271-297.

López-Casado, C., Sanz de Galdeano, C., Delgado, J., \& Peinado, M. (1995). The parameter b in the Betic Cordillera, the Rif and neighbouring areas. Its relations with the tectonics of the region. Tectonophysics, 248, 277-292.

López-Fernández, C., Pulgar, J., Gallart, J., González-Cortina, J., Díaz, J., \& Ruiz, M. (2008). Zonación Sismotectónica del NO de la Península Ibérica. Geo-Temas, 10, 1031-1034.

Lozano, C., Bermúdez, M., \& Ojeda, A. (2009). Evaluación del perfil de velocidad para estratos de suelo blando por medio de funciones de transferencia. XII Congreso Colombiano de Geología, Bogotá, Colombia.

Lungu, D., Aldea, A., Arion, A., Vacareanu, R., Petrescu, F., \& Cornea, T. (2002). WP01 Report: European distinctive features, Inventory database and typology. . RISK-UE project: An advanced approach to earthquake risk scenarios with applications to different European towns, Bucarest, Rumanía. 
Macau, A. (2008). Microzonificación sísmica. Contribución a los estudios de peligrosidad sísmica a escala local en zonas rurales y urbanas. Tesis Doctoral. Universidad Politécnica de Cataluña, España.

Macau, A., Figueras, S., Susagna, T., Colas, B., Le Cron, B., Bitri, A., . . Roullé, A. (2007). Microzonación sísmica en el Pirineo Oriental en términos de aceleroación e intensidad macrosísmica. 3ํo Congreso Nacional de Ingeniería Sísmica. Girona, España.

Manfredi, G., Prota, A., Verderame, G., De Luca, F., \& Ricci, P. (2014). 2012 Emilia Romagna earthquake, Italy: reinforced conrete buildings response. Bulletin of Earthquake Engineering, 12(5), 2275-2298.

Manfredi, G., Ricci, P., \& Verderame, G. (2012). Influence of Infill Panels and Their Distribution on Seismic Behavior of Existing Reinforced Concrete Buildings. The Open Construction and Building Technology Journal, 6(Suppl 1- M15), 236-253.

Martín, A. (1984). Riesgo Sísmico en la Península Ibérica. Tesis Doctoral, Universidad Politécnica de Madrid, España.

Martín, A., \& Sierra, J. (1984). New Seismic Hazard Map of Spain, based on Gumbel I Distribution. Engineering Geology, 20, 187-191.

Martín-Bourgón, P., Bernal, A., López de Alda, F., Ferreiro, E., \& Tena Dávila, M. (1996). Zonación sismotectónica de la Península Ibérica para su uso en estudios de peligrosidad sísmica. 6o Congreso Nacional y Conferencia Internacional de Geología Ambiental y Ordenación del Territorio, ITGE, 2, pp. 357-374. Madrid, España.

Martínez-Cuevas, S. (2014). Evaluación de la vulnerabilidad sísmica urbana basada en tipologías constructivas y disposición urbana de la edificación. Aplicación en la ciudad de Lorca, Región de Murcia. Tesis Doctoral. Universidad Politécnica de Madrid, España.

Martínez-Cuevas, S., \& Gaspar-Escribano, J. (2016). Reassessment of intensity estimates from vulnerability and damage distributions: the 2011 Lorca earthquake. Bulletin of Earthquake Engineering, 14(10), 2679-2703.

Martínez-Díaz, D. (2014). Estudio de la influencia de pilares cortos en la respuesta sísmica estructural de los edificios. Trabajo Fin de Máster. Universidad Politécncia de Cartagena, España.

Martínez-Pagán, P., Navarro, M., Pérez-Cuevas, J., Alcalá, F., García-Jerez, A., \& Sandoval, S. (2014). Shear-wave velocity based seismic microzonation of Lorca city (SE Spain) from MASW analysis. Near Surface Geophysics, 12(6), 739-749.

Martínez-Solares, J. (2001). Los efectos en España del terremoto de Lisboa (1 de noviembre de 1755). Madrid: Instituto Geográfico Nacional. Monografía 19. 
Martínez-Solares, J. (2012). Sismicidad pre-instrumental. Los grandes terremotos históricos en España. Enseñanza de las Ciencias de la Tierra, 19(3), 296-304.

Martínez-Solares, J., \& Mezcua, J. (2002). Catálogo sísmico de la Península Ibérica (880 a.C.1900). Instituto Geográfico Nacional, Madrid.

McGuire, R. (1976). EQRISK, Evaluation of earthquake risk to site. Open File report 7667, USGS, EEUU, $90 \mathrm{pp}$.

McGuire, R. (2004). Seismic Hazard and Risk Analysis. Earthquake Engineering Research Institute, Oakland, CA (EEUU).

MEH. (2017). Portal de la Dirección General del Catastro. Obtenido de Secretaría de Estado de Hacienda. Ministerio de Hacienda y Función Pública. Gobierno de España: http://www.catastro.meh.es/

Mena, U. (2002). Evaluación del riesgo sísmico en zonas urbanas. Tesis Doctoral. Universidad Politécnica de Cataluña, España.

Mena, U., Moliner, C., Pujades, L., \& Canas, J. (1999). Análisis de daño en edificios dañados por el terremoto del 2 de febrero de 1999, en la Región de Murcia. Informe interno. Departamento de Ingeniería del Terreno y Cartográfica. Universidad Politécnica de Cataluña, España.

Mezcua, J., \& Martínez-Solares, J. (1983). Sismicidad en el área Ibero-Magrebí. Instituto Geográfico Nacional. Publicación Técnica № 203. Madrid.

Mezcua, J., Rueda, J., \& García-Blanco, R. (2004). Reevaluation of historic earthquakes in Spain. Seismological Research Letters, 75, 75-81.

Mezcua, J., Rueda, J., \& García-Blanco, R. (2008). On the Strong Ground Motion Attenuation in Spain. Bulletin of the Seismological Society of America, 98(3), 1343-1353.

Mezcua, J., Rueda, J., \& García-Blanco, R. (2011). A new probabilistic seismic hazard study of Spain. Natural Hazards, 59, 1087-1108.

Milutinovic, Z., \& Trendafiloski, G. (2003). WP04. Vulnerability of current buildings. RISK-UE project: An advanced approach to earthquake risk scenarios with applications to different European towns. RISK-UE project: An advanced approach to earthquake risk scenarios with applications to different European towns, Skopje, Macedonia.

Molina, S. (1998). Sismotectónica y Peligrosidad Sísmica del Área de Contacto entre Iberia y África. Tesis Doctoral. Universidad de Granada, España.

Molina, S., Lindholm, C., \& Bugum, H. (2001). Probabilistic seismic hazard analysis: Zoning free versus zoning methodology. Bolletino di Geofisica Teorica e Applicata, 42, 19-39. 
Molina, S., Torres, Y., Benito, B., Navarro, M., \& Belizaire, D. (2014). Using the damage from 2010 Haiti earthquake for calibrating vulnerability models of typical structures in Portau-Prince (Haiti). Bulletin of Earthquake Engineering, 12(4), 1459-1478.

Moncayo, H. (2002). Utilización de métodos experimentales y de simulación numérica para la microzonificación sísmica de áreas urbanizadas en Andorra. Tesis Doctoral. Universidad Politécnica de Cataluña, España.

Mora, M., Ordaz, M., Yamin, L., \& Cardona, O. (2011). Relaciones beneficio-costo probabilistas de rehabilitación sísmica. 4o Congreso Nacional de Ingeniería Sísmica, Granada, España. Paper ID 60.

Moreno, R. (2006). Evaluación del riesgo sísmico en edificios mediante análisis estático no lineal. Aplicación a diversos escenarios sísmicos de Barcelona. Tesis Doctoral. Universidad Politécnica de Cataluña, España.

Moreno, R., \& Bairán, J. (2012). Influencia de los cerramientos de fábrica en el comportamiento sísmico de edificios de hormigón armado. Hormigón y acero, 64(258), 89-99.

Moreno, R., Aparicio, A., Pujades, L., \& Barbat, A. (2009). Vulnerabilidad sísmica de los edificios de hormigón armado con forjados reticulares. Hormigón y Acero, 251, 65-76.

Moreno, R., Bairán, J., Pujades, L., Aparicio, A., \& Barbat, A. (2004). Evaluación probabilista del comportamiento sísmico de edificios porticados de hormigón armado. Hormigón y acero, 232, 125-136.

Moreno, S. (2011). Estudio de la vulnerabilidad sísmica de edificios de hormigón armado. Trabajo Fin de Máster. Universitad Politécnica de Cataluña, España.

Mouroux, P., \& Le Brun, B. (2006). Presentation of RISK-UE Project. Bulletin of Earthquake Engineering, 4, 323-329.

Munuera, J. (1963). A study of seismicity on the Península Ibérica area. Instituto Geográfico y Catastral, Madrid, $50 \mathrm{pp}$.

Muñoz, D. (1983). Estudio del riesgo sísmico en el sur y en el sureste de la Península Ibérica. Tesis Doctoral. Universidad Complutense de Madrid.

Muñoz, D., \& Udías, A. (1992). Earthquake occurence and seismic zonation in South Spain. 10th World Conference on Earthquake Engineering, 1, págs. 483-487. Madrid.

Muñoz, D., Mayer- Rosa, D., Banda, E., \& Udías, A. (1984). A Probabilistic Calculation of Seismic Hazard of Southern Spain. Engineering Geology, 20, 49-61. 
Murphy, P. (2011). Quick field report: Lorca earthquake 11th May 2011. Broadway Malyan, Madrid, España.

Nakamura, Y. (1989). A method for dynamic characteristics estimation of subsurface using microtremors on the ground surface. Quarterly Report of Railway Technical Research Institute, 30, 25-33.

Navarro, M., García-Jerez, A., Alcalá, F., Vidal, F., \& Enomoto, T. (2014). Local site effect microzonation of Lorca town (SE Spain). Bulletin of Earthquake Engineering, 12(5), 1933-1959.

Navarro, M., García-Jerez, J., Alcalá, F., Vidal, F., Enamoto, T., Luzón, F., \& Creus, C. (2008). Vs30 Structure of Lorca town (SE Spain) from Ambient Noise Array Observations. 31st General Assembly of the European Seismological Commission ESC 2008, Hersonissos, Grecia.

Navarro, M., García-Jerez, J., Vidal, F., Enomoto, T., Pérez-Ruiz, J., Alcalá, F., . . . Iwatate, T. (2006). Características del movimiento de suelo a partir de medidas de vibración ambiental y registros de aceleración. 5a Asamblea Hispano-Portuguesa de Geodesia y Geofísica, Sevilla, España.

Navarro, M., Vidal, F., Enomorto, T., Alcalá, F., Sánchez, F., \& Abeki, N. (2007). Analysis of site effects weightiness on RC building seismic response. The Adra (SE Spain) example. Earthquake Engineering \& Structural Dynamics, 36, 1363-1383.

NCSE-02. (2002). Norma de Construcción Sismorresistente: Parte General y Edificación. Real Decreto 997/2002, Boletín Oficial del Estado No. 244, Madrid, España.

NCSE-94. (1994). Norma de Construcción Sismorresistente: Parte General y Edificación. Real Decreto 2543/1994, Boletín Oficial del Estado No. 33, Madrid, España.

Nuttli, O. (1985). Average Source-Parameter Relations for Plate Tectonic Earthquakes. Tectonophysics, 118, 161-174.

Occhiuzzi, A., Maddaloni, G., Caterino, N., Nestovito, G. (2012). Report preliminare sui danni registrati nel comune di Novi di Modena (MO) in seguito agli eventi sismici del 20 maggio, del 29 maggio e del 3 giugno 2012. Universidad de Nápoles, Italia.

Ordaz, M., Aguilar, A., \& Arboleda, J. (1999). CRISIS 99. Program for computing seismic risk hazard. Instituto de Ingeniería, Universidad Nacional Autónoma de México, México.

Ordaz, M., Aguilar, A., \& Arboleda, J. (2001). CRISIS 99-18. Ver.1.018. Program for Computing Seismic Risk. Instituto de Ingeniería, Universidad Nacional Autónoma de México, México. 
Ordaz, M., Martinelli, F., Aguilar, A., Arboleda, J., Meletti, C., \& D'Amico, V. (2008). CRISIS 2008, Ver. 3.8. Program for computing seismic hazard. Instituto de Ingeniería, Universidad Nacional Autónoma de México, México.

Ordaz, M., Martinelli, F., Aguilar, A., Arboleda, J., Meletti, C., \& D'Amico, V. (2012). CRISIS 2012. Program for computing seismic hazard. Instituto de Ingeniería, Universidad Nacional Autónoma de México, México.

Park, C., Miller, R., \& Xia, J. (1999). Multi-channel analysis of surface waves (MASW). Geophysics, 64(3), 800-808.

Park, R. (1986). Ductile design approach for reinforced concrete frames. Earthquake Spectra, 2(3), 565-619.

Park, Y., \& Ang, A. (1985). Mechanistic seismic damage model reinforced concrete. Journal of Structural Division, 111, 722-739.

Park, Y., Ang, A., \& Wen, Y. (1987). Damage limiting seismic design of buildings. Earthquake Spectra, 3(1), 1-26.

PDS-1. (1974). Norma Sismorresistente. Decreto 3209/1974 de 30 de Agosto de 1974. BOE del 21 de Noviembre de 1974, Madrid, España.

Peláez, J. (1999). Agregación y desagregación de aceleraciones esperadas en la Península Ibérica utilizando sismicidad de fondo. Tesis doctoral. Universidad de Granada, España.

Peláez, J., Delgado, J., \& López-Casado, C. (2005). A preliminary probabilistic seismic hazard assessment in terms of Arias intensity in southeastern Spain. Engineering Geology, 77, 139-151.

Perea, H., \& Atakan, K. (2007). Influence of slow active faults in probabilistic seismic hazard assessment: the northwestern margin of the València trough. Natural Hazards, 43, 379-396.

Perepérez, B. (2011). La configuración sísmica de los sistemas. Zuncho, 30, 21-30.

Perepérez, B. (2014a). Evolución y características del riesgo sísmico en España. Congreso Latinoamericano sobre patología de la construcción, tecnología de la rehabilitación y gestión del patrimonio, REHABEND 2014, pp. 422-429. Santander, España.

Perepérez, B. (2014b). La peligrosidad sísmica y el factor de riesgo. Informes de la Construcción, 66(534), 1-9.

Pérez-Cuevas, J., Martínez-Pagán, P., Alhama, I., Cánovas, M., \& Segura, F. (2013). Aplicación del método MASW para estudios sobre microzonificación sísmica en la ciudad de Lorca, España. VI Jornadas de introducción a la investigación de la Universidad Politécnica de Cartagena, España, (pp. 43-45). 
Pérez-Ruiz, J., Posadas, A., Lantada, N., \& Pujades, L. (2007). Métodos avanzadaos de generación de escenarios de riesgo sísmico. Aplicación a la ciudad de Motril (España). 3er Congreso Nacional de Ingeniería Sísmica. Gerona, España.

PGS-1. (1968). Norma Sismorresistente PGS-1. Comisión Interministerial de la Presidencia del Gobierno.Decreto 106/1969 del 16/01/1969, Madrid, España.

Phillips, W., \& Aki, K. (1986). Site amplification of coda waves from local earthquake in Central California. Bulletin of the Seismological Society of America, 76, 509-529.

PRISK. (1985). Principia Mechanica, LTD. PRISK Manual. Central Electricity Generating Board, Londres, Reino Unido.

Pujades, L., Barbat, A., \& Lantada, N. (2007). Evaluación del riesgo sísmico en zonas urbanas: desarrollo de escenarios. Revista internacional de Ingeniería de Estructuras, 12(1), 128.

RADIUS. (1999). Risk Asessment Tools for Diagnosis of Urban Areas Against Seismic Disasters. United Nations Initiative Towards Earthquake Safe Cities, United Nations, Ginebra, Suiza..

Ribó, A. (2010). GIS-based seismicmicrozonation. Development and application to earthquake hazard scenarios for La Vega Baja, SE Spain. Tesis Doctoral, Universidad de Barcelona, España.

Ricci, P. (2010). Seismic vulnerability of existing RC buildings. Tesis Doctoral. University of Naples Federico II, Italia.

Ricci, P., De Risi, M., Verderame, G., \& Manfredi, G. (2013). Influence of infill distribution and design typology on seismic performance of low- and mid-rise RC building. Bulleting of Earthquake Engineering, 11(5), 1585-1616.

Ricci, P., Verderame, G., \& Manfredi, G. (2011). Analytical investigation of elastic period of infilled RC MRF buildings. Engineering Structures, 33(2), 308-319.

Richter, C. (1935). An Instrumental Earthquake Scale. Bulletin of the Seismological Society of America, 25(1), 1-32.

Rivas-Medina, A., Martínez-Cuevas, S., Quirós, L., Gaspar-Escribano, J., \& Staller, A. (2014). Models for reproducing the damage scenario of the Lorca earthquake. Bulletin of Earthquake Engineering, 12(5), 2075-2093.

Roca, A., Irizarry, J., Lantada, N., Barbat, A., Goula, X., Pujades, L., \& Susagna, T. (2006). Método Avanzado para la Evaluación de la Vulnerabilidad y el Riesgo Sísmico. Aplicación a la Ciudad de Barcelona. Física de la Tierra, 18, 183-203. 
Roca, A., López-Arroyo, A., \& Suriñach, E. (1984). Application of the Gumbel III Law to Seismic Data from Southern Spain. Engineering Geology, 20, 63-71.

Roca, A., Oliveira, C., Ansal, A., \& Figueras, S. (2008). Local site effects and microzonation. In C. Oliveira, A. Roca, \& X. Goula, Assessing and managing earthquake risk. Geo-scientific and engineering knowledge for earthquake risk mitigation: developments, tools, techniques (pp. 67-90). Springer.

Romao, X., Costa, A., Paupério, E., Rodrigues, H., Vicente, R., \& Varum, H. (2013). Field observations and interpretation of the structural performance of constructions after the 11 May 2011 Lorca earthquake. Engineering Failure Analysis, 34, 670-692.

Rosa-Cintas, S., Galiana, J., Molina, S., Rosa-Herranz, J., García-Fernández, M., \& Jiménez, M. (2011). Soil characterization in urban areas of the Bajo Segura Basin (Southeast Spain) using H/V, F-K and ESAC methods. Journal of Applied Geophysics, 75, 543-557.

Rosa-Oliver, E., \& Blázquez, R. (2003). Procesos estocásticos en ingeniería civil. Madrid: Colegio de Ingenieros de Caminos, Canales y Puertos, 323 pp.

Roufaiel, M., \& Meyer, C. (1987). Analytical modelling of hysteretic behaviour of RC frames. Journal of Structural Division, ASCE, 113(3), 429-444.

Rueda, J., \& Mezcua, J. (2001). Sismicidad, Sismotectónica y Peligrosidad Sísmica en Galicia. Publicación Técnica 35. Instituto Geográfico Nacional. Madrid. 64 pp.

Rueda, J., \& Mezcua, J. (2002). Estudio del Terremoto de 23 de Septiembre de 2001 en Pego(Alicante). Obtención de una Relación mbLg -Mw para la Península Ibérica. Revista de la Sociedad Geológica de España, 15, 159-173.

Sabetta, F., \& Pugliese, A. (1996). Estimation of response spectra an simulation of nonstationary earthquake ground motions. Bulletin of the Seismological Society of America, 86(2), 337-352.

Safina, S. (2003). Vulnerabilidad sísmica de edificaciones esenciales. Análisis de su contribución al riesgo sísmico. Tesis Doctoral. Universidad Politécnica de Cataluña, España.

Salgado-Gálvez, M., Carreño, M., Cardona, O., \& Barbat, A. (2015). Probabilistic seismic hazard and risk assessment in Spain. Monographs of Seismic Engineering IS 69, International Centre for Numerical Methods in Engineering (CIMNE), Barcelona, España.

Sánchez Silva, M., \& García, L. (2001). Earthquake Damage Assessment Based on Fuzzy Logic and Neural Network. Earthquake Spectra, 17(1), 89-112. 
Sandi, H. (1983). Earthquake risk anda earthquake preparadness: some qualitative aspects anda quantification possibilities. Seminar on Earthquake Preparadness. UNDP/UNESCO/UNDRO Project for Earthquake Risk Reduction in the Balkan Region, (págs. 79-93). Athens.

Sandi, H. (1986). Vulnerability and risk analysis for individual structures and systems. 8th European Conference on Earthquake Engineering, (págs. 11-69). Lisboa, Portugal.

Sanz de Galdeano, C., Peláez, J., \& López-Casado, C. (2003). Seismic potential of the main active faults in the Granada Basin (southern Spain). Pure and Applied Geophysics, 160, 1537-1556.

Scherbaum, F., Bommer, J., Bungum, H., Cotton, F., \& Abrahamson, N. (2005). Composite ground-motion models and logic trees: methodology, sensitivities, and uncertainties. Bulletin of the Seismological Society of America, 95, 1575-1593.

Schmidt, V. (2010). Avances para estudios del riesgo sísmico a escala regional y local: aplicación a América Central y a la Bahía de Cádiz (Sur de España). Tesis Doctoral. Universidad Politécnica de Cataluña, España.

SEAOC. (1995). Performance based seismic engineering of buildings. VISION 2000. Structural Engineering Association of California, CA, EEUU.

Secanell, R., Bertil, D., Martin, C., Goula, X., Susagna, T., Tapia, M., . . . Fleta, J. (2008). Probabilistic seismic hazard assessment of the Pyrenean region. Journal of seismology, 12, 323-341.

Secanell, R., Goula, X., Susagna, T., Fleta, J., \& Roca, A. (2004). Seismic hazard zonation of Catalonia, Spain, integrating uncertainties. Journal of Seismology, 8, 24-40.

Serrano-Lanzarote, B., \& Temes-Córdovez, R. (2015). Vulnerabilidad y riesgo sísmico de los edificios residenciales estudiados dentro del Plan Especial de evaluación del riesgo sísmico en la Comunidad Valenciana. Informes de la Construcción, 67, 1-11.

SISMIMUR. (2006). Plan Especial de Protección Civil ante el Riesgo Sísmico en Región de Murcia. Dirección General de Protección Civil, Consejería de Presidencia de la Región de Murcia. Murcia, España.

SISMIMUR II. (2015). Plan Especial de Protección Civil ante el Riesgo Sísmico en Región de Murcia. Dirección General de Seguridad Ciudadana y Emergencias. Consejería de Presidencia de la Región de Murcia. Murcia, España.

Sokolov, V., \& Wenze, F. (2011). Influence of spatial correlation of strong ground motion on uncertainty in earthquake loss estimation. Earthquake Engineering \& Structural Dynamics, 40(9), 993-1009. 
Stafford, P., Strasser, F., \& Bommer, J. (2008). An evaluation of the applicability of the NGA models to ground-motion prediction in the Euro-Mediterranean region. Bulletin of Earthquake Engineering, 6, 149-177.

Susagna, T., Cabañas, L., Goula, X., Alcalde, J., \& Belvaux, M. (2012). Análisis de los parámetros de los acelerogramas registrados en los seísmos de Lorca, de interés para la Ingeniería. Física de la Tierra, 24, 213-234.

Tapia, M. (2006). Desarrollo y aplicación de métodos avanzados para la caracterización de la respuesta sísmica del suelo a escala regional y local. Tesis Doctoral. Universidad Politécnica de Cataluña, España.

Theodoulidis, N., Cultrera, G., De Rubeis, V., Cara, F., Panou, A., Pagani, M., \& Teves, P. (2008). Correlation between damage distribution and ambient noise $\mathrm{H} / \mathrm{V}$ spectral ratio: the SESAME project results. Bulletin of Earthquake Engineering, 6, 109-140.

Tomás, A., \& Díaz, E. (2013). Proposal of a form for post-earthquake rapid evaluation of buildings. Informe interno. Deparmento de Ingenieria Civil. Universidad Politécnica de Cartagena, España.

Trifunac, M., \& Brady, A. (1975). A study of the duration of strong earthquake motion. Bulletin of the Seismological Society of America, 65, 581-626.

UNISDR. (2011). GAR - Global Assessment Report for Disaster Risk Reduction. The United Nations Office for Disaster Risk Reduction (UNISDR), Ginebra, Suiza.

UNISDR. (2013). GAR- Global Assessment Report on Disaster Risk Reduction. The United Nations Office for Disaster Risk Reduction (UNISDR), Ginebra, Suiza.

USGS. (2016). US Geological Survey. Earthquake Statistics. Obtenido de https://earthquake.usgs.gov/earthquakes/browse/stats.php

Vacareanu, R., Lungu, D., Aldea, A., \& Arion, C. (2004). WP07 Report. Seismic Risk Scenarios Handbook. RISK-UE project: An advanced approach to earthquake risk scenarios with applications to different European towns, Bucarest, Rumanía.

Valcárcel, J. (2013). Análisis y gestión del riesgo sísmico de edificios y sistemas esenciales. Tesis Doctoral. Universidad Politécnica de Cataluña, España.

Valcárcel, J., Mora, M., Cardona, O., Pujades, L., Barbat, A., \& Bernal, G. (2013). Methodology and applications for the benefit cost analysis of the seismic risk reduction in building portfolios at broadscale. Natural Hazards, 69, 845-868.

Vargas, Y. (2013). Análisis estructural estático y dinámico probabilista de edificios de hormigón armado. Aspectos metodológicos y aplicaciones a la evaluación del daño. Tesis Doctoral. Universidad Politécnica de Cataluña, España. 
Vicente, R., Parodi, S., Lagomarsino, S., Varum, H., \& Mendes, J. (2008). Seismic vulnerability assessment, damage scenarios and loss estimation. A Case study of the old city centre of Coimbra, Portugal. 14th World Conference on Earthquake Engineering, Pekin, China.

Vidal, F., Feriche, M., \& Ontiveros, A. (2009). Basic Techniques for Quick and Rapid PostEarthquake Assessments of Building Safety. 8th International Workshop on Seismic Microzoning and Risk Reduction, Almería, España.

Vielma, J. (2008). Caracterización del comportamiento sísmico de edificios de hormigón armado mediante la respuesta no lineal. Tesis Doctoral. Universidad Politécnica de Cataluña, España.

Vielma, J., Barbat, A., \& Oller, S. (2008). Influencia de los cerramientos de fábrica en el comportamiento sísmico de edificios de hormigón armado. Hormigón y Acero, 59(248), 87-101.

Vielma, J., Barbat, A., \& Oller, S. (2009). Determinación de umbrales de daño sísmico en edificios porticados de armado proyectados conforme al EC-2 y EC-8. Homigón y Acero, 60(251), 77-87.

Vielma, J., Barbat, A., \& Oller, S. (2010). Seismic safety of limited ductility buildings. Bulletin of Earthquake Engineering, 8(1), 135-155.

Vilanova, S., \& Fonseca, F. (2007). Probabilistic seismic hazard assesment for Portugal. Bulletin of the Seismological Society of America, 97, 1702-1717.

Weibull, W. (1951). A statistical distribution function of wide applicability. ASME Journal of Applied Mechanics, 293-297.

Whitman, R., Anagnos, T., Kircher, C., Lagorio, H., Lawson, R., \& Schneider, P. (1997). Development of a national earthquake loss estimation methodology. Earthquake Spectra, 13(4), 643-661.

Whitman, R., Reed, J., \& Hong, S. (1973). Earthquake damage probability matrices. 5th World Conference on Earthquake Engineering, Roma, Italia.

Woessner, J., Laurentiu, D., Giardini, D., Crowley, G., Cotton, Grünthal, G., Valensise, G., ..., Stucchi, M. (2015). The European Seismic Hazard Mode: key components and results. Bulletin of Earthquake Engineering, 13(12), 3553-3596.

Woo, G. (1996). Kernel Estimation methods for seismic hazard area modelling. Bulletin of the Seismological Society of America, 86(2), 353-362.

Yépez, F. (1996). Metodología para la evaluación del riesgo sísmico de estructuras aplicando técnicas de simulación. Tesis Doctoral. Universidad Politécnica de Cataluña, España. 
Yépez, F., Barbat, A., \& Canas, J. (1994). Riesgo, peligrosidad y vulnerabilidad sísmica de edificios de mampostería. Monografía IS-12. Centro Internacional Métodos Numéricos en Ingeniería (CIMNE), Barcelona, España. 



\section{PUBLICACIONES DEL DOCTORANDO RELACIONADAS CON ESTA TESIS}

Tomás, A., Ródenas, J.L., \& García-Ayllón, S. (2017). Proposal for new values of behaviour modifiers for seismic vulnerability evaluation of reinforced concrete buildings applied to Lorca (Spain) using damage data from the 2011 earthquake. Bulletin of Earthquake Engineering, 1-20. Publicado online, DOI: 10.1007/s10518-017-0100-3.

García-Ayllón, S., Tomás, A., \& Ródenas, J.L. (2017). Advances in urban planning and territorial management in the city of Lorca after the earthquake of May 11, 2011. En: Syngellakis, S. (ed.), Management of Natural Disasters, WIT Press, 231-244, Southampton, Reino Unido.

Ródenas, J.L, Tomás, A., \& García-Ayllón, S. (2017). Advances in seismic vulnerability assessment of reinforced concrete buildings applied to the experience of Lorca (Spain) 2011 Earthquake. International Journal of Computational Methods and Experimental Measurements, 1-12. Artículo aceptado para publicación.

Tomás, A., García-Ayllón, S., \& Ródenas, J.L. Advances in seismic vulnerability assessment applied to post-earthquake scenarios. Earthquake Spectra. Artículo en revisión, remitido en julio de 2016. 

ANEXO A

\section{SELECCIÓN DE FICHAS ELABORADAS PARA LA IMPLEMENTACIÓN DE LA BASE DE DATOS}

\section{A.1. INTRODUCCIÓN}

En el capítulo 4 se expuso el procedimiento empleado para la implementación de la base de datos de daños reales en edificaciones de hormigón armado a partir de la información disponible del sismo de Lorca de 2011. Esta base de datos fue elaborada con objeto de comprobar el ajuste de las distintas variantes del Método del Índice de Vulnerabilidad (MIV), a partir de observaciones reales post-sismo.

En este proceso fue empleada una ficha que permitía registrar, para cada edificación evaluada, los daños sísmicos que presentaba y los parámetros urbanísticos con mayor influencia en su respuesta sísmica. De la muestra total de 1050 edificaciones analizadas, en este Anexo se incluye un extracto con algunas de las fichas elaboradas en la campaña de recopilación de datos para la evaluación del índice de vulnerabilidad y el correspondiente grado de daño de cada edificación.

\section{A.2. SELECCIÓN DE FICHAS}

A continuación se muestra una serie de ejemplos de las fichas empleadas para la elaboración de la base de datos, en función del grado de daño observado en la edificación (Figuras A.1 a A.24). Con objeto de preservar la privacidad de usuarios y propietarios de cada inmueble, se muestra parcialmente la dirección postal de los edificios. 


\section{DAÑOS EN EDIFICACIONES. SISMO DE LORCA 2011}

\section{DATOS GENERALES DE LA EDIFICACIÓN}

ID: 29

$\mathrm{N}^{\circ}$ de plantas sobre rasante: 2

Dirección: C/Núñez Arce,

Tipología edificatoria:

U. Man:

RC: $\searrow$

Otras:

\section{CONFIGURACIÓN URBANÍSTICA Y ARQUITECTÓNICA}

Irregularidad en planta:

Sí:

No:

Irregularidad en altura:

Sí:

No:

Junta sísmica entre edificios:

Sí:

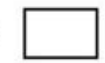

No:

Relación con edificios adyacentes: Mismo nivel

Dif. nivel:

$\square \square \square \square$

Posición del edif. en la manzana: Aislado:


Intermedio:

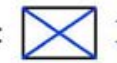
Esquina: अㅁ वप्त Planta blanda:
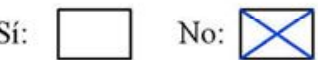

Columna corta: Sí: Terminal:

Relieve:

Llano:

Pendiente:

Notas:

\section{EVALUACIÓN DEL GRADO DE DAÑO MEDIO $\mu D$}

$\mu D=1$

- Fisuras en elementos no estructurales. Severidad leve
(ancho $>2 \mathrm{~mm}$ en menos del $20 \%$ de los elem. dañados).
$\bigotimes$ Cubierta $\bigotimes$ Cerramientos $\bigotimes$ Particiones interiores
- Sin daño en los elementos estructurales.

$\mu D=2$

- Fisuras en elementos no estructurales. Severidad moderada (ancho $>2 \mathrm{~mm}$ en más del $60 \%$ de los elem. dañados).

$\square$ Cubierta $\square$ Cerramientos $\square$ Particiones interiores

- Fisuras leves en elementos estructurales (tipo 1,2,3), con ancho $<2 \mathrm{~mm}$, en menos del $40 \%$ de los elem. dañados.

Notas:

Daños leves en cerramientos y cubierta $\mu D=3$

- Fisuras en elementos no estructurales. Severidad moderad (ancho $>2 \mathrm{~mm}$ en más del $60 \%$ de los elem. dañados).

$\square$ Cubierta $\square$ Cerramientos $\square$ Particiones interiores

- Fisuras leves en elementos estructurales (tipo 1, 2, 3), con ancho $<2 \mathrm{~mm}$, en más del $40 \%$ de los elem. dañados.

- Fisuras moderadas en elementos estructurales (tipo 1, 2, 3) con ancho $>2 \mathrm{~mm}$, en más del $20 \%$ de los elem. dañados

- Pérdida de recubrimiento y pandeo de las armacuras

$\mu D=4 \square$

- Colapso general $\square$ - Asiento de la cimentación $\square$

局近 所

Figura A.1. Ejemplo A. Ficha empleada en la campaña de recopilación de datos para la evaluación del índice de vulnerabilidad y el correspondiente grado de daño de cada edificación. 


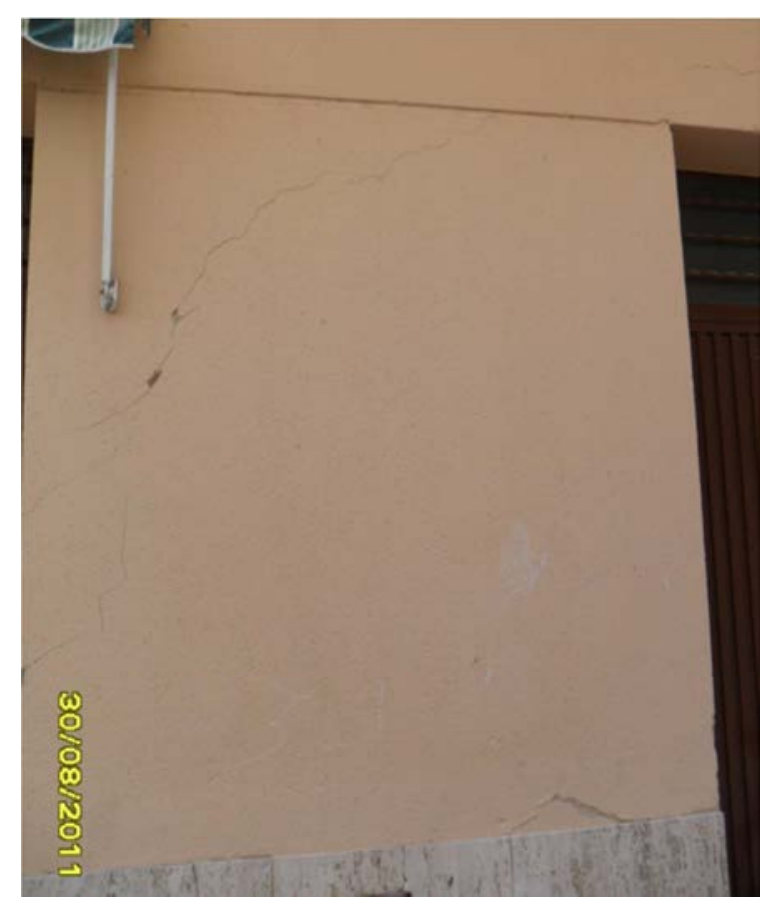

(a)

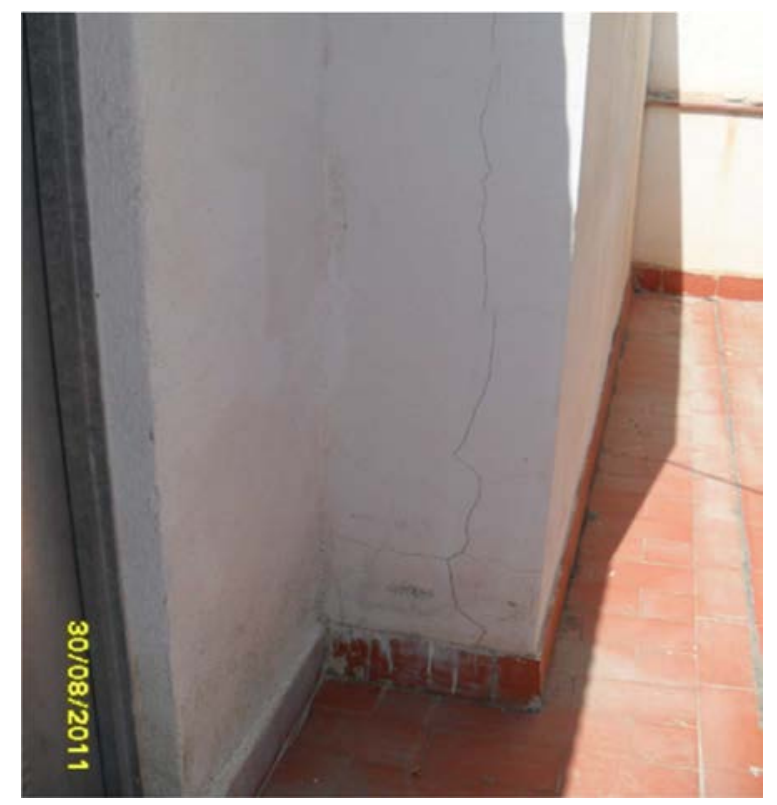

(c)

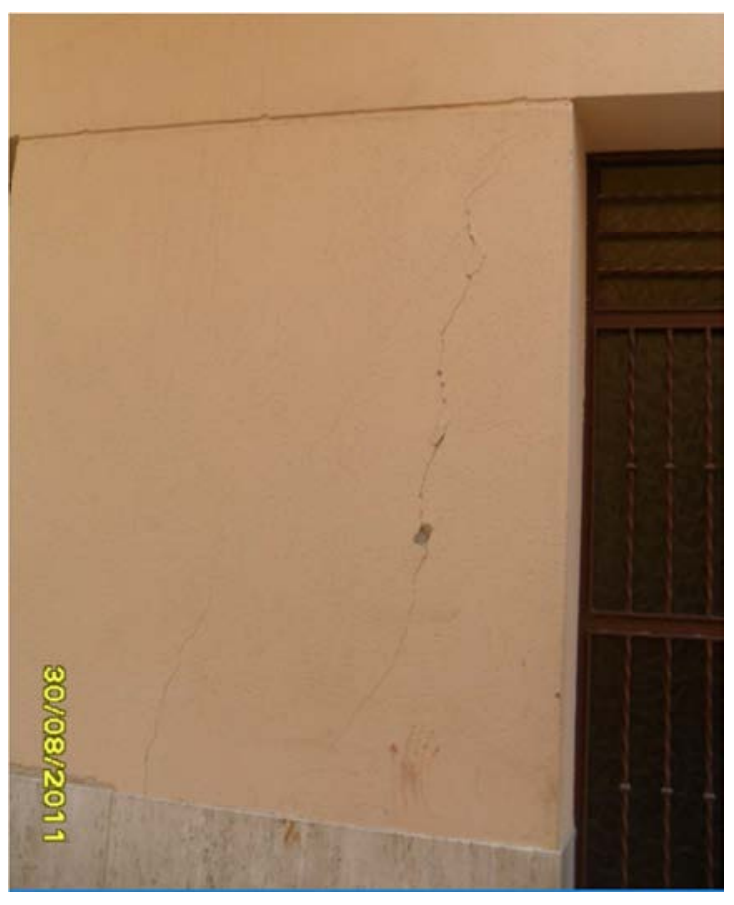

(b)

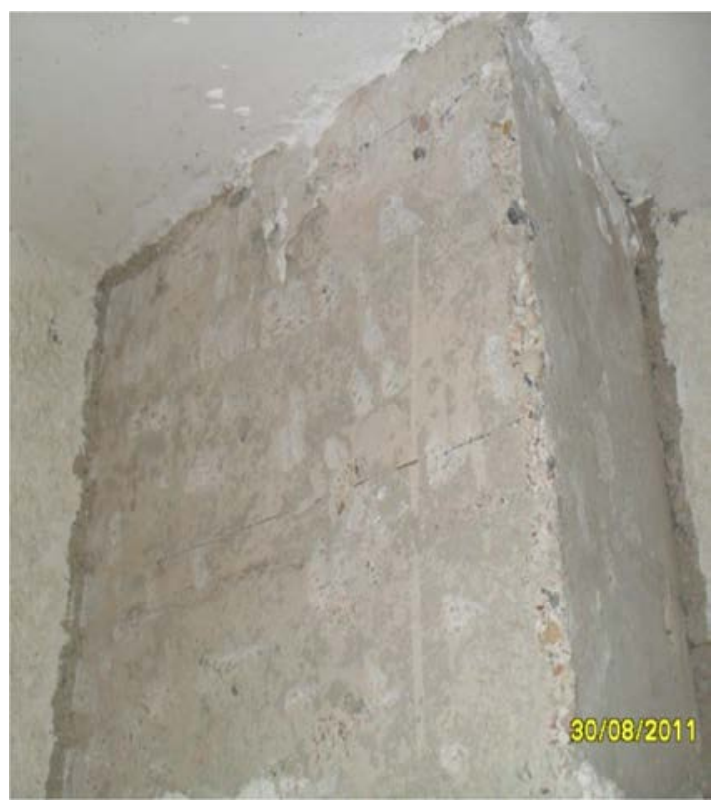

(d)

Figura A.2. Ejemplo A. Afecciones observadas en la edificación tras el sismo de Lorca. (a) y (b) Daños en cerramiento de fachada. (c) Daños en cubierta. (d) Inexistencia de daños en pilares de planta baja. 


\section{DAÑOS EN EDIFICACIONES. SISMO DE LORCA 2011}

\section{DATOS GENERALES DE LA EDIFICACIÓN}

ID: 330

$\mathrm{N}^{\circ}$ de plantas sobre rasante: 4

Dirección: C/Álamo,

Tipología edificatoria:

U. Man.

RC:

Otras:

\section{CONFIGURACIÓN URBANISTICA Y ARQUITECTÓNICA}

Irregularidad en planta:

Sí:

No:

Irregularidad en altura:

Sí:

No:

Junta sísmica entre edificios:

Sí:

No:

Relación con edificios adyacentes: Mismo nivel

Dif. nivel:

口叶

Posición del edif. en la manzana: Aislado:

$\square$ Intermedio:

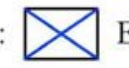
Esquina: 내 $\square$ त्त Planta blanda:
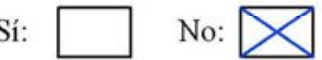

Columna corta: Sí: Terminal:

Relieve:

Llano:

Pendiente:

Notas:

\section{EVALUACIÓN DEL GRADO DE DAÑO MEDIO $\mu D$}

$$
\mu D=1
$$

- Fisuras en elementos no estructurales. Severidad leve (ancho $>2 \mathrm{~mm}$ en menos del $20 \%$ de los elem. dañados). $\bigotimes$ Cubierta $\bigotimes$ Cerramientos $\bigotimes$ Particiones interiores - Sin daño en los elementos estructurales.

$\mu D=2$

- Fisuras en elementos no estructurales. Severidad moderada (ancho $>2 \mathrm{~mm}$ en más del $60 \%$ de los elem. dañados).

$\square$ Cubierta $\square$ Cerramientos $\square$ Particiones interiores

- Fisuras leves en elementos estructurales (tipo 1, 2,3), con ancho $<2 \mathrm{~mm}$, en menos del $40 \%$ de los elem. dañados.

Notas:

Efecto golpeteo con edificio adyacente. Daños leves en fachada, cubierta y tabiquería interior $\mu D=3$

- Fisuras en elementos no estructurales. Severidad moderad (ancho $>2 \mathrm{~mm}$ en más del $60 \%$ de los elem. dañados).

$\square$ Cubierta $\square$ Cerramientos $\square$ Particiones interiores

- Fisuras leves en elementos estructurales (tipo 1, 2, 3), con ancho $<2 \mathrm{~mm}$, en más del $40 \%$ de los elem. dañados.

- Fisuras moderadas en elementos estructurales (tipo 1,2,3) con ancho $>2 \mathrm{~mm}$, en más del $20 \%$ de los elem. dañados.

- Pérdida de recubrimiento y pandeo de las armaduras.

$\mu D=4 \square$

- Colapso general $\square \quad$ - Asiento de la cimentación $\square$



Figura A.3. Ejemplo B. Ficha empleada en la campaña de recopilación de datos para la evaluación del índice de vulnerabilidad y el correspondiente grado de daño de cada edificación. 


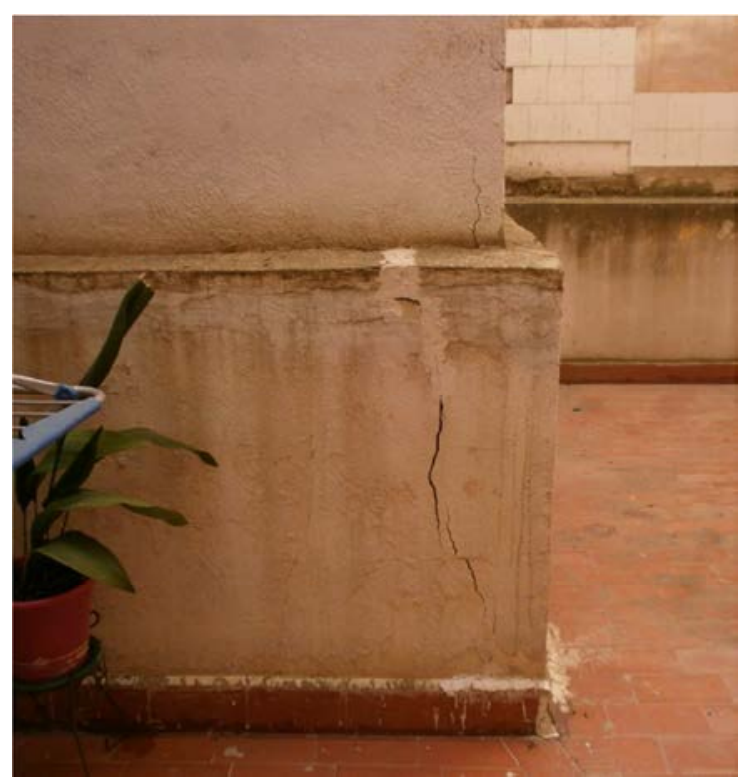

(a)

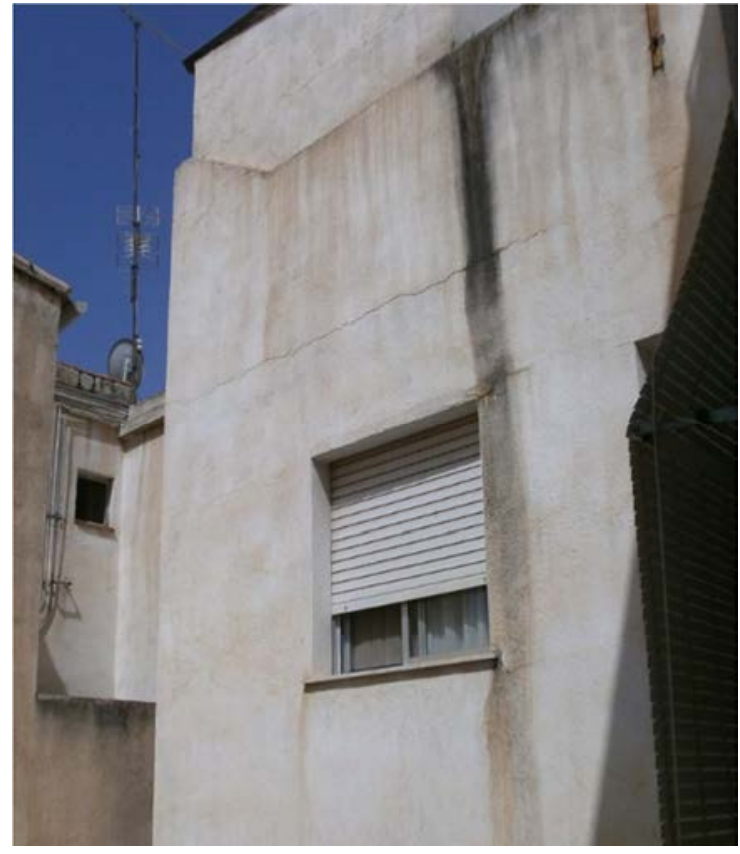

(c)

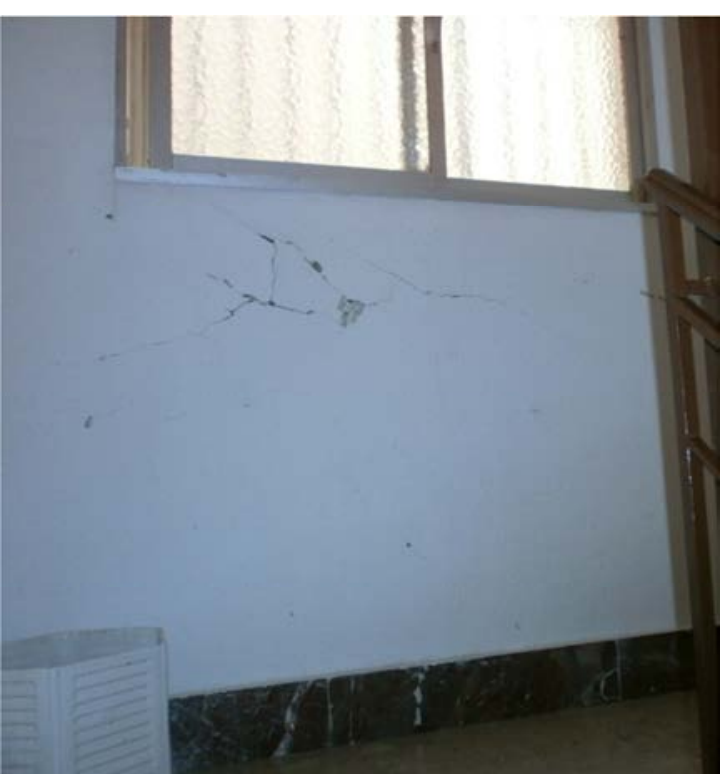

(b)

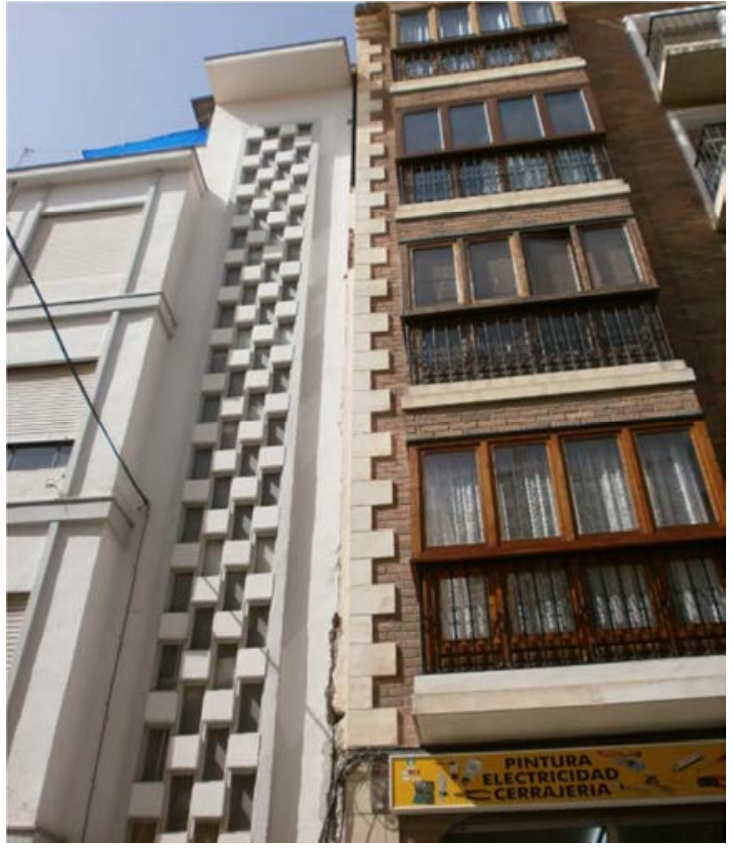

(d)

Figura A.4. Ejemplo B. Afecciones observadas en la edificación tras el sismo de Lorca. Daños en: (a) Cubierta. (b) Tabiquería interior. (c) Cerramiento. (d) Fachada, por efecto golpeteo. 


\section{DAÑOS EN EDIFICACIONES. SISMO DE LORCA 2011}

\section{DATOS GENERALES DE LA EDIFICACIÓN}

ID: 337

$\mathrm{N}^{\circ}$ de plantas sobre rasante: 4

Dirección: $\mathrm{C} /$ Huércal Overa,

Tipología edificatoria:

U. Man:

RC: $\square$

Otras:

\section{CONFIGURACIÓN URBANISTICA Y ARQUITECTÓNICA}

Irregularidad en planta:

Sí:

No:

Irregularidad en altura:

Sí:

No:

Junta sísmica entre edificios:

Sí:

$-\quad$ No:

Relación con edificios adyacentes: Mismo nivel

Dif. nivel:

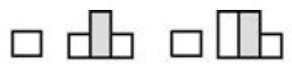

Posición del edif. en la manzana: Aislado:

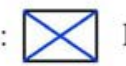
Intermedio:

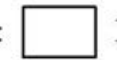
Esquina:

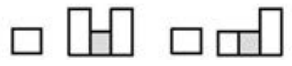
Planta blanda:
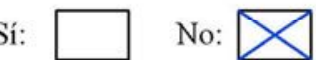

Columna corta: Sí: Terminal:

Relieve:

Llano:

Pendiente:

Notas:

Bloque aislado

EVALUACIÓN DEL GRADO DE DAÑO MEDIO $\mu D$

$\mu D=1$

- Fisuras en elementos no estructurales. Severidad leve
(ancho $>2$ mm en menos del $20 \%$ de los elem. dañados).
$\bigotimes$ Cubierta $\bigotimes$ Cerramientos $\bigotimes$ Particiones interiores
- Sin daño en los elementos estructurales.

$\mu D=2$

- Fisuras en elementos no estructurales. Severidad moderad (ancho $>2 \mathrm{~mm}$ en más del $60 \%$ de los elem. dañados).

$\square$ Cubierta $\square$ Cerramientos $\square$ Particiones interiores

- Fisuras leves en elementos estructurales (tipo 1, 2,3), con ancho $<2 \mathrm{~mm}$, en menos del $40 \%$ de los elem. dañados.

\footnotetext{
Notas:

Daños leves en fachada, cubierta y tabiquería interior
}

$\mu D=3$

- Fisuras en elementos no estructurales. Severidad moderad (ancho $>2 \mathrm{~mm}$ en más del $60 \%$ de los elem. dañados).

$\square$ Cubierta $\square$ Cerramientos $\square$ Particiones interiores

- Fisuras leves en elementos estructurales (tipo 1,2,3), con ancho $<2 \mathrm{~mm}$, en más del $40 \%$ de los elem. dañados.

- Fisuras moderadas en elementos estructurales (tipo 1, 2,3) con ancho $>2 \mathrm{~mm}$, en más del $20 \%$ de los elem. dañados

- Pérdida de recubrimiento y pandeo de las armaduras.

$\mu D=4 \square$

- Colapso general $\square \quad$ - Asiento de la cimentación $\square$

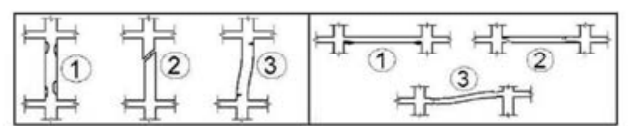

Figura A.5. Ejemplo C. Ficha empleada en la campaña de recopilación de datos para la evaluación del índice de vulnerabilidad y el correspondiente grado de daño de cada edificación. 


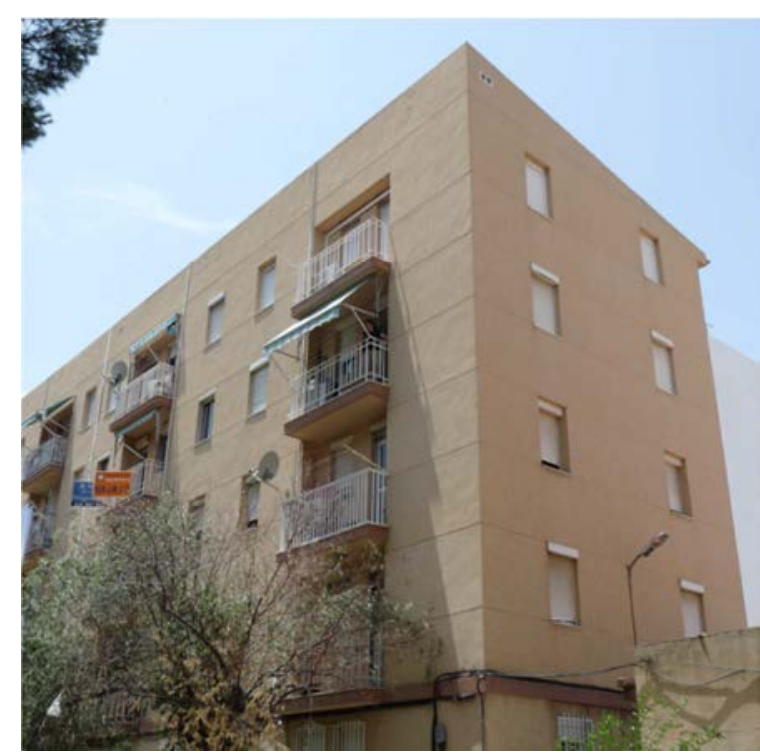

(a)

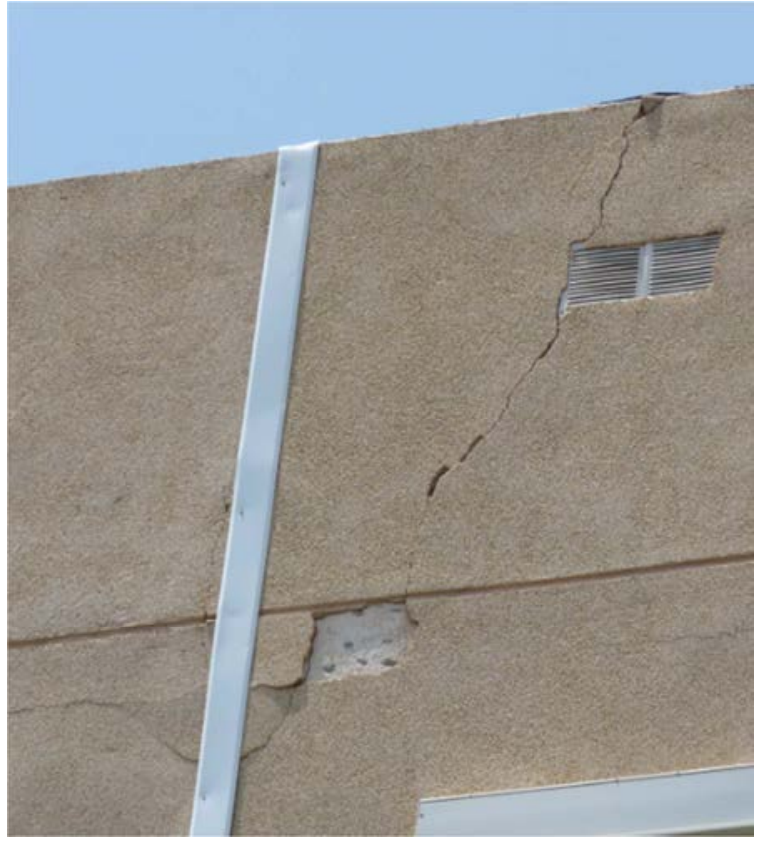

(c)

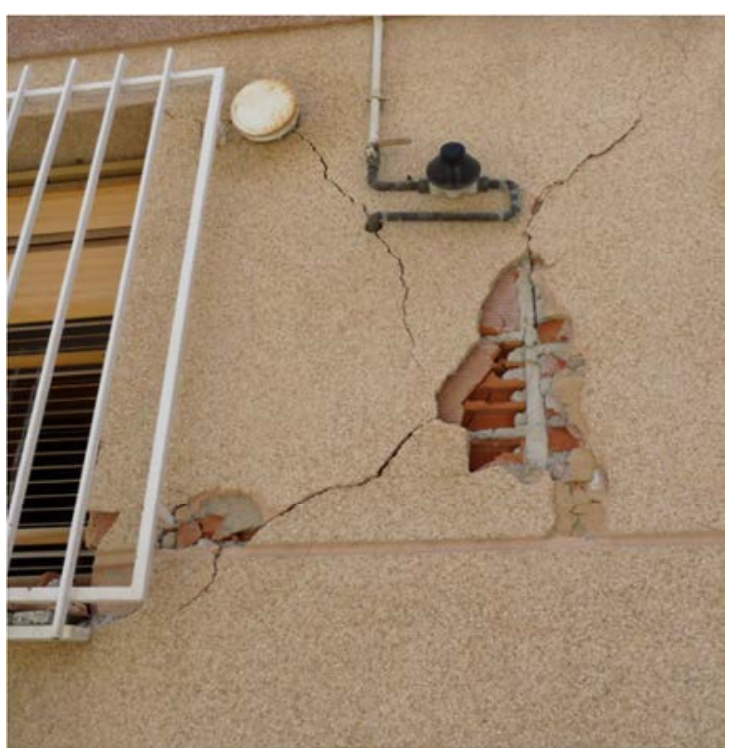

(b)

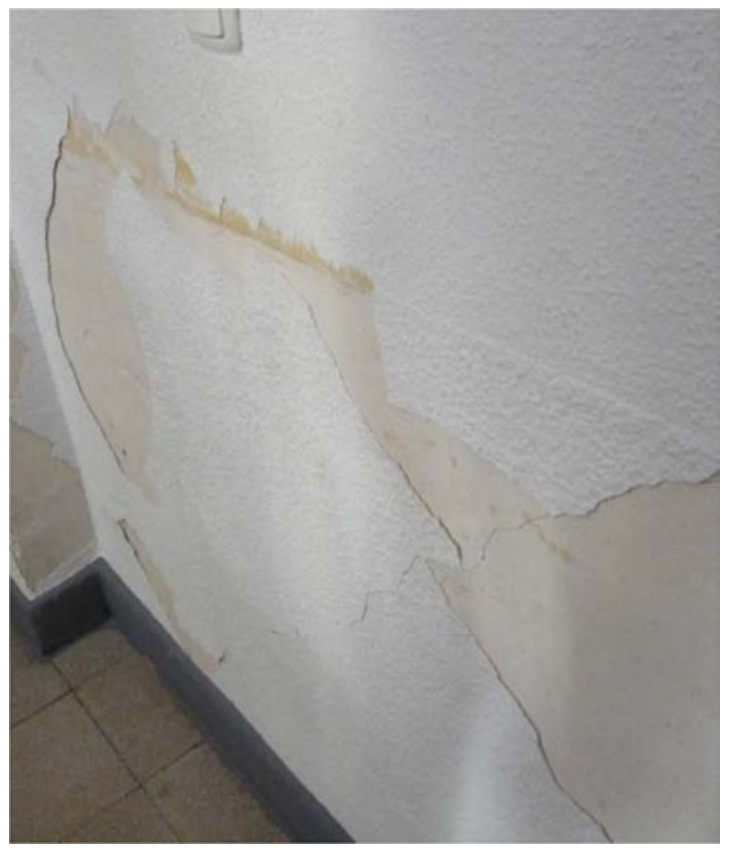

(d)

Figura A.6. Ejemplo C. Afecciones observadas en la edificación tras el sismo de Lorca. (a) Vista general del edificio. (b) Daños en cerramiento de fachada. (c) Daños en antepecho de cubierta. (d) Daños en tabiquería interior. 


\section{DAÑOS EN EDIFICACIONES. SISMO DE LORCA 2011}

\section{DATOS GENERALES DE LA EDIFICACIÓN}

ID: 399

$\mathrm{N}^{\circ}$ de plantas sobre rasante: 4

Dirección: C/Príncipe Alfonso,

Tipología edificatoria:

U. Man :

RC: $\searrow$

Otras:

\section{CONFIGURACIÓN URBANISTICA Y ARQUITECTÓNICA}

Irregularidad en planta:

Sí:

No:

Irregularidad en altura:

Sí:

No:

Junta sísmica entre edificios:

Sí:

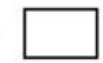

No:

Relación con edificios adyacentes: Mismo nivel:

Dif. nivel:

ब त्

Posición del edif. en la manzana: Aislado:

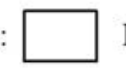
Intermedio:

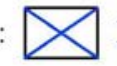
Esquina:

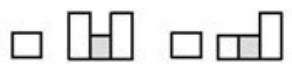
Planta blanda:
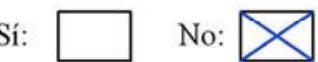

Columna corta: Sí: Terminal:

Relieve:

Llano:

Pendiente: Notas:

\section{EVALUACIÓN DEL GRADO DE DAÑO MEDIO $\mu D$}

$$
\mu D=1
$$

- Fisuras en elementos no estructurales. Severidad leve (ancho $>2 \mathrm{~mm}$ en menos del $20 \%$ de los elem. dañados). $\bigotimes$ Cubierta $\square$ Cerramientos $\square$ Particiones interiores - Sin daño en los elementos estructurales.

$$
\mu D=2
$$

- Fisuras en elementos no estructurales. Severidad moderad (ancho $>2 \mathrm{~mm}$ en más del $60 \%$ de los elem. dañados).

$\square$ Cubierta $\square$ Cerramientos $\square$ Particiones interiores

- Fisuras leves en elementos estructurales (tipo 1, 2, 3), con ancho $<2 \mathrm{~mm}$, en menos del $40 \%$ de los elem. dañados.

\section{Notas:}

Daños leves en tabiquería interior y cubierta $\mu D=3$

- Fisuras en elementos no estructurales. Severidad moderad (ancho $>2 \mathrm{~mm}$ en más del $60 \%$ de los elem. dañados).

$\square$ Cubierta $\square$ Cerramientos $\square$ Particiones interiores

- Fisuras leves en elementos estructurales (tipo 1,2,3), con ancho $<2 \mathrm{~mm}$, en más del $40 \%$ de los elem. dañados.

- Fisuras moderadas en elementos estructurales (tipo 1, 2, 3) con ancho $>2 \mathrm{~mm}$, en más del $20 \%$ de los elem. dañados.

- Pérdida de recubrimiento y pandeo de las armacuras

$\mu D=4 \square$

- Colapso general $\square$ - Asiento de la cimentación $\square$



Figura A.7. Ejemplo D. Ficha empleada en la campaña de recopilación de datos para la evaluación del índice de vulnerabilidad y el correspondiente grado de daño de cada edificación. 


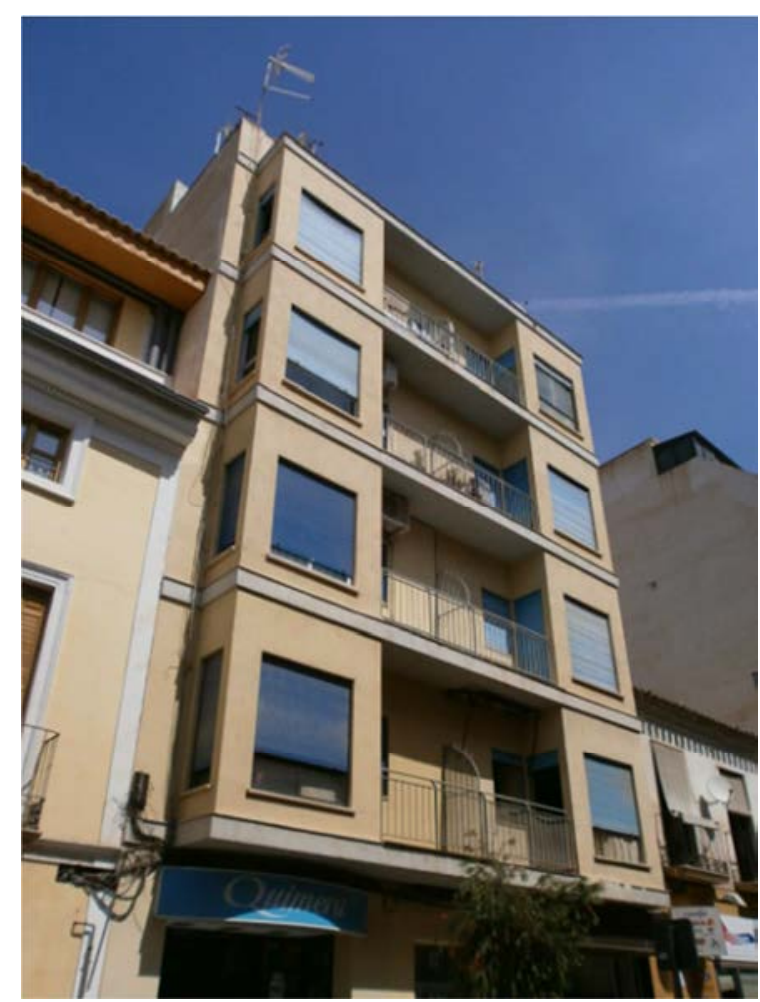

(a)

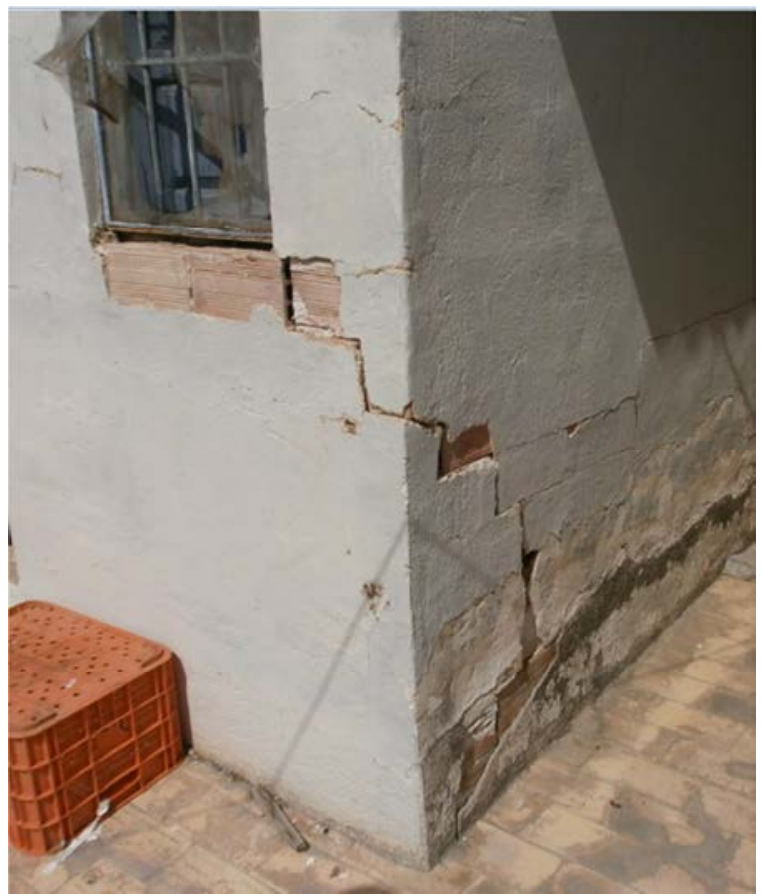

(c)



(b)

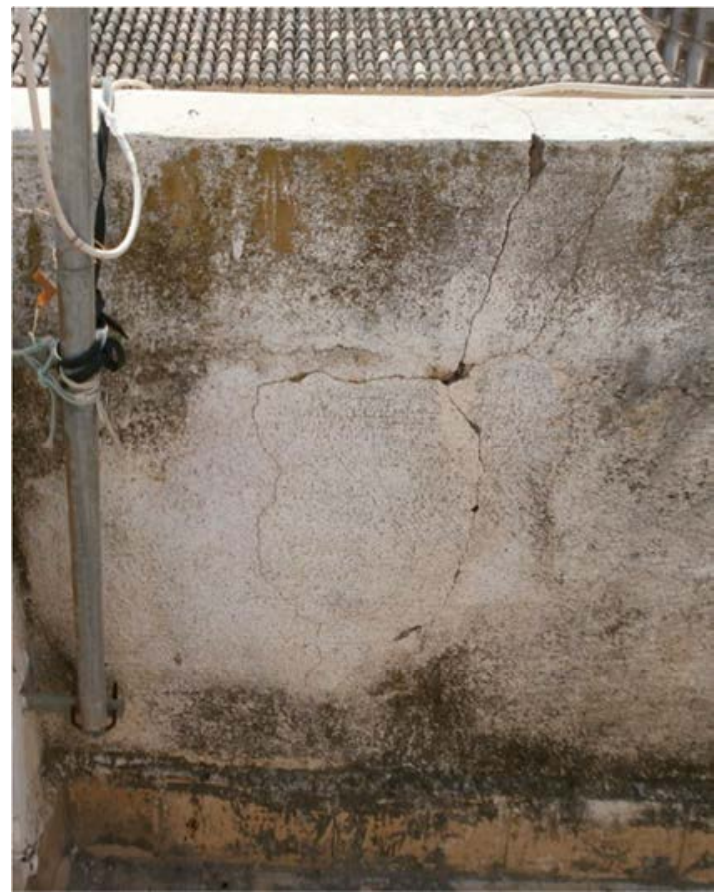

(d)

Figura A.8. Ejemplo D. Afecciones observadas en la edificación tras el sismo de Lorca. (a) Vista general del edificio. (b) Daños en tabiquería interior. (c) y (d) Daños en cubierta. 


\section{DAÑOS EN EDIFICACIONES. SISMO DE LORCA 2011}

\section{DATOS GENERALES DE LA EDIFICACIÓN}

ID: 41

$\mathrm{N}^{\circ}$ de plantas sobre rasante: 3

Dirección: C/Francisco Salzillo,

Tipología edificatoria:

U. Man:

RC: $\searrow$

Otras:

\section{CONFIGURACIÓN URBANISTICA Y ARQUITECTÓNICA}

Irregularidad en planta:

Sí:

No:

Irregularidad en altura:

Sí:

No:

Junta sísmica entre edificios:

Sí:

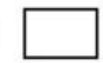

No:

Relación con edificios adyacentes: Mismo nivel

Dif. nivel:



Posición del edif. en la manzana: Aislado:

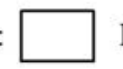
Intermedio:

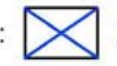
Esquina: 口매 Planta blanda:
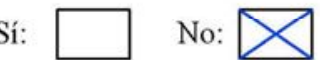

Columna corta: Sí: Terminal:

Relieve:

Llano:

Pendiente:

Notas:

\section{EVALUACIÓN DEL GRADO DE DAÑO MEDIO $\mu D$}

$$
\mu D=1
$$

- Fisuras en elementos no estructurales. Severidad leve (ancho $>2 \mathrm{~mm}$ en menos del $20 \%$ de los elem. dañados). $\square$ Cubierta $\square$ Cerramientos $\square$ Particiones interiores - Sin daño en los elementos estructurales.

$\mu D=2$

- Fisuras en elementos no estructurales. Severidad moderada (ancho > $2 \mathrm{~mm}$ en más del $60 \%$ de los elem. dañados).

$\bigotimes$ Cubierta $\square$ Cerramientos $\bigotimes$ Particiones interiores

- Fisuras leves en elementos estructurales (tipo 1, 2,3), con ancho $<2 \mathrm{~mm}$, en menos del $40 \%$ de los elem. dañados.

\footnotetext{
Notas:

Caída de antepecho de cubierta. Afecciones de carácter
} leve en pilares $\mu D=3$

- Fisuras en elementos no estructurales. Severidad moderad (ancho $>2 \mathrm{~mm}$ en más del $60 \%$ de los elem. dañados).

$\square$ Cubierta $\square$ Cerramientos $\square$ Particiones interiores

- Fisuras leves en elementos estructurales (tipo 1,2,3), con ancho $<2 \mathrm{~mm}$, en más del $40 \%$ de los elem. dañados.

- Fisuras moderadas en elementos estructurales (tipo 1, 2,3) con ancho $>2 \mathrm{~mm}$, en más del $20 \%$ de los elem. dañados

- Pérdida de recubrimiento y pandeo de las armaduras.

$\mu D=4$

- Colapso general $\square \quad$ - Asiento de la cimentación $\square$



Figura A.9. Ejemplo E. Ficha empleada en la campaña de recopilación de datos para la evaluación del índice de vulnerabilidad y el correspondiente grado de daño de cada edificación. 


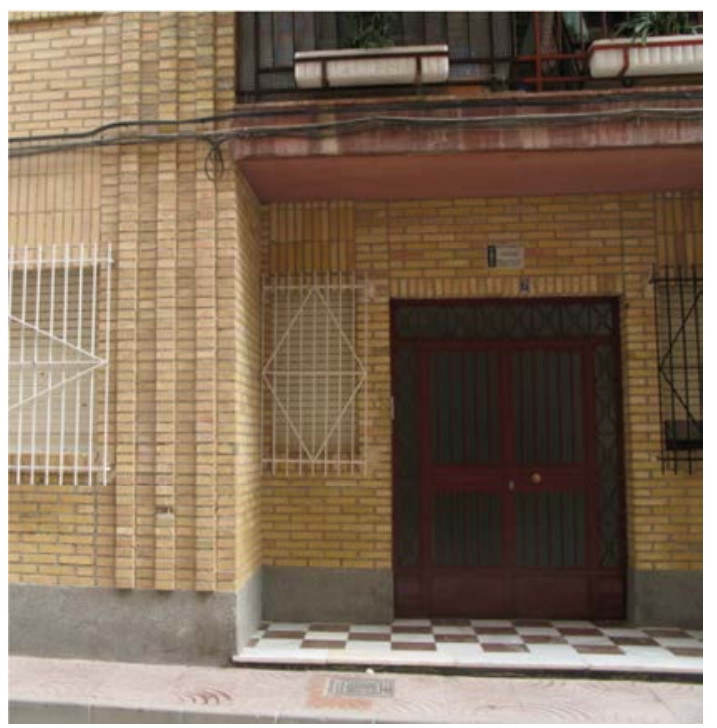

(a)

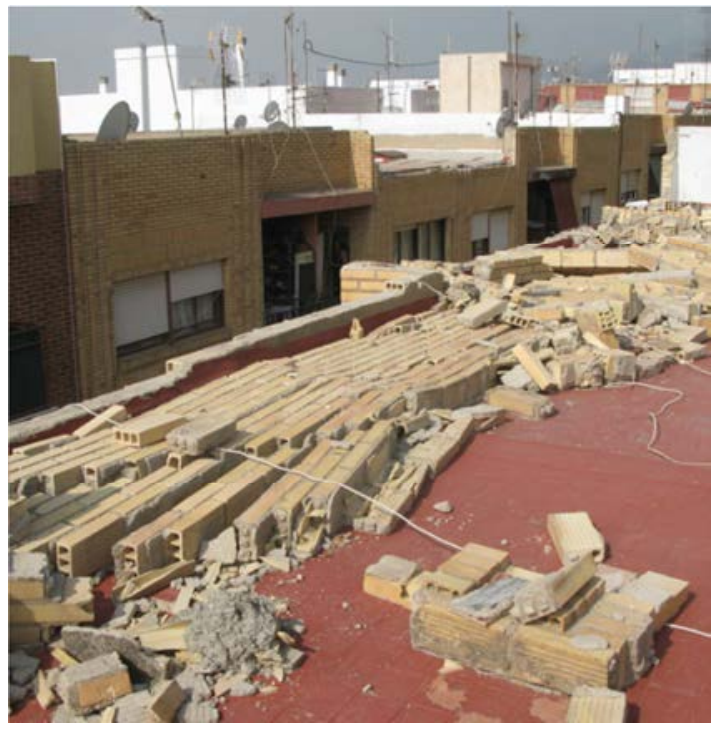

(c)

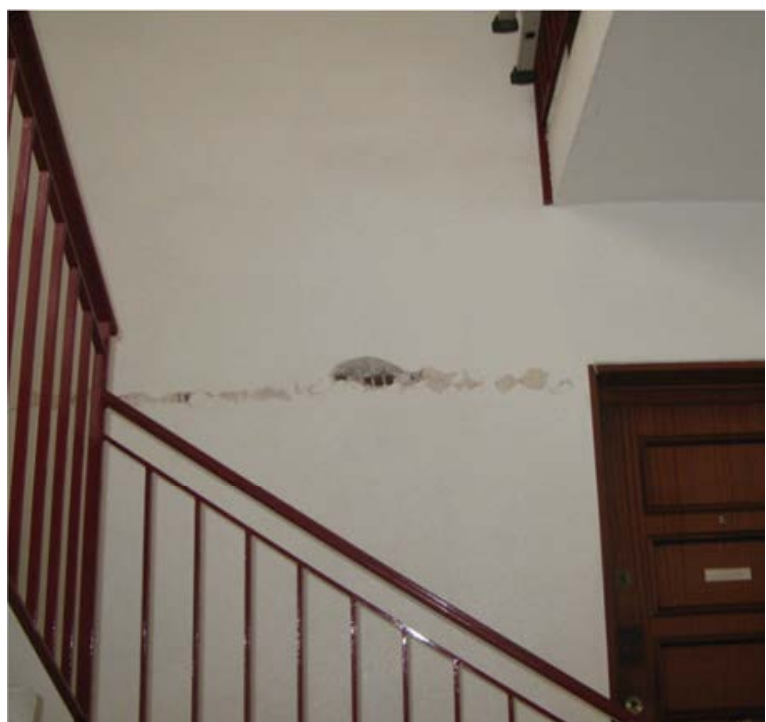

(b)



(d)

Figura A.10. Ejemplo E. Afecciones observadas en la edificación tras el sismo de Lorca. (a) Vista general del edificio. (b) Daños en tabiquería interior. (c) y (d) Daños en cubierta y caída de antepechos. 


\section{DAÑOS EN EDIFICACIONES. SISMO DE LORCA 2011}

\section{DATOS GENERALES DE LA EDIFICACIÓN}

ID: 110

$\mathrm{N}^{\circ}$ de plantas sobre rasante: 4

Dirección: Paseo de Guerra,

Tipología edificatoria:

U. Man:

RC: $\searrow$

Otras:

\section{CONFIGURACIÓN URBANISTICA Y ARQUITECTÓNICA}

$\begin{array}{lll}\text { Irregularidad en planta: } & \text { Sí: } \square \\ \text { Irregularidad en altura: } & \text { Sí: } \square \\ & \text { No: } \\ \text { Junta sísmica entre edificios: } & \text { Sí: } \square\end{array}$

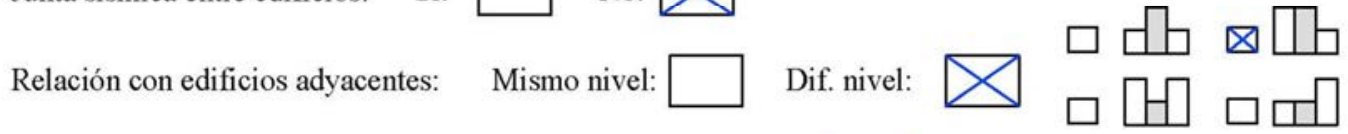
Posición del edif. en la manzana: Aislado: $\square$ Intermedio: $\square$ Esquina: $\square$ Terminal: $\square$
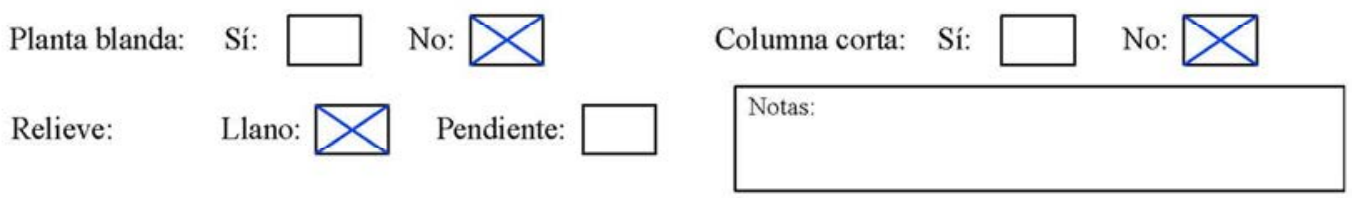

\section{EVALUACIÓN DEL GRADO DE DAÑO MEDIO $\mu \mathrm{D}$}

$$
\mu D=1
$$

- Fisuras en elementos no estructurales. Severidad leve (ancho $>2 \mathrm{~mm}$ en menos del $20 \%$ de los elem. dañados). $\square$ Cubierta $\square$ Cerramientos $\square$ Particiones interiores - Sin daño en los elementos estructurales.

$\mu D=2$

- Fisuras en elementos no estructurales. Severidad moderad (ancho $>2 \mathrm{~mm}$ en más del $60 \%$ de los elem. dañados).

$\bigotimes$ Cubierta $\square$ Cerramientos $\bigotimes$ Particiones interiores

- Fisuras leves en elementos estructurales (tipo 1, 2, 3), con ancho $<2 \mathrm{~mm}$, en menos del $40 \%$ de los elem. dañados.

Notas:

Efecto golpeteo con edificio adyacente. Fisuras de carácter leve en pilares $\mu D=3$

- Fisuras en elementos no estructurales. Severidad moderad (ancho $>2 \mathrm{~mm}$ en más del $60 \%$ de los elem. dañados).

$\square$ Cubierta $\square$ Cerramientos $\square$ Particiones interiores

- Fisuras leves en elementos estructurales (tipo 1, 2, 3), con ancho $<2 \mathrm{~mm}$, en más del $40 \%$ de los elem. dañados.

- Fisuras moderadas en elementos estructurales (tipo 1, 2,3) con ancho $>2 \mathrm{~mm}$, en más del $20 \%$ de los elem. dañados

- Pérdida de recubrimiento y pandeo de las armaduras.

$\mu D=4 \square$

- Colapso general $\square \quad$ - Asiento de la cimentación $\square$

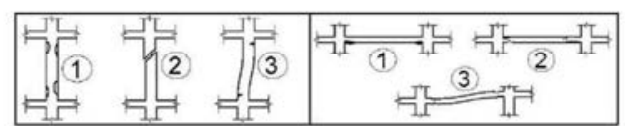

Figura A.11. Ejemplo F. Ficha empleada en la campaña de recopilación de datos para la evaluación del índice de vulnerabilidad y el correspondiente grado de daño de cada edificación. 


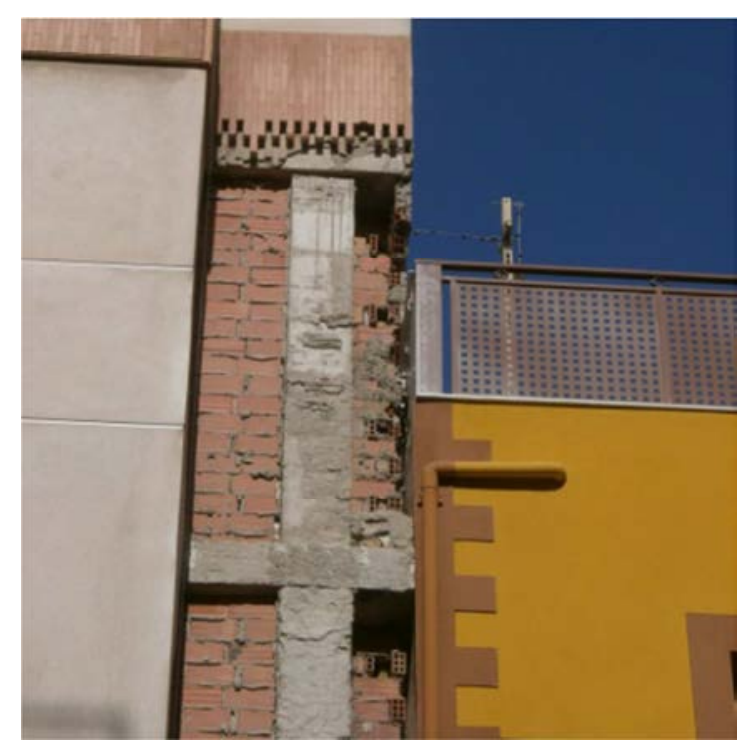

(a)



(c)

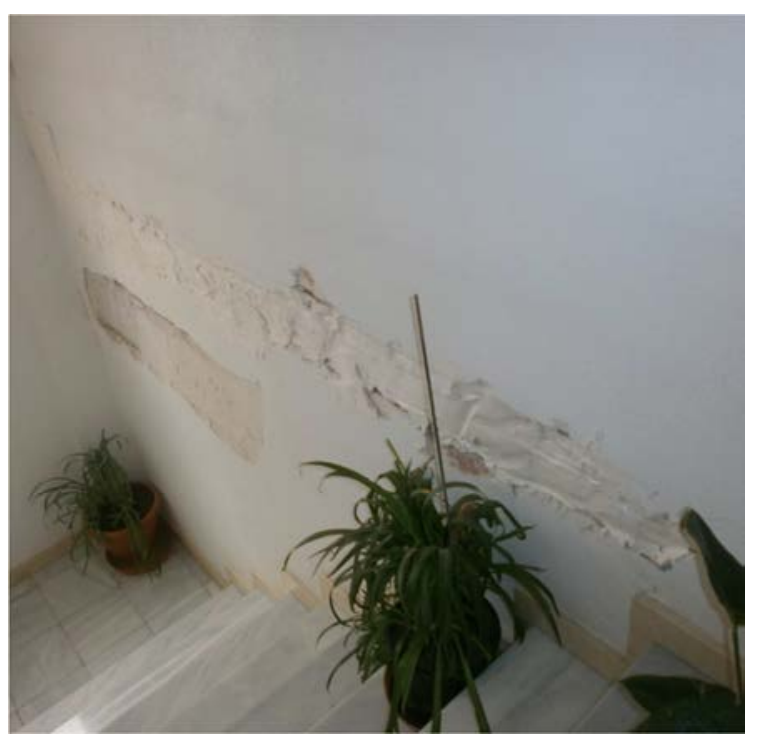

(b)

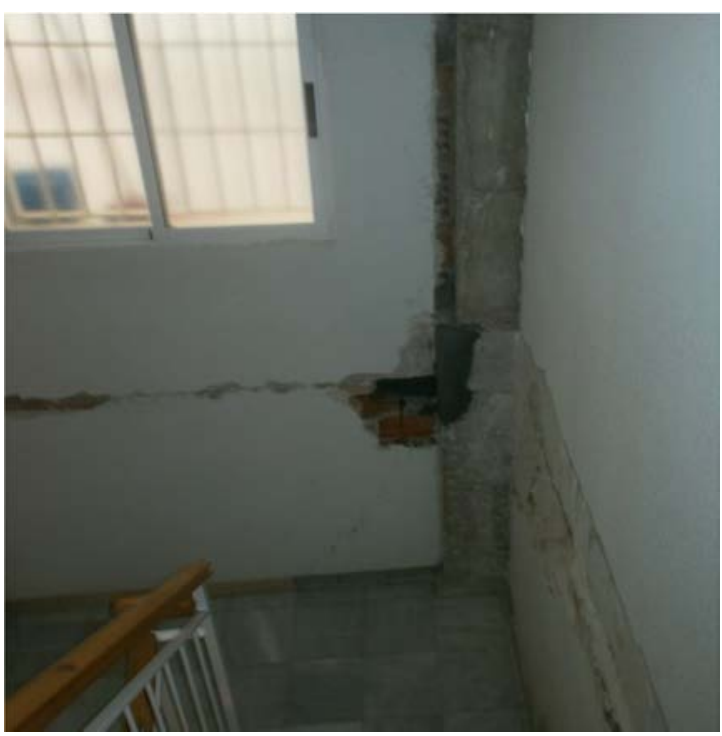

(d)

Figura A.12. Ejemplo F. Afecciones observadas en la edificación tras el sismo de Lorca. Daños en: (a) Fachada, por efecto golpeteo. (b) y (c) Tabiquería interior. (d) Tabiquería interior y pilares. 


\section{DAÑOS EN EDIFICACIONES. SISMO DE LORCA 2011}

\section{DATOS GENERALES DE LA EDIFICACIÓN}

ID: 191

$\mathrm{N}^{\circ}$ de plantas sobre rasante: 10

Dirección: C/Pintor Rebollo Zamora,

Tipología edificatoria:

U. Man:

RC: $\searrow$

Otras:

\section{CONFIGURACIÓN URBANISTICA Y ARQUITECTÓNICA}

Irregularidad en planta:

Sí:

No:

Irregularidad en altura:

Sí:

Junta sísmica entre edificios:

Sí:

$-\quad$ No:

Relación con edificios adyacentes: Mismo nivel

Dif. nivel:

Posición del edif. en la manzana: Aislado:

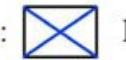
Intermedio:


Esquina: अㅁ वप्त Planta blanda:
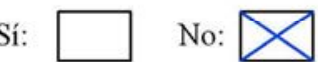

Columna corta: Sí: Terminal:

Relieve:

Llano:

Pendiente:

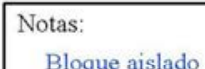

\section{EVALUACIÓN DEL GRADO DE DAÑO MEDIO $\mu D$}

$$
\mu D=1
$$

Fisuras en elementos no estructurales. Severidad leve (ancho $>2 \mathrm{~mm}$ en menos del $20 \%$ de los elem. dañados). $\square$ Cubierta $\square$ Cerramientos $\square$ Particiones interiores - Sin daño en los elementos estructurales.

$\mu D=2$

- Fisuras en elementos no estructurales. Severidad moderada (ancho > $2 \mathrm{~mm}$ en más del $60 \%$ de los elem. dañados).

$\bigotimes$ Cubierta $\square$ Cerramientos $\bigotimes$ Particiones interiores

- Fisuras leves en elementos estructurales (tipo 1,2,3), con ancho $<2 \mathrm{~mm}$, en menos del $40 \%$ de los elem. dañados.

\footnotetext{
Notas:

Daños en tabiquería interior generalizados, disminuyendo
} con la altura. Afecciones varias en zunchos de borde $\mu D=3$

- Fisuras en elementos no estructurales. Severidad moderad (ancho $>2 \mathrm{~mm}$ en más del $60 \%$ de los elem. dañados).

$\square$ Cubierta $\square$ Cerramientos $\square$ Particiones interiores - Fisuras leves en elementos estructurales (tipo 1, 2, 3), con ancho $<2 \mathrm{~mm}$, en más del $40 \%$ de los elem. dañados.

- Fisuras moderadas en elementos estructurales (tipo 1, 2,3) con ancho $>2 \mathrm{~mm}$, en más del $20 \%$ de los elem. dañados

- Pérdida de recubrimiento y pandeo de las armaduras.

$\mu D=4$

- Colapso general $\square$ - Asiento de la cimentación $\square$

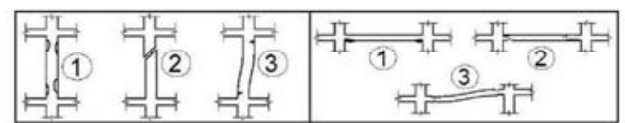

Figura A.13. Ejemplo G. Ficha empleada en la campaña de recopilación de datos para la evaluación del índice de vulnerabilidad y el correspondiente grado de daño de cada edificación. 




(a)

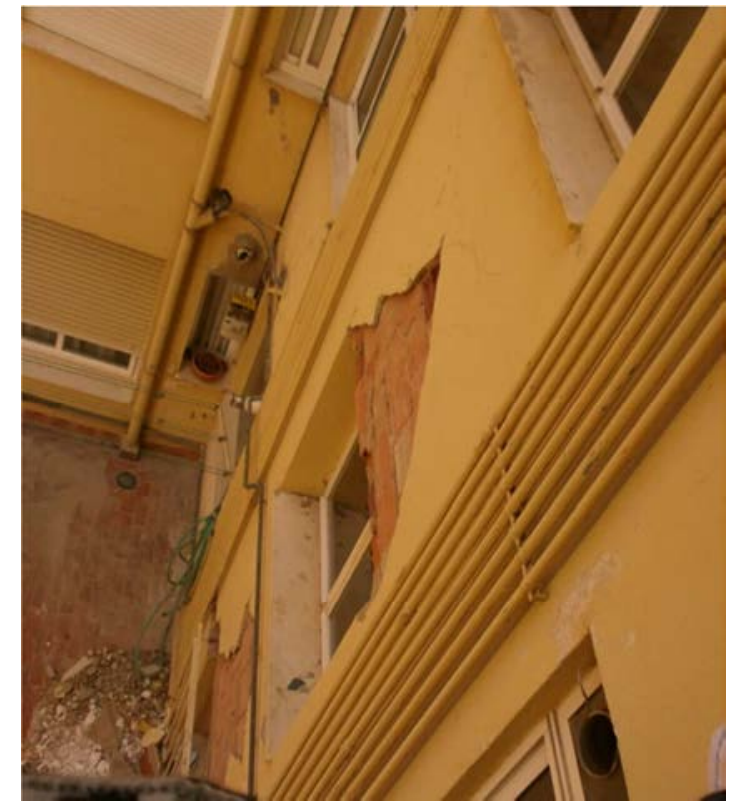

(c)

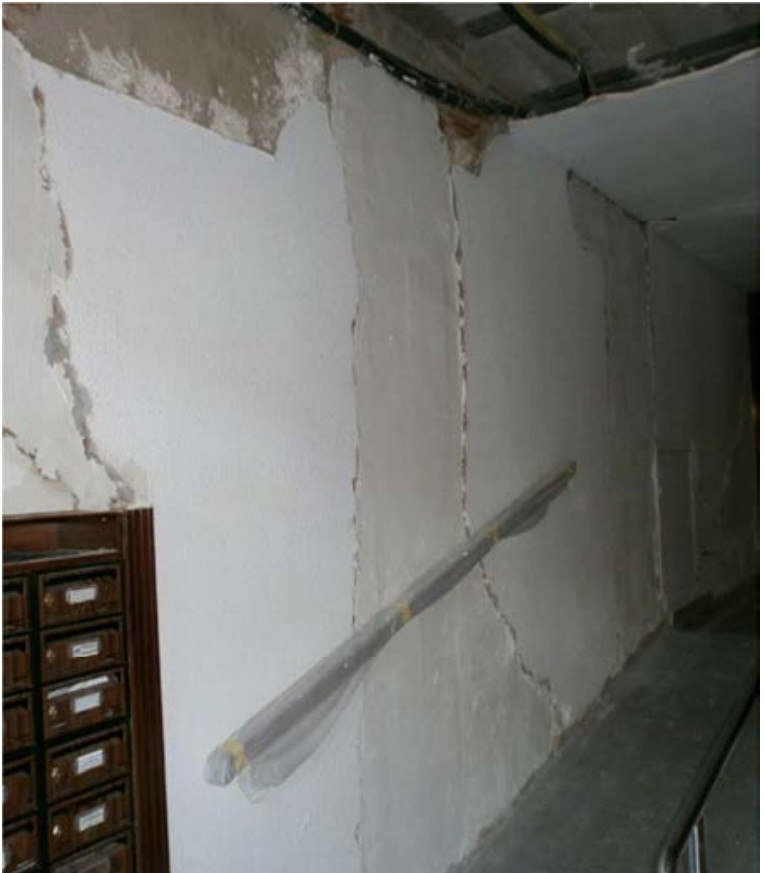

(b)

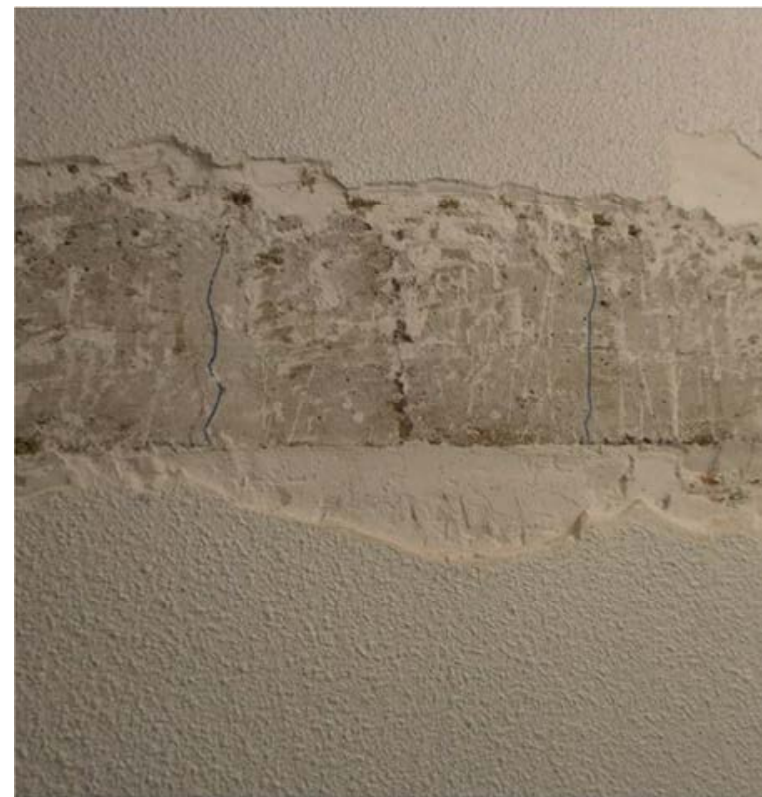

(d)

Figura A.14. Ejemplo G. Afecciones observadas en la edificación tras el sismo de Lorca. Daños en: (a) y (b) Tabiquería interior. (c) Cerramiento. (d) Vigas en zunchos de borde. 


\section{DAÑOS EN EDIFICACIONES. SISMO DE LORCA 2011}

\section{DATOS GENERALES DE LA EDIFICACIÓN}

ID: 207

$\mathrm{N}^{\circ}$ de plantas sobre rasante: 3

Dirección: C/Murillo,

Tipología edificatoria:

U. Man:

$\mathrm{RC}: \searrow$

Otras:

\section{CONFIGURACIÓN URBANÍSTICA Y ARQUITECTÓNICA}

$\begin{array}{lll}\text { Irregularidad en planta: } & \text { Sí: } \square \\ \text { Irregularidad en altura: } & \text { Sí: } \square \\ & \text { No: } \\ \text { Junta sísmica entre edificios: } & \text { Sí: } \square\end{array}$

Relación con edificios adyacentes: Mismo nivel:

Dif. nivel:

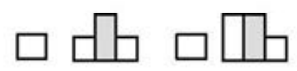

Posición del edif. en la manzana: Aislado:

Esquina: $\$ Terminal:

Planta blanda:
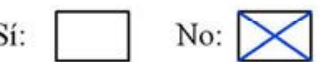

Columna corta: Sí:

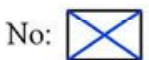

Relieve:

Llano:

Pendiente:

Notas:

\section{EVALUACIÓN DEL GRADO DE DAÑO MEDIO $\mu D$}

$$
\mu D=1
$$

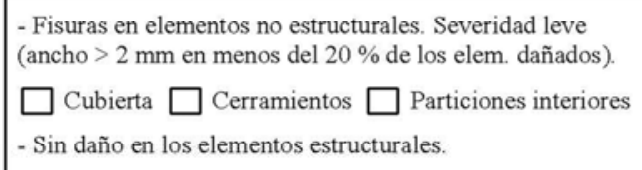

- Fisuras en elementos no estructurales. Severidad leve (ancho $>2 \mathrm{~mm}$ en menos del $20 \%$ de los elem. dañados). $\square$ Cubierta $\square$ Cerramientos $\square$ Particiones interiores - Sin daño en los elementos estructurales. $\mu D=2$

- Fisuras en elementos no estructurales. Severidad moderad (ancho $>2 \mathrm{~mm}$ en más del $60 \%$ de los elem. dañados).

$\bigotimes$ Cubierta $\square$ Cerramientos $\square$ Particiones interiores

- Fisuras leves en elementos estructurales (tipo 1, 2, 3), con ancho $<2 \mathrm{~mm}$, en menos del $40 \%$ de los elem. dañados.

\footnotetext{
Notas:

Daños en nudo viga-pilar de carácter leve. Daños generalizados en elementos no estructurales.
}

$\mu D=3$

- Fisuras en elementos no estructurales. Severidad moderad (ancho $>2 \mathrm{~mm}$ en más del $60 \%$ de los elem. dañados).

$\square$ Cubierta $\square$ Cerramientos $\square$ Particiones interiores - Fisuras leves en elementos estructurales (tipo 1, 2, 3), con ancho $<2 \mathrm{~mm}$, en más del $40 \%$ de los elem. dañados.

- Fisuras moderadas en elementos estructurales (tipo 1, 2,3) con ancho $>2 \mathrm{~mm}$, en más del $20 \%$ de los elem. dañados.

- Pérdida de recubrimiento y pandeo de las armaduras.

$\mu D=4 \square$

- Colapso general $\square \quad$ - Asiento de la cimentación $\square$

\begin{tabular}{|c|c|c|c|}
\hline $\int_{1}^{1}$ & $\sqrt{1}$ & $\sqrt{3}$ & (1) \\
\hline
\end{tabular}

Figura A.15. Ejemplo H. Ficha empleada en la campaña de recopilación de datos para la evaluación del índice de vulnerabilidad y el correspondiente grado de daño de cada edificación. 


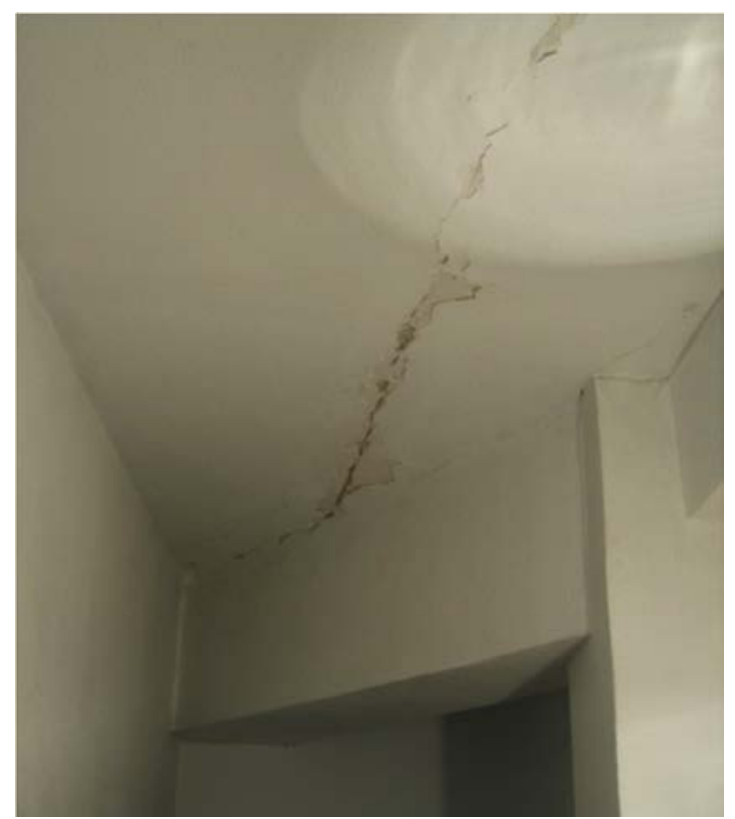

(a)

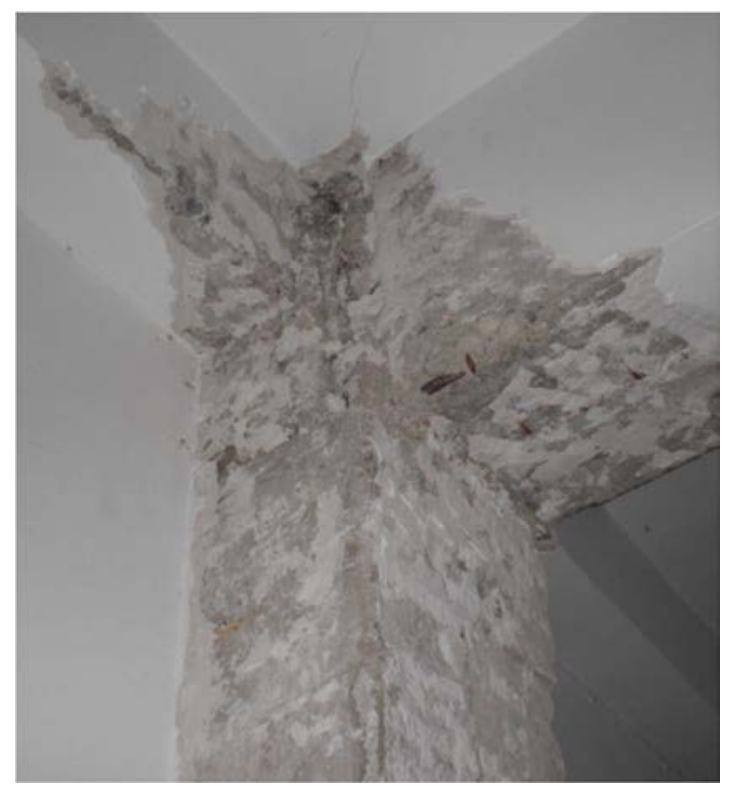

(c)

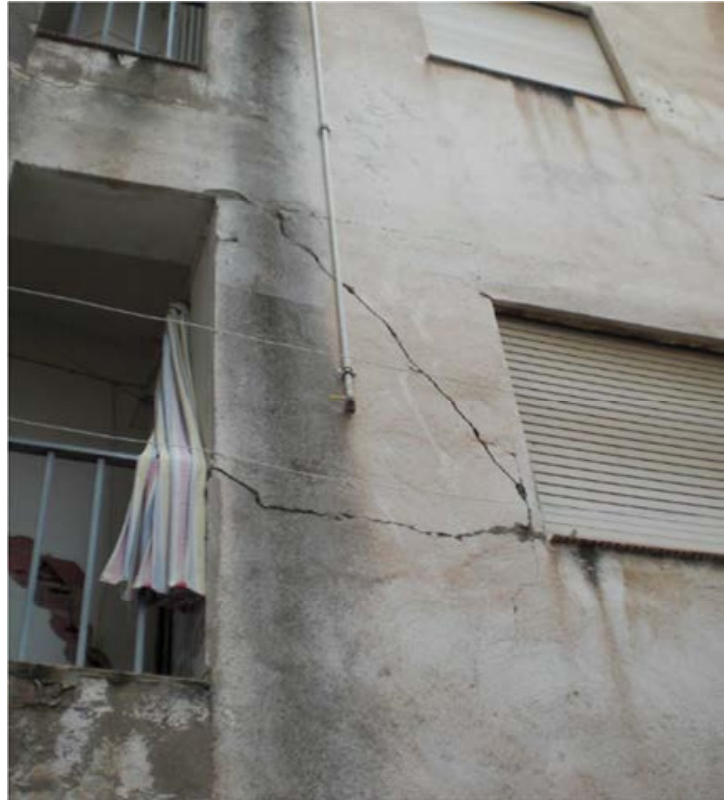

(b)

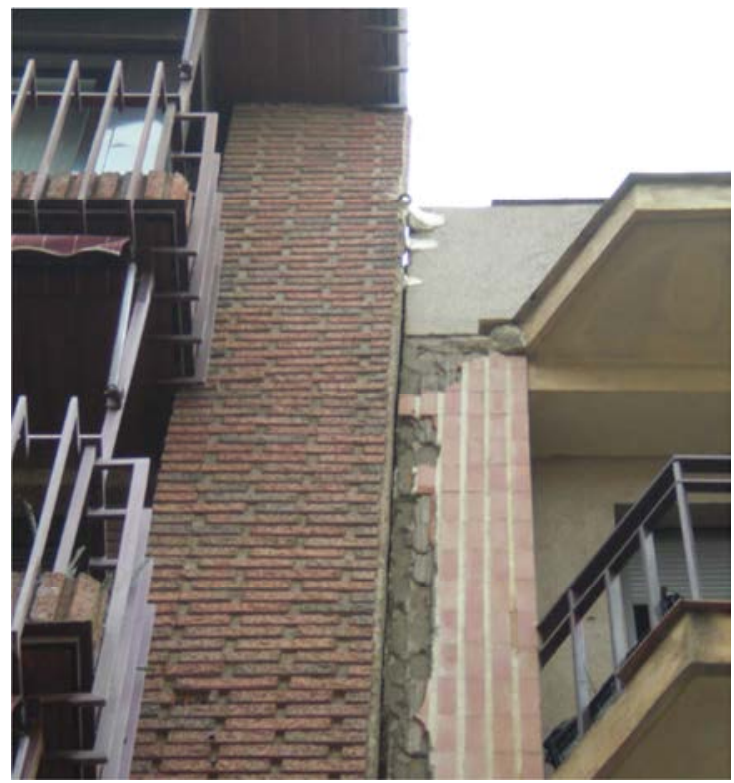

(d)

Figura A.16. Ejemplo H. Afecciones observadas en la edificación tras el sismo de Lorca. Daños en: (a) Tabiquería interior. (b) Cerramiento. (c) Nudo viga-pilar con desprendimiento del recubrimiento de hormigón. (d) Fachada, por efecto golpeteo. 


\section{DAÑOS EN EDIFICACIONES. SISMO DE LORCA 2011}

\section{DATOS GENERALES DE LA EDIFICACIÓN}

ID: 34

$\mathrm{N}^{\circ}$ de plantas sobre rasante: 3

Dirección: $\mathrm{C} /$ Jardineros.

Tipología edificatoria:

U. Man:

RC: $\searrow$

Otras:

\section{CONFIGURACIÓN URBANISTICA Y ARQUITECTÓNICA}

Irregularidad en planta:

Sí:

No:

Irregularidad en altura:

Sí:

Junta sísmica entre edificios:

Sí:

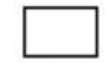

No:

Relación con edificios adyacentes:

Mismo nivel:

Dif. nivel:

Posición del edif. en la manzana: Aislado: Intermedio:

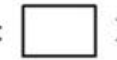
Esquina: $\$ Terminal:

Planta blanda: $\mathrm{S}$

No:

Columna corta: Sí:

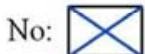

Relieve:

Llano:

Pendiente:

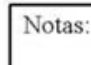

\section{EVALUACIÓN DEL GRADO DE DAÑO MEDIO $\mu D$}

$$
\mu D=1
$$

- Fisuras en elementos no estructurales. Severidad leve (ancho $>2 \mathrm{~mm}$ en menos del $20 \%$ de los elem. dañados). $\square$ Cubierta $\square$ Cerramientos $\square$ Particiones interiores - Sin daño en los elementos estructurales.

$$
\mu D=2
$$

- Fisuras en elementos no estructurales. Severidad moderada (ancho > $2 \mathrm{~mm}$ en más del $60 \%$ de los elem. dañados).

$\square$ Cubierta $\square$ Cerramientos $\square$ Particiones interiores

- Fisuras leves en elementos estructurales (tipo 1, 2, 3), con ancho $<2 \mathrm{~mm}$, en menos del $40 \%$ de los elem. dañados.

Notas:

Caída completa de antepecho de cubierta. Daños generalizados en pilares semisótano, por planta blanda $\mu D=3$

- Fisuras en elementos no estructurales. Severidad moderad (ancho > $2 \mathrm{~mm}$ en más del $60 \%$ de los elem. dañados).

$\bigotimes$ Cubierta $\bigotimes$ Cerramientos $\bigotimes$ Particiones interiores - Fisuras leves en elementos estructurales (tipo 1, 2, 3), con ancho $<2 \mathrm{~mm}$, en más del $40 \%$ de los elem. dañados.

- Fisuras moderadas en elementos estructurales (tipo 1, 2, 3) con ancho $>2 \mathrm{~mm}$, en más del $20 \%$ de los elem. dañados.

- Pérdida de recubrimiento y pandeo de las armaduras.

$\mu D=4$

- Colapso general $\square$ - Asiento de la cimentación $\square$

局 所

Figura A.17. Ejemplo I. Ficha empleada en la campaña de recopilación de datos para la evaluación del índice de vulnerabilidad y el correspondiente grado de daño de cada edificación. 


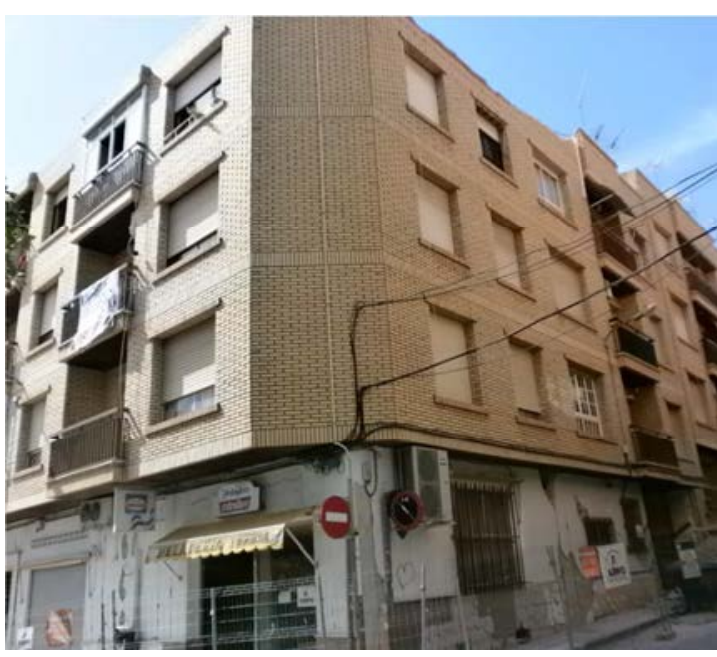

(a)

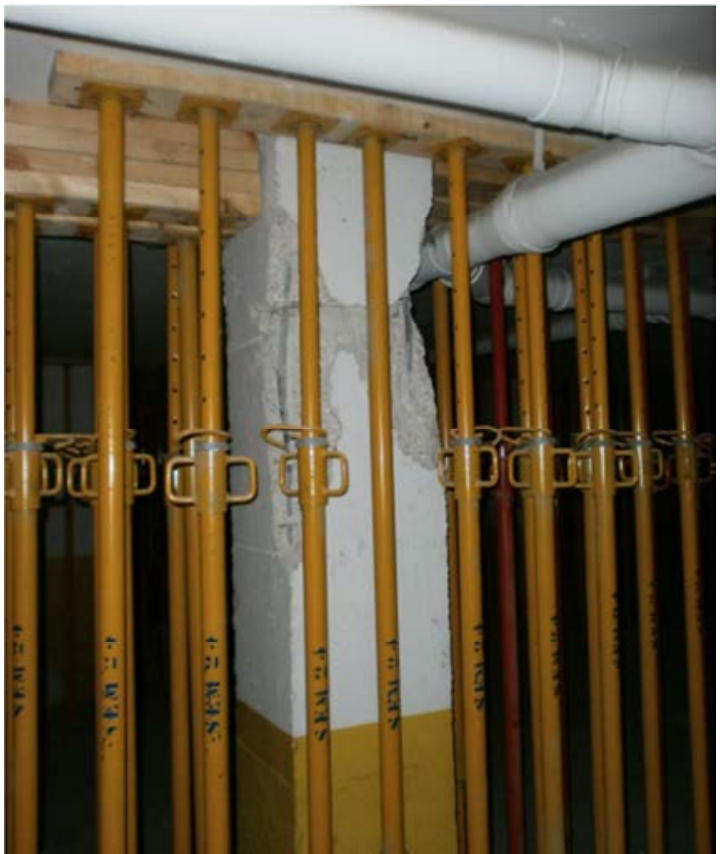

(c)

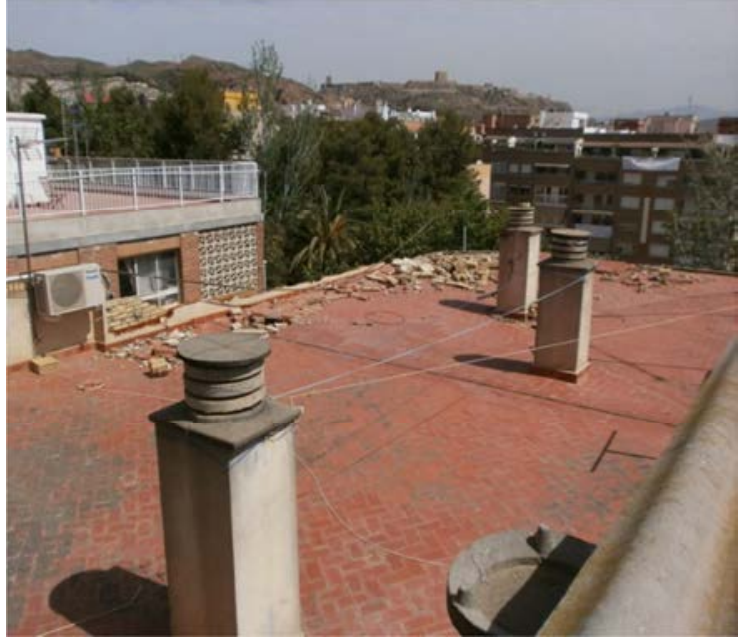

(b)

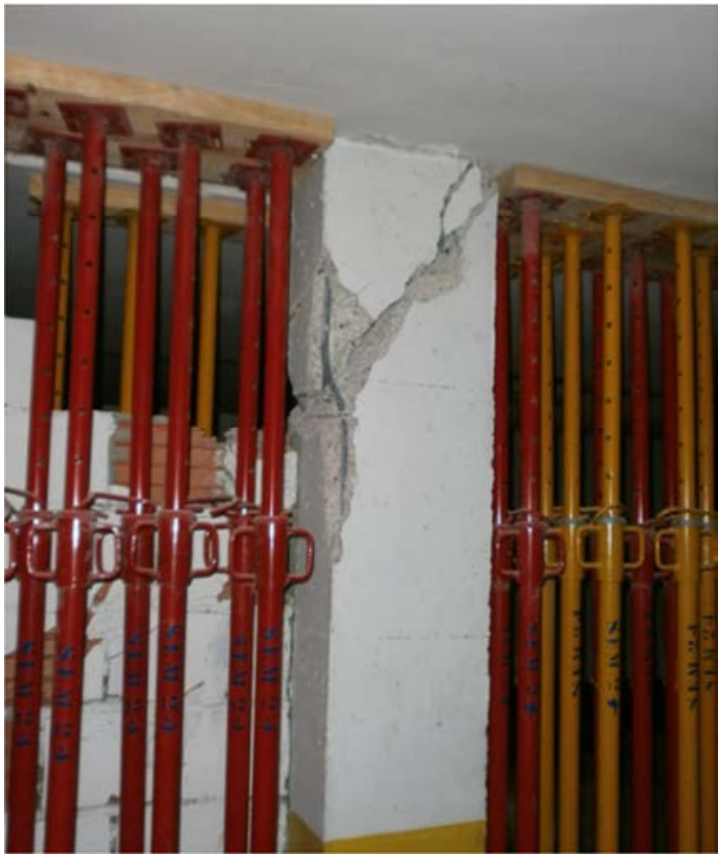

(d)

Figura A.18. Ejemplo I. Afecciones observadas en la edificación tras el sismo de Lorca. Daños en: (a), (b) y (c) Pilares cortos en planta baja, con pandeo de armadura longitudinal. (d) Vigas y tabiquería interior. 


\section{DAÑOS EN EDIFICACIONES. SISMO DE LORCA 2011}

\section{DATOS GENERALES DE LA EDIFICACIÓN}

ID: 171

$\mathrm{N}^{\circ}$ de plantas sobre rasante: 1

Dirección: C/Horno,

Tipología edificatoria:

U. Man:

RC: $\searrow$

Otras:

\section{CONFIGURACIÓN URBANISTICA Y ARQUITECTÓNICA}

Irregularidad en planta:

Sí:

No:

Irregularidad en altura:

Sí:

No:

Junta sísmica entre edificios:

Sí:



No:

Relación con edificios adyacentes: Mismo nivel

Dif. nivel:

Posición del edif. en la manzana: Aislado:

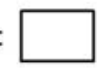
Intermedio:

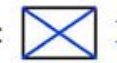
Esquina: 맘미 Planta blanda:
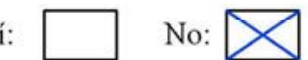

Columna corta: Sí: $\square$ No: $\square$

Relieve:

Llano:

Pendiente:

Notas:
Presencia de pilares cortos por interacción
de cerramientos.

\section{EVALUACIÓN DEL GRADO DE DAÑO MEDIO $\mu D$}

$$
\mu D=1
$$

- Fisuras en elementos no estructurales. Severidad leve (ancho $>2 \mathrm{~mm}$ en menos del $20 \%$ de los elem. dañados). $\square$ Cubierta $\square$ Cerramientos $\square$ Particiones interiores - Sin daño en los elementos estructurales. $\mu D=2$

- Fisuras en elementos no estructurales. Severidad moderad (ancho $>2 \mathrm{~mm}$ en más del $60 \%$ de los elem. dañados).

$\square$ Cubierta $\square$ Cerramientos $\square$ Particiones interiores

- Fisuras leves en elementos estructurales (tipo 1, 2,3), con ancho $<2 \mathrm{~mm}$, en menos del $40 \%$ de los elem. dañados.

Notas:

Daños graves en pilares cortos, con seccionamiento completo a cortante $\mu D=3$

- Fisuras en elementos no estructurales. Severidad moderad (ancho $>2 \mathrm{~mm}$ en más del $60 \%$ de los elem. dañados).

$\square$ Cubierta $\bigotimes$ Cerramientos $\bigotimes$ Particiones interiores - Fisuras leves en elementos estructurales (tipo 1, 2, 3), con ancho $<2 \mathrm{~mm}$, en más del $40 \%$ de los elem. dañados.

- Fisuras moderadas en elementos estructurales (tipo 1, 2,3) con ancho $>2 \mathrm{~mm}$, en más del $20 \%$ de los elem. dañados

- Pérdida de recubrimiento y pandeo de las armachras

$\mu D=4 \square$

- Colapso general $\square \quad$ - Asiento de la cimentación $\square$

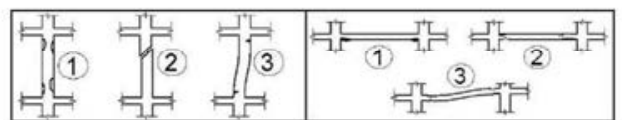

Figura A.19. Ejemplo J. Ficha empleada en la campaña de recopilación de datos para la evaluación del índice de vulnerabilidad y el correspondiente grado de daño de cada edificación. 


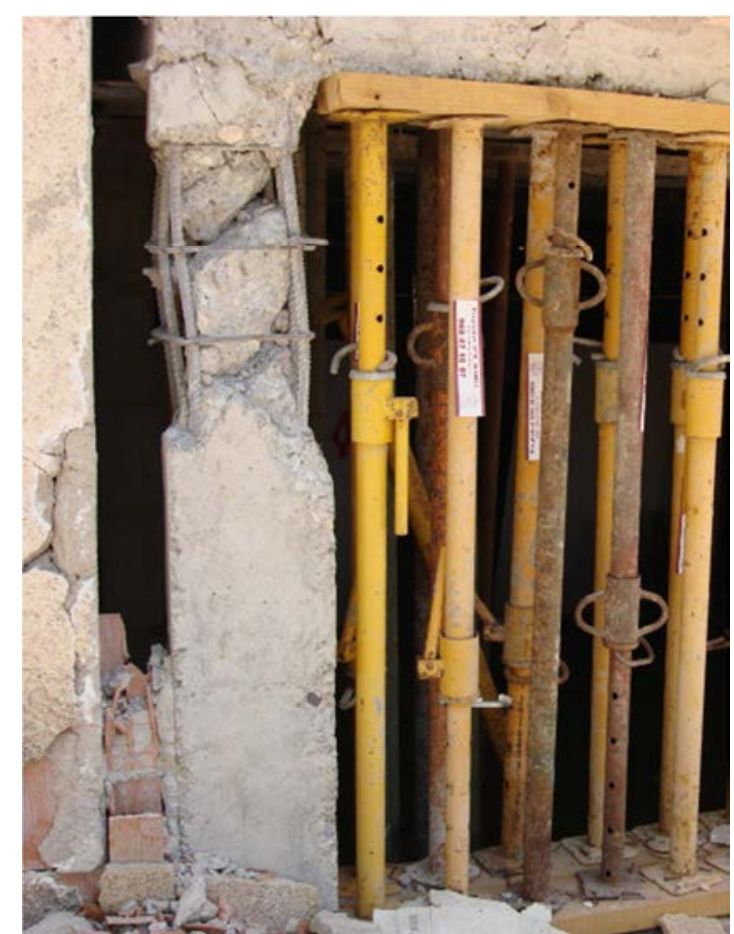

(a)

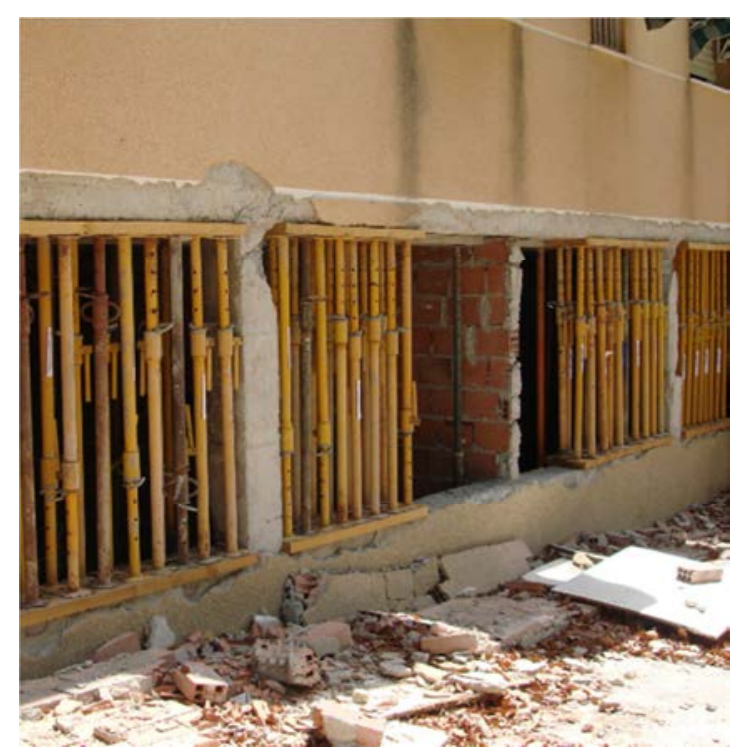

(c)

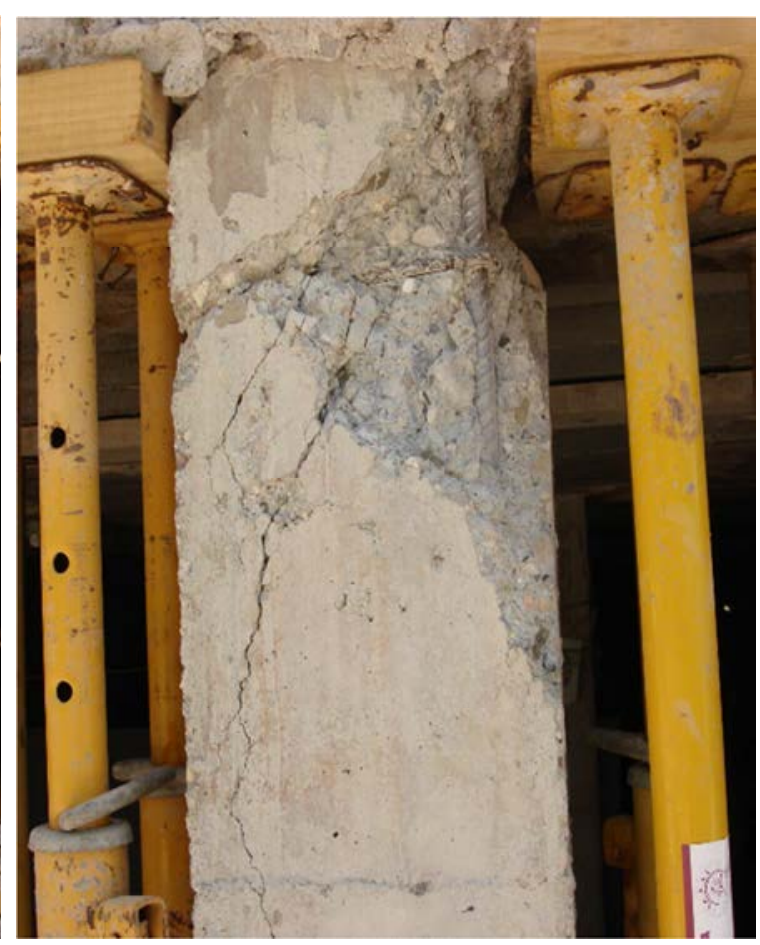

(b)

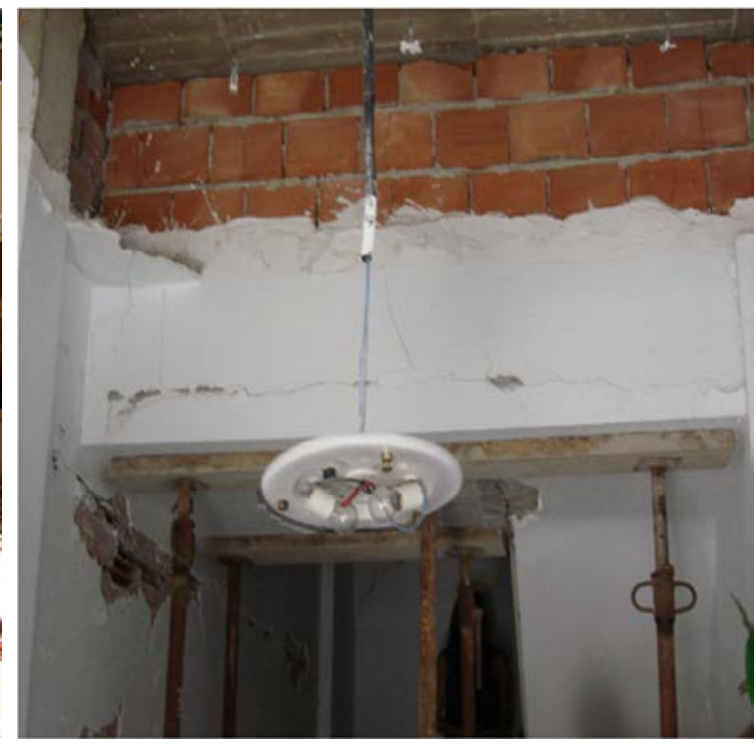

(d)

Figura A.20. Ejemplo J. Afecciones observadas en la edificación tras el sismo de Lorca. Daños en: (a), (b) y (c) Pilares cortos en planta baja, con pandeo de armadura longitudinal. (d) Vigas y tabiquería interior. 


\section{DAÑOS EN EDIFICACIONES. SISMO DE LORCA 2011}

\section{DATOS GENERALES DE LA EDIFICACIÓN}

ID: 281

$\mathrm{N}^{\circ}$ de plantas sobre rasante: 3

Dirección: Alameda Ramón y Cajal,

Tipología edificatoria:

U. Man:

RC: $\searrow$

Otras:

\section{CONFIGURACIÓN URBANISTICA Y ARQUITECTÓNICA}

$\begin{array}{lll}\text { Irregularidad en planta: } & \text { Sí: } & \text { No: } \square \\ \text { Irregularidad en altura: } & \text { Sí: } \square & \text { No: } \\ \text { Junta sísmica entre edificios: } & \text { Sí: } \square & \text { No: } \square\end{array}$

Relación con edificios adyacentes: $\quad$ Mismo nivel:

Dif. nivel:

Posición del edif. en la manzana: Aislado:

$\triangle$ Intermedio:

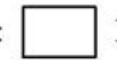
Esquina: अㅁ वप्त Planta blanda:


Columna corta: Sí: Terminal:

Relieve:

Llano:

Pendiente: Notas:

Complejo residencial tipo bloque aislado

\section{EVALUACIÓN DEL GRADO DE DAÑO MEDIO $\mu D$}

$$
\mu D=1
$$

Fisuras en elementos no estructurales. Severidad leve (ancho $>2 \mathrm{~mm}$ en menos del $20 \%$ de los elem. dañados). $\square$ Cubierta $\square$ Cerramientos $\square$ Particiones interiores - Sin daño en los elementos estructurales.

$\mu D=2$

- Fisuras en elementos no estructurales. Severidad moderad (ancho > $2 \mathrm{~mm}$ en más del $60 \%$ de los elem. dañados).

$\square$ Cubierta $\square$ Cerramientos $\square$ Particiones interiores

- Fisuras leves en elementos estructurales (tipo 1,2,3), con ancho $<2 \mathrm{~mm}$, en menos del $40 \%$ de los elem. dañados.

$$
\begin{aligned}
& \text { Notas: } \\
& \text { Daños graves en pilares, con seccionamiento completo a } \\
& \text { cortante }
\end{aligned}
$$

\section{$\mu D=3 \bigotimes$}

- Fisuras en elementos no estructurales. Severidad moderad (ancho $>2 \mathrm{~mm}$ en más del $60 \%$ de los elem. dañados).

$\bigotimes$ Cubierta $\square$ Cerramientos $\square$ Particiones interiores - Fisuras leves en elementos estructurales (tipo 1,2,3), con ancho $<2 \mathrm{~mm}$, en más del $40 \%$ de los elem. dañados.

- Fisuras moderadas en elementos estructurales (tipo 1,2,3) con ancho $>2 \mathrm{~mm}$, en más del $20 \%$ de los elem. dañados

- Pérdida de recubrimiento y pandeo de las armachras

$\mu D=4 \square$

- Colapso general $\square \quad$ - Asiento de la cimentación $\square$

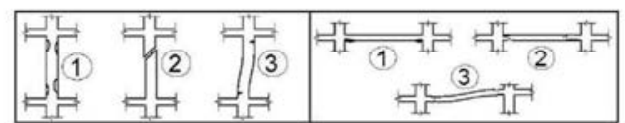

Figura A.21. Ejemplo K. Ficha empleada en la campaña de recopilación de datos para la evaluación del índice de vulnerabilidad y el correspondiente grado de daño de cada edificación. 


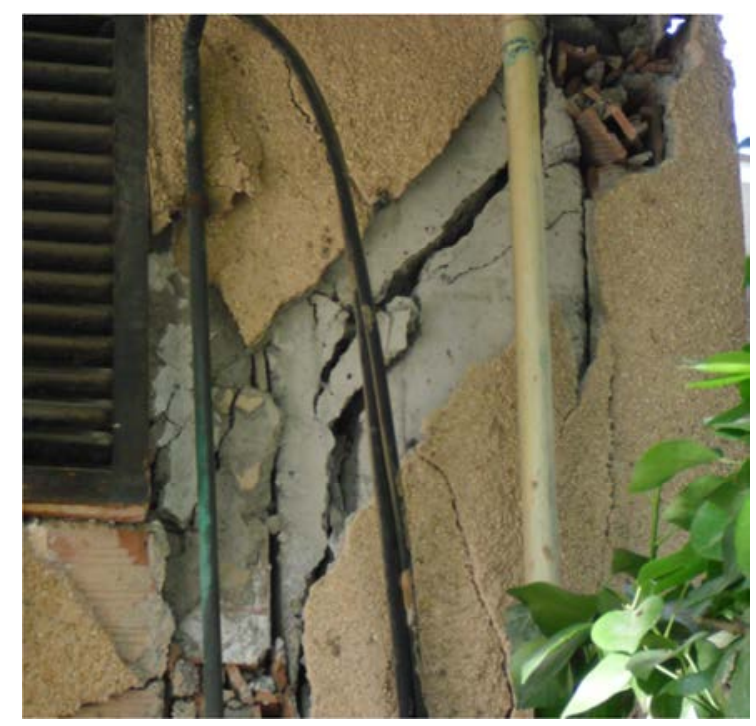

(a)

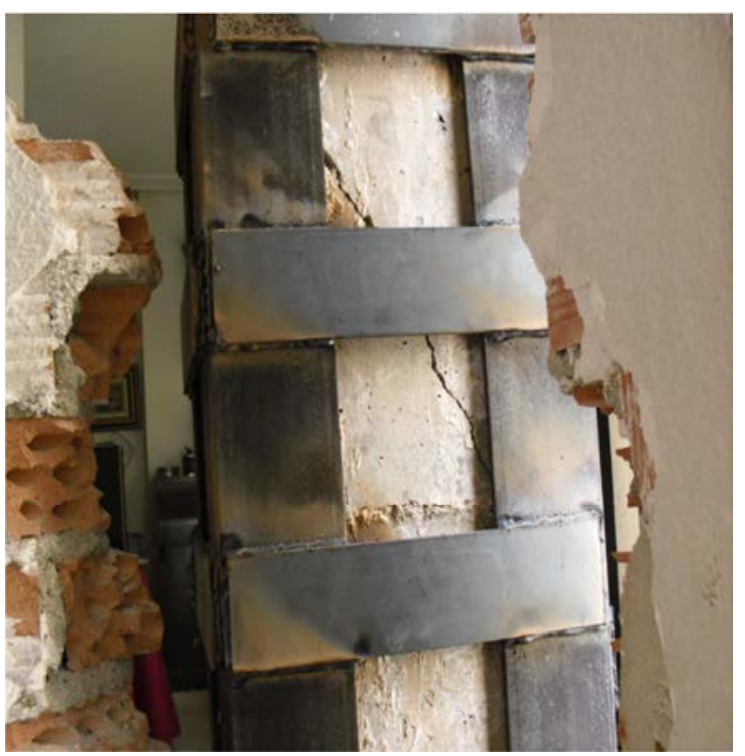

(c)

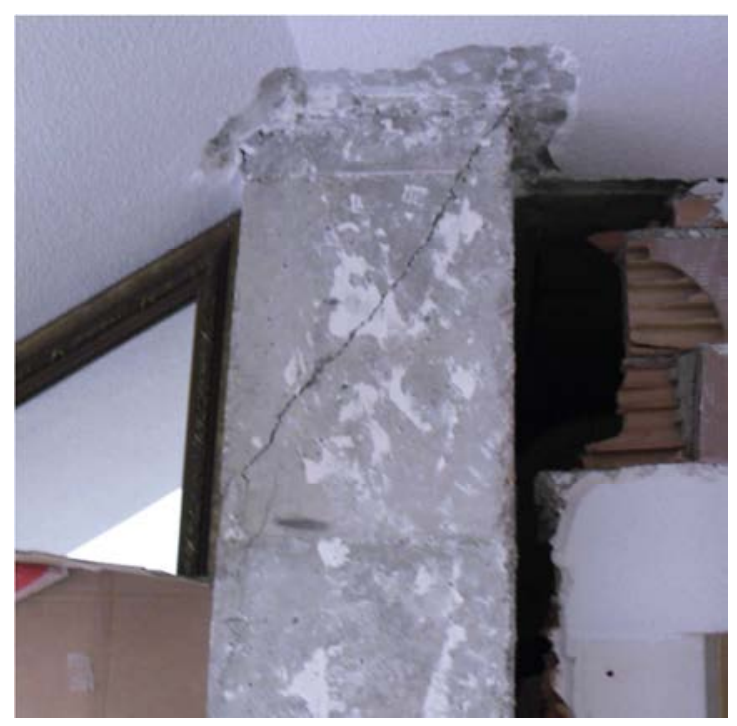

(b)

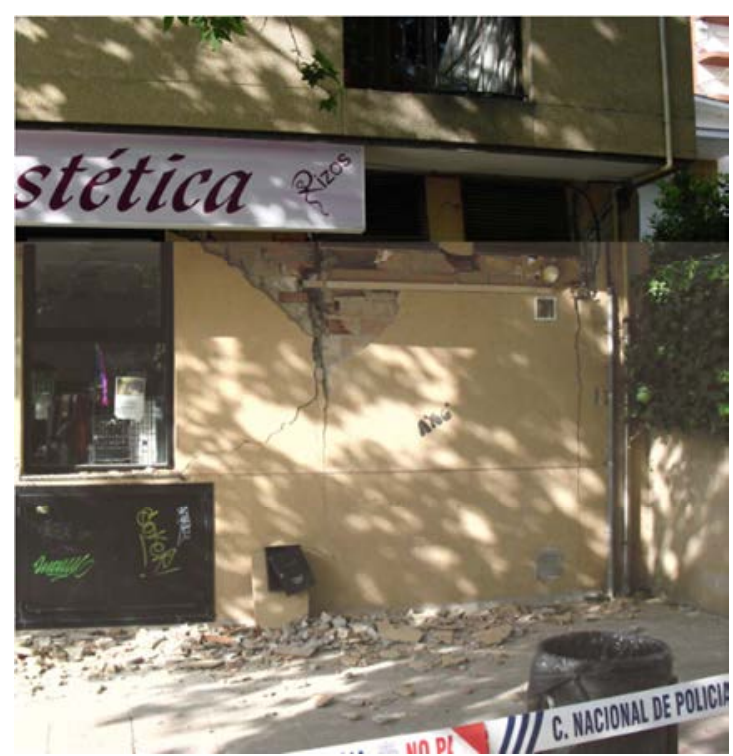

(d)

Figura A.22. Ejemplo K. Afecciones observadas en la edificación tras el sismo de Lorca. Daños en: (a), (b) y (c) Pilares, con seccionamiento completo a cortante. (d) Cerramiento en fachada. 


\section{DAÑOS EN EDIFICACIONES. SISMO DE LORCA 2011}

\section{DATOS GENERALES DE LA EDIFICACIÓN}

ID: 306

$\mathrm{N}^{\circ}$ de plantas sobre rasante: 4

Dirección: C/Pérez Casas, $\square$

Tipología edificatoria:

U. Man:

RC: $\searrow$

Otras:

Presencia de humedades generalizada

\section{CONFIGURACIÓN URBANÍSTICA Y ARQUITECTÓNICA}

Irregularidad en planta:

Sí:

No:

Irregularidad en altura:

Sí:

No:

Junta sísmica entre edificios:

Sí:

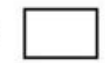

No:

Relación con edificios adyacentes: Mismo nivel

Dif. nivel:

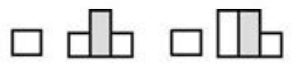

Posición del edif. en la manzana: Aislado:


Intermedio:

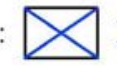
Esquina: 口매 Planta blanda:
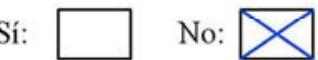

Columna corta: Sí: Terminal:

Relieve:

Llano:

Pendiente:

\section{Notas:}

\section{EVALUACIÓN DEL GRADO DE DAÑO MEDIO $\mu D$}

$$
\mu D=1
$$

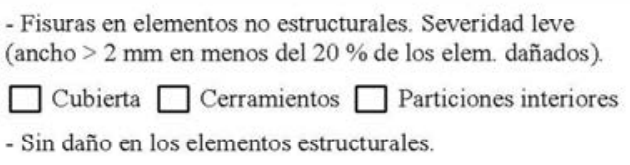

- Fisuras en elementos no estructurales. Severidad leve (ancho $>2 \mathrm{~mm}$ en menos del $20 \%$ de los elem. dañados). $\square$ Cubierta $\square$ Cerramientos $\square$ Particiones interiores - Sin daño en los elementos estructurales.

$$
\mu D=2
$$

- Fisuras en elementos no estructurales. Severidad moderad (ancho $>2 \mathrm{~mm}$ en más del $60 \%$ de los elem. dañados).

$\square$ Cubierta $\square$ Cerramientos $\square$ Particiones interiores

- Fisuras leves en elementos estructurales (tipo 1,2,3), con ancho $<2 \mathrm{~mm}$, en menos del $40 \%$ de los elem. dañados.

\section{Notas: \\ Daños generalizados en vigas y pilares de planta baja.} Efecto golpeteo con edificio adyacente $\mu D=3$

- Fisuras en elementos no estructurales. Severidad moderad (ancho $>2 \mathrm{~mm}$ en más del $60 \%$ de los elem. dañados).

$\square$ Cubierta $\square$ Cerramientos $\square$ Particiones interiores - Fisuras leves en elementos estructurales (tipo 1, 2, 3), con ancho $<2 \mathrm{~mm}$, en más del $40 \%$ de los elem. dañados.

- Fisuras moderadas en elementos estructurales (tipo 1, 2,3) con ancho $>2 \mathrm{~mm}$, en más del $20 \%$ de los elem. dañados.

- Pérdida de recubrimiento y pandeo de las armachras

$\mu D=4 \square$

- Colapso general $\square \quad$ - Asiento de la cimentación $\square$

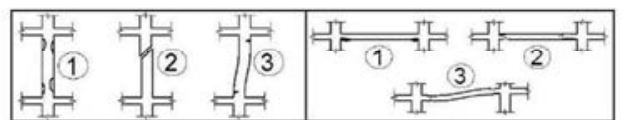

Figura A.23. Ejemplo L. Ficha empleada en la campaña de recopilación de datos para la evaluación del índice de vulnerabilidad y el correspondiente grado de daño de cada edificación. 


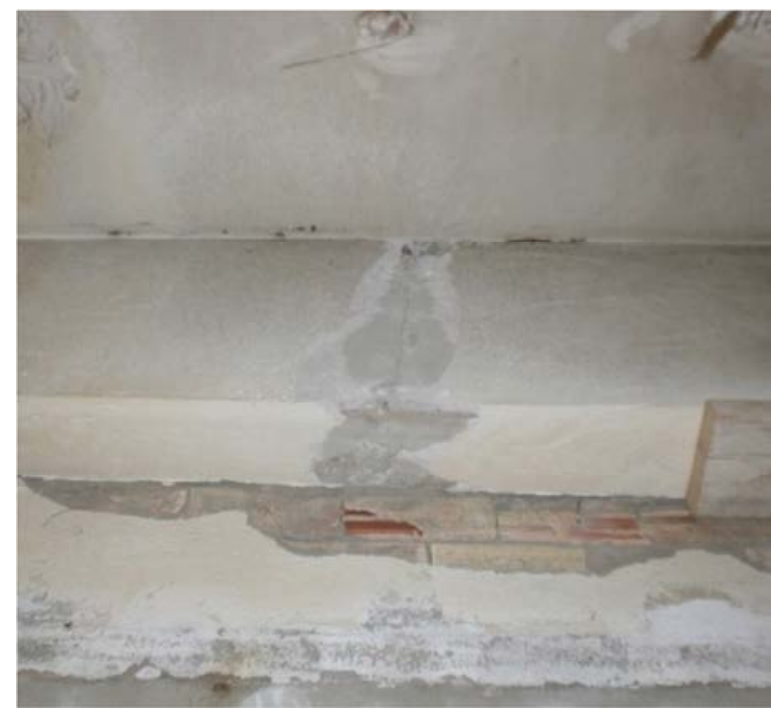

(a)

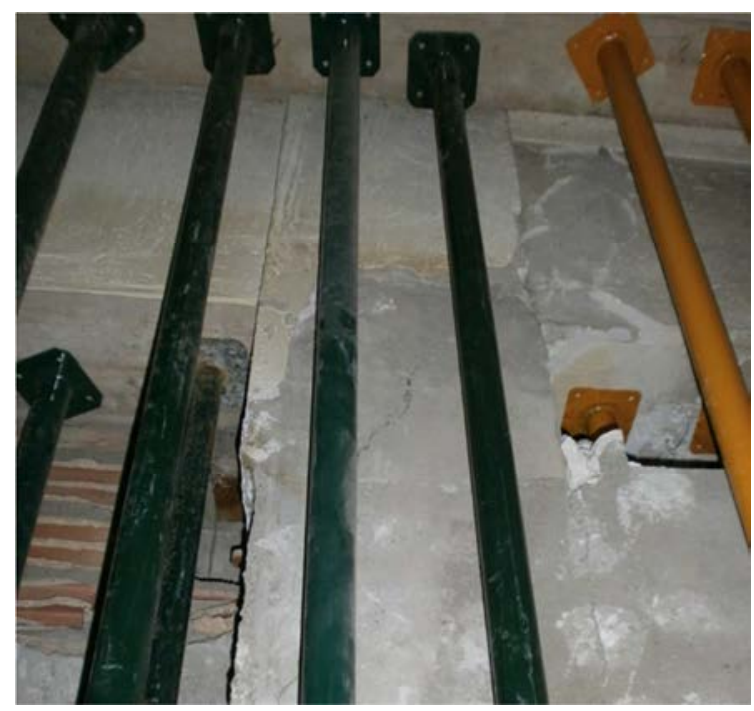

(c)



(b)

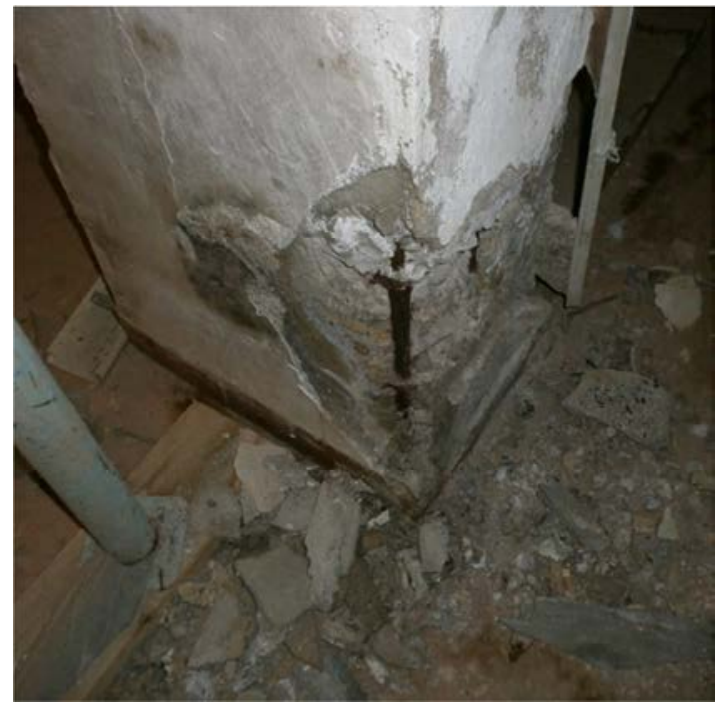

(d)

Figura A.24. Ejemplo L. Afecciones observadas en la edificación tras el sismo de Lorca. Daños en: (a) Vigas. (b) Tabiquería interior. (c) y (d) Pilares, de forma generalizada. 

ANEXO B

\section{RESUMEN DE LA BASE DE DATOS IMPLEMENTADA}

\section{B.1. INTRODUCCIÓN}

En este Anexo se muestra un resumen de la información disponible de las 364 edificaciones seleccionadas que componen la base de datos implementada a partir de las observaciones disponibles tras el sismo de Lorca de 2011.

\section{B.2. RESUMEN DE LA BASE DE DATOS}

En las Tablas B.1 y B.2 se recoge un extracto de la base de datos elaborada, dividido en los siguientes bloques:

A. Información general y observaciones de campo.

B. Obtención del índice de vulnerabilidad de cada edificación según el Método del Índice de Vulnerabilidad (MIV).

C. Obtención del grado de daño en cada edificación según la metodología LM1 de RISKUE para un sismo de intensidad VII en la escala EMS-98.

D. Obtención del grado de daño en cada edificación según la metodología LM1 de RISKUE para un sismo de intensidad VIII en la escala EMS-98.

Con objeto de preservar la privacidad de los usuarios y propietarios de cada inmueble, se muestra sólo parcialmente la referencia catastral de los edificios y se ha omitido su dirección postal. 
Tabla B.1. Resumen de la base de datos implementada. Bloque A Información general y observaciones de campo. Bloque B Obtención del índice de vulnerabilidad.

\begin{tabular}{|c|c|c|c|c|c|c|c|c|c|c|c|c|}
\hline \multicolumn{7}{|c|}{ A. INFORMACIÓN GENERAL Y OBSERVACIONES DE CAMPO } & \multicolumn{6}{|c|}{ B. OBTENCIÓN ÍNDICE DE VULNERABILIDAD } \\
\hline FID & REFCAT & SUPERFICIE & $\begin{array}{l}\text { NÚMERO DE } \\
\text { PLANTAS }\end{array}$ & AÑo & $\begin{array}{c}\text { GRADO DE } \\
\text { DAÑO EMS-98 }\end{array}$ & $\begin{array}{l}\text { TIPOLOGIA } \\
\text { BTM }\end{array}$ & $\mathrm{IV}_{\mathrm{V}}^{*} \mathrm{ED}_{-} \mathrm{MILO3}$ & $\mathrm{I}_{\mathrm{V}}^{*}{ }_{\mathrm{ED}} \mathrm{GIOOS}_{\mathrm{C}}$ & IV*ED_LAN07 & $\mathrm{IV}_{\mathrm{V}}^{*}$ ED_FER12 & IV*E_MAN16 & IV*ED_ROD17 \\
\hline 1 & $4495001 \times G$ & 109 & 1 & 1960 & 2 & $\mathrm{RC} 1$ & 0,724 & 0,584 & 0,792 & 0,724 & 0,704 & 0,804 \\
\hline 2 & $4707909 \times \mathrm{X}$ & 254 & 4 & 1984 & 2 & $\mathrm{RC1}$ & 0,644 & 0,524 & 0,402 & 0,544 & 0,524 & 0,584 \\
\hline 3 & $4699125 \times \mathrm{K}$ & 518 & 4 & 2008 & 1 & $\mathrm{RC1}$ & 0,514 & 0,534 & 0,422 & 0,464 & 0,444 & 0,524 \\
\hline 4 & $4699125 \times \mathrm{XG}$ & 518 & 2 & 2008 & 1 & $\mathrm{RC} 1$ & 0,474 & 0,514 & 0,422 & 0,424 & 0,444 & 0,564 \\
\hline 5 & $4505218 \times G$ & 198 & 2 & 2007 & 1 & $\mathrm{RC1}$ & 0,444 & 0,484 & 0,422 & 0,444 & 0,444 & 0,564 \\
\hline 6 & $5212017 \times \mathrm{X}$ & 247 & 3 & 1977 & 1 & $\mathrm{RC} 1$ & 0,684 & 0,544 & 0,502 & 0,644 & 0,624 & 0,764 \\
\hline 7 & $4600907 \times \mathrm{XG}$ & 343 & 4 & 1981 & 2 & $\mathrm{RC1}$ & 0,684 & 0,524 & 0,382 & 0,584 & 0,504 & 0,564 \\
\hline 8 & $4706024 \times G$ & 264 & 4 & 1986 & 1 & $\mathrm{RC} 1$ & 0,704 & 0,524 & 0,522 & 0,744 & 0,684 & 0,744 \\
\hline 9 & $4500021 \times G$ & 159 & 2 & 2003 & 2 & $\mathrm{RC1}$ & 0,444 & 0,484 & 0,422 & 0,504 & 0,524 & 0,564 \\
\hline 10 & $6015811 \times G$ & 506 & 4 & 1995 & 3 & $\mathrm{RC} 1$ & 0,724 & 0,564 & 0,602 & 0,784 & 0,924 & 0,904 \\
\hline 11 & $4395803 \times \mathrm{XG}$ & 180 & 2 & 1956 & 3 & $\mathrm{RC} 1$ & 0,684 & 0,544 & 0,672 & 0,624 & 0,584 & 0,684 \\
\hline 12 & $5414703 \times \mathrm{G}$ & 139 & 4 & 1962 & 1 & $\mathrm{RC} 1$ & 0,724 & 0,564 & 0,812 & 0,744 & 0,704 & 0,744 \\
\hline 13 & $4915909 \times \mathrm{XG}$ & 61 & 4 & 1997 & 1 & $\mathrm{RC1}$ & 0,484 & 0,484 & 0,422 & 0,564 & 0,524 & 0,524 \\
\hline 14 & $4704614 \times G$ & 149 & 4 & 1960 & 2 & $\mathrm{RC1}$ & 0,764 & 0,604 & 0,832 & 0,764 & 0,744 & 0,764 \\
\hline 15 & $4799021 \times G$ & 109 & 4 & 2009 & 0 & $\mathrm{RC} 1$ & 0,564 & 0,544 & 0,422 & 0,524 & 0,444 & 0,524 \\
\hline 16 & $6317008 \times G$ & 912 & 3 & 1972 & 2 & $\mathrm{RC} 1$ & 0,644 & 0,504 & 0,607 & 0,604 & 0,604 & 0,744 \\
\hline 17 & $5395005 \times \mathrm{G}$ & 167 & 3 & 1980 & 1 & $\mathrm{RC1}$ & 0,644 & 0,504 & 0,382 & 0,564 & 0,504 & 0,724 \\
\hline 18 & $4804013 \times \mathrm{XG}$ & 299 & 4 & 1968 & 2,5 & $\mathrm{RC1}$ & 0,724 & 0,564 & 0,732 & 0,624 & 0,624 & 0,664 \\
\hline 19 & $4697013 \times \mathrm{XG}$ & 674 & 4 & 1978 & 2 & $\mathrm{RC} 1$ & 0,684 & 0,524 & 0,422 & 0,604 & 0,544 & 0,684 \\
\hline 20 & $4396301 \times \mathrm{XG}$ & 185 & 3 & 1960 & 3 & $\mathrm{RC} 1$ & 0,644 & 0,504 & 0,712 & 0,624 & 0,624 & 0,724 \\
\hline 21 & $5802005 \times G$ & 411 & 3 & 1968 & 1 & $\mathrm{RC1}$ & 0,684 & 0,544 & 0,732 & 0,644 & 0,624 & 0,744 \\
\hline 22 & $4497608 \times G$ & 415 & 4 & 1994 & 1 & $\mathrm{RC1}$ & 0,704 & 0,524 & 0,482 & 0,724 & 0,644 & 0,704 \\
\hline 23 & $4809709 \times \mathrm{XG}$ & 355 & 2 & 1996 & 2 & $\mathrm{RC1}$ & 0,474 & 0,514 & 0,502 & 0,604 & 0,624 & 0,644 \\
\hline 24 & $4293001 \times G$ & 518 & 3 & 1981 & 3 & $\mathrm{RC} 1$ & 0,684 & 0,544 & 0,522 & 0,664 & 0,644 & 0,704 \\
\hline 25 & $4697018 \times G$ & 556 & 4 & 1979 & 1 & $\mathrm{RC} 1$ & 0,644 & 0,484 & 0,462 & 0,604 & 0,584 & 0,724 \\
\hline 26 & $4909807 \times G$ & 136 & 2 & 1992 & 1 & $\mathrm{RC1}$ & 0,664 & 0,524 & 0,342 & 0,544 & 0,464 & 0,604 \\
\hline 27 & $4505807 \times G$ & 297 & 3 & 1970 & 2 & $\mathrm{RC} 1$ & 0,704 & 0,544 & 0,667 & 0,644 & 0,604 & 0,844 \\
\hline
\end{tabular}

$I_{V}{ }_{E D}=$ Índice de vulnerabilidad representativo de la edificación; MILO3, GIO05, LAN07, FER12, MAN16, ROD17 = variantes del método MIV propuestas por Milutinovic \& Trendafiloski (2003), Giovinazzi (2005), Lantada (2007), Feriche (2012), Martínez-Cuevas \& Gaspar-Escribano (2016) y el modelo propuesto en esta tesis, respectivamente 


\begin{tabular}{|c|c|c|c|c|c|c|c|c|c|c|c|c|}
\hline \multicolumn{7}{|c|}{ A. INFORMACIÓN GENERAL Y OBSERVACIONES DE CAMPO } & \multicolumn{6}{|c|}{ B. OBTENCIÓN ÍNDICE DE VULNERABILIDAD } \\
\hline FID & REFCAT & SUPERFICIE & $\begin{array}{l}\text { NÚMERO DE } \\
\text { PLANTAS }\end{array}$ & AÑo & $\begin{array}{c}\text { GRADO DE } \\
\text { DAÑO EMS-98 }\end{array}$ & $\begin{array}{l}\text { TIPOLOGIA } \\
\text { BTM }\end{array}$ & $\mathrm{IV}_{\mathrm{V}}^{*} \mathrm{ED} / \mathrm{MILO3}$ & $I_{V}^{*} E D_{-}$GIO05 & IV ED_LAN07 & $\mathrm{I}_{\mathrm{V}}^{*}$ ED_FER12 & $I_{\text {ED_MAN16 }}^{*}$ & $I_{V}^{*}{ }_{E D}{ }^{R O D} 17$ \\
\hline 28 & $4804001 X G$ & 241 & 6 & 1976 & 1 & $\mathrm{RC1}$ & 0,724 & 0,564 & 0,482 & 0,644 & 0,604 & 0,664 \\
\hline 29 & $5314002 \times G$ & 462 & 4 & 1950 & 2,5 & $\mathrm{RC1}$ & 0,744 & 0,564 & 0,812 & 0,804 & 0,764 & 0,784 \\
\hline 30 & $4396501 \times G$ & 184 & 3 & 1960 & 2 & $\mathrm{RC1}$ & 0,644 & 0,504 & 0,712 & 0,624 & 0,624 & 0,724 \\
\hline 31 & $4193601 \times \mathrm{X}$ & 1.143 & 3 & 1981 & 3 & $\mathrm{RC1}$ & 0,724 & 0,564 & 0,522 & 0,784 & 0,684 & 0,824 \\
\hline 32 & $5115006 \times \mathrm{XG}$ & 303 & 4 & 1996 & 1 & $\mathrm{RC1}$ & 0,484 & 0,484 & 0,482 & 0,644 & 0,604 & 0,584 \\
\hline 33 & $4498001 \times G$ & 712 & 4 & 1981 & 1 & $\mathrm{RC1}$ & 0,764 & 0,584 & 0,562 & 0,824 & 0,724 & 0,784 \\
\hline 37 & $6117501 \times G$ & 1.026 & 3 & 1975 & 1 & $\mathrm{RC1}$ & 0,684 & 0,544 & 0,522 & 0,664 & 0,644 & 0,784 \\
\hline 34 & $4605009 \times \mathrm{G}$ & 251 & 4 & 1974 & 2 & $\mathrm{RC1}$ & 0,724 & 0,564 & 0,747 & 0,784 & 0,744 & 0,804 \\
\hline 35 & $4396801 \times G$ & 185 & 3 & 1960 & 3 & $\mathrm{RC1}$ & 0,644 & 0,504 & 0,712 & 0,624 & 0,624 & 0,724 \\
\hline 36 & $6318014 \times G$ & 455 & 3 & 1972 & 2 & $\mathrm{RC1}$ & 0,684 & 0,544 & 0,567 & 0,584 & 0,564 & 0,704 \\
\hline 37 & $4599009 \times \mathrm{XG}$ & 114 & 3 & 1970 & 1 & $\mathrm{RC1}$ & 0,684 & 0,544 & 0,647 & 0,584 & 0,544 & 0,784 \\
\hline 38 & $4806707 \times \mathrm{XG}$ & 206 & 2 & 1992 & 1 & $\mathrm{RC1}$ & 0,644 & 0,504 & 0,422 & 0,624 & 0,544 & 0,684 \\
\hline 39 & $4498048 \times G$ & 1.165 & 3 & 1978 & 2 & $\mathrm{RC1}$ & 0,744 & 0,584 & 0,482 & 0,804 & 0,644 & 0,944 \\
\hline 40 & $4392020 \times G$ & 342 & 2 & 2001 & 2 & $\mathrm{RC1}$ & 0,444 & 0,464 & 0,402 & 0,504 & 0,504 & 0,544 \\
\hline 41 & $4606210 \times \mathrm{G}$ & 170 & 4 & 1972 & 2 & $\mathrm{RC1}$ & 0,724 & 0,564 & 0,667 & 0,684 & 0,664 & 0,724 \\
\hline 42 & $5414901 \times \mathrm{G}$ & 140 & 3 & 1962 & 1 & $\mathrm{RC1}$ & 0,644 & 0,504 & 0,712 & 0,604 & 0,604 & 0,724 \\
\hline 43 & $3889302 \times \mathrm{XG}$ & 187 & 2 & 2009 & 2 & $\mathrm{RC1}$ & 0,464 & 0,484 & 0,502 & 0,544 & 0,524 & 0,644 \\
\hline 44 & $4395304 \times G$ & 216 & 2 & 1956 & 2 & $\mathrm{RC1}$ & 0,684 & 0,544 & 0,752 & 0,704 & 0,664 & 0,764 \\
\hline 45 & $4293809 \times G$ & 481 & 4 & 1974 & 3 & $\mathrm{RC1}$ & 0,724 & 0,564 & 0,587 & 0,684 & 0,784 & 0,844 \\
\hline 46 & $4698501 \times \mathrm{XG}$ & 237 & 4 & 1981 & 1 & $\mathrm{RC1}$ & 0,684 & 0,524 & 0,462 & 0,664 & 0,584 & 0,644 \\
\hline 47 & $5214011 \times \mathrm{G}$ & 396 & 4 & 1985 & 1 & $\mathrm{RC1}$ & 0,744 & 0,564 & 0,422 & 0,704 & 0,584 & 0,644 \\
\hline 48 & $4705011 \times \mathrm{X}$ & 246 & 3 & 1988 & 2 & $\mathrm{RC1}$ & 0,664 & 0,504 & 0,402 & 0,624 & 0,564 & 0,704 \\
\hline 49 & $4594706 \times \mathrm{XG}$ & 226 & 4 & 1977 & 2,5 & $\mathrm{RC1}$ & 0,724 & 0,524 & 0,542 & 0,704 & 0,664 & 0,724 \\
\hline 50 & $4395804 \times G$ & 180 & 2 & 1956 & 3 & $\mathrm{RC1}$ & 0,684 & 0,544 & 0,752 & 0,704 & 0,664 & 0,764 \\
\hline 51 & $4499204 \times \mathrm{KG}$ & 100 & 3 & 1965 & 2 & $\mathrm{RC1}$ & 0,744 & 0,584 & 0,812 & 0,764 & 0,744 & 0,864 \\
\hline 52 & $4603002 \times G$ & 161 & 2 & 2006 & 1 & $\mathrm{RC1}$ & 0,444 & 0,484 & 0,382 & 0,404 & 0,404 & 0,524 \\
\hline 53 & $6117701 \times G$ & 539 & 3 & 1970 & 2 & $\mathrm{RC1}$ & 0,704 & 0,544 & 0,647 & 0,624 & 0,584 & 0,824 \\
\hline
\end{tabular}

$I_{V}^{*}{ }_{E D}=$ Índice de vulnerabilidad representativo de la edificación; MIL03, GIO05, LAN07, FER12, MAN16, ROD17 = variantes del método MIV propuestas por Milutinovic \& Trendafiloski (2003), Giovinazzi (2005), Lantada (2007), Feriche (2012), Martínez-Cuevas \& Gaspar-Escribano (2016) y el modelo propuesto en esta tesis, respectivamente 


\begin{tabular}{|c|c|c|c|c|c|c|c|c|c|c|c|c|}
\hline \multicolumn{7}{|c|}{ A. INFORMACIÓN GENERAL Y OBSERVACIONES DE CAMPO } & \multicolumn{6}{|c|}{ B. OBTENCIÓN ÍNDICE DE VULNERABILIDAD } \\
\hline FID & REFCAT & SUPERFICIE & $\begin{array}{c}\text { NÚMERO DE } \\
\text { PLANTAS }\end{array}$ & AÑo & $\begin{array}{c}\text { GRADO DE } \\
\text { DAÑO EMS-98 }\end{array}$ & $\begin{array}{l}\text { TIPOLOGIA } \\
\text { BTM }\end{array}$ & $\mathrm{IV}_{\mathrm{V}}^{*} \mathrm{BDILO3}_{\mathrm{N}}$ & $I_{V}^{*} E D \_G 1005$ & $\mathrm{I}_{\mathrm{V}}^{*}{ }^{*}$ ED_LAN07 & $\mathrm{IV}_{\mathrm{V}}^{*}{ }_{\text {ED_FER12 }}$ & IV*E_MAN16 & $\mathrm{IV}_{\mathrm{V}}{ }^{*} \mathrm{EL}_{-} \mathrm{ROD} 17$ \\
\hline 54 & $4804601 \times G$ & 127 & 4 & 1973 & 1 & $\mathrm{RC1}$ & 0,724 & 0,564 & 0,707 & 0,744 & 0,704 & 0,764 \\
\hline 55 & $5415006 \times \mathrm{G}$ & 145 & 4 & 1979 & 1 & $\mathrm{RC1}$ & 0,684 & 0,524 & 0,422 & 0,624 & 0,544 & 0,684 \\
\hline 56 & $4604907 \times G$ & 216 & 4 & 1978 & 2,5 & $\mathrm{RC1}$ & 0,744 & 0,564 & 0,562 & 0,764 & 0,724 & 0,784 \\
\hline 57 & $5212001 \times \mathrm{G}$ & 239 & 3 & 1964 & 2 & $\mathrm{RC1}$ & 0,724 & 0,564 & 0,752 & 0,804 & 0,684 & 0,884 \\
\hline 58 & $4598251 \times G$ & 277 & 4 & 2002 & 1 & $\mathrm{RC1}$ & 0,484 & 0,484 & 0,402 & 0,544 & 0,504 & 0,504 \\
\hline 59 & $4499313 \times G$ & 111 & 3 & 2007 & 2 & $\mathrm{RC1}$ & 0,444 & 0,464 & 0,482 & 0,504 & 0,504 & 0,624 \\
\hline 60 & $5115204 \times \mathrm{G}$ & 131 & 3 & 2003 & 1 & $\mathrm{RC1}$ & 0,464 & 0,464 & 0,382 & 0,524 & 0,524 & 0,564 \\
\hline 61 & $4497615 \times G$ & 160 & 4 & 1970 & 2,5 & $\mathrm{RC1}$ & 0,724 & 0,564 & 0,627 & 0,564 & 0,524 & 0,684 \\
\hline 62 & $4705021 \times G$ & 220 & 2 & 1988 & 1 & $\mathrm{RC1}$ & 0,644 & 0,504 & 0,342 & 0,544 & 0,464 & 0,604 \\
\hline 63 & $4400410 \times \mathrm{G}$ & 60 & 2 & 1975 & 1 & $\mathrm{RC1}$ & 0,684 & 0,544 & 0,462 & 0,624 & 0,584 & 0,724 \\
\hline 64 & $5118908 \times G$ & 148 & 3 & 2010 & 1 & $\mathrm{RC1}$ & 0,504 & 0,484 & 0,422 & 0,524 & 0,484 & 0,604 \\
\hline 65 & $5414902 \times G$ & 139 & 3 & 1962 & 2 & $\mathrm{RC1}$ & 0,644 & 0,504 & 0,712 & 0,604 & 0,604 & 0,724 \\
\hline 66 & $6119501 \times \mathrm{G}$ & 1.188 & 4 & 1972 & 2 & $\mathrm{RC1}$ & 0,724 & 0,544 & 0,567 & 0,644 & 0,604 & 0,744 \\
\hline 67 & $5215912 \times G$ & 140 & 3 & 1957 & 3 & $\mathrm{RC1}$ & 0,724 & 0,584 & 0,732 & 0,684 & 0,644 & 0,744 \\
\hline 68 & $4701001 \times G$ & 290 & 3 & 2003 & 2 & $\mathrm{RC1}$ & 0,444 & 0,464 & 0,462 & 0,564 & 0,564 & 0,604 \\
\hline 69 & $5314908 \times G$ & 191 & 3 & 1972 & 2 & $\mathrm{RC1}$ & 0,704 & 0,564 & 0,627 & 0,664 & 0,624 & 0,764 \\
\hline 70 & $4400510 \times \mathrm{G}$ & 189 & 3 & 1990 & 1 & $\mathrm{RC1}$ & 0,604 & 0,464 & 0,382 & 0,544 & 0,504 & 0,644 \\
\hline 71 & $4502215 \times G$ & 120 & 3 & 1984 & 2 & $\mathrm{RC} 1$ & 0,724 & 0,564 & 0,482 & 0,644 & 0,604 & 0,624 \\
\hline 72 & $6119801 \times \mathrm{X}$ & 789 & 4 & 1972 & 3 & $\mathrm{RC1}$ & 0,704 & 0,524 & 0,627 & 0,664 & 0,664 & 0,724 \\
\hline 73 & $4601019 \times \mathrm{XG}$ & 248 & 4 & 1997 & 0 & $\mathrm{RC1}$ & 0,484 & 0,504 & 0,442 & 0,584 & 0,544 & 0,544 \\
\hline 74 & $4500208 \times G$ & 224 & 4 & 1990 & 1 & $\mathrm{RC1}$ & 0,684 & 0,524 & 0,482 & 0,684 & 0,604 & 0,664 \\
\hline 75 & $4601024 \times G$ & 146 & 4 & 1978 & 2 & $\mathrm{RC1}$ & 0,724 & 0,564 & 0,502 & 0,664 & 0,624 & 0,684 \\
\hline 76 & $5814701 \times \mathrm{G}$ & 920 & 4 & 2000 & 1 & $\mathrm{RC} 1$ & 0,484 & 0,484 & 0,422 & 0,564 & 0,524 & 0,524 \\
\hline 77 & $4495041 \times G$ & 214 & 4 & 2008 & 2 & $\mathrm{RC1}$ & 0,484 & 0,504 & 0,422 & 0,484 & 0,444 & 0,524 \\
\hline 78 & $4505202 \times G$ & 144 & 4 & 1978 & 3 & $\mathrm{RC} 1$ & 0,744 & 0,564 & 0,502 & 0,704 & 0,664 & 0,724 \\
\hline 79 & $4396601 \times \mathrm{XG}$ & 178 & 2 & 1955 & 3 & $\mathrm{RC1}$ & 0,684 & 0,544 & 0,752 & 0,704 & 0,664 & 0,764 \\
\hline 80 & $4696008 \times G$ & 536 & 2 & 2001 & 1 & $\mathrm{RC1}$ & 0,444 & 0,484 & 0,482 & 0,584 & 0,584 & 0,624 \\
\hline
\end{tabular}

$I_{V}{ }_{E D}=$ Índice de vulnerabilidad representativo de la edificación; MILO3, GIO05, LAN07, FER12, MAN16, ROD17 = variantes del método MIV propuestas por Milutinovic \& Trendafiloski (2003), Giovinazzi (2005), Lantada (2007), Feriche (2012), Martínez-Cuevas \& Gaspar-Escribano (2016) y el modelo propuesto en esta tesis, respectivamente 


\begin{tabular}{|c|c|c|c|c|c|c|c|c|c|c|c|c|}
\hline \multicolumn{7}{|c|}{ A. INFORMACIÓN GENERAL Y OBSERVACIONES DE CAMPO } & \multicolumn{6}{|c|}{ B. OBTENCIÓN ÍNDICE DE VULNERABILIDAD } \\
\hline FID & REFCAT & SUPERFICIE & $\begin{array}{l}\text { NÚMERO DE } \\
\text { PLANTAS }\end{array}$ & AÑo & $\begin{array}{c}\text { GRADO DE } \\
\text { DAÑO EMS-98 }\end{array}$ & $\begin{array}{l}\text { TIPOLOGIA } \\
\text { BTM }\end{array}$ & $\mathrm{IV}_{\mathrm{ED}-\mathrm{MILO3}}^{*}$ & $\mathrm{I}_{\mathrm{V}}^{*} \mathrm{ED}_{-} \mathrm{GIO05}$ & IV*ED_LAN07 & $I_{V}^{*}$ ED_FER12 & $\mathrm{IV}_{\text {ED_MAN16 }}^{*}$ & IV ED ROD17 \\
\hline 81 & $4700005 \times G$ & 205 & 2 & 1998 & 1 & $\mathrm{RC1}$ & 0,444 & 0,484 & 0,502 & 0,604 & 0,604 & 0,644 \\
\hline 82 & $4497604 \times G$ & 322 & 3 & 2006 & 2 & $\mathrm{RC1}$ & 0,444 & 0,484 & 0,422 & 0,444 & 0,444 & 0,564 \\
\hline 83 & $5107209 \times \mathrm{XG}$ & 583 & 2 & 1985 & 1 & $\mathrm{RC1}$ & 0,644 & 0,504 & 0,362 & 0,564 & 0,484 & 0,624 \\
\hline 84 & $4395303 \times \mathrm{G}$ & 216 & 2 & 1956 & 2,5 & $\mathrm{RC1}$ & 0,684 & 0,544 & 0,672 & 0,624 & 0,584 & 0,684 \\
\hline 85 & $4698109 \times \mathrm{XG}$ & 349 & 4 & 1970 & 3 & $\mathrm{RC1}$ & 0,724 & 0,564 & 0,587 & 0,584 & 0,684 & 0,844 \\
\hline 86 & $6015814 \times G$ & 84 & 3 & 1965 & 2 & $\mathrm{RC1}$ & 0,684 & 0,544 & 0,772 & 0,684 & 0,664 & 0,784 \\
\hline 87 & $4498003 \times G$ & 671 & 3 & 1979 & 2 & $\mathrm{RC1}$ & 0,704 & 0,544 & 0,522 & 0,724 & 0,684 & 0,824 \\
\hline 88 & $4495043 \times G$ & 133 & 4 & 1994 & 1 & $\mathrm{RC1}$ & 0,644 & 0,484 & 0,422 & 0,584 & 0,544 & 0,604 \\
\hline 89 & $4396604 \times G$ & 178 & 2 & 1955 & 3 & $\mathrm{RC1}$ & 0,684 & 0,544 & 0,752 & 0,704 & 0,664 & 0,764 \\
\hline 90 & $4293803 \times G$ & 152 & 3 & 1975 & 2 & $\mathrm{RC1}$ & 0,684 & 0,544 & 0,502 & 0,664 & 0,624 & 0,764 \\
\hline 91 & $4397501 \times G$ & 184 & 3 & 1960 & 3 & $\mathrm{RC1}$ & 0,644 & 0,504 & 0,712 & 0,624 & 0,624 & 0,724 \\
\hline 92 & $6318012 \times G$ & 183 & 3 & 1984 & 1 & $\mathrm{RC1}$ & 0,604 & 0,464 & 0,342 & 0,504 & 0,464 & 0,604 \\
\hline 93 & $6015805 \times G$ & 150 & 4 & 1996 & 2 & $\mathrm{RC1}$ & 0,484 & 0,504 & 0,402 & 0,564 & 0,524 & 0,504 \\
\hline 94 & $5802004 \times G$ & 337 & 1 & 1987 & 2 & $\mathrm{RC1}$ & 0,684 & 0,544 & 0,342 & 0,544 & 0,464 & 0,604 \\
\hline 95 & $4393101 \times \mathrm{XG}$ & 2.020 & 4 & 1992 & 3 & $\mathrm{RC1}$ & 0,684 & 0,524 & 0,462 & 0,704 & 0,784 & 0,844 \\
\hline 96 & $4393002 \times \mathrm{XG}$ & 400 & 2 & 2002 & 1,5 & $\mathrm{RC1}$ & 0,444 & 0,464 & 0,482 & 0,584 & 0,584 & 0,624 \\
\hline 97 & $4396606 \times \mathrm{XG}$ & 178 & 2 & 1955 & 3 & $\mathrm{RC1}$ & 0,684 & 0,544 & 0,672 & 0,624 & 0,584 & 0,684 \\
\hline 98 & $5414702 \times \mathrm{G}$ & 139 & 4 & 1962 & 2 & $\mathrm{RC1}$ & 0,724 & 0,564 & 0,712 & 0,644 & 0,604 & 0,644 \\
\hline 99 & $4806015 \times \mathrm{XG}$ & 253 & 3 & 2008 & 1 & $\mathrm{RC1}$ & 0,464 & 0,484 & 0,482 & 0,524 & 0,544 & 0,664 \\
\hline 100 & $4396401 \times G$ & 185 & 3 & 1960 & 3 & $\mathrm{RC1}$ & 0,644 & 0,504 & 0,712 & 0,624 & 0,624 & 0,724 \\
\hline 101 & $6117501 \times G$ & 1.026 & 3 & 1975 & 1 & $\mathrm{RC1}$ & 0,724 & 0,584 & 0,542 & 0,684 & 0,664 & 0,804 \\
\hline 102 & $6118501 \times G$ & 1.123 & 3 & 1977 & 2 & $\mathrm{RC1}$ & 0,704 & 0,544 & 0,522 & 0,704 & 0,684 & 0,824 \\
\hline 103 & $4293202 \times \mathrm{XG}$ & 338 & 4 & 1969 & 3 & $\mathrm{RC1}$ & 0,724 & 0,564 & 0,707 & 0,744 & 0,724 & 0,764 \\
\hline 104 & $4503709 \times \mathrm{X}$ & 375 & 2 & 1980 & 1 & $\mathrm{RC1}$ & 0,644 & 0,504 & 0,382 & 0,584 & 0,504 & 0,724 \\
\hline 105 & $6116301 \times G$ & 568 & 3 & 1970 & 3 & $\mathrm{RC1}$ & 0,664 & 0,504 & 0,607 & 0,524 & 0,544 & 0,784 \\
\hline 106 & $4395002 \times G$ & 870 & 2 & 1989 & 2,5 & $\mathrm{RC1}$ & 0,644 & 0,504 & 0,362 & 0,564 & 0,484 & 0,624 \\
\hline 107 & $4705003 \times G$ & 219 & 3 & 1980 & 2 & $\mathrm{RC1}$ & 0,644 & 0,504 & 0,362 & 0,544 & 0,484 & 0,704 \\
\hline
\end{tabular}

$I_{V}{ }_{E D}=$ Índice de vulnerabilidad representativo de la edificación; MILO3, GIO05, LAN07, FER12, MAN16, ROD17 = variantes del método MIV propuestas por Milutinovic \& Trendafiloski (2003), Giovinazzi (2005), Lantada (2007), Feriche (2012), Martínez-Cuevas \& Gaspar-Escribano (2016) y el modelo propuesto en esta tesis, respectivamente 


\begin{tabular}{|c|c|c|c|c|c|c|c|c|c|c|c|c|}
\hline \multicolumn{7}{|c|}{ A. INFORMACIÓN GENERAL Y OBSERVACIONES DE CAMPO } & \multicolumn{6}{|c|}{ B. OBTENCIÓN ÍNDICE DE VULNERABILIDAD } \\
\hline FID & REFCAT & SUPERFICIE & $\begin{array}{l}\text { NÚMERO DE } \\
\text { PLANTAS }\end{array}$ & AÑo & $\begin{array}{c}\text { GRADO DE } \\
\text { DAÑO EMS-98 }\end{array}$ & $\begin{array}{l}\text { TIPOLOGIA } \\
\text { BTM }\end{array}$ & $\mathrm{IV}_{\mathrm{E}}^{*} \mathrm{ED}$ MIL03 & $\mathrm{IV}_{\mathrm{V}}^{*} \mathrm{ED} \_\mathrm{GIO05}$ & IV ${ }^{*}$ ED_LAN07 & $\mathrm{IV}_{\mathrm{V}}^{*}$ ED_FER12 & $I_{E D}^{*}$ MAN16 & $\mathrm{IV}_{\mathrm{V}}^{*} \mathrm{ED}_{\mathrm{R}} \mathrm{ROD} 17$ \\
\hline 108 & $4799027 X G$ & 319 & 4 & 1991 & 1 & $\mathrm{RC1}$ & 0,684 & 0,524 & 0,382 & 0,584 & 0,504 & 0,564 \\
\hline 109 & $5215940 \times \mathrm{G}$ & 685 & 4 & 2010 & 3 & $\mathrm{RC1}$ & 0,524 & 0,524 & 0,502 & 0,604 & 0,564 & 0,644 \\
\hline 110 & $4799025 \times \mathrm{XG}$ & 220 & 2 & 1970 & 2 & $\mathrm{RC1}$ & 0,684 & 0,544 & 0,627 & 0,564 & 0,524 & 0,764 \\
\hline 111 & $4910203 \times \mathrm{KG}$ & 156 & 3 & 1973 & 2,5 & $\mathrm{RC1}$ & 0,724 & 0,584 & 0,647 & 0,684 & 0,644 & 0,784 \\
\hline 112 & $4497614 \times G$ & 208 & 3 & 1969 & 2,5 & $\mathrm{RC1}$ & 0,704 & 0,564 & 0,567 & 0,624 & 0,584 & 0,704 \\
\hline 113 & $4395806 \mathrm{XG}$ & 180 & 2 & 1956 & 3 & $\mathrm{RC1}$ & 0,684 & 0,544 & 0,672 & 0,624 & 0,584 & 0,684 \\
\hline 114 & $6118101 \times \mathrm{X}$ & 854 & 3 & 1975 & 1 & $\mathrm{RCl}$ & 0,704 & 0,544 & 0,422 & 0,624 & 0,584 & 0,724 \\
\hline 115 & $4395805 \times \mathrm{XG}$ & 180 & 2 & 1956 & 3 & $\mathrm{RC1}$ & 0,684 & 0,544 & 0,752 & 0,704 & 0,664 & 0,764 \\
\hline 116 & $4704602 \times G$ & 1.123 & 3 & 1985 & 1 & $\mathrm{RC1}$ & 0,684 & 0,544 & 0,502 & 0,664 & 0,624 & 0,684 \\
\hline 117 & $4703021 \times G$ & 392 & 3 & 1975 & 3 & $\mathrm{RC1}$ & 0,684 & 0,544 & 0,542 & 0,704 & 0,664 & 0,804 \\
\hline 118 & $4193801 \times G$ & 1.093 & 3 & 1977 & 2,5 & $\mathrm{RC1}$ & 0,744 & 0,604 & 0,542 & 0,704 & 0,664 & 0,804 \\
\hline 119 & $5815918 \times G$ & 365 & 4 & 2002 & 2 & $\mathrm{RC1}$ & 0,484 & 0,504 & 0,482 & 0,684 & 0,784 & 0,784 \\
\hline 120 & $4499301 \times G$ & 124 & 3 & 1985 & 2 & $\mathrm{RC1}$ & 0,684 & 0,544 & 0,522 & 0,664 & 0,644 & 0,704 \\
\hline 121 & $4594704 \times G$ & 208 & 3 & 1977 & 2 & $\mathrm{RC1}$ & 0,684 & 0,544 & 0,422 & 0,584 & 0,544 & 0,684 \\
\hline 122 & $4910202 \times G$ & 109 & 3 & 1995 & 1 & $\mathrm{RC1}$ & 0,684 & 0,544 & 0,422 & 0,584 & 0,544 & 0,604 \\
\hline 123 & $4505916 \times \mathrm{XG}$ & 242 & 3 & 2009 & 1 & $\mathrm{RC1}$ & 0,444 & 0,484 & 0,422 & 0,444 & 0,444 & 0,564 \\
\hline 124 & $6117502 \times G$ & 168 & 2 & 1975 & 1,5 & $\mathrm{RC1}$ & 0,744 & 0,584 & 0,442 & 0,644 & 0,604 & 0,744 \\
\hline 125 & $6317008 \times G$ & 912 & 3 & 1972 & 1 & $\mathrm{RC1}$ & 0,644 & 0,504 & 0,647 & 0,644 & 0,644 & 0,784 \\
\hline 126 & $4697003 \times G$ & 544 & 4 & 1991 & 1 & $\mathrm{RC1}$ & 0,524 & 0,544 & 0,402 & 0,564 & 0,524 & 0,584 \\
\hline 127 & $4396605 \times \mathrm{XG}$ & 178 & 2 & 1955 & 3 & $\mathrm{RC1}$ & 0,684 & 0,544 & 0,752 & 0,704 & 0,664 & 0,764 \\
\hline 128 & $5311016 \times \mathrm{XG}$ & 3.608 & 8 & 1980 & 1 & $\mathrm{RC1}$ & 0,764 & 0,564 & 0,522 & 0,684 & 0,644 & 0,664 \\
\hline 129 & $6218101 \times \mathrm{X}$ & 176 & 2 & 1986 & 1 & $\mathrm{RC1}$ & 0,664 & 0,504 & 0,442 & 0,684 & 0,604 & 0,744 \\
\hline 130 & $4498407 \times G$ & 199 & 4 & 1980 & 1 & $\mathrm{RC1}$ & 0,684 & 0,524 & 0,402 & 0,604 & 0,524 & 0,664 \\
\hline 131 & $4695007 \times \mathrm{XG}$ & 225 & 4 & 1976 & 2,5 & $\mathrm{RC1}$ & 0,684 & 0,524 & 0,462 & 0,584 & 0,584 & 0,644 \\
\hline 132 & $4703014 \times \mathrm{XG}$ & 180 & 3 & 2002 & 2 & $\mathrm{RC1}$ & 0,644 & 0,504 & 0,382 & 0,524 & 0,484 & 0,524 \\
\hline 133 & $4295012 \times G$ & 606 & 1 & 2002 & 1 & $\mathrm{RC1}$ & 0,444 & 0,464 & 0,402 & 0,504 & 0,504 & 0,544 \\
\hline 134 & $4600019 \times \mathrm{X}$ & 161 & 4 & 1986 & 1 & $\mathrm{RCI}$ & 0,684 & 0,524 & 0,402 & 0,604 & 0,524 & 0,584 \\
\hline
\end{tabular}

$I_{V}{ }_{E D}=$ Índice de vulnerabilidad representativo de la edificación; MILO3, GIO05, LAN07, FER12, MAN16, ROD17 = variantes del método MIV propuestas por Milutinovic \& Trendafiloski (2003), Giovinazzi (2005), Lantada (2007), Feriche (2012), Martínez-Cuevas \& Gaspar-Escribano (2016) y el modelo propuesto en esta tesis, respectivamente 


\begin{tabular}{|c|c|c|c|c|c|c|c|c|c|c|c|c|}
\hline \multicolumn{7}{|c|}{ A. INFORMACIÓN GENERAL Y OBSERVACIONES DE CAMPO } & \multicolumn{6}{|c|}{ B. OBTENCIÓN ÍNDICE DE VULNERABILIDAD } \\
\hline FID & REFCAT & SUPERFICIE & $\begin{array}{l}\text { NÚMERO DE } \\
\text { PLANTAS }\end{array}$ & AÑo & $\begin{array}{c}\text { GRADO DE } \\
\text { DAÑO EMS-98 }\end{array}$ & $\begin{array}{l}\text { TIPOLOGIA } \\
\text { BTM }\end{array}$ & IV*ED_MILO3 & $I_{V}^{*} E D_{-} G 1005$ & IV*ED_LANO7 & $I_{V}^{*}$ ED_FER12 & IV*ED_MAN16 & $\mathrm{IV}_{\mathrm{VE}-\mathrm{ROD} 17}$ \\
\hline 135 & $4598243 \times G$ & 174 & 4 & 1995 & 1 & $\mathrm{RC1}$ & 0,644 & 0,484 & 0,462 & 0,624 & 0,584 & 0,644 \\
\hline 136 & $4395801 \times G$ & 180 & 2 & 1956 & 3 & $\mathrm{RC1}$ & 0,684 & 0,544 & 0,752 & 0,704 & 0,664 & 0,764 \\
\hline 137 & $5311012 \times \mathrm{G}$ & 356 & 4 & 1966 & 2 & $\mathrm{RC1}$ & 0,724 & 0,564 & 0,692 & 0,624 & 0,584 & 0,624 \\
\hline 138 & $5415024 \times \mathrm{G}$ & 1.159 & 4 & 2000 & 2,5 & $\mathrm{RC1}$ & 0,484 & 0,484 & 0,462 & 0,604 & 0,564 & 0,564 \\
\hline 139 & $5001001 \times G$ & 1.278 & 9 & 1982 & 1 & $\mathrm{RC1}$ & 0,764 & 0,564 & 0,522 & 0,684 & 0,644 & 0,584 \\
\hline 140 & $5110014 \times G$ & 5.078 & 6 & 1981 & 2 & $\mathrm{RC1}$ & 0,684 & 0,524 & 0,442 & 0,604 & 0,564 & 0,624 \\
\hline 141 & $6118102 \times G$ & 578 & 3 & 1972 & 2 & $\mathrm{RC1}$ & 0,704 & 0,544 & 0,647 & 0,724 & 0,684 & 0,824 \\
\hline 142 & $5000602 \times \mathrm{G}$ & 1.086 & 5 & 1976 & 2,5 & $\mathrm{RC1}$ & 0,684 & 0,524 & 0,562 & 0,744 & 0,884 & 0,944 \\
\hline 142 & $5016051 \times G$ & 103 & 3 & 2005 & 1 & $\mathrm{RCl}$ & 0,464 & 0,504 & 0,422 & 0,484 & 0,444 & 0,564 \\
\hline 143 & $4700011 \times G$ & 104 & 3 & 1967 & 1 & $\mathrm{RC1}$ & 0,684 & 0,544 & 0,692 & 0,624 & 0,584 & 0,704 \\
\hline 144 & $6118401 \times G$ & 276 & 3 & 1969 & 3 & $\mathrm{RC1}$ & 0,724 & 0,564 & 0,607 & 0,664 & 0,664 & 0,744 \\
\hline 145 & $5704003 \times \mathrm{KG}$ & 348 & 1 & 1996 & 3 & $\mathrm{RC1}$ & 0,484 & 0,504 & 0,382 & 0,624 & 0,544 & 0,644 \\
\hline 146 & $6117102 \times G$ & 535 & 3 & 1970 & 2 & $\mathrm{RC1}$ & 0,704 & 0,544 & 0,667 & 0,624 & 0,604 & 0,844 \\
\hline 147 & $4710706 \times \mathrm{XG}$ & 370 & 3 & 1978 & 2 & $\mathrm{RC1}$ & 0,724 & 0,564 & 0,542 & 0,824 & 0,704 & 0,924 \\
\hline 148 & $4804003 \times G$ & 860 & 4 & 1999 & 2 & $\mathrm{RC1}$ & 0,544 & 0,544 & 0,402 & 0,544 & 0,504 & 0,504 \\
\hline 149 & $4805209 \times \mathrm{XG}$ & 183 & 2 & 1996 & 1 & $\mathrm{RC1}$ & 0,444 & 0,464 & 0,382 & 0,504 & 0,504 & 0,524 \\
\hline 150 & $5009804 \times G$ & 284 & 4 & 2003 & 1 & $\mathrm{RC1}$ & 0,524 & 0,544 & 0,422 & 0,564 & 0,524 & 0,524 \\
\hline 151 & $5716009 \times \mathrm{XG}$ & 554 & 4 & 2003 & 1,5 & $\mathrm{RC1}$ & 0,484 & 0,504 & 0,422 & 0,564 & 0,524 & 0,524 \\
\hline 152 & $6114302 \times G$ & 610 & 4 & 1998 & 1 & $\mathrm{RC1}$ & 0,524 & 0,504 & 0,462 & 0,644 & 0,564 & 0,564 \\
\hline 153 & $5311020 \times G$ & 457 & 3 & 1998 & 2 & $\mathrm{RC1}$ & 0,444 & 0,484 & 0,402 & 0,504 & 0,504 & 0,544 \\
\hline 154 & $5614701 \times G$ & 360 & 3 & 1971 & 2,5 & $\mathrm{RC1}$ & 0,684 & 0,544 & 0,627 & 0,664 & 0,624 & 0,764 \\
\hline 155 & $5514301 \times \mathrm{G}$ & 352 & 3 & 1971 & 3 & $\mathrm{RC1}$ & 0,684 & 0,544 & 0,667 & 0,704 & 0,664 & 0,804 \\
\hline 156 & $4496001 \times G$ & 185 & 3 & 1960 & 3 & $\mathrm{RC1}$ & 0,644 & 0,504 & 0,712 & 0,624 & 0,624 & 0,724 \\
\hline 157 & $5604104 \times G$ & 330 & 2 & 1971 & 1 & $\mathrm{RC1}$ & 0,724 & 0,584 & 0,587 & 0,724 & 0,784 & 0,924 \\
\hline 158 & $6117101 \times \mathrm{X}$ & 1.056 & 3 & 1971 & 2,5 & $\mathrm{RC1}$ & 0,704 & 0,544 & 0,667 & 0,724 & 0,704 & 0,844 \\
\hline 159 & $4915701 \times G$ & 314 & 5 & 1978 & 1 & $\mathrm{RC1}$ & 0,724 & 0,564 & 0,582 & 0,704 & 0,704 & 0,764 \\
\hline 160 & $5515601 \times G$ & 328 & 5 & 1970 & 1,5 & $\mathrm{RC1}$ & 0,764 & 0,604 & 0,707 & 0,644 & 0,604 & 0,764 \\
\hline
\end{tabular}

$I_{V}{ }_{E D}=$ Índice de vulnerabilidad representativo de la edificación; MILO3, GIO05, LAN07, FER12, MAN16, ROD17 = variantes del método MIV propuestas por Milutinovic \& Trendafiloski (2003), Giovinazzi (2005), Lantada (2007), Feriche (2012), Martínez-Cuevas \& Gaspar-Escribano (2016) y el modelo propuesto en esta tesis, respectivamente 


\begin{tabular}{|c|c|c|c|c|c|c|c|c|c|c|c|c|}
\hline \multicolumn{7}{|c|}{ A. INFORMACIÓN GENERAL Y OBSERVACIONES DE CAMPO } & \multicolumn{6}{|c|}{ B. OBTENCIÓN ÍNDICE DE VULNERABILIDAD } \\
\hline FID & REFCAT & SUPERFICIE & $\begin{array}{l}\text { NÚMERO DE } \\
\text { PLANTAS }\end{array}$ & AÑo & $\begin{array}{c}\text { GRADO DE } \\
\text { DAÑO EMS-98 }\end{array}$ & $\begin{array}{l}\text { TIPOLOGIA } \\
\text { BTM }\end{array}$ & $\mathrm{IV}_{\mathrm{V}}^{*} \mathrm{ED}_{\mathrm{N}} \mathrm{MILO3}$ & $I_{V}^{*} E D_{-} G 1005$ & IV*E_LAN07 & $\mathrm{I}_{\mathrm{V}}^{*}$ ED_FER12 & IV*ED_MAN16 & $I_{V}^{*} E_{E-R O D 17}$ \\
\hline 161 & $4907009 \times G$ & 155 & 3 & 2003 & 2 & $\mathrm{RC1}$ & 0,444 & 0,484 & 0,382 & 0,484 & 0,484 & 0,524 \\
\hline 162 & $6118901 \times G$ & 279 & 3 & 1969 & 3 & $\mathrm{RC1}$ & 0,724 & 0,564 & 0,607 & 0,664 & 0,664 & 0,744 \\
\hline 163 & $4702813 \times \mathrm{XG}$ & 103 & 3 & 1975 & 2 & $\mathrm{RC1}$ & 0,684 & 0,544 & 0,442 & 0,604 & 0,564 & 0,704 \\
\hline 164 & $5395010 \times \mathrm{G}$ & 170 & 4 & 1989 & 1 & $\mathrm{RC1}$ & 0,724 & 0,564 & 0,422 & 0,664 & 0,544 & 0,604 \\
\hline 165 & $5097401 \times G$ & 531 & 10 & 1984 & 2 & $\mathrm{RC1}$ & 0,764 & 0,564 & 0,522 & 0,684 & 0,644 & 0,584 \\
\hline 166 & $4395802 \times G$ & 180 & 2 & 1956 & 3 & $\mathrm{RC1}$ & 0,684 & 0,544 & 0,752 & 0,704 & 0,664 & 0,764 \\
\hline 167 & $5914901 \times G$ & 920 & 4 & 1990 & 2 & $\mathrm{RCl}$ & 0,644 & 0,484 & 0,422 & 0,644 & 0,744 & 0,804 \\
\hline 168 & $5715027 \times G$ & 3.659 & 4 & 1998 & 2 & $\mathrm{RC1}$ & 0,524 & 0,524 & 0,442 & 0,584 & 0,544 & 0,544 \\
\hline 169 & $4194803 \times G$ & 475 & 3 & 1981 & 1 & $\mathrm{RC1}$ & 0,704 & 0,544 & 0,522 & 0,724 & 0,684 & 0,744 \\
\hline 170 & $5108013 \times \mathrm{XG}$ & 341 & 7 & 1989 & 1 & $\mathrm{RC1}$ & 0,684 & 0,524 & 0,482 & 0,684 & 0,604 & 0,664 \\
\hline 172 & $5105001 \times G$ & 1.396 & 7 & 1975 & 2 & $\mathrm{RC1}$ & 0,684 & 0,524 & 0,502 & 0,644 & 0,624 & 0,764 \\
\hline 173 & $4600007 \times G$ & 106 & 3 & 1973 & 1,5 & $\mathrm{RC1}$ & 0,684 & 0,544 & 0,567 & 0,584 & 0,564 & 0,704 \\
\hline 174 & $5296901 \times G$ & 426 & 4 & 2005 & 1 & $\mathrm{RC1}$ & 0,484 & 0,484 & 0,382 & 0,444 & 0,404 & 0,484 \\
\hline 175 & $5914601 \times G$ & 646 & 4 & 1990 & 2 & $\mathrm{RC1}$ & 0,644 & 0,484 & 0,422 & 0,584 & 0,544 & 0,604 \\
\hline 176 & $5105004 \times G$ & 1.695 & 4 & 2005 & 1,5 & $\mathrm{RC1}$ & 0,544 & 0,544 & 0,462 & 0,564 & 0,684 & 0,764 \\
\hline 177 & $4293810 \times \mathrm{XG}$ & 263 & 3 & 1976 & 3 & $\mathrm{RC1}$ & 0,684 & 0,544 & 0,522 & 0,684 & 0,644 & 0,784 \\
\hline 178 & $4902001 \times G$ & 1.379 & 10 & 1973 & 2 & $\mathrm{RC1}$ & 0,804 & 0,604 & 0,727 & 0,704 & 0,724 & 0,664 \\
\hline 179 & $4697011 X G$ & 617 & 4 & 1973 & 3 & $\mathrm{RC} 1$ & 0,724 & 0,564 & 0,587 & 0,684 & 0,784 & 0,844 \\
\hline 180 & $5006008 \times G$ & 301 & 3 & 1973 & 2 & $\mathrm{RC1}$ & 0,684 & 0,544 & 0,647 & 0,684 & 0,644 & 0,784 \\
\hline 181 & $5115610 \times \mathrm{G}$ & 169 & 3 & 1973 & 2 & $\mathrm{RC1}$ & 0,704 & 0,544 & 0,587 & 0,664 & 0,624 & 0,764 \\
\hline 182 & $4295014 \times G$ & 259 & 2 & 1999 & 2 & $\mathrm{RC1}$ & 0,484 & 0,504 & 0,382 & 0,604 & 0,524 & 0,644 \\
\hline 183 & $4705004 \times G$ & 319 & 3 & 1979 & 1 & $\mathrm{RC1}$ & 0,684 & 0,544 & 0,462 & 0,624 & 0,584 & 0,724 \\
\hline 184 & $5212002 \times G$ & 428 & 2 & 1970 & 3 & $\mathrm{RC1}$ & 0,684 & 0,544 & 0,587 & 0,524 & 0,484 & 0,724 \\
\hline 185 & $5111024 \times G$ & 1.380 & 4 & 1988 & 2 & $\mathrm{RC1}$ & 0,724 & 0,564 & 0,442 & 0,644 & 0,564 & 0,624 \\
\hline 186 & $4806001 \times G$ & 356 & 2 & 2000 & 1 & $\mathrm{RC1}$ & 0,484 & 0,524 & 0,482 & 0,584 & 0,584 & 0,624 \\
\hline 187 & $5108002 \times G$ & 294 & 4 & 1992 & 2 & $\mathrm{RC1}$ & 0,644 & 0,484 & 0,382 & 0,544 & 0,504 & 0,564 \\
\hline 188 & $6216237 \times G$ & 364 & 3 & 2008 & 2 & $\mathrm{RC1}$ & 0,444 & 0,464 & 0,382 & 0,404 & 0,404 & 0,524 \\
\hline
\end{tabular}

$I_{V}{ }_{E D}=$ Índice de vulnerabilidad representativo de la edificación; MILO3, GIO05, LAN07, FER12, MAN16, ROD17 = variantes del método MIV propuestas por Milutinovic \& Trendafiloski (2003), Giovinazzi (2005), Lantada (2007), Feriche (2012), Martínez-Cuevas \& Gaspar-Escribano (2016) y el modelo propuesto en esta tesis, respectivamente 


\begin{tabular}{|c|c|c|c|c|c|c|c|c|c|c|c|c|}
\hline \multicolumn{7}{|c|}{ A. INFORMACIÓN GENERAL Y OBSERVACIONES DE CAMPO } & \multicolumn{6}{|c|}{ B. OBTENCIÓN ÍNDICE DE VULNERABILIDAD } \\
\hline FID & REFCAT & SUPERFICIE & $\begin{array}{l}\text { NÚMERO DE } \\
\text { PLANTAS }\end{array}$ & AÑo & $\begin{array}{c}\text { GRADO DE } \\
\text { DAÑO EMS-98 }\end{array}$ & $\begin{array}{l}\text { TIPOLOGIA } \\
\text { BTM }\end{array}$ & $\mathrm{IV}_{\mathrm{E}}^{*} \mathrm{ED}$ MIL03 & $\mathrm{I}_{V}^{*}$ ED_GIO05 & IV*ED_LAN07 & $I_{V}^{*}$ ED_FER12 & $I^{*}{ }_{E D}{ }_{-}$MAN16 & $\mathrm{IV}_{\mathrm{E}}^{*} \mathrm{ED}_{\mathrm{R}} \mathrm{ROD17}$ \\
\hline 189 & $5116016 \times \mathrm{XG}$ & 124 & 4 & 1998 & 2 & $\mathrm{RC} 1$ & 0,484 & 0,504 & 0,462 & 0,604 & 0,564 & 0,564 \\
\hline 190 & $4998501 \times G$ & 139 & 2 & 2007 & 1 & $\mathrm{RC1}$ & 0,444 & 0,484 & 0,462 & 0,484 & 0,484 & 0,604 \\
\hline 191 & $4803004 X G$ & 146 & 4 & 1994 & 2 & $\mathrm{RC1}$ & 0,684 & 0,504 & 0,402 & 0,604 & 0,524 & 0,584 \\
\hline 192 & $4395302 \times \mathrm{XG}$ & 216 & 2 & 1956 & 2 & $\mathrm{RC1}$ & 0,684 & 0,544 & 0,752 & 0,704 & 0,664 & 0,764 \\
\hline 193 & $5716025 \times \mathrm{G}$ & 465 & 4 & 2004 & 0 & $\mathrm{RC} 1$ & 0,484 & 0,484 & 0,482 & 0,624 & 0,584 & 0,584 \\
\hline 194 & $4605016 \times \mathrm{XG}$ & 238 & 2 & 1970 & 1 & $\mathrm{RC1}$ & 0,684 & 0,544 & 0,547 & 0,484 & 0,444 & 0,684 \\
\hline 195 & $4903009 \times \mathrm{XG}$ & 1.017 & 8 & 1983 & 2 & $\mathrm{RC} 1$ & 0,764 & 0,564 & 0,482 & 0,644 & 0,604 & 0,544 \\
\hline 196 & $4193602 \times G$ & 554 & 3 & 1996 & 3 & $\mathrm{RC} 1$ & 0,644 & 0,504 & 0,462 & 0,624 & 0,584 & 0,604 \\
\hline 197 & $4903015 \mathrm{XG}$ & 91 & 7 & 2002 & 1 & $\mathrm{RC1}$ & 0,524 & 0,524 & 0,382 & 0,524 & 0,484 & 0,484 \\
\hline 198 & $5110004 \times G$ & 630 & 3 & 1995 & 1 & $\mathrm{RC} 1$ & 0,644 & 0,504 & 0,422 & 0,624 & 0,544 & 0,684 \\
\hline 199 & $4903001 \times G$ & 158 & 7 & 1993 & 2 & $\mathrm{RC} 1$ & 0,684 & 0,524 & 0,482 & 0,644 & 0,604 & 0,664 \\
\hline 200 & $4807005 \times G$ & 416 & 3 & 1979 & 1 & $\mathrm{RC1}$ & 0,644 & 0,504 & 0,342 & 0,544 & 0,464 & 0,684 \\
\hline 201 & $5112802 \times \mathrm{G}$ & 855 & 3 & 2000 & 2 & $\mathrm{RC} 1$ & 0,484 & 0,504 & 0,422 & 0,524 & 0,524 & 0,564 \\
\hline 202 & $5107014 \times \mathrm{XG}$ & 505 & 7 & 1973 & 2 & $\mathrm{RC1}$ & 0,724 & 0,564 & 0,687 & 0,704 & 0,684 & 0,744 \\
\hline 203 & $5119201 \times G$ & 693 & 4 & 2007 & 2 & $\mathrm{RC} 1$ & 0,504 & 0,484 & 0,482 & 0,644 & 0,744 & 0,824 \\
\hline 204 & $5311005 \times G$ & 129 & 7 & 2010 & 1 & $\mathrm{RC} 1$ & 0,524 & 0,504 & 0,462 & 0,564 & 0,484 & 0,564 \\
\hline 205 & $5196909 \times \mathrm{XG}$ & 983 & 4 & 1992 & 2,5 & $\mathrm{RC1}$ & 0,644 & 0,484 & 0,482 & 0,644 & 0,604 & 0,664 \\
\hline 206 & $6014201 \times G$ & 460 & 4 & 2001 & 1 & $\mathrm{RC1}$ & 0,484 & 0,484 & 0,422 & 0,564 & 0,524 & 0,524 \\
\hline 207 & $5196908 \times G$ & 369 & 4 & 1992 & 0 & $\mathrm{RC1}$ & 0,644 & 0,484 & 0,482 & 0,644 & 0,604 & 0,664 \\
\hline 208 & $5214007 \times \mathrm{G}$ & 1.208 & 3 & 2002 & 3 & $\mathrm{RC} 1$ & 0,444 & 0,464 & 0,482 & 0,644 & 0,784 & 0,824 \\
\hline 209 & $5004805 \times G$ & 640 & 4 & 2002 & 1 & $\mathrm{RC} 1$ & 0,444 & 0,464 & 0,462 & 0,564 & 0,564 & 0,564 \\
\hline 210 & $4905010 \times \mathrm{G}$ & 191 & 4 & 1970 & 2 & $\mathrm{RC1}$ & 0,724 & 0,564 & 0,607 & 0,544 & 0,504 & 0,664 \\
\hline 211 & $4604220 \times G$ & 111 & 4 & 1965 & 2 & $\mathrm{RC} 1$ & 0,744 & 0,564 & 0,752 & 0,724 & 0,684 & 0,724 \\
\hline 212 & $4703006 \times \mathrm{XG}$ & 438 & 4 & 1974 & 2,5 & $\mathrm{RC1}$ & 0,744 & 0,564 & 0,627 & 0,684 & 0,664 & 0,724 \\
\hline 213 & $4495040 \times G$ & 155 & 3 & 1992 & 2 & $\mathrm{RC} 1$ & 0,644 & 0,504 & 0,342 & 0,544 & 0,464 & 0,604 \\
\hline 214 & $4903013 \times \mathrm{XG}$ & 2.821 & 7 & 1981 & 3 & $\mathrm{RC1}$ & 0,744 & 0,584 & 0,442 & 0,624 & 0,564 & 0,624 \\
\hline 215 & $4601014 \times G$ & 405 & 4 & 1974 & 1,5 & $\mathrm{RC1}$ & 0,724 & 0,564 & 0,587 & 0,624 & 0,584 & 0,644 \\
\hline
\end{tabular}

$I_{V}{ }_{E D}=$ Índice de vulnerabilidad representativo de la edificación; MILO3, GIO05, LAN07, FER12, MAN16, ROD17 = variantes del método MIV propuestas por Milutinovic \& Trendafiloski (2003), Giovinazzi (2005), Lantada (2007), Feriche (2012), Martínez-Cuevas \& Gaspar-Escribano (2016) y el modelo propuesto en esta tesis, respectivamente 


\begin{tabular}{|c|c|c|c|c|c|c|c|c|c|c|c|c|}
\hline \multicolumn{7}{|c|}{ A. INFORMACIÓN GENERAL Y OBSERVACIONES DE CAMPO } & \multicolumn{6}{|c|}{ B. OBTENCIÓN ÍNDICE DE VULNERABILIDAD } \\
\hline FID & REFCAT & SUPERFICIE & $\begin{array}{l}\text { NÚMERO DE } \\
\text { PLANTAS }\end{array}$ & AÑo & $\begin{array}{c}\text { GRADO DE } \\
\text { DAÑO EMS-98 }\end{array}$ & $\begin{array}{l}\text { TIPOLOGIA } \\
\text { BTM }\end{array}$ & $\mathrm{I}_{\mathrm{V}}^{*} \mathrm{ED}_{-} \mathrm{MILO3}$ & $I_{V}^{*} E D \_G 1005$ & IV ${ }^{*}$ ED_LAN07 & $I_{V}^{*}$ ED_FER12 & IV*ED_MAN16 & $I_{V}^{*}{ }_{E D} R_{R O D 17}$ \\
\hline 216 & $5314003 \times \mathrm{X}$ & 200 & 4 & 1970 & 2 & $\mathrm{RC1}$ & 0,724 & 0,564 & 0,707 & 0,624 & 0,604 & 0,764 \\
\hline 217 & $5802021 X G$ & 258 & 1 & 2008 & 1 & $\mathrm{RC} 1$ & 0,444 & 0,464 & 0,422 & 0,444 & 0,444 & 0,564 \\
\hline 218 & $4189006 \times \mathrm{XG}$ & 211 & 1 & 2011 & 1 & $\mathrm{RC1}$ & 0,444 & 0,464 & 0,382 & 0,404 & 0,404 & 0,524 \\
\hline 219 & $5212020 \times \mathrm{G}$ & 100 & 2 & 1961 & 1 & $\mathrm{RC1}$ & 0,684 & 0,544 & 0,752 & 0,684 & 0,644 & 0,764 \\
\hline 220 & $4598240 \times G$ & 229 & 4 & 1985 & 0 & $\mathrm{RC1}$ & 0,684 & 0,524 & 0,402 & 0,604 & 0,524 & 0,584 \\
\hline 221 & $4393102 X G$ & 363 & 2 & 1996 & 2 & $\mathrm{RC1}$ & 0,464 & 0,484 & 0,502 & 0,624 & 0,624 & 0,644 \\
\hline 222 & $4600020 \times G$ & 153 & 3 & 1981 & 2 & $\mathrm{RC1}$ & 0,644 & 0,504 & 0,342 & 0,544 & 0,464 & 0,604 \\
\hline 223 & $5311013 \times \mathrm{X}$ & 281 & 3 & 1966 & 1 & $\mathrm{RC1}$ & 0,684 & 0,544 & 0,632 & 0,564 & 0,524 & 0,644 \\
\hline 224 & $4604610 \times G$ & 378 & 4 & 2000 & 2 & $\mathrm{RC1}$ & 0,514 & 0,514 & 0,502 & 0,644 & 0,604 & 0,604 \\
\hline 225 & $5000301 \times G$ & 927 & 5 & 1980 & 2 & $\mathrm{RC1}$ & 0,684 & 0,524 & 0,442 & 0,624 & 0,564 & 0,704 \\
\hline 226 & $4697001 \times G$ & 512 & 4 & 1989 & 2 & $\mathrm{RC1}$ & 0,644 & 0,484 & 0,482 & 0,704 & 0,804 & 0,864 \\
\hline 227 & $4604607 \times \mathrm{XG}$ & 317 & 4 & 1984 & 1,5 & $\mathrm{RC1}$ & 0,704 & 0,524 & 0,482 & 0,724 & 0,644 & 0,704 \\
\hline 228 & $4495017 \times G$ & 357 & 4 & 1990 & 2 & $\mathrm{RC1}$ & 0,684 & 0,524 & 0,402 & 0,604 & 0,524 & 0,584 \\
\hline 229 & $4395005 \times G$ & 796 & 3 & 1999 & 2 & $\mathrm{RC1}$ & 0,544 & 0,544 & 0,462 & 0,604 & 0,564 & 0,604 \\
\hline 230 & $5004810 \times G$ & 703 & 6 & 1974 & 2 & $\mathrm{RC1}$ & 0,724 & 0,564 & 0,707 & 0,724 & 0,704 & 0,764 \\
\hline 231 & $4295001 \times G$ & 713 & 1 & 1990 & 2 & $\mathrm{RC} 1$ & 0,604 & 0,464 & 0,442 & 0,604 & 0,564 & 0,704 \\
\hline 232 & $4803010 \times \mathrm{X}$ & 937 & 3 & 1997 & 2,5 & $\mathrm{RC1}$ & 0,484 & 0,484 & 0,462 & 0,604 & 0,564 & 0,604 \\
\hline 233 & $4293805 \times G$ & 164 & 4 & 1969 & 2 & $\mathrm{RC} 1$ & 0,744 & 0,584 & 0,707 & 0,844 & 0,724 & 0,844 \\
\hline 234 & $5006003 \times \mathrm{X}$ & 585 & 7 & 1970 & 2 & $\mathrm{RC1}$ & 0,724 & 0,564 & 0,607 & 0,524 & 0,504 & 0,664 \\
\hline 235 & $5105009 \times \mathrm{XG}$ & 710 & 7 & 1981 & 1 & $\mathrm{RC1}$ & 0,724 & 0,564 & 0,402 & 0,604 & 0,524 & 0,584 \\
\hline 236 & $4701007 \times G$ & 674 & 4 & 1975 & 2 & $\mathrm{RC1}$ & 0,724 & 0,564 & 0,482 & 0,644 & 0,604 & 0,664 \\
\hline 237 & $4706709 \times \mathrm{XG}$ & 116 & 4 & 1970 & 1,5 & RC1 & 0,744 & 0,564 & 0,707 & 0,684 & 0,644 & 0,804 \\
\hline 238 & $5111026 \times \mathrm{G}$ & 188 & 3 & 1975 & 2,5 & $\mathrm{RC} 1$ & 0,684 & 0,544 & 0,442 & 0,604 & 0,564 & 0,704 \\
\hline 239 & $4291615 \times \mathrm{XG}$ & 314 & 2 & 1993 & 2 & $\mathrm{RC1}$ & 0,644 & 0,504 & 0,362 & 0,564 & 0,484 & 0,624 \\
\hline 240 & $5311023 \times \mathrm{G}$ & 122 & 3 & 1980 & 1 & $\mathrm{RC} 1$ & 0,644 & 0,504 & 0,362 & 0,564 & 0,484 & 0,704 \\
\hline 241 & $5107015 \times \mathrm{XG}$ & 347 & 7 & 1987 & 2 & $\mathrm{RC1}$ & 0,724 & 0,564 & 0,402 & 0,644 & 0,524 & 0,584 \\
\hline 242 & $4905004 \times G$ & 1.075 & 8 & 1975 & 2 & $\mathrm{RC} 1$ & 0,764 & 0,604 & 0,522 & 0,704 & 0,644 & 0,664 \\
\hline
\end{tabular}

$I_{V}{ }_{E D}=$ Índice de vulnerabilidad representativo de la edificación; MILO3, GIO05, LAN07, FER12, MAN16, ROD17 = variantes del método MIV propuestas por Milutinovic \& Trendafiloski (2003), Giovinazzi (2005), Lantada (2007), Feriche (2012), Martínez-Cuevas \& Gaspar-Escribano (2016) y el modelo propuesto en esta tesis, respectivamente 


\begin{tabular}{|c|c|c|c|c|c|c|c|c|c|c|c|c|}
\hline \multicolumn{7}{|c|}{ A. INFORMACIÓN GENERAL Y OBSERVACIONES DE CAMPO } & \multicolumn{6}{|c|}{ B. OBTENCIÓN ÍNDICE DE VULNERABILIDAD } \\
\hline FID & REFCAT & SUPERFICIE & $\begin{array}{l}\text { NÚMERO DE } \\
\text { PLANTAS }\end{array}$ & AÑo & $\begin{array}{c}\text { GRADO DE } \\
\text { DAÑO EMS-98 }\end{array}$ & $\begin{array}{c}\text { TIPOLOGIA } \\
\text { BTM }\end{array}$ & $\mathrm{IV}_{\mathrm{ED}-\mathrm{MILO3}}^{*}$ & $\mathrm{I}_{\mathrm{V}}^{*} \mathrm{ED}_{-} \mathrm{GIO05}$ & IV*ED_LAN07 & $I_{V}^{*}$ ED_FER12 & $\mathrm{IV}_{\text {ED_MAN16 }}^{*}$ & IV ED_ROD17 \\
\hline 243 & 5097219XG & 411 & 2 & 2005 & 1 & $\mathrm{RC1}$ & 0,444 & 0,464 & 0,522 & 0,544 & 0,544 & 0,664 \\
\hline 244 & 4191103XG & 353 & 4 & 1974 & 2,5 & $\mathrm{RC1}$ & 0,764 & 0,604 & 0,607 & 0,644 & 0,604 & 0,664 \\
\hline 245 & $4498203 \times G$ & 1.071 & 5 & 2007 & 2 & $\mathrm{RC1}$ & 0,504 & 0,504 & 0,422 & 0,604 & 0,644 & 0,724 \\
\hline 246 & $4293808 \times G$ & 226 & 4 & 2005 & 2 & $\mathrm{RC1}$ & 0,544 & 0,504 & 0,382 & 0,524 & 0,444 & 0,524 \\
\hline 247 & $5107007 \times G$ & 985 & 3 & 1987 & 3 & $\mathrm{RC1}$ & 0,484 & 0,504 & 0,482 & 0,604 & 0,604 & 0,704 \\
\hline 248 & $5000802 \times G$ & 828 & 5 & 1975 & 2 & $\mathrm{RC1}$ & 0,724 & 0,564 & 0,562 & 0,724 & 0,684 & 0,744 \\
\hline 249 & $4294801 \times G$ & 745 & 4 & 1984 & 2 & $\mathrm{RC1}$ & 0,724 & 0,564 & 0,502 & 0,704 & 0,624 & 0,684 \\
\hline 250 & $4804615 \times \mathrm{XG}$ & 573 & 4 & 1990 & 1 & $\mathrm{RC1}$ & 0,684 & 0,524 & 0,362 & 0,564 & 0,484 & 0,544 \\
\hline 251 & $4804614 X G$ & 145 & 4 & 1996 & 2 & $\mathrm{RC1}$ & 0,524 & 0,524 & 0,382 & 0,584 & 0,504 & 0,484 \\
\hline 252 & $4700012 \times G$ & 148 & 3 & 1965 & 2 & $\mathrm{RC1}$ & 0,684 & 0,544 & 0,672 & 0,604 & 0,564 & 0,684 \\
\hline 253 & $5615235 \mathrm{XG}$ & 333 & 4 & 2010 & 1,5 & $\mathrm{RC1}$ & 0,524 & 0,504 & 0,422 & 0,524 & 0,444 & 0,524 \\
\hline 254 & $4193604 \times G$ & 527 & 3 & 1976 & 2 & $\mathrm{RC1}$ & 0,684 & 0,544 & 0,422 & 0,584 & 0,544 & 0,684 \\
\hline 255 & $5415809 \times \mathrm{XG}$ & 103 & 2 & 1970 & 2 & $\mathrm{RC1}$ & 0,684 & 0,544 & 0,587 & 0,524 & 0,484 & 0,724 \\
\hline 256 & $4604221 \times G$ & 111 & 2 & 1965 & 1 & $\mathrm{RC1}$ & 0,684 & 0,544 & 0,632 & 0,564 & 0,524 & 0,644 \\
\hline 257 & $3993201 \times G$ & 770 & 1 & 1998 & 1 & $\mathrm{RC1}$ & 0,444 & 0,464 & 0,422 & 0,524 & 0,524 & 0,564 \\
\hline 258 & $5814012 \times G$ & 266 & 4 & 1990 & 3 & $\mathrm{RC1}$ & 0,684 & 0,524 & 0,482 & 0,744 & 0,804 & 0,864 \\
\hline 259 & $5099601 \times \mathrm{XG}$ & 953 & 4 & 1995 & 2,5 & $\mathrm{RC1}$ & 0,644 & 0,484 & 0,422 & 0,584 & 0,544 & 0,604 \\
\hline 260 & $4905002 \times G$ & 299 & 4 & 1970 & 1 & $\mathrm{RC1}$ & 0,724 & 0,564 & 0,607 & 0,544 & 0,504 & 0,664 \\
\hline 261 & $6015408 \times G$ & 355 & 4 & 2001 & 3 & $\mathrm{RC1}$ & 0,484 & 0,484 & 0,462 & 0,604 & 0,564 & 0,564 \\
\hline 262 & $4395604 \times G$ & 218 & 2 & 1956 & 2,5 & $\mathrm{RC1}$ & 0,684 & 0,544 & 0,752 & 0,704 & 0,664 & 0,764 \\
\hline 263 & $4495015 \times G$ & 169 & 4 & 1990 & 1 & $\mathrm{RC1}$ & 0,644 & 0,484 & 0,402 & 0,564 & 0,524 & 0,584 \\
\hline 264 & $4495808 \times G$ & 922 & 3 & 2008 & 1 & $\mathrm{RC1}$ & 0,484 & 0,484 & 0,482 & 0,544 & 0,504 & 0,624 \\
\hline 265 & $4698106 \times \mathrm{XG}$ & 563 & 4 & 1988 & 1 & $\mathrm{RC1}$ & 0,684 & 0,524 & 0,382 & 0,584 & 0,504 & 0,564 \\
\hline 266 & $4698105 \times \mathrm{XG}$ & 1.268 & 4 & 1981 & 1,5 & $\mathrm{RC1}$ & 0,784 & 0,624 & 0,582 & 0,804 & 0,904 & 0,884 \\
\hline 267 & $5804701 \times G$ & 190 & 1 & 2001 & 2,5 & $\mathrm{RC1}$ & 0,444 & 0,464 & 0,482 & 0,584 & 0,584 & 0,624 \\
\hline 268 & $4498048 \times G$ & 1.165 & 4 & 1978 & 1,5 & $\mathrm{RC1}$ & 0,724 & 0,564 & 0,462 & 0,624 & 0,584 & 0,644 \\
\hline 269 & $4903008 \times G$ & 1.654 & 11 & 1983 & 1 & $\mathrm{RC1}$ & 0,764 & 0,564 & 0,602 & 0,744 & 0,724 & 0,664 \\
\hline
\end{tabular}

$I_{V}{ }_{E D}=$ Índice de vulnerabilidad representativo de la edificación; MILO3, GIO05, LAN07, FER12, MAN16, ROD17 = variantes del método MIV propuestas por Milutinovic \& Trendafiloski (2003), Giovinazzi (2005), Lantada (2007), Feriche (2012), Martínez-Cuevas \& Gaspar-Escribano (2016) y el modelo propuesto en esta tesis, respectivamente 


\begin{tabular}{|c|c|c|c|c|c|c|c|c|c|c|c|c|}
\hline \multicolumn{7}{|c|}{ A. INFORMACIÓN GENERAL Y OBSERVACIONES DE CAMPO } & \multicolumn{6}{|c|}{ B. OBTENCIÓN ÍNDICE DE VULNERABILIDAD } \\
\hline FID & REFCAT & SUPERFICIE & $\begin{array}{c}\text { NÚMERO DE } \\
\text { PLANTAS }\end{array}$ & AÑo & $\begin{array}{c}\text { GRADO DE } \\
\text { DAÑO EMS-98 }\end{array}$ & $\begin{array}{l}\text { TIPOLOGIA } \\
\text { BTM }\end{array}$ & $\mathrm{IV}_{\mathrm{V}}^{*} \mathrm{BDILO3}_{\mathrm{N}}$ & $I_{V}^{*} E D \_G 1005$ & $\mathrm{I}_{\mathrm{V}}^{*}{ }^{*}$ ED_LAN07 & $\mathrm{IV}_{\mathrm{V}}^{*}{ }_{\text {ED_FER12 }}$ & IV*E_MAN16 & $\mathrm{IV}_{\mathrm{V}}{ }^{*} \mathrm{EL}_{-} \mathrm{ROD} 17$ \\
\hline 306 & $4602905 \times G$ & 196 & 4 & 1968 & 3 & $\mathrm{RC1}$ & 0,724 & 0,564 & 0,732 & 0,644 & 0,624 & 0,664 \\
\hline 270 & $4905904 \times G$ & 391 & 7 & 1981 & 2 & $\mathrm{RC1}$ & 0,644 & 0,484 & 0,382 & 0,544 & 0,504 & 0,564 \\
\hline 271 & $4698103 \times \mathrm{XG}$ & 471 & 4 & 2004 & 1 & $\mathrm{RC1}$ & 0,484 & 0,484 & 0,402 & 0,524 & 0,504 & 0,504 \\
\hline 272 & $4702501 \times G$ & 328 & 7 & 1964 & 3 & $\mathrm{RC1}$ & 0,684 & 0,524 & 0,752 & 0,644 & 0,644 & 0,684 \\
\hline 273 & $4807024 X G$ & 578 & 3 & 2001 & 1 & $\mathrm{RC1}$ & 0,444 & 0,464 & 0,382 & 0,484 & 0,484 & 0,524 \\
\hline 274 & $5108012 \times G$ & 1.226 & 7 & 1992 & 2 & $\mathrm{RC1}$ & 0,684 & 0,524 & 0,402 & 0,604 & 0,524 & 0,584 \\
\hline 275 & $4804007 \times G$ & 2.434 & 9 & 1988 & 2 & $\mathrm{RC1}$ & 0,784 & 0,584 & 0,602 & 0,824 & 0,924 & 0,864 \\
\hline 276 & $4805202 \times \mathrm{G}$ & 333 & 4 & 1989 & 1 & $\mathrm{RC1}$ & 0,684 & 0,524 & 0,462 & 0,664 & 0,584 & 0,644 \\
\hline 277 & $4291004 \times G$ & 387 & 1 & 1970 & 2 & $\mathrm{RC1}$ & 0,684 & 0,544 & 0,507 & 0,444 & 0,404 & 0,644 \\
\hline 278 & $4805203 \times \mathrm{KG}$ & 646 & 4 & 1995 & 0 & $\mathrm{RC1}$ & 0,644 & 0,484 & 0,382 & 0,544 & 0,504 & 0,564 \\
\hline 279 & $4804010 \times G$ & 246 & 4 & 1997 & 1 & $\mathrm{RC1}$ & 0,524 & 0,504 & 0,382 & 0,564 & 0,484 & 0,484 \\
\hline 280 & $4805204 \times G$ & 830 & 4 & 1984 & 2 & $\mathrm{RC1}$ & 0,564 & 0,564 & 0,482 & 0,684 & 0,604 & 0,664 \\
\hline 281 & $4291008 \times G$ & 4.454 & 4 & 2001 & 2,5 & $\mathrm{RC1}$ & 0,604 & 0,564 & 0,502 & 0,884 & 0,844 & 0,924 \\
\hline 282 & $4191102 \times G$ & 515 & 4 & 1981 & 3 & $\mathrm{RC1}$ & 0,684 & 0,524 & 0,462 & 0,664 & 0,584 & 0,644 \\
\hline 283 & $4706036 \times \mathrm{KG}$ & 196 & 4 & 1979 & 1 & $\mathrm{RC1}$ & 0,724 & 0,564 & 0,602 & 0,764 & 0,724 & 0,784 \\
\hline 284 & $4598254 \times G$ & 311 & 4 & 2007 & 2 & $\mathrm{RC1}$ & 0,524 & 0,504 & 0,402 & 0,504 & 0,424 & 0,504 \\
\hline 285 & $4695010 \times \mathrm{KG}$ & 208 & 3 & 1978 & 1 & $\mathrm{RC1}$ & 0,684 & 0,544 & 0,422 & 0,584 & 0,544 & 0,684 \\
\hline 286 & $6015404 \times G$ & 624 & 4 & 1990 & 3 & $\mathrm{RC} 1$ & 0,704 & 0,524 & 0,502 & 0,744 & 0,664 & 0,724 \\
\hline 287 & $5814011 \times \mathrm{XG}$ & 454 & 4 & 1993 & 2,5 & $\mathrm{RC1}$ & 0,684 & 0,524 & 0,402 & 0,604 & 0,524 & 0,584 \\
\hline 288 & $5296904 \times G$ & 419 & 4 & 2002 & 1 & $\mathrm{RC1}$ & 0,484 & 0,484 & 0,482 & 0,624 & 0,584 & 0,584 \\
\hline 289 & $4908003 \times \mathrm{KG}$ & 358 & 4 & 1986 & 1 & $\mathrm{RC1}$ & 0,704 & 0,524 & 0,382 & 0,624 & 0,544 & 0,604 \\
\hline 290 & $6417002 \times G$ & 225 & 4 & 2000 & 1 & $\mathrm{RC1}$ & 0,544 & 0,504 & 0,502 & 0,724 & 0,644 & 0,644 \\
\hline 291 & $4697021 \times G$ & 583 & 4 & 1991 & 2 & $\mathrm{RC} 1$ & 0,644 & 0,484 & 0,382 & 0,544 & 0,504 & 0,564 \\
\hline 292 & $5311014 \times \mathrm{XG}$ & 301 & 7 & 1971 & 1,5 & $\mathrm{RC1}$ & 0,724 & 0,564 & 0,607 & 0,624 & 0,604 & 0,664 \\
\hline 293 & $6114901 \times \mathrm{G}$ & 1.105 & 4 & 2003 & 3 & $\mathrm{RC} 1$ & 0,484 & 0,484 & 0,422 & 0,624 & 0,724 & 0,724 \\
\hline 294 & $4393005 \times G$ & 2.830 & 4 & 1995 & 3 & $\mathrm{RC1}$ & 0,564 & 0,564 & 0,442 & 0,724 & 0,764 & 0,824 \\
\hline 295 & $4604901 \times G$ & 131 & 4 & 1973 & 2 & $\mathrm{RC1}$ & 0,744 & 0,564 & 0,707 & 0,784 & 0,744 & 0,804 \\
\hline
\end{tabular}

$I_{V}{ }_{E D}=$ Índice de vulnerabilidad representativo de la edificación; MILO3, GIO05, LAN07, FER12, MAN16, ROD17 = variantes del método MIV propuestas por Milutinovic \& Trendafiloski (2003), Giovinazzi (2005), Lantada (2007), Feriche (2012), Martínez-Cuevas \& Gaspar-Escribano (2016) y el modelo propuesto en esta tesis, respectivamente 


\begin{tabular}{|c|c|c|c|c|c|c|c|c|c|c|c|c|}
\hline \multicolumn{7}{|c|}{ A. INFORMACIÓN GENERAL Y OBSERVACIONES DE CAMPO } & \multicolumn{6}{|c|}{ B. OBTENCIÓN ÍNDICE DE VULNERABILIDAD } \\
\hline FID & REFCAT & SUPERFICIE & $\begin{array}{l}\text { NÚMERO DE } \\
\text { PLANTAS }\end{array}$ & AÑo & $\begin{array}{c}\text { GRADO DE } \\
\text { DAÑO EMS-98 }\end{array}$ & $\begin{array}{l}\text { TIPOLOGIA } \\
\text { BTM }\end{array}$ & $\mathrm{IV}_{\mathrm{ED}-\mathrm{MILO3}}^{*}$ & $\mathrm{I}_{\mathrm{V}}^{*} \mathrm{ED}_{-} \mathrm{GIO05}$ & IV*ED_LAN07 & $I_{V}^{*}$ ED_FER12 & $I_{E D}{ }^{*}{ }_{1}$ MAN16 & IV ED_ROD17 \\
\hline 296 & $5414701 \times G$ & 139 & 4 & 1962 & 1,5 & $\mathrm{RC1}$ & 0,724 & 0,564 & 0,812 & 0,744 & 0,704 & 0,744 \\
\hline 297 & $4697008 \times \mathrm{XG}$ & 229 & 4 & 1989 & 1,5 & $\mathrm{RC1}$ & 0,684 & 0,524 & 0,402 & 0,604 & 0,524 & 0,584 \\
\hline 298 & $4799026 \mathrm{XG}$ & 1.344 & 4 & 1991 & 1,5 & $\mathrm{RC1}$ & 0,724 & 0,564 & 0,422 & 0,664 & 0,544 & 0,604 \\
\hline 299 & $6015405 \times \mathrm{XG}$ & 309 & 4 & 2002 & 1 & $\mathrm{RC1}$ & 0,544 & 0,504 & 0,382 & 0,604 & 0,524 & 0,524 \\
\hline 300 & $5615233 \times \mathrm{GG}$ & 433 & 4 & 2011 & 1,5 & $\mathrm{RC1}$ & 0,524 & 0,504 & 0,382 & 0,484 & 0,404 & 0,484 \\
\hline 301 & $6098008 \times G$ & 502 & 1 & 1985 & 2 & $\mathrm{RC1}$ & 0,644 & 0,504 & 0,422 & 0,684 & 0,744 & 0,884 \\
\hline 302 & $6216235 \mathrm{XG}$ & 751 & 4 & 2005 & 1 & $\mathrm{RC1}$ & 0,484 & 0,484 & 0,462 & 0,524 & 0,484 & 0,564 \\
\hline 303 & $6217005 \mathrm{XG}$ & 212 & 2 & 1967 & 3 & $\mathrm{RC1}$ & 0,684 & 0,544 & 0,772 & 0,704 & 0,664 & 0,784 \\
\hline 304 & $5110027 \times G$ & 1.522 & 3 & 1992 & 2 & $\mathrm{RC1}$ & 0,644 & 0,504 & 0,442 & 0,704 & 0,764 & 0,904 \\
\hline 305 & $4804613 \times \mathrm{XG}$ & 295 & 4 & 1995 & 1 & $\mathrm{RC1}$ & 0,684 & 0,524 & 0,382 & 0,584 & 0,504 & 0,564 \\
\hline 306 & $5116029 \times \mathrm{XG}$ & 757 & 2 & 2010 & 1,5 & $\mathrm{RC1}$ & 0,504 & 0,484 & 0,382 & 0,484 & 0,444 & 0,564 \\
\hline 307 & $4704609 \times G$ & 92 & 4 & 1989 & 1 & $\mathrm{RC1}$ & 0,684 & 0,524 & 0,482 & 0,684 & 0,604 & 0,664 \\
\hline 308 & $4703028 \times G$ & 746 & 5 & 2009 & 2 & $\mathrm{RC1}$ & 0,544 & 0,524 & 0,482 & 0,644 & 0,704 & 0,784 \\
\hline 309 & $6118502 \times \mathrm{G}$ & 1.116 & 3 & 1976 & 2 & $\mathrm{RC1}$ & 0,684 & 0,544 & 0,522 & 0,664 & 0,644 & 0,784 \\
\hline 310 & $4698101 \times G$ & 352 & 4 & 1983 & 1 & $\mathrm{RC1}$ & 0,684 & 0,524 & 0,482 & 0,684 & 0,604 & 0,664 \\
\hline 311 & $5006005 \times G$ & 345 & 7 & 1993 & 1 & $\mathrm{RC1}$ & 0,684 & 0,524 & 0,482 & 0,684 & 0,604 & 0,664 \\
\hline 312 & 6119701XG & 398 & 3 & 1972 & 2 & $\mathrm{RC1}$ & 0,664 & 0,504 & 0,607 & 0,624 & 0,644 & 0,744 \\
\hline 313 & $4293004 \times G$ & 515 & 3 & 1996 & 1 & $\mathrm{RC1}$ & 0,484 & 0,484 & 0,342 & 0,544 & 0,464 & 0,524 \\
\hline 314 & $6118505 \times \mathrm{XG}$ & 552 & 3 & 1972 & 1 & $\mathrm{RC1}$ & 0,684 & 0,544 & 0,627 & 0,664 & 0,624 & 0,764 \\
\hline 315 & $5309016 \mathrm{XG}$ & 705 & 4 & 1991 & 2 & $\mathrm{RC1}$ & 0,644 & 0,484 & 0,422 & 0,584 & 0,544 & 0,564 \\
\hline 316 & $4498003 \times G$ & 671 & 3 & 1979 & 2 & $\mathrm{RC1}$ & 0,704 & 0,544 & 0,522 & 0,724 & 0,684 & 0,824 \\
\hline 317 & $6015001 \times G$ & 832 & 4 & 1970 & 2,5 & $\mathrm{RC1}$ & 0,684 & 0,524 & 0,587 & 0,544 & 0,484 & 0,684 \\
\hline 318 & $4395602 \times G$ & 218 & 2 & 1956 & 2,5 & $\mathrm{RC1}$ & 0,684 & 0,544 & 0,752 & 0,704 & 0,664 & 0,764 \\
\hline 319 & $5198801 \times G$ & 3.173 & 4 & 2001 & 3 & $\mathrm{RC1}$ & 0,544 & 0,524 & 0,482 & 0,744 & 0,584 & 0,664 \\
\hline 320 & $4804017 \times G$ & 215 & 6 & 1976 & 2,5 & $\mathrm{RC1}$ & 0,744 & 0,584 & 0,562 & 0,764 & 0,684 & 0,824 \\
\hline 321 & $5105005 \times G$ & 2.701 & 11 & 1976 & 1 & $\mathrm{RC1}$ & 0,844 & 0,644 & 0,642 & 0,804 & 0,764 & 0,704 \\
\hline 322 & 5415815XG & 695 & 4 & 2009 & 1,5 & $\mathrm{RC1}$ & 0,524 & 0,504 & 0,502 & 0,604 & 0,524 & 0,604 \\
\hline
\end{tabular}

$I_{V}{ }_{E D}=$ Índice de vulnerabilidad representativo de la edificación; MILO3, GIO05, LAN07, FER12, MAN16, ROD17 = variantes del método MIV propuestas por Milutinovic \& Trendafiloski (2003), Giovinazzi (2005), Lantada (2007), Feriche (2012), Martínez-Cuevas \& Gaspar-Escribano (2016) y el modelo propuesto en esta tesis, respectivamente 


\begin{tabular}{|c|c|c|c|c|c|c|c|c|c|c|c|c|}
\hline \multicolumn{7}{|c|}{ A. INFORMACIÓN GENERAL Y OBSERVACIONES DE CAMPO } & \multicolumn{6}{|c|}{ B. OBTENCIÓN ÍNDICE DE VULNERABILIDAD } \\
\hline FID & REFCAT & SUPERFICIE & $\begin{array}{l}\text { NÚMERO DE } \\
\text { PLANTAS }\end{array}$ & AÑo & $\begin{array}{c}\text { GRADO DE } \\
\text { DAÑO EMS-98 }\end{array}$ & $\begin{array}{l}\text { TIPOLOGIA } \\
\text { BTM }\end{array}$ & IV ${ }^{*} \mathrm{ED}_{-} \mathrm{MILO3}$ & $\mathrm{IV}_{\mathrm{V}}^{*} \mathrm{ED}_{-} \mathrm{GIO05}$ & IV*ED_LAN07 & $\mathrm{IV}_{V}^{*}$ ED_FER12 & IV*ED_MAN16 & $\mathrm{IV}_{\mathrm{ED}}^{*}$ ROD17 \\
\hline 323 & $4804016 \mathrm{XG}$ & 227 & 4 & 1989 & 1 & $\mathrm{RC} 1$ & 0,684 & 0,524 & 0,382 & 0,584 & 0,504 & 0,564 \\
\hline 324 & $6117702 \times G$ & 539 & 3 & 1970 & 3 & $\mathrm{RC1}$ & 0,704 & 0,544 & 0,647 & 0,604 & 0,584 & 0,824 \\
\hline 325 & $5214016 \times \mathrm{XG}$ & 2.801 & 4 & 2007 & 2 & $\mathrm{RC1}$ & 0,544 & 0,524 & 0,502 & 0,604 & 0,524 & 0,604 \\
\hline 326 & $4818611 \times G$ & 524 & 4 & 2007 & 1 & $\mathrm{RC} 1$ & 0,524 & 0,504 & 0,382 & 0,484 & 0,404 & 0,484 \\
\hline 327 & $6118201 \times G$ & 278 & 3 & 1970 & 3 & $\mathrm{RC1}$ & 0,724 & 0,564 & 0,607 & 0,544 & 0,544 & 0,744 \\
\hline 328 & $5814301 \times G$ & 7.045 & 4 & 2007 & 2 & $\mathrm{RC} 1$ & 0,484 & 0,484 & 0,422 & 0,544 & 0,644 & 0,684 \\
\hline 329 & $5315204 \times G$ & 250 & 3 & 1997 & 1 & $\mathrm{RCl}$ & 0,544 & 0,504 & 0,402 & 0,624 & 0,544 & 0,544 \\
\hline 330 & $4603008 \times \mathrm{G}$ & 293 & 1 & 1950 & 2 & $\mathrm{RC1}$ & 0,684 & 0,544 & 0,672 & 0,624 & 0,584 & 0,684 \\
\hline 331 & $6216006 \times \mathrm{XG}$ & 1.550 & 4 & 1993 & 2,5 & $\mathrm{RC} 1$ & 0,684 & 0,524 & 0,462 & 0,724 & 0,784 & 0,844 \\
\hline 332 & $5314005 \times G$ & 1.233 & 4 & 2003 & 2 & $\mathrm{RC1}$ & 0,504 & 0,484 & 0,482 & 0,664 & 0,624 & 0,584 \\
\hline 333 & $4395306 \times \mathrm{XG}$ & 216 & 2 & 1956 & 3 & $\mathrm{RC} 1$ & 0,684 & 0,544 & 0,672 & 0,624 & 0,584 & 0,684 \\
\hline 334 & $5105010 \times \mathrm{G}$ & 723 & 7 & 2001 & 1 & $\mathrm{RC1}$ & 0,524 & 0,504 & 0,382 & 0,564 & 0,484 & 0,484 \\
\hline 335 & $4905006 \times \mathrm{XG}$ & 137 & 4 & 1970 & 1,5 & $\mathrm{RC1}$ & 0,724 & 0,564 & 0,607 & 0,544 & 0,504 & 0,664 \\
\hline 336 & $4600022 \times G$ & 412 & 4 & 1994 & 1,5 & $\mathrm{RC1}$ & 0,684 & 0,524 & 0,402 & 0,584 & 0,524 & 0,584 \\
\hline 337 & $5000802 \times G$ & 828 & 5 & 1975 & 2 & $\mathrm{RC1}$ & 0,684 & 0,524 & 0,462 & 0,664 & 0,584 & 0,644 \\
\hline 338 & $5108022 \times \mathrm{G}$ & 332 & 4 & 1965 & 1 & $\mathrm{RC} 1$ & 0,724 & 0,564 & 0,712 & 0,644 & 0,604 & 0,644 \\
\hline 339 & $4801016 \mathrm{XG}$ & 2.676 & 3 & 1986 & 3 & $\mathrm{RC1}$ & 0,644 & 0,504 & 0,422 & 0,664 & 0,744 & 0,844 \\
\hline 340 & $4501507 X \mathrm{XG}$ & 217 & 4 & 1970 & 2 & $\mathrm{RC} 1$ & 0,724 & 0,564 & 0,627 & 0,564 & 0,524 & 0,684 \\
\hline 341 & $5000801 \times G$ & 420 & 10 & 1975 & 3 & $\mathrm{RC1}$ & 0,844 & 0,644 & 0,702 & 0,864 & 0,824 & 0,764 \\
\hline 342 & $6118504 \times G$ & 353 & 3 & 1976 & 2 & $\mathrm{RC1}$ & 0,704 & 0,544 & 0,502 & 0,704 & 0,664 & 0,804 \\
\hline 343 & $6114306 \times \mathrm{XG}$ & 298 & 4 & 1993 & 2 & $\mathrm{RC} 1$ & 0,684 & 0,524 & 0,382 & 0,584 & 0,504 & 0,564 \\
\hline 345 & $4808301 \times G$ & 96 & 3 & 1986 & 1 & $\mathrm{RC1}$ & 0,644 & 0,504 & 0,442 & 0,644 & 0,564 & 0,704 \\
\hline 346 & $4804009 \times \mathrm{K}$ & 214 & 4 & 1968 & 3 & $\mathrm{RC} 1$ & 0,724 & 0,564 & 0,712 & 0,644 & 0,604 & 0,644 \\
\hline 347 & $5395009 \times \mathrm{XG}$ & 354 & 2 & 1965 & 2 & $\mathrm{RC} 1$ & 0,684 & 0,544 & 0,652 & 0,564 & 0,544 & 0,664 \\
\hline 348 & $6116201 \times \mathrm{G}$ & 290 & 3 & 1975 & 2 & $\mathrm{RC} 1$ & 0,664 & 0,504 & 0,482 & 0,624 & 0,644 & 0,744 \\
\hline 350 & $4908002 \times G$ & 378 & 4 & 1985 & 1 & $\mathrm{RC1}$ & 0,684 & 0,524 & 0,382 & 0,584 & 0,504 & 0,564 \\
\hline 351 & $5311010 \times \mathrm{X}$ & 255 & 3 & 1963 & 1 & $\mathrm{RC1}$ & 0,784 & 0,624 & 0,712 & 0,644 & 0,604 & 0,644 \\
\hline
\end{tabular}

$I_{V}{ }_{E D}=$ Índice de vulnerabilidad representativo de la edificación; MILO3, GIO05, LAN07, FER12, MAN16, ROD17 = variantes del método MIV propuestas por Milutinovic \& Trendafiloski (2003), Giovinazzi (2005), Lantada (2007), Feriche (2012), Martínez-Cuevas \& Gaspar-Escribano (2016) y el modelo propuesto en esta tesis, respectivamente 


\begin{tabular}{|c|c|c|c|c|c|c|c|c|c|c|c|c|}
\hline \multicolumn{7}{|c|}{ A. INFORMACIÓN GENERAL Y OBSERVACIONES DE CAMPO } & \multicolumn{6}{|c|}{ B. OBTENCIÓN ÍNDICE DE VULNERABILIDAD } \\
\hline FID & REFCAT & SUPERFICIE & $\begin{array}{c}\text { NÚMERO DE } \\
\text { PLANTAS }\end{array}$ & AÑo & $\begin{array}{c}\text { GRADO DE } \\
\text { DAÑO EMS-98 }\end{array}$ & $\begin{array}{l}\text { TIPOLOGIA } \\
\text { BTM }\end{array}$ & $I_{V}^{*}$ ED_MILO3 & $\mathrm{IV}_{\mathrm{V}}^{*} \mathrm{DD}_{-} \mathrm{GIO05}$ & IV ED_LAN07 & $\mathrm{IV}_{\mathrm{V}}^{*}$ ED_FER12 & IV*ED_MAN16 & IV ${ }_{E D}^{*}$ ROD17 \\
\hline 352 & $4395605 \times \mathrm{XG}$ & 218 & 2 & 1956 & 3 & $\mathrm{RC} 1$ & 0,684 & 0,544 & 0,772 & 0,704 & 0,684 & 0,784 \\
\hline 353 & $4909701 \times G$ & 775 & 4 & 1981 & 1 & $\mathrm{RC1}$ & 0,724 & 0,564 & 0,382 & 0,584 & 0,504 & 0,564 \\
\hline 354 & $4805206 \times \mathrm{XG}$ & 168 & 4 & 1963 & 1 & RC1 & 0,724 & 0,564 & 0,752 & 0,684 & 0,644 & 0,684 \\
\hline 355 & $4293201 \times G$ & 323 & 4 & 1975 & 2,5 & $\mathrm{RC1}$ & 0,724 & 0,564 & 0,542 & 0,704 & 0,664 & 0,724 \\
\hline 356 & $4604613 \times \mathrm{XG}$ & 105 & 2 & 1984 & 1,5 & $\mathrm{RC} 1$ & 0,644 & 0,504 & 0,422 & 0,624 & 0,544 & 0,684 \\
\hline 357 & $4901801 \times G$ & 1.117 & 8 & 1978 & 2 & $\mathrm{RC} 1$ & 0,804 & 0,604 & 0,602 & 0,724 & 0,724 & 0,624 \\
\hline 358 & $4598250 \times \mathrm{G}$ & 149 & 4 & 1968 & 2 & $\mathrm{RC1}$ & 0,724 & 0,564 & 0,732 & 0,664 & 0,624 & 0,664 \\
\hline 359 & $4905005 \times G$ & 516 & 7 & 1991 & 1,5 & $\overline{R C 1}$ & 0,684 & 0,524 & 0,402 & 0,604 & 0,524 & 0,584 \\
\hline 360 & $5110028 \times G$ & 964 & 3 & 1995 & 1 & $\mathrm{RC} 1$ & 0,644 & 0,504 & 0,422 & 0,624 & 0,544 & 0,684 \\
\hline 361 & $4604605 \times \mathrm{XG}$ & 131 & 2 & 1993 & 2 & $\mathrm{RC} 1$ & 0,644 & 0,504 & 0,382 & 0,584 & 0,504 & 0,644 \\
\hline 362 & $5416017 \times \mathrm{XG}$ & 211 & 3 & 1975 & 1 & $\mathrm{RC} 1$ & 0,524 & 0,524 & 0,502 & 0,604 & 0,564 & 0,644 \\
\hline 363 & $4914006 \times \mathrm{KG}$ & 120 & 2 & 1969 & 2 & $\mathrm{RC1}$ & 0,684 & 0,524 & 0,382 & 0,584 & 0,504 & 0,564 \\
\hline 364 & $5316105 \times G$ & 182 & 4 & 1982 & 1 & $\mathrm{RC} 1$ & 0,644 & 0,504 & 0,712 & 0,624 & 0,624 & 0,724 \\
\hline
\end{tabular}

$I_{V}{ }_{E D}=$ Índice de vulnerabilidad representativo de la edificación; MILO3, GIO05, LAN07, FER12, MAN16, ROD17 = variantes del método MIV propuestas por Milutinovic \& Trendafiloski (2003), Giovinazzi (2005), Lantada (2007), Feriche (2012), Martínez-Cuevas \& Gaspar-Escribano (2016) y el modelo propuesto en esta tesis, respectivamente 
Tabla B.2. Resumen de la base de datos implementada. Bloques C y D Obtención del grado medio de daño para uno sismo de intensidad $I_{E M S-98}=$ VII y VIII, respectivamente.

\begin{tabular}{|c|c|c|c|c|c|c|c|c|c|c|c|c|}
\hline \multirow[b]{2}{*}{ FID } & \multicolumn{6}{|c|}{ C. OBTENCIÓN GRADO DE DAÑO SEGÚN MÉTODO LM1 (I = VII) } & \multicolumn{6}{|c|}{ D. OBTENCIÓN GRADO DE DAÑO SEGÚN MÉTODO LMI (I = VIII) } \\
\hline & $\begin{array}{c}\mu D^{*} \text { _MIL03 } \\
(I=V I I)\end{array}$ & $\begin{array}{c}\mu D^{*} \text { _GIO05 } \\
(I=V I I)\end{array}$ & $\begin{array}{c}\mu D^{*} \text { _LAN07 } \\
(I=\text { VII })\end{array}$ & $\begin{array}{c}\mu D^{*} \text { _FER12 } \\
(I=\text { VII })\end{array}$ & $\begin{array}{c}\mu D^{*} \text { _MAN16 } \\
(I=V I I)\end{array}$ & $\begin{array}{c}\mu D^{*} \text { _ROD17 } \\
(I=V I I)\end{array}$ & $\begin{array}{c}\mu D^{*} \text { _MIL03 } \\
(I=V I I I)\end{array}$ & $\begin{array}{c}\mu D^{*} \_G 1005 \\
(I=V I I I)\end{array}$ & $\begin{array}{c}\mu D^{*} \text { _LANO7 } \\
(I=V I I I)\end{array}$ & $\begin{array}{c}\mu D^{*} \text { _FER12 } \\
(I=V I I I)\end{array}$ & $\begin{array}{c}\mu D^{*} \text { _MAN16 } \\
(I=\text { VIII })\end{array}$ & $\begin{array}{c}\mu D^{*} \text { ROD17 } \\
(I=\text { VIII })\end{array}$ \\
\hline 1 & 1,01 & 0,53 & 1,34 & 1,01 & 0,93 & 1,41 & 1,89 & 1,10 & 2,34 & 1,89 & 1,76 & 2,42 \\
\hline 2 & 0,71 & 0,39 & 0,21 & 0,44 & 0,39 & 0,53 & 1,41 & 0,85 & 0,48 & 0,93 & 0,85 & 1,10 \\
\hline 3 & 0,38 & 0,42 & 0,23 & 0,29 & 0,26 & 0,39 & 0,81 & 0,89 & 0,53 & 0,64 & 0,58 & 0,85 \\
\hline 4 & 0,31 & 0,38 & 0,23 & 0,24 & 0,26 & 0,48 & 0,67 & 0,81 & 0,53 & 0,53 & 0,58 & 1,01 \\
\hline 5 & 0,26 & 0,32 & 0,23 & 0,26 & 0,26 & 0,48 & 0,58 & 0,71 & 0,53 & 0,58 & 0,58 & 1,01 \\
\hline 6 & 0,85 & 0,44 & 0,35 & 0,71 & 0,64 & 1,20 & 1,64 & 0,93 & 0,77 & 1,41 & 1,30 & 2,15 \\
\hline 7 & 0,85 & 0,39 & 0,19 & 0,53 & 0,36 & 0,48 & 1,64 & 0,85 & 0,43 & 1,10 & 0,78 & 1,01 \\
\hline 8 & 0,93 & 0,39 & 0,39 & 1,10 & 0,85 & 1,10 & 1,76 & 0,85 & 0,84 & 2,02 & 1,64 & 2,02 \\
\hline 9 & 0,26 & 0,32 & 0,23 & 0,36 & 0,39 & 0,48 & 0,58 & 0,71 & 0,53 & 0,78 & 0,85 & 1,01 \\
\hline 10 & 1,01 & 0,48 & 0,58 & 1,30 & 2,15 & 2,02 & 1,89 & 1,01 & 1,19 & 2,28 & 3,21 & 3,09 \\
\hline 11 & 0,85 & 0,44 & 0,80 & 0,64 & 0,53 & 0,85 & 1,64 & 0,93 & 1,57 & 1,30 & 1,10 & 1,64 \\
\hline 12 & 1,01 & 0,48 & 1,45 & 1,10 & 0,93 & 1,10 & 1,89 & 1,01 & 2,47 & 2,02 & 1,76 & 2,02 \\
\hline 13 & 0,32 & 0,32 & 0,23 & 0,48 & 0,39 & 0,39 & 0,71 & 0,71 & 0,53 & 1,01 & 0,85 & 0,85 \\
\hline 14 & 1,20 & 0,58 & 1,57 & 1,20 & 1,10 & 1,20 & 2,15 & 1,20 & 2,61 & 2,15 & 2,02 & 2,15 \\
\hline 15 & 0,48 & 0,44 & 0,23 & 0,39 & 0,26 & 0,39 & 1,01 & 0,93 & 0,53 & 0,85 & 0,58 & 0,85 \\
\hline 16 & 0,71 & 0,36 & 0,59 & 0,58 & 0,58 & 1,10 & 1,41 & 0,78 & 1,22 & 1,20 & 1,20 & 2,02 \\
\hline 17 & 0,71 & 0,36 & 0,19 & 0,48 & 0,36 & 1,01 & 1,41 & 0,78 & 0,43 & 1,01 & 0,78 & 1,89 \\
\hline 18 & 1,01 & 0,48 & 1,05 & 0,64 & 0,64 & 0,78 & 1,89 & 1,01 & 1,94 & 1,30 & 1,30 & 1,52 \\
\hline 19 & 0,85 & 0,39 & 0,23 & 0,58 & 0,44 & 0,85 & 1,64 & 0,85 & 0,53 & 1,20 & 0,93 & 1,64 \\
\hline 20 & 0,71 & 0,36 & 0,96 & 0,64 & 0,64 & 1,01 & 1,41 & 0,78 & 1,81 & 1,30 & 1,30 & 1,89 \\
\hline 21 & 0,85 & 0,44 & 1,05 & 0,71 & 0,64 & 1,10 & 1,64 & 0,93 & 1,94 & 1,41 & 1,30 & 2,02 \\
\hline 22 & 0,93 & 0,39 & 0,32 & 1,01 & 0,71 & 0,93 & 1,76 & 0,85 & 0,70 & 1,89 & 1,41 & 1,76 \\
\hline 23 & 0,31 & 0,38 & 0,35 & 0,58 & 0,64 & 0,71 & 0,67 & 0,81 & 0,77 & 1,20 & 1,30 & 1,41 \\
\hline 24 & 0,85 & 0,44 & 0,39 & 0,78 & 0,71 & 0,93 & 1,64 & 0,93 & 0,84 & 1,52 & 1,41 & 1,76 \\
\hline 25 & 0,71 & 0,32 & 0,29 & 0,58 & 0,53 & 1,01 & 1,41 & 0,71 & 0,64 & 1,20 & 1,10 & 1,89 \\
\hline 26 & 0,78 & 0,39 & 0,15 & 0,44 & 0,29 & 0,58 & 1,52 & 0,85 & 0,35 & 0,93 & 0,64 & 1,20 \\
\hline 27 & 0,93 & 0,44 & 0,79 & 0,71 & 0,58 & 1,64 & 1,76 & 0,93 & 1,54 & 1,41 & 1,20 & 2,69 \\
\hline
\end{tabular}

$\mu_{D}{ }^{*}=$ daño medio representativo según metodología LM1 de RISK-UE; MILO3, GIO05, LAN07, FER12, MAN16, ROD17 = variantes del método MIV propuestas por Milutinovic \& Trendafiloski (2003), Giovinazzi (2005), Lantada (2007), Feriche (2012), Martínez-Cuevas \& Gaspar-Escribano (2016) y el modelo propuesto en esta tesis, respectivamente 


\begin{tabular}{|c|c|c|c|c|c|c|c|c|c|c|c|c|}
\hline \multirow[b]{2}{*}{ FID } & \multicolumn{6}{|c|}{ C. OBTENCIÓN GRADO DE DAÑO SEGÚN MÉTODO LM1 (I = VII) } & \multicolumn{6}{|c|}{ D. OBTENCIÓN GRADO DE DAÑO SEGÚN MÉTODO LM1 (I = VIII) } \\
\hline & $\begin{array}{c}\mu D^{*} \text { _MIL03 } \\
(I=V I I)\end{array}$ & $\begin{array}{c}\mu D_{*}^{*} G 1005 \\
(I=V I I)\end{array}$ & $\begin{array}{c}\mu D^{*} \text { _LAN07 } \\
(I=V I I)\end{array}$ & $\begin{array}{c}\mu D^{*} \text { _FER12 } \\
(I=V I I)\end{array}$ & $\begin{array}{c}\mu D^{*} \text { _MAN16 } \\
(I=V I I)\end{array}$ & $\begin{array}{c}\mu D^{*} \text { _ROD17 } \\
(I=V I I)\end{array}$ & $\begin{array}{c}\mu D^{*} \text { _MIL03 } \\
(I=V I I I)\end{array}$ & $\begin{array}{c}\mu D_{*}^{*}{ }_{\text {GIOOS5 }} \\
(I=V I I I)\end{array}$ & $\begin{array}{c}\mu D^{*} \text { _LAN07 } \\
(I=V I I I)\end{array}$ & $\begin{array}{c}\mu D^{*} \text { _FER12 } \\
(I=V I I I)\end{array}$ & $\begin{array}{c}\mu D^{*} \text { _MAN16 } \\
(I=V I I I)\end{array}$ & $\begin{array}{c}\mu D^{*} \text { _ROD17 } \\
(I=V I I I)\end{array}$ \\
\hline 28 & 1,01 & 0,48 & 0,32 & 0,71 & 0,58 & 0,78 & 1,89 & 1,01 & 0,70 & 1,41 & 1,20 & 1,52 \\
\hline 29 & 1,10 & 0,48 & 1,45 & 1,41 & 1,20 & 1,30 & 2,02 & 1,01 & 2,47 & 2,42 & 2,15 & 2,28 \\
\hline 30 & 0,71 & 0,36 & 0,96 & 0,64 & 0,64 & 1,01 & 1,41 & 0,78 & 1,81 & 1,30 & 1,30 & 1,89 \\
\hline 31 & 1,01 & 0,48 & 0,39 & 1,30 & 0,85 & 1,52 & 1,89 & 1,01 & 0,84 & 2,28 & 1,64 & 2,55 \\
\hline 32 & 0,32 & 0,32 & 0,32 & 0,71 & 0,58 & 0,53 & 0,71 & 0,71 & 0,70 & 1,41 & 1,20 & 1,10 \\
\hline 33 & 1,20 & 0,53 & 0,48 & 1,52 & 1,01 & 1,30 & 2,15 & 1,10 & 1,00 & 2,55 & 1,89 & 2,28 \\
\hline 37 & 0,85 & 0,44 & 0,39 & 0,78 & 0,71 & 1,30 & 1,64 & 0,93 & 0,84 & 1,52 & 1,41 & 2,28 \\
\hline 34 & 1,01 & 0,48 & 1,12 & 1,30 & 1,10 & 1,41 & 1,89 & 1,01 & 2,04 & 2,28 & 2,02 & 2,42 \\
\hline 35 & 0,71 & 0,36 & 0,96 & 0,64 & 0,64 & 1,01 & 1,41 & 0,78 & 1,81 & 1,30 & 1,30 & 1,89 \\
\hline 36 & 0,85 & 0,44 & 0,49 & 0,53 & 0,48 & 0,93 & 1,64 & 0,93 & 1,03 & 1,10 & 1,01 & 1,76 \\
\hline 37 & 0,85 & 0,44 & 0,72 & 0,53 & 0,44 & 1,30 & 1,64 & 0,93 & 1,43 & 1,10 & 0,93 & 2,28 \\
\hline 38 & 0,71 & 0,36 & 0,23 & 0,64 & 0,44 & 0,85 & 1,41 & 0,78 & 0,53 & 1,30 & 0,93 & 1,64 \\
\hline 39 & 1,10 & 0,53 & 0,32 & 1,41 & 0,71 & 2,28 & 2,02 & 1,10 & 0,70 & 2,42 & 1,41 & 3,34 \\
\hline 40 & 0,26 & 0,29 & 0,21 & 0,36 & 0,36 & 0,44 & 0,58 & 0,64 & 0,48 & 0,78 & 0,78 & 0,93 \\
\hline 41 & 1,01 & 0,48 & 0,79 & 0,85 & 0,78 & 1,01 & 1,89 & 1,01 & 1,54 & 1,64 & 1,52 & 1,89 \\
\hline 42 & 0,71 & 0,36 & 0,96 & 0,58 & 0,58 & 1,01 & 1,41 & 0,78 & 1,81 & 1,20 & 1,20 & 1,89 \\
\hline 43 & 0,29 & 0,32 & 0,35 & 0,44 & 0,39 & 0,71 & 0,64 & 0,71 & 0,77 & 0,93 & 0,85 & 1,41 \\
\hline 44 & 0,85 & 0,44 & 1,14 & 0,93 & 0,78 & 1,20 & 1,64 & 0,93 & 2,07 & 1,76 & 1,52 & 2,15 \\
\hline 45 & 1,01 & 0,48 & 0,54 & 0,85 & 1,30 & 1,64 & 1,89 & 1,01 & 1,12 & 1,64 & 2,28 & 2,69 \\
\hline 46 & 0,85 & 0,39 & 0,29 & 0,78 & 0,53 & 0,71 & 1,64 & 0,85 & 0,64 & 1,52 & 1,10 & 1,41 \\
\hline 47 & 1,10 & 0,48 & 0,23 & 0,93 & 0,53 & 0,71 & 2,02 & 1,01 & 0,53 & 1,76 & 1,10 & 1,41 \\
\hline 48 & 0,78 & 0,36 & 0,21 & 0,64 & 0,48 & 0,93 & 1,52 & 0,78 & 0,48 & 1,30 & 1,01 & 1,76 \\
\hline 49 & 1,01 & 0,39 & 0,43 & 0,93 & 0,78 & 1,01 & 1,89 & 0,85 & 0,92 & 1,76 & 1,52 & 1,89 \\
\hline 50 & 0,85 & 0,44 & 1,14 & 0,93 & 0,78 & 1,20 & 1,64 & 0,93 & 2,07 & 1,76 & 1,52 & 2,15 \\
\hline 51 & 1,10 & 0,53 & 1,45 & 1,20 & 1,10 & 1,76 & 2,02 & 1,10 & 2,47 & 2,15 & 2,02 & 2,82 \\
\hline 52 & 0,26 & 0,32 & 0,19 & 0,21 & 0,21 & 0,39 & 0,58 & 0,71 & 0,43 & 0,48 & 0,48 & 0,85 \\
\hline 53 & 0,93 & 0,44 & 0,72 & 0,64 & 0,53 & 1,52 & 1,76 & 0,93 & 1,43 & 1,30 & 1,10 & 2,55 \\
\hline
\end{tabular}

$\mu_{D}{ }^{*}=$ daño medio representativo según metodología LM1 de RISK-UE; MILO3, GIO05, LAN07, FER12, MAN16, ROD17 = variantes del método MIV propuestas por Milutinovic \& Trendafiloski (2003), Giovinazzi (2005), Lantada (2007), Feriche (2012), Martínez-Cuevas \& Gaspar-Escribano (2016) y el modelo propuesto en esta tesis, respectivamente 


\begin{tabular}{|c|c|c|c|c|c|c|c|c|c|c|c|c|}
\hline \multirow[b]{2}{*}{ FID } & \multicolumn{6}{|c|}{ C. OBTENCIÓN GRADO DE DAÑO SEGÚN MÉTODO LM1 (I = VII) } & \multicolumn{6}{|c|}{ D. OBTENCIÓN GRADO DE DAÑO SEGÚN MÉTODO LM1 (I = VIII) } \\
\hline & $\begin{array}{c}\mu D^{*} \text { _MIL03 } \\
(I=V I I)\end{array}$ & $\begin{array}{c}\mu D_{*}^{*} G 1005 \\
(I=V I I)\end{array}$ & $\begin{array}{c}\mu D^{*} \text { _LAN07 } \\
(I=V I I)\end{array}$ & $\begin{array}{c}\mu D^{*} \text { _FER12 } \\
(I=V I I)\end{array}$ & $\begin{array}{c}\mu D^{*} \text { _MAN16 } \\
(I=V I I)\end{array}$ & $\begin{array}{c}\mu D^{*} \text { _ROD17 } \\
(I=V I I)\end{array}$ & $\begin{array}{c}\mu D^{*} \text { _MIL03 } \\
(I=V I I I)\end{array}$ & $\begin{array}{c}\mu D_{*}^{*}{ }_{\text {GIOOS5 }} \\
(I=V I I I)\end{array}$ & $\begin{array}{c}\mu D^{*} \text { _LAN07 } \\
(I=V I I I)\end{array}$ & $\begin{array}{c}\mu D^{*} \text { _FER12 } \\
(I=V I I I)\end{array}$ & $\begin{array}{c}\mu D^{*} \text { _MAN16 } \\
(I=V I I I)\end{array}$ & $\begin{array}{c}\mu D^{*} \text { _ROD17 } \\
(1=\text { VIII })\end{array}$ \\
\hline 54 & 1,01 & 0,48 & 0,94 & 1,10 & 0,93 & 1,20 & 1,89 & 1,01 & 1,78 & 2,02 & 1,76 & 2,15 \\
\hline 55 & 0,85 & 0,39 & 0,23 & 0,64 & 0,44 & 0,85 & 1,64 & 0,85 & 0,53 & 1,30 & 0,93 & 1,64 \\
\hline 56 & 1,10 & 0,48 & 0,48 & 1,20 & 1,01 & 1,30 & 2,02 & 1,01 & 1,00 & 2,15 & 1,89 & 2,28 \\
\hline 57 & 1,01 & 0,48 & 1,14 & 1,41 & 0,85 & 1,89 & 1,89 & 1,01 & 2,07 & 2,42 & 1,64 & 2,96 \\
\hline 58 & 0,32 & 0,32 & 0,21 & 0,44 & 0,36 & 0,36 & 0,71 & 0,71 & 0,48 & 0,93 & 0,78 & 0,78 \\
\hline 59 & 0,26 & 0,29 & 0,32 & 0,36 & 0,36 & 0,64 & 0,58 & 0,64 & 0,70 & 0,78 & 0,78 & 1,30 \\
\hline 60 & 0,29 & 0,29 & 0,19 & 0,39 & 0,39 & 0,48 & 0,64 & 0,64 & 0,43 & 0,85 & 0,85 & 1,01 \\
\hline 61 & 1,01 & 0,48 & 0,65 & 0,48 & 0,39 & 0,85 & 1,89 & 1,01 & 1,32 & 1,01 & 0,85 & 1,64 \\
\hline 62 & 0,71 & 0,36 & 0,15 & 0,44 & 0,29 & 0,58 & 1,41 & 0,78 & 0,35 & 0,93 & 0,64 & 1,20 \\
\hline 63 & 0,85 & 0,44 & 0,29 & 0,64 & 0,53 & 1,01 & 1,64 & 0,93 & 0,64 & 1,30 & 1,10 & 1,89 \\
\hline 64 & 0,36 & 0,32 & 0,23 & 0,39 & 0,32 & 0,58 & 0,78 & 0,71 & 0,53 & 0,85 & 0,71 & 1,20 \\
\hline 65 & 0,71 & 0,36 & 0,96 & 0,58 & 0,58 & 1,01 & 1,41 & 0,78 & 1,81 & 1,20 & 1,20 & 1,89 \\
\hline 66 & 1,01 & 0,44 & 0,49 & 0,71 & 0,58 & 1,10 & 1,89 & 0,93 & 1,03 & 1,41 & 1,20 & 2,02 \\
\hline 67 & 1,01 & 0,53 & 1,05 & 0,85 & 0,71 & 1,10 & 1,89 & 1,10 & 1,94 & 1,64 & 1,41 & 2,02 \\
\hline 68 & 0,26 & 0,29 & 0,29 & 0,48 & 0,48 & 0,58 & 0,58 & 0,64 & 0,64 & 1,01 & 1,01 & 1,20 \\
\hline 69 & 0,93 & 0,48 & 0,65 & 0,78 & 0,64 & 1,20 & 1,76 & 1,01 & 1,32 & 1,52 & 1,30 & 2,15 \\
\hline 70 & 0,58 & 0,29 & 0,19 & 0,44 & 0,36 & 0,71 & 1,20 & 0,64 & 0,43 & 0,93 & 0,78 & 1,41 \\
\hline 71 & 1,01 & 0,48 & 0,32 & 0,71 & 0,58 & 0,64 & 1,89 & 1,01 & 0,70 & 1,41 & 1,20 & 1,30 \\
\hline 72 & 0,93 & 0,39 & 0,65 & 0,78 & 0,78 & 1,01 & 1,76 & 0,85 & 1,32 & 1,52 & 1,52 & 1,89 \\
\hline 73 & 0,32 & 0,36 & 0,26 & 0,53 & 0,44 & 0,44 & 0,71 & 0,78 & 0,58 & 1,10 & 0,93 & 0,93 \\
\hline 74 & 0,85 & 0,39 & 0,32 & 0,85 & 0,58 & 0,78 & 1,64 & 0,85 & 0,70 & 1,64 & 1,20 & 1,52 \\
\hline 75 & 1,01 & 0,48 & 0,35 & 0,78 & 0,64 & 0,85 & 1,89 & 1,01 & 0,77 & 1,52 & 1,30 & 1,64 \\
\hline 76 & 0,32 & 0,32 & 0,23 & 0,48 & 0,39 & 0,39 & 0,71 & 0,71 & 0,53 & 1,01 & 0,85 & 0,85 \\
\hline 77 & 0,32 & 0,36 & 0,23 & 0,32 & 0,26 & 0,39 & 0,71 & 0,78 & 0,53 & 0,71 & 0,58 & 0,85 \\
\hline 78 & 1,10 & 0,48 & 0,35 & 0,93 & 0,78 & 1,01 & 2,02 & 1,01 & 0,77 & 1,76 & 1,52 & 1,89 \\
\hline 79 & 0,85 & 0,44 & 1,14 & 0,93 & 0,78 & 1,20 & 1,64 & 0,93 & 2,07 & 1,76 & 1,52 & 2,15 \\
\hline 80 & 0,26 & 0,32 & 0,32 & 0,53 & 0,53 & 0,64 & 0,58 & 0,71 & 0,70 & 1,10 & 1,10 & 1,30 \\
\hline
\end{tabular}

$\mu_{D}{ }^{*}=$ daño medio representativo según metodología LM1 de RISK-UE; MILO3, GIO05, LAN07, FER12, MAN16, ROD17 = variantes del método MIV propuestas por Milutinovic \& Trendafiloski (2003), Giovinazzi (2005), Lantada (2007), Feriche (2012), Martínez-Cuevas \& Gaspar-Escribano (2016) y el modelo propuesto en esta tesis, respectivamente 


\begin{tabular}{|c|c|c|c|c|c|c|c|c|c|c|c|c|}
\hline \multirow[b]{2}{*}{ FID } & \multicolumn{6}{|c|}{ C. OBTENCIÓN GRADO DE DAÑO SEGÚN MÉTODO LM1 (I = VII) } & \multicolumn{6}{|c|}{ D. OBTENCIÓN GRADO DE DAÑO SEGÚN MÉTODO LM1 (I = VIII) } \\
\hline & $\begin{array}{c}\mu D^{*} \text { _MIL03 } \\
(I=V I I)\end{array}$ & $\begin{array}{c}\mu D^{*} \_ \text {GIO0S } \\
(I=V I I)\end{array}$ & $\begin{array}{c}\mu D^{*} \text { _LAN07 } \\
(I=V I I)\end{array}$ & $\begin{array}{c}\mu D^{*} \text { _FER12 } \\
(I=V I I)\end{array}$ & $\begin{array}{c}\mu D^{*} \text { _MAN16 } \\
(I=V I I)\end{array}$ & $\begin{array}{c}\mu D^{*} \text { _ROD17 } \\
(I=V I I)\end{array}$ & $\begin{array}{c}\mu D^{*} \text { MILO3 } \\
(I=V I I I)\end{array}$ & $\begin{array}{c}\mu D^{*} \text { _GIO05 } \\
(I=V I I I)\end{array}$ & $\begin{array}{c}\mu D^{*} \text { LAN07 } \\
(I=\text { VIII) }\end{array}$ & $\begin{array}{c}\mu D^{*} \text { _FER12 } \\
(I=V I I I)\end{array}$ & $\begin{array}{c}\mu D^{*} \text { _MAN16 } \\
(I=\text { VIII })\end{array}$ & $\begin{array}{c}\mu D^{*}{ }_{\text {ROD }} \text { ROD } \\
(\mathrm{I}=\mathrm{VIII})\end{array}$ \\
\hline 81 & 0,26 & 0,32 & 0,35 & 0,58 & 0,58 & 0,71 & 0,58 & 0,71 & 0,77 & 1,20 & 1,20 & 1,41 \\
\hline 82 & 0,26 & 0,32 & 0,23 & 0,26 & 0,26 & 0,48 & 0,58 & 0,71 & 0,53 & 0,58 & 0,58 & 1,01 \\
\hline 83 & 0,71 & 0,36 & 0,17 & 0,48 & 0,32 & 0,64 & 1,41 & 0,78 & 0,39 & 1,01 & 0,71 & 1,30 \\
\hline 84 & 0,85 & 0,44 & 0,80 & 0,64 & 0,53 & 0,85 & 1,64 & 0,93 & 1,57 & 1,30 & 1,10 & 1,64 \\
\hline 85 & 1,01 & 0,48 & 0,54 & 0,53 & 0,85 & 1,64 & 1,89 & 1,01 & 1,12 & 1,10 & 1,64 & 2,69 \\
\hline 86 & 0,85 & 0,44 & 1,24 & 0,85 & 0,78 & 1,30 & 1,64 & 0,93 & 2,20 & 1,64 & 1,52 & 2,28 \\
\hline 87 & 0,93 & 0,44 & 0,39 & 1,01 & 0,85 & 1,52 & 1,76 & 0,93 & 0,84 & 1,89 & 1,64 & 2,55 \\
\hline 88 & 0,71 & 0,32 & 0,23 & 0,53 & 0,44 & 0,58 & 1,41 & 0,71 & 0,53 & 1,10 & 0,93 & 1,20 \\
\hline 89 & 0,85 & 0,44 & 1,14 & 0,93 & 0,78 & 1,20 & 1,64 & 0,93 & 2,07 & 1,76 & 1,52 & 2,15 \\
\hline 90 & 0,85 & 0,44 & 0,35 & 0,78 & 0,64 & 1,20 & 1,64 & 0,93 & 0,77 & 1,52 & 1,30 & 2,15 \\
\hline 91 & 0,71 & 0,36 & 0,96 & 0,64 & 0,64 & 1,01 & 1,41 & 0,78 & 1,81 & 1,30 & 1,30 & 1,89 \\
\hline 92 & 0,58 & 0,29 & 0,15 & 0,36 & 0,29 & 0,58 & 1,20 & 0,64 & 0,35 & 0,78 & 0,64 & 1,20 \\
\hline 93 & 0,32 & 0,36 & 0,21 & 0,48 & 0,39 & 0,36 & 0,71 & 0,78 & 0,48 & 1,01 & 0,85 & 0,78 \\
\hline 94 & 0,85 & 0,44 & 0,15 & 0,44 & 0,29 & 0,58 & 1,64 & 0,93 & 0,35 & 0,93 & 0,64 & 1,20 \\
\hline 95 & 0,85 & 0,39 & 0,29 & 0,93 & 1,30 & 1,64 & 1,64 & 0,85 & 0,64 & 1,76 & 2,28 & 2,69 \\
\hline 96 & 0,26 & 0,29 & 0,32 & 0,53 & 0,53 & 0,64 & 0,58 & 0,64 & 0,70 & 1,10 & 1,10 & 1,30 \\
\hline 97 & 0,85 & 0,44 & 0,80 & 0,64 & 0,53 & 0,85 & 1,64 & 0,93 & 1,57 & 1,30 & 1,10 & 1,64 \\
\hline 98 & 1,01 & 0,48 & 0,96 & 0,71 & 0,58 & 0,71 & 1,89 & 1,01 & 1,81 & 1,41 & 1,20 & 1,41 \\
\hline 99 & 0,29 & 0,32 & 0,32 & 0,39 & 0,44 & 0,78 & 0,64 & 0,71 & 0,70 & 0,85 & 0,93 & 1,52 \\
\hline 100 & 0,71 & 0,36 & 0,96 & 0,64 & 0,64 & 1,01 & 1,41 & 0,78 & 1,81 & 1,30 & 1,30 & 1,89 \\
\hline 101 & 1,01 & 0,53 & 0,43 & 0,85 & 0,78 & 1,41 & 1,89 & 1,10 & 0,92 & 1,64 & 1,52 & 2,42 \\
\hline 102 & 0,93 & 0,44 & 0,39 & 0,93 & 0,85 & 1,52 & 1,76 & 0,93 & 0,84 & 1,76 & 1,64 & 2,55 \\
\hline 103 & 1,01 & 0,48 & 0,94 & 1,10 & 1,01 & 1,20 & 1,89 & 1,01 & 1,78 & 2,02 & 1,89 & 2,15 \\
\hline 104 & 0,71 & 0,36 & 0,19 & 0,53 & 0,36 & 1,01 & 1,41 & 0,78 & 0,43 & 1,10 & 0,78 & 1,89 \\
\hline 105 & 0,78 & 0,36 & 0,59 & 0,39 & 0,44 & 1,30 & 1,52 & 0,78 & 1,22 & 0,85 & 0,93 & 2,28 \\
\hline 106 & 0,71 & 0,36 & 0,17 & 0,48 & 0,32 & 0,64 & 1,41 & 0,78 & 0,39 & 1,01 & 0,71 & 1,30 \\
\hline 107 & 0,71 & 0,36 & 0,17 & 0,44 & 0,32 & 0,93 & 1,41 & 0,78 & 0,39 & 0,93 & 0,71 & 1,76 \\
\hline
\end{tabular}

$\mu_{D}{ }^{*}=$ daño medio representativo según metodología LM1 de RISK-UE; MILO3, GIO05, LAN07, FER12, MAN16, ROD17 = variantes del método MIV propuestas por Milutinovic \& Trendafiloski (2003), Giovinazzi (2005), Lantada (2007), Feriche (2012), Martínez-Cuevas \& Gaspar-Escribano (2016) y el modelo propuesto en esta tesis, respectivamente 


\begin{tabular}{|c|c|c|c|c|c|c|c|c|c|c|c|c|}
\hline \multirow[b]{2}{*}{ FID } & \multicolumn{6}{|c|}{ C. OBTENCIÓN GRADO DE DAÑO SEGÚN MÉTODO LM1 (I = VII) } & \multicolumn{6}{|c|}{ D. OBTENCIÓN GRADO DE DAÑO SEGÚN MÉTODO LM1 (I = VIII) } \\
\hline & $\begin{array}{c}\mu D^{*}=\mathrm{MILO3} \\
(1=\mathrm{VII})\end{array}$ & $\begin{array}{c}\mu D_{*}^{*} G 1005 \\
(I=V I I)\end{array}$ & $\begin{array}{c}\mu D^{*} \text { _LAN07 } \\
(I=V I I)\end{array}$ & $\begin{array}{c}\mu D^{*} \text { _FER12 } \\
(I=V I I)\end{array}$ & $\begin{array}{c}\mu D^{*} \text { _MAN16 } \\
(I=V I I)\end{array}$ & $\begin{array}{c}\mu D^{*} \text { _ROD17 } \\
(I=V I I)\end{array}$ & $\begin{array}{c}\mu D^{*} \text { _MILO3 } \\
(I=V I I I)\end{array}$ & $\begin{array}{c}\mu D^{*} \text { _GIO05 } \\
(I=V I I I)\end{array}$ & $\begin{array}{c}\mu D^{*} \text { _LAN07 } \\
(I=V I I I)\end{array}$ & $\begin{array}{c}\mu D^{*} \text { _FER12 } \\
(I=V I I I)\end{array}$ & $\begin{array}{c}\mu D^{*} \text { _MAN16 } \\
(I=V I I I)\end{array}$ & $\begin{array}{c}\mu D^{*} \text { _ROD17 } \\
(1=\text { VIII })\end{array}$ \\
\hline 108 & 0,85 & 0,39 & 0,19 & 0,53 & 0,36 & 0,48 & 1,64 & 0,85 & 0,43 & 1,10 & 0,78 & 1,01 \\
\hline 109 & 0,39 & 0,39 & 0,35 & 0,58 & 0,48 & 0,71 & 0,85 & 0,85 & 0,77 & 1,20 & 1,01 & 1,41 \\
\hline 110 & 0,85 & 0,44 & 0,65 & 0,48 & 0,39 & 1,20 & 1,64 & 0,93 & 1,32 & 1,01 & 0,85 & 2,15 \\
\hline 111 & 1,01 & 0,53 & 0,72 & 0,85 & 0,71 & 1,30 & 1,89 & 1,10 & 1,43 & 1,64 & 1,41 & 2,28 \\
\hline 112 & 0,93 & 0,48 & 0,49 & 0,64 & 0,53 & 0,93 & 1,76 & 1,01 & 1,03 & 1,30 & 1,10 & 1,76 \\
\hline 113 & 0,85 & 0,44 & 0,80 & 0,64 & 0,53 & 0,85 & 1,64 & 0,93 & 1,57 & 1,30 & 1,10 & 1,64 \\
\hline 114 & 0,93 & 0,44 & 0,23 & 0,64 & 0,53 & 1,01 & 1,76 & 0,93 & 0,53 & 1,30 & 1,10 & 1,89 \\
\hline 115 & 0,85 & 0,44 & 1,14 & 0,93 & 0,78 & 1,20 & 1,64 & 0,93 & 2,07 & 1,76 & 1,52 & 2,15 \\
\hline 116 & 0,85 & 0,44 & 0,35 & 0,78 & 0,64 & 0,85 & 1,64 & 0,93 & 0,77 & 1,52 & 1,30 & 1,64 \\
\hline 117 & 0,85 & 0,44 & 0,43 & 0,93 & 0,78 & 1,41 & 1,64 & 0,93 & 0,92 & 1,76 & 1,52 & 2,42 \\
\hline 118 & 1,10 & 0,58 & 0,43 & 0,93 & 0,78 & 1,41 & 2,02 & 1,20 & 0,92 & 1,76 & 1,52 & 2,42 \\
\hline 119 & 0,32 & 0,36 & 0,32 & 0,85 & 1,30 & 1,30 & 0,71 & 0,78 & 0,70 & 1,64 & 2,28 & 2,28 \\
\hline 120 & 0,85 & 0,44 & 0,39 & 0,78 & 0,71 & 0,93 & 1,64 & 0,93 & 0,84 & 1,52 & 1,41 & 1,76 \\
\hline 121 & 0,85 & 0,44 & 0,23 & 0,53 & 0,44 & 0,85 & 1,64 & 0,93 & 0,53 & 1,10 & 0,93 & 1,64 \\
\hline 122 & 0,85 & 0,44 & 0,23 & 0,53 & 0,44 & 0,58 & 1,64 & 0,93 & 0,53 & 1,10 & 0,93 & 1,20 \\
\hline 123 & 0,26 & 0,32 & 0,23 & 0,26 & 0,26 & 0,48 & 0,58 & 0,71 & 0,53 & 0,58 & 0,58 & 1,01 \\
\hline 124 & 1,10 & 0,53 & 0,26 & 0,71 & 0,58 & 1,10 & 2,02 & 1,10 & 0,58 & 1,41 & 1,20 & 2,02 \\
\hline 125 & 0,71 & 0,36 & 0,72 & 0,71 & 0,71 & 1,30 & 1,41 & 0,78 & 1,43 & 1,41 & 1,41 & 2,28 \\
\hline 126 & 0,39 & 0,44 & 0,21 & 0,48 & 0,39 & 0,53 & 0,85 & 0,93 & 0,48 & 1,01 & 0,85 & 1,10 \\
\hline 127 & 0,85 & 0,44 & 1,14 & 0,93 & 0,78 & 1,20 & 1,64 & 0,93 & 2,07 & 1,76 & 1,52 & 2,15 \\
\hline 128 & 1,20 & 0,48 & 0,39 & 0,85 & 0,71 & 0,78 & 2,15 & 1,01 & 0,84 & 1,64 & 1,41 & 1,52 \\
\hline 129 & 0,78 & 0,36 & 0,26 & 0,85 & 0,58 & 1,10 & 1,52 & 0,78 & 0,58 & 1,64 & 1,20 & 2,02 \\
\hline 130 & 0,85 & 0,39 & 0,21 & 0,58 & 0,39 & 0,78 & 1,64 & 0,85 & 0,48 & 1,20 & 0,85 & 1,52 \\
\hline 131 & 0,85 & 0,39 & 0,29 & 0,53 & 0,53 & 0,71 & 1,64 & 0,85 & 0,64 & 1,10 & 1,10 & 1,41 \\
\hline 132 & 0,71 & 0,36 & 0,19 & 0,39 & 0,32 & 0,39 & 1,41 & 0,78 & 0,43 & 0,85 & 0,71 & 0,85 \\
\hline 133 & 0,26 & 0,29 & 0,21 & 0,36 & 0,36 & 0,44 & 0,58 & 0,64 & 0,48 & 0,78 & 0,78 & 0,93 \\
\hline 134 & 0,85 & 0,39 & 0,21 & 0,58 & 0,39 & 0,53 & 1,64 & 0,85 & 0,48 & 1,20 & 0,85 & 1,10 \\
\hline
\end{tabular}

$\mu_{D}{ }^{*}=$ daño medio representativo según metodología LM1 de RISK-UE; MILO3, GIO05, LAN07, FER12, MAN16, ROD17 = variantes del método MIV propuestas por Milutinovic \& Trendafiloski (2003), Giovinazzi (2005), Lantada (2007), Feriche (2012), Martínez-Cuevas \& Gaspar-Escribano (2016) y el modelo propuesto en esta tesis, respectivamente 


\begin{tabular}{|c|c|c|c|c|c|c|c|c|c|c|c|c|}
\hline \multirow[b]{2}{*}{ FID } & \multicolumn{6}{|c|}{ C. OBTENCIÓN GRADO DE DAÑO SEGÚN MÉTODO LM1 (I = VII) } & \multicolumn{6}{|c|}{ D. OBTENCIÓN GRADO DE DAÑO SEGÚN MÉTODO LMI (I = VIII) } \\
\hline & $\begin{array}{c}\mu D^{*}=\text { MIL03 } \\
(I=V I I)\end{array}$ & $\begin{array}{c}\mu D^{*}=\text { GIO05 } \\
(I=V I I)\end{array}$ & $\begin{array}{c}\mu D^{*} \text { _LAN07 } \\
(I=V I I)\end{array}$ & $\begin{array}{c}\mu D^{*} \text { _FER12 } \\
(I=V I I)\end{array}$ & $\begin{array}{c}\mu D^{*} \text { _MAN16 } \\
(I=V I I)\end{array}$ & $\begin{array}{c}\mu D^{*}=\text { ROD17 } \\
(I=V I I)\end{array}$ & $\begin{array}{c}\mu D^{*} \_ \text {MIL03 } \\
(I=V I I I)\end{array}$ & $\begin{array}{c}\mu D^{*} \text { _GIO05 } \\
(I=V I I I)\end{array}$ & $\begin{array}{c}\mu D^{*} \text { LANOT } \\
(I=V I I I)\end{array}$ & $\begin{array}{c}\mu D^{*} \text { _FER12 } \\
(I=V I I I)\end{array}$ & $\begin{array}{c}\mu D^{*} \text { _MAN16 } \\
(I=\text { VIII })\end{array}$ & $\begin{array}{c}\mu D^{*}=\text { ROD17 } \\
(I=V I I I)\end{array}$ \\
\hline 135 & 0,71 & 0,32 & 0,29 & 0,64 & 0,53 & 0,71 & 1,41 & 0,71 & 0,64 & 1,30 & 1,10 & 1,41 \\
\hline 136 & 0,85 & 0,44 & 1,14 & 0,93 & 0,78 & 1,20 & 1,64 & 0,93 & 2,07 & 1,76 & 1,52 & 2,15 \\
\hline 137 & 1,01 & 0,48 & 0,88 & 0,64 & 0,53 & 0,64 & 1,89 & 1,01 & 1,69 & 1,30 & 1,10 & 1,30 \\
\hline 138 & 0,32 & 0,32 & 0,29 & 0,58 & 0,48 & 0,48 & 0,71 & 0,71 & 0,64 & 1,20 & 1,01 & 1,01 \\
\hline 139 & 1,20 & 0,48 & 0,39 & 0,85 & 0,71 & 0,53 & 2,15 & 1,01 & 0,84 & 1,64 & 1,41 & 1,10 \\
\hline 140 & 0,85 & 0,39 & 0,26 & 0,58 & 0,48 & 0,64 & 1,64 & 0,85 & 0,58 & 1,20 & 1,01 & 1,30 \\
\hline 141 & 0,93 & 0,44 & 0,72 & 1,01 & 0,85 & 1,52 & 1,76 & 0,93 & 1,43 & 1,89 & 1,64 & 2,55 \\
\hline 142 & 0,85 & 0,39 & 0,48 & 1,10 & 1,89 & 2,28 & 1,64 & 0,85 & 1,00 & 2,02 & 2,96 & 3,34 \\
\hline 142 & 0,29 & 0,36 & 0,23 & 0,32 & 0,26 & 0,48 & 0,64 & 0,78 & 0,53 & 0,71 & 0,58 & 1,01 \\
\hline 143 & 0,85 & 0,44 & 0,88 & 0,64 & 0,53 & 0,93 & 1,64 & 0,93 & 1,69 & 1,30 & 1,10 & 1,76 \\
\hline 144 & 1,01 & 0,48 & 0,59 & 0,78 & 0,78 & 1,10 & 1,89 & 1,01 & 1,22 & 1,52 & 1,52 & 2,02 \\
\hline 145 & 0,32 & 0,36 & 0,19 & 0,64 & 0,44 & 0,71 & 0,71 & 0,78 & 0,43 & 1,30 & 0,93 & 1,41 \\
\hline 146 & 0,93 & 0,44 & 0,79 & 0,64 & 0,58 & 1,64 & 1,76 & 0,93 & 1,54 & 1,30 & 1,20 & 2,69 \\
\hline 147 & 1,01 & 0,48 & 0,43 & 1,52 & 0,93 & 2,15 & 1,89 & 1,01 & 0,92 & 2,55 & 1,76 & 3,21 \\
\hline 148 & 0,44 & 0,44 & 0,21 & 0,44 & 0,36 & 0,36 & 0,93 & 0,93 & 0,48 & 0,93 & 0,78 & 0,78 \\
\hline 149 & 0,26 & 0,29 & 0,19 & 0,36 & 0,36 & 0,39 & 0,58 & 0,64 & 0,43 & 0,78 & 0,78 & 0,85 \\
\hline 150 & 0,39 & 0,44 & 0,23 & 0,48 & 0,39 & 0,39 & 0,85 & 0,93 & 0,53 & 1,01 & 0,85 & 0,85 \\
\hline 151 & 0,32 & 0,36 & 0,23 & 0,48 & 0,39 & 0,39 & 0,71 & 0,78 & 0,53 & 1,01 & 0,85 & 0,85 \\
\hline 152 & 0,39 & 0,36 & 0,29 & 0,71 & 0,48 & 0,48 & 0,85 & 0,78 & 0,64 & 1,41 & 1,01 & 1,01 \\
\hline 153 & 0,26 & 0,32 & 0,21 & 0,36 & 0,36 & 0,44 & 0,58 & 0,71 & 0,48 & 0,78 & 0,78 & 0,93 \\
\hline 154 & 0,85 & 0,44 & 0,65 & 0,78 & 0,64 & 1,20 & 1,64 & 0,93 & 1,32 & 1,52 & 1,30 & 2,15 \\
\hline 155 & 0,85 & 0,44 & 0,79 & 0,93 & 0,78 & 1,41 & 1,64 & 0,93 & 1,54 & 1,76 & 1,52 & 2,42 \\
\hline 156 & 0,71 & 0,36 & 0,96 & 0,64 & 0,64 & 1,01 & 1,41 & 0,78 & 1,81 & 1,30 & 1,30 & 1,89 \\
\hline 157 & 1,01 & 0,53 & 0,54 & 1,01 & 1,30 & 2,15 & 1,89 & 1,10 & 1,12 & 1,89 & 2,28 & 3,21 \\
\hline 158 & 0,93 & 0,44 & 0,79 & 1,01 & 0,93 & 1,64 & 1,76 & 0,93 & 1,54 & 1,89 & 1,76 & 2,69 \\
\hline 159 & 1,01 & 0,48 & 0,53 & 0,93 & 0,93 & 1,20 & 1,89 & 1,01 & 1,09 & 1,76 & 1,76 & 2,15 \\
\hline 160 & 1,20 & 0,58 & 0,94 & 0,71 & 0,58 & 1,20 & 2,15 & 1,20 & 1,78 & 1,41 & 1,20 & 2,15 \\
\hline
\end{tabular}

$\mu_{D}{ }^{*}=$ daño medio representativo según metodología LM1 de RISK-UE; MILO3, GIO05, LAN07, FER12, MAN16, ROD17 = variantes del método MIV propuestas por Milutinovic \& Trendafiloski (2003), Giovinazzi (2005), Lantada (2007), Feriche (2012), Martínez-Cuevas \& Gaspar-Escribano (2016) y el modelo propuesto en esta tesis, respectivamente 


\begin{tabular}{|c|c|c|c|c|c|c|c|c|c|c|c|c|}
\hline \multirow[b]{2}{*}{ FID } & \multicolumn{6}{|c|}{ C. OBTENCIÓN GRADO DE DAÑO SEGÚN MÉTODO LM1 (I = VII) } & \multicolumn{6}{|c|}{ D. OBTENCIÓN GRADO DE DAÑO SEGÚN MÉTODO LMI (I = VIII) } \\
\hline & $\begin{array}{c}\mu D^{*} \text { _MILO3 } \\
(I=V I I)\end{array}$ & $\begin{array}{c}\mu D^{*} \_ \text {GIO05 } \\
(I=V I I)\end{array}$ & $\begin{array}{c}\mu D^{*} \text { _LAN07 } \\
(I=V I I)\end{array}$ & $\begin{array}{c}\mu D^{*} \text { _FER12 } \\
(I=\text { VII })\end{array}$ & $\begin{array}{c}\mu D^{*} \text { _MAN16 } \\
(I=V I I)\end{array}$ & $\begin{array}{c}\mu D^{*} \text { _ROD17 } \\
(I=\text { VII })\end{array}$ & $\begin{array}{c}\mu D^{*} \_ \text {MIL03 } \\
(I=V I I I)\end{array}$ & $\begin{array}{c}\mu D^{*} \text { _GIO05 } \\
(I=\text { VIII) }\end{array}$ & $\begin{array}{c}\mu D^{*} \text { _LAN07 } \\
(I=\text { VIII })\end{array}$ & $\begin{array}{c}\mu D^{*} \text { FER12 } \\
(I=V I I I)\end{array}$ & $\begin{array}{c}\mu D^{*} \text { _MAN16 } \\
(I=\text { VIII })\end{array}$ & $\begin{array}{c}\mu D^{*}{ }^{*} \text { ROD17 } \\
(I=V I I I)\end{array}$ \\
\hline 161 & 0,26 & 0,32 & 0,19 & 0,32 & 0,32 & 0,39 & 0,58 & 0,71 & 0,43 & 0,71 & 0,71 & 0,85 \\
\hline 162 & 1,01 & 0,48 & 0,59 & 0,78 & 0,78 & 1,10 & 1,89 & 1,01 & 1,22 & 1,52 & 1,52 & 2,02 \\
\hline 163 & 0,85 & 0,44 & 0,26 & 0,58 & 0,48 & 0,93 & 1,64 & 0,93 & 0,58 & 1,20 & 1,01 & 1,76 \\
\hline 164 & 1,01 & 0,48 & 0,23 & 0,78 & 0,44 & 0,58 & 1,89 & 1,01 & 0,53 & 1,52 & 0,93 & 1,20 \\
\hline 165 & 1,20 & 0,48 & 0,39 & 0,85 & 0,71 & 0,53 & 2,15 & 1,01 & 0,84 & 1,64 & 1,41 & 1,10 \\
\hline 166 & 0,85 & 0,44 & 1,14 & 0,93 & 0,78 & 1,20 & 1,64 & 0,93 & 2,07 & 1,76 & 1,52 & 2,15 \\
\hline 167 & 0,71 & 0,32 & 0,23 & 0,71 & 1,10 & 1,41 & 1,41 & 0,71 & 0,53 & 1,41 & 2,02 & 2,42 \\
\hline 168 & 0,39 & 0,39 & 0,26 & 0,53 & 0,44 & 0,44 & 0,85 & 0,85 & 0,58 & 1,10 & 0,93 & 0,93 \\
\hline 169 & 0,93 & 0,44 & 0,39 & 1,01 & 0,85 & 1,10 & 1,76 & 0,93 & 0,84 & 1,89 & 1,64 & 2,02 \\
\hline 170 & 0,85 & 0,39 & 0,32 & 0,85 & 0,58 & 0,78 & 1,64 & 0,85 & 0,70 & 1,64 & 1,20 & 1,52 \\
\hline 172 & 0,85 & 0,39 & 0,35 & 0,71 & 0,64 & 1,20 & 1,64 & 0,85 & 0,77 & 1,41 & 1,30 & 2,15 \\
\hline 173 & 0,85 & 0,44 & 0,49 & 0,53 & 0,48 & 0,93 & 1,64 & 0,93 & 1,03 & 1,10 & 1,01 & 1,76 \\
\hline 174 & 0,32 & 0,32 & 0,19 & 0,26 & 0,21 & 0,32 & 0,71 & 0,71 & 0,43 & 0,58 & 0,48 & 0,71 \\
\hline 175 & 0,71 & 0,32 & 0,23 & 0,53 & 0,44 & 0,58 & 1,41 & 0,71 & 0,53 & 1,10 & 0,93 & 1,20 \\
\hline 176 & 0,44 & 0,44 & 0,29 & 0,48 & 0,85 & 1,20 & 0,93 & 0,93 & 0,64 & 1,01 & 1,64 & 2,15 \\
\hline 177 & 0,85 & 0,44 & 0,39 & 0,85 & 0,71 & 1,30 & 1,64 & 0,93 & 0,84 & 1,64 & 1,41 & 2,28 \\
\hline 178 & 1,41 & 0,58 & 1,03 & 0,93 & 1,01 & 0,78 & 2,42 & 1,20 & 1,91 & 1,76 & 1,89 & 1,52 \\
\hline 179 & 1,01 & 0,48 & 0,54 & 0,85 & 1,30 & 1,64 & 1,89 & 1,01 & 1,12 & 1,64 & 2,28 & 2,69 \\
\hline 180 & 0,85 & 0,44 & 0,72 & 0,85 & 0,71 & 1,30 & 1,64 & 0,93 & 1,43 & 1,64 & 1,41 & 2,28 \\
\hline 181 & 0,93 & 0,44 & 0,54 & 0,78 & 0,64 & 1,20 & 1,76 & 0,93 & 1,12 & 1,52 & 1,30 & 2,15 \\
\hline 182 & 0,32 & 0,36 & 0,19 & 0,58 & 0,39 & 0,71 & 0,71 & 0,78 & 0,43 & 1,20 & 0,85 & 1,41 \\
\hline 183 & 0,85 & 0,44 & 0,29 & 0,64 & 0,53 & 1,01 & 1,64 & 0,93 & 0,64 & 1,30 & 1,10 & 1,89 \\
\hline 184 & 0,85 & 0,44 & 0,54 & 0,39 & 0,32 & 1,01 & 1,64 & 0,93 & 1,12 & 0,85 & 0,71 & 1,89 \\
\hline 185 & 1,01 & 0,48 & 0,26 & 0,71 & 0,48 & 0,64 & 1,89 & 1,01 & 0,58 & 1,41 & 1,01 & 1,30 \\
\hline 186 & 0,32 & 0,39 & 0,32 & 0,53 & 0,53 & 0,64 & 0,71 & 0,85 & 0,70 & 1,10 & 1,10 & 1,30 \\
\hline 187 & 0,71 & 0,32 & 0,19 & 0,44 & 0,36 & 0,48 & 1,41 & 0,71 & 0,43 & 0,93 & 0,78 & 1,01 \\
\hline 188 & 0,26 & 0,29 & 0,19 & 0,21 & 0,21 & 0,39 & 0,58 & 0,64 & 0,43 & 0,48 & 0,48 & 0,85 \\
\hline
\end{tabular}

$\mu_{D}{ }^{*}=$ daño medio representativo según metodología LM1 de RISK-UE; MILO3, GIO05, LAN07, FER12, MAN16, ROD17 = variantes del método MIV propuestas por Milutinovic \& Trendafiloski (2003), Giovinazzi (2005), Lantada (2007), Feriche (2012), Martínez-Cuevas \& Gaspar-Escribano (2016) y el modelo propuesto en esta tesis, respectivamente 


\begin{tabular}{|c|c|c|c|c|c|c|c|c|c|c|c|c|}
\hline \multirow[b]{2}{*}{ FID } & \multicolumn{6}{|c|}{ C. OBTENCIÓN GRADO DE DAÑO SEGÚN MÉTODO LM1 (I = VII) } & \multicolumn{6}{|c|}{ D. OBTENCIÓN GRADO DE DAÑO SEGÚN MÉTODO LMI (I = VIII) } \\
\hline & $\begin{array}{c}\mu D^{*} \text { _MIL03 } \\
(I=V I I)\end{array}$ & $\begin{array}{c}\mu D^{*} \_ \text {GIO0S } \\
(I=V I I)\end{array}$ & $\begin{array}{c}\mu D^{*} \text { _LAN07 } \\
(I=V I I)\end{array}$ & $\begin{array}{c}\mu D^{*} \text { _FER12 } \\
(I=V I I)\end{array}$ & $\begin{array}{c}\mu D^{*} \text { _MAN16 } \\
(I=V I I)\end{array}$ & $\begin{array}{c}\mu D^{*} \text { _ROD17 } \\
(I=V I I)\end{array}$ & $\begin{array}{c}\mu D^{*} \text { MILO3 } \\
(I=V I I I)\end{array}$ & $\begin{array}{c}\mu D^{*} \text { _GIO005 } \\
(I=V I I I)\end{array}$ & $\begin{array}{c}\mu D^{*} \text { LAN07 } \\
(I=\text { VIII) }\end{array}$ & $\begin{array}{c}\mu D^{*} \text { _FER12 } \\
(I=V I I I)\end{array}$ & $\begin{array}{c}\mu D^{*} \text { _MAN16 } \\
(I=V I I I)\end{array}$ & $\begin{array}{c}\mu D^{*}{ }_{\text {ROD }} \text { ROD } \\
(\mathrm{I}=\mathrm{VIII})\end{array}$ \\
\hline 189 & 0,32 & 0,36 & 0,29 & 0,58 & 0,48 & 0,48 & 0,71 & 0,78 & 0,64 & 1,20 & 1,01 & 1,01 \\
\hline 190 & 0,26 & 0,32 & 0,29 & 0,32 & 0,32 & 0,58 & 0,58 & 0,71 & 0,64 & 0,71 & 0,71 & 1,20 \\
\hline 191 & 0,85 & 0,36 & 0,21 & 0,58 & 0,39 & 0,53 & 1,64 & 0,78 & 0,48 & 1,20 & 0,85 & 1,10 \\
\hline 192 & 0,85 & 0,44 & 1,14 & 0,93 & 0,78 & 1,20 & 1,64 & 0,93 & 2,07 & 1,76 & 1,52 & 2,15 \\
\hline 193 & 0,32 & 0,32 & 0,32 & 0,64 & 0,53 & 0,53 & 0,71 & 0,71 & 0,70 & 1,30 & 1,10 & 1,10 \\
\hline 194 & 0,85 & 0,44 & 0,44 & 0,32 & 0,26 & 0,85 & 1,64 & 0,93 & 0,94 & 0,71 & 0,58 & 1,64 \\
\hline 195 & 1,20 & 0,48 & 0,32 & 0,71 & 0,58 & 0,44 & 2,15 & 1,01 & 0,70 & 1,41 & 1,20 & 0,93 \\
\hline 196 & 0,71 & 0,36 & 0,29 & 0,64 & 0,53 & 0,58 & 1,41 & 0,78 & 0,64 & 1,30 & 1,10 & 1,20 \\
\hline 197 & 0,39 & 0,39 & 0,19 & 0,39 & 0,32 & 0,32 & 0,85 & 0,85 & 0,43 & 0,85 & 0,71 & 0,71 \\
\hline 198 & 0,71 & 0,36 & 0,23 & 0,64 & 0,44 & 0,85 & 1,41 & 0,78 & 0,53 & 1,30 & 0,93 & 1,64 \\
\hline 199 & 0,85 & 0,39 & 0,32 & 0,71 & 0,58 & 0,78 & 1,64 & 0,85 & 0,70 & 1,41 & 1,20 & 1,52 \\
\hline 200 & 0,71 & 0,36 & 0,15 & 0,44 & 0,29 & 0,85 & 1,41 & 0,78 & 0,35 & 0,93 & 0,64 & 1,64 \\
\hline 201 & 0,32 & 0,36 & 0,23 & 0,39 & 0,39 & 0,48 & 0,71 & 0,78 & 0,53 & 0,85 & 0,85 & 1,01 \\
\hline 202 & 1,01 & 0,48 & 0,86 & 0,93 & 0,85 & 1,10 & 1,89 & 1,01 & 1,66 & 1,76 & 1,64 & 2,02 \\
\hline 203 & 0,36 & 0,32 & 0,32 & 0,71 & 1,10 & 1,52 & 0,78 & 0,71 & 0,70 & 1,41 & 2,02 & 2,55 \\
\hline 204 & 0,39 & 0,36 & 0,29 & 0,48 & 0,32 & 0,48 & 0,85 & 0,78 & 0,64 & 1,01 & 0,71 & 1,01 \\
\hline 205 & 0,71 & 0,32 & 0,32 & 0,71 & 0,58 & 0,78 & 1,41 & 0,71 & 0,70 & 1,41 & 1,20 & 1,52 \\
\hline 206 & 0,32 & 0,32 & 0,23 & 0,48 & 0,39 & 0,39 & 0,71 & 0,71 & 0,53 & 1,01 & 0,85 & 0,85 \\
\hline 207 & 0,71 & 0,32 & 0,32 & 0,71 & 0,58 & 0,78 & 1,41 & 0,71 & 0,70 & 1,41 & 1,20 & 1,52 \\
\hline 208 & 0,26 & 0,29 & 0,32 & 0,71 & 1,30 & 1,52 & 0,58 & 0,64 & 0,70 & 1,41 & 2,28 & 2,55 \\
\hline 209 & 0,26 & 0,29 & 0,29 & 0,48 & 0,48 & 0,48 & 0,58 & 0,64 & 0,64 & 1,01 & 1,01 & 1,01 \\
\hline 210 & 1,01 & 0,48 & 0,59 & 0,44 & 0,36 & 0,78 & 1,89 & 1,01 & 1,22 & 0,93 & 0,78 & 1,52 \\
\hline 211 & 1,10 & 0,48 & 1,14 & 1,01 & 0,85 & 1,01 & 2,02 & 1,01 & 2,07 & 1,89 & 1,64 & 1,89 \\
\hline 212 & 1,10 & 0,48 & 0,65 & 0,85 & 0,78 & 1,01 & 2,02 & 1,01 & 1,32 & 1,64 & 1,52 & 1,89 \\
\hline 213 & 0,71 & 0,36 & 0,15 & 0,44 & 0,29 & 0,58 & 1,41 & 0,78 & 0,35 & 0,93 & 0,64 & 1,20 \\
\hline 214 & 1,10 & 0,53 & 0,26 & 0,64 & 0,48 & 0,64 & 2,02 & 1,10 & 0,58 & 1,30 & 1,01 & 1,30 \\
\hline 215 & 1,01 & 0,48 & 0,54 & 0,64 & 0,53 & 0,71 & 1,89 & 1,01 & 1,12 & 1,30 & 1,10 & 1,41 \\
\hline
\end{tabular}

$\mu_{D}{ }^{*}=$ daño medio representativo según metodología LM1 de RISK-UE; MILO3, GIO05, LAN07, FER12, MAN16, ROD17 = variantes del método MIV propuestas por Milutinovic \& Trendafiloski (2003), Giovinazzi (2005), Lantada (2007), Feriche (2012), Martínez-Cuevas \& Gaspar-Escribano (2016) y el modelo propuesto en esta tesis, respectivamente 


\begin{tabular}{|c|c|c|c|c|c|c|c|c|c|c|c|c|}
\hline \multirow[b]{2}{*}{ FID } & \multicolumn{6}{|c|}{ C. OBTENCIÓN GRADO DE DAÑO SEGÚN MÉTODO LM1 (I = VII) } & \multicolumn{6}{|c|}{ D. OBTENCIÓN GRADO DE DAÑO SEGÚN MÉTODO LM1 (I = VIII) } \\
\hline & $\begin{array}{c}\mu D^{*} \text { _MIL03 } \\
(I=V I I)\end{array}$ & $\begin{array}{c}\mu D^{*} \text { _GIO05 } \\
(I=\text { VII })\end{array}$ & $\begin{array}{c}\mu D^{*} \text { _LAN07 } \\
(I=V I I)\end{array}$ & $\begin{array}{c}\mu D^{*} \text { _FER12 } \\
(I=V I I)\end{array}$ & $\begin{array}{c}\mu D^{*} \text { _MAN16 } \\
(I=\text { VII })\end{array}$ & $\begin{array}{c}\mu D^{*} \text { _ROD17 } \\
(I=V I I)\end{array}$ & $\begin{array}{c}\mu D^{*} \text { _MILO3 } \\
(I=\text { VIII) }\end{array}$ & $\begin{array}{c}\mu D^{*} \text { _GIO05 } \\
(I=V I I I)\end{array}$ & $\begin{array}{c}\mu D^{*} \text { _LAN07 } \\
(I=\text { VIII })\end{array}$ & $\begin{array}{c}\mu D^{*} \text { _FER12 } \\
(I=\text { VIII })\end{array}$ & $\begin{array}{c}\mu D^{*} \text { _MAN16 } \\
(I=V I I I)\end{array}$ & $\begin{array}{c}\mu D^{*}{ }_{\text {_ROD17 }} \\
(\mathrm{I}=\mathrm{VIII})\end{array}$ \\
\hline 216 & 1,01 & 0,48 & 0,94 & 0,64 & 0,58 & 1,20 & 1,89 & 1,01 & 1,78 & 1,30 & 1,20 & 2,15 \\
\hline 217 & 0,26 & 0,29 & 0,23 & 0,26 & 0,26 & 0,48 & 0,58 & 0,64 & 0,53 & 0,58 & 0,58 & 1,01 \\
\hline 218 & 0,26 & 0,29 & 0,19 & 0,21 & 0,21 & 0,39 & 0,58 & 0,64 & 0,43 & 0,48 & 0,48 & 0,85 \\
\hline 219 & 0,85 & 0,44 & 1,14 & 0,85 & 0,71 & 1,20 & 1,64 & 0,93 & 2,07 & 1,64 & 1,41 & 2,15 \\
\hline 220 & 0,85 & 0,39 & 0,21 & 0,58 & 0,39 & 0,53 & 1,64 & 0,85 & 0,48 & 1,20 & 0,85 & 1,10 \\
\hline 221 & 0,29 & 0,32 & 0,35 & 0,64 & 0,64 & 0,71 & 0,64 & 0,71 & 0,77 & 1,30 & 1,30 & 1,41 \\
\hline 222 & 0,71 & 0,36 & 0,15 & 0,44 & 0,29 & 0,58 & 1,41 & 0,78 & 0,35 & 0,93 & 0,64 & 1,20 \\
\hline 223 & 0,85 & 0,44 & 0,67 & 0,48 & 0,39 & 0,71 & 1,64 & 0,93 & 1,34 & 1,01 & 0,85 & 1,41 \\
\hline 224 & 0,38 & 0,38 & 0,35 & 0,71 & 0,58 & 0,58 & 0,81 & 0,81 & 0,77 & 1,41 & 1,20 & 1,20 \\
\hline 225 & 0,85 & 0,39 & 0,26 & 0,64 & 0,48 & 0,93 & 1,64 & 0,85 & 0,58 & 1,30 & 1,01 & 1,76 \\
\hline 226 & 0,71 & 0,32 & 0,32 & 0,93 & 1,41 & 1,76 & 1,41 & 0,71 & 0,70 & 1,76 & 2,42 & 2,82 \\
\hline 227 & 0,93 & 0,39 & 0,32 & 1,01 & 0,71 & 0,93 & 1,76 & 0,85 & 0,70 & 1,89 & 1,41 & 1,76 \\
\hline 228 & 0,85 & 0,39 & 0,21 & 0,58 & 0,39 & 0,53 & 1,64 & 0,85 & 0,48 & 1,20 & 0,85 & 1,10 \\
\hline 229 & 0,44 & 0,44 & 0,29 & 0,58 & 0,48 & 0,58 & 0,93 & 0,93 & 0,64 & 1,20 & 1,01 & 1,20 \\
\hline 230 & 1,01 & 0,48 & 0,94 & 1,01 & 0,93 & 1,20 & 1,89 & 1,01 & 1,78 & 1,89 & 1,76 & 2,15 \\
\hline 231 & 0,58 & 0,29 & 0,26 & 0,58 & 0,48 & 0,93 & 1,20 & 0,64 & 0,58 & 1,20 & 1,01 & 1,76 \\
\hline 232 & 0,32 & 0,32 & 0,29 & 0,58 & 0,48 & 0,58 & 0,71 & 0,71 & 0,64 & 1,20 & 1,01 & 1,20 \\
\hline 233 & 1,10 & 0,53 & 0,94 & 1,64 & 1,01 & 1,64 & 2,02 & 1,10 & 1,78 & 2,69 & 1,89 & 2,69 \\
\hline 234 & 1,01 & 0,48 & 0,59 & 0,39 & 0,36 & 0,78 & 1,89 & 1,01 & 1,22 & 0,85 & 0,78 & 1,52 \\
\hline 235 & 1,01 & 0,48 & 0,21 & 0,58 & 0,39 & 0,53 & 1,89 & 1,01 & 0,48 & 1,20 & 0,85 & 1,10 \\
\hline 236 & 1,01 & 0,48 & 0,32 & 0,71 & 0,58 & 0,78 & 1,89 & 1,01 & 0,70 & 1,41 & 1,20 & 1,52 \\
\hline 237 & 1,10 & 0,48 & 0,94 & 0,85 & 0,71 & 1,41 & 2,02 & 1,01 & 1,78 & 1,64 & 1,41 & 2,42 \\
\hline 238 & 0,85 & 0,44 & 0,26 & 0,58 & 0,48 & 0,93 & 1,64 & 0,93 & 0,58 & 1,20 & 1,01 & 1,76 \\
\hline 239 & 0,71 & 0,36 & 0,17 & 0,48 & 0,32 & 0,64 & 1,41 & 0,78 & 0,39 & 1,01 & 0,71 & 1,30 \\
\hline 240 & 0,71 & 0,36 & 0,17 & 0,48 & 0,32 & 0,93 & 1,41 & 0,78 & 0,39 & 1,01 & 0,71 & 1,76 \\
\hline 241 & 1,01 & 0,48 & 0,21 & 0,71 & 0,39 & 0,53 & 1,89 & 1,01 & 0,48 & 1,41 & 0,85 & 1,10 \\
\hline 242 & 1,20 & 0,58 & 0,39 & 0,93 & 0,71 & 0,78 & 2,15 & 1,20 & 0,84 & 1,76 & 1,41 & 1,52 \\
\hline
\end{tabular}

$\mu_{D}{ }^{*}=$ daño medio representativo según metodología LM1 de RISK-UE; MILO3, GIO05, LAN07, FER12, MAN16, ROD17 = variantes del método MIV propuestas por Milutinovic \& Trendafiloski (2003), Giovinazzi (2005), Lantada (2007), Feriche (2012), Martínez-Cuevas \& Gaspar-Escribano (2016) y el modelo propuesto en esta tesis, respectivamente 


\begin{tabular}{|c|c|c|c|c|c|c|c|c|c|c|c|c|}
\hline \multirow[b]{2}{*}{ FID } & \multicolumn{6}{|c|}{ C. OBTENCIÓN GRADO DE DAÑO SEGÚN MÉTODO LM1 (I = VII) } & \multicolumn{6}{|c|}{ D. OBTENCIÓN GRADO DE DAÑO SEGÚN MÉTODO LMI (I = VIII) } \\
\hline & $\begin{array}{c}\mu D^{*} \text { _MIL03 } \\
(I=V I I)\end{array}$ & $\begin{array}{c}\mu D^{*} \_ \text {GIO0S } \\
(I=V I I)\end{array}$ & $\begin{array}{c}\mu D^{*} \text { _LAN07 } \\
(I=V I I)\end{array}$ & $\begin{array}{c}\mu D^{*} \text { _FER12 } \\
(I=V I I)\end{array}$ & $\begin{array}{c}\mu D^{*} \text { _MAN16 } \\
(I=V I I)\end{array}$ & $\begin{array}{c}\mu D^{*} \text { _ROD17 } \\
(I=V I I)\end{array}$ & $\begin{array}{c}\mu D^{*} \text { MILO3 } \\
(I=V I I I)\end{array}$ & $\begin{array}{c}\mu D^{*} \text { _GIO05 } \\
(I=V I I I)\end{array}$ & $\begin{array}{c}\mu D^{*} \text { LAN07 } \\
(I=\text { VIII) }\end{array}$ & $\begin{array}{c}\mu D^{*} \text { _FER12 } \\
(I=V I I I)\end{array}$ & $\begin{array}{c}\mu D^{*} \text { _MAN16 } \\
(I=V I I I)\end{array}$ & $\begin{array}{c}\mu D^{*}{ }_{\text {ROD }} \text { ROD } \\
(\mathrm{I}=\mathrm{VIII})\end{array}$ \\
\hline 243 & 0,26 & 0,29 & 0,39 & 0,44 & 0,44 & 0,78 & 0,58 & 0,64 & 0,84 & 0,93 & 0,93 & 1,52 \\
\hline 244 & 1,20 & 0,58 & 0,59 & 0,71 & 0,58 & 0,78 & 2,15 & 1,20 & 1,22 & 1,41 & 1,20 & 1,52 \\
\hline 245 & 0,36 & 0,36 & 0,23 & 0,58 & 0,71 & 1,01 & 0,78 & 0,78 & 0,53 & 1,20 & 1,41 & 1,89 \\
\hline 246 & 0,44 & 0,36 & 0,19 & 0,39 & 0,26 & 0,39 & 0,93 & 0,78 & 0,43 & 0,85 & 0,58 & 0,85 \\
\hline 247 & 0,32 & 0,36 & 0,32 & 0,58 & 0,58 & 0,93 & 0,71 & 0,78 & 0,70 & 1,20 & 1,20 & 1,76 \\
\hline 248 & 1,01 & 0,48 & 0,48 & 1,01 & 0,85 & 1,10 & 1,89 & 1,01 & 1,00 & 1,89 & 1,64 & 2,02 \\
\hline 249 & 1,01 & 0,48 & 0,35 & 0,93 & 0,64 & 0,85 & 1,89 & 1,01 & 0,77 & 1,76 & 1,30 & 1,64 \\
\hline 250 & 0,85 & 0,39 & 0,17 & 0,48 & 0,32 & 0,44 & 1,64 & 0,85 & 0,39 & 1,01 & 0,71 & 0,93 \\
\hline 251 & 0,39 & 0,39 & 0,19 & 0,53 & 0,36 & 0,32 & 0,85 & 0,85 & 0,43 & 1,10 & 0,78 & 0,71 \\
\hline 252 & 0,85 & 0,44 & 0,80 & 0,58 & 0,48 & 0,85 & 1,64 & 0,93 & 1,57 & 1,20 & 1,01 & 1,64 \\
\hline 253 & 0,39 & 0,36 & 0,23 & 0,39 & 0,26 & 0,39 & 0,85 & 0,78 & 0,53 & 0,85 & 0,58 & 0,85 \\
\hline 254 & 0,85 & 0,44 & 0,23 & 0,53 & 0,44 & 0,85 & 1,64 & 0,93 & 0,53 & 1,10 & 0,93 & 1,64 \\
\hline 255 & 0,85 & 0,44 & 0,54 & 0,39 & 0,32 & 1,01 & 1,64 & 0,93 & 1,12 & 0,85 & 0,71 & 1,89 \\
\hline 256 & 0,85 & 0,44 & 0,67 & 0,48 & 0,39 & 0,71 & 1,64 & 0,93 & 1,34 & 1,01 & 0,85 & 1,41 \\
\hline 257 & 0,26 & 0,29 & 0,23 & 0,39 & 0,39 & 0,48 & 0,58 & 0,64 & 0,53 & 0,85 & 0,85 & 1,01 \\
\hline 258 & 0,85 & 0,39 & 0,32 & 1,10 & 1,41 & 1,76 & 1,64 & 0,85 & 0,70 & 2,02 & 2,42 & 2,82 \\
\hline 259 & 0,71 & 0,32 & 0,23 & 0,53 & 0,44 & 0,58 & 1,41 & 0,71 & 0,53 & 1,10 & 0,93 & 1,20 \\
\hline 260 & 1,01 & 0,48 & 0,59 & 0,44 & 0,36 & 0,78 & 1,89 & 1,01 & 1,22 & 0,93 & 0,78 & 1,52 \\
\hline 261 & 0,32 & 0,32 & 0,29 & 0,58 & 0,48 & 0,48 & 0,71 & 0,71 & 0,64 & 1,20 & 1,01 & 1,01 \\
\hline 262 & 0,85 & 0,44 & 1,14 & 0,93 & 0,78 & 1,20 & 1,64 & 0,93 & 2,07 & 1,76 & 1,52 & 2,15 \\
\hline 263 & 0,71 & 0,32 & 0,21 & 0,48 & 0,39 & 0,53 & 1,41 & 0,71 & 0,48 & 1,01 & 0,85 & 1,10 \\
\hline 264 & 0,32 & 0,32 & 0,32 & 0,44 & 0,36 & 0,64 & 0,71 & 0,71 & 0,70 & 0,93 & 0,78 & 1,30 \\
\hline 265 & 0,85 & 0,39 & 0,19 & 0,53 & 0,36 & 0,48 & 1,64 & 0,85 & 0,43 & 1,10 & 0,78 & 1,01 \\
\hline 266 & 1,30 & 0,64 & 0,53 & 1,41 & 2,02 & 1,89 & 2,28 & 1,30 & 1,09 & 2,42 & 3,09 & 2,96 \\
\hline 267 & 0,26 & 0,29 & 0,32 & 0,53 & 0,53 & 0,64 & 0,58 & 0,64 & 0,70 & 1,10 & 1,10 & 1,30 \\
\hline 268 & 1,01 & 0,48 & 0,29 & 0,64 & 0,53 & 0,71 & 1,89 & 1,01 & 0,64 & 1,30 & 1,10 & 1,41 \\
\hline 269 & 1,20 & 0,48 & 0,58 & 1,10 & 1,01 & 0,78 & 2,15 & 1,01 & 1,19 & 2,02 & 1,89 & 1,52 \\
\hline
\end{tabular}

$\mu_{D}{ }^{*}=$ daño medio representativo según metodología LM1 de RISK-UE; MILO3, GIO05, LAN07, FER12, MAN16, ROD17 = variantes del método MIV propuestas por Milutinovic \& Trendafiloski (2003), Giovinazzi (2005), Lantada (2007), Feriche (2012), Martínez-Cuevas \& Gaspar-Escribano (2016) y el modelo propuesto en esta tesis, respectivamente 


\begin{tabular}{|c|c|c|c|c|c|c|c|c|c|c|c|c|}
\hline \multirow[b]{2}{*}{ FID } & \multicolumn{6}{|c|}{ C. OBTENCIÓN GRADO DE DAÑO SEGÚN MÉTODO LM1 (I = VII) } & \multicolumn{6}{|c|}{ D. OBTENCIÓN GRADO DE DAÑO SEGÚN MÉTODO LM1 (I = VIII) } \\
\hline & $\begin{array}{c}\mu D^{*} \text { _MIL03 } \\
(I=V I I)\end{array}$ & $\begin{array}{c}\mu D^{*} \text { _GIO05 } \\
(I=\text { VII })\end{array}$ & $\begin{array}{c}\mu D^{*} \text { _LAN07 } \\
(I=V I I)\end{array}$ & $\begin{array}{c}\mu D^{*} \text { _FER12 } \\
(I=V I I)\end{array}$ & $\begin{array}{c}\mu D^{*} \text { _MAN16 } \\
(I=\text { VII })\end{array}$ & $\begin{array}{c}\mu D^{*} \text { _ROD17 } \\
(I=V I I)\end{array}$ & $\begin{array}{c}\mu D^{*} \text { _MILO3 } \\
(I=V I I I)\end{array}$ & $\begin{array}{c}\mu D^{*} \text { _GIO05 } \\
(I=V I I I)\end{array}$ & $\begin{array}{c}\mu D^{*} \text { _LAN07 } \\
(I=\text { VIII })\end{array}$ & $\begin{array}{c}\mu D^{*} \text { _FER12 } \\
(I=V I I I)\end{array}$ & $\begin{array}{c}\mu D^{*} \text { _MAN16 } \\
(I=V I I I)\end{array}$ & $\begin{array}{c}\mu D^{*}{ }_{\text {_ROD17 }} \\
(\mathrm{I}=\mathrm{VIII})\end{array}$ \\
\hline 306 & 1,01 & 0,48 & 1,05 & 0,71 & 0,64 & 0,78 & 1,89 & 1,01 & 1,94 & 1,41 & 1,30 & 1,52 \\
\hline 270 & 0,71 & 0,32 & 0,19 & 0,44 & 0,36 & 0,48 & 1,41 & 0,71 & 0,43 & 0,93 & 0,78 & 1,01 \\
\hline 271 & 0,32 & 0,32 & 0,21 & 0,39 & 0,36 & 0,36 & 0,71 & 0,71 & 0,48 & 0,85 & 0,78 & 0,78 \\
\hline 272 & 0,85 & 0,39 & 1,14 & 0,71 & 0,71 & 0,85 & 1,64 & 0,85 & 2,07 & 1,41 & 1,41 & 1,64 \\
\hline 273 & 0,26 & 0,29 & 0,19 & 0,32 & 0,32 & 0,39 & 0,58 & 0,64 & 0,43 & 0,71 & 0,71 & 0,85 \\
\hline 274 & 0,85 & 0,39 & 0,21 & 0,58 & 0,39 & 0,53 & 1,64 & 0,85 & 0,48 & 1,20 & 0,85 & 1,10 \\
\hline 275 & 1,30 & 0,53 & 0,58 & 1,52 & 2,15 & 1,76 & 2,28 & 1,10 & 1,19 & 2,55 & 3,21 & 2,82 \\
\hline 276 & 0,85 & 0,39 & 0,29 & 0,78 & 0,53 & 0,71 & 1,64 & 0,85 & 0,64 & 1,52 & 1,10 & 1,41 \\
\hline 277 & 0,85 & 0,44 & 0,36 & 0,26 & 0,21 & 0,71 & 1,64 & 0,93 & 0,79 & 0,58 & 0,48 & 1,41 \\
\hline 278 & 0,71 & 0,32 & 0,19 & 0,44 & 0,36 & 0,48 & 1,41 & 0,71 & 0,43 & 0,93 & 0,78 & 1,01 \\
\hline 279 & 0,39 & 0,36 & 0,19 & 0,48 & 0,32 & 0,32 & 0,85 & 0,78 & 0,43 & 1,01 & 0,71 & 0,71 \\
\hline 280 & 0,48 & 0,48 & 0,32 & 0,85 & 0,58 & 0,78 & 1,01 & 1,01 & 0,70 & 1,64 & 1,20 & 1,52 \\
\hline 281 & 0,58 & 0,48 & 0,35 & 1,89 & 1,64 & 2,15 & 1,20 & 1,01 & 0,77 & 2,96 & 2,69 & 3,21 \\
\hline 282 & 0,85 & 0,39 & 0,29 & 0,78 & 0,53 & 0,71 & 1,64 & 0,85 & 0,64 & 1,52 & 1,10 & 1,41 \\
\hline 283 & 1,01 & 0,48 & 0,58 & 1,20 & 1,01 & 1,30 & 1,89 & 1,01 & 1,19 & 2,15 & 1,89 & 2,28 \\
\hline 284 & 0,39 & 0,36 & 0,21 & 0,36 & 0,24 & 0,36 & 0,85 & 0,78 & 0,48 & 0,78 & 0,53 & 0,78 \\
\hline 285 & 0,85 & 0,44 & 0,23 & 0,53 & 0,44 & 0,85 & 1,64 & 0,93 & 0,53 & 1,10 & 0,93 & 1,64 \\
\hline 286 & 0,93 & 0,39 & 0,35 & 1,10 & 0,78 & 1,01 & 1,76 & 0,85 & 0,77 & 2,02 & 1,52 & 1,89 \\
\hline 287 & 0,85 & 0,39 & 0,21 & 0,58 & 0,39 & 0,53 & 1,64 & 0,85 & 0,48 & 1,20 & 0,85 & 1,10 \\
\hline 288 & 0,32 & 0,32 & 0,32 & 0,64 & 0,53 & 0,53 & 0,71 & 0,71 & 0,70 & 1,30 & 1,10 & 1,10 \\
\hline 289 & 0,93 & 0,39 & 0,19 & 0,64 & 0,44 & 0,58 & 1,76 & 0,85 & 0,43 & 1,30 & 0,93 & 1,20 \\
\hline 290 & 0,44 & 0,36 & 0,35 & 1,01 & 0,71 & 0,71 & 0,93 & 0,78 & 0,77 & 1,89 & 1,41 & 1,41 \\
\hline 291 & 0,71 & 0,32 & 0,19 & 0,44 & 0,36 & 0,48 & 1,41 & 0,71 & 0,43 & 0,93 & 0,78 & 1,01 \\
\hline 292 & 1,01 & 0,48 & 0,59 & 0,64 & 0,58 & 0,78 & 1,89 & 1,01 & 1,22 & 1,30 & 1,20 & 1,52 \\
\hline 293 & 0,32 & 0,32 & 0,23 & 0,64 & 1,01 & 1,01 & 0,71 & 0,71 & 0,53 & 1,30 & 1,89 & 1,89 \\
\hline 294 & 0,48 & 0,48 & 0,26 & 1,01 & 1,20 & 1,52 & 1,01 & 1,01 & 0,58 & 1,89 & 2,15 & 2,55 \\
\hline 295 & 1,10 & 0,48 & 0,94 & 1,30 & 1,10 & 1,41 & 2,02 & 1,01 & 1,78 & 2,28 & 2,02 & 2,42 \\
\hline
\end{tabular}

$\mu_{D}{ }^{*}=$ daño medio representativo según metodología LM1 de RISK-UE; MILO3, GIO05, LAN07, FER12, MAN16, ROD17 = variantes del método MIV propuestas por Milutinovic \& Trendafiloski (2003), Giovinazzi (2005), Lantada (2007), Feriche (2012), Martínez-Cuevas \& Gaspar-Escribano (2016) y el modelo propuesto en esta tesis, respectivamente 


\begin{tabular}{|c|c|c|c|c|c|c|c|c|c|c|c|c|}
\hline \multirow[b]{2}{*}{ FID } & \multicolumn{6}{|c|}{ C. OBTENCIÓN GRADO DE DAÑO SEGÚN MÉTODO LM1 (I = VII) } & \multicolumn{6}{|c|}{ D. OBTENCIÓN GRADO DE DAÑO SEGÚN MÉTODO LMI (I = VIII) } \\
\hline & $\begin{array}{c}\mu D^{*} \text { _MIL03 } \\
(I=V I I)\end{array}$ & $\begin{array}{c}\mu D^{*} \text { _GIO05 } \\
(I=\text { VII })\end{array}$ & $\begin{array}{c}\mu D^{*} \text { _LAN07 } \\
(I=V I I)\end{array}$ & $\begin{array}{c}\mu D^{*} \text { _FER12 } \\
(I=V I I)\end{array}$ & $\begin{array}{c}\mu D^{*} \text { _MAN16 } \\
(I=V I I)\end{array}$ & $\begin{array}{c}\mu D^{*} \text { _ROD17 } \\
(I=V I I)\end{array}$ & $\begin{array}{c}\mu D^{*} \text { MILO3 } \\
(I=V I I I)\end{array}$ & $\begin{array}{c}\mu D^{*} \text { _GIO05 } \\
(I=V I I I)\end{array}$ & $\begin{array}{c}\mu D^{*} \text { LAN07 } \\
(I=\text { VIII) }\end{array}$ & $\begin{array}{c}\mu D^{*} \text { _FER12 } \\
(I=V I I I)\end{array}$ & $\begin{array}{c}\mu D^{*} \text { _MAN16 } \\
(I=V I I I)\end{array}$ & $\begin{array}{c}\mu D^{*}{ }_{\text {ROD }} \text { ROD } \\
(\mathrm{I}=\mathrm{VIII})\end{array}$ \\
\hline 296 & 1,01 & 0,48 & 1,45 & 1,10 & 0,93 & 1,10 & 1,89 & 1,01 & 2,47 & 2,02 & 1,76 & 2,02 \\
\hline 297 & 0,85 & 0,39 & 0,21 & 0,58 & 0,39 & 0,53 & 1,64 & 0,85 & 0,48 & 1,20 & 0,85 & 1,10 \\
\hline 298 & 1,01 & 0,48 & 0,23 & 0,78 & 0,44 & 0,58 & 1,89 & 1,01 & 0,53 & 1,52 & 0,93 & 1,20 \\
\hline 299 & 0,44 & 0,36 & 0,19 & 0,58 & 0,39 & 0,39 & 0,93 & 0,78 & 0,43 & 1,20 & 0,85 & 0,85 \\
\hline 300 & 0,39 & 0,36 & 0,19 & 0,32 & 0,21 & 0,32 & 0,85 & 0,78 & 0,43 & 0,71 & 0,48 & 0,71 \\
\hline 301 & 0,71 & 0,36 & 0,23 & 0,85 & 1,10 & 1,89 & 1,41 & 0,78 & 0,53 & 1,64 & 2,02 & 2,96 \\
\hline 302 & 0,32 & 0,32 & 0,29 & 0,39 & 0,32 & 0,48 & 0,71 & 0,71 & 0,64 & 0,85 & 0,71 & 1,01 \\
\hline 303 & 0,85 & 0,44 & 1,24 & 0,93 & 0,78 & 1,30 & 1,64 & 0,93 & 2,20 & 1,76 & 1,52 & 2,28 \\
\hline 304 & 0,71 & 0,36 & 0,26 & 0,93 & 1,20 & 2,02 & 1,41 & 0,78 & 0,58 & 1,76 & 2,15 & 3,09 \\
\hline 305 & 0,85 & 0,39 & 0,19 & 0,53 & 0,36 & 0,48 & 1,64 & 0,85 & 0,43 & 1,10 & 0,78 & 1,01 \\
\hline 306 & 0,36 & 0,32 & 0,19 & 0,32 & 0,26 & 0,48 & 0,78 & 0,71 & 0,43 & 0,71 & 0,58 & 1,01 \\
\hline 307 & 0,85 & 0,39 & 0,32 & 0,85 & 0,58 & 0,78 & 1,64 & 0,85 & 0,70 & 1,64 & 1,20 & 1,52 \\
\hline 308 & 0,44 & 0,39 & 0,32 & 0,71 & 0,93 & 1,30 & 0,93 & 0,85 & 0,70 & 1,41 & 1,76 & 2,28 \\
\hline 309 & 0,85 & 0,44 & 0,39 & 0,78 & 0,71 & 1,30 & 1,64 & 0,93 & 0,84 & 1,52 & 1,41 & 2,28 \\
\hline 310 & 0,85 & 0,39 & 0,32 & 0,85 & 0,58 & 0,78 & 1,64 & 0,85 & 0,70 & 1,64 & 1,20 & 1,52 \\
\hline 311 & 0,85 & 0,39 & 0,32 & 0,85 & 0,58 & 0,78 & 1,64 & 0,85 & 0,70 & 1,64 & 1,20 & 1,52 \\
\hline 312 & 0,78 & 0,36 & 0,59 & 0,64 & 0,71 & 1,10 & 1,52 & 0,78 & 1,22 & 1,30 & 1,41 & 2,02 \\
\hline 313 & 0,32 & 0,32 & 0,15 & 0,44 & 0,29 & 0,39 & 0,71 & 0,71 & 0,35 & 0,93 & 0,64 & 0,85 \\
\hline 314 & 0,85 & 0,44 & 0,65 & 0,78 & 0,64 & 1,20 & 1,64 & 0,93 & 1,32 & 1,52 & 1,30 & 2,15 \\
\hline 315 & 0,71 & 0,32 & 0,23 & 0,53 & 0,44 & 0,48 & 1,41 & 0,71 & 0,53 & 1,10 & 0,93 & 1,01 \\
\hline 316 & 0,93 & 0,44 & 0,39 & 1,01 & 0,85 & 1,52 & 1,76 & 0,93 & 0,84 & 1,89 & 1,64 & 2,55 \\
\hline 317 & 0,85 & 0,39 & 0,54 & 0,44 & 0,32 & 0,85 & 1,64 & 0,85 & 1,12 & 0,93 & 0,71 & 1,64 \\
\hline 318 & 0,85 & 0,44 & 1,14 & 0,93 & 0,78 & 1,20 & 1,64 & 0,93 & 2,07 & 1,76 & 1,52 & 2,15 \\
\hline 319 & 0,44 & 0,39 & 0,32 & 1,10 & 0,53 & 0,78 & 0,93 & 0,85 & 0,70 & 2,02 & 1,10 & 1,52 \\
\hline 320 & 1,10 & 0,53 & 0,48 & 1,20 & 0,85 & 1,52 & 2,02 & 1,10 & 1,00 & 2,15 & 1,64 & 2,55 \\
\hline 321 & 1,64 & 0,71 & 0,70 & 1,41 & 1,20 & 0,93 & 2,69 & 1,41 & 1,40 & 2,42 & 2,15 & 1,76 \\
\hline 322 & 0,39 & 0,36 & 0,35 & 0,58 & 0,39 & 0,58 & 0,85 & 0,78 & 0,77 & 1,20 & 0,85 & 1,20 \\
\hline
\end{tabular}

$\mu_{D}{ }^{*}=$ daño medio representativo según metodología LM1 de RISK-UE; MILO3, GIO05, LAN07, FER12, MAN16, ROD17 = variantes del método MIV propuestas por Milutinovic \& Trendafiloski (2003), Giovinazzi (2005), Lantada (2007), Feriche (2012), Martínez-Cuevas \& Gaspar-Escribano (2016) y el modelo propuesto en esta tesis, respectivamente 


\begin{tabular}{|c|c|c|c|c|c|c|c|c|c|c|c|c|}
\hline \multirow[b]{2}{*}{ FID } & \multicolumn{6}{|c|}{ C. OBTENCIÓN GRADO DE DAÑO SEGÚN MÉTODO LM1 (I = VII) } & \multicolumn{6}{|c|}{ D. OBTENCIÓN GRADO DE DAÑO SEGÚN MÉTODO LM1 (I = VIII) } \\
\hline & $\begin{array}{c}\mu D^{*}=\mathrm{MILO3} \\
(1=\mathrm{VII})\end{array}$ & $\begin{array}{c}\mu D^{*} \text { GIOOS } \\
(I=V I I)\end{array}$ & $\begin{array}{c}\mu D^{*} \text { _LAN07 } \\
(I=V I I)\end{array}$ & $\begin{array}{c}\mu D^{*} \text { _FER12 } \\
(I=V I I)\end{array}$ & $\begin{array}{c}\mu D^{*} \text { _MAN16 } \\
(I=V I I)\end{array}$ & $\begin{array}{c}\mu D^{*} \text { _ROD17 } \\
(I=V I I)\end{array}$ & $\begin{array}{c}\mu D^{*} \text { _MIL03 } \\
(I=V I I I)\end{array}$ & $\begin{array}{c}\mu D_{*}^{*}{ }_{\text {GIOOS5 }} \\
(I=V I I I)\end{array}$ & $\begin{array}{c}\mu D^{*} \text { _LAN07 } \\
(I=V I I I)\end{array}$ & $\begin{array}{c}\mu D^{*} \text { _FER12 } \\
(I=V I I I)\end{array}$ & $\begin{array}{c}\mu D^{*} \text { _MAN16 } \\
(I=V I I I)\end{array}$ & $\begin{array}{c}\mu D^{*} \text { _ROD17 } \\
(I=V I I I)\end{array}$ \\
\hline 323 & 0,85 & 0,39 & 0,19 & 0,53 & 0,36 & 0,48 & 1,64 & 0,85 & 0,43 & 1,10 & 0,78 & 1,01 \\
\hline 324 & 0,93 & 0,44 & 0,72 & 0,58 & 0,53 & 1,52 & 1,76 & 0,93 & 1,43 & 1,20 & 1,10 & 2,55 \\
\hline 325 & 0,44 & 0,39 & 0,35 & 0,58 & 0,39 & 0,58 & 0,93 & 0,85 & 0,77 & 1,20 & 0,85 & 1,20 \\
\hline 326 & 0,39 & 0,36 & 0,19 & 0,32 & 0,21 & 0,32 & 0,85 & 0,78 & 0,43 & 0,71 & 0,48 & 0,71 \\
\hline 327 & 1,01 & 0,48 & 0,59 & 0,44 & 0,44 & 1,10 & 1,89 & 1,01 & 1,22 & 0,93 & 0,93 & 2,02 \\
\hline 328 & 0,32 & 0,32 & 0,23 & 0,44 & 0,71 & 0,85 & 0,71 & 0,71 & 0,53 & 0,93 & 1,41 & 1,64 \\
\hline 329 & 0,44 & 0,36 & 0,21 & 0,64 & 0,44 & 0,44 & 0,93 & 0,78 & 0,48 & 1,30 & 0,93 & 0,93 \\
\hline 330 & 0,85 & 0,44 & 0,80 & 0,64 & 0,53 & 0,85 & 1,64 & 0,93 & 1,57 & 1,30 & 1,10 & 1,64 \\
\hline 331 & 0,85 & 0,39 & 0,29 & 1,01 & 1,30 & 1,64 & 1,64 & 0,85 & 0,64 & 1,89 & 2,28 & 2,69 \\
\hline 332 & 0,36 & 0,32 & 0,32 & 0,78 & 0,64 & 0,53 & 0,78 & 0,71 & 0,70 & 1,52 & 1,30 & 1,10 \\
\hline 333 & 0,85 & 0,44 & 0,80 & 0,64 & 0,53 & 0,85 & 1,64 & 0,93 & 1,57 & 1,30 & 1,10 & 1,64 \\
\hline 334 & 0,39 & 0,36 & 0,19 & 0,48 & 0,32 & 0,32 & 0,85 & 0,78 & 0,43 & 1,01 & 0,71 & 0,71 \\
\hline 335 & 1,01 & 0,48 & 0,59 & 0,44 & 0,36 & 0,78 & 1,89 & 1,01 & 1,22 & 0,93 & 0,78 & 1,52 \\
\hline 336 & 0,85 & 0,39 & 0,21 & 0,53 & 0,39 & 0,53 & 1,64 & 0,85 & 0,48 & 1,10 & 0,85 & 1,10 \\
\hline 337 & 0,85 & 0,39 & 0,29 & 0,78 & 0,53 & 0,71 & 1,64 & 0,85 & 0,64 & 1,52 & 1,10 & 1,41 \\
\hline 338 & 1,01 & 0,48 & 0,96 & 0,71 & 0,58 & 0,71 & 1,89 & 1,01 & 1,81 & 1,41 & 1,20 & 1,41 \\
\hline 339 & 0,71 & 0,36 & 0,23 & 0,78 & 1,10 & 1,64 & 1,41 & 0,78 & 0,53 & 1,52 & 2,02 & 2,69 \\
\hline 340 & 1,01 & 0,48 & 0,65 & 0,48 & 0,39 & 0,85 & 1,89 & 1,01 & 1,32 & 1,01 & 0,85 & 1,64 \\
\hline 341 & 1,64 & 0,71 & 0,92 & 1,76 & 1,52 & 1,20 & 2,69 & 1,41 & 1,75 & 2,82 & 2,55 & 2,15 \\
\hline 342 & 0,93 & 0,44 & 0,35 & 0,93 & 0,78 & 1,41 & 1,76 & 0,93 & 0,77 & 1,76 & 1,52 & 2,42 \\
\hline 343 & 0,85 & 0,39 & 0,19 & 0,53 & 0,36 & 0,48 & 1,64 & 0,85 & 0,43 & 1,10 & 0,78 & 1,01 \\
\hline 345 & 0,71 & 0,36 & 0,26 & 0,71 & 0,48 & 0,93 & 1,41 & 0,78 & 0,58 & 1,41 & 1,01 & 1,76 \\
\hline 346 & 1,01 & 0,48 & 0,96 & 0,71 & 0,58 & 0,71 & 1,89 & 1,01 & 1,81 & 1,41 & 1,20 & 1,41 \\
\hline 347 & 0,85 & 0,44 & 0,73 & 0,48 & 0,44 & 0,78 & 1,64 & 0,93 & 1,45 & 1,01 & 0,93 & 1,52 \\
\hline 348 & 0,78 & 0,36 & 0,32 & 0,64 & 0,71 & 1,10 & 1,52 & 0,78 & 0,70 & 1,30 & 1,41 & 2,02 \\
\hline 350 & 0,85 & 0,39 & 0,19 & 0,53 & 0,36 & 0,48 & 1,64 & 0,85 & 0,43 & 1,10 & 0,78 & 1,01 \\
\hline 351 & 1,30 & 0,64 & 0,96 & 0,71 & 0,58 & 0,71 & 2,28 & 1,30 & 1,81 & 1,41 & 1,20 & 1,41 \\
\hline
\end{tabular}

$\mu_{D}{ }^{*}=$ daño medio representativo según metodología LM1 de RISK-UE; MILO3, GIO05, LAN07, FER12, MAN16, ROD17 = variantes del método MIV propuestas por Milutinovic \& Trendafiloski (2003), Giovinazzi (2005), Lantada (2007), Feriche (2012), Martínez-Cuevas \& Gaspar-Escribano (2016) y el modelo propuesto en esta tesis, respectivamente 


\begin{tabular}{|c|c|c|c|c|c|c|c|c|c|c|c|c|}
\hline \multirow[b]{2}{*}{ FID } & \multicolumn{6}{|c|}{ C. OBTENCIÓN GRADO DE DAÑO SEGÚN MÉTODO LM1 (I = VII) } & \multicolumn{6}{|c|}{ D. OBTENCIÓN GRADO DE DAÑO SEGÚN MÉTODO LM1 (I = VIII) } \\
\hline & $\begin{array}{c}\mu D^{*} \text { _MIL03 } \\
(1=V I I)\end{array}$ & $\begin{array}{c}\mu D^{*}{ }_{-G I O 05} \\
(I=V I I)\end{array}$ & $\begin{array}{c}\mu D^{*} \text { _LAN07 } \\
(I=V I I)\end{array}$ & $\begin{array}{c}\mu D^{*} \text { _FER12 } \\
(I=V I I)\end{array}$ & $\begin{array}{c}\mu D^{*} \text { _MAN16 } \\
(I=V I I)\end{array}$ & $\begin{array}{c}\mu D^{*} \text { _ROD17 } \\
(I=V I I)\end{array}$ & $\begin{array}{c}\mu D_{*}^{*} \text { MIL03 } \\
(I=V I I I)\end{array}$ & $\begin{array}{c}\mu D^{*} \text { GIOOS } \\
(I=V I I I)\end{array}$ & $\begin{array}{c}\mu D^{*} \text { _LAN07 } \\
(I=\text { VIII })\end{array}$ & $\begin{array}{c}\mu D^{*} \text { _FER12 } \\
(I=V I I I)\end{array}$ & $\begin{array}{c}\mu D^{*} \text { _MAN16 } \\
(I=V I I I)\end{array}$ & $\begin{array}{c}\mu D^{*} \text { _ROD17 } \\
(I=V I I I)\end{array}$ \\
\hline 352 & 0,85 & 0,44 & 1,24 & 0,93 & 0,85 & 1,30 & 1,64 & 0,93 & 2,20 & 1,76 & 1,64 & 2,28 \\
\hline 353 & 1,01 & 0,48 & 0,19 & 0,53 & 0,36 & 0,48 & 1,89 & 1,01 & 0,43 & 1,10 & 0,78 & 1,01 \\
\hline 354 & 1,01 & 0,48 & 1,14 & 0,85 & 0,71 & 0,85 & 1,89 & 1,01 & 2,07 & 1,64 & 1,41 & 1,64 \\
\hline 355 & 1,01 & 0,48 & 0,43 & 0,93 & 0,78 & 1,01 & 1,89 & 1,01 & 0,92 & 1,76 & 1,52 & 1,89 \\
\hline 356 & 0,71 & 0,36 & 0,23 & 0,64 & 0,44 & 0,85 & 1,41 & 0,78 & 0,53 & 1,30 & 0,93 & 1,64 \\
\hline 357 & 1,41 & 0,58 & 0,58 & 1,01 & 1,01 & 0,64 & 2,42 & 1,20 & 1,19 & 1,89 & 1,89 & 1,30 \\
\hline 358 & 1,01 & 0,48 & 1,05 & 0,78 & 0,64 & 0,78 & 1,89 & 1,01 & 1,94 & 1,52 & 1,30 & 1,52 \\
\hline 359 & 0,85 & 0,39 & 0,21 & 0,58 & 0,39 & 0,53 & 1,64 & 0,85 & 0,48 & 1,20 & 0,85 & 1,10 \\
\hline 360 & 0,71 & 0,36 & 0,23 & 0,64 & 0,44 & 0,85 & 1,41 & 0,78 & 0,53 & 1,30 & 0,93 & 1,64 \\
\hline 361 & 0,71 & 0,36 & 0,19 & 0,53 & 0,36 & 0,71 & 1,41 & 0,78 & 0,43 & 1,10 & 0,78 & 1,41 \\
\hline 362 & 0,39 & 0,39 & 0,35 & 0,58 & 0,48 & 0,71 & 0,85 & 0,85 & 0,77 & 1,20 & 1,01 & 1,41 \\
\hline 363 & 0,85 & 0,39 & 0,19 & 0,53 & 0,36 & 0,48 & 1,64 & 0,85 & 0,43 & 1,10 & 0,78 & 1,01 \\
\hline 364 & 0,71 & 0,36 & 0,96 & 0,64 & 0,64 & 1,01 & 1,41 & 0,78 & 1,81 & 1,30 & 1,30 & 1,89 \\
\hline
\end{tabular}

$\mu_{D}^{*}=$ daño medio representativo según metodología LM1 de RISK-UE; MILO3, GIO05, LAN07, FER12, MAN16, ROD17 = variantes del método MIV propuestas por Milutinovic \& Trendafiloski (2003), Giovinazzi (2005), Lantada (2007), Feriche (2012), Martínez-Cuevas \& Gaspar-Escribano (2016) y el modelo propuesto en esta tesis, respectivamente 